\title{
Moisture diffusion through neat and glass-fiber reinforced vinyl ester resin containing nanoclay
}

\author{
Hiteshkumar T. Rana \\ West Virginia University
}

Follow this and additional works at: https://researchrepository.wvu.edu/etd

\section{Recommended Citation}

Rana, Hiteshkumar T., "Moisture diffusion through neat and glass-fiber reinforced vinyl ester resin containing nanoclay" (2003). Graduate Theses, Dissertations, and Problem Reports. 1357. https://researchrepository.wvu.edu/etd/1357

This Thesis is protected by copyright and/or related rights. It has been brought to you by the The Research Repository @ WVU with permission from the rights-holder(s). You are free to use this Thesis in any way that is permitted by the copyright and related rights legislation that applies to your use. For other uses you must obtain permission from the rights-holder(s) directly, unless additional rights are indicated by a Creative Commons license in the record and/ or on the work itself. This Thesis has been accepted for inclusion in WVU Graduate Theses, Dissertations, and Problem Reports collection by an authorized administrator of The Research Repository @ WVU. For more information, please contact researchrepository@mail.wvu.edu. 


\title{
Moisture Diffusion through Neat and Glass-Fiber Reinforced Vinyl Ester Resin Containing Nanoclay
}

\author{
Hiteshkumar T. Rana
}

Thesis submitted to the College of Engineering and Mineral Resources at West Virginia University in partial fulfillment of the requirements for the degree of

\author{
Master of Science \\ in \\ Chemical Engineering
}

Rakesh K. Gupta, Ph.D., Chair

Hota V. S. GangaRao, Ph.D.

Charter Stinespring, Ph.D.

Department of Chemical Engineering

Morgantown, West Virginia

2003

Keywords: Vinyl ester, moisture diffusion, nanocomposites, nanoclays, montmorillonite, glass-fibers, salt solution, alkaline solution

Copyright 2003 Hiteshkumar T. Rana 


\title{
ABSTRACT \\ Moisture Diffusion through Neat and Glass-Fiber Reinforced Vinyl Ester \\ Resin Containing Nanoclay
}

\author{
Hiteshkumar T. Rana
}

\begin{abstract}
Moisture diffusion was studied through neat resin as well as glass-fiber reinforced vinyl ester samples, both containing up to $5 \mathrm{wt} \%$ montmorillonite clay. Transient and steadystate diffusion experiments were carried out with both neat resin as well as glass-fiber reinforced samples. Effect of saline and alkaline solutions on the process of diffusion was studied. It was found that the diffusivity decreased due to the presence of nanoclay in polymer. SEM images of FRPs were taken after two months of immersion in distilled water at room temperature. The SEM images revealed that the presence of clay indeed protected the glass-fibers. Effect of temperature was studied by conducting transient diffusion experiment at several temperatures. Dynamic Mechanical Analysis (DMA) was conducted on nanocomposite samples to understand the variations in the molecular structure. Glass transition temperature and storage modulus in torsion were found to increase significantly with increasing amount of nanoclay in polymer. Tensile tests and impact tests were carried out to quantify the influence of nanoparticles on mechanical properties of nanocomposite samples. Tensile modulus was found to increase with increasing amount of nanoclay at all clay-loading levels. However, impact strength was found to increase only at low clay loading levels. Thermogravimetric analysis (TGA) was also conducted on nanocomposites. The results showed that there were no obvious differences between the weight-loss patterns of the nanocomposites and those of the neat resin.
\end{abstract}




\section{ACKNOWLEDGEMENTS}

I would like to thank Dr. Dady Dadyburjor for giving me an opportunity to pursue Master's studies in Chemical Engineering Department at West Virginia University.

I am highly indebted to Dr. Rakesh Gupta for being my advisor, guiding my way and providing invaluable inputs throughout my research. A deep sense of gratitude to Dr. Hota Ganga Rao, Dr. Charter Stinespring, Dr. Aleksey Drozdov, Dr. P. V. Vijay and Dr. Joseph Shaeiwitz for their help at all stages of my work. I would like to acknowledge Dr. Peter Stansberry for helping me design some of the crucial experiments. I would like to thank Dr. John Penn for helping me understand the chemistry of glass-fibers. I would like to acknowledge Mr. Mahesh Iyer for conducting TGA tests on my samples. I would also like to thank Mr. Joseph Scott Jones for helping me with the SEM imaging.

I would like to acknowledge Mr. Jim Hall for patiently listening to all my requests and providing technical help whenever needed.

I would like to thank Mr. Apoorva Shah, Dr. Sushant Agarwal, Dr. Adam AlMulla, Mr. Travis Crites and Mr. Fares Alsewailem for being wonderful colleagues and for providing valuable inputs throughout the project.

I would like to thank the US Department of Transportation and Federal Highway Administration for providing funding for this project.

“Thank You Very Much" Vasvi for being a very loving, caring and understanding wife. I would like to express my deep sense of gratitude for my parents and my brother for their constant love and blessings. 


\section{TABLE OF CONTENTS}

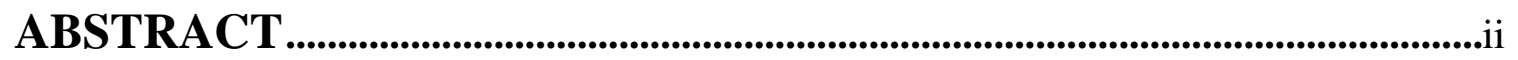

ACKNOWLEDGEMENTS..........................................................................ii

TABLE OF CONTENTS ................................................................................. iv

LIST OF TABLES..............................................................................................vii

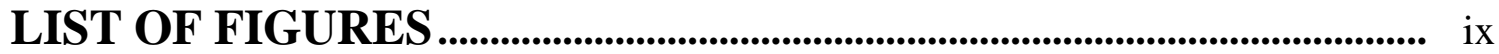

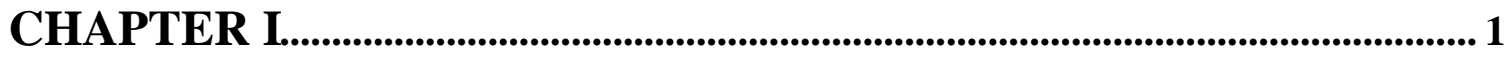

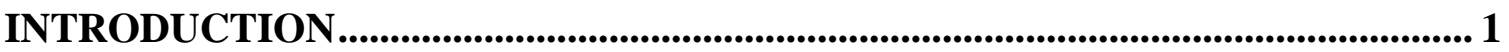

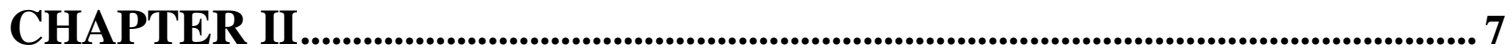

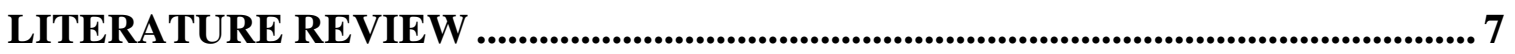

2.1. DETERMINING THE DIFFUSIVITY FROM TRANSIENT DIFFUSION EXPERIMENTS ......... 9

2.2. DETERMINING THE DIFFUSIVITY FROM STEADY STATE DIFFUSION EXPERIMENTS . 11

2.3. REPRESENTATIVE RESULTS FOR DIFFUSION OF WATER THROUGH THERMOSETTING

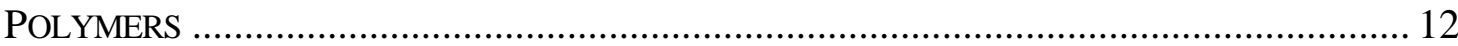

2.3.1. Chemistry of Vinyl Ester.......................................................................... 12

2.3.2. Representative Results for Diffusion of Water through Vinyl Ester ............... 14

2.3.3. Effect of Temperature on the Diffusion of water through the Matrix .............. 16

2.3.4. Effect of Glass-Fiber Reinforcement on the Process of Diffusion................... 18

2.3.5. Proposed Mechanisms for Water Transport through a Network of Polymer

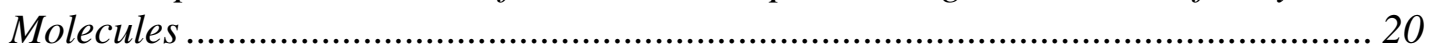

2.4. THEORIES EXPLAINING ANOMALOUS DIFFUSION BEHAVIOR .................................. 22

2.4.1. Time-Dependent Boundary Conditions...................................................... 23

2.4.2. Model based on Polymer Relaxation ............................................................ 25

2.4.3. Model based on Langmuir type of Behavior .................................................. 27

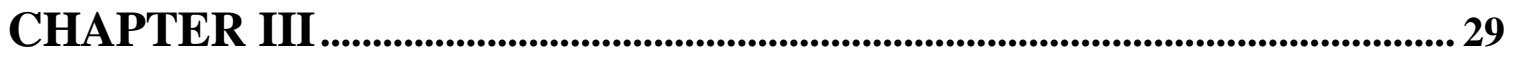

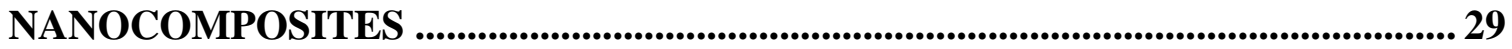

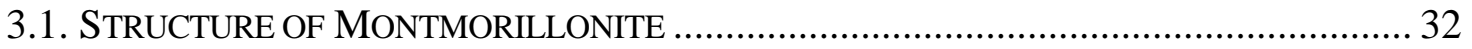

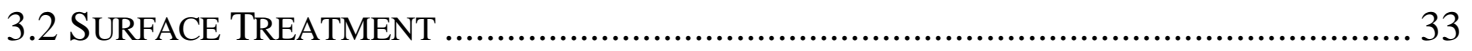

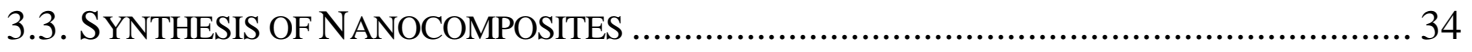

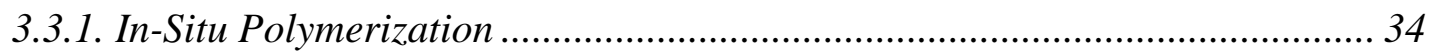

3.3.2. Solution Approach …………………………......................................... 35

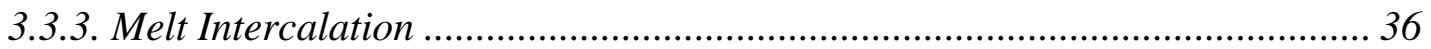

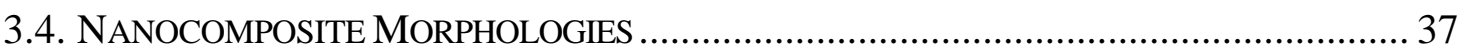

3.5. PROPERTIES OF NANOCOMPOSITES …………….............................................. 38

3.6. THEORY EXPLAINING THE MECHANICAL BEHAVIOR OF POLYMER NANOCOMPOSITES

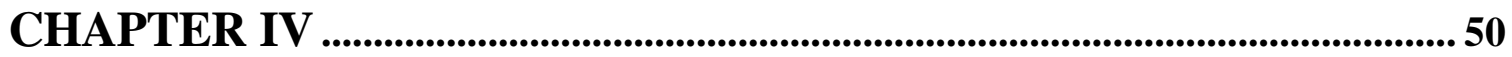

MOISTURE DIFFUSION THROUGH NANOCOMPOSITES ..................................50 
4.1. THEORY EXPLAINING THE VARIATIONS IN RELATIVE PERMEABILITY WITH CLAY

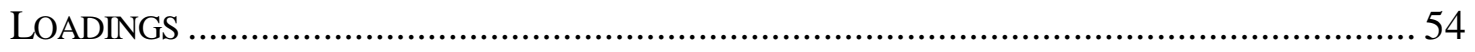

4.2. THEORY EXPLAINING VARIATIONS IN DIFFUSION COEFFICIENT WITH CLAY

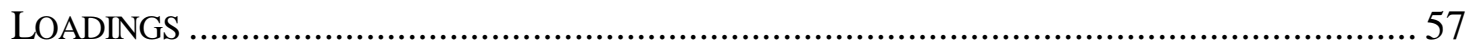

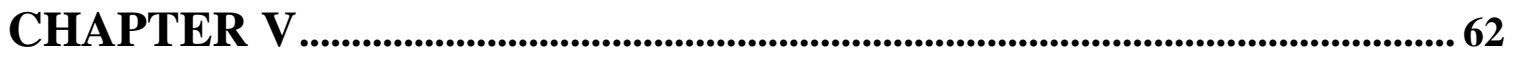

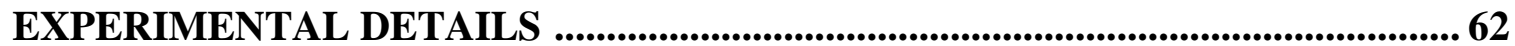

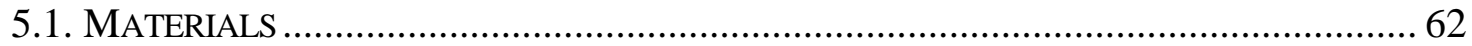

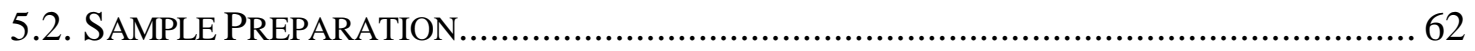

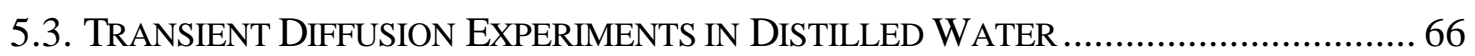

5.4. TRANSIENT DifFUSION EXPERIMENTS IN ALKALINE AND SALINE SOLUTIONS ........ 68

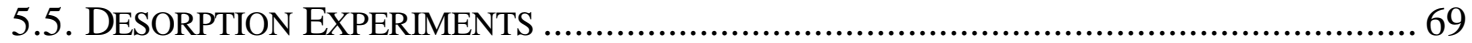

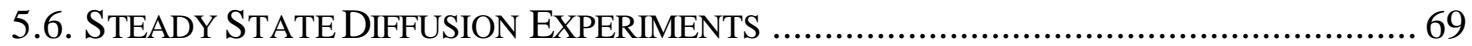

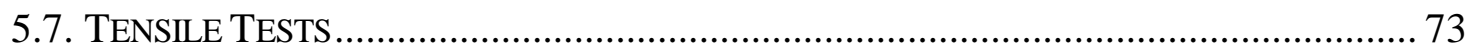

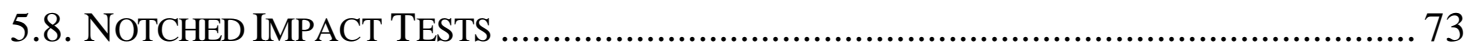

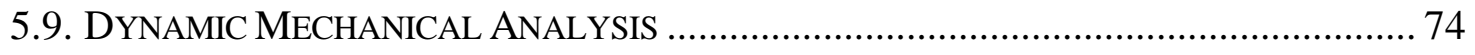

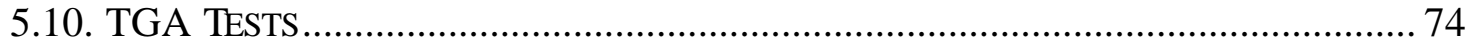

5.11. SCANNING ELECTRON MICROSCOPY .............................................................. 75

CHAPTER VI ................................................................................................... 76

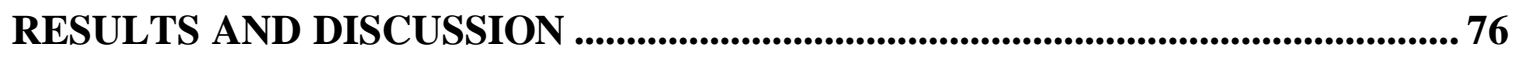

6.1. TRANSIENT DIFFUSION EXPERIMENTS IN DISTILLED WATER AT ROOM

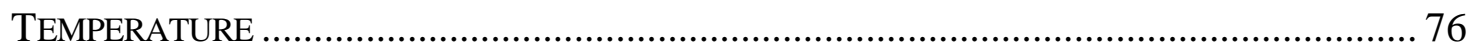

6.2. TRANSIENT DIFFUSION EXPERIMENTS IN DISTILLED WATER AT $62^{\circ} \mathrm{C} \ldots \ldots \ldots \ldots \ldots . . . . . . . . .93$

6.3. TRANSIENT DIFFUSION EXPERIMENTS IN DISTILLED WATER AT $42.5^{\circ} \mathrm{C}$................ 95

6.4. TRANSIENT DIFFUSION EXPERIMENT IN DISTILLED WATER AT $4{ }^{\circ} \mathrm{C} \ldots \ldots \ldots \ldots \ldots \ldots . . . . . . . . . . .101$

6.5. TRANSIENT DIFFUSION EXPERIMENTS IN ALKAUNE AND SALINE SOLUTIONS AT

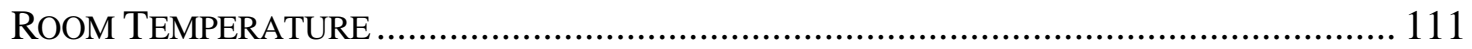

6.6. TRANSIENT DIFFUSION EXPERIMENTS IN ALKALINE AND SALINE SOLUTIONS AT $42.5^{\circ} \mathrm{C}$

6.7. TRANSIENT DIFFUSION EXPERIMENTS IN ALKALINE AND SALINE SOLUTIONS AT $4{ }^{\circ} \mathrm{C}$

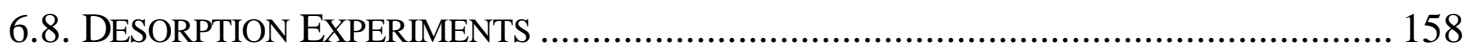

6.9. STEADY STATE DIFFUSION EXPERIMENTS ........................................................ 165

6.10. COMPARISON OF DIFFUSION COEFFICIENTS OBTAINED FROM TRANSIENT AND

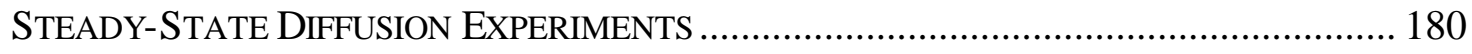

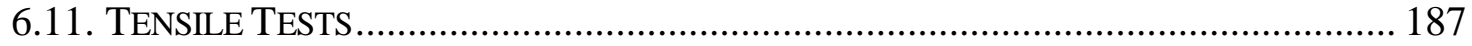

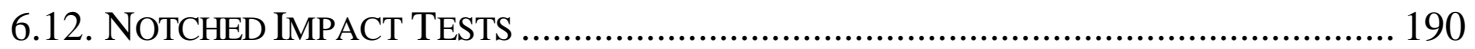

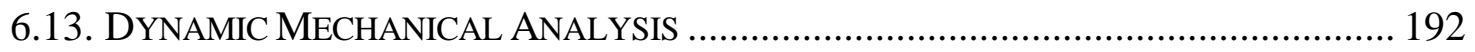

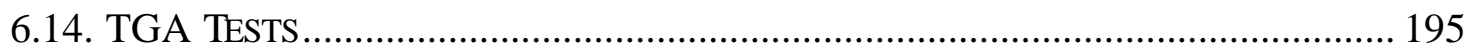

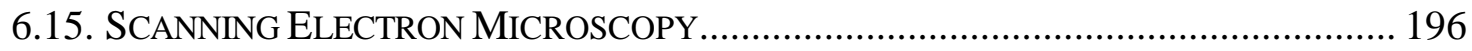

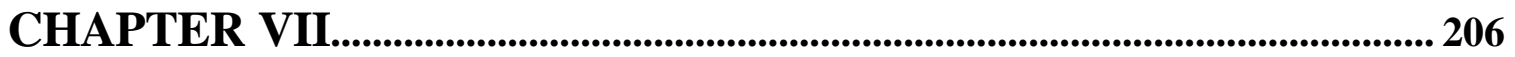

CONCLUSIONS AND RECOMMENDATIONS............................................................ 206

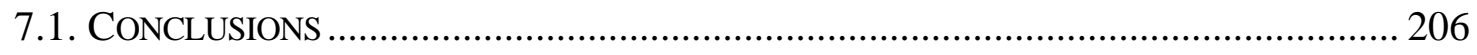




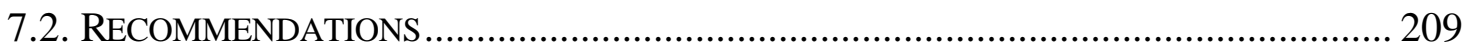

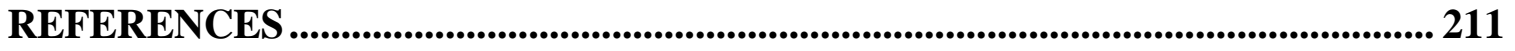

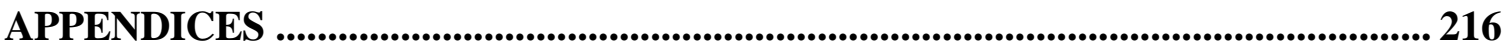

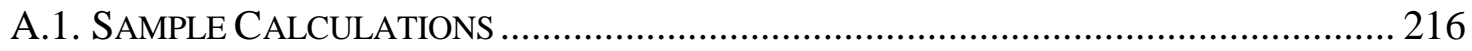

A.1.1. Sample Calculation for Diffusion Coefficient in un-reinforced samples in

Transient Diffusion experiments.................................................................... 216

A.1.2. Sample Calculation for Diffusion Coefficient in un-reinforced Sample in Steady State Diffusion Experiments................................................................. 217

A.1.3. Sample Calculation for Tensile Tests.......................................................... 219

A.1.4. Sample Calculation for Diffusion Coefficient in FRP Sample in Transient

Diffusion experiments ....................................................................................... 220

A.1.5. Sample Calculation for Amount of Moisture interacted with glass fibers ... 222

A.1.6. Validity of Approximate Solution of Transient Diffusion Experiments....... 224

A.1.7. Extrapolated values of Equilibrium Moisture Contents............................. 225

A.1.8. Estimating the value of aspect ratio $\alpha$.................................................... 226

A.1.9. Calculation of Theoretical Flux Ratios in Steady-State Experiments on FRP

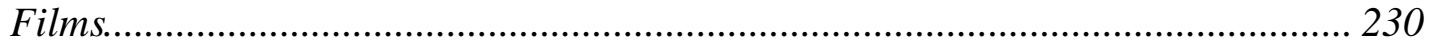

A.1.10. Suggested Film Thickness for Experiments in Alkaline Solution ............... 236

A.2. RAW DATA............................................................................................ 237 


\section{LIST OF TABLES}

Table I. Relative Advantages and Disadvantages of Thermosetting and Thermoplastic

Matrix Materials

Table II. Fickian Diffusion Coefficients for Epoxy, Vinyl Ester and Isopolyester Films 15

Table III. Equilibrium Moisture Content for Epoxy, Vinyl Ester and Isopolyester Films 15

Table IV. Diffusion test results on post cured samples .................................................. 43

Table V. Summary of diffusion model parameters....................................................... 44

Table VI. Variation of Glass Transition Temperature of nanocomposite samples with clay

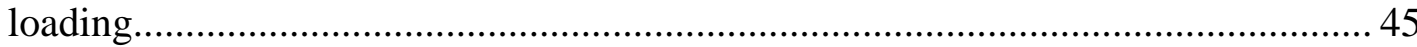

Table VII. Results of Transient Diffusion Experiments in Distilled Water at $25^{\circ} \mathrm{C} \ldots \ldots . .78$

Table VIII. Diffusivities obtained from Truncated experimental data for Transient

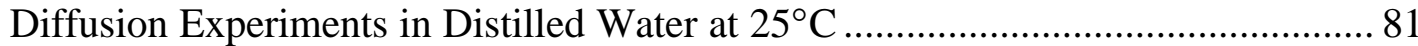

Table IX. Comparison of moisture content of un-reinforced and glass-fiber reinforced samples.

Table X. Absolute amount of water interacted with glass-fibers in FRP samples .......... 87

Table XI. Estimated Diffusion Coefficients and Equilibrium Moisture Contents at $42.5^{\circ} \mathrm{C}$

Table XII. Results of transient diffusion experiments with un-reinforced samples at $4{ }^{\circ} \mathrm{C}$

Table XIII. Results of transient diffusion experiments on FRP films immersed in distilled

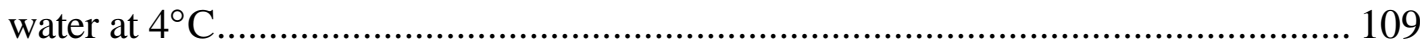

Table XIV. Diffusion Coefficients in 0.1M NaCl Solutions ....................................... 117

Table XV. Equilibrium Moisture Contents in Alkaline and Saline Solutions ................ 117

Table XVI. Estimated Diffusion Coefficients and Equilibrium Moisture Contents at $28^{\circ} \mathrm{C}$ for samples immersed in $13 \mathrm{pH} \mathrm{NaOH}$ solution............................................. 118

Table XVII. Diffusion coefficients in $0.1 \mathrm{M} \mathrm{NaCl}$ solution ......................................... 122

Table XVIII. Un-corrected equilibrium moisture contents in $0.1 \mathrm{M} \mathrm{NaCl}$ solution........ 122

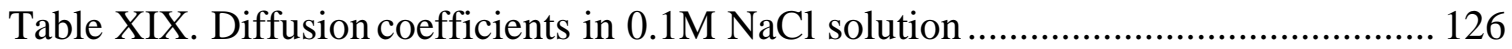

Table XX. Corrected equilibrium moisture contents in $0.1 \mathrm{M} \mathrm{NaCl}$ solution................. 126

Table XXI. Moisture content of samples before they started being dissolved in $0.1 \mathrm{M}$ $\mathrm{NaCl}$ at $42.5^{\circ} \mathrm{C}$

Table XXII. Estimated Diffusion Coefficients and Equilibrium Moisture Contents at $42.5^{\circ} \mathrm{C}$ for the samples immersed in $0.1 \mathrm{M} \mathrm{NaCl}$ solution

Table XXIII. Moisture content of samples at $42.5^{\circ} \mathrm{C}$ before they started being dissolved in $\mathrm{NaOH}$ solution having a $\mathrm{pH}$ of 13

Table XXIV. Estimated Diffusion Coefficients and Equilibrium Moisture Contents for samples immersed in $13 \mathrm{pH} \mathrm{NaOH}$ at $42.5^{\circ} \mathrm{C}$

Table XXV. Diffusion Coefficients in $0.1 \mathrm{M} \mathrm{NaCl}$ and $13 \mathrm{pH} \mathrm{NaOH}$ Solutions at $4^{\circ} \mathrm{C} 146$

Table XXVI. Equilibrium Moisture Content in $0.1 \mathrm{M} \mathrm{NaCl}$ and $13 \mathrm{pH} \mathrm{NaOH}$ solutions at $4^{\circ} \mathrm{C}$

Table XXVII. Diffusion Coefficients in $0.1 \mathrm{M} \mathrm{NaCl}$ and $13 \mathrm{pH} \mathrm{NaOH}$ Solutions at $4^{\circ} \mathrm{C}$ 155

Table XXVIII. Equilibrium Moisture Contents in $0.1 \mathrm{M} \mathrm{NaCl}$ and $13 \mathrm{pH} \mathrm{NaOH}$ solutions at $4^{\circ} \mathrm{C}$ 
Table XXIX. Comparison of diffusion coefficients for desorption and absorption at $25^{\circ} \mathrm{C}$

Table XXX. Diffusivities of representative samples calculated for three consecutive

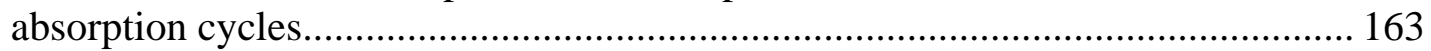

Table XXXI. Diffusion coefficients calculated from steady state diffusion experiments

Table XXXII. Variation in Normalized flux with clay content .................................... 168

Table XXXIII. Steady-State diffusion coefficient of water molecules in FRP films ..... 171

Table XXXIV. Comparison of Experimental and Theoretical Flux Ratio ...................... 176

Table XXXV. Comparison of Diffusion Coefficients obtained from Transient Diffusion

Experiments and Steady-State Diffusion Experiments ........................................... 180

Table XXXVI. Aspect ratio of nanoclay in nanocomposites with various clay loadings

Table XXXVII. Variation in Tensile Properties of Nanocomposites with weight percent of Cloisite $10 A^{\circledR}$ 189

Table XXXVIII. Variation in Impact Strength of Nanocomposites with weight percent of Cloisite $10 \mathrm{~A}^{\circledR}$ 


\section{LIST OF FIGURES}

Figure 1. Coordinate system for unidirectional diffusion process ...................................... 9

Figure 2. Schematic representation of polymer film exposed to different water

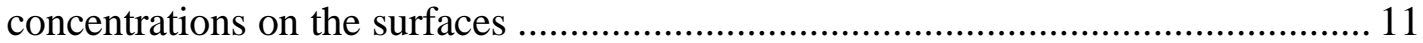

Figure 3. Synthesis of Vinyl Ester ........................................................................... 13

Figure 4. Schematic representation of cross-linked vinyl ester ....................................... 14

Figure 5. Graphical method of determining diffusion parameters, $C_{o}$ and $C_{e q} \ldots \ldots \ldots \ldots \ldots . .25$

Figure 6. Structure of Illite Clay Mineral ................................................................... 30

Figure 7. Structure of Kaolinite Clay Mineral............................................................ 30

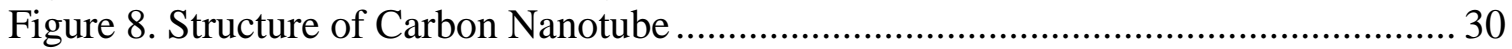

Figure 9. Structure of Montmorillonite Clay ................................................................. 33

Figure 10. Cation-Exchange process between Alkylammonium ion and Cations initially intercalated between the clay platelet .................................................................. 34

Figure 11. Schematic diagram of In-Situ Polymerization ............................................... 35

Figure 12. Schematic diagram of Solution Approach.................................................... 36

Figure 13. Schematic diagram of Melt Intercalation ....................................................... 36

Figure 14. Nanocomposite Morphologies....................................................................... 37

Figure 15. Compressive (A) yield strength and (B) moduli for the pristine epoxy polymer and the exfoliated epoxy-clay nanocomposites prepared from three different kinds of organomontmorillonites. The epoxide resin and curing agent used in this system are EPON 826 and JEFFAMINE D-230, respectively ……………………………...... 38

Figure 16. Stress-strain curves for (A) a pristine polyurethane elastomer; (B) a polyurethane-clay nanocomposite prepared from organomontmorillonite (5 wt \%) 39

Figure 17. Relative Permeability $\left(\mathrm{P}_{\mathrm{c}} / \mathrm{P}_{\mathrm{o}}\right)$ versus volume fraction silicate for montmorillonite-poly ( $\varepsilon$-caprolactone) nanocomposite films

Figure 18. Montmorillonite content dependence of permeability coefficient of water vapor in polyimide-clay hybrids ............................................................................ 40

Figure 19. Montmorillonite content dependence of permeability coefficient of $\mathrm{He}$ in polyimide-clay hybrid

Figure 20. Montmorillonite content dependence of permeability coefficient of $\mathrm{O}_{2}$ in

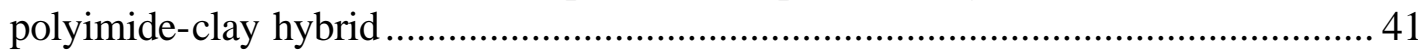

Figure 21. A model for the path of a diffusing gas through the polyimide-clay hybrid ... 41

Figure 22. Montmorillonite content dependence of thermal expansion coefficiet of polyimide-clay hybrid at: (a) $150^{\circ} \mathrm{C}$ (b) $200^{\circ} \mathrm{C}$ (c) $250^{\circ} \mathrm{C}$, and (d) $295^{\circ} \mathrm{C}$

Figure 23. Variation in Relative Permeability with Organomontmorillonite Clay loading

Figure 24. Variation in Diffusion Coefficient with Organomontmorillonite Clay loading

.

Figure 25. Heat-distortion temperature of Nylon6/clay Nanocomposites ......................... 46

Figure 26. Flexural Strength and Flexural Modulus of Nylon 6/clay Nanocompsites ..... 47

Figure 27. Effect of montmorillonite content on tensile modulus for Low molecular weight (LMW), Medium molecular weight (MMW) and High molecular weight (HMW) Nylon 6 nanocomposites.. 
Figure 28. Effect of montmorillonite content on yield strength for Low molecular weight (LMW), Medium molecular weight (MMW) and High molecular weight (HMW)

Nylon 6 nanocomposites 48

Figure 29. Membrane containing periodically arrayed infinitely long flakes ................. 51

Figure 30. Volume Element of Polymer Nanocomposite Film ..................................... 54

Figure 31. Relative Permeability of Cloisite $10 A ®$ and VMC vinyl ester resin nanocomposites. ( $\mathrm{L}=180 \mathrm{~nm}, \mathrm{~W}=1 \mathrm{~nm}$ ). Volume fraction was calculated using $\rho_{\text {clay }}=2.66 \mathrm{~g} / \mathrm{cc}$ and $\rho_{\text {polymer }}=1.075 \mathrm{~g} / \mathrm{cc}($ Shah, 2001) 56

Figure 32. Relative Water uptake $\Phi=\frac{M_{t}}{M_{\infty}}$ versus Normalaized time $\frac{\sqrt{t}}{2 l}$ for a

DERAKANE 411-350 resin sample (Thickness $=0.18452 \mathrm{~mm})$ containing $5 \mathrm{wt} \%$ of Cloisite $10 \mathrm{~A}^{\circledR}$ clay (Solid line: model prediction, Circles: Experimental data) .......60 60 Figure 33. Water uptake curves of $5 \mathrm{wt} \%$ Cloisite $10 \mathrm{~A}^{\circledR}$-DERAKANE 411-350 vinyl ester resin at $25^{\circ} \mathrm{C}$ 61

Figure 34. DSC Scan of non post-cured neat DERAKANE 411-350 Momentum resin .. 63 Figure 35. DSC Scan of post-cured neat DERAKANE 411-350 Momentum resin ......... 64

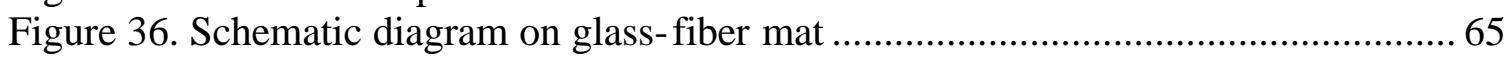

Figure 37. Experimental set-up for Steady-State Experiments.................................... 71

Figure 38. $M_{t} / M_{\infty}$ versus $t^{1 / 2} / 2 l$ for samples containing $0 \mathrm{wt} \%$ Cloisite $10 \mathrm{~A}^{\circledR}$ at $25^{\circ} \mathrm{C} \ldots 76$ Figure 39. $M_{t} / M_{\infty}$ versus $t^{1 / 2} / 2 l$ for samples containing $1 \mathrm{wt} \%$ Cloisite $10 \mathrm{~A}^{\circledR}$ at $25^{\circ} \mathrm{C} \ldots 77$ Figure $40 . M_{t} / M_{\infty}$ versus $t^{1 / 2} / 2 l$ for samples containing $2 \mathrm{wt} \%$ Cloisite $10 \mathrm{~A}^{\circledR}$ at $25^{\circ} \mathrm{C} \ldots 77$ Figure 41. $M_{t} / M_{\infty}$ versus $t^{1 / 2} / 2 l$ for samples containing $5 \mathrm{wt} \%$ Cloisite $10 \mathrm{~A}^{\circledR}$ at $25^{\circ} \mathrm{C} \ldots 78$ Figure 42 . Truncated $M_{t} / M_{\infty}$ versus $t^{1 / 2} / 2 l$ for samples containing $0 \mathrm{wt} \%$ Cloisite $10 \mathrm{~A}^{\circledR}$ at $25^{\circ} \mathrm{C}$ 79

Figure 43. Truncated $M_{t} / M_{\infty}$ versus $t^{1 / 2} / 2 l$ for samples containing $1 \mathrm{wt} \%$ Cloisite $10 \mathrm{~A}^{\circledR}$ at $25^{\circ} \mathrm{C}$ 80

Figure 44. Truncated $M_{t} / M_{\infty}$ versus $t^{1 / 2} / 2 l$ for samples containing 5 wt $\%$ Cloisite $10 \mathrm{~A}^{\circledR}$ at $25^{\circ} \mathrm{C}$ 80

Figure 45. Diffusion coefficient versus weight percent of Cloisite $10 \mathrm{~A}^{\circledR}$ clay in polymer at $25^{\circ} \mathrm{C}$ 82

Figure 46. Equilibrium moisture content versus weight percent of Cloisite $10 \mathrm{~A}^{\circledR}$ clay in polymer at $25^{\circ} \mathrm{C}$ 82

Figure 47. $M_{t} / M_{\infty}$ versus $t^{1 / 2} / 2 l$ for FRP samples containing $0 \mathrm{wt} \%$ Cloisite $10 \mathrm{~A}^{\circledR}$ immersed in distilled water at $25^{\circ} \mathrm{C}$

Figure 48. Corrected percentage weight gain versus $t^{1 / 2}$ for FRP samples containing 0 wt $\%$ Cloisite $10 \mathrm{~A}^{\circledR}$ immersed in distilled water at $25^{\circ} \mathrm{C}$

Figure 49. Corrected percentage weight gain versus $t^{1 / 2}$ for FRP samples containing 1 wt $\%$ Cloisite $10 \mathrm{~A}^{\circledR}$ immersed in distilled water at $25^{\circ} \mathrm{C}$

Figure 50. Corrected percentage weight gain versus $t^{1 / 2}$ for FRP samples containing 2 wt $\%$ Cloisite $10 \mathrm{~A}^{\circledR}$ immersed in distilled water at $25^{\circ} \mathrm{C}$ 85

Figure 51. Corrected percentage weight gain versus $t^{1 / 2}$ for FRP samples containing 5 $\mathrm{wt} \%$ Cloisite $10 \mathrm{~A}^{\circledR}$ immersed in distilled water at $25^{\circ} \mathrm{C}$ 86 86

Figure 52. Schematic representation of water-front propagation in FRP samples (A) Without nanoclay (B) With nanoclay 88 
Figure 53. Weight change of silane treated glass-fiber mat when it is exposed to $77 \% \mathrm{RH}$

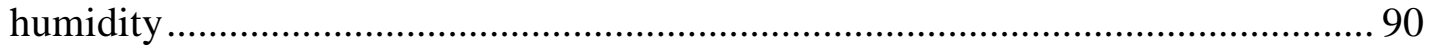

Figure 54. Application of tri-methoxy silane sizing to glass-fibers............................ 90 Figure 55. Water molecules attacking $\mathrm{SiOCH}_{3}$ bonds .......................................... 91

Figure 56. Water molecules forming hydrogen bonds with liberated alcohol molecules 92 Figure 57. Water molecules forming hydrogen bonds with $-\mathrm{OH}$ groups of silane ......... 92

Figure 58. Water molecules breaking strong S-O-Si bond ....................................... 93

Figure 59. (a) Degraded samples after immersion in distilled water at $62^{\circ} \mathrm{C}$ for 4 days (b)

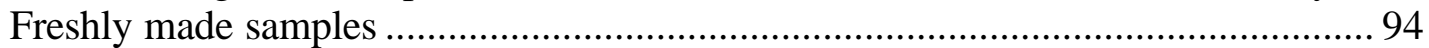

Figure 60. Percentage weight gain versus $t^{1 / 2}$ for samples containing $0 \mathrm{wt} \%$ Cloisite $10 \mathrm{~A}^{\circledR}$

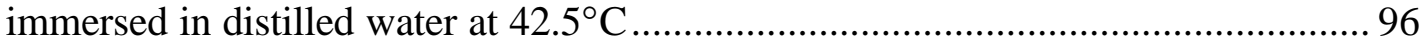

Figure 61. Percentage weight gain versus $t^{1 / 2}$ for samples containing $1 \mathrm{wt} \%$ Cloisite $10 \mathrm{~A}^{\circledR}$

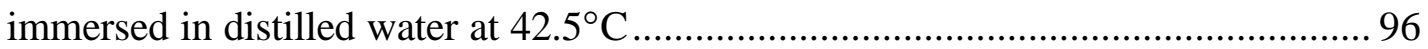

Figure 62. Percentage weight gain versus $t^{1 / 2}$ for samples containing $2 \mathrm{wt} \%$ Cloisite $10 \mathrm{~A}^{\circledR}$

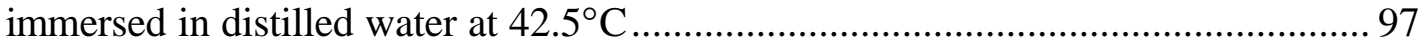

Figure 63. Percentage weight gain versus $t^{1 / 2}$ for samples containing $5 \mathrm{wt} \%$ Cloisite $10 \mathrm{~A}^{\circledR}$ immersed in distilled water at $42.5^{\circ} \mathrm{C}$ 97

Figure 64. Percentage weight gain versus $t^{1 / 2}$ for FRP samples containing $0 \mathrm{wt} \%$ Cloisite $10 \mathrm{~A}^{\circledR}$ immersed in distilled water at $42.5^{\circ} \mathrm{C}$ 99

Figure 65. Percentage weight gain versus $t^{1 / 2}$ for FRP samples containing $1 \mathrm{wt} \%$ Cloisite $10 \mathrm{~A}^{\circledR}$ immersed in distilled water at $42.5^{\circ} \mathrm{C}$

Figure 66. Percentage weight gain versus $t^{1 / 2}$ for FRP samples containing $2 \mathrm{wt} \%$ Cloisite $10 \mathrm{~A}^{\circledR}$ immersed in distilled water at $42.5^{\circ} \mathrm{C}$ 100

Figure 67. Percentage weight gain versus $t^{1 / 2}$ for FRP samples containing $5 \mathrm{wt} \%$ Cloisite $10 \mathrm{~A}^{\circledR}$ immersed in distilled water at $42.5^{\circ} \mathrm{C}$ 100

Figure 68. $M_{t} / M_{\infty}$ versus $t^{1 / 2} / 2 l$ for samples containing $0 \mathrm{wt} \%$ Cloisite $10 \mathrm{~A}^{\circledR}$ at $4^{\circ} \mathrm{C} \ldots 102$ Figure 69. $M_{t} / M_{\infty}$ versus $t^{1 / 2} / 2 l$ for samples containing $1 \mathrm{wt} \%$ Cloisite $10 \mathrm{~A}^{\circledR}$ at $4^{\circ} \mathrm{C} \ldots 102$ Figure 70. $M_{t} / M_{\infty}$ versus $t^{1 / 2} / 2 l$ for samples containing $2 \mathrm{wt} \%$ Cloisite $10 \mathrm{~A}^{\circledR}$ at $4^{\circ} \mathrm{C} \ldots 103$ Figure $71 . M_{t} / M_{\infty}$ versus $t^{1 / 2} / 2 l$ for samples containing 5 wt $\%$ Cloisite $10 \mathrm{~A}^{\circledR}$ at $4^{\circ} \mathrm{C} \ldots 103$ Figure 72. Effect of temperature on the diffusivity of un-reinforced samples 105

Figure 73. Effect of temperature on the equilibrium moisture contents of un-reinforced samples. 105

Figure 74. Corrected $M_{t} / M_{\infty}$ versus $t^{1 / 2} / 2 l$ for FRP samples containing 0 wt $\%$ Cloisite $10 \mathrm{~A}^{\circledR}$ at $4^{\circ} \mathrm{C}$ 107

Figure 75. Corrected $M_{t} / M_{\infty}$ versus $t^{1 / 2} / 2 l$ for FRP samples containing $1 \mathrm{wt} \%$ Cloisite $10 \mathrm{~A}^{\circledR}$ at $4^{\circ} \mathrm{C}$.

Figure 76. Corrected $M_{t} / M_{\infty}$ versus $t^{1 / 2} / 2 l$ for FRP samples containing $2 \mathrm{wt} \%$ Cloisite $10 \mathrm{~A}^{\circledR}$ at $4^{\circ} \mathrm{C}$

Figure 77. Corrected $M_{t} / M_{\infty}$ versus $t^{1 / 2} / 2 l$ for FRP samples containing 5 wt $\%$ Cloisite $10 \mathrm{~A}^{\circledR}$ at $4^{\circ} \mathrm{C}$

Figure 78. Variation in diffusion coefficient of FRP with various clay loading levels .. 109 Figure 79. Variation in Equilibrium moisture content with various clay loading levels 110 Figure 80. (A) Actual thickness used in calculations (B) Apparent thickness if there were no fibers 
Figure 81. $M_{t} / M_{\infty}$ Versus $t^{1 / 2} / 2 l$ for samples containing $0 \mathrm{wt} \%$ Cloisite $10 \mathrm{~A}^{\circledR}$ immersed in

$0.1 \mathrm{M} \mathrm{NaCl}$ solution at $28^{\circ} \mathrm{C}$

Figure 82. $M_{t} / M_{\infty}$ Versus $t^{1 / 2} / 2 l$ for samples containing $1 \mathrm{wt} \%$ Cloisite $10 \mathrm{~A}^{\circledR}$ immersed in

$0.1 \mathrm{M} \mathrm{NaCl}$ solution at $28^{\circ} \mathrm{C}$

Figure 83. $M_{t} / M_{\infty}$ Versus $t^{1 / 2} / 2 l$ for samples containing $2 \mathrm{wt} \%$ Cloisite $10 \mathrm{~A}^{\circledR}$ immersed in

$0.1 \mathrm{M} \mathrm{NaCl}$ solution at $28^{\circ} \mathrm{C}$

Figure 84. $M_{t} / M_{\infty}$ Versus $t^{1 / 2} / 2 l$ for samples containing $5 \mathrm{wt} \%$ Cloisite $10 \mathrm{~A}^{\circledR}$ immersed in

$0.1 \mathrm{M} \mathrm{NaCl}$ solution at $28^{\circ} \mathrm{C}$

Figure 85. Percentage weight gain versus $t^{1 / 2}$ for samples containing $0 \mathrm{wt} \%$ Cloisite $10 \mathrm{~A}^{\circledR}$ immersed in $\mathrm{NaOH}$ solution having a $\mathrm{pH}$ of 13 at $28^{\circ} \mathrm{C}$

Figure 86. Percentage weight gain versus $t^{1 / 2}$ for samples containing $1 \mathrm{wt} \%$ Cloisite $10 \mathrm{~A}^{\circledR}$ immersed in $\mathrm{NaOH}$ solution having a $\mathrm{pH}$ of 13 at $28^{\circ} \mathrm{C}$

Figure 87. Percentage weight gain versus $t^{1 / 2}$ for samples containing $2 \mathrm{wt} \%$ Cloisite $10 \mathrm{~A}^{\circledR}$ immersed in $\mathrm{NaOH}$ solution having a $\mathrm{pH}$ of 13 at $28^{\circ} \mathrm{C}$

Figure 88. Percentage weight gain versus $t^{1 / 2}$ for samples containing $5 \mathrm{wt} \%$ Cloisite $10 \mathrm{~A}^{\circledR}$ immersed in $\mathrm{NaOH}$ solution having a $\mathrm{pH}$ of 13 at $28^{\circ} \mathrm{C}$

Figure 89. Variation in Diffusion coefficient with weight percent of Cloisite $10 \mathrm{~A}^{\circledR} \ldots . .118$

Figure 90. Variation in Equilibrium Moisture Content with weight percent of Cloisite $10 \mathrm{~A}^{\circledR}$

Figure 91. $M_{t} / M_{\infty}$ Versus $t^{1 / 2} / 2 l$ for FRP samples containing $0 \mathrm{wt} \%$ Cloisite $10 \mathrm{~A}^{\circledR}$ immersed in $0.1 \mathrm{M} \mathrm{NaCl}$ solution at $25^{\circ} \mathrm{C}$

Figure 92. Corrected $M_{t} / M_{\infty}$ Versus $t^{1 / 2} / 2 l$ for FRP samples containing $0 \mathrm{wt} \%$ Cloisite

$10 \mathrm{~A}^{\circledR}$ immersed in $0.1 \mathrm{M} \mathrm{NaCl}$ solution at $25^{\circ} \mathrm{C}$

Figure 93. $M_{t} / M_{\infty}$ Versus $t^{1 / 2} / 2 l$ for FRP samples containing $1 \mathrm{wt} \%$ Cloisite $10 \mathrm{~A}^{\circledR}$ immersed in $0.1 \mathrm{M} \mathrm{NaCl}$ solution at $25^{\circ} \mathrm{C}$

Figure 94. $M_{t} / M_{\infty}$ Versus $t^{1 / 2} / 2 l$ for FRP samples containing $2 \mathrm{wt} \%$ Cloisite $10 \mathrm{~A}^{\circledR}$ immersed in $0.1 \mathrm{M} \mathrm{NaCl}$ solution at $25^{\circ} \mathrm{C}$

Figure 95 . $M_{t} / M_{\infty}$ Versus $t^{1 / 2} / 2 l$ for FRP samples containing $5 \mathrm{wt} \%$ Cloisite $10 \mathrm{~A}^{\circledR}$ immersed in $0.1 \mathrm{M} \mathrm{NaCl}$ solution at $25^{\circ} \mathrm{C}$

Figure 96. Chemistry between Silane and $\mathrm{CI}$ ions

Figure 97. Percentage weight gain versus $t^{1 / 2}$ for FRP samples containing $0 \mathrm{wt} \%$ Cloisite

$10 \mathrm{~A}^{\circledR}$ immersed in $13 \mathrm{pH} \mathrm{NaOH}$ solution at $25^{\circ} \mathrm{C}$ 128

Figure 98. Percentage weight gain versus $t^{1 / 2}$ for FRP samples containing $1 \mathrm{wt} \%$ Cloisite

$10 \mathrm{~A}^{\circledR}$ immersed in $13 \mathrm{pH} \mathrm{NaOH}$ solution at $25^{\circ} \mathrm{C}$ 128

Figure 99. Percentage weight gain versus $t^{1 / 2}$ for FRP samples containing $2 \mathrm{wt} \%$ Cloisite

$10 \mathrm{~A}^{\circledR}$ immersed in $13 \mathrm{pH} \mathrm{NaOH}$ solution at $25^{\circ} \mathrm{C}$ 129

Figure 100. Percentage weight gain versus $t^{1 / 2}$ for FRP samples containing $5 \mathrm{wt} \%$

Cloisite $10 \mathrm{~A}^{\circledR}$ immersed in $13 \mathrm{pH} \mathrm{NaOH}$ solution at $25^{\circ} \mathrm{C}$

Figure 101. Percentage weight gain versus $t^{1 / 2}$ for samples containing $0 \mathrm{wt} \%$ Cloisite

$10 \mathrm{~A}^{\circledR}$ immersed in $0.1 \mathrm{M} \mathrm{NaCl}$ solution at $42.5^{\circ} \mathrm{C}$

Figure 102. Percentage weight gain versus $t^{1 / 2}$ for samples containing $1 \mathrm{wt} \%$ Cloisite

$10 \mathrm{~A}^{\circledR}$ immersed in $0.1 \mathrm{M} \mathrm{NaCl}$ solution at $42.5^{\circ} \mathrm{C}$.

Figure 103. Percentage weight gain versus $t^{1 / 2}$ for samples containing $2 \mathrm{wt} \%$ Cloisite

$10 \mathrm{~A}^{\circledR}$ immersed in $0.1 \mathrm{M} \mathrm{NaCl}$ solution at $42.5^{\circ} \mathrm{C}$ 
Figure 104. Percentage weight gain versus $t^{1 / 2}$ for samples containing $5 \mathrm{wt} \%$ Cloisite $10 \mathrm{~A}^{\circledR}$ immersed in $0.1 \mathrm{M} \mathrm{NaCl}$ solution at $42.5^{\circ} \mathrm{C}$.

Figure 105. Percentage weight gain versus $t^{1 / 2}$ for samples containing $0 \mathrm{wt} \%$ Cloisite

$10 \mathrm{~A}^{\circledR}$ immersed in $\mathrm{NaOH}$ solution having a $\mathrm{pH}$ of 13 at $42.5^{\circ} \mathrm{C}$ 134

Figure 106. Percentage weight gain versus $t^{1 / 2}$ for samples containing $1 \mathrm{wt} \%$ Cloisite

$10 \mathrm{~A}^{\circledR}$ immersed in $\mathrm{NaOH}$ solution having a $\mathrm{pH}$ of 13 at $42.5^{\circ} \mathrm{C}$

Figure 107. Percentage weight gain versus $t^{1 / 2}$ for samples containing $2 \mathrm{wt} \%$ Cloisite

$10 \mathrm{~A}^{\circledR}$ immersed in $\mathrm{NaOH}$ solution having a $\mathrm{pH}$ of 13 at $42.5^{\circ} \mathrm{C}$

Figure 108. Percentage weight gain versus $t^{1 / 2}$ for samples containing $5 \mathrm{wt} \%$ Cloisite

$10 \mathrm{~A}^{\circledR}$ immersed in $\mathrm{NaOH}$ solution having a $\mathrm{pH}$ of 13 at $42.5^{\circ} \mathrm{C}$ 136

Figure 109. Percentage weight gain versus $t^{1 / 2}$ for FRP samples containing $0 \mathrm{wt} \%$ Cloisite $10 \mathrm{~A}^{\circledR}$ immersed in $0.1 \mathrm{M} \mathrm{NaCl}$ solution at $42.5^{\circ} \mathrm{C}$ 138

Figure 110. Percentage weight gain versus $t^{1 / 2}$ for FRP samples containing $1 \mathrm{wt} \%$ Cloisite $10 \mathrm{~A}^{\circledR}$ immersed in $0.1 \mathrm{M} \mathrm{NaCl}$ solution at $42.5^{\circ} \mathrm{C}$ 138

Figure 111. Percentage weight gain versus $t^{1 / 2}$ for FRP samples containing $2 \mathrm{wt} \%$ Cloisite $10 \mathrm{~A}^{\circledR}$ immersed in $0.1 \mathrm{M} \mathrm{NaCl}$ solution at $42.5^{\circ} \mathrm{C}$ 139

Figure 112. Percentage weight gain versus $t^{1 / 2}$ for FRP samples containing $5 \mathrm{wt} \%$ Cloisite $10 \mathrm{~A}^{\circledR}$ immersed in $0.1 \mathrm{M} \mathrm{NaCl}$ solution at $42.5^{\circ} \mathrm{C}$ 139

Figure 113. Percentage weight gain versus $t^{1 / 2}$ for FRP samples containing 0 wt $\%$ Cloisite $10 \mathrm{~A}^{\circledR}$ immersed in $13 \mathrm{pH} \mathrm{NaOH}$ solution at $42.5^{\circ} \mathrm{C}$ 140

Figure 114. Percentage weight gain versus $t^{1 / 2}$ for FRP samples containing $1 \mathrm{wt} \%$ Cloisite $10 \mathrm{~A}^{\circledR}$ immersed in $13 \mathrm{pH} \mathrm{NaOH}$ solution at $42.5^{\circ} \mathrm{C}$ 140

Figure 115. Percentage weight gain versus $t^{1 / 2}$ for FRP samples containing $2 \mathrm{wt} \%$ Cloisite $10 \mathrm{~A}^{\circledR}$ immersed in $13 \mathrm{pH} \mathrm{NaOH}$ solution at $42.5^{\circ} \mathrm{C}$ 141

Figure 116. Percentage weight gain versus $t^{1 / 2}$ for FRP samples containing $5 \mathrm{wt} \%$ Cloisite $10 \mathrm{~A}^{\circledR}$ immersed in $13 \mathrm{pH} \mathrm{NaOH}$ solution at $42.5^{\circ} \mathrm{C}$ 141

Figure 117. $M_{t} / M_{\infty}$ versus $t^{1 / 2} / 2 l$ for samples containing $0 \mathrm{wt} \%$ Cloisite $10 \mathrm{~A}^{\circledR}$ immersed in $0.1 \mathrm{M} \mathrm{NaCl}$ solution at $4^{\circ} \mathrm{C}$ 142

Figure 118. $M_{t} / M_{\infty}$ versus $t^{1 / 2} / 2 l$ for samples containing $1 \mathrm{wt} \%$ Cloisite $10 \mathrm{~A}^{\circledR}$ immersed in $0.1 \mathrm{M} \mathrm{NaCl}$ solution at $4^{\circ} \mathrm{C}$

Figure 119. $M_{t} / M_{\infty}$ versus $t^{1 / 2} / 2 l$ for samples containing $2 \mathrm{wt} \%$ Cloisite $10 \mathrm{~A}^{\circledR}$ immersed in $0.1 \mathrm{M} \mathrm{NaCl}$ solution at $4^{\circ} \mathrm{C}$

Figure 120. $M_{t} / M_{\infty}$ versus $t^{1 / 2} / 2 l$ for samples containing $5 \mathrm{wt} \%$ Cloisite $10 \mathrm{~A}^{\circledR}$ immersed in $0.1 \mathrm{M} \mathrm{NaCl}$ solution at $4^{\circ} \mathrm{C}$ 144

Figure 121. $M_{t} / M_{\infty}$ versus $t^{1 / 2} / 2 l$ for samples containing $0 \mathrm{wt} \%$ Cloisite $10 \mathrm{~A}^{\circledR}$ immersed in $13 \mathrm{pH} \mathrm{NaOH}$ solution at $4^{\circ} \mathrm{C}$

Figure 122 . $M_{t} / M_{\infty}$ versus $t^{1 / 2} / 2 l$ for samples containing $1 \mathrm{wt} \%$ Cloisite $10 \mathrm{~A}^{\circledR}$ immersed in $13 \mathrm{pH} \mathrm{NaOH}$ solution at $4^{\circ} \mathrm{C}$.... 145

Figure 123. $M_{t} / M_{\infty}$ versus $t^{1 / 2} / 2 l$ for samples containing $2 \mathrm{wt} \%$ Cloisite $10 \mathrm{~A}^{\circledR}$ immersed in $13 \mathrm{pH} \mathrm{NaOH}$ solution at $4^{\circ} \mathrm{C}$ 145

Figure 124. $M_{t} / M_{\infty}$ versus $t^{1 / 2} / 2 l$ for samples containing $5 \mathrm{wt} \%$ Cloisite $10 \mathrm{~A}^{\circledR}$ immersed in $13 \mathrm{pH} \mathrm{NaOH}$ solution at $4^{\circ} \mathrm{C}$ 146

Figure 125. Variation in diffusion coefficient with wt $\%$ Cloisite $10 \mathrm{~A}^{\circledR}$ for the samples immersed in $0.1 \mathrm{M} \mathrm{NaCl}$ solution. 
Figure 126. Variation in equilibrium moisture content with wt $\%$ Cloisite $10 \mathrm{~A}^{\circledR}$ for the samples immersed in $0.1 \mathrm{M} \mathrm{NaCl}$ solution

Figure 127. Variation in diffusion coefficient with wt\% Cloisite $10 \mathrm{~A}^{\circledR}$ for the samples immersed in $13 \mathrm{pH} \mathrm{NaOH}$ solution.

Figure 128. Variation in equilibrium moisture content with wt $\%$ Cloisite $10 \mathrm{~A}^{\circledR}$ for the samples immersed in $13 \mathrm{pH} \mathrm{NaOH}$ solution.

Figure 129. Corrected $M_{t} / M_{\infty}$ versus $t^{1 / 2} / 2 l$ for FRP samples containing $0 \mathrm{wt} \%$ Cloisite $10 \mathrm{~A}^{\circledR}$ immersed in $0.1 \mathrm{M} \mathrm{NaCl}$ solution at $4^{\circ} \mathrm{C}$

Figure 130. Corrected $M_{t} / M_{\infty}$ versus $t^{1 / 2} / 2 l$ for FRP samples containing 1 wt $\%$ Cloisite $10 \mathrm{~A}^{\circledR}$ immersed in $0.1 \mathrm{M} \mathrm{NaCl}$ solution at $4^{\circ} \mathrm{C}$

Figure 131. Corrected $M_{t} / M_{\infty}$ versus $t^{1 / 2} / 2 l$ for FRP samples containing 2 wt $\%$ Cloisite $10 \mathrm{~A}^{\circledR}$ immersed in $0.1 \mathrm{M} \mathrm{NaCl}$ solution at $4^{\circ} \mathrm{C}$

Figure 132. Corrected $M_{t} / M_{\infty}$ versus $t^{1 / 2} / 2 l$ for FRP samples containing 5 wt $\%$ Cloisite $10 \mathrm{~A}^{\circledR}$ immersed in $0.1 \mathrm{M} \mathrm{NaCl}$ solution at $4^{\circ} \mathrm{C}$

Figure 133. Corrected $M_{t} / M_{\infty}$ versus $t^{1 / 2} / 2 l$ for FRP samples containing $0 \mathrm{wt} \%$ Cloisite

$10 \mathrm{~A}^{\circledR}$ immersed in $13 \mathrm{pH} \mathrm{NaOH}$ solution at $4^{\circ} \mathrm{C}$

Figure 134. Corrected $M_{t} / M_{\infty}$ versus $t^{1 / 2} / 2 l$ for FRP samples containing 1 wt $\%$ Cloisite

$10 \mathrm{~A}^{\circledR}$ immersed in $13 \mathrm{pH} \mathrm{NaOH}$ solution at $4^{\circ} \mathrm{C}$

Figure 135. Corrected $M_{t} / M_{\infty}$ versus $t^{1 / 2} / 2 l$ for FRP samples containing 2 wt $\%$ Cloisite

$10 \mathrm{~A}^{\circledR}$ immersed in $13 \mathrm{pH} \mathrm{NaOH}$ solution at $4^{\circ} \mathrm{C}$

Figure 136. Corrected $M_{t} / M_{\infty}$ versus $t^{1 / 2} / 2 l$ for FRP samples containing 5 wt $\%$ Cloisite

$10 \mathrm{~A}^{\circledR}$ immersed in $13 \mathrm{pH} \mathrm{NaOH}$ solution at $4^{\circ} \mathrm{C}$

Figure 137. Variations in diffusion coefficients with various clay loadings for the FRP samples immersed in $0.1 \mathrm{M} \mathrm{NaCl}$ solution at $4^{\circ} \mathrm{C}$.

Figure 138. Variations equilibrium moisture contents with various clay loadings for the

FRP samples immersed in $0.1 \mathrm{M} \mathrm{NaCl}$ solution at $4^{\circ} \mathrm{C}$.

Figure 139. Variations in diffusion coefficients with various clay loadings for the FRP samples immersed in $13 \mathrm{pH} \mathrm{NaOH}$ solution at $4{ }^{\circ} \mathrm{C}$

Figure 140. Variations equilibrium moisture contents with various clay loadings for the

FRP samples immersed in $13 \mathrm{pH} \mathrm{NaOH}$ solution at $4^{\circ} \mathrm{C}$

Figure 141. Normalized weight-loss curves for the samples containing $0 \mathrm{wt} \%$ Cloisite $10 A^{\circledR}$ clay

Figure 142. Normalized weight-loss curves for the samples containing $1 \mathrm{wt} \%$ Cloisite $10 \mathrm{~A}^{\circledR}$ clay

Figure 143. Normalized weight-loss curves for the samples containing 2 wt $\%$ Cloisite $10 \mathrm{~A}^{\circledR}$ clay.

Figure 144. Normalized weight-loss curves for the samples containing $5 \mathrm{wt} \%$ Cloisite $10 \mathrm{~A}^{\circledR}$ clay

Figure 145. Weight change versus time for a neat resin sample ................................ 162

Figure 146. Weight change versus time for a sample containing $5 \mathrm{wt} \%$ Cloisite $10 \mathrm{~A}^{\circledR} 162$

Figure 147. Superimposition of short-time desorption data for the neat resin sample on the complete desorption curve of neat resin.

Figure 148 Superimposition of short-time desorption data for the $5 \mathrm{wt} \%$ clay containing

sample on the complete desorption curve of for similar samples 164 
Figure 149. Weight gain versus time for assemblies covered with a polymeric film containing $0 \mathrm{wt} \%$ Cloisite $10 \mathrm{~A}^{\circledR}$

Figure 150. Weight gain versus time for assemblies covered with a polymeric film containing $1 \mathrm{wt} \%$ Cloisite $10 \mathrm{~A}^{\circledR}$

Figure 151. Weight gain versus time for assemblies covered with a polymeric film containing $2 \mathrm{wt} \%$ Cloisite $10 \mathrm{~A}^{\circledR}$

Figure 152. Weight gain versus time for assemblies covered with a polymeric film containing 5 wt $\%$ Cloisite $10 \mathrm{~A}^{\circledR}$

Figure 153. Normalized flux versus weight percent Cloisite $10 \mathrm{~A}^{\circledR}$

Figure 154. Weight gain versus time for assemblies covered with FRP film containing 0 wt \% Cloisite $10 \mathrm{~A}^{\circledR}$

Figure 155. Weight gain versus time for assemblies covered with FRP film containing 1 wt $\%$ Cloisite $10 \mathrm{~A}^{\circledR}$

Figure 156. Weight gain versus time for assemblies covered with FRP film containing 2 wt $\%$ Cloisite $10 A^{\circledR}$

Figure 157. Weight gain versus time for assemblies covered with FRP film containing 5 wt $\%$ Cloisite $10 \mathrm{~A}^{\circledR}$

Figure 158. Schematic Diagram of Resistance provided by FRP film

Figure 159. (a) Ribbon reinforced composite plate (b) Parameters describing plate construction.

Figure 160. SEM image of freshly prepared FRP sample

Figure 161. Normalized Weight Gain Curves for Glass-Reinforced as well as Unreinforced Samples immersed in Distilled Water at $4^{\circ} \mathrm{C}$

Figure 162. Normalized mass uptake for samples containing $1 \mathrm{wt} \%$ Cloisite $10 \mathrm{~A}^{\circledR}$ (Solid line: Fit of equation 15 with $R=0.61$

Figure 163. Normalized mass uptake for samples containing $2 \mathrm{wt} \%$ Cloisite $10 \mathrm{~A}^{\circledR}$ (Solid line: Predictions of equation 15 with $R=0.61$

Figure 164. Normalized mass uptake for samples containing $5 \mathrm{wt} \%$ Cloisite $10 \mathrm{~A}^{\circledR}$ (Solid line: Predictions of equation 15 with $R=0.61$

Figure 165. Typical Stress-Strain curve for the neat resin sample

Figure 166. Variation in Tensile Modulus of Nanocomposites with weight percent of Cloisite $10 \mathrm{~A}^{\circledR}$

Figure 167. Variation in Tensile Strength of Nanocomposites with weight percent of Cloisite $10 \mathrm{~A}^{\circledR}$

Figure 168. Variation in Strain at break with weight percent of Cloisite $10 A^{\circledR}$ 189

Figure 169. Variation in Impact Strength of Nanocomposites with weight percent of Cloisite $10 \mathrm{~A}^{\circledR}$

Figure 170. Variation in storage modulus $\left(\mathrm{G}^{\prime}\right)$ with temperature as a function of wt\% Cloisite $10 \mathrm{~A}^{\circledR}$ clay.

Figure 171. Variation in loss modulus (G”) with temperature as a function of wt\% Cloisite $10 \mathrm{~A}^{\circledR}$ clay.

Figure 172. Variation in $\tan \delta$ with temperature as a function of wt $\%$ Cloisite $10 A^{\circledR}$ clay

Figure 173. Fractional Weight loss versus Temperature

Figure 174. SEM of "Reference" Sample (900X) Arrow shows circular cross-section of a fiber 
Figure 175. SEM of "Reference" Sample (1000X) Arrow shows adhesion between fiber and resin

Figure 176. SEM of "Reference" Sample (1000X) Arrow shows adhesion between fiber and resin

Figure 177. SEM of FRP sample containing no nanoclay (Location: Closer to the surface exposed to distilled water) (1000X) Arrows show damage and crack on fibers .... 199

Figure 178. SEM of FRP sample containing no nanoclay (Location: Closer to the sur face exposed to distilled water) (2000X) Arrow shows damage to fiber surface 199

Figure 179. SEM of FRP sample containing no nanoclay (Location: Closer to the surface exposed to distilled water) (2000X) Arrow shows damage to glass-fiber. 200

Figure 180. SEM of FRP sample containing no nanoclay (Location: Away from the surface exposed to distilled water) (1000X) Arrow shows distorted cross-section of glass-fiber.

Figure 181. SEM of FRP sample containing no nanoclay (Location: Away from the surface exposed to distilled water) (1200X) 201

Figure 182. SEM of FRP sample containing no nanoclay (Location: Away from the surface exposed to distilled water) (1000X)

201

Figure 183. SEM of FRP sample containing $5 \mathrm{wt} \%$ Cloisite $10 \mathrm{~A}^{\circledR}$ Clay (Location: Closer to the surface exposed to distilled water) (1000X) Arrow shows circular crosssection of glass-fiber 203

Figure 184. SEM of FRP sample containing $5 \mathrm{wt} \%$ Cbisite $10 \mathrm{~A}^{\circledR}$ Clay (Location: Closer to the surface exposed to distilled water) (2000X) 204

Figure 185. SEM of FRP sample containing $5 \mathrm{wt} \%$ Cloisite $10 \mathrm{~A}^{\circledR}$ Clay (Location: Away from the surface exposed to distilled water) (1200X) Arrow shows adhesion between fiber and resin 204

Figure 186. SEM of FRP sample containing $5 \mathrm{wt} \%$ Cloisite $10 \mathrm{~A}^{\circledR}$ Clay (Location: Away from the surface exposed to distilled water) (900X) 205 


\section{CHAPTER I}

\section{INTRODUCTION}

Applications of fiber reinforced polymer (FRP) composites in automobile, aircraft, marine, construction and other industries are increasing at a rapid rate. Indeed a synergistic combination of a thermosetting polymer matrix and reinforcing fibers imparts high strength-to-weight ratio, high stiffness-to-weight ratio, excellent durability and low density to FRPs, which, in turn, make them a potential substitute for metals. The modulus-to-weight ratio and the tensile strength-to-weight ratio for fiber reinforced polymer composites can be much higher than those for metals or alloys (Mallick, 1993).

The basic constituent materials of FRPs are polymeric resin and reinforcing fibers. High-strength and high-modulus fibers embedded in a matrix are the major load carrying members of FRPs whereas, the role of the matrix is: 1) to maintain the orientation of fibers; 2) to distribute stresses between fibers uniformly; 3) to protect the fibers against adverse environmental conditions; 4) and to protect the fibers from mechanical abrasion. The matrix plays a minor role in the tensile load-carrying capacity of a composite structure but it influences the interlaminar shear and in-plane shear properties significantly. Although both fibers and matrix maintain their chemical and physical identity, their combination gives rise to mechanical properties that cannot be achieved with either of the constituents acting alone. Epoxies, polyesters, vinyl esters and phenolics are the most commonly employed thermosets for FRP applications. Thermoplastics, such as Nylons, polycarbonates, polyether-ether ketone (PEEK), polysulfone (PSUL), polyamide-imide (PAI), polyphenylene sulfide (PPS) and polyether 
imide (PEI) are also used as matrix materials. Relative advantages and disadvantages of both thermosetting and thermoplastic matrices are summarized in Table I. It can be inferred from Table I that thermoset matrices have mechanical properties that are more suitable for structural FRP applications as opposed to thermoplastic matrices that are subject to changes in hardness with temperature. The most common reinforcing fibers in commercial use are glass fibers, carbon fibers and Kevlar 49. Sometimes boron, silicon carbide or aluminum oxide fibers are also used.

Table I. Relative Advantages and Disadvantages of Thermosetting and Thermoplastic Matrix Materials

\begin{tabular}{|c|c|c|}
\hline Resin Type & Advantage & Disadvantage \\
\hline \multirow{4}{*}{ Thermoset } & High tensile modulus & Limited storage life \\
\cline { 2 - 3 } & High tensile strength & Long fabrication life \\
\cline { 2 - 3 } & High thermal stability & Low strains-to- failure \\
\cline { 2 - 3 } & High chemical resistance & Low impact strength \\
\cline { 2 - 3 } & Low creep & \\
\cline { 2 - 3 } & Low stress relaxation & \\
\hline \multirow{4}{*}{ Thermoplastic } & Unlimited storage life & High melt/solution viscosity \\
\cline { 2 - 3 } & Shorter fabrication time & Low creep resistance \\
\cline { 2 - 3 } & Post formability & Low thermal stability \\
\cline { 2 - 3 } & Ease of repair & Low chemical resistance \\
\cline { 2 - 3 } & Ease of handling & \\
\cline { 2 - 3 } & Recyclability & \\
\cline { 2 - 3 } & High impact strength & \\
\cline { 2 - 3 } & & \\
\hline
\end{tabular}

FRPs are invariably exposed to varying environments, both in storage and in operation. Since water is omnipresent in the environment, concern has arisen about the nature of the interaction of water with these materials, and the effects of water on the material properties of FRPs. There is also a potential for exposure to saline and alkaline conditions depending up on the type of application. Such unwholesome environments may adversely affect the properties of the matrix polymer and the composite. 
The effect of hot- and cold-water environments on the tensile strength of epoxyglass-fiber composites was studied in early stages of their development (Ishai, 1975). Results indicated that longitudinal tensile strength and transverse tensile strength decreased significantly after weathering in hot and cold water. SEM images of weathered samples clearly showed physical damage to the fibers. In another study by Selzer and Friedrich (1995) it was reported that water molecules could diffuse to the fiber-matrix interface, and this caused weakening of the interface. The matrix material could be plasticized or degraded due to absorption of water (Chin et al., 1999) resulting in deteriorated mechanical properties. Kajorncheappunngam et al. (2002) and Sen et al. (2002) also recorded large reductions in tensile properties of FRPs after extended immersion in acid, alkaline and salt solution.

It is therefore essential, before choosing a matrix for structural applications having a potential service life of 4 to 5 decades, to know how much water the matrix can absorb before it is saturated and the rate at which saturation is attained. It is, therefore, desirable that a material takes as long a time as possible before it is completely saturated with moisture. Recently, there has been great interest in developing glass fiber reinforced composites for construction and repair of bridges and other civil structures (GangaRao and Craigo, 1999). Attempts have been made to rehabilitate concrete structures by applying GFRP wraps on them and testing the durability of the composite system (Kshirsagar et al., 2000). Theories have been proposed to explain the transport of water through polymeric matrix materials and innovative approaches have been employed to minimize the diffusion of water molecules through polymer (Shah, 2001). Much more exploration is required in this direction before one can accurately predict the long-term 
durability and performance data for FRPs that can be used in design calculations. To understand the mechanism of water transport in both glass fiber-reinforced and unreinforced polymer, it is required to estimate the diffusivity and permeability of material at several different temperatures. It is also important to study how fillers may alter water transport through polymeric matrices so that they may be synergistically used with matrix materials. This knowledge will enable us to minimize the adverse effects of moisture on the mechanical properties of FRPs and will help us to design more durable composites of the future. This is the subject of the present research.

The proposed study includes the following objectives:

1. Measuring the diffusion coefficients, equilibrium moisture content and establishing the mechanism of water diffusion through neat and Glass Fiber-Reinfoced DERAKANE 411-350 Momentum vinyl ester resin.

2. Reducing the diffusion coefficient through FRPs by dispersing nanoclay in the matrix.

3. Studying the effect of clay loading on the diffusion propertied of FRPs by varying the amount of clay (1 wt \%, $2 \mathrm{wt} \%, 5 \mathrm{wt} \%)$.

4. Studying the effect of alkaline and saline solutions on the diffusion of water through FRPs.

5. Taking SEM images of damage at the surface of glass fiber after prolonged immersion of FRP in distilled water. 
6. Determining the changes in tensile strength, and impact strength of vinyl ester-clay nanocomposites with varying amounts of nanoclay and correlating the results with available theories.

7. Using DMA to study the structural changes due to immersion in distilled water for extended periods.

To recapitulate, diffusion of water through FRPs will be studied gravimetrically, by performing transient water uptake experiments on glass fiber-reinforced as well as unreinforced nanocomposites in distilled water, alkaline solutions, and saline solutions. Diffusion mechanism will be proposed for both glass fiber-reinforced and un-reinforced nanocomposites based on the experimental results. Equations will also be proposed to predict the changes in diffusion behavior with temperature. SEM images will be taken to estimate the damage of the fiber surface after extended exposure to distilled water. Tensile tests and fracture tests will be carried out on un-reinforced nanocomposites with various clay loadings. Results of these experiments will be correlated with available theories. DMA tests will be carried out to study changes in glass transition temperature $\left(\mathrm{T}_{\mathrm{g}}\right)$, storage modulus and loss modulus with clay loading.

The present research has been funded by the U.S. Department of Transportation and Federal Highway Administration. The specific application is the enhancement of longevity of highway pavements employing FRP composite dowels for jointed plain concrete pavements and FRP bars as reinforcement in continuously reinforced concrete pavement. 
Sections that follow cover a review of what has been substantiated and documented so far about the moisture transport in glassy, thermosetting matrix materials with an emphasis on vinyl ester resins. They also include an introduction to nanocomposites and explain how nano materials can be used not only to hinder the transport of water molecules in matrix but also to reinforce the matrix. Verification of this idea and studying critical issue on diffusion of water through glass fiber-reinforced and un-reinforced vinyl ester-clay nanocomposites is the focus of the present research. 


\section{CHAPTER II}

\section{LITERATURE REVIEW}

FRPs are invariably exposed to varying environments, both in storage and in operation. Since water is omnipresent in the environment, concern has arisen about the nature of the interaction of water with these materials, and the effects of water on the material properties of FRPs. In the specific application under consideration, the FRP dowel bars might also get exposed to concrete pore solution which is alkaline in nature. Salt is used to melt the snow on the pavements during the winter season. The dowel bars might also get in contact with the salt solution resulting from melting snow. Such unwholesome environments may adversely affect the properties of the matrix polymer and the composite. Some examples of how these harsh environments can affect the mechanical properties are discussed in the subsequent sections.

The effect of hot- and cold-water environments on the tensile strength epoxyglass fiber composites was studied in early stages of their development (Ishai, 1975). Results indicated that longitudinal tensile strength dropped by $29 \%$ and $3 \%$ after weathering in hot- and cold-water respectively. Losses in transverse tensile strength were $31 \%$ and $10 \%$ respectively for the same weathering conditions. SEM images of weathered samples clearly showed physical damage to the fibers.

In another study by Selzer and Friedrich (1995) it was reported that water molecules could diffuse to the fiber-matrix interface, and this caused weakening of the interface. Studies showed that water absorbed in the matrix exists in two forms, 1) bound water and 2) free or mobile water (Klotz and Browstow, 1996). It was concluded that free or mobile water causes irreversible changes in the material resulting in permanent 
decrease in strength of the composite material. The matrix material can be plasticized or degraded due to absorption of water (Chin et al., 1999) resulting in deteriorated mechanical properties.

Todo et al. (2000) reported the effects of moisture absorption on the dynamic interlaminar fracture toughness of carbon/epoxy composites. These authors reported as much as $22.7 \%$ decrease in interlaminar fracture toughness after conditioning the samples in $90 \%$ relative humidity environment at $80^{\circ} \mathrm{C}$ for 1500 hours. Researchers also postulated the degradation mechanisms due to the moisture absorption on the basis of experimental results and fractographic studies.

Kajorncheappunngam et al. (2002) reported more than $70 \%$ loss in tensile strength of glass-fiber reinforced epoxy samples due to immersion in $1 \mathrm{M} \mathrm{HCl}$ solution at room temperature and $5 \mathrm{M} \mathrm{NaOH}$ solution at $60^{\circ} \mathrm{C}$ for 5 months. These authors also reported $24 \%$ and $48 \%$ loss in tensile strength of the same composite material after immersion in distilled water for 5 months at room temperature and $60^{\circ} \mathrm{C}$ respectively. Extended immersion of the same FRP in saturated salt solution seemed to have least effect on their mechanical properties.

Sen et al. (2002) tested durability of E-Glass/Vinyl ester reinforcement in alkaline solution. It was reported in their study that the FRP lost $63 \%$ of its original tensile strength due immersion in simulated pore solution having a pH between 13.35 and 13.5.

Considerable amount of effort has been made in the past to understand the transport of water in glassy polymers. Attempts have been made to determine the nature of water and the transport mechanism of water molecules inside polymer networks. The 
articles cited in this chapter review what has been documented so far about water transport in polymeric materials.

\subsection{Determining the Diffusivity from Transient Diffusion Experiments}

The classical theory of diffusion has been derived from Fick's law, which considers that the driving force for diffusion through a thin film is a concentration gradient. When Fick's law of diffusion is combined with a mass balance, Fick's Second law of diffusion is obtained. Two basic assumptions are involved in the subsequent derivation:

1. Diffusivity, $D$, of the diffusing species is independent of the concentration.

2. Diffusion is unidirectional, normal to the plane of the film.

Fick's second law of diffusion is represented mathematically by:

$$
\frac{\partial c}{\partial t}=D \frac{\partial^{2} c}{\partial x^{2}}
$$

Where,

$x=$ Position (see Figure 1)

$t=$ Time

$c=$ Water concentration at time $t$ at a point a distance $x$ from the mid plane

$D=$ Diffusivity

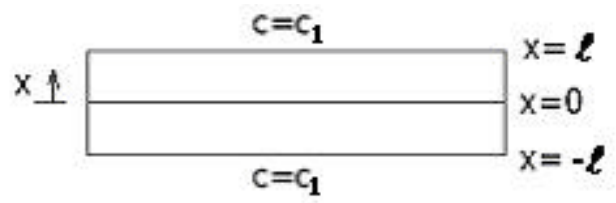

Figure 1. Coordinate system for unidirectional diffusion process 
When a thin film of polymer is exposed to humid environments, water uptake $M_{t}$ can be obtained by solving equation 1 with constant boundary conditions (Crank, 1975). The solution is:

$$
\frac{M_{t}}{M_{\infty}}=\left[1-\sum_{0}^{\infty} \frac{8}{(2 n+1)^{2} \pi^{2}} \exp \left[\frac{-D(2 n+1)^{2} \pi^{2} t}{4 l^{2}}\right]\right]
$$

Where,

$M_{\infty}=$ Equilibrium moisture uptake

$2 l=$ Sample thickness

The corresponding solution of Fick's law at short times is:

$$
\frac{M_{t}}{M_{\infty}}=2\left(\frac{D t}{l^{2}}\right)^{1 / 2}\left\{\pi^{-1 / 2}+2 \sum_{1}^{\infty}(-1)^{n} \operatorname{ierfc} \frac{n l}{\sqrt{D t}}\right\}
$$

Equation 3 can be simplified for $\frac{D t}{4 l^{2}}<0.05$ (Singh et al., 1991, for example). The result is:

$$
\frac{M_{t}}{M_{\infty}}=4\left(\frac{D t}{\pi(2 l)^{2}}\right)^{\frac{1}{2}}
$$

The diffusivity can be determined from the initial slope of $M_{t} / M_{\infty}$ versus $\sqrt{t} / 2 l$. 


\subsection{Determining the Diffusivity from Steady State Diffusion Experiments}

When a constant concentration gradient of water is applied across a film of polymer as shown in Figure 2, water diffuses into the polymer from the surface that is exposed to higher concentration, travels through the thickness of polymer film and leaves the film from the surface that is exposed to relatively lower concentration. Once the steady state is reached, diffusion coefficient of the polymer can be calculated from the following equation:

Diffusion coefficient $=\frac{\text { Water flux }}{\text { Concentrat ion Gradient }}$

Where,

Water flux $=$ Mass of water diffusing per unit time/Area

Concentration Gradient $=\left(C_{1}-C_{2}\right) / \mathrm{L}$

and

$C_{l}=$ Concentration of water at the surface of polymer exposed to higher concentration $C_{2}=$ Concentration of water at the surface of polymer exposed to lower concentration $L=$ Thickness of polymer film

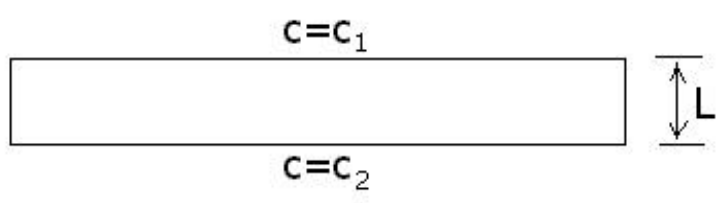

Figure 2. Schematic representation of polymer film exposed to different water concentrations on the surfaces 


\subsection{Representative Results for Diffusion of Water through Thermosetting Polymers}

Chin et al. (1999) pointed out that in glassy polymers, diffusion behavior could be characterized as follows:

1. Case I or Fickian: Rate of diffusion of the penetrant is much less than the polymer segment mobility, i.e., in a transient experiment, the mass uptake is proportional to the square root of time.

2. Case II: Rate of diffusion is much greater than polymer segment mobility, i.e., in a transient experiment, the mass uptake is proportional to time.

3. Anomalous or non-Fickian: Rate of diffusion is comparable with polymer segment mobility

Sections that follow review experimental results of transient diffusion experiments on various polymer matrices materials with an emphasis on vinyl ester resin.

\subsubsection{Chemistry of Vinyl Ester}

It is important to understand the chemical structure of the resin before analyzing the experimental results of diffusion in any polymer. Knowledge of the chemical nature of the resin and number of hydrophilic groups on the polymer chain gives us an idea about the possible interactions between water molecules and the polymer chain.

Unsaturated vinyl ester resin is synthesized by a reaction between an unsaturated carboxylic acid and an epoxy resin. Commonly employed carboxylic acids for the production of vinyl ester resin are methacrylic acid and acrylic acid. A variety of vinyl 
esters can be synthesized by altering the chemistry of the epoxy resin. A schematic representation of vinyl ester synthesis is shown in Figure 3.

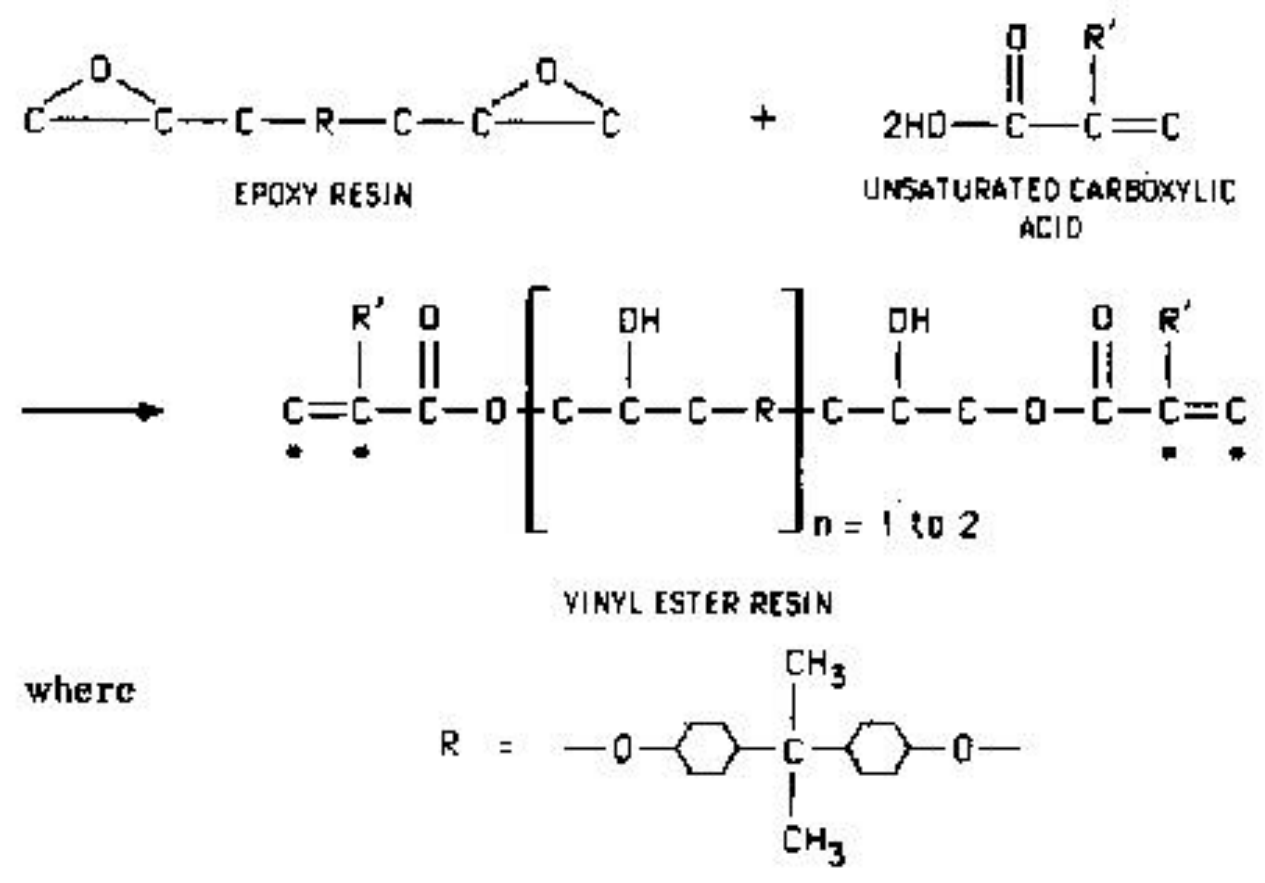

and

$$
R^{\prime}=-\mathrm{H} \text { or }-\mathrm{CH}_{3}
$$

Figure 3. Synthesis of Vinyl Ester

(Mallick, 1993)

The vinyl ester molecule has unsaturation sites $(\mathrm{C}=\mathrm{C})$ on the ends, therefore cross-linking can take place only at the ends. This is done using styrene that is also used as a solvent to dissolve commercial vinyl ester resins. Typical weight percentages of styrene in the commercial vinyl ester ranges from $35 \%$ to $50 \%$. Styrene acts as a crosslinking agent in the curing reaction and forms a link between unsaturation points of two adjacent vinyl ester molecules. The curing reaction for vinyl ester resins is initiated by adding small quantities of a catalyst, such as an organic peroxide. A schematic representation of cross-linked vinyl ester resin is shown in Figure 4. 


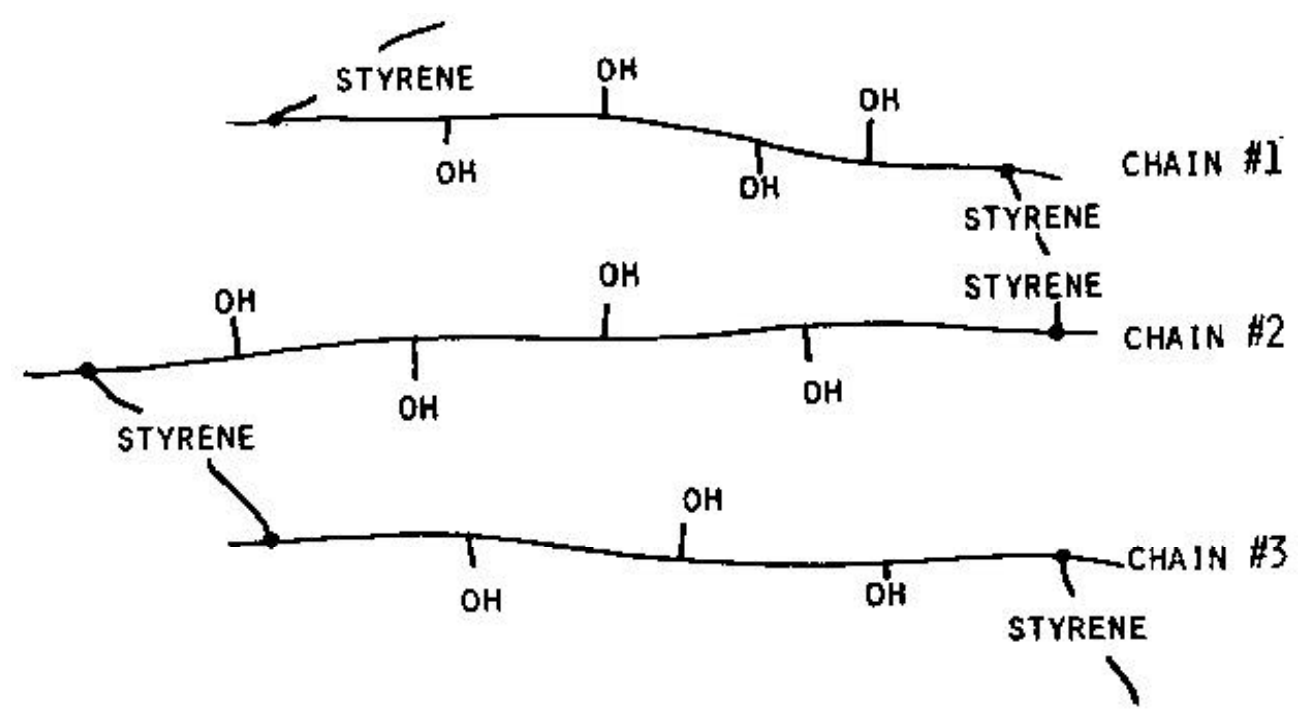

Figure 4. Schematic representation of cross-linked vinyl ester

(Mallick, 1993)

As seen from Figure 4, a cross-linked vinyl ester molecule contains a number of hydroxyl groups along its length. These groups can form hydrogen bonds with water molecules trapping them inside the network of polymer chains. However, hydroxyl groups may also form hydrogen bonds with similar groups on a glass fiber surface resulting in excellent wet-out and good adhesion with glass fibers.

\subsubsection{Representative Results for Diffusion of Water through Vinyl Ester}

Chin et al. (1999) carried out a comparative study of epoxy, vinyl ester and isopolyester matrices. These authors immersed polymer samples in different liquids and verified that diffusion of water in all the three matrices was Fickian in nature.Their results are shown in Table II. Water uptake for epoxy was found to be the greatest among the three resins studied and uptake of water in vinyl ester was found to be the lowest indicating that water uptake of resin depends on the chemical structure of the resin. Epoxy has a higher concentration of hydrophilic hydroxide groups located along the 
backbone as well as amine groups from the hardener used in curing epoxies, and these groups attract water molecules. Sorptive affinity towards water is directly proportional to the number and polarity of the hydrophilic groups present in the polymer. Tables II and III show the values of diffusion coefficients and equilibrium moisture content respectively.

Table II. Fickian Diffusion Coefficients for Epoxy, Vinyl Ester and Isopolyester Films (Chin et al., 1999)

\begin{tabular}{|c|c|c|c|}
\hline \multicolumn{2}{|c|}{} & \multicolumn{2}{|c|}{ Diffusion Coefficient, $\mathrm{D}\left(\times 10^{9} \mathrm{~cm}^{2} / \mathrm{s}\right)$} \\
\hline Matrix & Sorbent & $22^{\circ} \mathrm{C}$ & $60^{\circ} \mathrm{C}$ \\
\hline \multirow{2}{*}{$\begin{array}{c}\text { Epoxy } \\
\text { EPON 828RS }\end{array}$} & Distilled Water & 0.53 & 13.6 \\
\cline { 2 - 4 } & Salt Solution & 1.04 & 8.54 \\
\cline { 2 - 4 } & Pore Solution & 0.67 & 9.82 \\
\hline \multirow{2}{*}{$\begin{array}{c}\text { Vinyl Ester } \\
\text { Derakane }\end{array}$} & Distilled Water & 6.88 & 19.0 \\
\cline { 2 - 4 } & Salt Solution & 8.75 & 24.5 \\
\cline { 2 - 4 } & Pore Solution & 8.72 & 24.3 \\
\hline \multirow{2}{*}{ Isopolyester } & Distilled Water & 8.93 & 41.9 \\
\cline { 2 - 4 } Aropol 7240-T-15 & Salt Solution & 11.7 & --- \\
\cline { 2 - 4 } & Pore Solution & 8.89 & --- \\
\hline
\end{tabular}

Table III. Equilibrium Moisture Content for Epoxy, Vinyl Ester and Isopolyester Films

(Chin et al., 1999)

\begin{tabular}{|c|l|c|r|}
\hline \multicolumn{2}{|c|}{} & \multicolumn{2}{|c|}{ Equilibrium Moisture Content (wt\%) } \\
\hline Matrix & Sorbent & $22^{\circ} \mathrm{C}$ & $60^{\circ} \mathrm{C}$ \\
\hline \multirow{2}{*}{ Epoxy } & Distilled Water & $1.42 \pm 0.03$ & $2.00 \pm 0.10$ \\
\cline { 2 - 4 } & Salt Solution & $1.79 \pm 0.04$ & $1.93 \pm 0.08$ \\
\cline { 2 - 4 } & Pore Solution & $1.64 \pm 0.04$ & $1.88 \pm 0.06$ \\
\hline \multirow{3}{*}{$\begin{array}{c}\text { Vinyl Ester } \\
\text { DerakaneTM 411-350PA }\end{array}$} & Distilled Water & $0.52 \pm 0.01$ & $0.62 \pm 0.05$ \\
\cline { 2 - 4 } & Salt Solution & $0.55 \pm 0.01$ & $0.69 \pm 0.04$ \\
\cline { 2 - 4 } & Pore Solution & $0.49 \pm 0.04$ & $0.64 \pm 0.03$ \\
\hline Isopolyester & Distilled Water & $0.56 \pm 0.02$ & $0.50 \pm 0.08$ \\
\cline { 2 - 4 } Aropol 7240-T-15 & Salt Solution & $0.55 \pm 0.03$ & $0.45 \pm 0.10$ \\
\cline { 2 - 4 } & Pore Solution & $0.50 \pm 0.04$ & $0.49 \pm 0.05$ \\
\hline
\end{tabular}


Verghese et al. (1999) carried out diffusion studies on DERAKANE 411-400 vinyl ester resins. They reported Fickian diffusion behavior. The diffusion coefficient and equilibrium moisture content at $25^{\circ} \mathrm{C}$ were reported to be $1.18 \times 10^{-8} \mathrm{~cm}^{2} / \mathrm{s}$ and $0.97 \mathrm{wt} \%$ respectively. A possible explanation for different authors reporting different values of diffusion coefficient for vinyl ester resins is that different types of the vinyl ester resin have been used in each individual study. Each vinyl ester has a unique chemical structure, and this chemical structure combined with different processing conditions leads to different extents of cure, cross-linking and microstructure. The effect of these factors is reflected in terms of different equilibrium moisture contents and moisture diffusion coefficients.

\subsubsection{Effect of Temperature on the Diffusion of water through the Matrix}

Vanlandingham et al. (1999) studied moisture diffusion in epoxy EPON 828PACM 20 system as a function of epoxy-amine stoichiometry. It was reported that most of the epoxy samples did not reach stable saturation even after 3000-4000 hours of exposure to various temperature and humidity conditions. Deviations from Fickian diffusion were more pronounced at elevated temperatures and this led them to conclude that the mechanisms responsible for non-Fickian behavior might depend on temperature. The equilibrium moisture content was a strong function of relative humidity of the chamber, and moisture levels for samples in the $85 \% \mathrm{RH}$ environment were approximately $15-25 \%$ higher than corresponding values in the samples in $75 \% \mathrm{RH}$ at room temperature. The effect of temperature on equilibrium moisture was insignificant for samples exhibiting Fickian absorption. However, the effect did appear to be 
significant for the samples exhibiting non-Fickian absorption. Moisture levels for samples exhibiting non-Fickian diffusion in the $50^{\circ} \mathrm{C}, 85 \% \mathrm{RH}$ environment greatly exceeded moisture levels for similar samples in $20^{\circ} \mathrm{C}, 85 \% \mathrm{RH}$. Researchers postulated that as the temperature approaches the glass transition temperature of the polymer, there are fewer interactions between the polymer chain and water molecules. As a result, lesser enthalpy in required for a water molecule to move into the free volume in the polymer network, and this increases the saturation level sharply. Diffusion coefficient values were found to be a very strong function of temperature. Diffusion coefficient values at $20^{\circ} \mathrm{C}$ were found to range between $4 \times 10^{-10} \mathrm{~cm}^{2} / \mathrm{s}$ and $3 \times 10^{-10} \mathrm{~cm}^{2} / \mathrm{s}$. These values shot up by almost an order of magnitude at $50^{\circ} \mathrm{C}$, and ranged between $2 \times 10^{-9} \mathrm{~cm}^{2} / \mathrm{s}$ to $8 \times 10^{-9} \mathrm{~cm}^{2} / \mathrm{s}$. Furthermore, diffusion coefficient values were found to be independent of the humidity level of the conditioning chamber. The variation in the diffusion coefficient in glassy polymers below their glass transition temperature has been modeled by several authors using the Arrhenius relationship:

$D=D_{0} \exp \left(\frac{-E}{R T}\right)$

Where,

$D_{0}=$ Constant coefficient

$E=$ Activation Energy

$R=$ Universal gas constant

$T=$ Absolute temperature

Verghese et al. (1999) reported an increase in the diffusion coefficient of DERAKAME 411-400 vinyl ester resin with increase in temperature. They employed 
equation 8 to fit the experimental data and found that the activation energy was approximately $38.41 \mathrm{~kJ} / \mathrm{mol}$. They also reported an increase in the equilibrium moisture content with increasing temperatures.

\subsubsection{Effect of Glass-Fiber Reinforcement on the Process of Diffusion}

Ishai (1975) showed that the diffusion behavior of moisture through neat EPON 828 epoxy resin could be quite different from diffusion through a composite made of the same resin and E-glass fibers. SEM images of damaged fiber-polymer interface as well as damaged fibers were also taken as a part of the study. There were drastic changes in the sorption curve of the composite samples, and these led to the conclusion that the degradation of fibers was rapid once water molecules reached the fiber-polymer interface. It was also reported that the damage was more for the samples exposed to $80^{\circ} \mathrm{C}$ water than those exposed to $20^{\circ} \mathrm{C}$ water. Similar results were obtained by Dewimille and Bunsell (1983) who also found the composite (DGEBA/Anhydride with E-Glass) degraded when exposed to water at temperatures above $80^{\circ} \mathrm{C}$. However, Marsh et al. (1984) reported diffusion results that do not agree with those of shai (1975). It was reported that, for neat as well as E-glass fiber reinforced bisphenol A and cresol novolac resins, the sorption by the composite was the same as that for the neat resin if the volume of the glass was corrected for. This led them to conclude that water did not enter the interface between the fiber and the polymer.

Apparent disagreement in the experimental results of different researchers can be explained by understanding the nature of the interface between the fiber and polymer. For better load distribution on the fibers, it is desirable that there be chemical bonding between fiber and polymer. Glass is an inorganic material, whereas the polymeric matrix 
is organic. These two materials are not compatible with each other unless the surface of the glass-fiber is treated to modify the surface. Such chemicals are known as coupling agents. Silica $\left(\mathrm{SiO}_{2}\right)$ of glass fiber is hygroscopic and readily absorbs water. Water absorbed on the glass-fiber surface breaks down into hydroxyl groups. Coupling agents have the gerneral foumula $\mathrm{R}-\mathrm{SiX}_{3}$ where $\mathrm{R}$ is an organic radical that is compatible with the polymer matrix and $\mathrm{X}$ is a hydrolizable organic group such as an alcohol. On heating, water is eliminated between the $-\mathrm{OH}$ pairs at the hydrated silica surface and the alcohol group of silane and this causes the formation of strong bond between glass-fibers and the matrix polymer. When these bonds are strong, the presence of glass will have negligible effect on the diffusion behavior of the resin, i.e. diffusion trends similar to that reported by Marsh et al. (1984) will be observed. However, If the bonds are weak and can be displaced by hydrogen bonding with water molecules, debonding and degradation of the FRP will be seen confirming the observations of Ishai (1975).

Klotz et al. (1996) studied nature of water in glass-fiber reinforced epoxy using ${ }^{2} \mathrm{H}-\mathrm{NMR}$ and verified the presence of two types of water: 1) bound water and 2) free water. It was reported that bound water behaves differently from free water. Bound water reached saturation at $21^{\circ} \mathrm{C}$ after about 900 hours but a state of saturation for mobile water was never achieved. When the same experiment was repeated at $70^{\circ} \mathrm{C}$, bound water reached saturation within 24 hours. Flexural strength data were used to prove that free water caused irreversible changes in the material. 


\subsubsection{Proposed Mechanisms for Water Transport through a Network of Polymer}

\section{Molecules}

Adamson (1980) proposed a three-stage process of water absorption. First, the absorbed water occupies the free volume present in the form of voids. In the second stage, water becomes bound to network sites causing swelling. In the third stage, water enters densely crosslinked regions. Barrie et al. (1984) added one more possibility to Adamson's work by saying that water molecules might cluster inside the polymer network and other authors have used this concept to explain the non-linear isotherm observed at high activities.

Wong and Broutman (1985) suggested that polymer networks consist of two regions in which water molecules possess different mobilities. By considering the distribution of water molecules among these regions, it is possible to describe the concentration dependency of the diffusion coefficient in the sorption and resorption process.

Apicella et al. (1985) proposed three modes of sorption: 1) bulk dissolution of water in the polymer network 2) moisture absorption onto the surface of vacuoles which define the excess free volume of the glassy structure 3) hydrogen bonding between polymer hydrophilic groups and water

Litt (1986) explained gaseous diffusion through polymer using free volume concepts. Author suggested that a gas molecule in a polymer matrix could jump under three conditions: 
1. A hole opens next to it (from segmental oscillation of polymer) large enough to allow the molecule to jump (Passive Diffusion)

2. A hole opens which is smaller than the gas molecule, but the kinetic energy of the gas molecule allows it to enlarge the hole and jump by compressing neighboring segments (Activation)

3. Once compressed, the segments cannot relax on the segmental oscillation time scale, and thus can assist the gas molecule to jump into other small holes (Activated Diffusion)

This approach has been successfully used to correlate diffusivity with activation energy for a wide variety of penetrants in polyethylene and poly vinyl acetate. It is also possible to reproduce the non-Arrhenius change in diffusivity with temperature for diffusion.

Chen et al. (2001) proposed a model describing the diffusion behavior of small molecule penetrants in dense polymer membranes based on percolation theory, the fractal theory, the free-volume theory, and the random-walk theory. 


\subsection{Theories Explaining Anomalous Diffusion Behavior}

Typical characteristics of Fickian diffusion are summarized below (Comyn, 1983):

1. Both uptake and desorption plots of $\frac{M_{t}}{M_{\infty}}$ versus $\frac{t^{1 / 2}}{2 l}$ are initially linear.

2. This linear region extends to at least $\frac{M_{t}}{M_{\infty}}=0.6$ for uptake.

3. Beyond the linear region, the curves are concave against the abscissa.

4. Uptake curves obtained by plotting $\frac{M_{t}}{M_{\infty}}$ versus $\frac{t^{1 / 2}}{2 l}$ (reduced sorption curves) should coincide regardless of film thickness.

5. Plots of uptake and desorption will only coincide when $D$ does not vary with the concentration of the penetrant.

This type of diffusion typically occurs when the time scale over which molecules rearrange themselves is much shorter than the time scale of diffusion, and the surface concentration reaches the equilibrium value almost instantaneously. This does not always happen in reality. Sometimes the diffusion process is accompanied by significant swelling of the polymer, which transforms the polymer from a glassy state to a partially rubbery state (McMaster and Soane, 1989). In this case, known as Case II diffusion, mass increases linearly with time rather than the square root of time as predicted by equation 4 (Kumar and Gupta, 1998). Case II diffusion behavior is attributed to time dependent relaxation of polymer chains of glassy polymer. Deviation from Fickian diffusion may also arise due to interaction of diffusing species with specific groups on the polymer chains. Large deviations from Fickian diffusion are reported (Shah et al., 2002) when the 
diffusing species interacts with fillers present in the polymer. Some of the theories proposed to explain such anomalous diffusion behavior are reported in sub-sections of this chapter.

\subsubsection{Time-Dependent Boundary Conditions}

When a glassy polymer is immersed in water, the surface concentration may not reach equilibrium instantaneously and hence, deviation from the Fickian diffusion is observed. Time-varying surface concentration of the penetrant in glassy polymers was first observed by Long and Richman (1960) in glassy poly vinyl acetate and cellulose acetate. It was reported that the surface concentration increased with time and could reach only $30 \%$ of the equilibrium value after 1275 minutes of exposure to methyl iodide vapors. Based on the ir finding, they proposed a time-dependent boundary condition.

$$
C_{s}=C_{o}+\left(C_{e q}-C_{o}\right)\left(1-e^{-\beta t}\right)
$$

Where,

$C_{s}=$ Surface concentration at time $t$

$C_{o}=$ Initial surface concentration

$C_{e q}=$ Equilibrium concentration

$\beta=$ Inverse of relaxation time

$t=$ Time

The diffusion coefficient, which was assumed to remain constant during the diffusion process, was modified in the following way:

$$
D=D_{F}\left(C_{e q} / C_{o}\right)^{2}
$$


Where,

$D_{F}=$ Diffusivity for Fickian diffusion

Weitsman and Tsotsis (1994) derived following expression for diffusion using the time-dependent boundary conditions mentioned above:

$$
\begin{aligned}
& \frac{M_{t}}{2 l}=C_{o}-\frac{8 C_{o}}{\pi^{2}} \sum_{0}^{\infty} \frac{\exp \left[\frac{-D(2 n+1)^{2} \pi^{2} t}{4 l^{2}}\right]}{(2 n+1)^{2}}+\left(C_{e q}-C_{o}\right)-\left(C_{e q}-C_{o}\right) \exp [-\beta t]\left(D / \beta l^{2}\right)^{1 / 2} \tan \left(\beta l^{2} / D\right)^{1 / 2} \\
& -8 \frac{\left(C_{e q}-C_{o}\right)}{\pi^{2}} \sum_{0}^{\infty} \frac{\exp \left[\frac{-D(2 n+1)^{2} \pi^{2} t}{4 l^{2}}\right]}{(2 n+1)^{2}\left[1-(2 n+1)^{2}\left(\frac{D \pi^{2}}{4 \beta l^{2}}\right)\right.}
\end{aligned}
$$

Diffusivity parameters can be calculated using a simple graphical method. Tangents are drawn to moisture mass gain versus $\sqrt{t}$ curve, at its initial region and leveling off region. The point of intersection of the two tangents gives the value of $C_{o}$. $C_{e q}$ is the equilibrium moisture content as shown in Figure 5. Equation 10 can be used to calculate the diffusivity once $C_{o}, C_{e q}$, and $D_{F}$ are known. Experimental data are fitted to equation 11 and "best fit" value of $\beta$ is found. Authors successfully fitted experimental data on diffusion in epoxy and found a value of $\beta$ to be approximately $1 / 4928 \mathrm{~h}^{-1}$, which lay in the middle of the mechanical relaxation times of epoxies. 


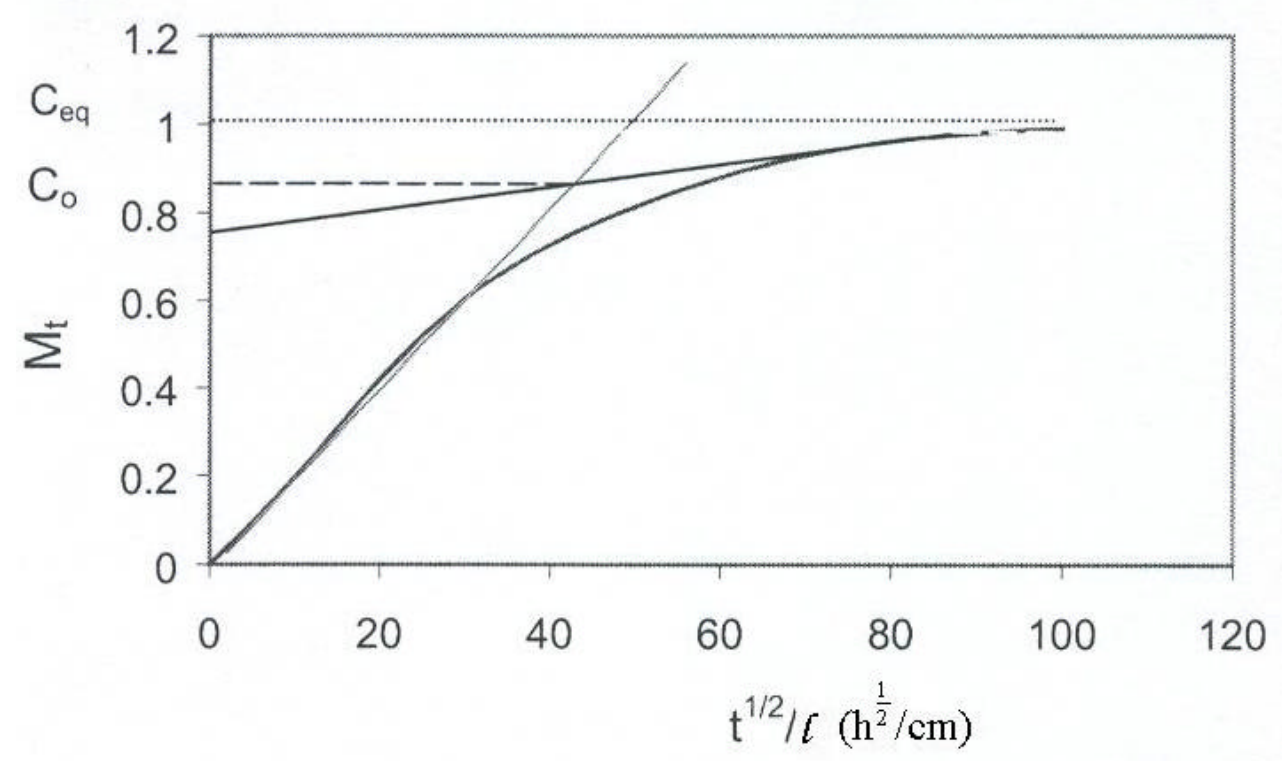

Figure 5. Graphical method of determining diffusion parameters, $C_{o}$ and $C_{e q}$.

(Weitsman and Tsotsis, 1994)

\subsubsection{Model based on Polymer Relaxation}

Berens and Hopfenberg (1979) found that, during the diffusion of organic vapor in PVC and polystyrene, the diffusion process follows Fickian diffusion only when the penetrant pressures are low. When the penetrant pressures are reasonably high, equilibrium is reached rather slowly. To explain this anomaly they proposed a diffusion model based on polymer relaxation. They suggested that diffusion is controlled by the following two factors:

1. Rapid Fickian sorption

2. Slow relaxation of polymer

The diffusion process was described as a sum of two independent mechanisms, Fickian and Non-Fickian. The total water absorbed, $M_{t}$, at time $t$ per unit weight of polymer was given by equation 12 .

$M_{t}=M_{t F}+M_{t R}$ 
Where,

$M_{t}=$ Total amount absorbed

$M_{t F}=$ Fickian contribution to the total amount absorbed

$M_{t R}=$ Non-Fickian contribution to the total amount absorbed

$M_{t F}$ can be written as a fraction of the water absorbed obtained from Fick's solution:

$M_{t F}=\Phi_{F}\left[1-\sum \frac{8}{(2 n+1)^{2} \pi^{2}} \exp \left[\frac{-D(2 n+1)^{2} \pi^{2} t}{4 l^{2}}\right]\right]$

$M_{t R}$ was found assuming a first-order rate proportional to the difference between $M_{t F}$ and $M_{\infty, R}$, the equilibrium amount of absorption due to relaxation.

$\frac{d M_{t R}}{d t}=k\left(M_{\infty, R}-M_{t, R}\right)$

Equation 14 is integrated over time to get the total $M_{t R}$.

$M_{t R}=\sum_{i} M_{\infty i}\left(1-e^{-k_{i} t}\right)$

Since the polymer has a spectrum of relaxation times, summation over the entire spectrum is required for desired accuracy.

The overall diffusion behavior can be described by the following equation:

$M_{t F}=\Phi_{F}\left[1-\sum \frac{8}{(2 n+1)^{2} \pi^{2}} \exp \left[\frac{-D(2 n+1)^{2} \pi^{2} t}{4 l^{2}}\right]\right]+\Phi_{R}\left(\sum_{i} M_{\infty i}\left(1-e^{-k_{i} t}\right)\right)$

$M_{t F}$ term dominates when polymer relaxation times are very small and this results in Fickian diffusion but when the relaxation times are large, the contribution from the $M_{t R}$ 
term cannot be neglected. Peppas and Sahlin (1991) successfully applied this model and explained the diffusion behavior of TGDDM-DDS epoxy resin.

\subsubsection{Model based on Langmuir type of Behavior}

Some of the water molecules diffusing through the polymer matrix may get attached to the specific groups on the polymer chain and become "bound" at that location. At the same time, some of the "bound" molecules might be able to "free" themselves from the site at which they were previously attached. Carter and Kibler (1978) based their theory on the idea that moisture exists in the polymer in either "bound phase" or "mobile phase". Molecules of the mobile phase are assumed to diffuse through the matrix polymer with a constant diffusion coefficient, $D_{\gamma}$. The probability per unit time that a water molecule is bounded to a site whose chemical nature is not known is $\gamma$. The probability per unit time that a bound water molecule is emitted from the bound site and becomes mobile is $\beta$. The local weight fraction reaches equilibrium, $M_{\infty}$, when the number of mobile molecules per unit volume, $\mathrm{n}$, and the number of bound molecules per unit volume, $\mathrm{N}$, approach values such that equation 17 is satisfied.

$\gamma n=\beta N$

When $\gamma$ and $\beta$ are small compared to the parameters that determine the rate of saturation for one-dimensional specimen of thickness $2 \delta$, the moisture uptake is given by:

$M_{t}=M_{\infty}\left[\frac{\beta}{\gamma+\beta} e^{-\gamma t}\left[1-\frac{8}{\pi^{2}} \sum_{0}^{\infty} \frac{1}{(2 n+1)^{2}} e^{-K(2 n+1)^{2} t}\right]+\frac{\beta}{\gamma+\beta}\left(e^{-\beta t}-e^{-\gamma t}\right)+\left(1-e^{-\beta t}\right)\right]$;

$2 \gamma, 2 \beta<1 / K$ 
Where,

$$
K=\pi^{2} D_{\gamma} /(2 \delta)^{2}
$$

When $\gamma=0$ is substituted in equation 18, it reduces to the solution of Fick's second law of diffusion. At small exposure times $(K t<0.7)$, equation 18 is approximated by its more convenient form 20 . On the other hand, for the large exposure times $(t>1 / K)$, equation 18 reduces to equation 21 .

$$
\begin{aligned}
& M_{t} \approx \frac{4}{\pi^{3 / 2}}\left(1-\frac{\beta}{\gamma+\beta} M_{\infty}\right) \sqrt{K t} \\
& M_{t}=M_{\infty}\left(1-\frac{\gamma}{\gamma+\beta} e^{-\beta t}\right)
\end{aligned}
$$

Some of the applications of this model can be found in Bonniau and Bunsell (1981) as well as Marsh, et al. (1984). The latter researchers also reported $\gamma$ and $\beta$ to be dependent of partial pressure of the penetrant and temperature. 


\section{CHAPTER III}

\section{NANOCOMPOSITES}

The term "nanocomposite" describes a two-phase material where the dispersed phase has at least one nanometer scale dimensions. One can characterize three types of nanocomposites, depending on how many dimensions of the dispersed particles are in the nanometer range. When all three dimensions of the particles are in nanometer range, they are called isodimentional nanoparticles, e.g. spherical silica nanoparticles. Sometimes two dimensions of the particles are of nanometer scale and the third is larger, forming an elongated structure. Carbon nanotubes are a good example of this type of nanoparticles. The third type of nanoparticles consists of particles that have only one dimension in the nanometer range. Those particles exist in the form of sheets of one to a few nanometers thick and hundreds of nanometer long. A typical example of this type of nanoparticle is layered silicates. Amongst all the potential nanocomposite precursors, those based on clay and layered silicates have been more widely investigated probably because the starting clay materials are easily available and because their intercalation chemistry has been studied for a long time (Alexandre and Dubois, 2000). The various types of clay minerals are Montmorillonite, Illite, Kaolinite and Attapulgite. Structure of two of these clay minerals are shown in Figures 6 and 7. Structure of carbon nanotube is also shown in Figure 8 . 


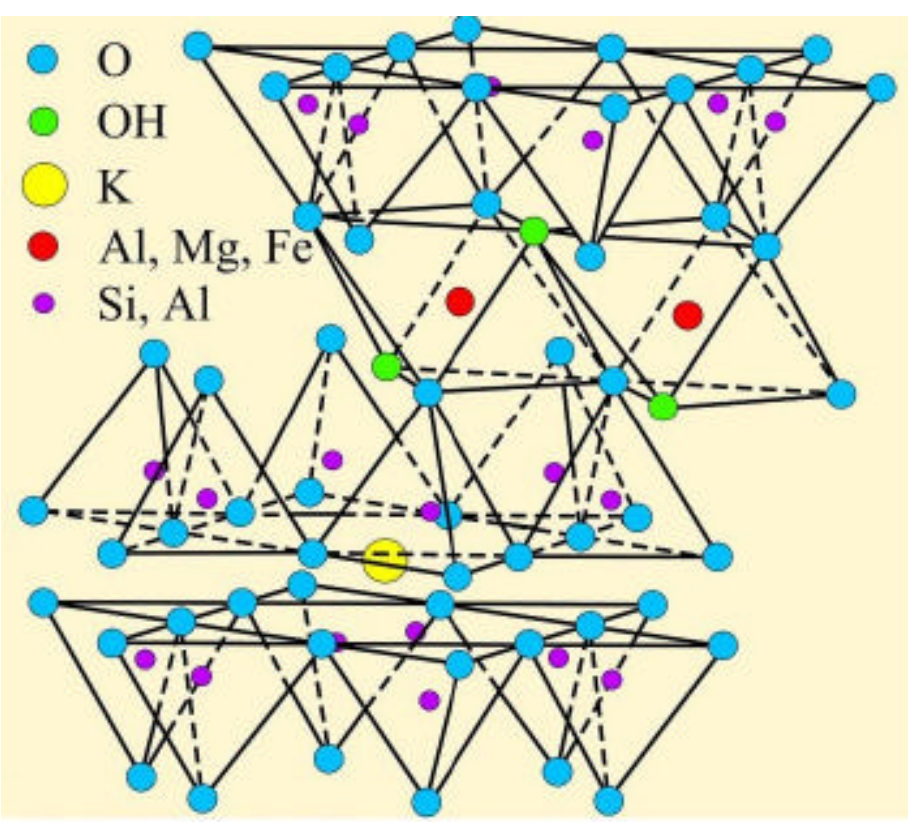

Figure 6. Structure of Illite Clay Mineral

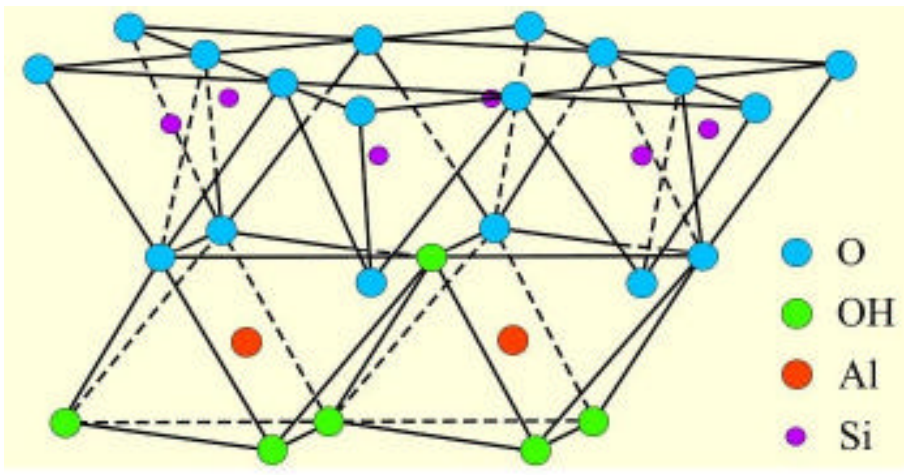

Figure 7. Structure of Kaolinite Clay Mineral

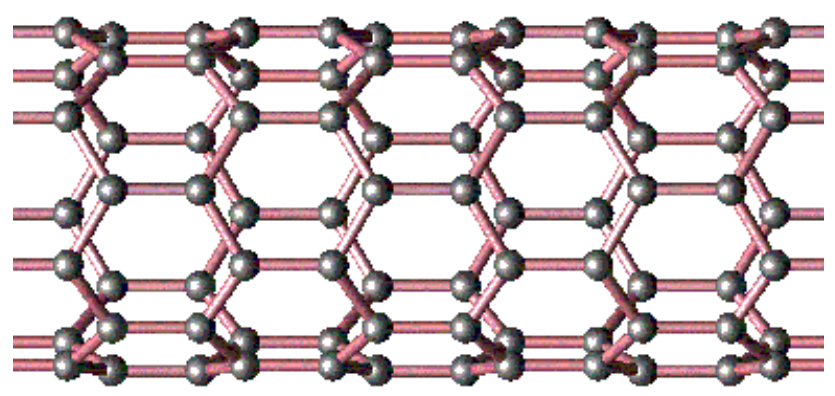

Figure 8. Structure of Carbon Nanotube 
Illinite is a non-swelling clay and hence not compatible with polymeric matrix materials. Kaolinite and Attapulgite clays have low cation exchange capacities (CEC) as compared to Montmorillonite. The amount of cations that can be exchanged with organic ions is expressed in milli equivalents per 100 grams of dry clay and is known as the CEC of the clay. Kaolin also has a small basal spacing, and so the penetration of intercalant into the space between the individual layers is limited. On the other hand, Montmorillonite has following obvious advantages over the other clay minerals, which make it popular in making nanocomposites:

1. Flat plate-like structure with a large aspect ratio in the range of 200-1500.

2. High CEC in the range of 70 to $140 \mathrm{mg}$ per $100 \mathrm{~g}$ of dry clay as compared to other clay minerals.

3. Bentonite is the most abundantly available clay, which contains more than $50 \%$ montmorillonite.

4. Montmorillonite is a Smectite (swelling clay) type of clay that makes it more compatible with a polymeric matrix.

5. Montmorillonite has a plate-like shape with a high aspect ratio. Hence, at the same loading, it leads to a better permeation barrier when compared to Attapulgite clay, which has a needle like structure.

6. Montmorillonite develops similar increase in modulus and tensile strength at loading of 3-5\% as compared to $20-60 \%$ loading of other fillers such as Kaolin and carbon black. Subsequent sections provide an overview of structure of nanoclays and different techniques used to obtain polymer-layered silicates nanocomposites. 


\subsection{Structure of Montmorillonite}

The crystal lattice of Montmorillonite, the most commonly used nano-filler (Figure 9) consists of two-dimensional layers where a central octahedral sheet of alumina or magnesia is fused to two external silica tetrahedron layers by the tip so that the oxygen atoms of the octahedral sheet also belong to tetrahedral sheets (Alexandre and Dubois, 2000). Si atoms in the tetrahedral sheets are coordinated with 4 oxygen atoms located at the 4 corners of the tetrahedron. $\mathrm{Al}$ or $\mathrm{Mg}$ atoms in the octahedral sheets are coordinated with 6 oxygen atoms or hydroxyl groups located at the 6 corners of a regular octahedron. The three layers form a clay platelet or the unit cell of nanoclay. The thickness of the platelet is around 1 nanometer and the lateral dimensions of the platelet may vary from hundreds to thousands of nanometers. In nature, clay platelets organize themselves to form a stack with a "Van der Waals" gap in between them called the interlayer or the gallery. In the natural form of nanoclay, tetravalent $\mathrm{Si}$ atoms in the tetrahedral sheet are partly replaced by trivalent $\mathrm{Al}$ atoms and/or trivalent $\mathrm{Al}$ atoms in the octahedral sheet are partly substituted by divalent atoms such as Fe or Mg. The lack of positive charge in the unit cell results in a net negative charge on the surface of the clay platelet. This negative charge is counterbalanced by alkali or alkaline ions (e.g. $\mathrm{Na}^{+}$or $\mathrm{Ca}^{++}$) situated in the interlayer. These ions in the interlayer can be substituted with organic cations. This type of substitution makes the clay compatible with organic polymers. 


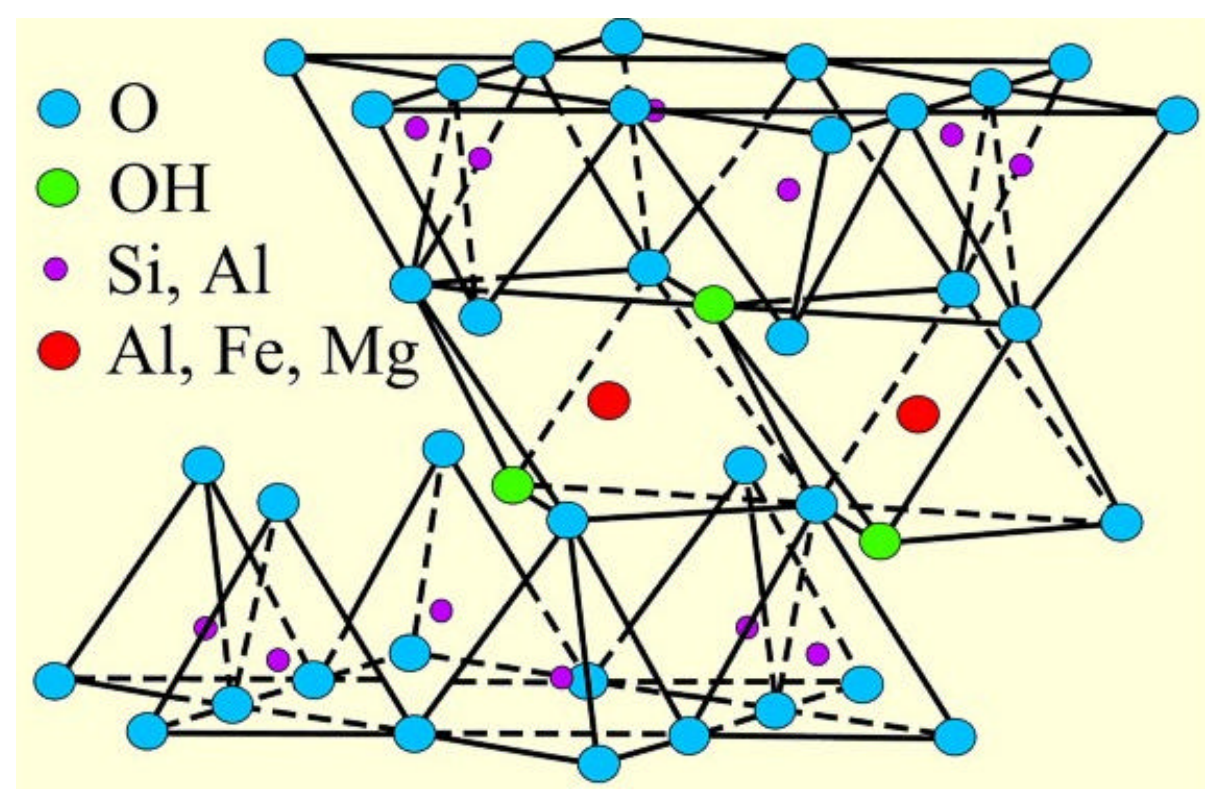

Figure 9. Structure of Montmorillonite Clay

\subsection{Surface Treatment}

Nanoclay, as it occurs in nature, is a completely inorganic material. To make it compatible with organic materials it is given a surface treatment involving a compatibilizer. The compatibilizer molecule has a hydrophilic functional group (which likes polar materials such as, water or clay) and one organophilic functional group (which likes organic polymer molecules). The most popular compatibilizing agents are alkylammonium ions because they can be exchanged easily with the ions situated in the interlayer. Amino acids and silanes have also been used in the past as compatibilizing agents. The compatibilizing agent not only makes the clay compatible with the polymer but also increases the interlayer distance to as much at $2.0 \mathrm{~nm}$. The increased interlayer distance provides enough room for polymer chains to intercalate in between the platelets. Figure 10 shows a schematic representation of the consequence of surface treatment using alkylammonium ions. 


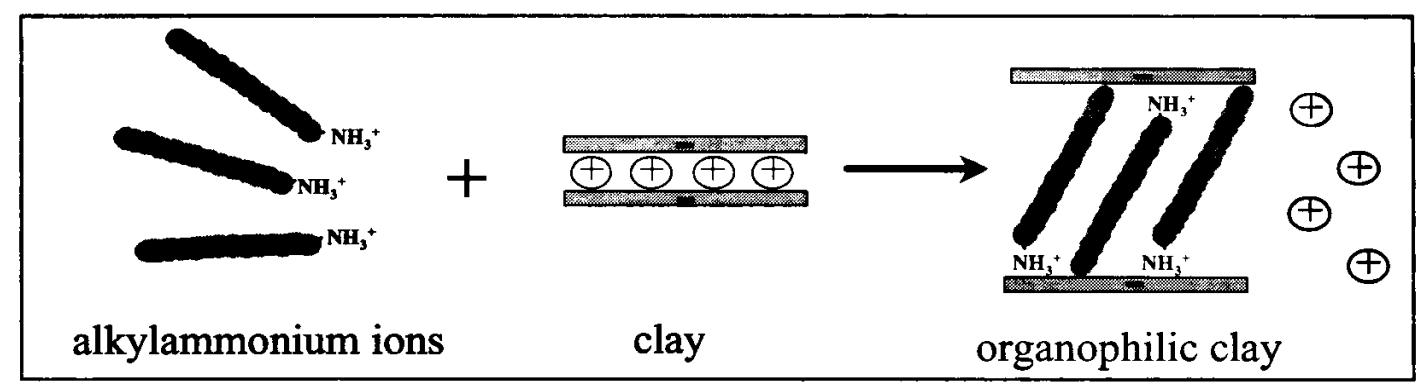

Figure 10. Cation-Exchange process between Alkylammonium ion and Cations initially intercalated between the clay platelet

(Kornmann, 1998)

\subsection{Synthesis of Nanocomposites}

Interlayer distance between the clay platelets increases by a significant amount on application of the compatibilizing agent. This makes it possible for the monomer or polymer molecule to enter the gallery. Individual clay platelets can then be dispersed in to the polymer. The process of clay platelets getting randomly dispersed in the polymer is called exfoliation. Different methods of achieving exfoliation are being practiced depending on the polymeric system used. The subsequent sub-sections give a brief review of these methods.

\subsubsection{In-Situ Polymerization}

This process is conventionally used to synthesize a thermoset-clay nanocomposite. The organoclay (surface treated clay) is swollen in the monomer. The degree of exfoliation achieved in this method depends sensitively on the polarity of the monomer molecules, the surface treatment of the clay, swelling temperature and degree 
of agitation. Then, the reaction is initiated by addition of a curing agent. Figure 11 shows schematic diagram of in-situ polymerization.

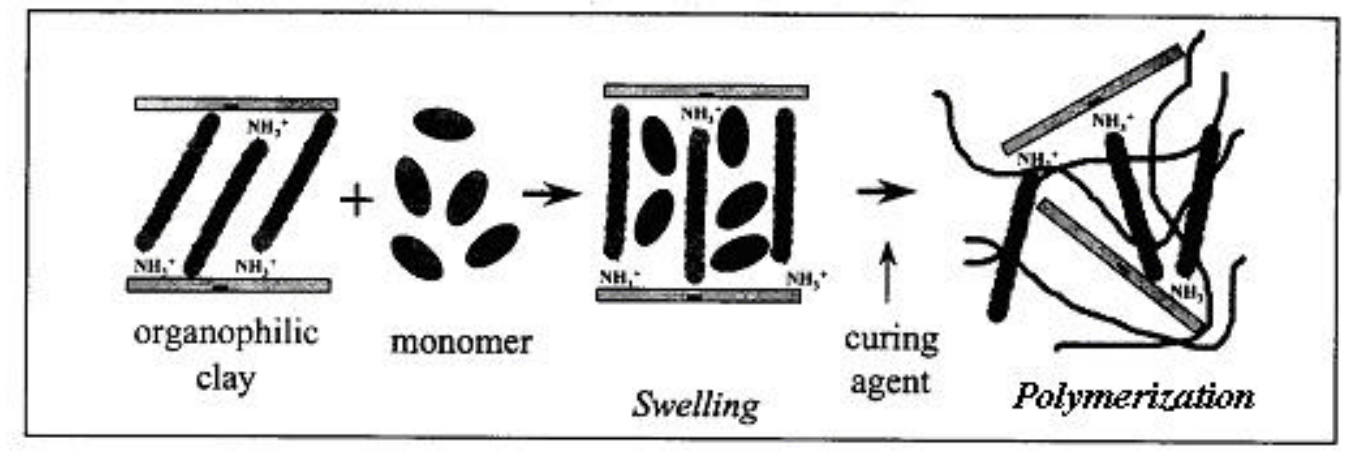

Figure 11. Schematic diagram of In-Situ Polymerization

(Kornmann, 1998)

During the swelling phase, the high surface energy of the clay attracts polar monomer molecules so that they diffuse between the clay platelets. Later, the polymerization reaction lowers the overall polarity of the intercalated molecules and displaces the thermodynamic equilibrium in such a way that more polar molecules are driven in between the clay layers delaminating the clay eventually.

\subsubsection{Solution Approach}

Polar solvents can be used to synthesize nanocomposites. In this situation, organoclay is swollen in the solvent. Polymer, dissolved in the same solvent, is added in to the solution of swollen clay. The polymer intercalates between the clay platelets and the Solvent is then removed by evaporation under vacuum. This approach is not very practical for industrial use due to the problems associated with removing a large quantity of solvent. Nevertheless, this process offers the possibilities of synthesizing intercalated nanocomposites based on polymers with low or even no polarity. A schematic diagram of this process is shown in Figure 12. 


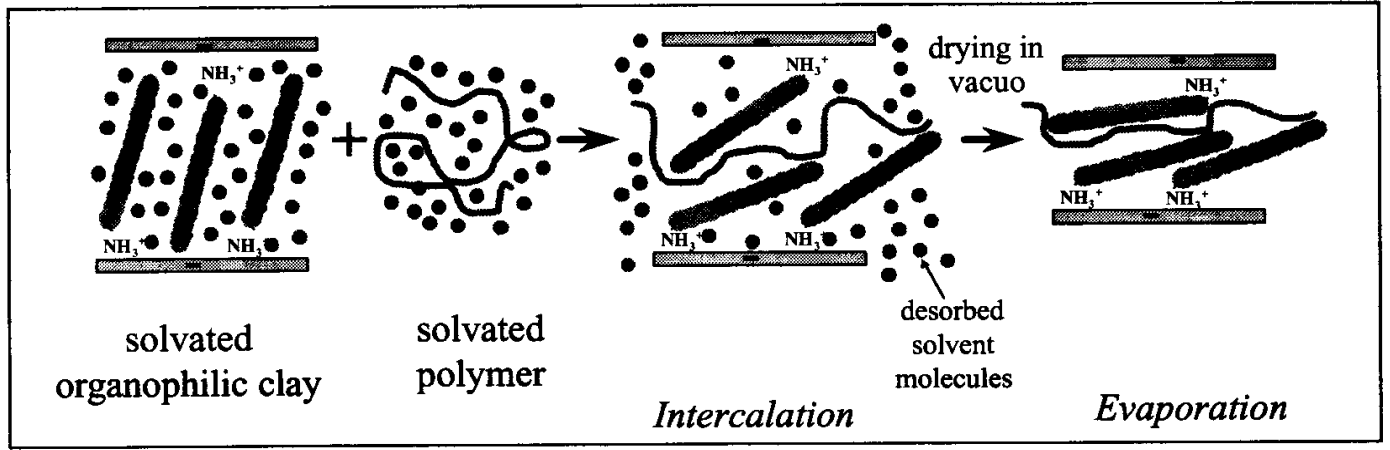

Note: Black dots are solvent molecules

Figure 12. Schematic diagram of Solution Approach

(Kornmann, 1998)

\subsubsection{Melt Intercalation}

Melt intercalation is used to synthesize nanocomposites based on thermoplastics. Molten thermoplastic is directly blended with organoclay in an extruder in order to optimize the polymer-clay interactions. The mixture is then heated and molded into any desired shape and the nanocomposite is formed. The melt intercalation process is becoming increasingly popular because of its simplicity for application in industry. A schematic diagram of this process is shown in Figure 13.

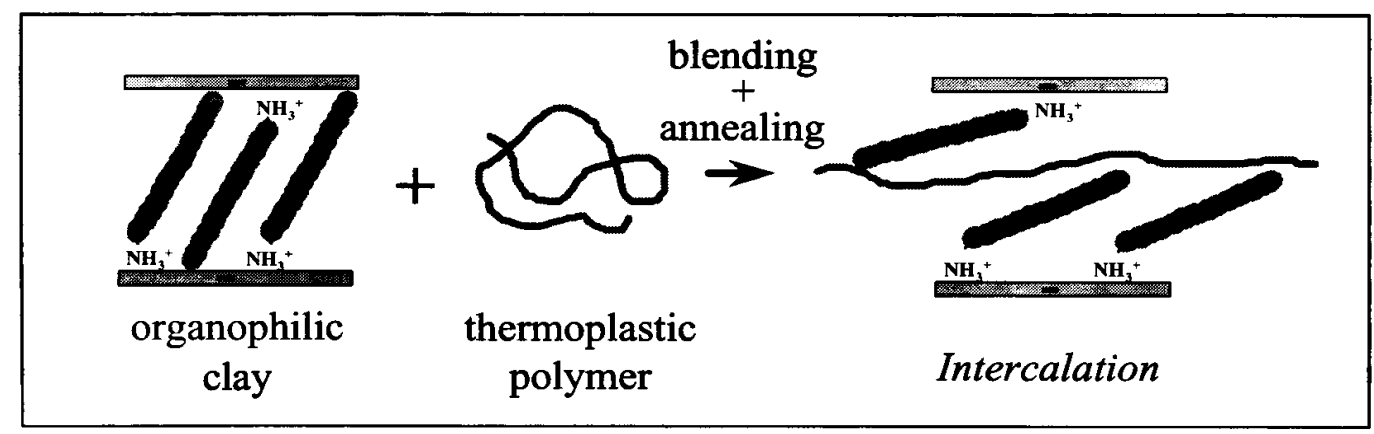

Figure 13. Schematic diagram of Melt Intercalation

(Kornmann, 1998) 


\subsection{Nanocomposite Morphologies}

Depending on the interaction between the clay platelets and polymer molecules, three different morphologies of nanocomposites are obtained: 1) Conventional composite 2) Intercalated composite and 3) Delaminated/Exfoliated composite. When the polymer chains are not able to penetrate between the clay platelets, the stack of platelets remains intact and a conventional composite is obtained. Sometimes the polymer chains are able to intercalate between the clay platelets but the platelets still aren't dispersed in the polymer. This type of morphology is known as intercalated composite. When the clay platelets are randomly dispersed throughout in the polymer the morphology is called exfoliated or delaminated composite. It is exfoliated/delaminated morphology of nanocomposite, which gives the maximum benefits in terms of improving the properties of the polymer. Property enhancements are obtained due to molecular scale interactions between the polymer and the clay surface. These interactions are greater in the exfoliated morphology, where the clay particles present the largest surface area. In this situation the clay exists as individual platelets. Nanocomposite morphologies are shown in Figure 14.

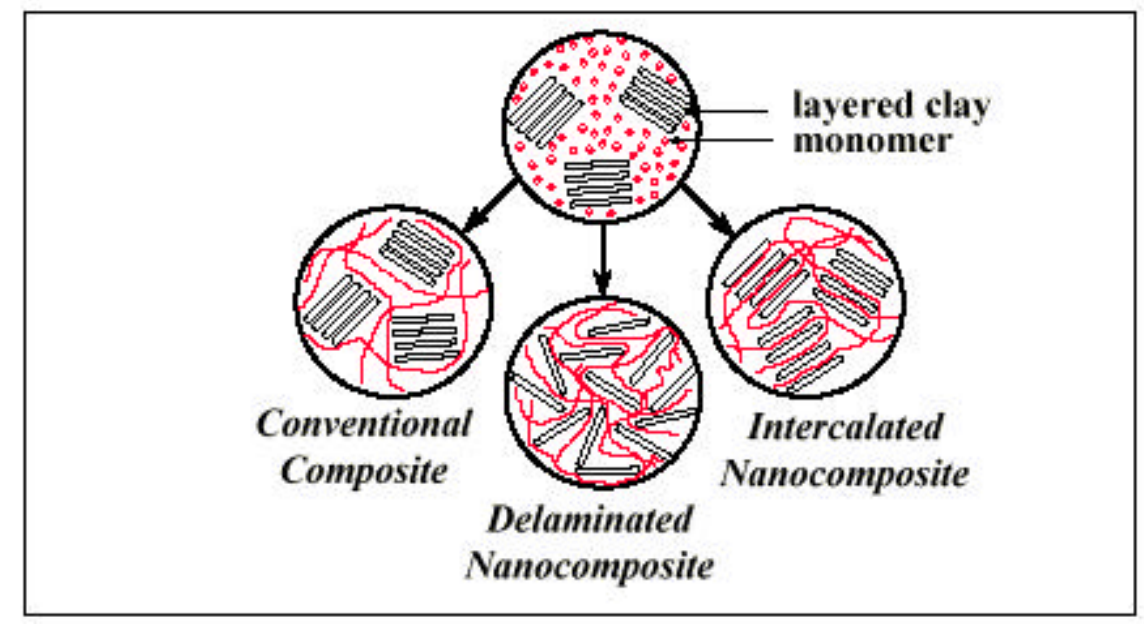

Figure 14. Nanocomposite Morphologies

(Alexandre and Dubois, 2000) 


\subsection{Properties of Nanocomposites}

Nanoclays not only act as filler to reduce the cost but also reinforce the polymer. They are found to increase Young's modulus, flexural modulus, tensile strength, fire retardation properties and barrier properties to gases and liquids. Massam and Pinnavaia (1998) also reported an increase in the yield strength with clay loading for epoxy-based nanocomposites (Figure 15).
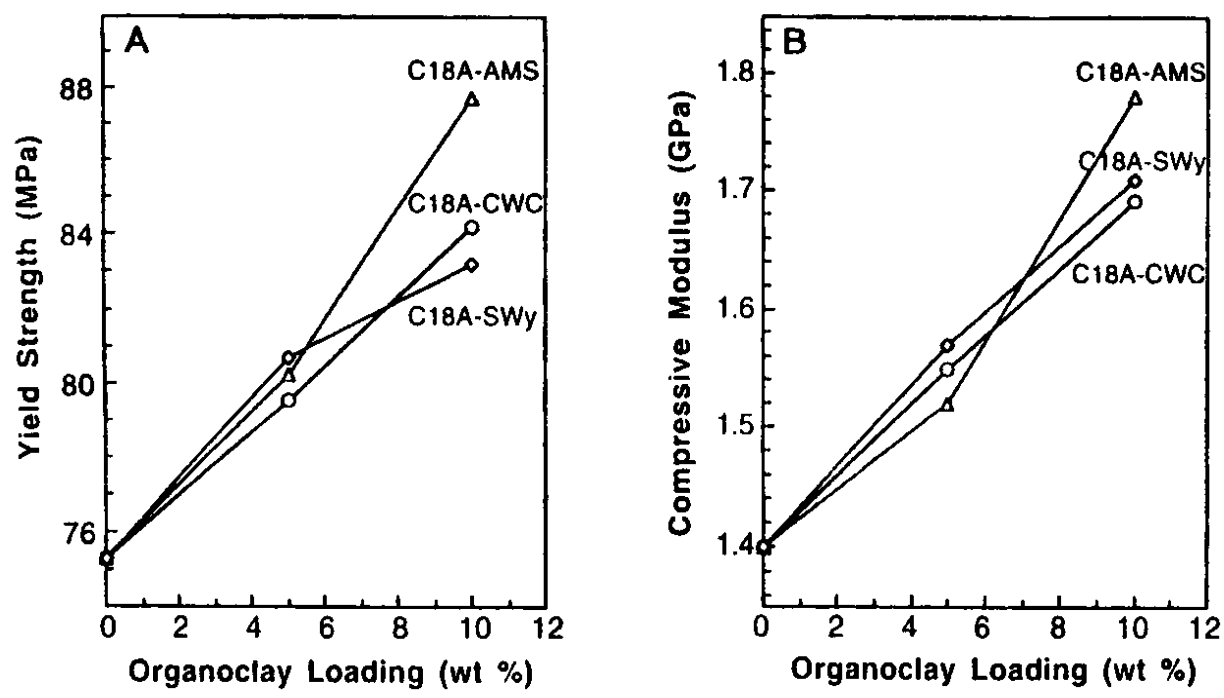

Figure 15. Compressive (A) yield strength and (B) moduli for the pristine epoxy polymer and the exfoliated epoxy-clay nanocomposites prepared from three different kinds of organomontmorillonites. The epoxide resin and curing agent used in this system are EPON 826 and JEFFAMINE D-230, respectively

(Massam and Pinnavaia, 1998)

Wang and Pinnavaia (1998) confirmed that polyurethane-organomontmorillonite nanocomposites have a higher modulus of elasticity than pristine polyurethane (Figure 16). Figure 17 shows that $4.8 \%(\mathrm{v} / \mathrm{v})$ of montmorillonite in poly( $\varepsilon$-caprolactone) can reduce the water permeability of polymer by almost a factor of 5 (Messersmith and Giannelis, 1995). 


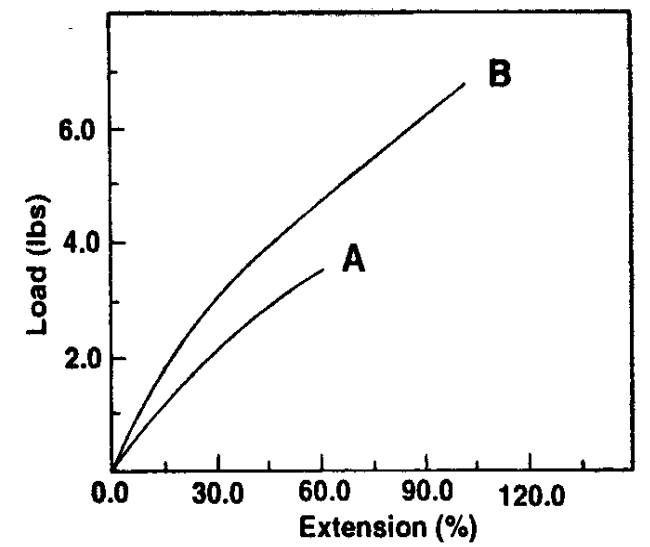

Figure 16. Stress-strain curves for (A) a pristine polyurethane elastomer; (B) a polyurethane-clay nanocomposite prepared from organomontmorillonite $(5 \mathrm{wt} \%)$

(Wang and Pinnavaia, 1998)

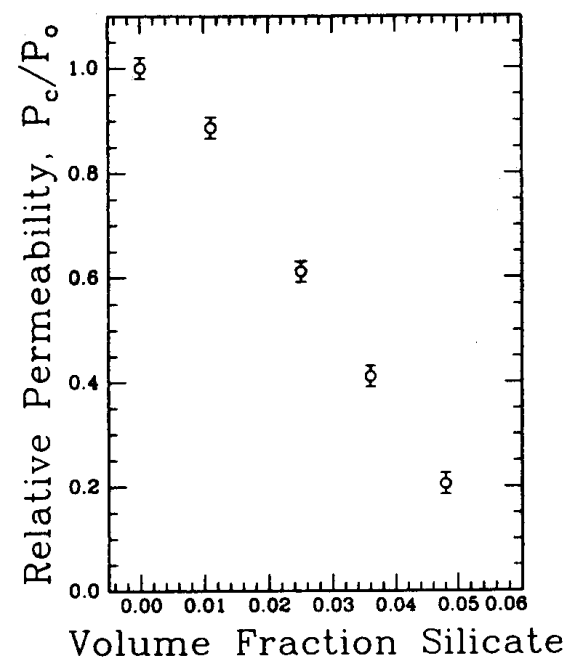

Note: $\mathrm{P}_{c}$ is permeability of nanocomposite and $\mathrm{P}_{\mathrm{o}}$ is permeability of pristine polymer

Figure 17. Relative Permeability $\left(\mathbf{P}_{\mathrm{c}} / \mathbf{P}_{0}\right)$ versus volume fraction silicate for montmorillonite-poly $(\varepsilon-$ caprolactone) nanocomposite films

(Messersmith and Giannelis, 1995)

According to Yano et al. (1993), the permeability of water vapor through a polymeric film drops by a factor of 5 , the permeability of helium drops by a factor of 10 and the permeability of oxygen drops by a factor of 10 on addition of 8 wt $\%$ 
montmorillonite clay in a polyimide (Figures 18, 19 and 22). The drop in permeability was attributed to the exfoliated nature of clay platelets in the polymer. Randomly oriented platelets provide a physical barrier to the penetrant molecules by increasing the path traveled by the penetrant molecules. This mechanism is termed as "tortuous path" impedance (Figure 21). It was also reported in the same study that the nanocomposite had a lower thermal expansivity as compared to that of the pristine polyimide (Figure 22).

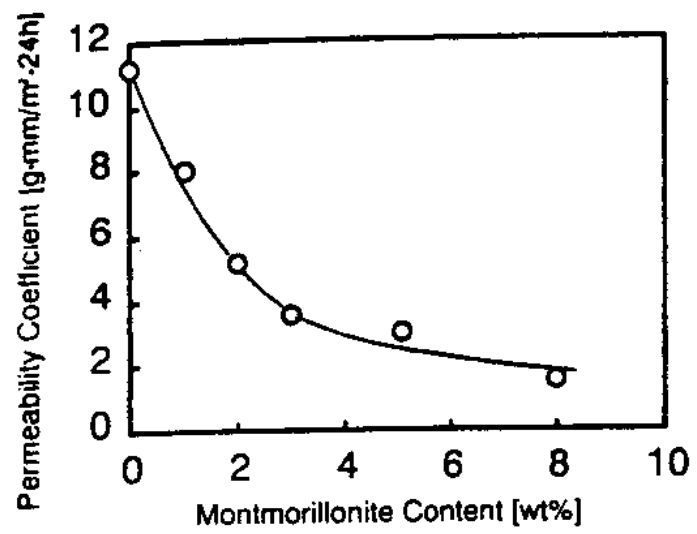

Figure 18. Montmorillonite content dependence of permeability coefficient of water vapor in polyimide -clay hybrids

(Yano et al., 1993)

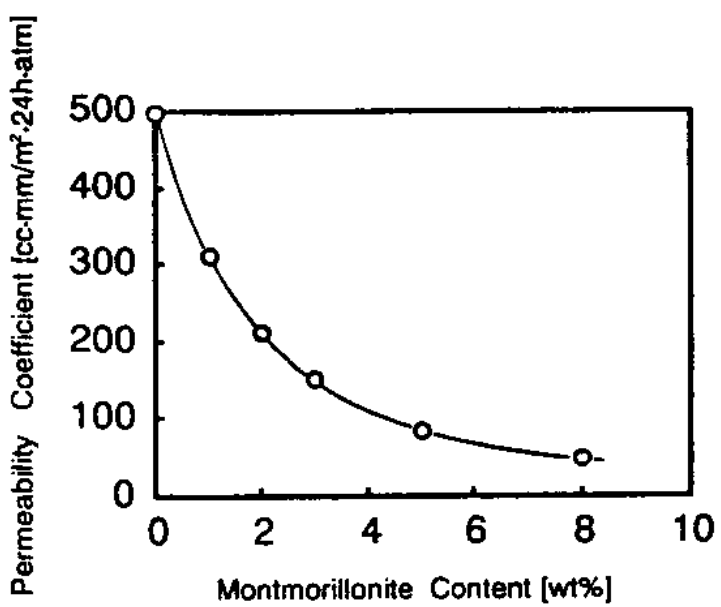

Figure 19. Montmorillonite content dependence of permeability coefficient of He in polyimide-clay hybrid

(Yano et al., 1993) 


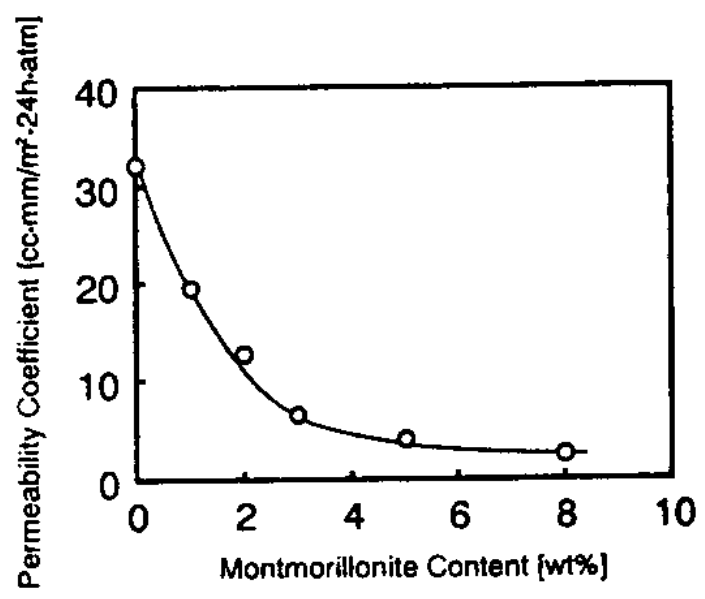

Figure 20. Montmorillonite content dependence of permeability coefficient of $\mathrm{O}_{2}$ in polyimide-clay hybrid

(Yano et al., 1993)

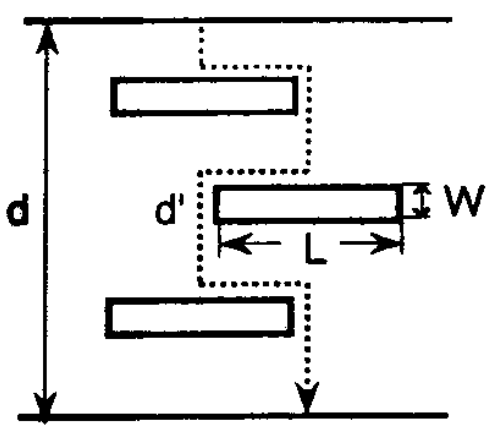

Total path of a diffusing gas

$$
\begin{aligned}
d^{\prime}= & d+d \cdot L \cdot V f / 2 W \\
& d: \text { thickness of a film } \\
& L \text { : length of a clay } \\
& W: \text { width of a clay } \\
& V f: \text { volume fraction of a clay }
\end{aligned}
$$

Tortuousity factor

$$
\begin{aligned}
\tau & =d^{\prime} / d \\
& =1+L \cdot V f / 2 W
\end{aligned}
$$

Equation for a permeability coefficient

$$
\begin{aligned}
\mathrm{PC} & =\mathrm{Pp} / \tau \\
& =\mathrm{Pp} /(1+\mathrm{L} \cdot \mathrm{V} f / 2 \mathrm{~W}) \\
& \mathrm{Pp}: \text { permeability coefficient of } \\
& \text { a matrix polymer }
\end{aligned}
$$

Figure 21. A model for the path of a diffusing gas through the polyimide-clay hybrid

(Yano et al., 1993) 


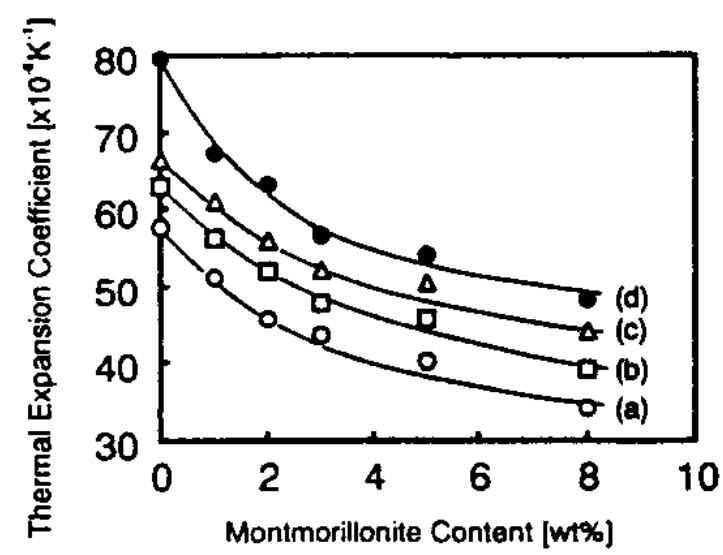

Figure 22. Montmorillonite content dependence of thermal expansion coefficiet of polyimide-clay hybrid at: (a) $150^{\circ} \mathrm{C}$ (b) $200^{\circ} \mathrm{C}$ (c) $250^{\circ} \mathrm{C}$, and (d) $295^{\circ} \mathrm{C}$

(Yano et al., 1993)

Shah (2001) studied moisture diffusion through vinyl ester/clay nanocomposites. Nanocomposites were prepared by adding Montmorillonite nanoclay in DERAKANETM 411-350 epoxy vinyl ester resin and transient diffusion experiments were carried out. It was found that diffusivity of water through the resin decreased with increasing clay content. However, equilibrium moisture content, glass transition temperature, and the elastic modulus increased with increasing amount of clay. Results of the diffusion tests are summarized in Table IV. 
Table IV. Diffusion test results on post cured samples

(Shah et al., 2001)

\begin{tabular}{|c|c|c|}
\hline System & $\begin{array}{l}\text { Diffusion Coefficient } \\
\qquad\left(\times 10^{+6} \mathrm{~mm}^{2} / \mathrm{s}\right)\end{array}$ & $\begin{array}{c}\text { Equilibrium Moisture } \\
\text { Content weight percent }(\%)\end{array}$ \\
\hline Neat Resin & $0.919(0.030)$ & $0.434(0.012)$ \\
\hline $0.5 \mathrm{wt} \% \mathrm{VMC}$ & $0.534(0.025)$ & $0.691(0.004)$ \\
\hline $1.0 \mathrm{wt} \% \mathrm{VMC}$ & $0.368(0.041)$ & $0.862(0.005)$ \\
\hline $2.5 \mathrm{wt} \% \mathrm{VMC}$ & $0.238(0.019)$ & $1.056(0.021)$ \\
\hline $5.0 \mathrm{wt} \% \mathrm{VMC}$ & $0.198(0.008)$ & $1.166(0.021)$ \\
\hline $0.5 \mathrm{wt} \%$ Cloisite $10 \mathrm{~A}^{(\mathbb{R}}$ & $0.452(0.025)$ & $0.828(0.007)$ \\
\hline $1.0 \mathrm{wt} \%$ Cloisite $\left.10 \mathrm{~A}^{(}\right)$ & $0.337(0.026)$ & $0.927(0.011)$ \\
\hline $2.5 \mathrm{wt} \%$ Cloisite $10 \mathrm{~A}^{(\mathbb{R}}$ & $0.239(0.021)$ & $1.109(0.005)$ \\
\hline $5.0 \mathrm{wt} \%$ Cloisite $10 \mathrm{~A}^{\circledR}$ & $0.125(0.015)$ & $1.484(0.011)$ \\
\hline 0.66 wt $\%$ Cloisite $\left.\mathrm{Na}^{(}\right)$ & $0.654(0.253)$ & $0.901(0.01)$ \\
\hline 3.25 wt $\%$ Cloisite $\left.\mathrm{Na}^{(}\right)$ & $0.513(0.195)$ & $1.126(0.026)$ \\
\hline
\end{tabular}

Note: Numbers in brackets are standard deviations.

It is evident from Table IV that diffusion coefficient decreases with increasing amount of clay in polymer. However, equilibrium moisture uptake increases with increasing amount of clay in polymer. It was also reported in the study that diffusion through polymer clay nanocomposites showed considerable amount of deviation from Fickian behavior, especially at high clay loadings. Higher equilibrium moisture content and non-Fickian behavior were explained by saying that the clay was much more hydrophilic than hydrogen bonded interactions of water with $-\mathrm{OH}$ groups present in polymer chain. The water molecules were believed to be absorbed onto the clay surface and become bounded. Langmuir type diffusion model was successfully applied to the nanocomposite samples and it was concluded that the ratio of mobile water molecules to bound water molecules decreases with increasing amount of clay, meaning that there are 
lesser mobile molecules in samples with higher clay loading. Moreover, diffusion coefficient of mobile molecules, $D_{\gamma}$, remained unchanged for a given polymer-clay system. This was an implication that the reduction in diffusion coefficient is mostly due to the immobilization of water on the clay surface. Table $\mathrm{V}$ shows various model parameters calculated in the study. Researchers were unable to convincingly explain Fickian type of diffusion observed at very low clay loadings. This anomaly was explained by guesstimating that in cases of very low clay loading, there are fewer number of adsorption sites available on clay surface and hence, Fickian diffusion might dominate.

Table V. Summary of diffusion model parameters

(Shah et al., 2001)

\begin{tabular}{|c|c|c|c|c|c|c|c|c|}
\hline Sample & $\begin{array}{c}0.5 \% \\
\mathrm{VMC}\end{array}$ & $\begin{array}{c}1.0 \% \\
\mathrm{VMC}\end{array}$ & $\begin{array}{c}2.5 \% \\
\mathrm{VMC}\end{array}$ & $\begin{array}{c}5.0 \% \\
\mathrm{VMC}\end{array}$ & $\begin{array}{c}0.5 \% \\
10 \mathrm{~A}\end{array}$ & $\begin{array}{c}1.0 \% \\
10 \mathrm{~A}\end{array}$ & $\begin{array}{c}2.5 \% \\
10 \mathrm{~A}\end{array}$ & $\begin{array}{c}5.0 \% \\
10 \mathrm{~A}\end{array}$ \\
\hline $\begin{array}{c}\mathrm{D}_{\mathrm{F}} \times 10^{+6} \\
\mathrm{~mm}^{2} / \mathrm{s}\end{array}$ & 0.5339 & 0.3683 & 0.2381 & 0.1976 & 0.4519 & 0.3365 & 0.2393 & 0.1254 \\
\hline $\mathrm{E}_{\mathrm{F}}^{2}$ & 0.0024 & 0.012 & 0.0218 & 0.0261 & 0.0081 & 0.0491 & 0.0766 & 0.1271 \\
\hline$\gamma, \mathrm{h}^{-1}$ & - & - & 0.0098 & 0.0232 & - & 0.0093 & 0.0125 & 0.0324 \\
\hline$\beta, \mathrm{h}^{-1}$ & - & - & 0.0452 & 0.049 & - & 0.0295 & 0.0279 & 0.0279 \\
\hline $\begin{array}{c}D_{\gamma} \times 10^{+6} \\
\mathrm{~mm}^{2} / \mathrm{s}\end{array}$ & - & - & 0.394 & 0.4234 & - & 0.5184 & 0.5371 & 0.5975 \\
\hline $\mathrm{E}_{\mathrm{L}}^{2}$ & - & - & 0.0122 & 0.0098 & - & 0.0183 & 0.0055 & 0.0067 \\
\hline $\mathrm{n} / \mathrm{N}$ & - & - & 4.612 & 2.112 & - & 3.172 & 2.232 & 0.8611 \\
\hline
\end{tabular}

Note: $\mathrm{E}$ refer to $\left(\mathrm{E}_{\mathrm{exp}}-\mathrm{E}_{\mathrm{cal}}\right)^{2}$

$\mathrm{L}$ refers to Langmuir adsorption theory F refers to Fick's

Author also reported a 50\% drop in water vapor permeability and a $85 \%$ drop in the diffusion coefficient of DERAKANE 411-350 vinyl ester resin containing of 5 wt $\%$ 
of organomontmorillonite clay. Results are shown in Figure 23 and Figure 24. An increase in the glass transition temperature was also reported in the same studies (Table VI).

Table VI. Variation of Glass Transition Temperature of nanocomposite samples with clay loading

\begin{tabular}{|c|c|}
\hline Wt \% Cloisite $\left.10 \mathrm{~A}^{(}\right)$ & Glass Transition Temperature $\left({ }^{\circ} \mathrm{C}\right)$ \\
\hline 0 & 97.97 \\
\hline 0.5 & 101.51 \\
\hline 1.0 & 104.7 \\
\hline 2.5 & 112.73 \\
\hline 5.0 & 117.34 \\
\hline
\end{tabular}

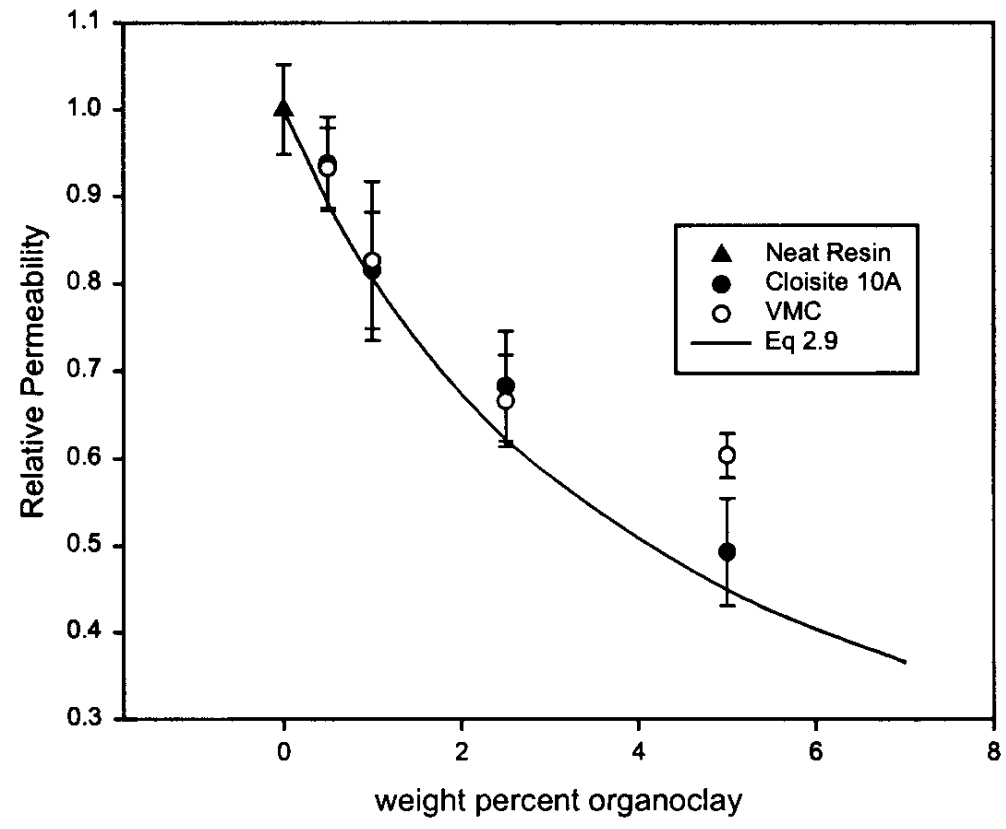

Figure 23. Variation in Relative Permeability with Organomontmorillonite Clay loading

(Shah et al., 2001) 


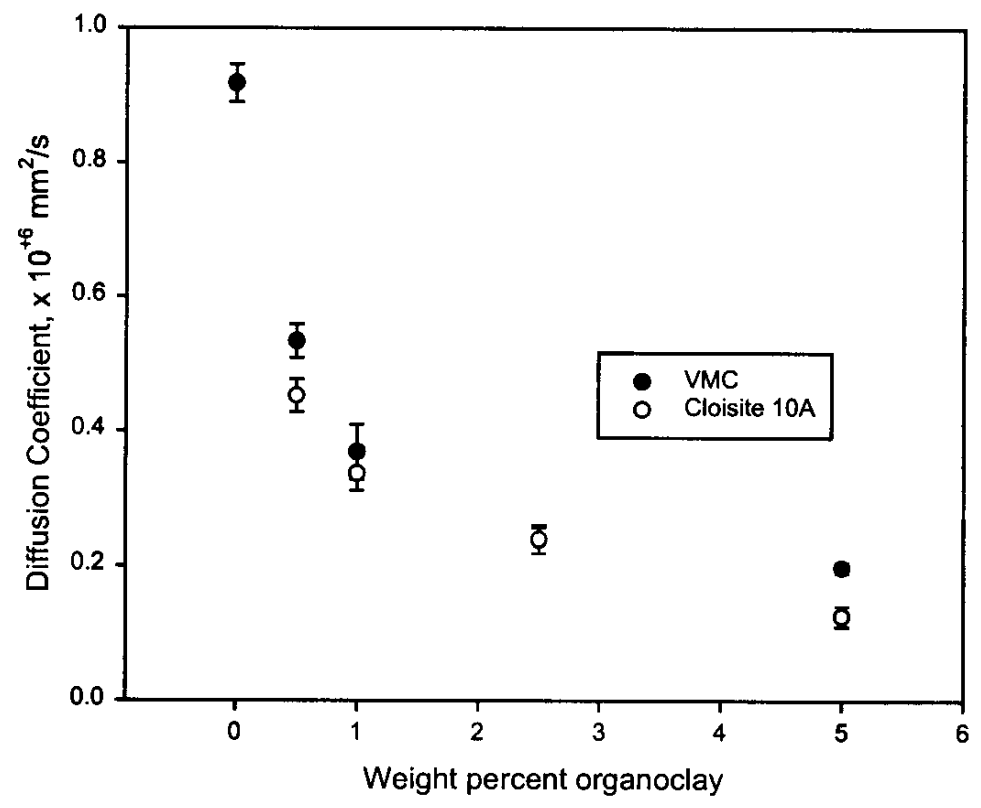

Figure 24. Variation in Diffusion Coefficient with Organomontmorillonite Clay loading

(Shah et al., 2001)

Figure 25 shows that the heat-distortion temperature of Nylon 6 increases by more than $60^{\circ} \mathrm{C}$ on addition of $5 \mathrm{wt} \%$ of organomontmorillonite (Liu et al., 1998). Flexural strength and flexure modulus were also found to increase without loss of impact strength for clay loading below $5 \mathrm{wt} \%$ (Figure 26).

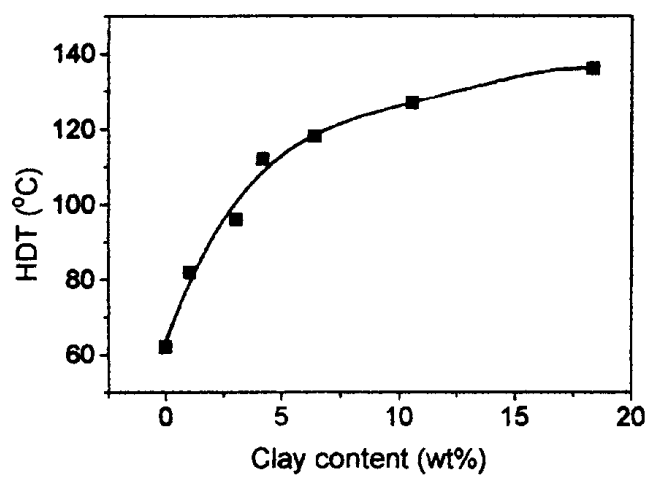

Figure 25. Heat-distortion temperature of Nylon6/clay Nanocomposites (Liu et al., 1998) 


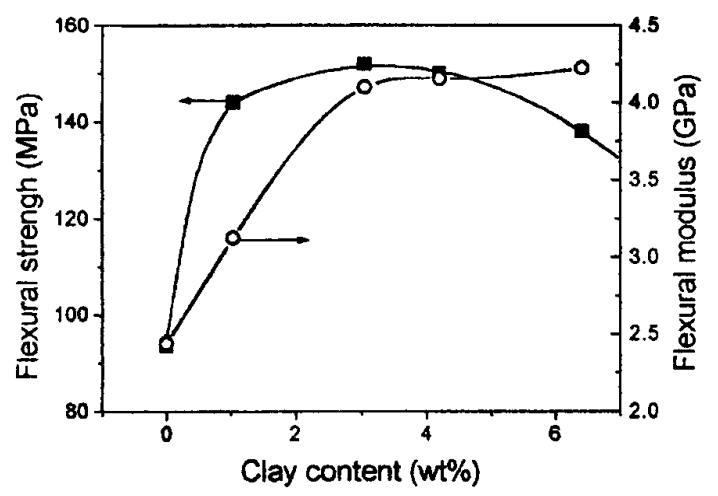

Figure 26. Flexural Strength and Flexural Modulus of Nylon 6/clay Nanocompsites

(Liu et al., 1998)

An increase in tensile modulus and yield strength with clay loading were also reported by Fornes et al. (2001) for nanocomposites based on low-, medium- and highmolecular weight nylon 6 (Figures 27 and 28).

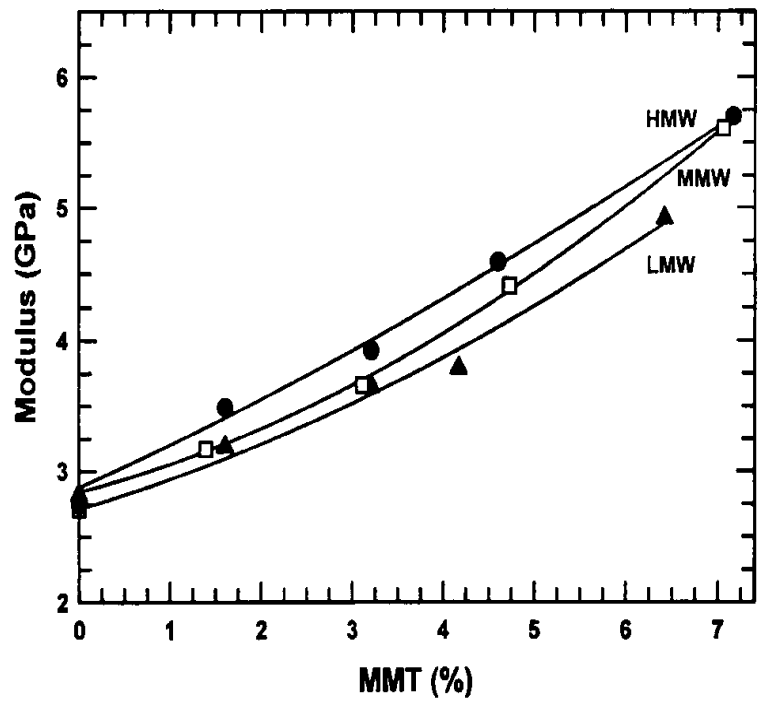

Figure 27. Effect of montmorillonite content on tensile modulus for Low molecular weight (LMW), Medium molecular weight (MMW) and High molecular weight (HMW) Nylon 6 nanocomposites

(Fornes et al., 2001) 


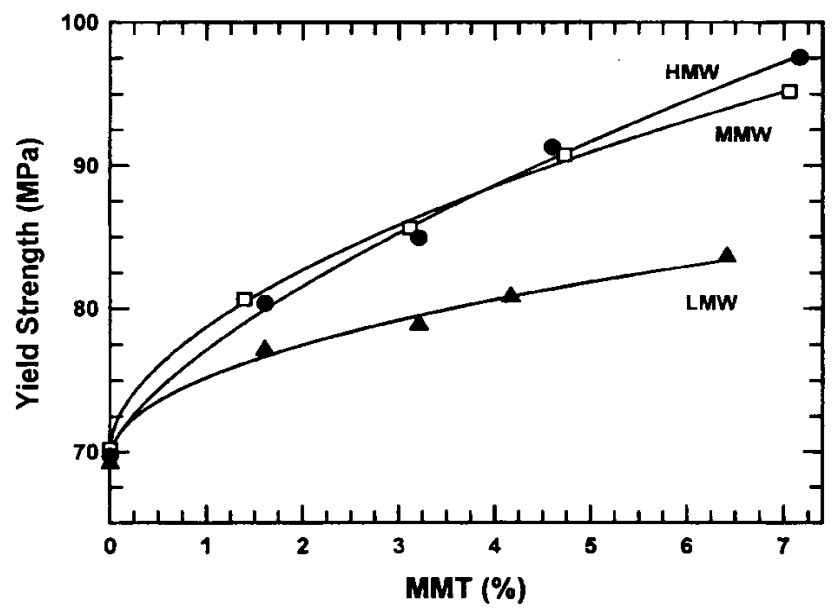

Figure 28. Effect of montmorillonite content on yield strength for Low molecular weight (LMW), Medium molecular weight (MMW) and High molecular weight (HMW) Nylon 6 nanocomposites

(Fornes et al., 2001)

\subsection{Theory Explaining the Mechanical Behavior of Polymer Nanocomposites}

Drozdov et al. (2003) have suggested that the presence of nanoclay in the polymer imposes a constraint on the mobility of macromolecules, which is reflected in terms of the improved mechanical properties of the nanocomposites. These authors also proposed the following equation to explain changes in the elastic modulus, E, with various clay loading levels:

$\sigma(t)=E \varepsilon_{e}(t)\left[1-\varphi\left(\varepsilon_{e}(t)\right)\right]$

where,

$\varphi\left(\varepsilon_{e}\right)=a\left[1-\exp \left(\frac{-\varepsilon_{e}}{e}\right)\right.$

$E=$ Elastic modulus

$\varepsilon_{e}=$ Elastic strain

$\varphi\left(\varepsilon_{e}(t)\right)=$ Coefficient of proportionality 
$a=$ Limiting value of $\varphi$ at large elastic strains

$e=$ Mathematical parameter

This model is intrinsic in clay loading levels and experimental data at various clay-loading levels is required to find the parameters $a, e$ and $E$. Tensile test data of Shah et al. (2001) were used to find the best fitting parameters. It was concluded in the study that the elastic modulus (which is proportional to "free" chains) decreased due to the addition of clay in vinyl ester. 


\section{CHAPTER IV}

\section{MOISTURE DIFFUSION THROUGH NANOCOMPOSITES}

Attempts have been made in the past to explain the diffusion of a small solute through a polymer membrane containing a suspension of impermeable objects. A welldocumented example is that of a membrane filled with periodically arrayed impermeable spheres (Maxwell, 1881). The diffusion coefficient in this case is expressed as:

$$
\frac{D_{0}}{D}=\frac{1+\frac{\phi}{2}}{1-\phi}
$$

Where $D_{0}$ is the diffusion coefficient without any spheres and $\phi$ is the volume fraction of the spheres. The above equation is valid only for dilute solutions $(\phi<0.1)$. This equation is independent of the size of the spheres but not valid when the membrane contains spheres of different sizes.

Similar results for a membrane containing periodically arrayed infinite cylinders oriented parallel to the membrane surface lead to the following expression (Raleigh, 1892):

$$
\frac{D_{0}}{D}=\frac{1+\phi}{1-\phi}
$$

Once again, the equation is valid only for dilute solutions $(\phi<0.1)$. The situation is completely different when the continuous phase is filled with infinitely long impermeable flakes, oriented perpendicular to the diffusion (Cussler et al., 1988). The result in this case is: 
$\frac{D_{0}}{D}=1+\frac{\alpha^{2} \phi^{2}}{1-\phi}$

Where $\alpha$ is the aspect ratio, half the second longest dimension of the flakes divided by the shortest dimension. The derivation of the above equation is as follows:

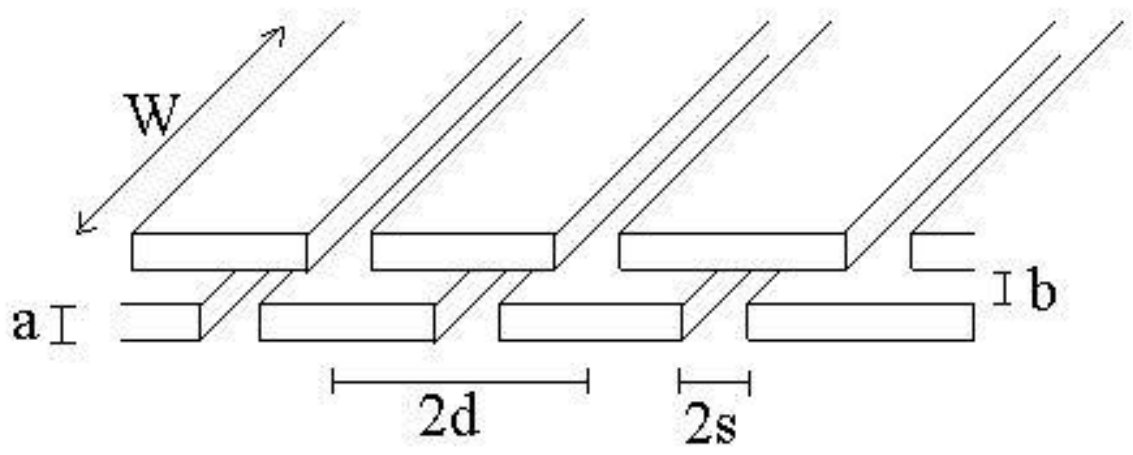

Figure 29. Membrane containing periodically arrayed infinitely long flakes

Consider a unit cell of area $(2 d W)$ where $W$ is the depth (Figure 29). The total flux $J_{0}$ through this unit cell when no flakes are present is:

$J_{0}=\frac{D(2 d W)}{l} \Delta C$

Here, $l$ is the total thickness of the membrane and $\Delta C$ is the difference in concentration of the solute across the membrane. In other words, the resistance to flow across the membrane is:

$\frac{D \Delta C}{J_{0}}=\frac{l}{2 d W}$

When the membrane contains one layer of periodically spaced flakes, the resistance can be approximately given by: 
$\frac{D \Delta C}{J_{1}}=\frac{l}{2 d W}+\frac{b}{d W} \ln \left(\frac{b}{2 s}\right)+\frac{a}{2 s W}$

Here, $J_{l}$ is the flux in the presence of one layer of flakes, $a$ is the thickness of a flake and $b$ is the spacing between the two consecutive layers if there are more than one layers. The first term on the right hand side of the above equation is resistance without flakes. The second term is the resistance of the constriction into and out of the slit of width $2 s$. The third term is the resistance of the slit itself. The above equation can be extended for $N$ layers of equally spaced layers:

$$
\frac{D \Delta C}{J_{N}}=\frac{l}{2 d W}+\frac{b}{d W} \ln \left(\frac{b}{2 s}\right)+\frac{N a}{2 s W}+\frac{1}{2}(N-1) \frac{d}{b W}
$$

Where the fourth term on the right hand side of the equation is the resistance to the horizontal flow between the two consecutive layers of spheres. It has a coefficient of $1 / 2$ because once the diffusing species encounter a flake; it has 2 different ways to proceed. When equation 30 is divided by equation 28 and rearranged, the following expression is obtained:

$\frac{J_{0}}{J_{N}}=1+\frac{2 b}{l} \ln \left(\frac{d}{2 s}\right)+\frac{N d a}{s l}+\frac{(N-1)}{b l} d^{2}$

When $N$ is very large $(N-1)$ can be replaced by $N$. The Second term on the right hand side of the above equation can also be ignored when $N$ is significantly large. More over $l$ equals $N(a+b)$. The above equation, then reduces to:

$$
\frac{J_{0}}{J_{N}}=1+\frac{d a}{s(a+b)}+\frac{d^{2}}{b(a+b)}
$$


For uniformly spaced flake layers, volume fraction of flakes $\phi$ is related to parameters $a$ and $b$ by the following expression:

$\phi=\frac{a}{a+b}$

Using above equality in equation 32 , the following expression can be derived:

$\frac{J_{0}}{J_{N}}=1+\sigma \alpha \phi+\alpha^{2} \frac{\phi^{2}}{1-\phi}$

Where, $\sigma(=s / a)$ characterizes the shape of the slit and $\alpha(=d / a)$ characterizes the shape of the flake. When the slit gap is very small and the wiggles within the film are dominant $(\sigma / \alpha<<1)$, the above equation reduces to:

$\frac{J_{0}}{J_{N}}=1+\alpha^{2} \frac{\phi^{2}}{1-\phi}$

Equation 26 is obtained when the above equation is written in terms of ratio of diffusivities.

More complex equations for the flake-filled membranes have been proposed by Aris (1986), Falla et al. (1996) and Wakeham and Mason (1979). These equations have additional resistances that affect the diffusion through flake-filled membranes. The geometry of nanoclay platelets is similar to that of flake layer. Therefore, the first attempt to explain the diffusion through polymer-clay nanocomposite was based on the idea that all the clay platelets are oriented parallel to the film surface. This theory was proposed by Yano et al. (1993), and it is based on the assumption that there is no interaction between the clay in the nanocomposite and water molecules diffusing through it. On the contrary, Drozdov et al. (2003) have proposed a theory based on the assumption that clay is 
hydrophilic and that it interacts with water molecules diffusing through nanocomposites. The subsequent sections cited in this chapter review these two theories.

\subsection{Theory Explaining the Variations in Relative Permeability with Clay Loadings}

Yano et al. (1993), assumed that there is no interaction between the clay platelets and water molecules and proposed a theory to predict the variations in water permeability with various clay loadings.

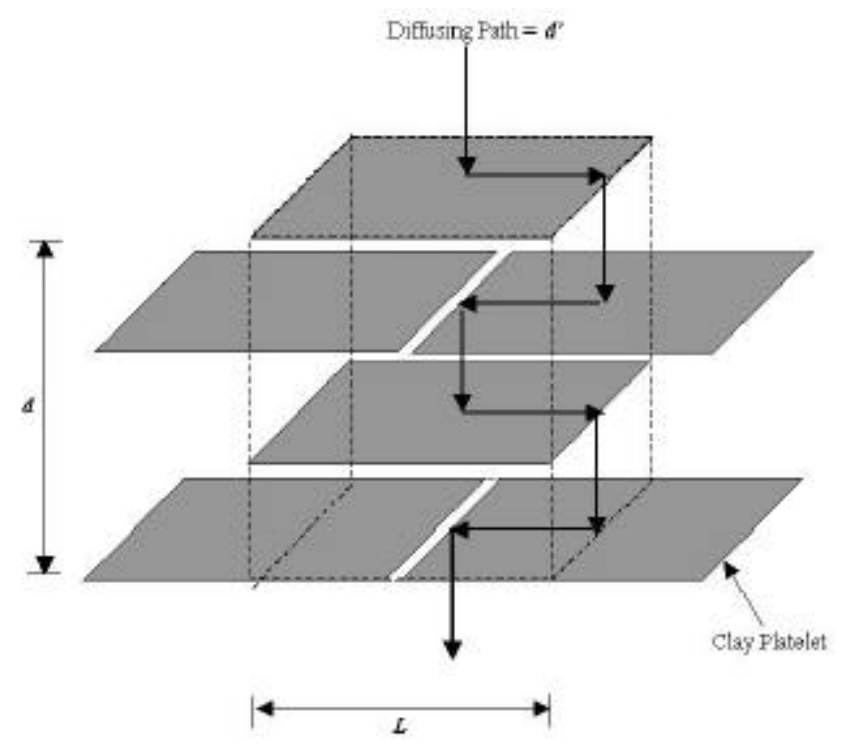

Figure 30. Volume Element of Polymer Nanocomposite Film

Figure 30 shows a portion of the polymer nanocomposite film (shown by the dotted cube) of surface area equal to that of a clay platelet. The thickness of the film is $d$ i.e., the diffusing molecule traverses distance $d$ in the absence of clay. Assuming no interaction between the diffusing molecule and clay in a nanocomposite, the diffusing molecule traverses a distance that is longer than $d$, and this is referred to as $d^{\prime}$. The new 
path length of the diffusing molecule will be longer than d, by a distance equal to $n \frac{L}{2}$, where $n$ is the effective number of clay platelets encountered during diffusion, and $L$ is the length of each plate.

The volume fraction of clay platelets in the volume of interest can be expressed as:

$V_{f}=\frac{n \cdot A \cdot W}{A \cdot d}$

Where,

$A=$ Surface area of the volume element

$W=$ Width of a clay platelet

Equation 36 can be rearranged in terms of effective number of clay platelets encountered during diffusion:

$n=V_{f} \frac{d}{W}$

The new path length can be expressed as:

$d^{\prime}=d+d \frac{L}{2 W} V_{f}$

Tortuosity of the path due to the presence of clay is defined as:

$$
\tau=\frac{d}{d^{\prime}}=\frac{1}{\left[1+\left(\frac{L}{2 W}\right) V_{f}\right]}
$$

Hence, relative permeability can be expressed as:

$$
\frac{P_{c}}{P_{p}}=\frac{1}{\left[1+\left(\frac{L}{2 W}\right) V_{f}\right]}
$$


Where, $P_{c}$ and $P_{p}$ are the pearmeabilities of the nanocomposites and the pristine polymer respectively.

At any given temperature, permeability $(P)$ is related to the diffusivity $(D)$ by the following expression:

$P=D \times S$

Here, $S$ is the solubility of the diffusing species in the film.

Shah (2001) found the diffusivities and solubilities of water in vinyl ester nanocomposites from the weight gain diffusion experiments. He used equation 41 to calculate the permeability of the nanocomposites with various clay loadings. The TEM images of clay morphology showed $L=180 \mathrm{~nm}$ and $W=1 \mathrm{~nm}$. The following figure shows a plot of $P_{d} / P_{p}$ versus volume fraction of montmorillonite in DERAKANE 411-350 epoxy vinyl ester resin. The solid line in Figure 31 shows relative permeability predicted by equation 40 .

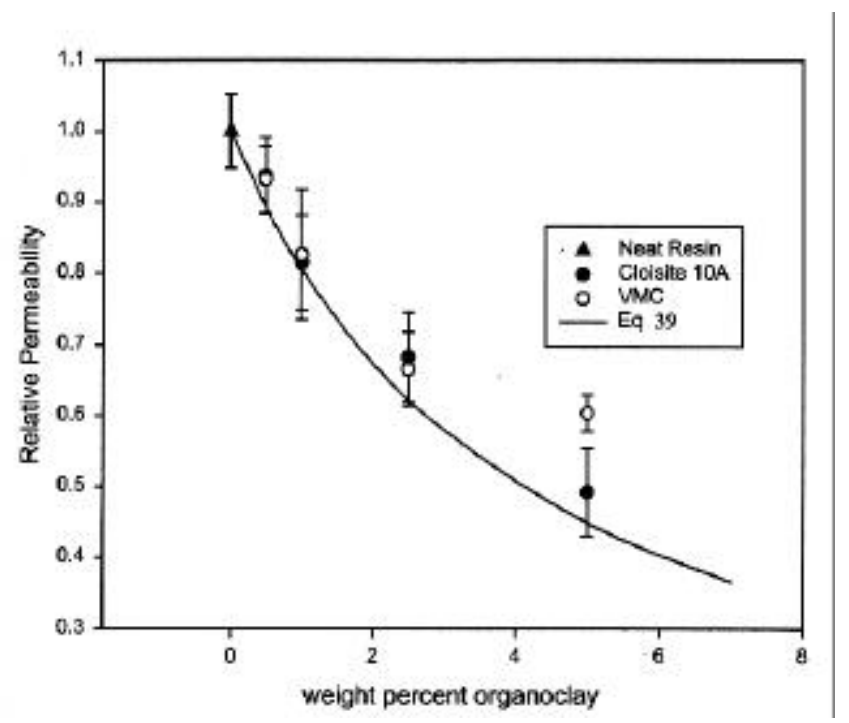

Figure 31. Relative Permeability of Cloisite 10A® and VMC vinyl ester resin nanocomposites. $(\mathrm{L}=180 \mathrm{~nm}, \mathrm{~W}=1 \mathrm{~nm})$. Volume fraction was calculated using $\rho_{\text {clay }}=2.66 \mathrm{~g} / \mathrm{cc}$ and $\rho_{\text {polymer }}=1.075$ g/cc (Shah, 2001) 
Figure 31 suggests that there is a fair agreement between the calculated permeability values and those predicted by equation 40 .

\subsection{Theory Explaining Variations in Diffusion Coefficient with Clay Loadings}

Drozdov et al. (2003) have proposed a model for moisture diffusion in polymer containing nanoclay based on the experimental work of Shah et al. (2002). The model is developed in Cartesian coordinates for a rectangular plate of polymer nanocomposite having a thickness of $2 l$, where the x-axis lies perpendicular to the plane of the plate and the other two axes lie in the plane of the plate. The following assumptions are involved in the development of this model:

1. Rate of sorption in glassy polymers noticeably exceeds the rate of diffusion. i.e. concentration of water at surface of the sample reaches a constant value $\left(n_{1}^{o}\right)$ as soon as the sample is immersed in water. This assumption is also supported by the work of Chen et al. (2001).

2. Diffusion occurs through the polymer matrix only. Water molecules do not penetrate through clay platelets; instead they get immobilized on the surface of clay platelets.

3. Water molecules do not leave the surface of a clay platelet once they are immobilized on the platelet.

4. Diffusion coefficient (D) depends on the volume of the filler content because the presence of particles results in decay in the molecular mobility of polymeric molecules, which provides the driving force.

5. Adsorption of water molecules on the surfaces of filler is determined by a first-order kinetic equation. 
6. Rate of adsorption, $\kappa$, and the maximum concentration of unoccupied sites $\left(n_{1}^{o}\right)$ are functions of clay content, because the presence of nano-particles affects mobility of chains in the polymeric matrix, and, as a consequence, their chemical potential.

7. Moisture content before starting of transient diffusion experiment is zero.

A fraction of water molecules entering the nanocomposite get immobilized on the surfaces of the clay platelets increasing the concentration of water in clay, and the rest of the water molecules increase the moisture concentration in matrix. Therefore, Diffusion of water through the matrix is described by following mass balance equation:

$$
\frac{\partial n}{\partial t}=-\frac{\partial J}{\partial x}-\frac{\partial n_{1}}{\partial t}
$$

Where,

$t=$ Time

$x=$ Position

$n=$ Moisture concentration at time $t$ at position $x$ in matrix

$J=$ Mass flux of water

$n_{l}=$ Concentration of water molecules immobilized at the surfaces of clay platelet

The mass flux still obeys Fick's equation:

$$
J=-D \frac{\partial n}{\partial x}
$$

Where,

$D=$ Diffusion coefficient 
Adsorption of water molecules on the surfaces of the clay platelets is determined by the following first order kinetic equation:

$\frac{\partial n_{1}}{\partial t}=\kappa n\left(n_{1}^{o}-n_{1}\right)$

Where,

$n_{1}^{o}=$ Total number of sites where the molecules can be immobilized

Above equation implies that the rate of adsorption is proportional to the concentration of the water in the matrix, $n$, and to the current number of "unoccupied sites" on the surfaces of the clay platelet.

Assumption 1 facilitates the use of the following equation as a boundary condition.

$\left.n(t, x)\right|_{x= \pm l}=n^{o}$

Where,

$n^{o}=$ Equilibrium moisture concentration in the matrix on the faces

If the moisture content in a sample before starting the transient experiment is neglected, then equations 46 and 47 can be used as initial conditions to solve the problem defined by 42.

$\left.n(t, x)\right|_{t=0}=0$

$\left.n_{1}(t, x)\right|_{t=0}=0$

This system of partial differential equations is solved numerically using the above listed boundary conditions and initial conditions for parameters $D, \kappa$, and the ratio $\frac{n_{1}^{o}}{n^{o}}$. Details of the numerical solution can be found in Drozdov et al. (2003). Experimental 
data from the work of Shah (2001) were used for the convergence of the numerical solution. The following figure shows a comparison of model predictions and the experimental data.

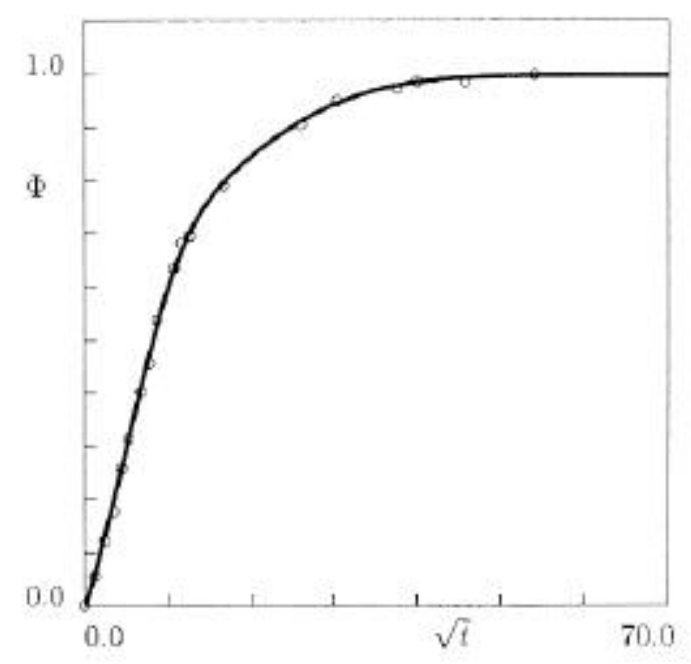

Figure 32. Relative Water uptake $\Phi=\frac{M_{t}}{M_{\infty}}$ versus Normalaized time $\frac{\sqrt{t}}{2 l}$ for a DERAKANE 411350 resin sample $($ Thickness $=0.18452 \mathrm{~mm})$ containing $5 \mathrm{wt} \%$ of Cloisite $10 \mathrm{~A}^{\circledR}$ clay (Solid line: model prediction, Circles: Experimental data)

As seen from Figure 32, there is a very good agreement between the experimental data and the numerical analysis. Figure 33 shows experimental water uptake curves for $5 \mathrm{wt} \%$ Cloisite $10 \mathrm{~A}^{\circledR}$ nanocomposites. A solid line in Figure 33 shows Fickian solution. 


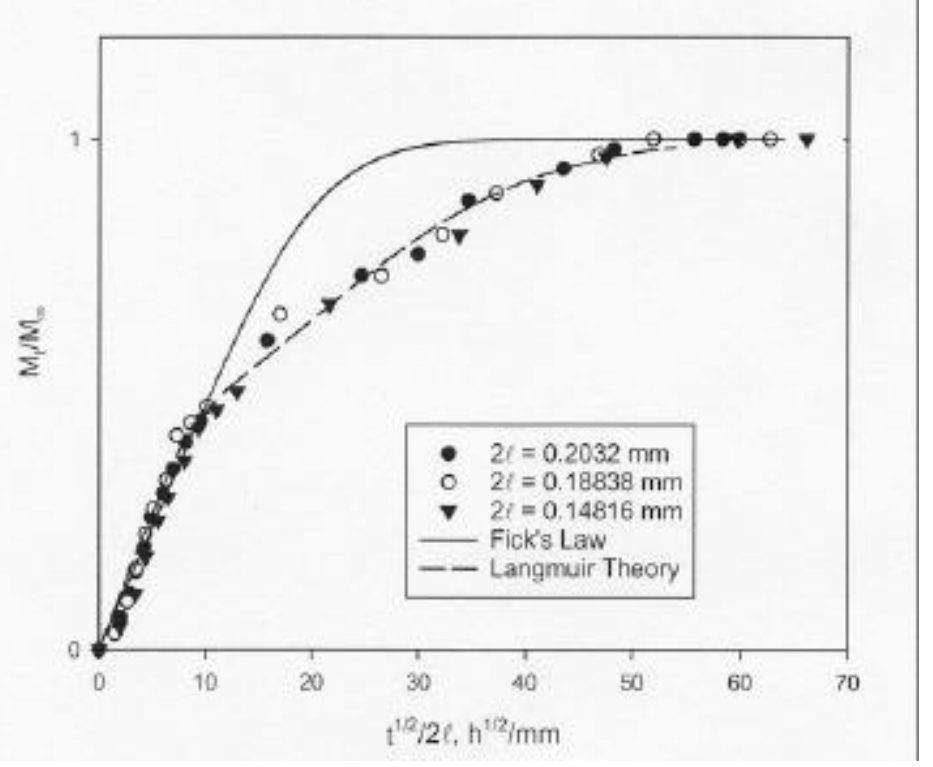

Figure 33. Water uptake curves of $5 \mathrm{wt} \%$ Cloisite $10 A^{\circledR}$-DERAKANE 411-350 vinyl ester resin at $25^{\circ} \mathrm{C}$

It can be clearly seen from Figure 33 that the nanocomposites show significant amount of non-Fickian behavior. It can be seen that the Fick's solution is not very accurate when used to predict the water uptake of nanocomposites. On the other hand, the parameters $\left(D, \kappa\right.$, and the ratio $\left.\frac{n_{1}^{o}}{n^{o}}\right)$ found using Drozdov's theory can be accurately used to reproduce the normalized weight gain curve as seen from Figure 32. The theory assumes that the diffusion in the absence of clay is perfectly Fickian and hence the theory cannot be applied when the neat resin shows non-Fickian diffusion. 


\section{CHAPTER V}

\section{EXPERIMENTAL DETAILS}

Two types of diffusion experiments were carried out as a part of this study: 1) Transient diffusion experiments and 2) Steady state diffusion experiments. The mechanical and dynamic mechanical properties of nanocomposites were also studied as a function of clay. Materials used in this study, sample preparation and experimental procedures are covered in this chapter.

\subsection{Materials}

The resin used in this study was DERAKANE 411-350 Momentum epoxy vinyl ester resin obtained from Dow Chemical Company. The resin contained 45\% dissolved styrene. The resin was cured at room temperature, as recommended by Dow Chemical Company. 1 wt $\%$ of methyl ethyl ketone peroxide ( $9 \%$ active oxygen) was used as an initiator and 0.03 wt $\%$ of $6 \%$ cobalt naphthenate was used as catalyst. Both chemicals were obtained from Sigma Aldrich Company. Nanocomposites were made using Cloisite $10 \mathrm{~A}^{\circledR}$ clay obtained from Southern Clay Products. Sodium hydroxide and calcium chloride used in the study were obtained from Aldrich Chemical Company. Sodium chloride and Red sealing wax were obtained from Fisher Scientific Company.

\subsection{Sample Preparation}

Samples of neat vinyl ester were prepared by pouring the mixture of resin, initiator and catalyst into a Teflon mold. Typical dimensions of the samples used for transient diffusion experiments were $5 \mathrm{~cm} \times 1.25 \mathrm{~cm}$. Sample thicknesses varied between 
$0.02 \mathrm{~cm}$ and $0.07 \mathrm{~cm}$. The polymer was allowed to cure at room temperature for 24 hours. Post curing of the samples was carried out in an oven at $95^{\circ} \mathrm{C}$ for 3 hours. Nanocomposite samples for the diffusion experiments were prepared by manually mixing different weight percentages of Cloisite $10 \mathrm{~A}^{\circledR}$ in resin and degasifying before addition of initiator and catalyst. The mixture of clay and resin was stirred thoroughly for at least 20 minutes to assure the homogeneity of the mixture before addition of initiator and catalyst. DSC was used to obtain themograms of the neat resin samples. Both the non post-cured as well as post-cured samples were heated from room temperature to $150^{\circ} \mathrm{C}$ at a heating rate of $10^{\circ} \mathrm{C}$ per minute. Figures 34 and 35 show the DSC scans of non post-cured and post-cured neat resin samples respectively.

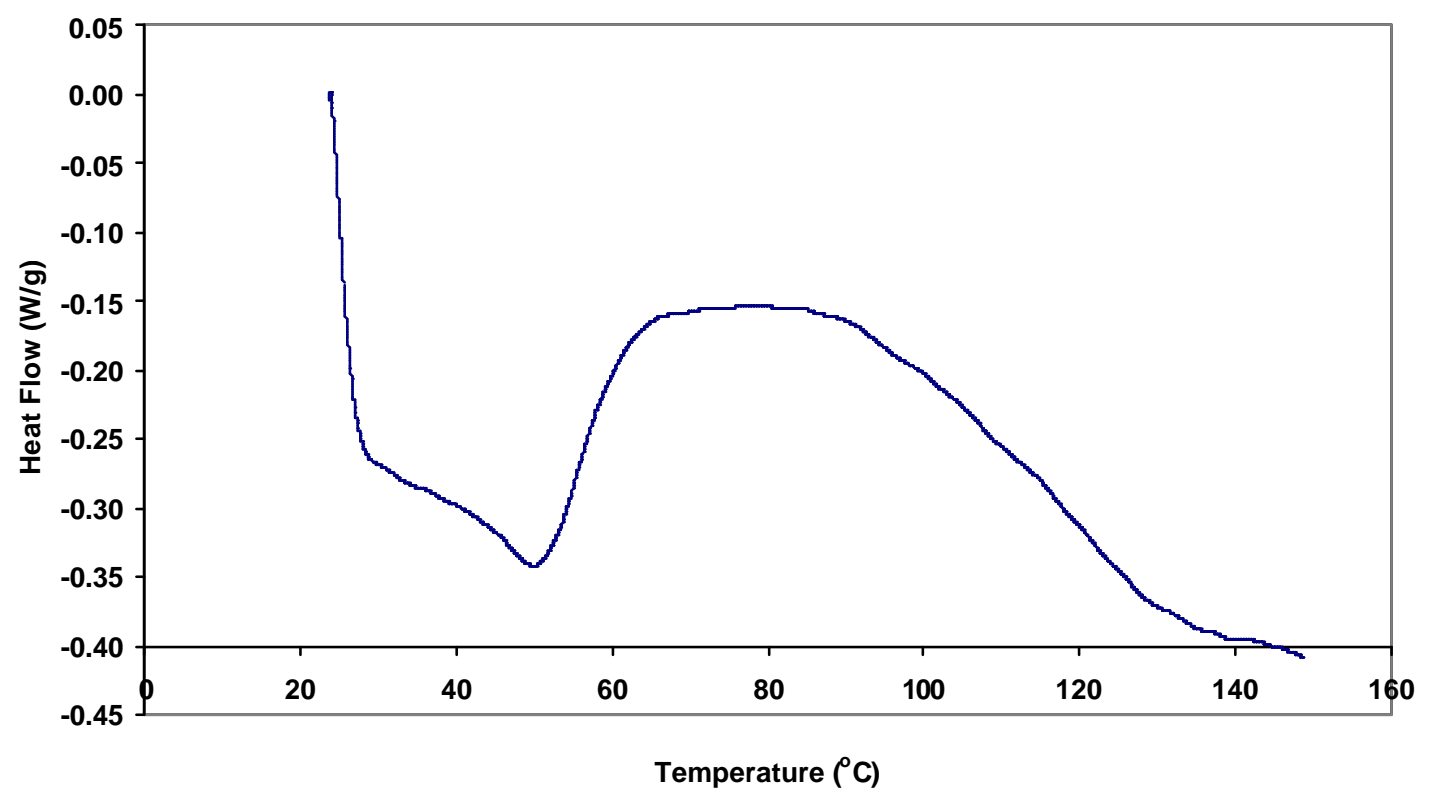

Figure 34. DSC Scan of non post-cured neat DERAKANE 411-350 Momentum resin 


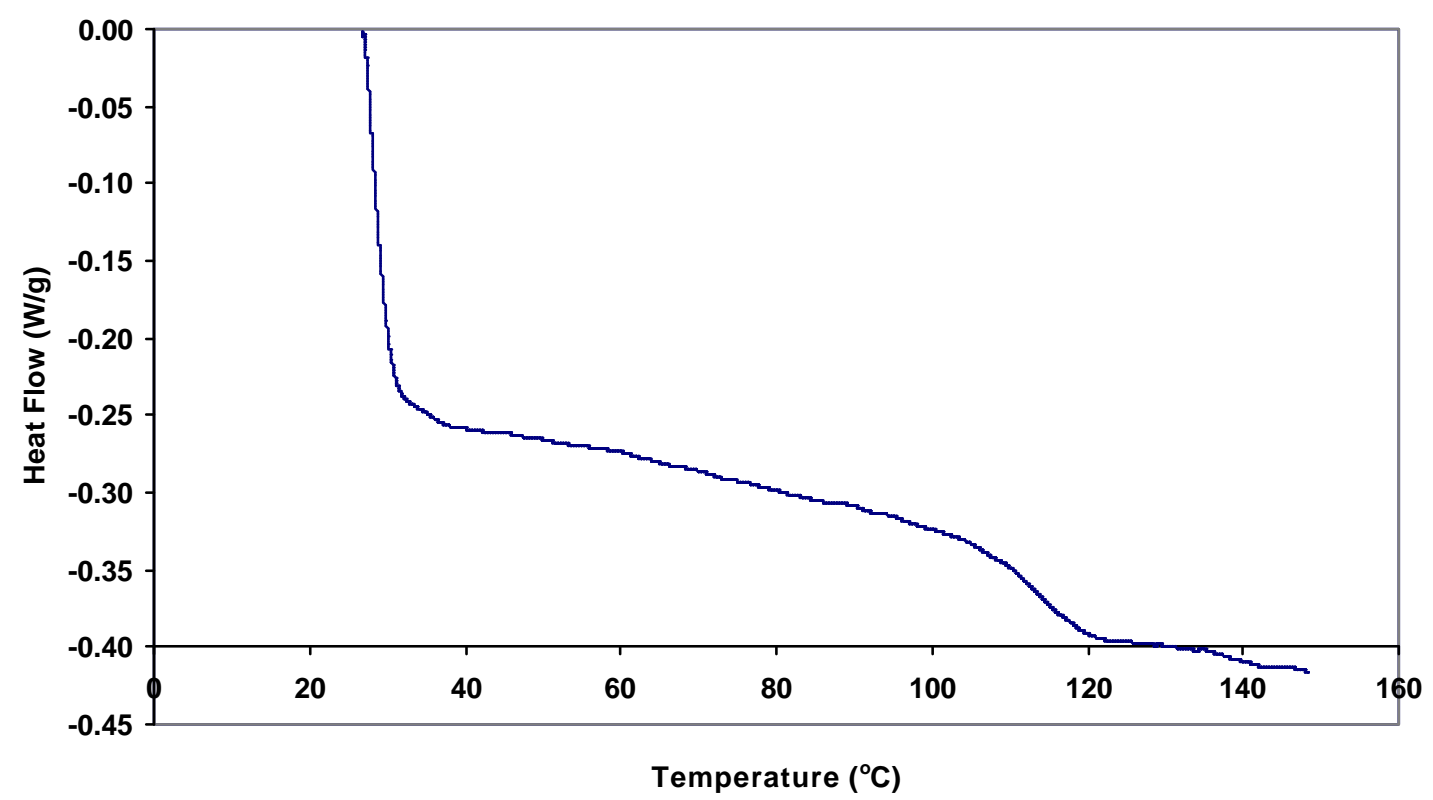

Figure 35. DSC Scan of post-cured neat DERAKANE 411-350 Momentum resin

The presence of exothermic peak in the DSC scan of non post-cured sample (Figure 34) indicated that the sample was not completely cured. The $T_{g}$ of the non postcured sample was approximately $47^{\circ} \mathrm{C}$. The $\mathrm{T}_{\mathrm{g}}$ of the post-cured neat resin samples was approximately $117^{\circ} \mathrm{C}$ (Figure 35). No exothermic peak was recorded for the post-cured neat resin sample after the $T_{g}$ has passed indicating that the sample was completely cured. Shah (2001) also performed DSC scans on DERAKANE 411-350 resin and found that the glass-transition temperatures of non post-cured and post-cured resins were approximately $59.44^{\circ} \mathrm{C}$ and $97.87^{\circ} \mathrm{C}$ respectively. The $\mathrm{T}_{\mathrm{g}}$ values recorded by Shah were significantly different from the corresponding values recorded in the present study indicating that the chemical structure of the resin used in both the studies is different.

Rectangular samples of GFRP having a dimension of approximately $4 \mathrm{~cm} \times 1.5$ $\mathrm{cm}$ were prepared. One layer of E-glass fiber mat (24 ounce, 0-90 orientation) was used 
to provide reinforcement to the vinyl ester resin. The glass-fiber roving was manufactured by PPG industries. Figure 36 shows a schematic representation of the glass fiber mat used in the present study.
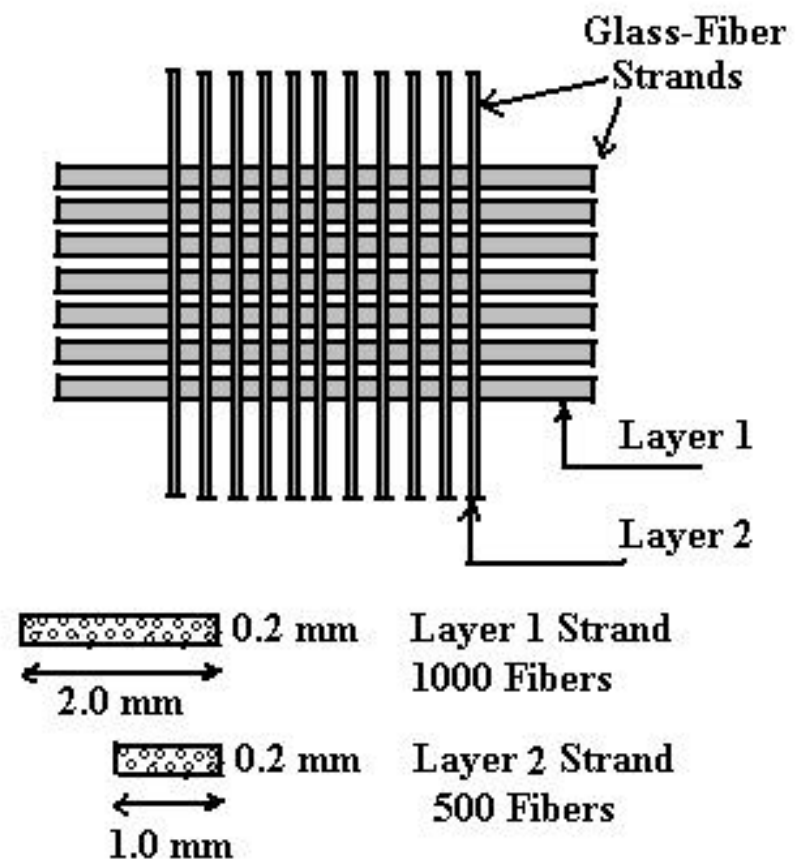

Figure 36. Schematic diagram on glass-fiber mat

Two layers of glass-fiber strands were stacked on top of each other. The geometry of the layers is also shown in Figure 36. The total thickness of the fiber-mat was found to be $0.5 \mathrm{~mm}$. However, the sum of the thicknesses of the each individual layer was $0.4 \mathrm{~mm}$ indicating that there was $0.1 \mathrm{~mm}$ gap between the two layers. There were also small gaps between the two adjacent strands in a given layer. These gaps were found to be $0.18 \mathrm{~mm}$ and $1.0 \mathrm{~mm}$ for layer 1 and layer 2 respectively.

Hand lay-up technique was used to prepare FRP samples. A piece of fiber-mat having dimensions of approximately $25 \mathrm{~cm} \times 4 \mathrm{~cm}$ was placed on a sheet of Teflon. A 
mixture of resin and the appropriate amount of Cloisite $10 \mathrm{~A}^{\circledR}$ clay was stirred vigorously for at least 30 minutes. Appropriate amount of catalyst and initiator were added to the reaction mixture and the mixture was poured on to the piece of fiber-mat until the mat was completely soaked by the reaction mixture. Another sheet of Teflon was placed on top of soaked fiber-mat and a weight of $10 \mathrm{Kg}$ was applied to squeeze out the excess resin. This weight was removed after 24 hours, and samples of approximately $2.5 \mathrm{~cm} \times$ $1.5 \mathrm{~cm}$ were cut out from the thin sheet of FRP. Edges of the cut samples were sealed using the same reaction mixture that was used to make the FRP. Samples of FRP were prepared with $0 \mathrm{wt} \%, 1 \mathrm{wt} \%, 2 \mathrm{wt} \%$ and $5 \mathrm{wt} \%$ of Cloisite $10 \mathrm{~A}^{\circledR}$ clay in polymer. All the samples were post cured at $95^{\circ} \mathrm{C}$ for 3 hours.

\subsection{Transient Diffusion Experiments in Distilled Water}

Post-cured samples without glass-fibers were immersed in distilled water at different temperatures: $4^{\circ} \mathrm{C}, 25^{\circ} \mathrm{C}, 42.5^{\circ} \mathrm{C}$ and $62^{\circ} \mathrm{C}$. A Fisher Scientific Isotemp ${ }^{\circledR} 500$ Series oven was used whenever the experiments were carried out at temperatures above room temperature. A Hotpoint No-Frost CTX 18P Refrigerator-Freezer was used to conduct diffusion experiments at temperatures lower than room temperature. Samples were periodically removed, blotted dry with Kimberly Clarke lint-free tissue, weighed and re-immersed in water. A Mettler electronic balance (least count of $1 \mu \mathrm{g}$ ) was used to weigh the samples. Samples were weighed after every 30 minutes for the first 3 hours after immersion, every hour for the next 12 hours, every 12 hours for the next 2 days and every day for the rest of the experiment. Each experiment was continued until there was no mass gain reported over a period of 10 days. Data obtained for at least 45 samples 
were used to calculate the average diffusion coefficient of the material. The diffusion coefficients and equilibrium moisture contents were calculated from the sorption curve as explained in section 2.1 .

FRP samples having various amounts of nano-filler were immersed in distilled water at three different temperatures: $4^{\circ} \mathrm{C}, 25^{\circ} \mathrm{C}$ and $42.5^{\circ} \mathrm{C}$. Diffusion of water through FRPs was studied gravimetrically, by performing transient water uptake experiments as was done for the un-reinforced nanocomposites. The diffusion coefficients and equilibrium moisture contents were calculated from the sorption curve as explained in section 2.1. The results showed that there were significant variations in the equilibrium moisture contents of the same type of FRP samples. This was expected because each sample contained different amount of glass fibers. In other words, the weight percent of fibers in the samples varied slightly from sample to sample. To find an accurate estimate of the amount of water inside the resin, the weight gain curves had to be corrected for the weight of the glass-fibers. The weight of glass-fibers in a given sample was estimated using the area of the sample as explained in appendix A.1.4. The weight of the glass-fiber was, then, subtracted from each experimental reading. This treatment did not affect the diffusivities obtained using un-corrected data.

$$
\frac{M_{t}-M_{0}}{M_{\infty}-M_{0}}=\frac{\left(M_{t}-M_{g}\right)-\left(M_{0}-M_{g}\right)}{\left(M_{\infty}-M_{g}\right)-\left(M_{0}-M_{g}\right)}
$$

Here $M_{g}$ is the mass of the glass-fiber in a given sample. As seen from the above equation, the correction for the weight of the glass fiber did not change the shape of the weight gain curve and thus, resulting in the same diffusivity values that were obtained 
from the un-corrected data. However, the correction yielded accurate values of moisture contents inside the resin.

\subsection{Transient Diffusion Experiments in Alkaline and Saline Solutions}

In order to understand the diffusion of water in polymer immersed in alkaline and saline solutions, transient diffusion experiments were performed at three different temperatures: $4^{\circ} \mathrm{C}, 28^{\circ} \mathrm{C}$ and $42.5^{\circ} \mathrm{C}$. As before, a Fisher Scientific Isotemp ${ }^{\circledR} 500$ Series oven was used whenever the experiments were carried out at $42.5^{\circ} \mathrm{C}$ while a Hotpoint No-Frost CTX 18P Refrigerator-Freezer was used to conduct diffusion experiments at $4^{\circ} \mathrm{C}$. A solution having a $\mathrm{pH}$ of 13 was prepared by dissolving the appropriate amount of solid $\mathrm{NaOH}$ in distilled water. Similarly, $0.1 \mathrm{M} \mathrm{NaCl}$ solution was prepared by dissolving solid $\mathrm{NaCl}$ in distilled water and the $\mathrm{pH}$ of the salt solution was measured to be 7.0. Polymer samples containing $0 \mathrm{wt} \%, 1 \mathrm{wt} \%, 2 \mathrm{wt} \%$, and $5 \mathrm{wt} \%$ of Cloisite $10 \mathrm{~A}^{\circledR}$ nanoclay were immersed in these solutions and their weight gain was measured periodically. Typical dimensions of the sample were $5 \mathrm{~cm} \times 1.25 \mathrm{~cm}$. The thickness of the samples varied between $0.02 \mathrm{~cm}$ and $0.07 \mathrm{~cm}$. Beakers containing solutions were closed at the top using aluminum foil to avoid evaporation of water. No loss of water took place and concentrations of solutions were found to be constant during the period of experiments. The temperature of the solutions was maintained constant throughout the experiments.

FRP samples having various amounts of nano-filler were immersed in $0.1 \mathrm{M} \mathrm{NaCl}$ solution and $0.1 \mathrm{M} \mathrm{NaOH}$ solution at three different temperatures: $4^{\circ} \mathrm{C}, 25^{\circ} \mathrm{C}$ and $42.5^{\circ} \mathrm{C}$. Typical dimensions of the sample were $2.5 \mathrm{~cm} \times 1.5 \mathrm{~cm}$. The thickness of the samples varied between $0.05 \mathrm{~cm}$ and $0.10 \mathrm{~cm}$. Diffusion of water through FRPs was studied 
gravimetrically, by performing transient water uptake experiments as was done for the un-reinforced nanocomposites. The diffusion coefficients and equilibrium moisture contents were calculated from the sorption curve as explained in section 2.1 after applying correction for the weight of the glass-fibers.

\subsection{Desorption Experiments}

Nanocomposite samples (similar to the ones that were used in transient diffusion experiments) containing various amounts of Cloisite $10 \mathrm{~A}^{\circledR}$ were saturated with water by keeping them immersed in distilled water at $25^{\circ} \mathrm{C}$ for more than 2 months. Those samples were, then, put inside a controlled humidity chamber having a humidity of $20 \% \mathrm{RH}$. Temperature of the humidity chamber was found to be $25^{\circ} \mathrm{C}$ throughout the experiments. All the samples were weighed periodically to understand the desorption behavior of these

samples. Plots of $M_{t} / M_{\infty}$ versus $t^{1 / 2} / 2 l$ were made for all the un-reinforced samples. Where $M_{t}$ and $M_{\infty}$ are mass loss at time $t$ and at equilibrium respectively. $t$ is time and $2 l$ is the thickness of the sample. Here, the equilibrium was considered to have been attained when no weight loss was recorded over a period of 5 days. Diffusion coefficients for desorption were calculated from the initial slope of the normalized weight-loss curves as was done in the transient diffusion experiments.

\subsection{Steady State Diffusion Experiments}

In the transient method of determining diffusion coefficients of polymer containing nanoclay, the polymer is completely immersed in distilled water, and it is periodically weighed until it is completely saturated with water. However, there is a 
possibility that the diffusion coefficient thus calculated might not give accurate results in predicting the steady state rate of water transmission through polymeric films containing clay. Since the clay is hydrophilic, water molecules adsorb on to the surface of clay platelets i.e. moisture is present in two forms inside the polymer: 1) bound moisture and 2) free moisture. The bound moisture certainly affects the results of transient experiments. Therefore, another experimental set-up was developed to determine the steady state rate of water transmission and to calculate a value of the diffusion coefficient, which is independent of the amount of bound moisture in the polymer.

A desiccant method as described in ASTM E 96-00 was used to determine the steady state permeability of polymer films. In this case a polymer film was attached to the open mouth of an aluminum dish containing $4.0 \mathrm{~g}$ of anhydrous $\mathrm{CaCh}$ desiccant (obtained from Aldrich Chemical Co.), and the sealed assembly was placed in a controlled humidity chamber at high relative humidity (Figure 37). The diameter of the aluminum dish was $5.07 \mathrm{~cm}$ and red sealing wax was used to seal the polymer on top of the dish. Due to the presence of desiccant, the relative humidity inside the dish was very low (taken as $0 \% \mathrm{RH}$ for calculation purpose) and the humidity of the chamber was kept constant at $77 \% \mathrm{RH}$. The temperature inside the controlled humidity chamber was found to be $25^{\circ} \mathrm{C}$ throughout the experiment. The gradient of water concentrations across the two surfaces of the polymeric film causes water molecules to diffuse through the polymer. Periodic weighing of the assembly using a Mettler electronic balance (least count of $1 \mathrm{mg}$ ) allows for the rate of water transmission through the polymer into the desiccant to be determined. In order to achieve steady state faster, the polymer specimens 
were saturated with water at the relative humidity level of the chamber before sealing them on top of the dish.

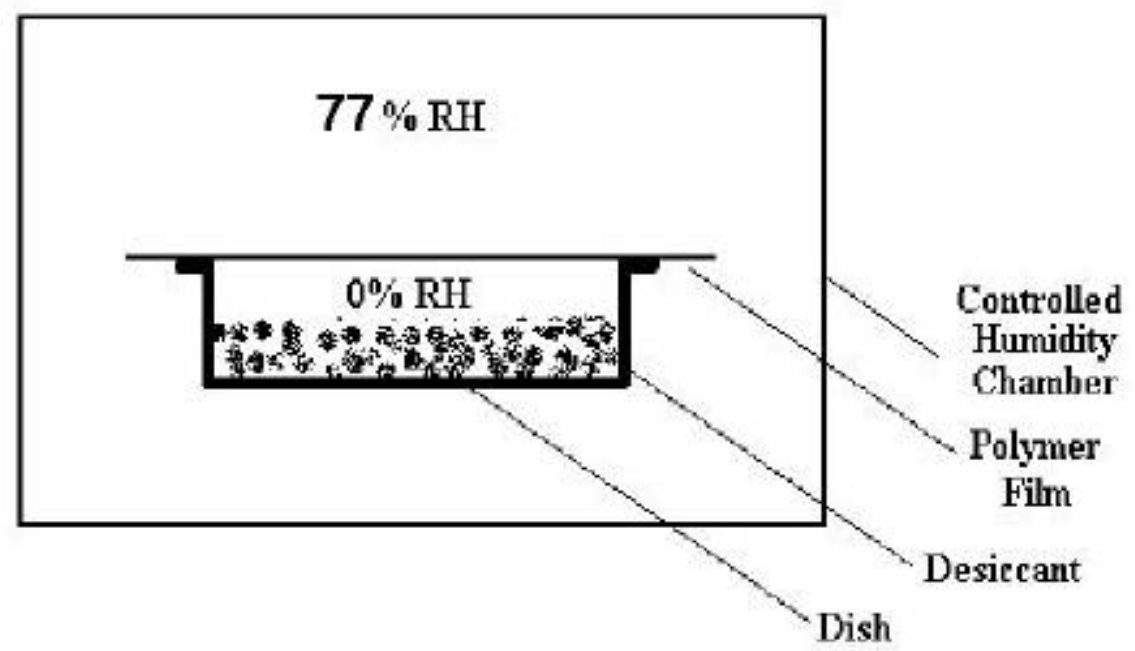

Figure 37. Experimental set-up for Steady-State Experiments

Once a steady state is reached, mass gain of assembly versus time plot becomes a straight line. This slope is used in calculating the diffusion coefficient of the specimen film as explained in section 2.2.

Similar steady-state experiments were also performed with FRP films having one layer of fiber mat reinforcement. Fiber mat used in the study was the same that was used in transient diffusion experiments.

The density of the polymer was calculated from water displacement experiments. Dry polymer films of known weight were immersed in a measuring cylinder having a least count of $0.1 \mathrm{ml}$ and the change in volume was measured. Polymer density was calculated using the following equation: 
Density $\rho=\frac{m}{v}$

Where, $m=$ Mass of polymer film and $v=$ Volume of water displaced

The water concentration difference across the film was obtained from a separate set of experiments. Nanocomposite films were saturated with water at chamber humidity level at the temperature of interest. Saturated films were weighed. Then the same films were placed in a closed container filled with granular calcium chloride desiccant. Films were allowed to get desorbed and weights of the films were taken periodically. When the weight of the films stopped decreasing it was assumed that the films contained no moisture. Absolute amount of water contained in the saturated film was calculated as the difference of weight of water-saturated film and dry film. Saturation concentrations of the films were calculated using the following equation:

Saturation concentration $=\frac{\text { Absolute Amount of Water in the Film }}{\text { Volume of the Film }}$

Here, it is assumed that this saturation concentration is the same as the concentration of water on the film surface that is exposed to the humidity of the chamber. Knowing that anhydrous calcium chloride is a very strong desiccant, concentration of water on the film surface exposed to the desiccant was assumed to be zero. The saturation concentrations used for the FRP films were the same that were used for the un-reinforced nanocomposite films because one surface of the FRP film was equilibrated with the chamber humidity and the other surface was equilibrated with the humidity inside the assembly. 
Steady state diffusion experiments were also carried out on FRP films containing various amounts of nanoclay to understand the effect of presence of glass-fibers on the diffusion behavior. One layer of glass- fiber mat reinforcement was used in all the FRP films. Assemblies similar to that shown in Figure 37 were prepared with FRP films attached on top of aluminum dishes. Assemblies were kept inside the controlled humidity chamber maintained at $77 \% \mathrm{RH}$ and $25^{\circ} \mathrm{C}$. Assemblies were periodically weighed and weight-gain of every assembly was plotted against time. The equilibrium concentrations of the two surfaces of the FRP films were assumed to be the same as that of the corresponding un-reinfoced nanocomposite film. Using the steady-state slope of weightgain versus time plot, diffusion coefficients were calculated.

\subsection{Tensile Tests}

Tensile tests on neat and nanocomposite samples were performed according to ASTM D-638 using a $100 \mathrm{kN}$ Instron machine, model 8501, at a displacement rate of $0.254 \mathrm{~mm} / \mathrm{min}$. The strain was measured independently using an Instron extensometer affixed to the mid-point of the specimen. Variations in tensile modulus, tensile strength and strain at break with various clay loadings were studied. The room temperature was found to be constant at $29^{\circ} \mathrm{C}$ throughout the tensile testing of all the specimens.

\subsection{Notched Impact Tests}

Impact tests on neat and nanocomposite samples were performed on a $2 \mathrm{ft} . \mathrm{lb}$ Instron/Satec BLI Impact Tester. A $2.54 \mathrm{~mm}$ notch was made in all the specimens according to ASTM D 256. The dimensions of the specimens were $6.5 \mathrm{~cm} \times 1.5 \mathrm{~cm}$. The 
thicknesses of the specimens varied between $7 \mathrm{~mm}$ to $9 \mathrm{~mm}$. Variations in impact strength with various clay loadings were recorded at $29^{\circ} \mathrm{C}$.

\subsection{Dynamic Mechanical Analysis}

Dynamic mechanical analysis of nanocomposite samples was carried out on a Rheometrics RMS-800 Instrument. Nanocomposite samples containing $1 \mathrm{wt} \%, 2 \mathrm{wt} \%$ and $5 \mathrm{wt} \%$ clay were prepared along with neat resin samples. Dimensions of the samples were approximately $6.5 \mathrm{~cm} \times 1.2 \mathrm{~cm} \times 0.13 \mathrm{~cm}$. Rectangular torsion tests were carried out with temperature sweep from $40^{\circ} \mathrm{C}$ to $140^{\circ} \mathrm{C}$. All the samples were tested at 6.28 radian/second frequency and at $0.01 \%$ strain. Variations in storage modulus $\left(\mathrm{G}^{\prime}\right)$, loss modulus (G') and glass transition temperature $\left(\mathrm{T}_{\mathrm{g}}\right)$ with various clay loadings were studied.

\subsection{TGA Tests}

Thermo-Gravimetric Analysis (TGA) tests were conducted on nanocomposite samples as well as neat vinyl ester resin in Perkin Elmer Thermogravimetric analyser (TGA 7) instrument to understand the weigh loss of the material as the temperature was increased. These tests were designed to give an insight of the flammability properties of the nanocomposites. All the samples were heated in air from room temperature to $200^{\circ} \mathrm{C}$ at a heating rate of $10^{\circ} \mathrm{C} / \mathrm{min}$ and thereafter, the heating rate was $5^{\circ} \mathrm{C} / \mathrm{min}$ until the temperature reached $550^{\circ} \mathrm{C}$. Fractional weight losses as a function of temperature for all the samples were recorded. 


\subsection{Scanning Electron Microscopy}

Scanning electron micrographs of freshly made FRP samples, which did not contain nanoclay, were taken. Those were recognized as "Reference" samples. FRP samples containing $0 \mathrm{wt} \%$ and $5 \mathrm{wt} \%$ of Cloisite $10 \mathrm{~A}^{\circledR}$ were immersed in distilled water at room temperature for 2 months. After 2 months of immersion, samples were taken out of distilled water and were allowed to dry in a desiccant chamber containing anhydrous calcium chloride desiccant for more than 7 days. Samples were then kept in $400 \mathrm{~mm} \mathrm{Hg}$ vacuum for 15 minutes to ensure that there was no water inside the samples. FRP samples were, then, fractured by applying bending force. Fractured surfaces of the samples were coated with gold in SPI-MODULE ${ }^{\mathrm{TM}}$ sputter coater. Scanning electron micrographs of fractured surfaces were taken and were compared with the micrographs of the "Reference" samples. 


\section{CHAPTER VI}

\section{RESULTS AND DISCUSSION}

\subsection{Transient Diffusion Experiments in Distilled Water at Room Temperature}

A graph of $M_{t} / M_{\infty}$ versus $t^{1 / 2} / 2 l$ was plotted for all the un-reinforced samples. Where $M_{t}$ and $M_{\infty}$ are mass uptake of water at time $t$ and at saturation respectively. $t$ is time and $2 l$ is the thickness of the sample. From the initial slopes of these curves, diffusion coefficients were calculated according to the method explained in section 2.1. Raw data of the experiments can be found in appendix A.2. Water uptake curves are shown in Figure 38 to Figure 41 and the results are summarized in Table VII. Results of Shah (2001) are shown for the purpose of comparison. It should be noted that Shah had used DERAKANE 411-350 vinyl ester resin which is not exactly the same as the resin used in the present study.

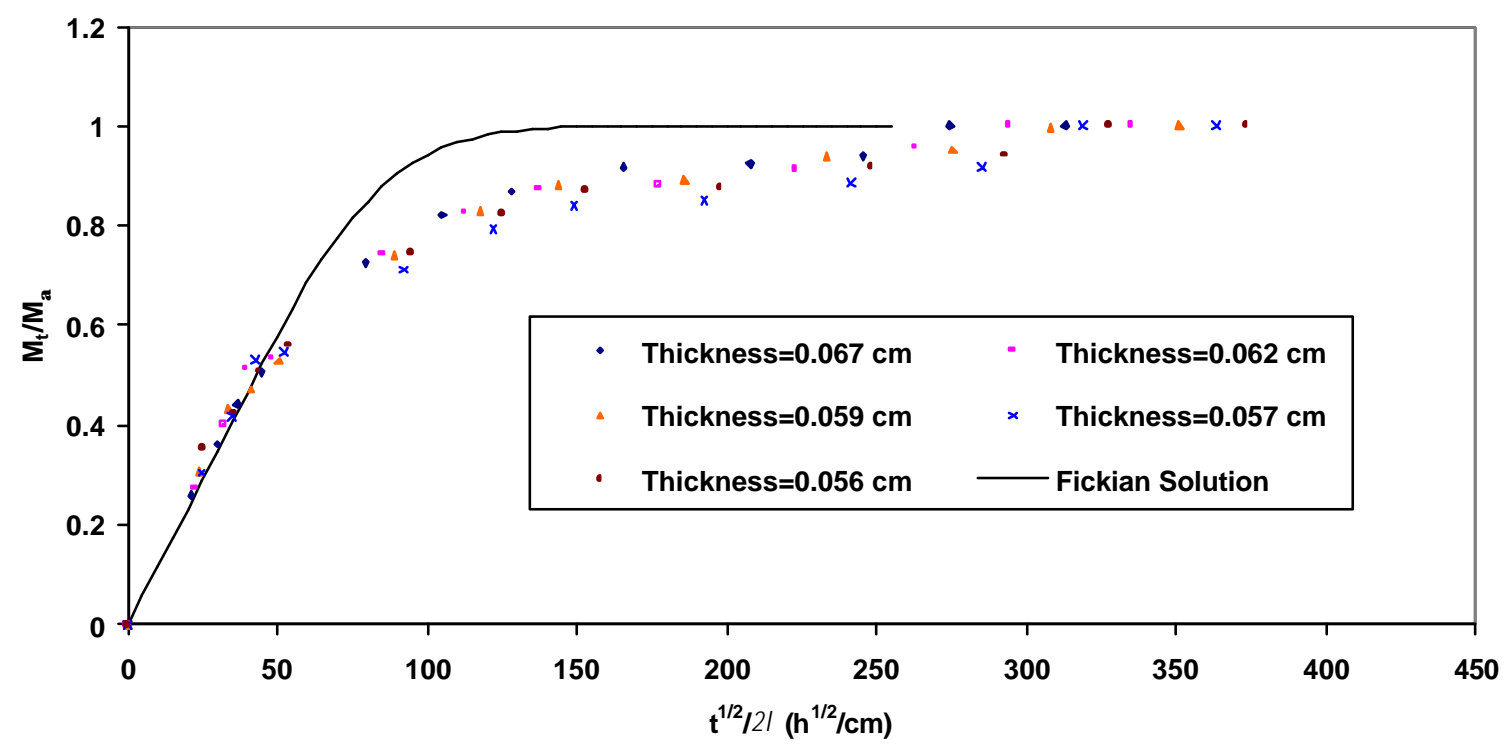

Figure 38. $M_{t} / M_{\infty}$ versus $t^{1 / 2} / 2 l$ for samples containing 0 wt $\%$ Cloisite $10 \mathrm{~A}^{\circledR}$ at $25^{\circ} \mathrm{C}$ 


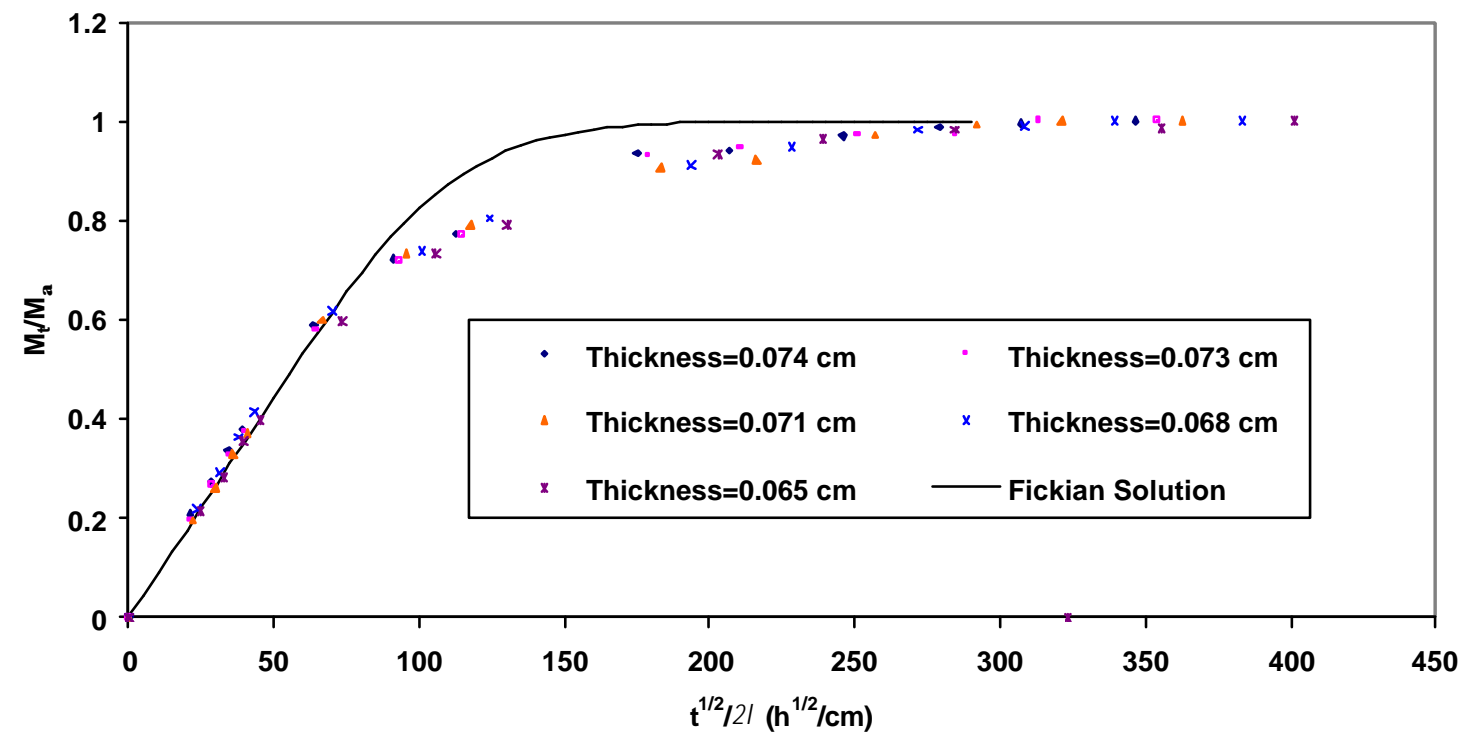

Figure 39. $M_{t} / M_{\infty}$ versus $t^{1 / 2} / 2 l$ for samples containing $1 \mathrm{wt} \%$ Cloisite $_{10 \mathrm{~A}^{\circledR}}$ at $25^{\circ} \mathrm{C}$

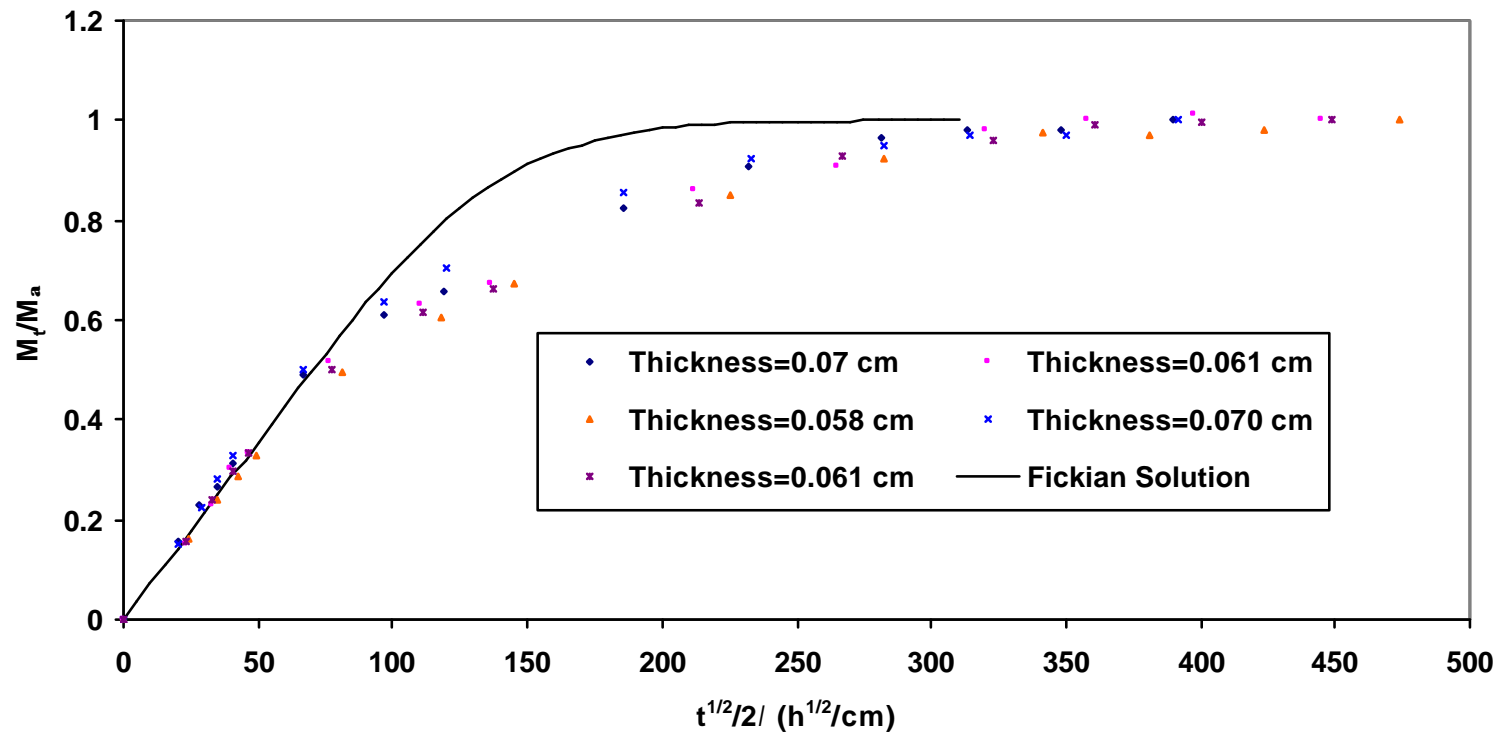

Figure 40. $M_{t} / M_{\infty}$ versus $t^{1 / 2} / 2 l$ for samples containing 2 wt $\%$ Cloisite $10 A^{\circledR}$ at $25^{\circ} \mathrm{C}$ 


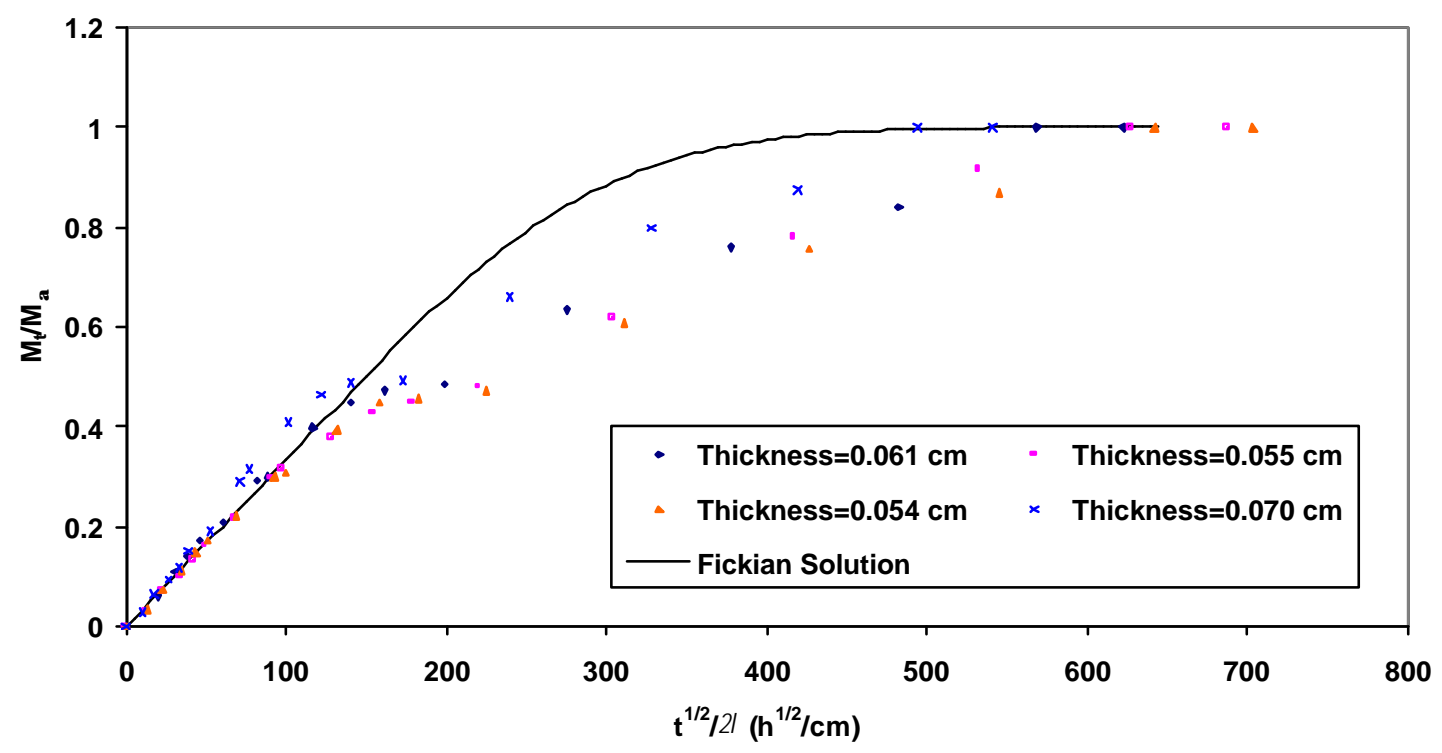

Figure 41. $M_{t} / M_{\infty}$ versus $t^{1 / 2} / 2 l$ for samples containing $5 \mathrm{wt} \%$ Cloisite $10 \mathrm{~A}^{\circledR}$ at $25^{\circ} \mathrm{C}$

Table VII. Results of Transient Diffusion Experiments in Distilled Water at $25^{\circ} \mathrm{C}$

\begin{tabular}{|c|c|c|c|c|}
\hline $\begin{array}{c}\text { Wt \% Cloisite } \\
10 \mathrm{~A}^{\circledR}\end{array}$ & $\mathrm{D} \times 10^{+9}\left(\mathrm{~cm}^{2} / \mathrm{s}\right)$ & $\begin{array}{c}\text { Equilibrium } \\
\text { Moisture }\end{array}$ & $\begin{array}{c}\mathrm{D} \times 10^{+9}\left(\mathrm{~cm}^{2} / \mathrm{s}\right) \\
\mathrm{Shah}(2001)\end{array}$ & $\begin{array}{c}\text { Equilibrium } \\
\text { Moisture } \\
\text { Shah }(2001)\end{array}$ \\
\hline 0 & $7.36(0.33)$ & $0.66 \%(0.03)$ & 9.19 & $0.434 \%$ \\
\hline 1 & $4.01(0.43)$ & $1.13 \%(0.06)$ & 3.37 & $0.927 \%$ \\
\hline 2 & $2.76(0.38)$ & $1.34 \%(0.05)$ & --- & --- \\
\hline 5 & $0.609(0.08)$ & $2.08 \%(0.13)$ & 1.25 & $1.484 \%$ \\
\hline
\end{tabular}

Note: Values shown in the brackets are standard deviations

It is clear from Figure 38 to 41 that the diffusion of water in DERAKANE 411350 MOMENTUM ${ }^{\mathrm{TM}}$ resin was non-Fickian. The deviations from the Fickian behavior became more pronounced as the clay content in the resin was increased. Even the neat resin samples showed non-Fickian characteristics when the time-scale for experiments was long enough. This type of non-Fickian behavior could be attributed to the physical ageing of the resin during the experiments. These results were, however, different from 
the results of Shah (2001). He did not report any non-Fickian behavior in neat DERAKANE 411-350 resin. The time-scale of experiment for Shah's experiments was 10-12 days. The effect of ageing might not have been pronounced in his experiments during such short period of time. Moreover, the thickness of the samples used by Shah was approximately $1 / 2$ of the thickness of the samples of the present work. The weight gain data obtained during the present research were truncated appropriately and the diffusion coefficients were recalculated to prove the consistency of the results. Plots of $M_{t} / M_{\infty}$ versus $t^{1 / 2} / 2 l$ obtained from truncated experimental data are shown in Figures 42 to 44. The diffusivities calculated from the truncated data are shown in Table VIII. Once again, results of Shah (2001) are shown for comparison.

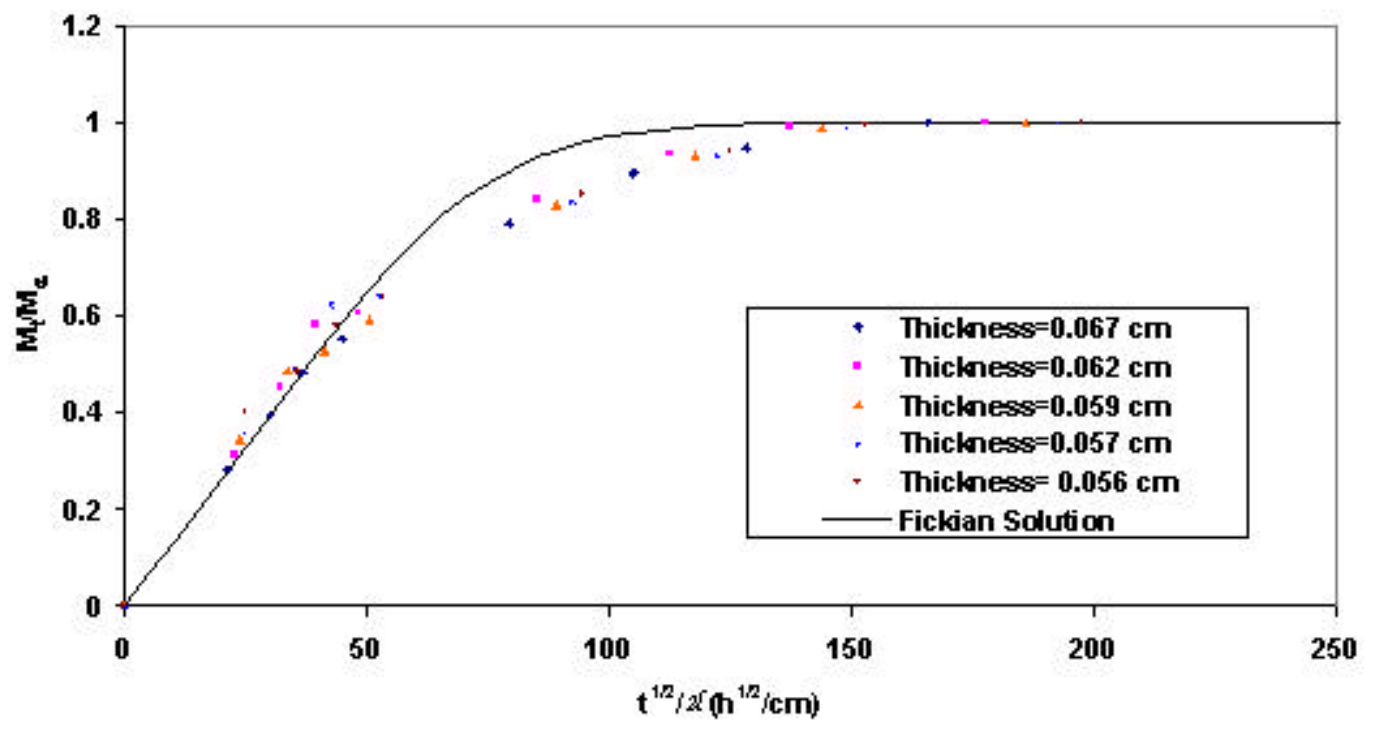

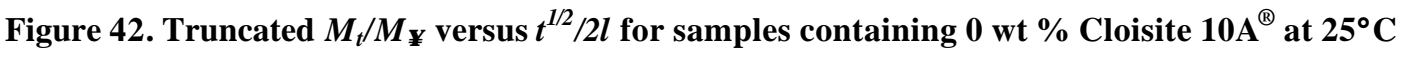




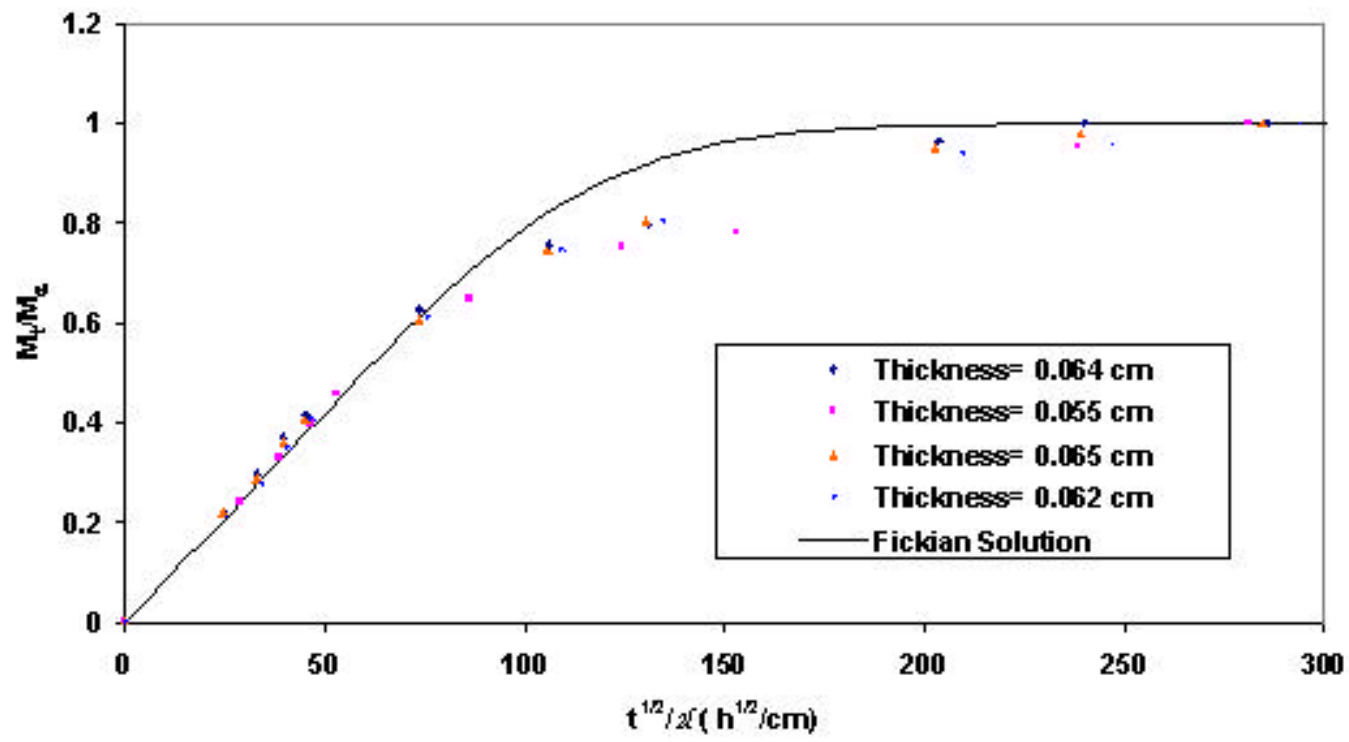

Figure 43. Truncated $M_{t} / M_{\infty}$ versus $t^{1 / 2} / 2 l$ for samples containing $1 \mathrm{wt} \%$ Cloisite $^{10 \mathrm{~A}^{\circledR}}$ at $25^{\circ} \mathrm{C}$

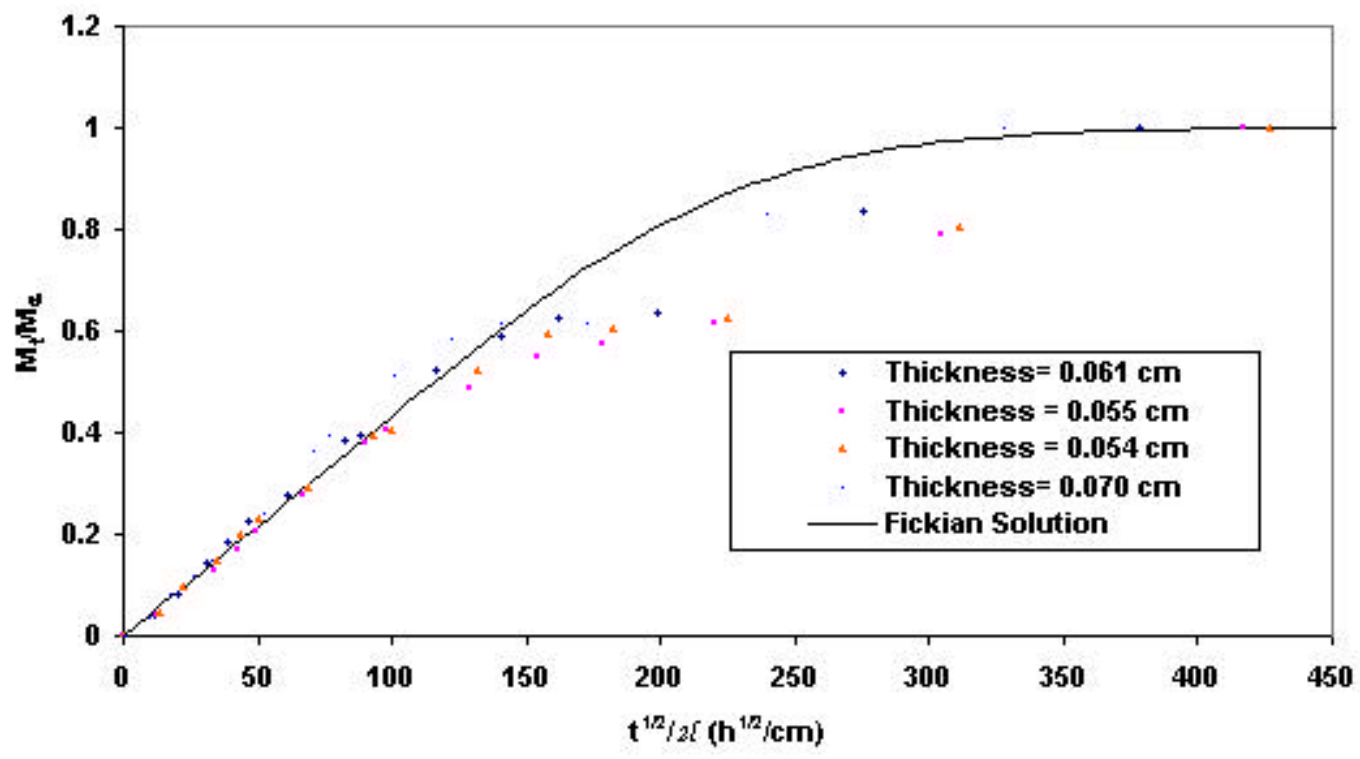

Figure 44. Truncated $M_{t} / M_{\infty}$ versus $t^{1 / 2} / 2 l$ for samples containing $5 \mathrm{wt} \%$ Cloisite $10 \mathrm{~A}^{\circledR}$ at $25^{\circ} \mathrm{C}$ 
Table VIII. Diffusivities obtained from Truncated experimental data for Transient Diffusion Experiments in Distilled Water at $25^{\circ} \mathrm{C}$

\begin{tabular}{|c|c|c|c|c|}
\hline $\begin{array}{c}\text { Wt \% Cloisite } \\
10 A^{\circledR}\end{array}$ & $\mathrm{D} \times 10^{+9}\left(\mathrm{~cm}^{2} / \mathrm{s}\right)$ & $\begin{array}{c}\text { Equilibrium } \\
\text { Moisture }\end{array}$ & $\begin{array}{c}\mathrm{D} \times 10^{+9}\left(\mathrm{~cm}^{2} / \mathrm{s}\right) \\
\text { Shah }(2001)\end{array}$ & $\begin{array}{c}\text { Equilibrium } \\
\text { Moisture } \\
\text { Shah }(2001)\end{array}$ \\
\hline 0 & $9.42(0.55)$ & $0.59 \%(0.02)$ & 9.19 & $0.434 \%$ \\
\hline 1 & $3.82(0.45)$ & $1.11 \%(0.05)$ & 3.37 & $0.927 \%$ \\
\hline 2 & $2.76(0.38)$ & $1.34 \%(0.05)$ & --- & --- \\
\hline 5 & $1.02(0.14)$ & $1.61 \%(0.08)$ & 1.25 & $1.484 \%$ \\
\hline
\end{tabular}

Note: Values shown in the brackets are standard deviations

It is seen from Figures 43 to 45 that the Fickian solution fits the truncated experimental data very well for the initial times. However, Figures 43 and 44 suggest that there are some differences in the truncated experimental data and the theoretical solution for larger times. Shah also recorded similar deviations from the Fickian behavior for the clay-containing samples. It is clearly seen from Table VIII that there is a good agreement between the diffusivities obtained from the truncated experimental data of the present work and the diffusivities reported by Shah. The diffusivities calculated in this work are based on the experimental data obtained over a longer period of time and are, thus, more accurate than those reported by Shah. 


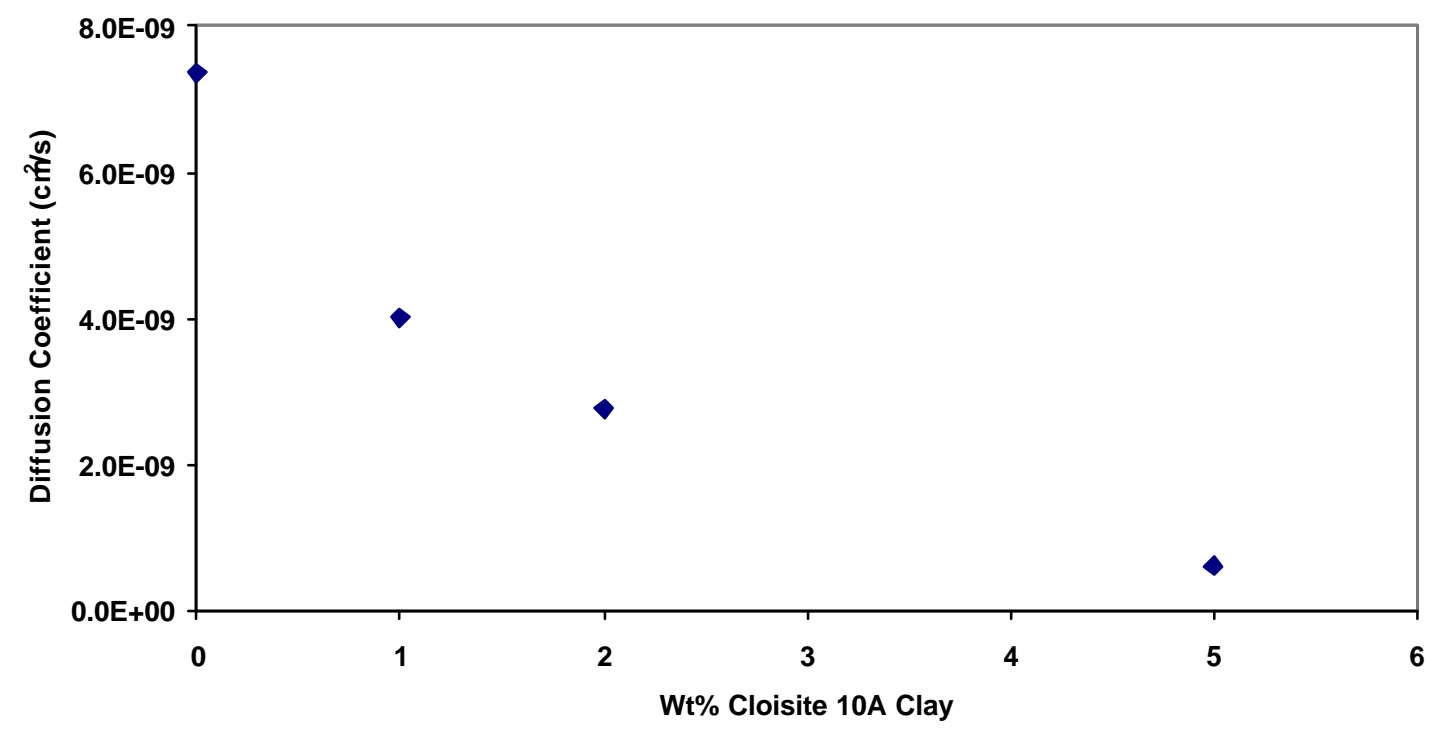

Figure 45. Diffusion coefficient versus weight percent of Cloisite $10 \mathrm{~A}^{\circledR}$ clay in polymer at $25^{\circ} \mathrm{C}$

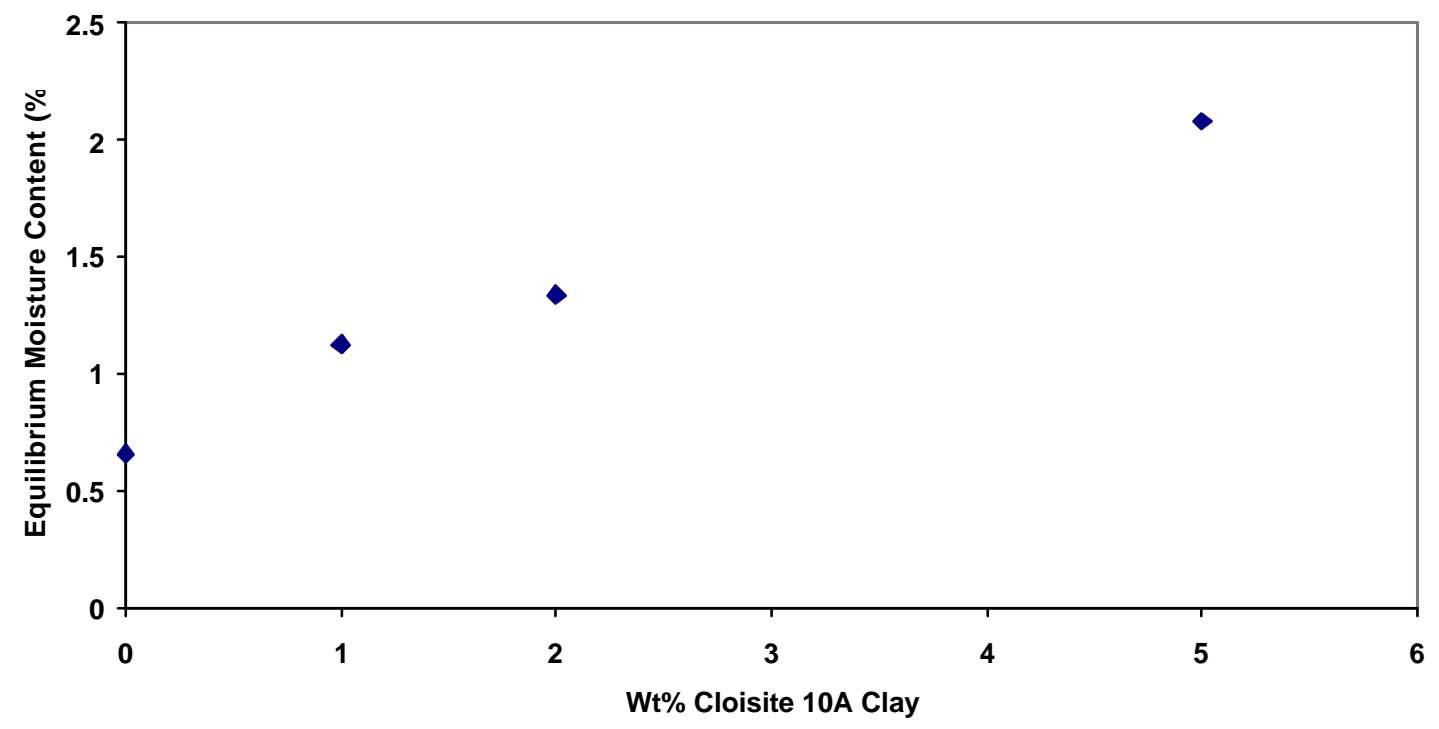

Figure 46. Equilibrium moisture content versus weight percent of Cloisite $10 \mathrm{~A}^{\circledR}$ clay in polymer at $25^{\circ} \mathrm{C}$

Figure 45 shows diffusion coefficients plotted against weight percent of clay in polymer. It is evident from the graph that as the clay content in the polymer increases the diffusion coefficient goes down. Addition of $1 \mathrm{wt} \%$ of clay in polymer brings down the diffusion coefficient by approximately 46\%. A $63 \%$ drop in diffusion coefficient value 
can be achieved by adding 2 wt $\%$ of clay in polymer. The diffusion coefficient decreases by approximately $91 \%$ by addition of 5 wt $\%$ of clay in polymer. From the nature of the graph it is clear that higher wt $\%$ of clay in polymer would not give further significant drops in diffusion coefficient values.

A plot of equilibrium moisture content versus weight percentage of clay in polymer is shown in Figure 46. The equilibrium moisture content increases with increasing amount of clay in polymer. The time taken to achieve equilibrium moisture content also increases with increasing amount of clay. For example, neat resin samples took approximately 15-20 days to reach the equilibrium moisture content whereas samples with $5 \mathrm{wt} \%$ clay took approximately 50-60 days to reach equilibrium. This meant that the clay platelets were preferentially absorbing water molecules and not allowing them to diffuse ahead. Water molecules kept on getting absorbed until the clay platelet was completely saturated with water. Once the platelet was saturated, the additional water molecules encountering the platelet followed the tortuous path to diffuse. This could be the reason why the time to attain equilibrium increased with increasing amount of clay in polymer.

The increased amount of equilibrium moisture content could really be an important issue when the FRP is exposed to freeze thaw conditions. The higher amount of water in the resin might cause crack development in the polymer and degrade the mechanical properties of FRP.

A graph of $M_{t} / M_{\infty}$ versus $t^{1 / 2} / 2 l$ was also plotted for all the FRP samples. Figure 47 shows a plot for a representative neat resin samples. 


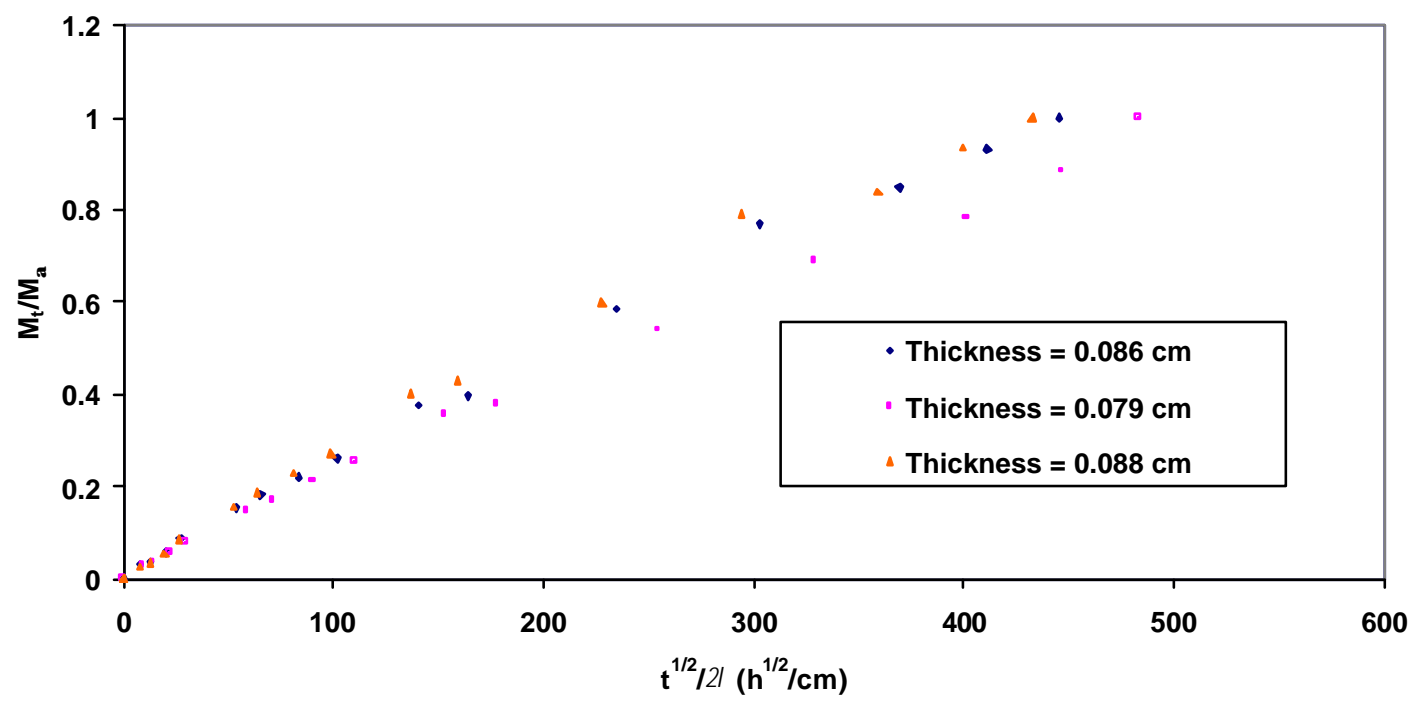

Figure 47. $M_{t} / M_{\infty}$ versus $t^{1 / 2} / 2 l$ for FRP samples containing $0 \mathrm{wt} \%$ Cloisite $10 \mathrm{~A}^{\circledR}$ immersed in distilled water at $25^{\circ} \mathrm{C}$

Figure 47 clearly shows that the samples did not show equilibrium even after 2 months of immersion period. The samples also showed abnormally high amount of moisture uptake therefore the experiments were discontinued after 2 months. Moreover, the experimental data for samples showed large variations in moisture content because of the possible variations in the glass-fiber content. Therefore it was required to apply some corrections for the weight of the glass-fibers. Initially, it was assumed that all the water molecules entering an FRP sample remain in the matrix polymer and the mass uptakes of all types of FRP samples were corrected for the weight of the glass-fibers. Weight of the glass-fibers in every sample was calculated from the surface area of the sample (see appendix A.1.4.). Weight of the glass in a sample was, then, subtracted from all the experimental readings of mass uptake. Plots of corrected percentage weight gain versus $t^{1 / 2}$ are shown in Figure 48 to Figure 51. 


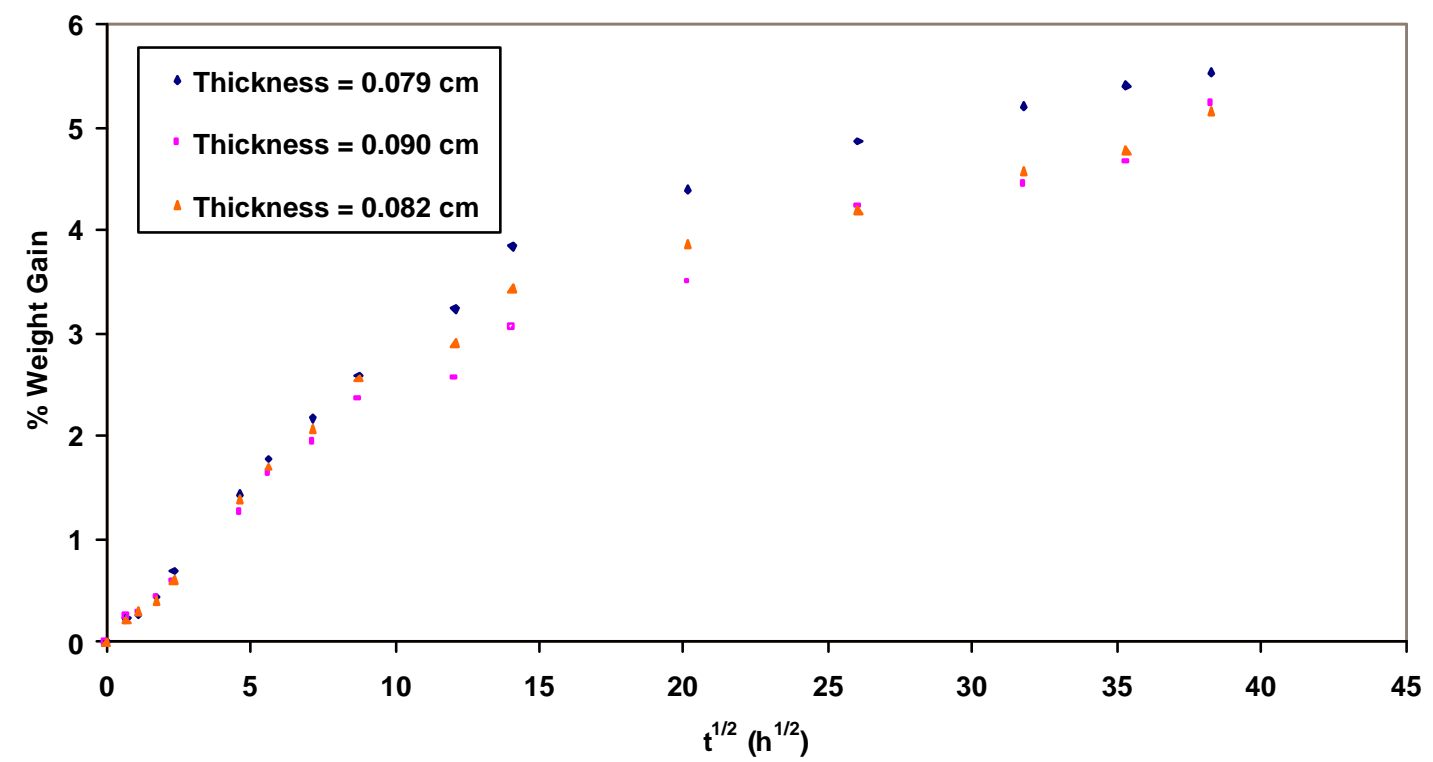

Figure 48. Corrected percentage weight gain versus $t^{1 / 2}$ for FRP samples containing 0 wt $\%$ Cloisite $10 \mathrm{~A}^{\circledR}$ immersed in distilled water at $25^{\circ} \mathrm{C}$

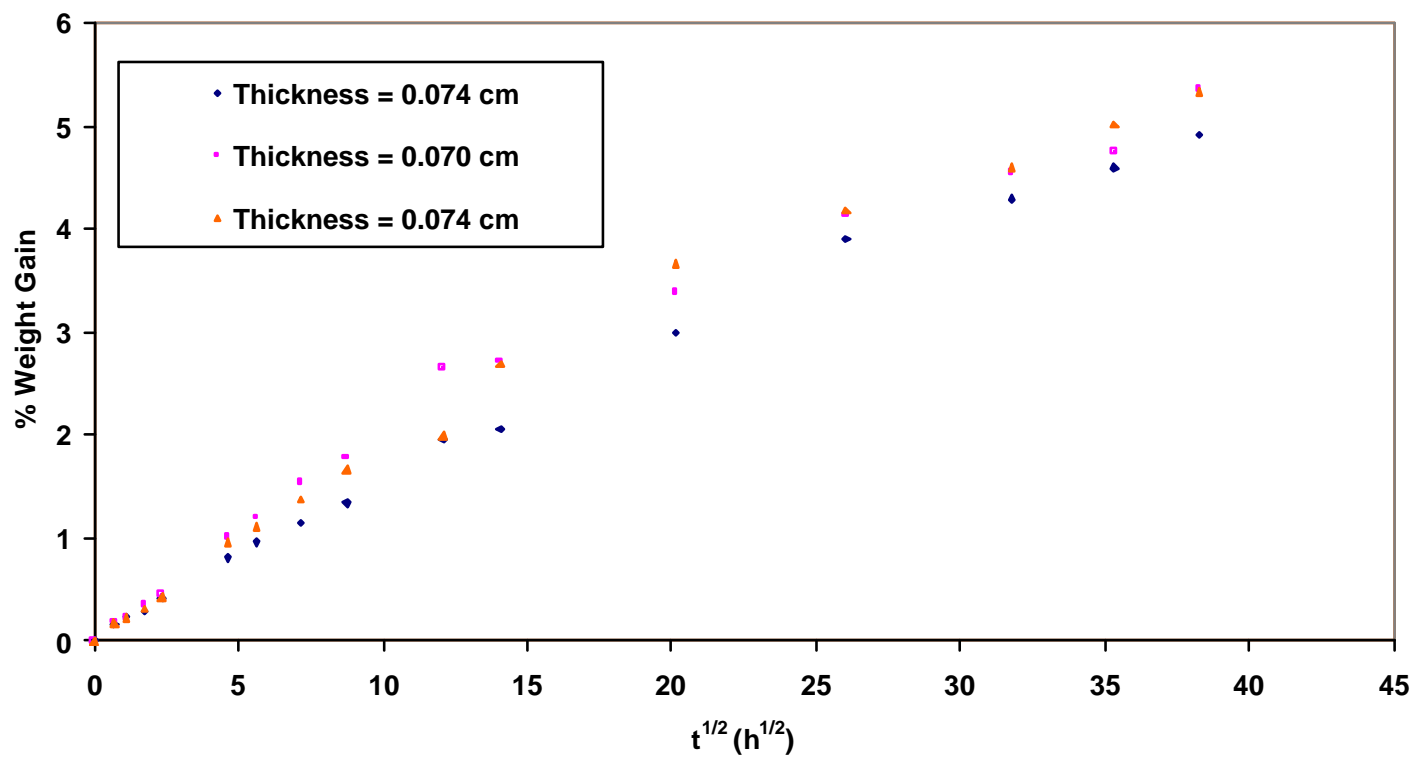

Figure 49. Corrected percentage weight gain versus $t^{1 / 2}$ for FRP samples containing 1 wt $\%$ Cloisite $10 \mathrm{~A}^{\circledR}$ immersed in distilled water at $25^{\circ} \mathrm{C}$ 


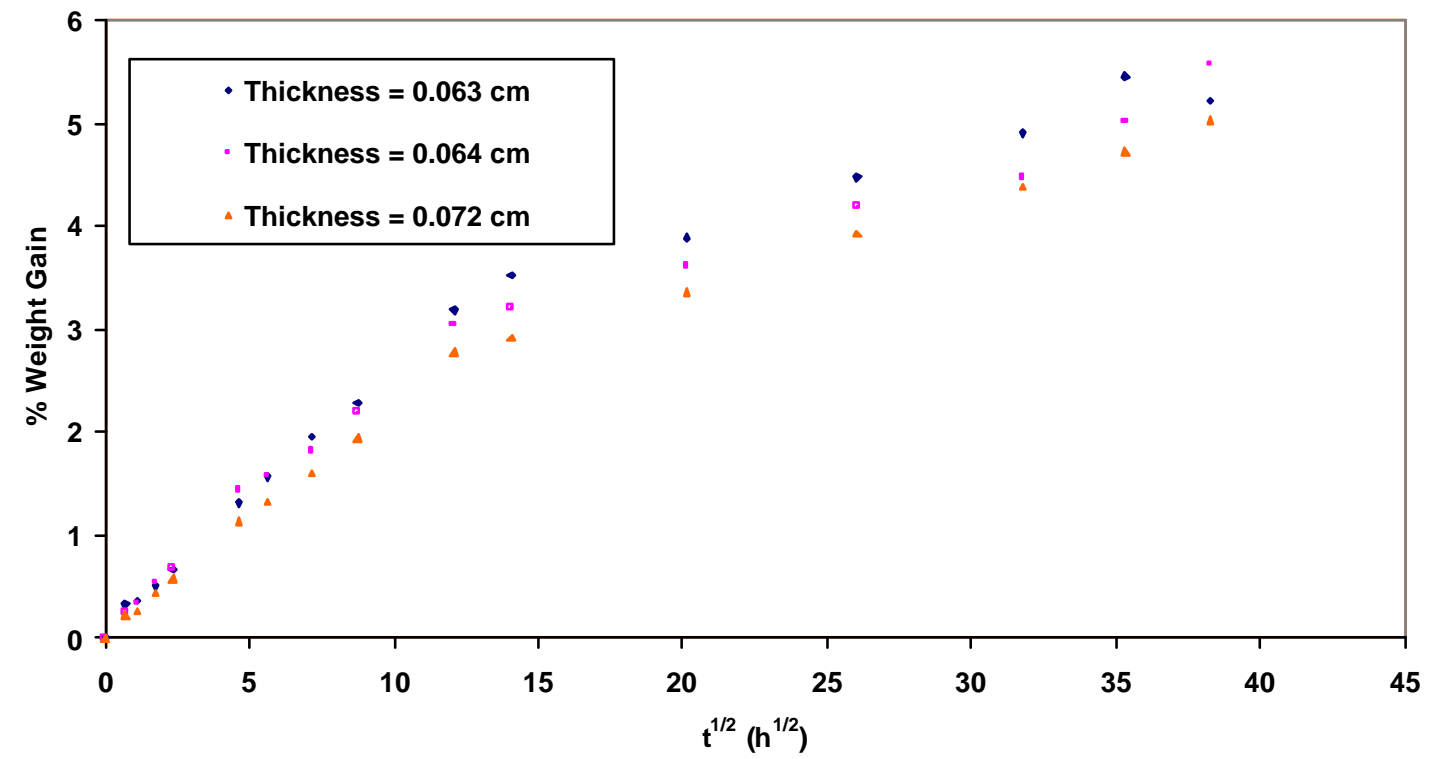

Figure 50. Corrected percentage weight gain versus $t^{1 / 2}$ for FRP samples containing $2 \mathrm{wt} \%$ Cloisite $10 \mathrm{~A}^{\circledR}$ immersed in distilled water at $25^{\circ} \mathrm{C}$

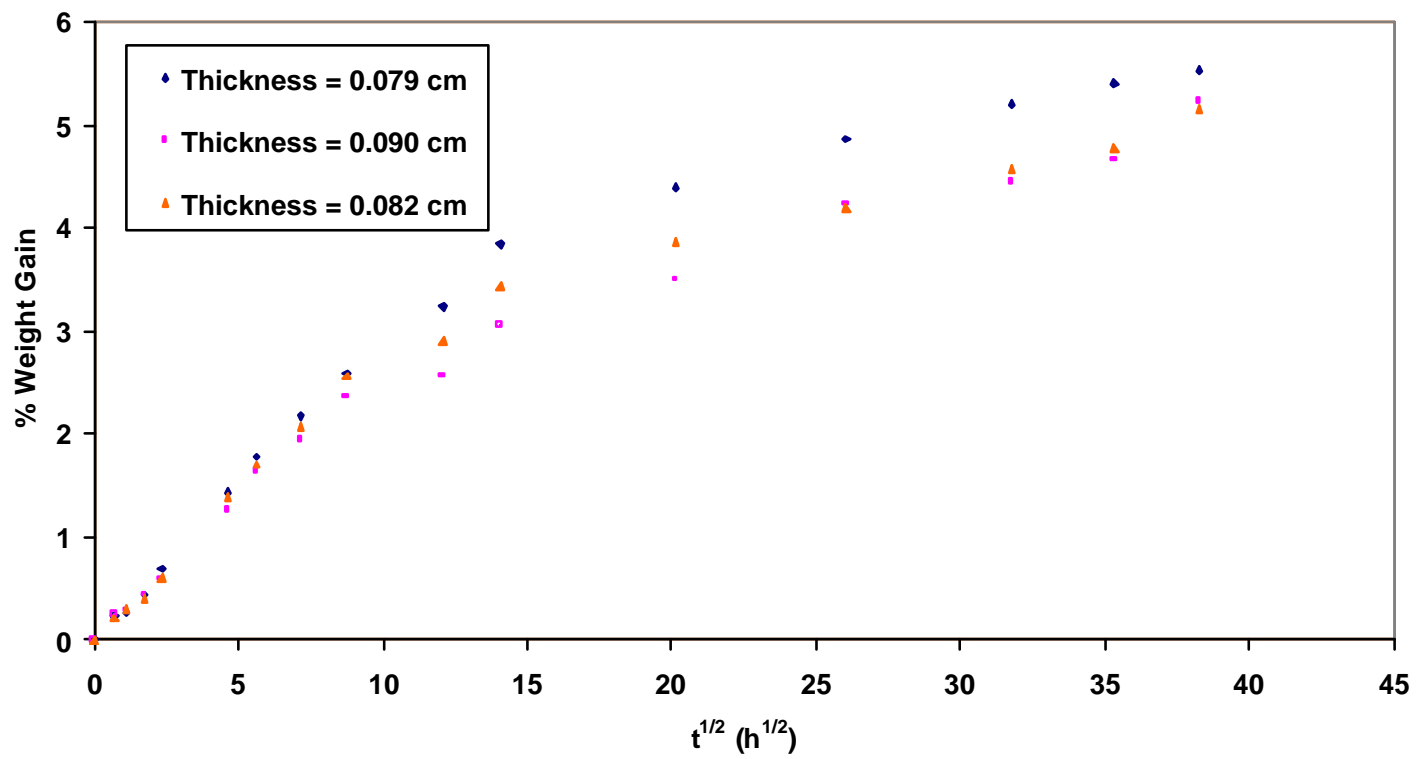

Figure 51. Corrected percentage weight gain versus $t^{1 / 2}$ for FRP samples containing $5 \mathrm{wt} \%$ Cloisite $10 \mathrm{~A}^{\circledR}$ immersed in distilled water at $25^{\circ} \mathrm{C}$ 
None of the FRP samples immersed in distilled water at $25^{\circ} \mathrm{C}$ seemed to be equilibrated even after 2 months of immersion. All the experiments were discontinued after 2 months. All the samples showed abnormally high moisture content in the resin. Experimental results were compared with the transient experiments with un-reinforced samples. Table IX shows the comparison of moisture content of the samples.

Table IX. Comparison of moisture content of un-reinforced and glass-fiber reinforced samples

\begin{tabular}{|c|c|c|c|}
\hline $\begin{array}{c}\text { Wt \% Cloisite } \\
10 \mathrm{~A}^{\circledR}\end{array}$ & $\begin{array}{c}\text { Equilibrium } \\
\text { Moisture } \\
\text { (Un-reinforced) }\end{array}$ & $\begin{array}{c}\text { Moisture } \\
\text { Content after 2 } \\
\text { Months } \\
\text { (Reinforced) }\end{array}$ & $\begin{array}{c}\text { Excess } \\
\text { Moisture in } \\
\text { Reinforced } \\
\text { Samples }\end{array}$ \\
\hline 0 & $0.66 \%(0.03)$ & $5.02 \%(0.23)$ & $4.360 \%$ \\
\hline 1 & $1.13 \%(0.06)$ & $5.21 \%(0.25)$ & $4.078 \%$ \\
\hline 2 & $1.34 \%(0.05)$ & $5.27 \%(0.28)$ & $3.934 \%$ \\
\hline 5 & $2.08 \%(0.13)$ & $5.30 \%(0.20)$ & $3.221 \%$ \\
\hline
\end{tabular}

Note: Values shown in the brackets are standard deviations

From the knowledge of previous experiments with un-reinforced samples, it was reasonable to assume that the resin was saturated with moisture during the immersion period of 2 months. This led to the belief that the excess moisture absorbed by the FRP samples, somehow, interacted with glass-fibers. Table $\mathrm{X}$ shows the absolute amount of water interacted per unit milligram of glass-fibers (see appendix A.1.5. for detailed calculations).

Table X. Absolute amount of water interacted with glass-fibers in FRP samples

\begin{tabular}{|c|c|}
\hline $\begin{array}{c}\mathrm{Wt} \% \text { Cloisite } \\
10 \mathrm{~A}^{\circledR} \text { in Resin }\end{array}$ & $\begin{array}{c}\text { mg of water } \\
\text { interacted per } \\
\text { mg of glass }\end{array}$ \\
\hline 0 & $0.02983(0.001)$ \\
\hline 1 & $0.02025(0.001)$ \\
\hline 2 & $0.01768(0.002)$ \\
\hline 5 & $0.01984(0.001)$ \\
\hline
\end{tabular}

Note: Values shown in the brackets are standard deviations 
Table X shows that considerably less amount of water interacted in two months with glass-fibers when Cloisite $10 \mathrm{~A}^{\circledR}$ clay is present in the matrix polymer. These results were not surprising because when water molecules encountered the clay platelets during the process diffusion in nanocomposites, the molecules got adsorbed on to the surface of clay platelets. Diffusing water molecules could only move ahead when all the clay platelets are saturated with water. This resulted in slower propagation of water-front in the nanocomposite samples. This hypothesis was also supported by the transient diffusion experiments on unreinforced samples where, samples of neat resin were saturated in 20 days whereas, $5 \mathrm{wt} \%$ nanocomposite samples (of comparable thickness) were saturated in 60 days. Due to the slower propagation of water-front in the FRP samples with nanoclay, the resin of these samples took longer time to saturate as compared to resin without nanoclay.

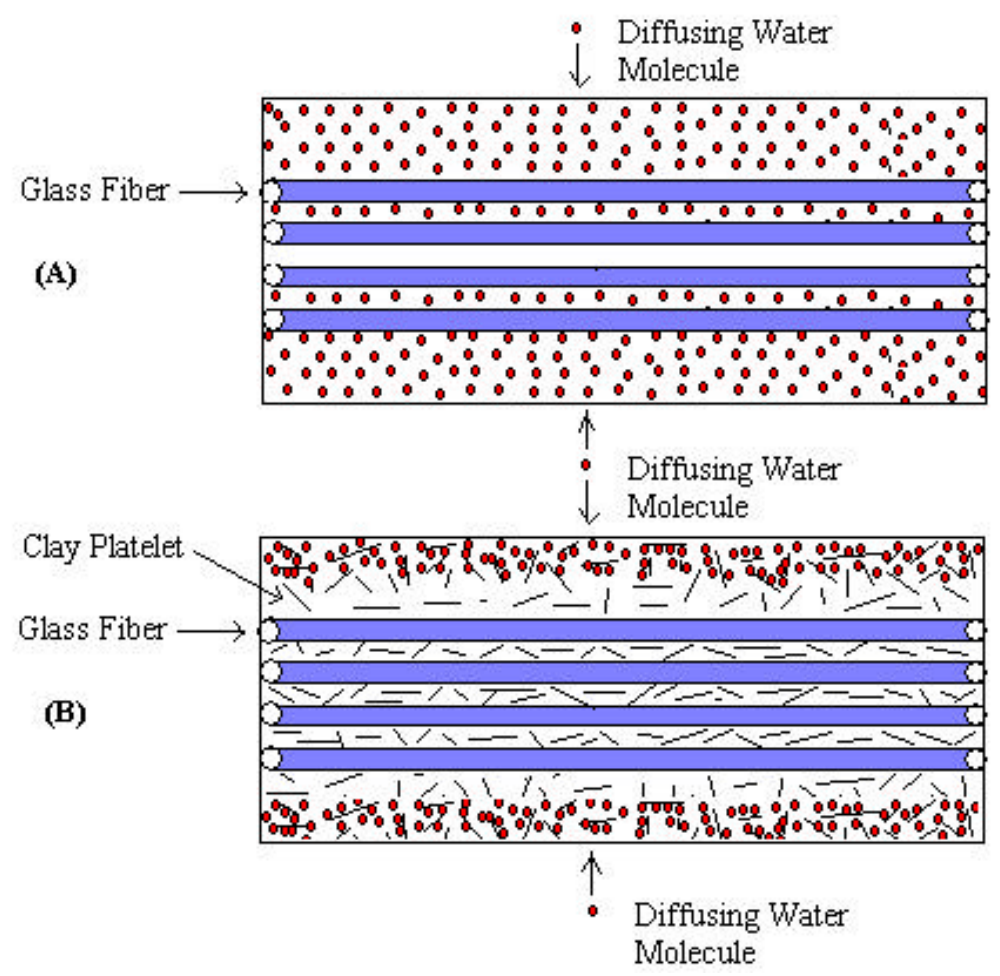

Figure 52. Schematic representation of water-front propagation in FRP samples (A) Without nanoclay (B) With nanoclay 
If it is assumed that the interactions between the glass-fibers and water initiated only after the resin was saturated then, these interactions were delayed by few days due to the presence of the clay. This is schematically shown in Figure 52. The FRP sample shown in Figure 52 (A) does not contain nanoclay as opposed to sample shown in Figure 52(B), which contains few weight percentages of nanoclay. After a given amount of time, the number of molecules entering both the FRP sample is nearly the same. However, as shown in Figure 52(B), the front of diffusing water molecules propagated slowly because of the immobilization of water molecules on the clay platelets as well as the tortuousity of path. As a result, the interaction between the glass-fibers and water molecules was delayed. Since the experiments were discontinued after 2 months, less number of water molecules could interact with glass- fibers when the resin contained nanoclay.

Glass, by nature, is a completely inorganic material. All commercial glass-fibers are treated with sizing material to make them compatible with the resin system. A typical weight percent of sizing material in commercial glass-fiber is 0.5 to $0.6 \%$. The most commonly used sizing materials applied to glass-fibers for thermoset compatibility are based on methoxy silanes and/or ethoxy silanes. These types of sizing materials have very high affinity for water. They react with water so readily that they are sometimes used as moisture scavengers in polymeric systems. Figure 53 shows a typical weight change of silane treated glass-fiber mat when it is exposed to $77 \%$ RH humidity. The experimental data can be found in appendix A.2. It is seen from the Figure 53 that the treated glass fibers absorb moisture from the humid environment resulting in increase in weight. The weight of fiber mat goes through maxima and then drops rapidly suggesting 
that the products of the reaction between the sizing material and water are leaving the surface of the glass-fiber.

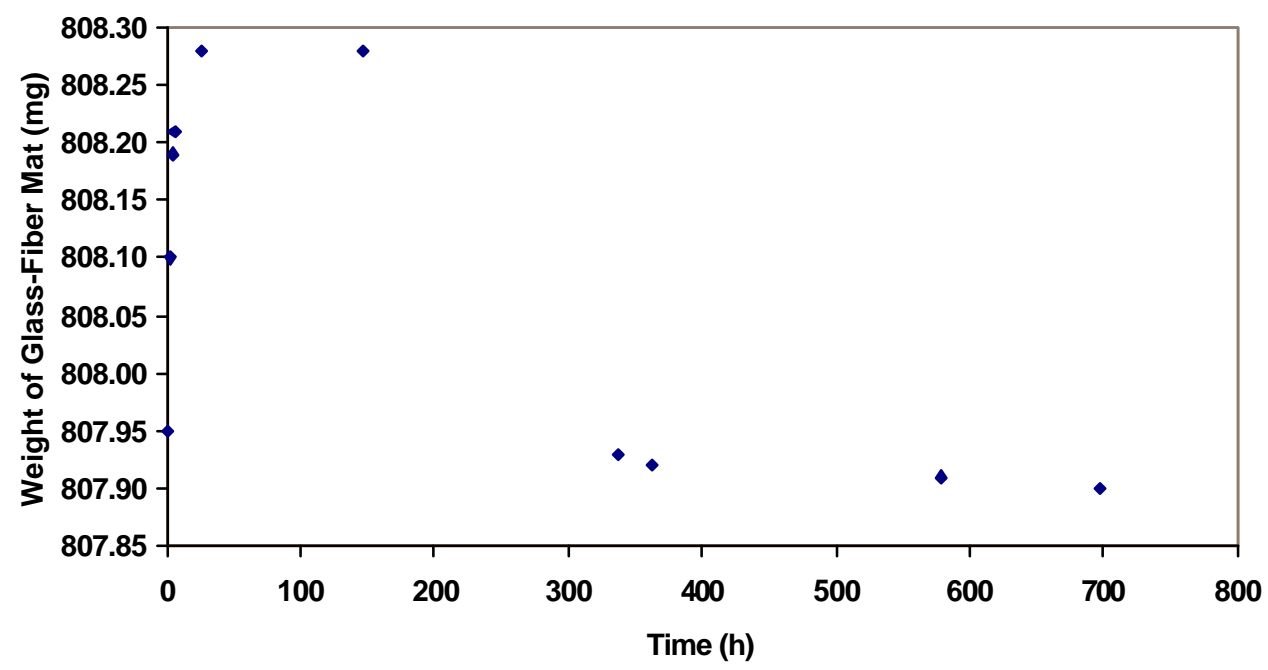

Figure 53. Weight change of silane treated glass-fiber mat when it is exposed to $77 \%$ RH humidity

In order to understand the abnormally high moisture content of FRP samples, it is necessary to understand the chemical interaction between sizing material and water. Figure 54 shows how tri-methoxy-silane sizings improve the compatibility between the glass-fibers and the resin.

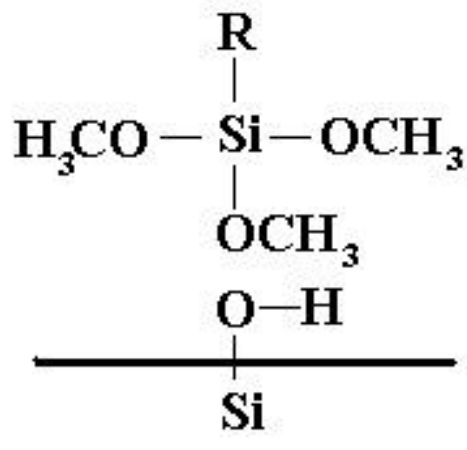

Glass
$\mathrm{CH}_{3} \mathrm{OH}$

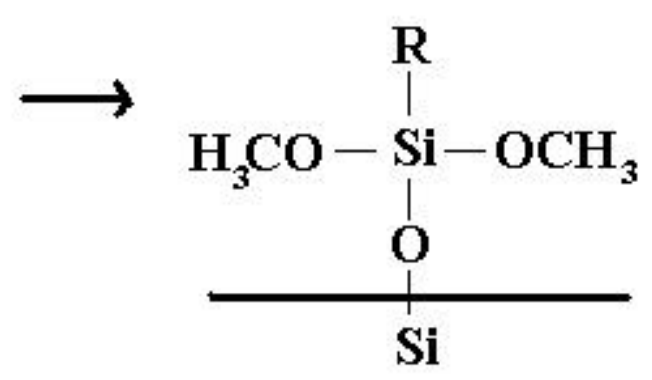

Glass

Figure 54. Application of tri-methoxy silane sizing to glass-fibers 
A molecule of alcohol is eliminated due to the interaction of sizing material and hydrated silica $\left(\mathrm{SiO}_{2}\right)$ of glass during the sizing process and a strong $\mathrm{SiO}-\mathrm{Si}$ bond is formed between the glass and the sizing material. The sizing material has an organic group $-\mathrm{R}$ that is compatible with the resin system. This type of molecular arrangement makes the glass-fibers compatible with the matrix. When this sizing material comes in contact with moisture molecules, a series of events occur:

1. Since $\mathrm{SiOH}$ bond is more stable than $\mathrm{SiOCH}_{3}$ or $\mathrm{SiOCH} \mathrm{CH}_{3}$, Silanes immediately reacts with water. The reaction can be shown as:

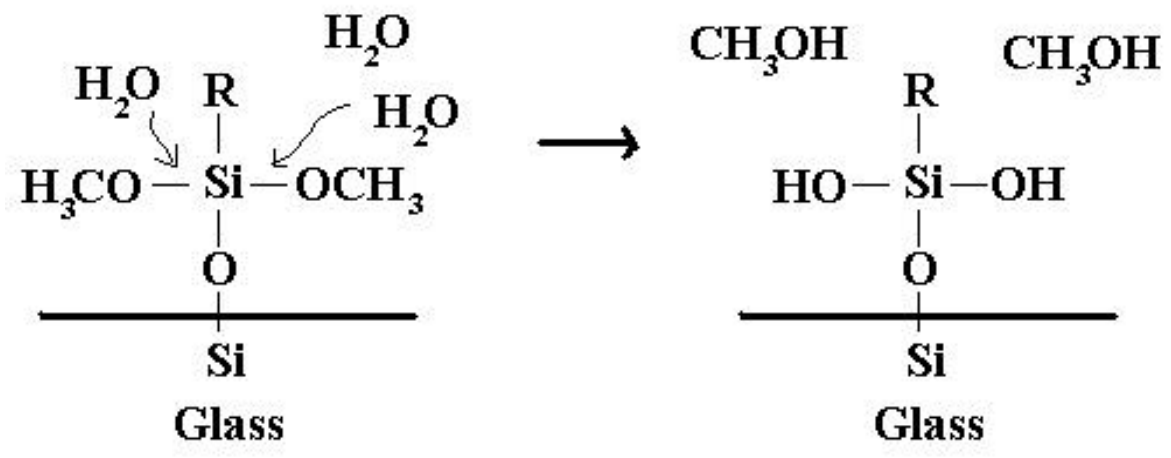

Figure 55. Water molecules attacking $\mathrm{Si}-\mathrm{OCH}_{3}$ bonds

2. Liberated alcohol molecules are free to diffuse in the resin system. $-\mathrm{OH}$ groups of these alcohol molecules can form hydrogen bonds with more water molecules: 


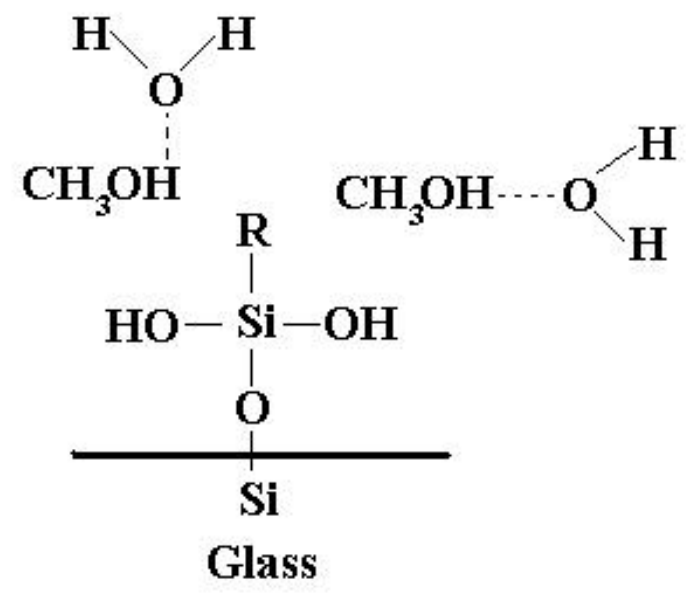

Figure 56. Water molecules forming hydrogen bonds with liberated alcohol molecules

3. The $-\mathrm{OH}$ groups - still attached to $\mathrm{Si}$ of the sizing material- can form hydrogen bonds with still more water molecules:

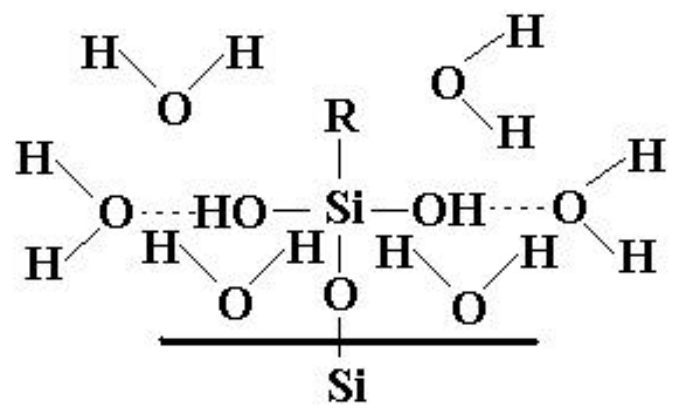

Glass

Figure 57. Water molecules forming hydrogen bonds with -OH groups of silane

4. Increasing number of water molecules in the vicinity of the sizing material can, then, attack the strong $\mathrm{SiO}$-Si bond and cause complete delamination between the glass and the matrix: 


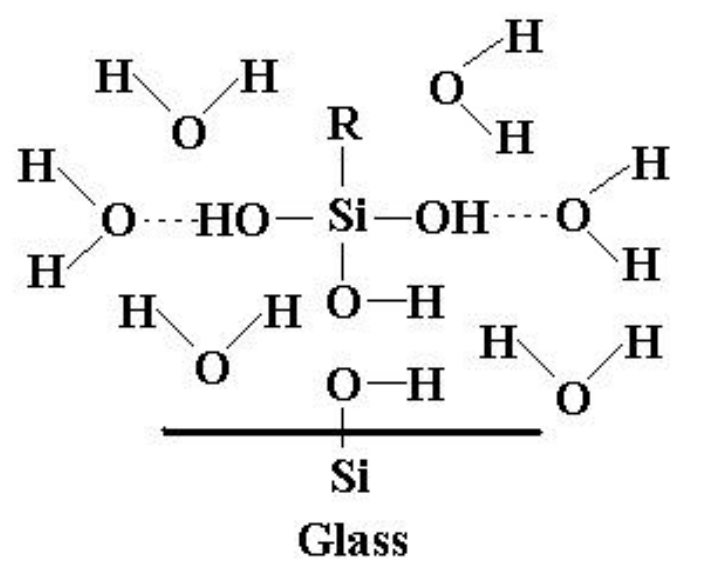

Figure 58. Water molecules breaking strong S-O-Si bond

5. Delamination causes void formation and more water molecules can occupy these voids and contribute to abnormally high moisture content of FRP samples.

\subsection{Transient Diffusion Experiments in Distilled Water at $62^{\circ} \mathrm{C}$}

Transient diffusion experiments in distilled water at $62^{\circ} \mathrm{C}$ were carried out to understand the effect of higher temperatures on the diffusion behavior of vinyl ester- clay nanocomposites. Polymer samples were immersed in a beaker containing distilled water. The beaker was closed at the top using aluminum foil and was kept in a Fisher Scientific Isotemp $^{\circledR} 500$ Series oven. The control knob of oven was set in such a way that the temperature of distilled water remained at $62^{\circ} \mathrm{C}$ throughout the experiment. Periodic weight gains of samples were recorded. Temperature of distilled water was also recorded periodically and was found to be constant at $62^{\circ} \mathrm{C}$. All the samples were marked with permanent marker prior to immersion in distilled water at $62^{\circ} \mathrm{C}$.

All the samples immersed in distilled water at $62^{\circ} \mathrm{C}$ degraded so badly after 4 days that it was impossible to calculate either diffusion coefficient or equilibrium moisture content. Figure 59 shows images of degraded samples. 


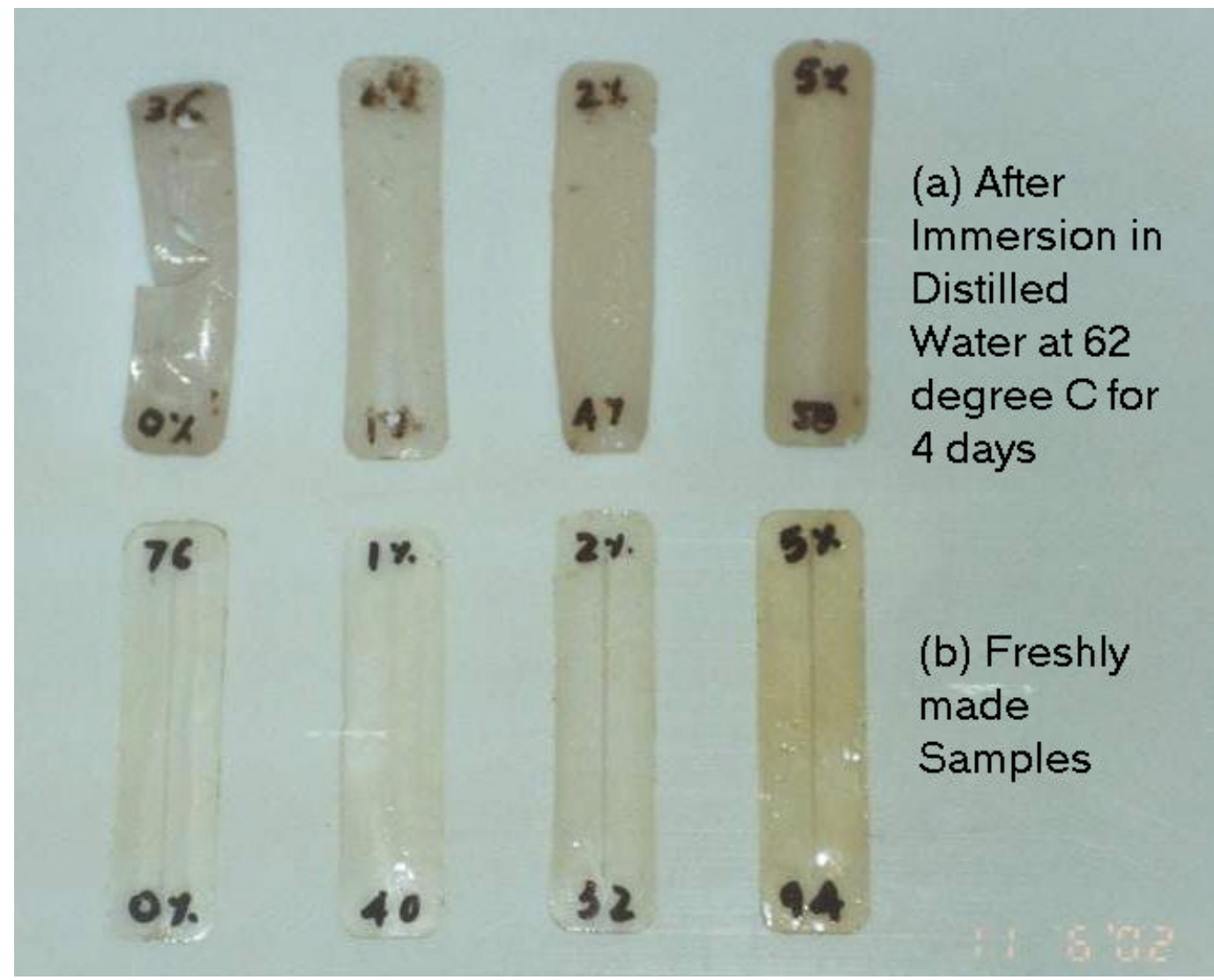

Figure 59. (a) Degraded samples after immersion in distilled water at $62^{\circ} \mathrm{C}$ for 4 days (b) Freshly made samples

Note: Number before "\%" sign indicates the weight percentage of Cloisite $10 \mathrm{~A}^{\circledR}$ nanoclay in polymer.

Figure 59 is, nonetheless, excellent proof of the effectiveness of the nanoclay. The sample with no nanoclay $\left(1^{\text {st }}\right.$ row, $1^{\text {st }}$ column in Figure 59) was torn out of shape after being exposed to water at $62^{\circ} \mathrm{C}$. The sample containing $1 \mathrm{wt} \%$ of Cloisite $10 \mathrm{~A}^{\circledR}\left(1^{\text {st }}\right.$ row, $2^{\text {nd }}$ column) was also degraded but to a lesser extent as compared to the sample without nanoclay. The markings on the sample are not clearly visible indicating that the surface of the sample is damaged. The sample with 2 wt $\%$ of Cloisite $10 A^{\circledR}\left(1^{\text {st }}\right.$ row, $3^{\text {rd }}$ column $)$ has lesser surface degradation as the markings on the sample are still legible. Apparently, there is little or no surface damage to the sample containing $5 \mathrm{wt} \%$ of Cloisite $10 \mathrm{~A}^{\circledR}\left(1^{\text {st }}\right.$ row, $4^{\text {th }}$ column) but the sample lost weight indicating that the polymer had disintegrated. 
Images of freshly made samples are shown in $2^{\text {nd }}$ row of Figure 59 for the purpose of comparison with the degraded samples.

It was concluded from transient diffusion experiment in distilled water at $62^{\circ} \mathrm{C}$ water that the application of these nanocomposite materials in submerged conditions at such a high temperature is not advisable. Since the behavior of diffusion in distilled water at $62^{\circ} \mathrm{C}$ was known, the experiments were not repeated for alkaline and salt solution at this temperature. Instead, a temperature of $42.5^{\circ} \mathrm{C}$ was chosen for further diffusion studies.

\subsection{Transient Diffusion Experiments in Distilled Water at $42.5^{\circ} \mathrm{C}$}

Transient diffusion experiments in distilled water at $42.5^{\circ} \mathrm{C}$ were carried out to understand the effect of higher temperatures on the diffusion behavior of vinyl ester- clay nanocomposites. Polymer samples were immersed in beakers containing distilled water. These beakers were closed at the top using aluminum foil and were kept in a Fisher Scientific Isotemp ${ }^{\circledR} 500$ Series oven. The control knob of oven was set in such a way that the temperature of distilled water remained at $42.5^{\circ} \mathrm{C}$ throughout the experiment. Periodic weight gains of samples were recorded. Plots of percentage weight gain versus $t^{1 / 2}$ are shown in Figures 60 to 63. 


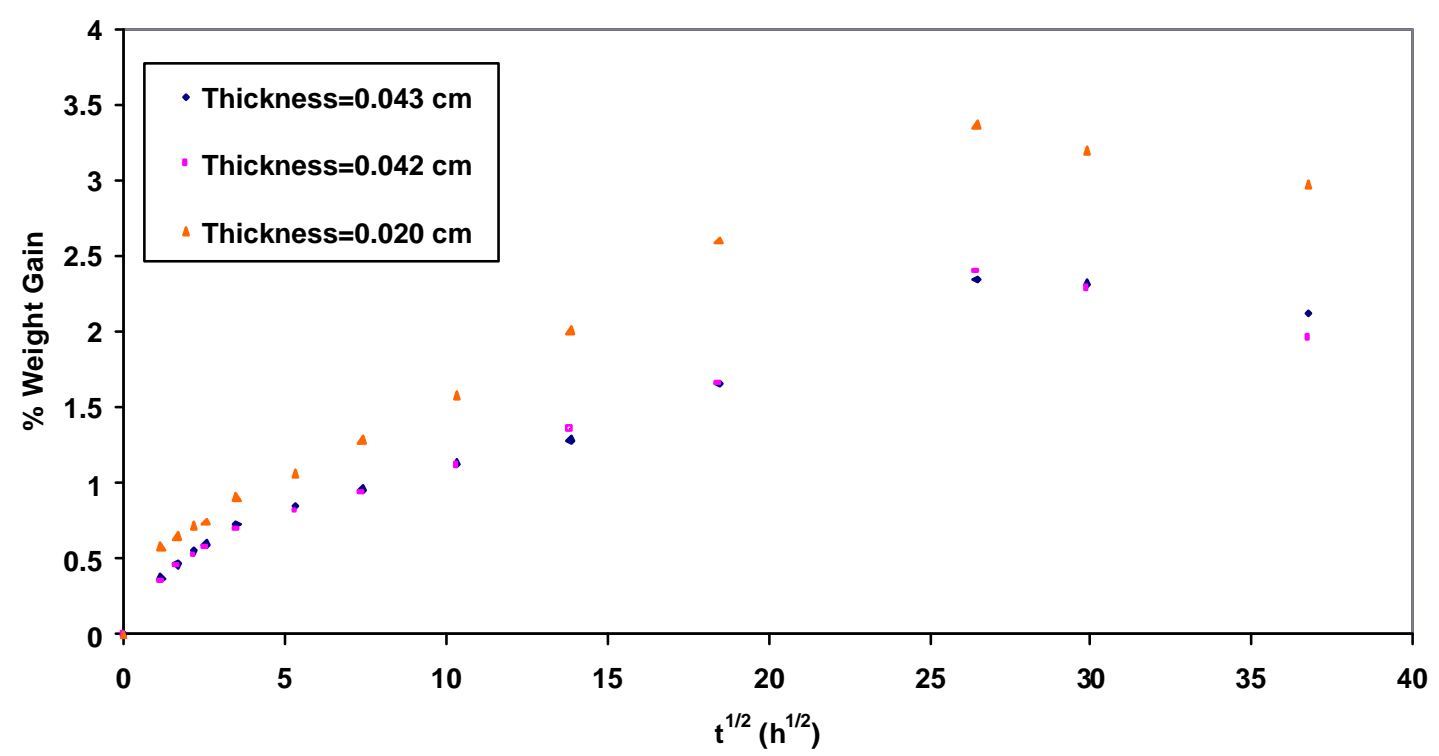

Figure 60. Percentage weight gain versus $t^{1 / 2}$ for samples containing 0 wt $\%$ Cloisite $10 A^{\circledR}$ immersed in distilled water at $42.5^{\circ} \mathrm{C}$

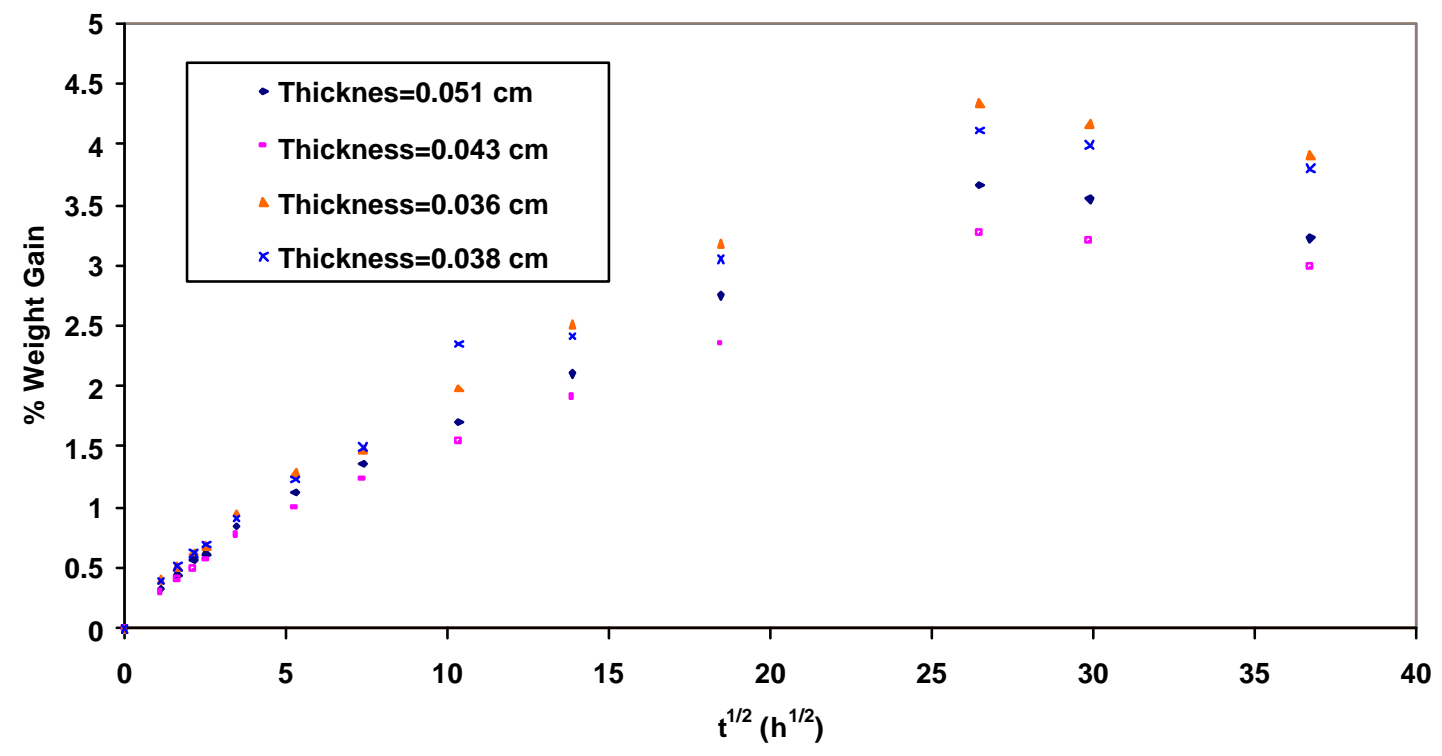

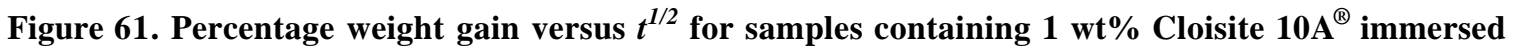
in distilled water at $42.5^{\circ} \mathrm{C}$ 


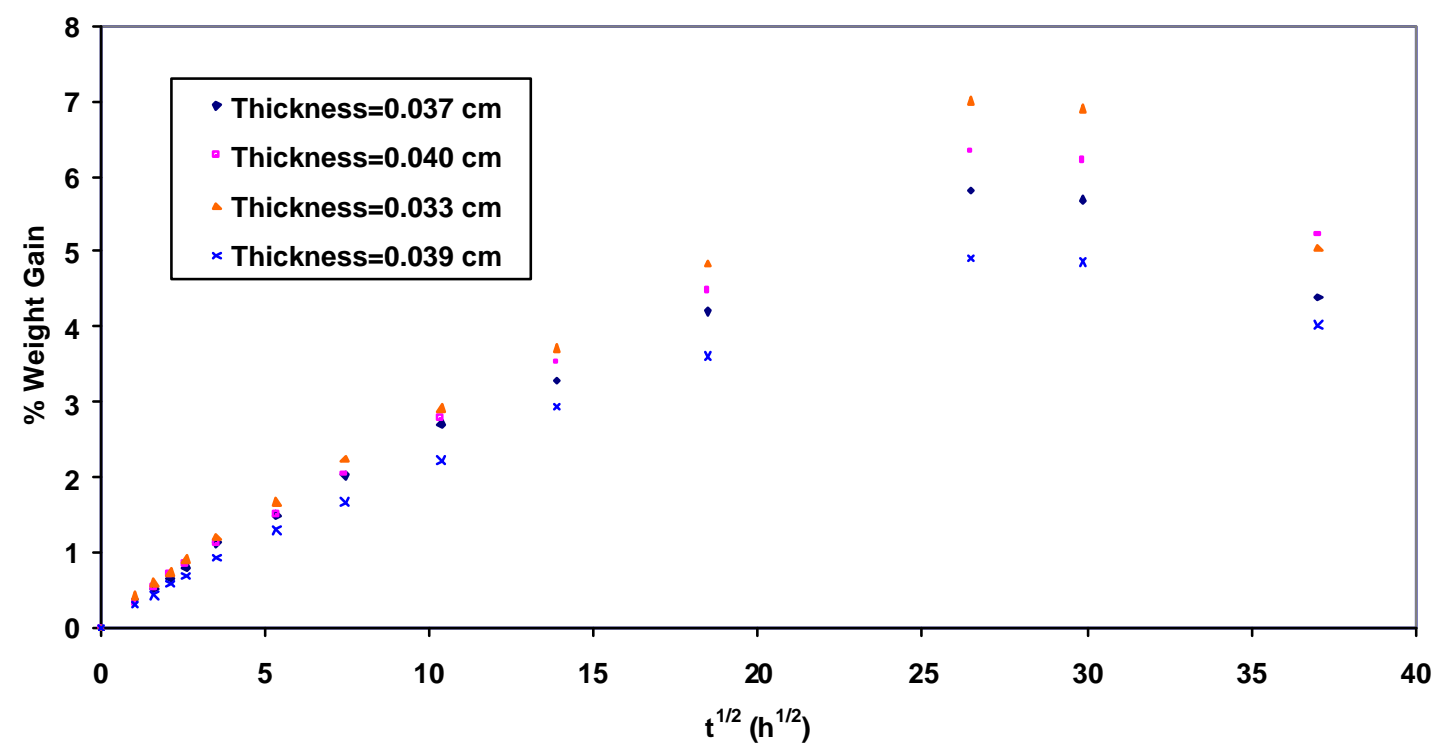

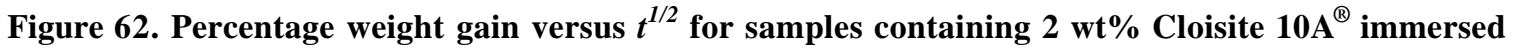
in distilled water at $42.5^{\circ} \mathrm{C}$

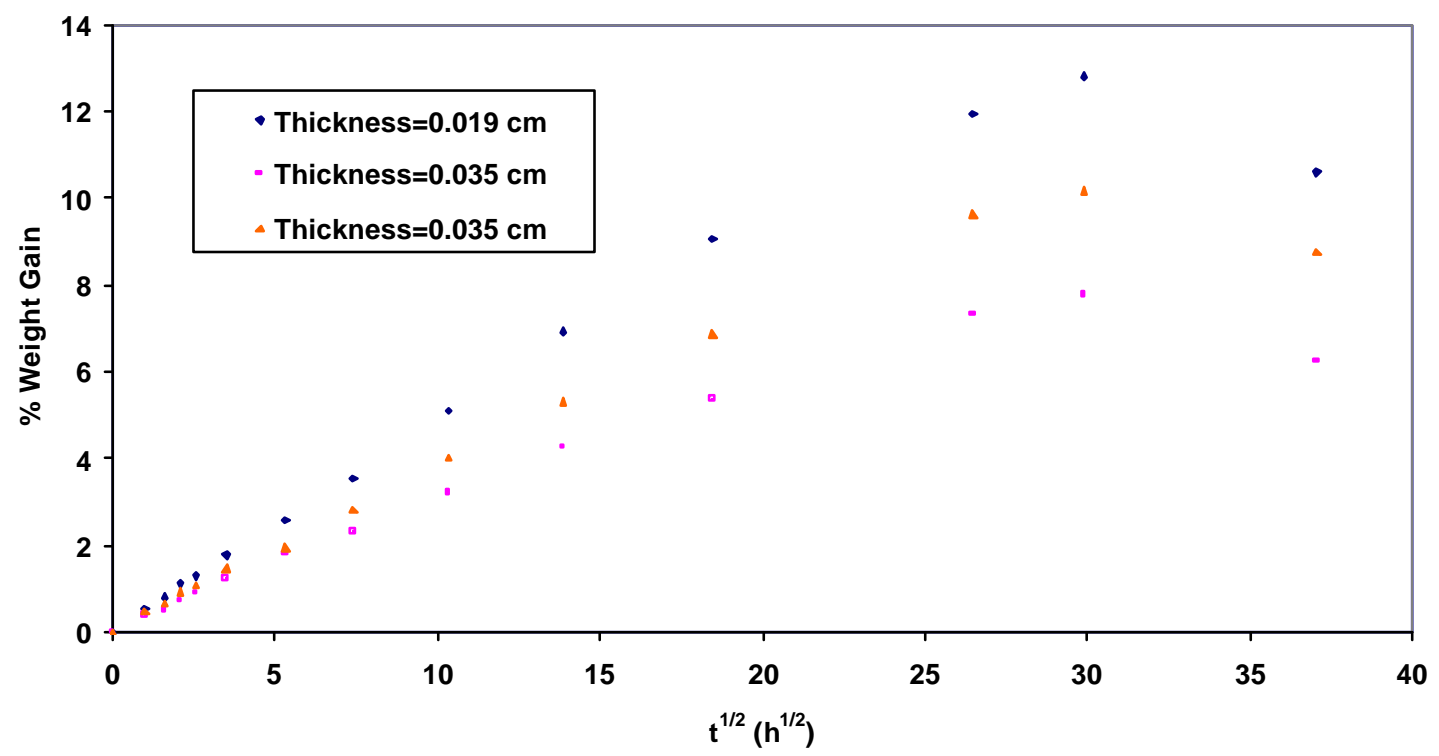

Figure 63. Percentage weight gain versus $t^{1 / 2}$ for samples containing 5 wt $\%$ Cloisite $10 A^{\circledR}$ immersed in distilled water at $42.5^{\circ} \mathrm{C}$ 
It is evident from Figures 60 to 63 that the moisture content of all the samples immersed in distilled water at $42^{\circ} \mathrm{C}$ increased almost linearly with $t^{1 / 2}$ for the initial 650 hours of immersion and then the samples started loosing weight. This was a clear indication that the water molecules reacted with vinyl ester. A visual inspection of the samples revealed tiny circular craters on the surface of the degraded samples. This indicated the possibility that some of the reaction products were in gaseous form. As these products bubbled out of the samples, they created tiny circular craters on the surface. It was not possible to accurately calculate the diffusion coefficients for this case because the samples did not reach equilibrium. However, the equilibrium moisture contents were estimated using the available experimental data at $25^{\circ} \mathrm{C}$ and $4{ }^{\circ} \mathrm{C}$ (appendix A.1.7.). The diffusivities of water molecules in nanocomposites at $42.5^{\circ} \mathrm{C}$ were estimated using the experimental data for initial few hours and the estimated equilibrium moisture contents. The results are shown in Table XI.

Table XI. Estimated Diffusion Coefficients and Equilibrium Moisture Contents at $42.5^{\circ} \mathrm{C}$

\begin{tabular}{|c|c|c|}
\hline $\begin{array}{l}\text { Wt\% Cloisite } \\
10 A^{\circledR}\end{array}$ & $\begin{array}{c}\text { Diffusion } \\
\text { Coefficient } \\
\mathrm{D} \times 10^{+9}\left(\mathrm{~cm}^{2} / \mathrm{s}\right)\end{array}$ & $\begin{array}{c}\text { Equilibrium } \\
\text { Moisture Content }\end{array}$ \\
\hline 0 & $16.43(1.47)$ & $0.709 \%$ \\
\hline 1 & $4.01(1.08)$ & $1.359 \%$ \\
\hline 2 & $2.72(0.44)$ & $1.703 \%$ \\
\hline 5 & $0.93(0.40)$ & $3.010 \%$ \\
\hline
\end{tabular}

Note: Values shown in the brackets are standard deviations

A similar phenomenon was observed when FRP samples with various amounts of nanoclay were immersed in distilled water at $42.5^{\circ} \mathrm{C}$. Percentage weight gain versus $t^{1 / 2}$ for FRP samples is shown in Figures 64 to 67. 


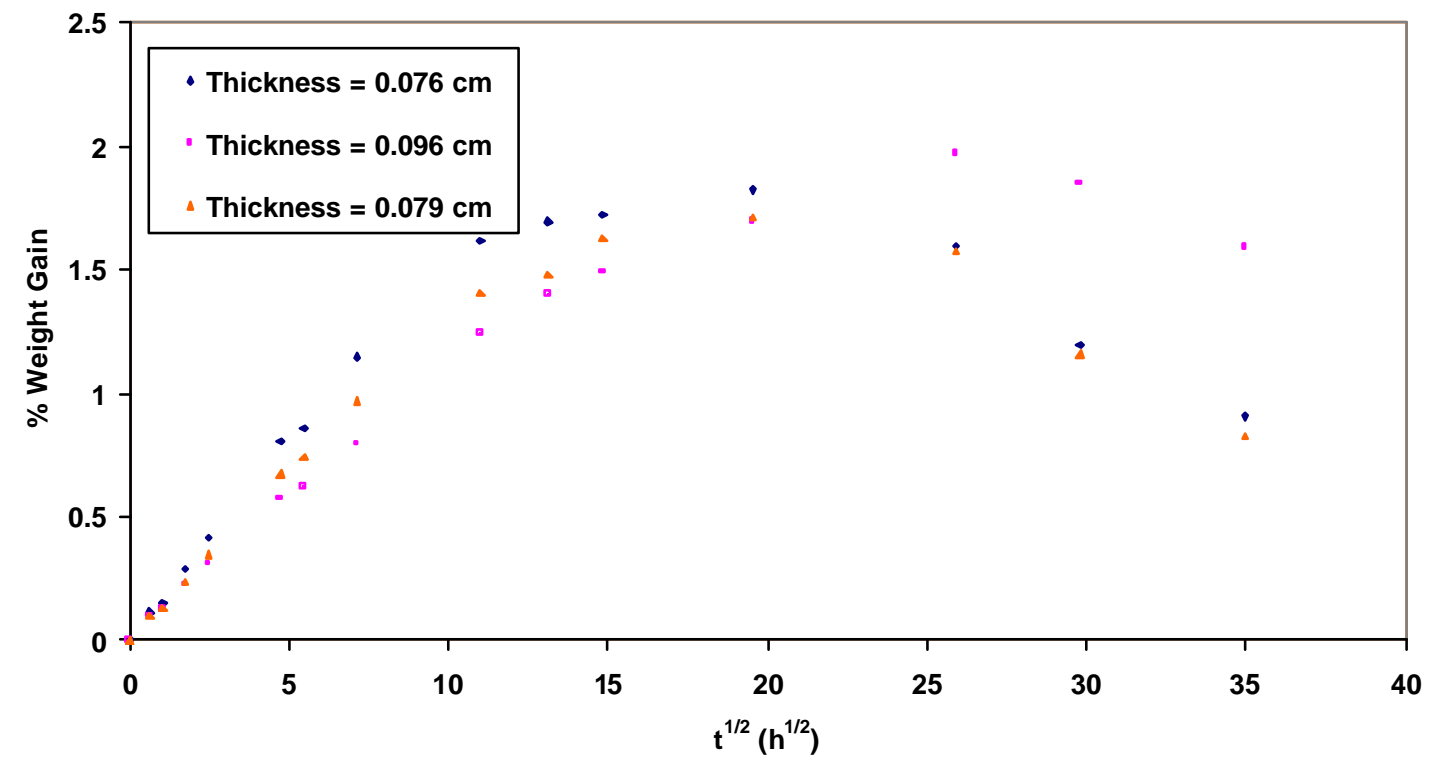

Figure 64. Percentage weight gain versus $t^{1 / 2}$ for FRP samples containing 0 wt $\%$ Cloisite $10 A^{\circledR}$ immersed in distilled water at $42.5^{\circ} \mathrm{C}$

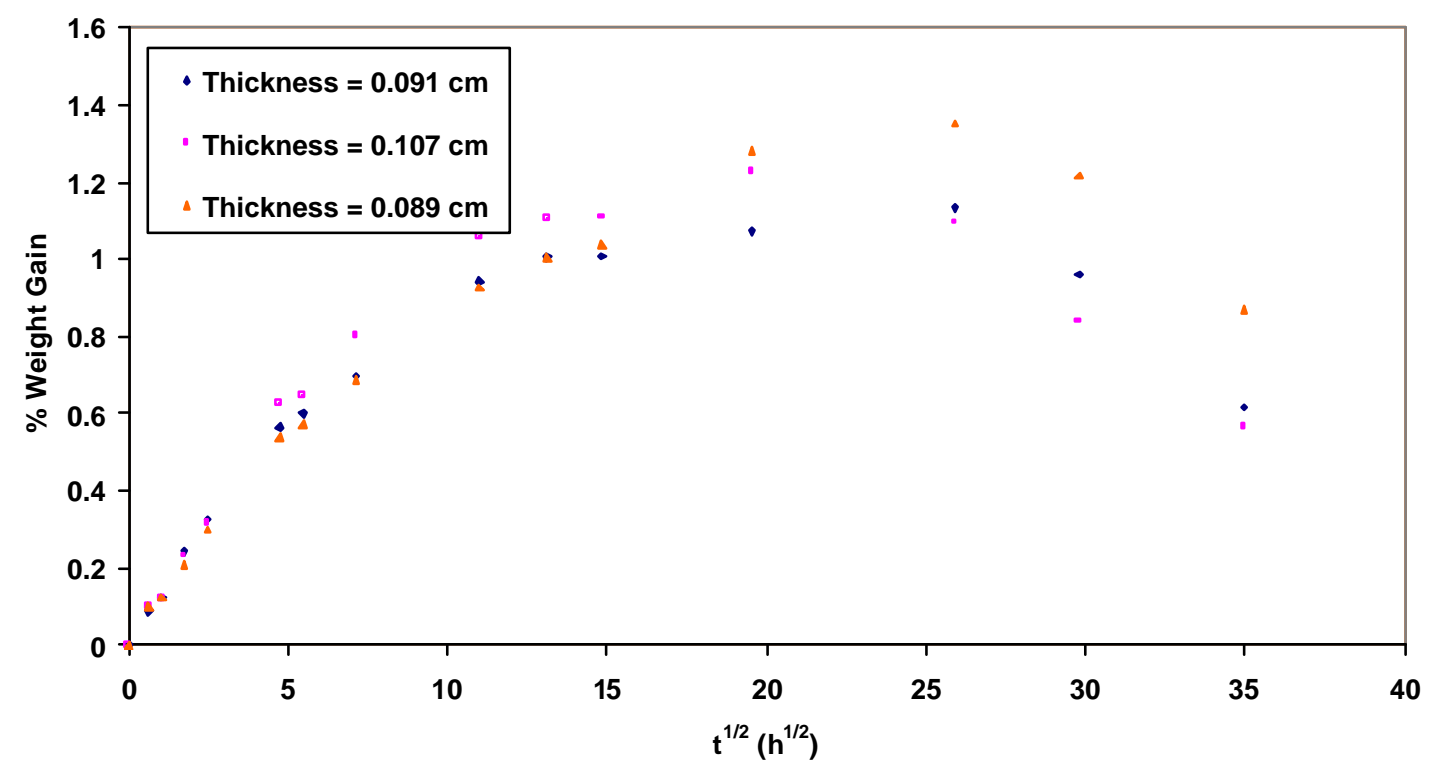

Figure 65. Percentage weight gain versus $t^{1 / 2}$ for FRP samples containing $1 \mathrm{wt}^{\%}$ Cloisite $10 \mathrm{~A}^{\circledR}$ immersed in distilled water at $42.5^{\circ} \mathrm{C}$ 


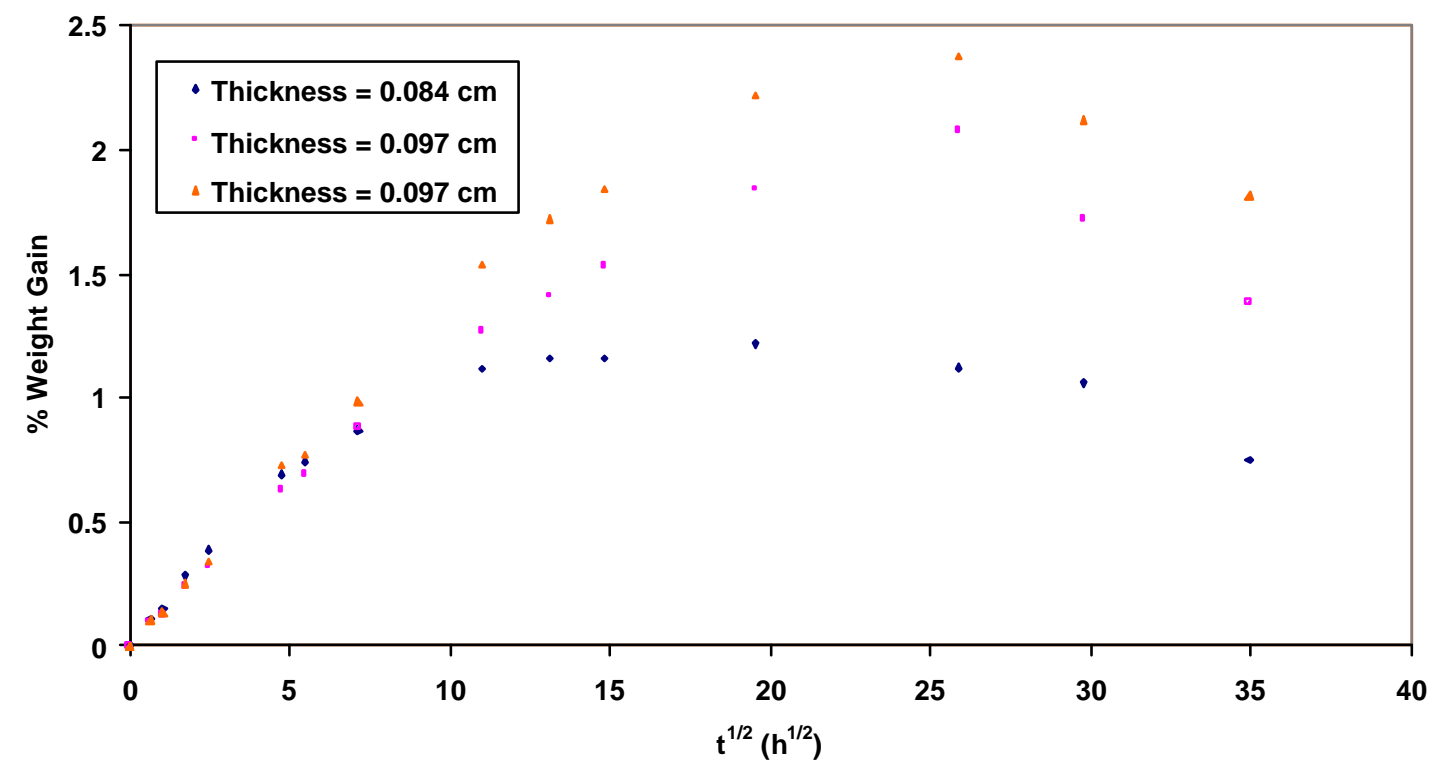

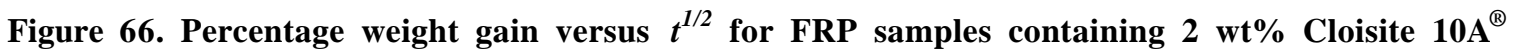
immersed in distilled water at $42.5^{\circ} \mathrm{C}$

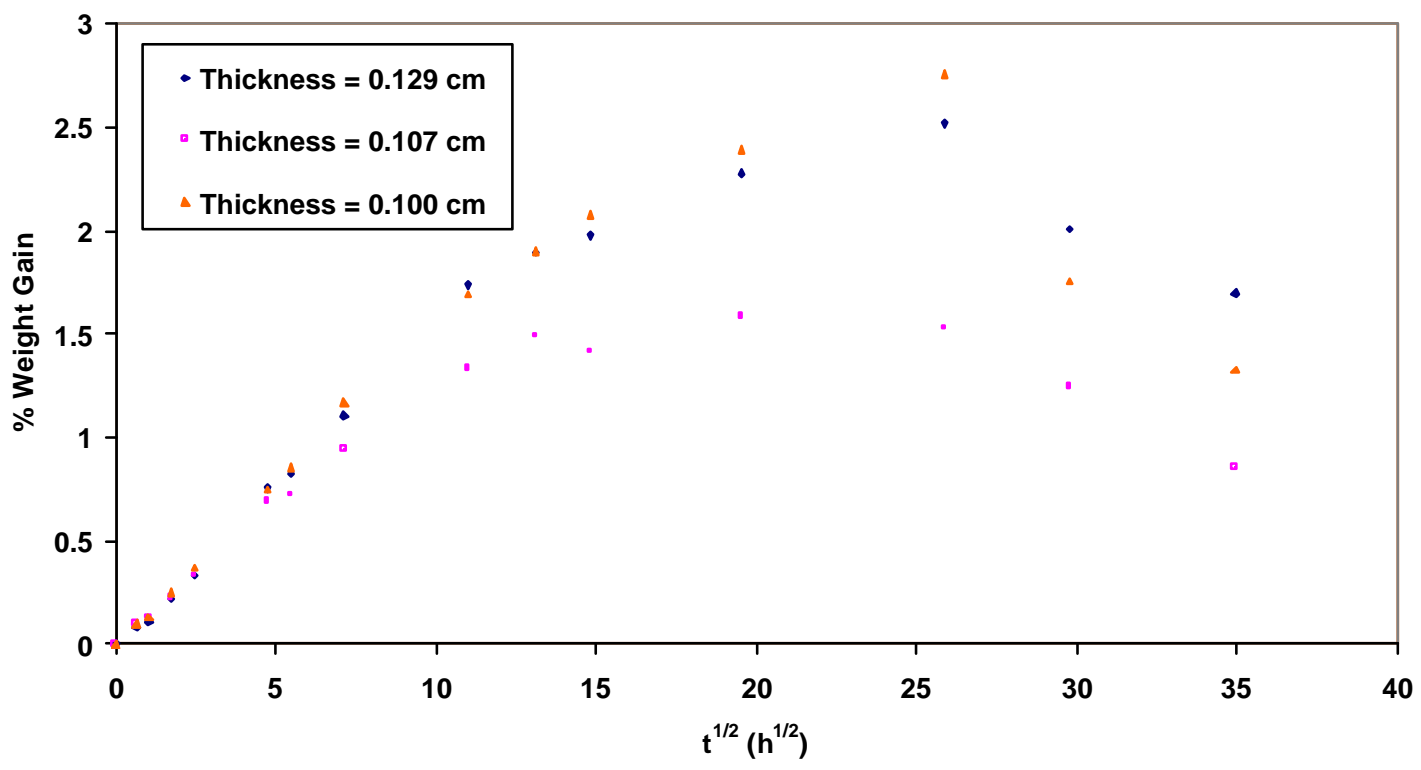

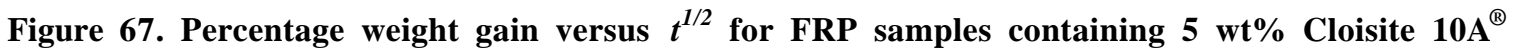
immersed in distilled water at $42.5^{\circ} \mathrm{C}$ 
Percentage weight gain for FRP samples plotted in Figures 64 to 67 were based on the total weight of the FRP sample, i.e. no correction factors for the weight of the fibers were applied to the experimental values. The weight of all the samples increased almost linearly for the first 225 hours and then started dropping. This suggested that the resin hydrolyzed severely during the experiment. The sizing material of the glass-fibers might also have reacted with the water molecules. No conclusions could be drawn about the exact nature of the chemical interactions from these experimental data. Nevertheless, it was reasonable to conclude that FRPs based on DERAKANE 411-350 MOMENTUM vinyl ester could not be used in water-submerged condition at $42.5^{\circ} \mathrm{C}$.

\subsection{Transient Diffusion Experiment in Distilled Water at $4^{\circ} \mathrm{C}$}

A graph of $M_{t} / M_{\infty}$ versus $t^{1 / 2} / 2 l$ was plotted for all the un-reinforced samples. Here $M_{t}$ and $M_{\infty}$ are mass uptake of water at time $t$ and at saturation respectively. $t$ is time and $2 l$ is the thickness of the sample. From the initial slopes of these curves, diffusion coefficients for the un-reinforced samples were calculated according to the method explained in section 2.1. Water uptake curves are shown in Figure 68 to Figure 71. 


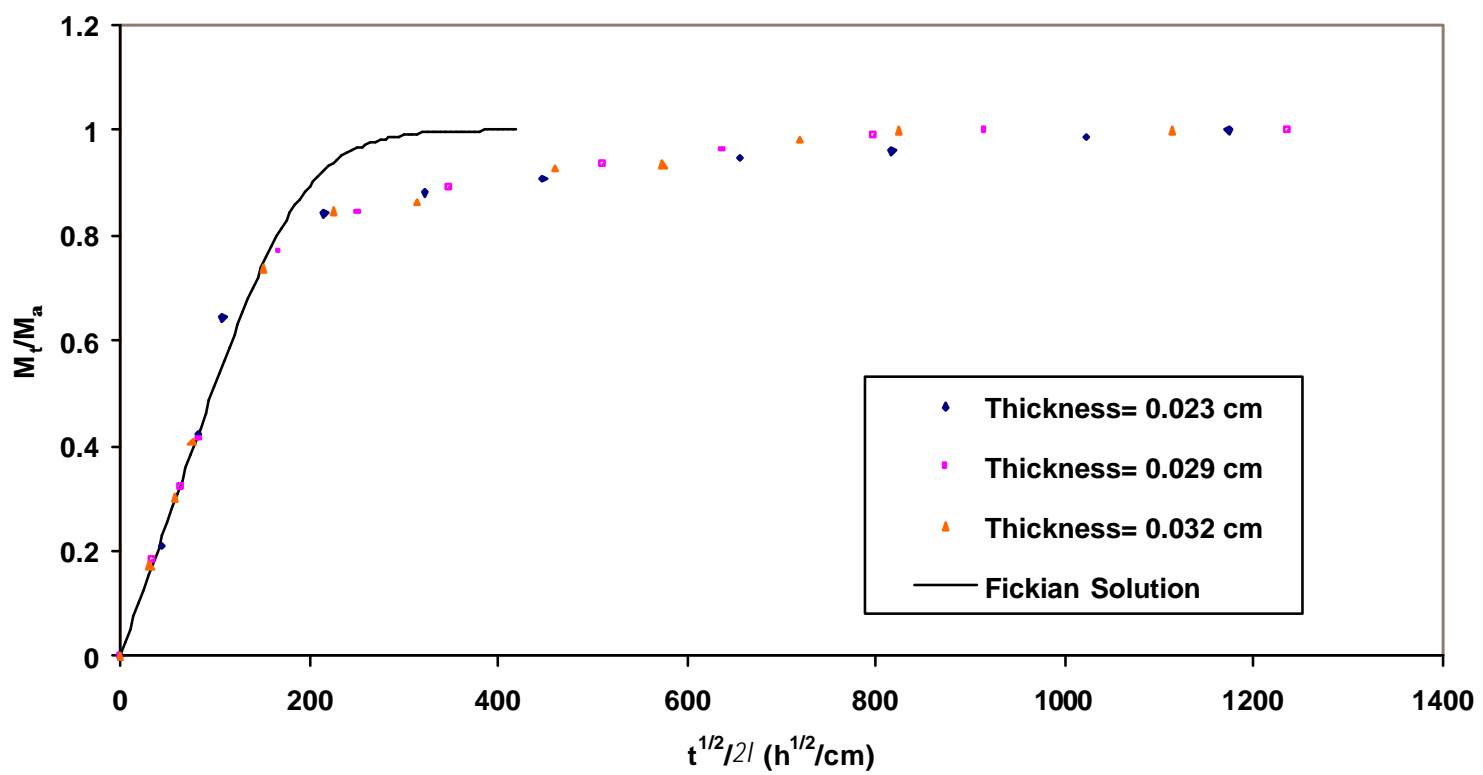

Figure 68. $M_{t} / M_{\infty}$ versus $t^{1 / 2} / 2 l$ for samples containing 0 wt $\%$ Cloisite $10 \mathrm{~A}^{\circledR}$ at $4^{\circ} \mathrm{C}$

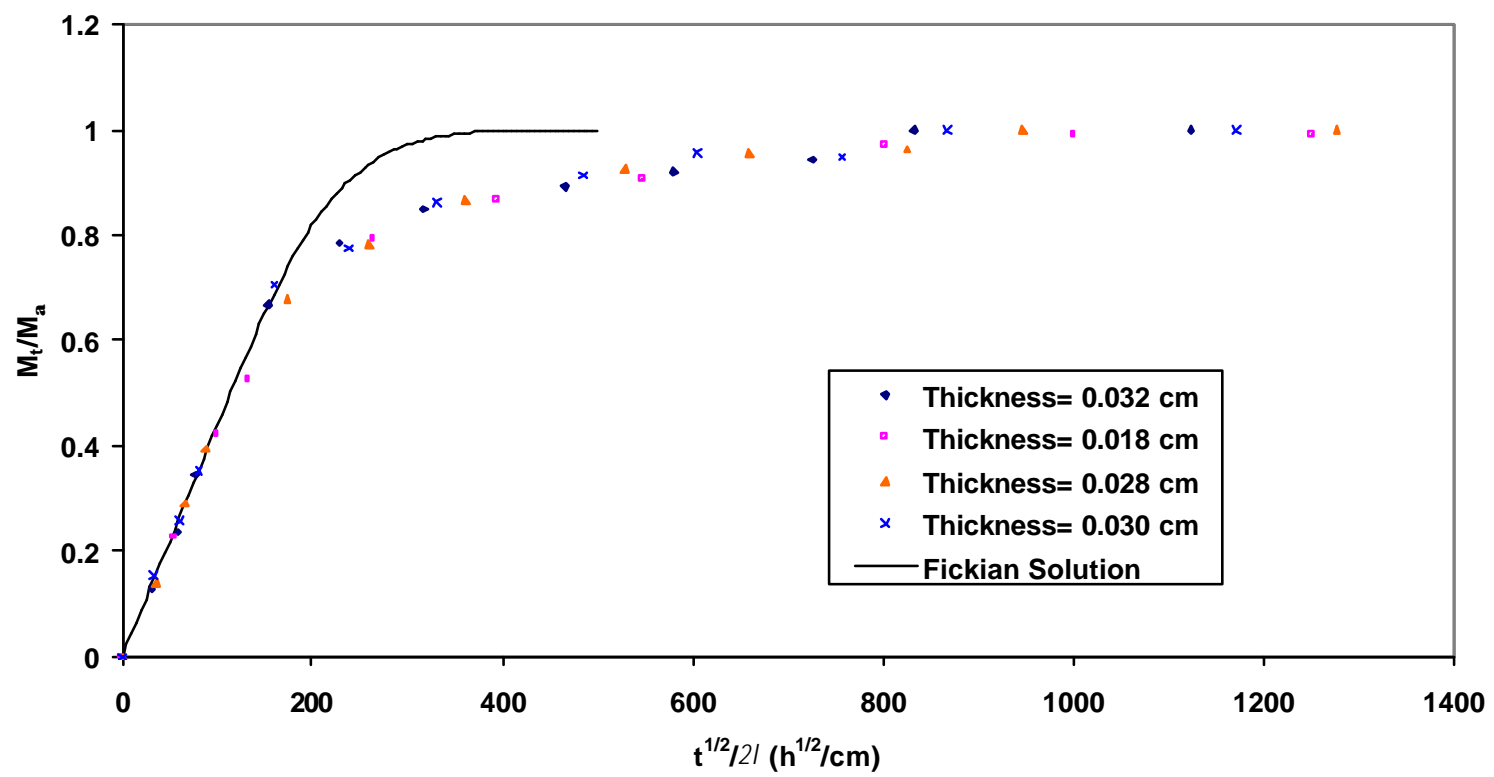

Figure 69. $M_{t} / M_{\infty}$ versus $t^{1 / 2} / 2 l$ for samples containing $1 \mathrm{wt} \%$ Cloisite $10 \mathrm{~A}^{\circledR}$ at $4^{\circ} \mathrm{C}$ 


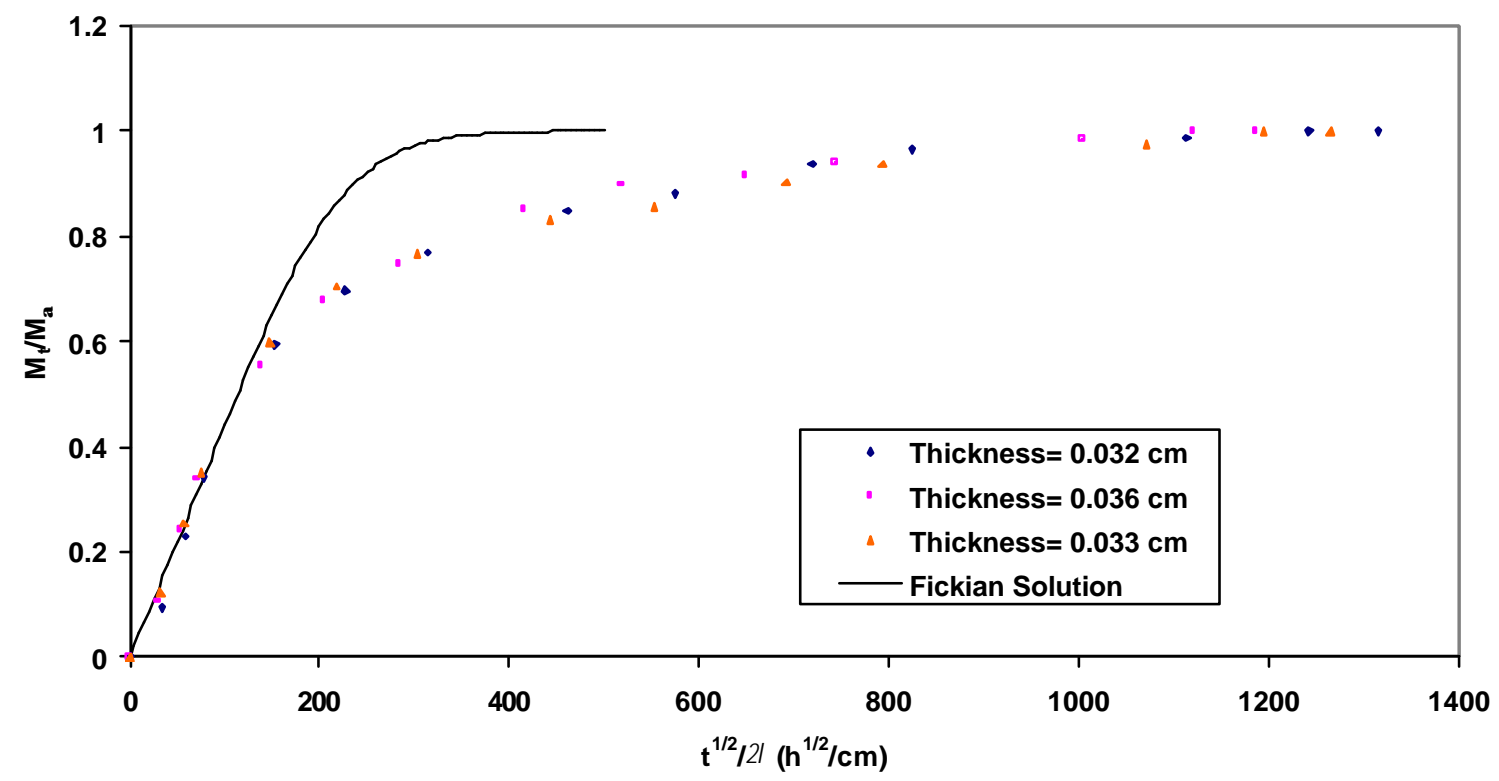

Figure 70. $M_{t} / M_{\infty}$ versus $t^{1 / 2} / 2 l$ for samples containing 2 wt $\%$ Cloisite $10 \mathrm{~A}^{\circledR}$ at $4^{\circ} \mathrm{C}$

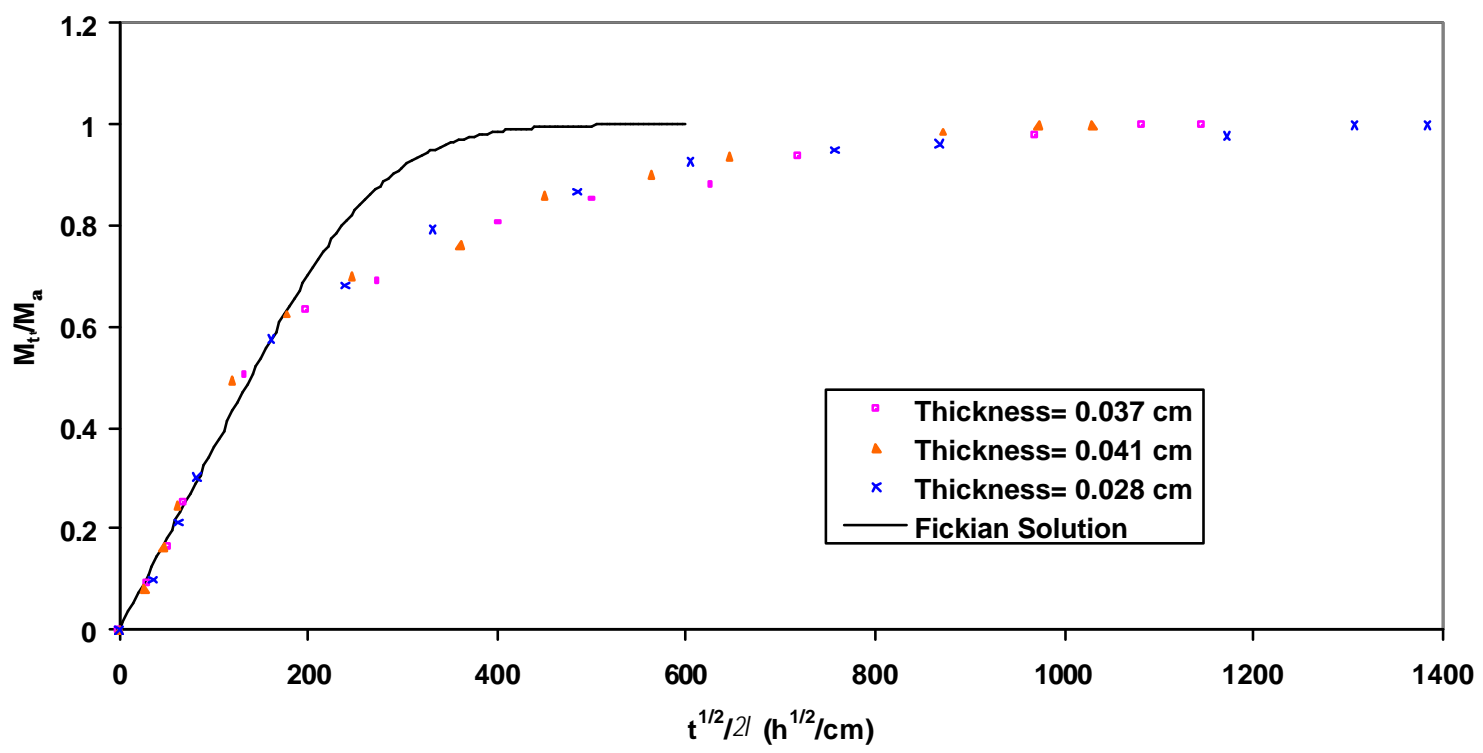

Figure 71. $M_{t} / M_{\infty}$ versus $t^{1 / 2} / 2 l$ for samples containing 5 wt $\%$ Cloisite $10 \mathrm{~A}^{\circledast}$ at $4^{\circ} \mathrm{C}$ 
Diffusivities of these samples were calculated from the initial slope of these weight gain curves and are shown in Table XII along with the equilibrium moisture contents.

Table XII. Results of transient diffusion experiments with un-reinforced samples at $4^{\circ} \mathrm{C}$

\begin{tabular}{|c|c|c|}
\hline $\begin{array}{c}\text { Wt \% Cloisite } \\
10 A^{\circledR}\end{array}$ & $\mathrm{D} \times 10^{+9}\left(\mathrm{~cm}^{2} / \mathrm{s}\right)$ & $\begin{array}{c}\text { Equilibrium } \\
\text { Moisture }\end{array}$ \\
\hline 0 & $1.43(0.10)$ & $0.60 \%(0.03)$ \\
\hline 1 & $1.05(0.03)$ & $0.85 \%(0.03)$ \\
\hline 2 & $1.05(0.12)$ & $0.90 \%(0.02)$ \\
\hline 5 & $0.71(0.07)$ & $0.97 \%(0.03)$ \\
\hline
\end{tabular}

Note: Values shown in the brackets are standard deviations

As expected, both the diffusivities and equilibrium moisture contents at $4^{\circ} \mathrm{C}$ are much lower than the corresponding values for the same type of samples at $25^{\circ} \mathrm{C}$ (see Table VII). Figures 72 and 73 show the effect of temperature on the diffusivity and equilibrium moisture content of the un-reinforced samples respectively. The diffusion coefficient at $4{ }^{\circ} \mathrm{C}$ was found to drop by approximately $42 \%$ by incorporation of $5 \mathrm{wt} \%$ of exfoliated nanoclay. Lowered equilibrium moisture contents of all the nanocomposite samples indicated that the adsorption of water on clay-platelets was an energy-activated process and less water molecules were able to adsorb on to the clay-platelets at the low temperature. 


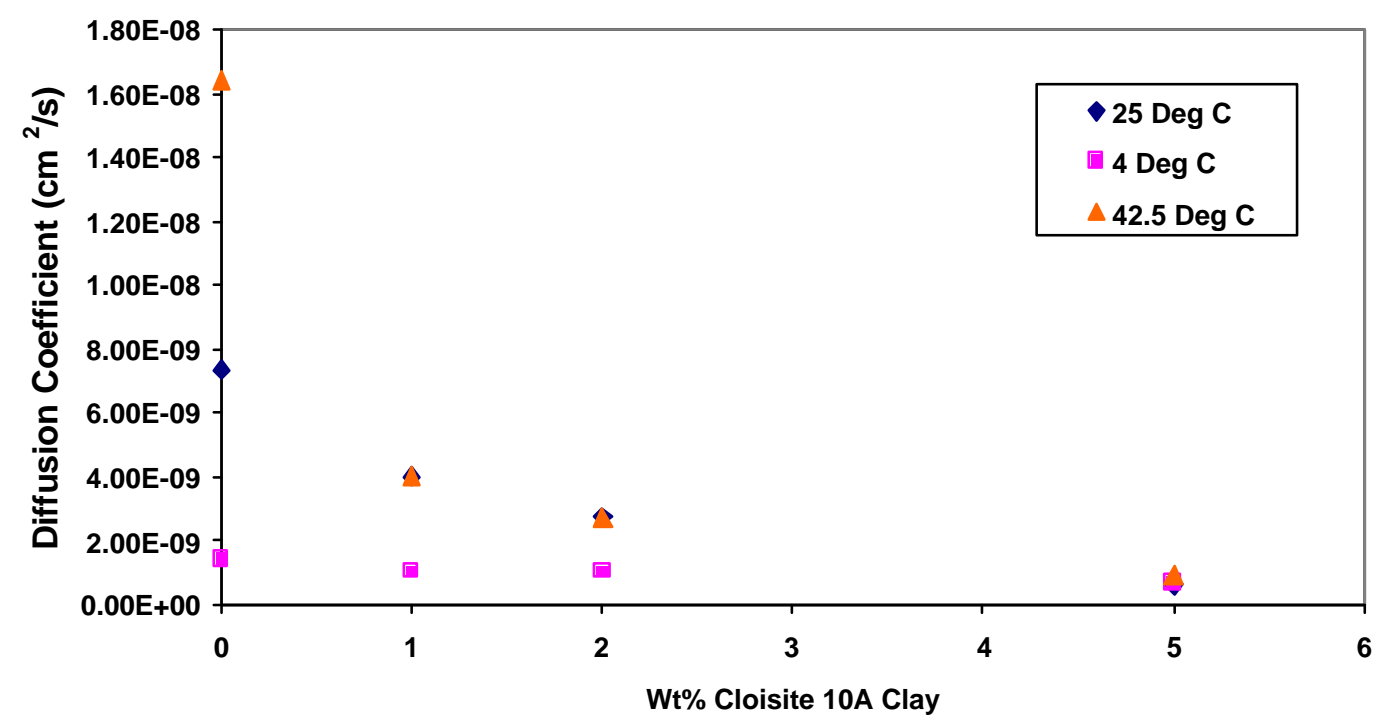

Figure 72. Effect of temperature on the diffusivity of un-reinforced samples

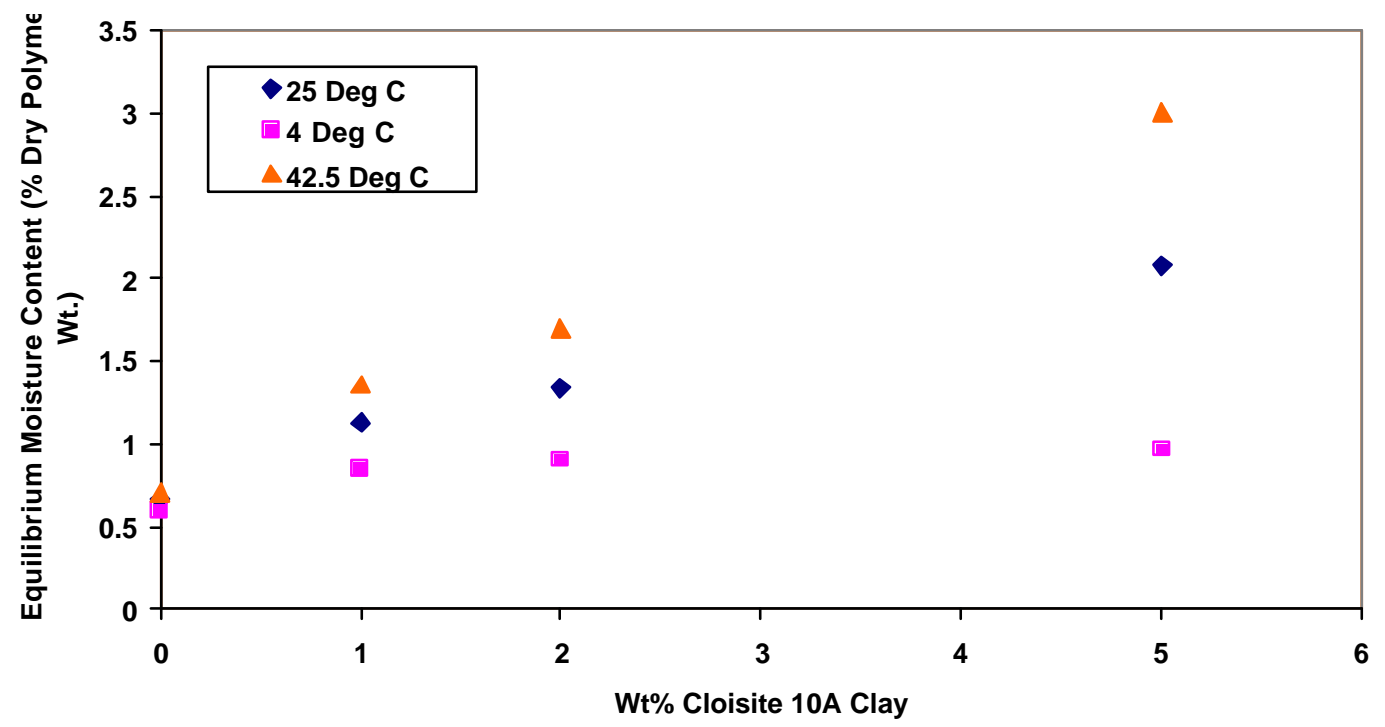

Figure 73. Effect of temperature on the equilibrium moisture contents of un-reinforced samples 
Assuming Arrhenius type of relationship between diffusivity and temperature (equation 8), activation energy for diffusion of water in to the neat resin was calculated using experimental data at $25^{\circ} \mathrm{C}, 42.5^{\circ} \mathrm{C}$ and $4^{\circ} \mathrm{C}$. Activation energy $(E)$ and $D_{o}$ were found to be approximately $46.518 \mathrm{~kJ} / \mathrm{mol}$ and $0.90239 \mathrm{~cm}^{2} / \mathrm{s}$ respectively. Diffusion in nanocomposite samples was accompanied by simultaneous adsorption of water molecules on clay platelets. The rate constant of this adsorption process was also a function of temperature. Therefore, it was not possible to calculate the activation energy for diffusion in nanocomposite samples.

Transient diffusion experiments with FRP samples were also carried out in distilled water at $4{ }^{\circ} \mathrm{C}$. FRP films containing various amounts of nanoclay were immersed in distilled water at $4^{\circ} \mathrm{C}$ and weighed periodically as was done in all other transient diffusion experiments. Experimental data were corrected for the weight of the glass (as explained earlier) and the corrected $M_{t} / M_{\infty}$ were plotted versus $t^{1 / 2} / 2 l$. It was found that the correction for the weight of the glass fibers did not affect the value of diffusivity but it affected only the equilibrium moisture content. Figure 74 to 77 show plots of corrected normalized mass uptake. 


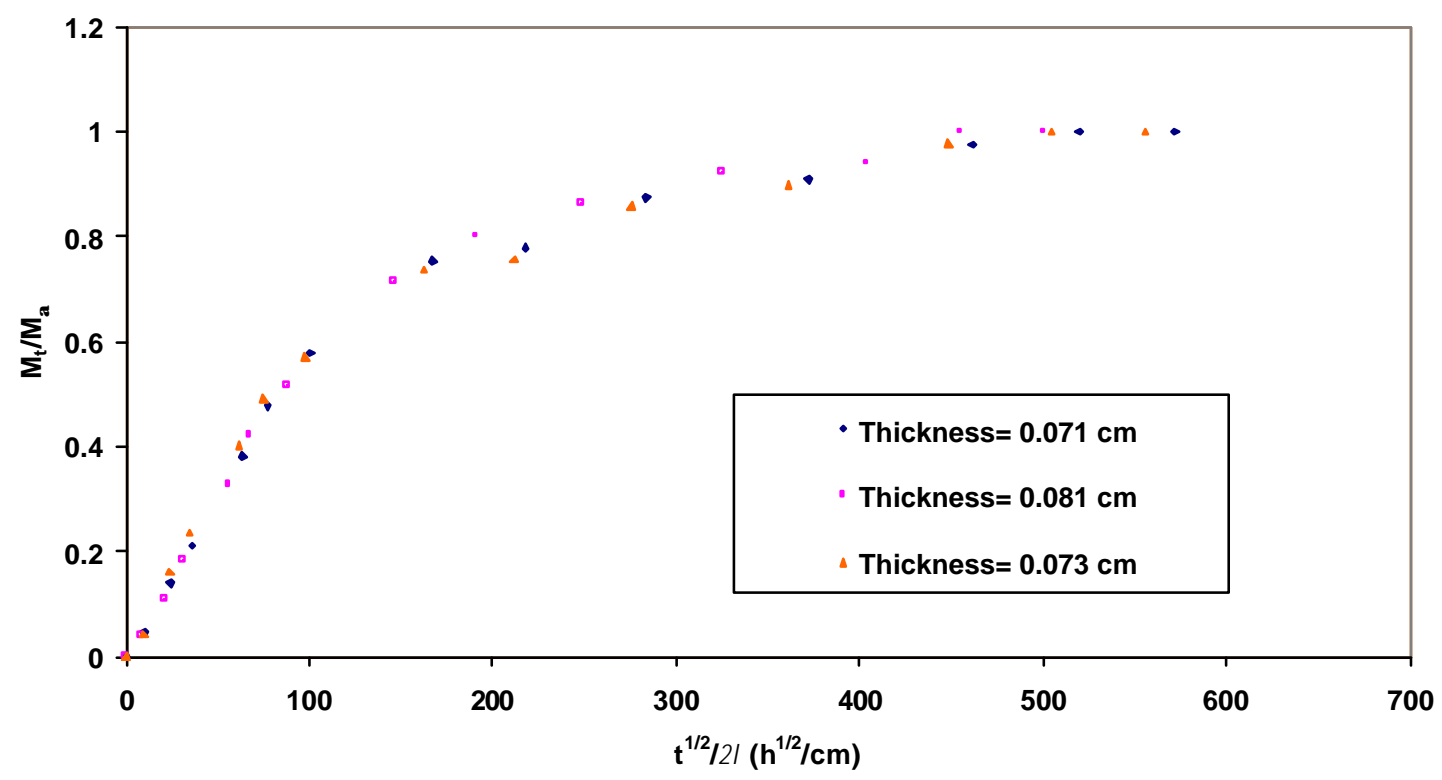

Figure 74. Correcte d $M_{t} / M_{\infty}$ versus $t^{1 / 2} / 2 l$ for FRP samples containing 0 wt $\%$ Cloisite $10 A^{\circledR}$ at $4^{\circ} \mathrm{C}$

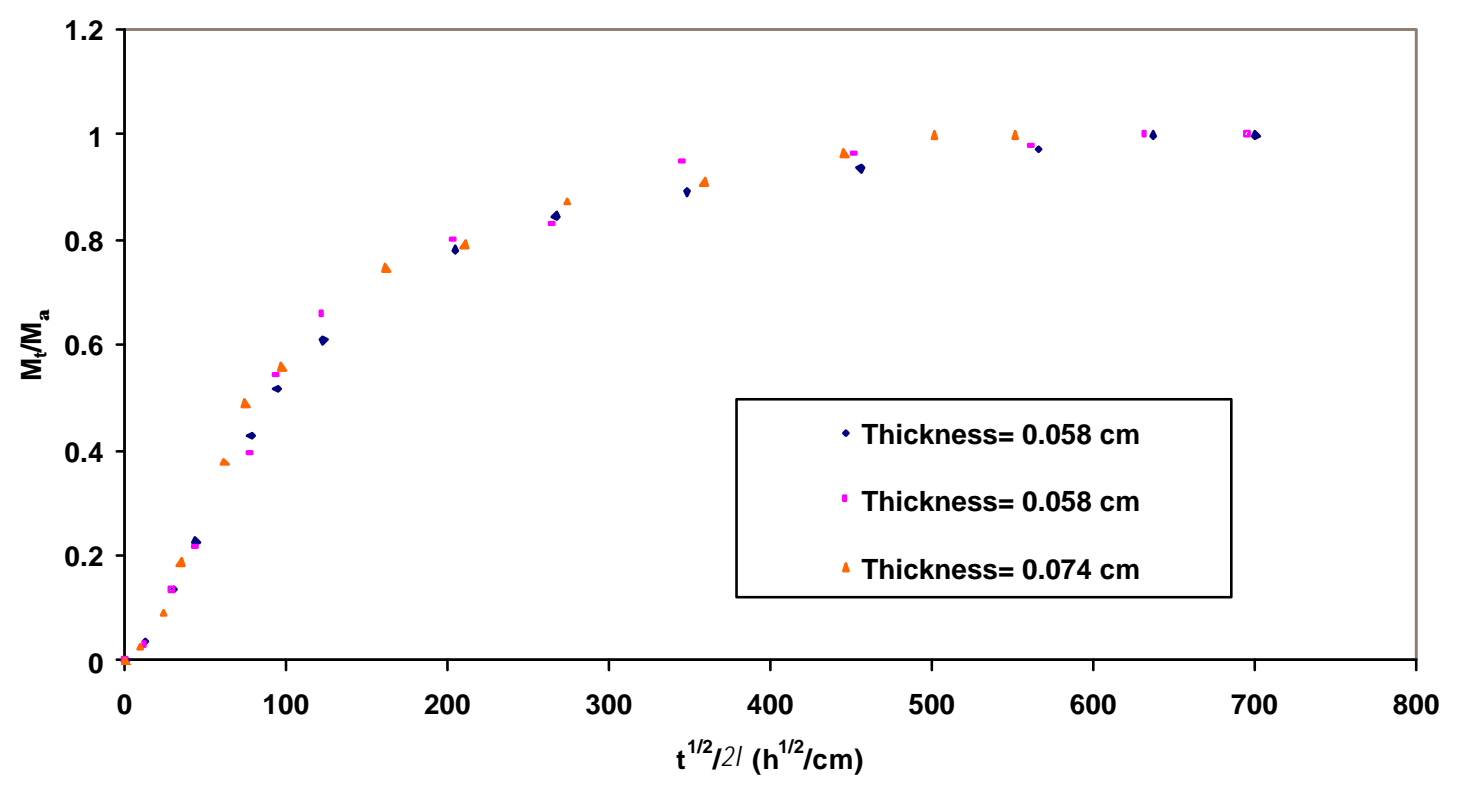

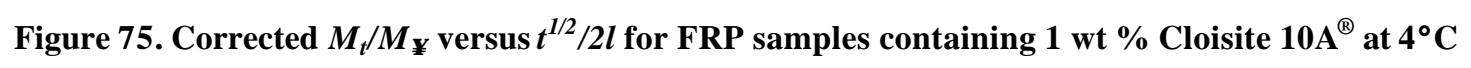




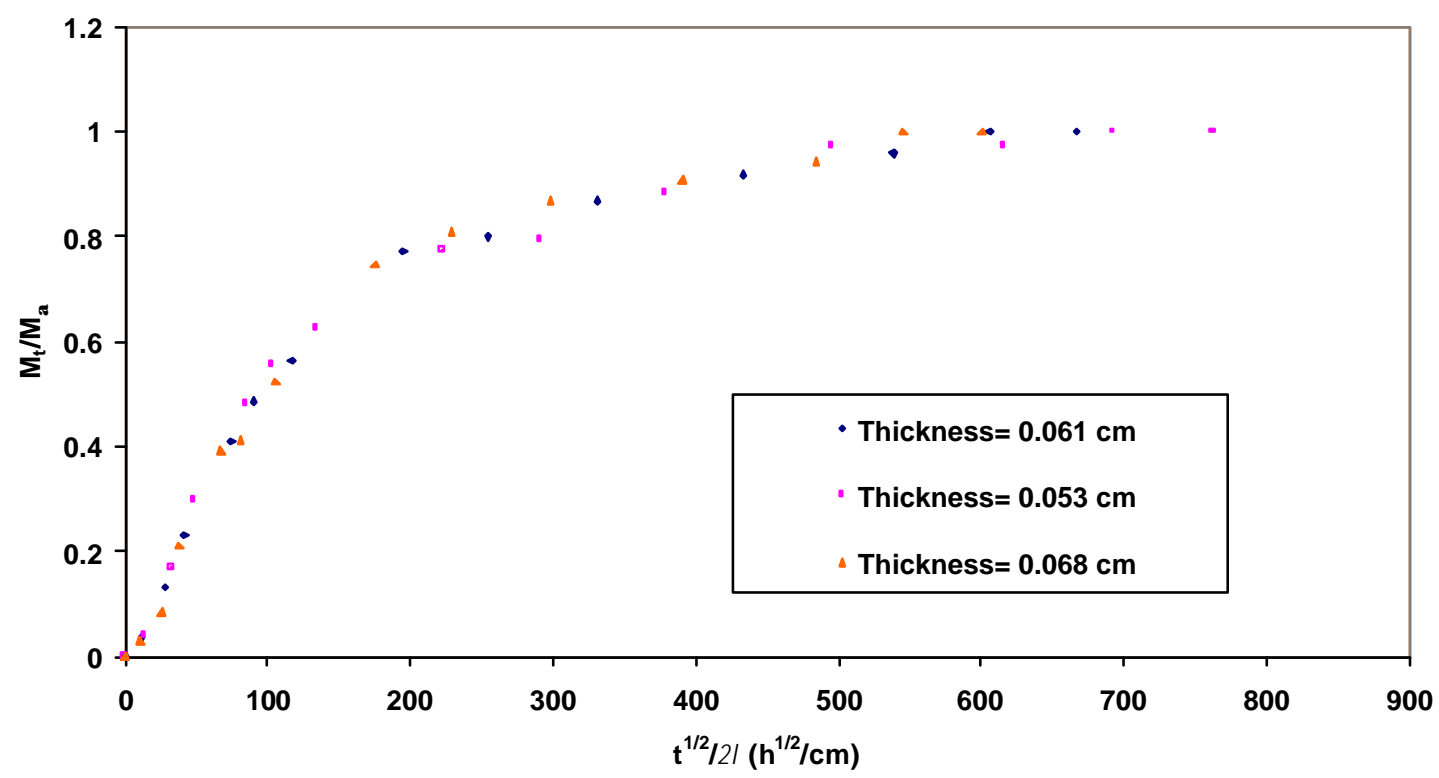

Figure 76. Corrected $M_{t} / M_{\infty}$ versus $t^{1 / 2} / 2 l$ for FRP samples containing 2 wt $\%$ Cloisite $10 A^{\circledR}$ at $4^{\circ} \mathrm{C}$

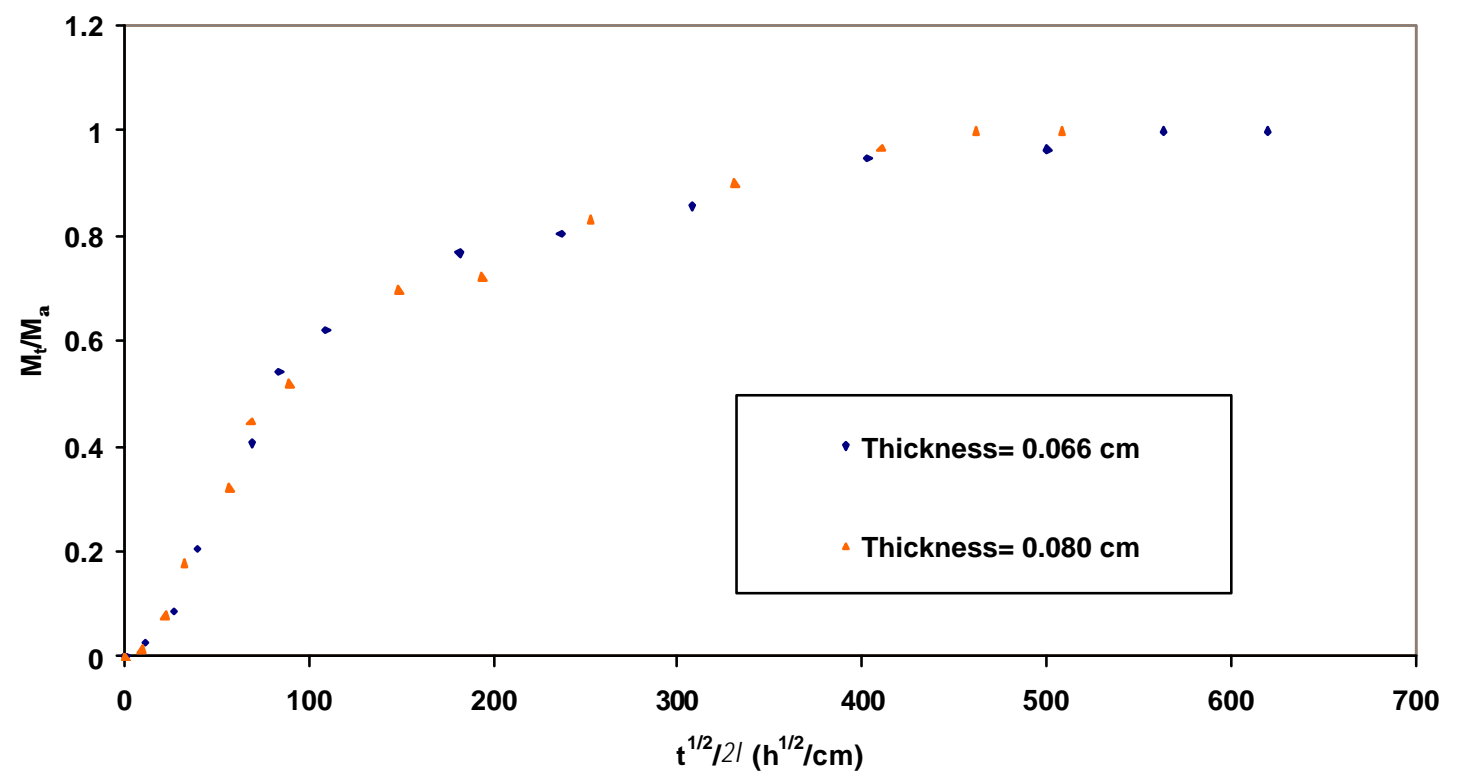

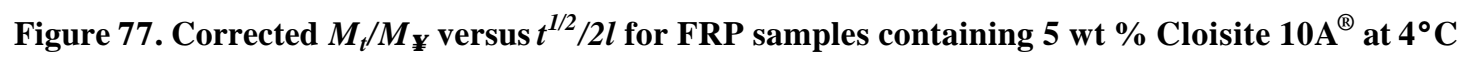


Diffusion coefficients were calculated from the initial slopes of corrected normalized weight gain curves. Equilibrium moisture content of the resin was also calculated from the experimental data. The diffusion coefficients and equilibrium moisture contents thus obtained are shown in Table XIII. Results of un-reinforced samples are also shown as a basis of comparison. Variations in diffusivity and equilibrium moisture contents are also shown graphically in Figure 78 and 79 respectively.

Table XIII. Results of transient diffusion experiments on FRP films immersed in distilled water at $4^{\circ} \mathrm{C}$

\begin{tabular}{|c|c|c|c|c|}
\hline $\begin{array}{c}\text { Wt \% Cloisite } \\
10 \mathrm{~A}^{\circledR}\end{array}$ & $\begin{array}{c}\mathrm{D} \times 10^{+9}\left(\mathrm{~cm}^{2} / \mathrm{s}\right) \\
\text { FRP }\end{array}$ & $\begin{array}{c}\mathrm{D} \times 10^{+9}\left(\mathrm{~cm}^{2} / \mathrm{s}\right) \\
\text { Un-reinforced }\end{array}$ & $\begin{array}{c}\text { Equilibrium } \\
\text { Moisture } \\
\text { FRP } \\
\text { Matrix Only })\end{array}$ & $\begin{array}{c}\text { Equilibrium } \\
\text { Moisture } \\
\text { Un-reinforced }\end{array}$ \\
\hline 0 & $2.04(0.29)$ & $1.43(0.10)$ & $1.07 \%(0.06)$ & $0.60 \%(0.03)$ \\
\hline 1 & $1.54(0.23)$ & $1.05(0.03)$ & $0.93 \%(0.07)$ & $0.85 \%(0.03)$ \\
\hline 2 & $1.67(0.09)$ & $1.05(0.12)$ & $1.34 \%(0.10)$ & $0.90 \%(0.02)$ \\
\hline 5 & $1.59(0.00)$ & $0.71(0.07)$ & $1.37 \%(0.30)$ & $0.97 \%(0.03)$ \\
\hline
\end{tabular}

Note: Values shown in the brackets are standard deviations

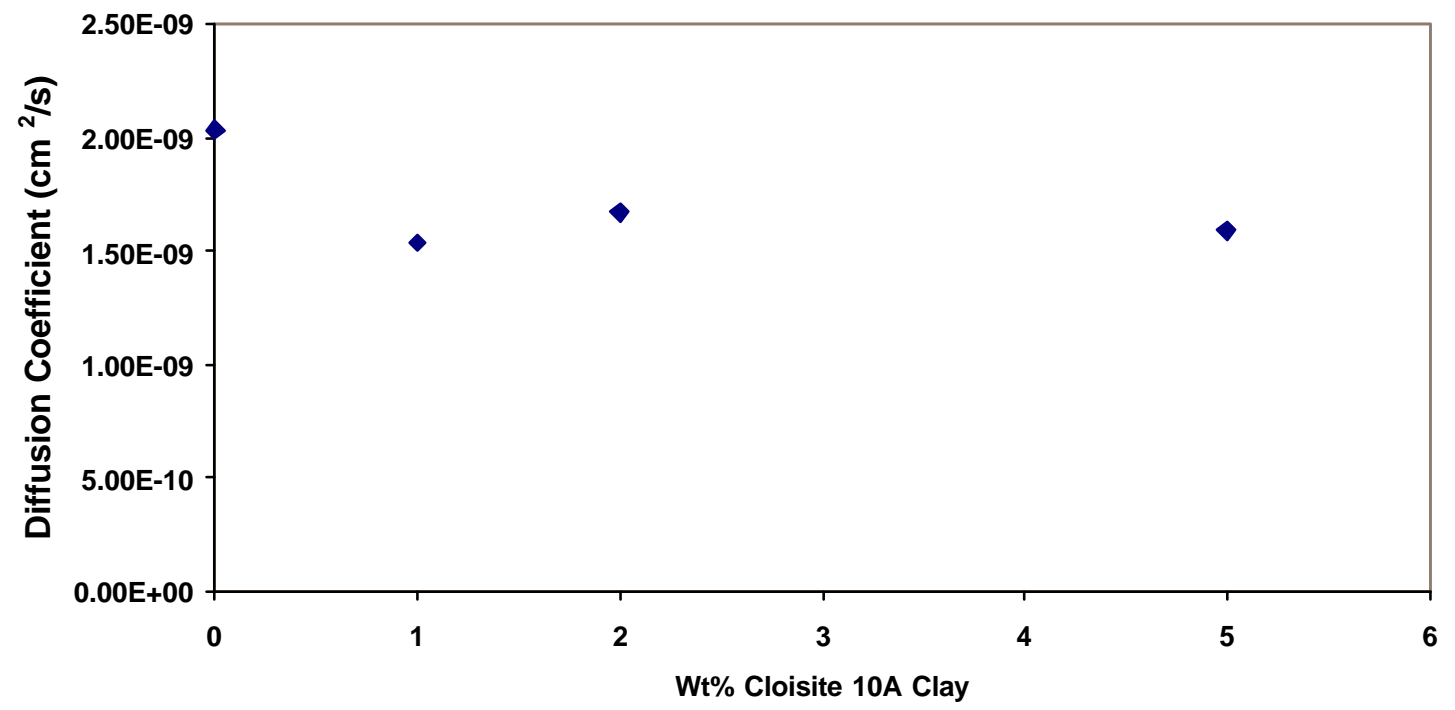

Figure 78. Variation in diffusion coefficient of FRP with various clay loading levels 


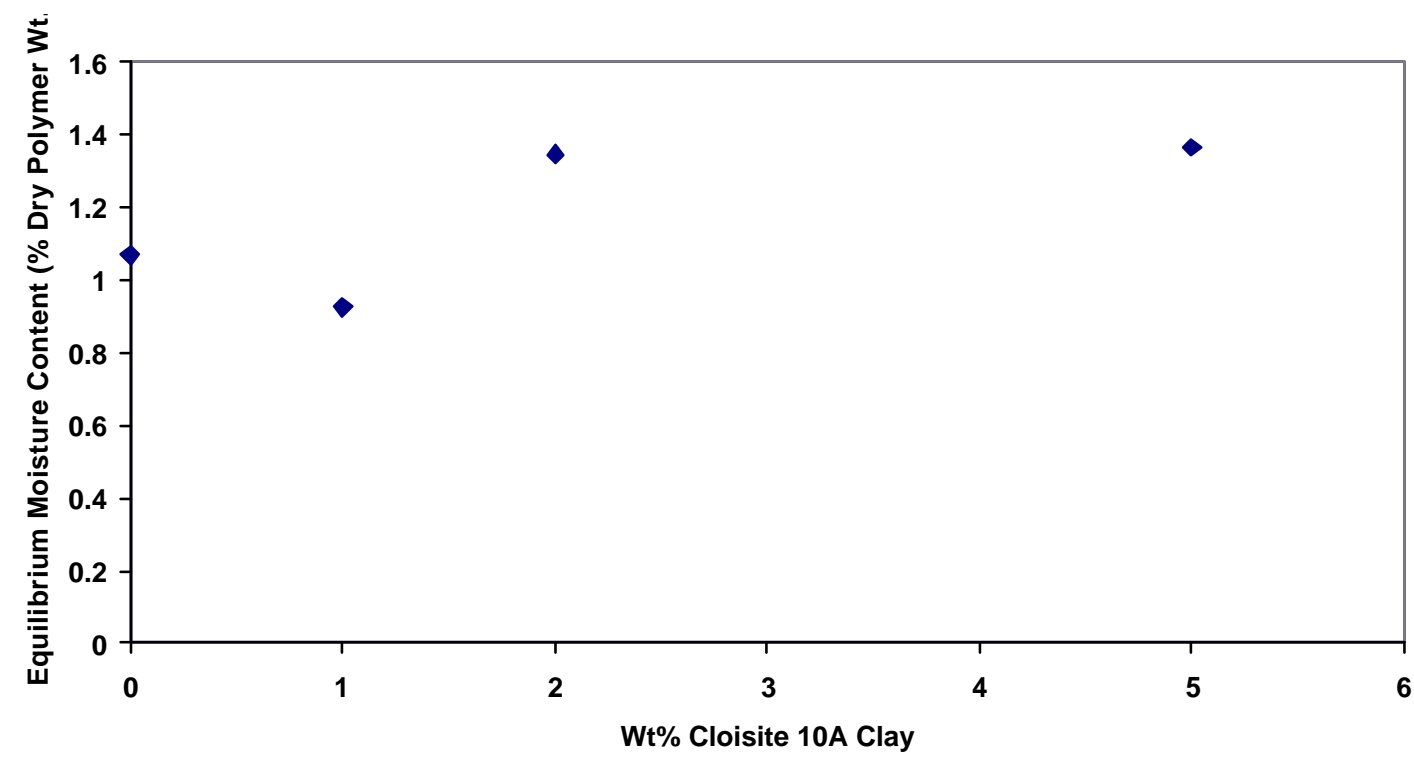

Figure 79. Variation in Equilibrium moisture content with various clay loading levels

As seen from Table XIII, the diffusion coefficients of the FRPs were somewhat higher than those for the corresponding un-reinforced nano-composites. This was expected because no thickness correction for the glass-fiber mat was applied to the experimental data, i.e. the sample thickness used in the calculations were higher than the actual thickness of the resin film if there were no fibers. As will be explained in section 6.9 , the presence of fibers provided very little additional resistance to the diffusing water molecules. However, the presence of fiber-mat increased the thickness of the sample significantly. This is graphically explained by Figure 80 . 


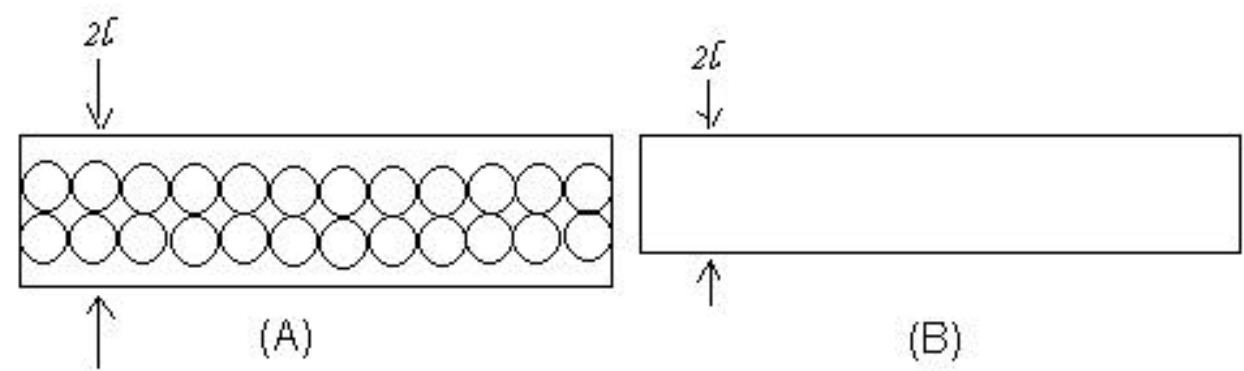

Figure 80. (A) Actual thickness used in calculations (B) Apparent thickness if there were no fibers

Corrected equilibrium moisture contents of the FRPs were noticeably higher than those for the corresponding un-reinforced nanocomposites (Table XIII). This indicates that even at low temperatures, interactions between the silanes and water molecules are significant. However, the moisture contents were not abnormally high indicating that water molecules were not able to break strong $\mathrm{SiO}-\mathrm{Si}$ bond between glass and silane and consequently, no debonding occurred.

\subsection{Transient Diffusion Experiments in Alkaline and Saline Solutions at Room Temperature}

In order to understand the diffusion of water in polymer immersed in alkaline and saline solutions, transient diffusion experiments were performed at $28^{\circ} \mathrm{C}$. A solution having a $\mathrm{pH}$ of 13 was prepared by dissolving the appropriate amount of solid $\mathrm{NaOH}$ in distilled water. Similarly, a $0.1 \mathrm{M} \mathrm{NaCl}$ solution was prepared by dissolving solid $\mathrm{NaCl}$ in distilled water and the $\mathrm{pH}$ of salt solution was recorded to be 7.0. Polymer samples containing 0 wt $\%, 1$ wt $\%, 2 \mathrm{wt} \%$, and $5 \mathrm{wt} \%$ of Cloisite $10 \mathrm{~A}^{\circledR}$ nanoclay were immersed in these solutions and periodic weight gain of the samples was noted. Typical dimensions of the samples were $5 \mathrm{~cm} \times 1.25 \mathrm{~cm}$. The thickness of the sample varied 
between $0.02 \mathrm{~cm}$ and $0.05 \mathrm{~cm}$. The beakers containing solutions were closed at top using aluminum foil to avoid evaporation of water. No loss of water was reported and concentrations of solutions were found to be constant during the period of experiments. The temperature of the solutions was maintained at $28^{\circ} \mathrm{C}$ throughout the experiments.

A graph of $M_{t} / M_{\infty}$ versus $t^{1 / 2} / 2 l$ was plotted for all the samples; $M_{t}$ and $M_{\infty}$ are mass uptake of solution at time $t$ and at infinity time respectively. Mass uptake curves for $\mathrm{NaCl}$ solutions are shown in Figure 81 to 84 . From the initial slopes of these curves, diffusion coefficients were calculated according to the method explained in section 2.1. All the samples immersed in $\mathrm{NaOH}$ solutions dissolved after 9-10 days of immersion. $M_{\infty}$ values were not obtained during the experiments for these samples. Therefore, percentage weight gains of samples were plotted against $t^{1 / 2}$. Curves are shown in Figure 85 to 88 .

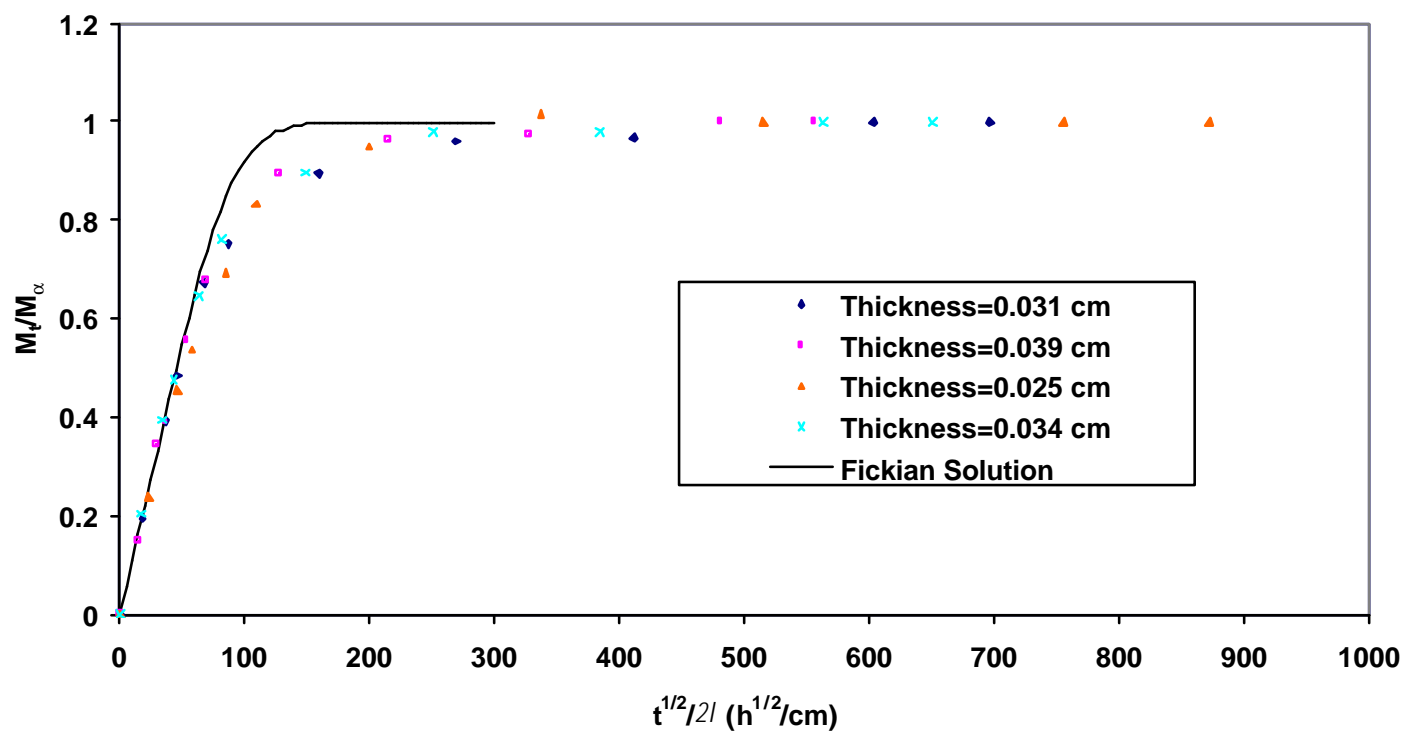

Figure 81. $M_{t} / M_{\infty}$ Versus $t^{1 / 2} / 2 l$ for samples containing $0 \mathrm{wt} \%$ Cloisite $10 \mathrm{~A}^{\circledR}$ immersed in $0.1 \mathrm{M} \mathrm{NaCl}$ solution at $28^{\circ} \mathrm{C}$ 


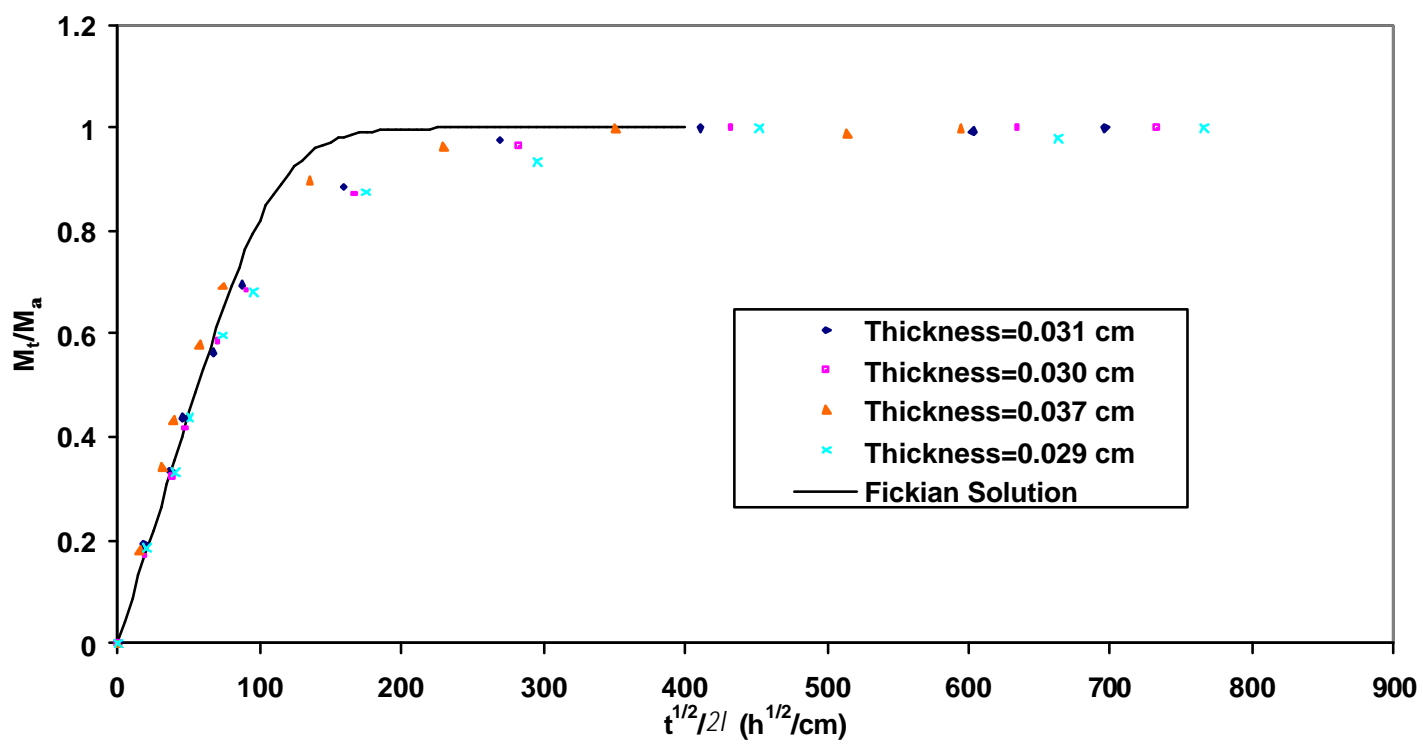

Figure 82. $M_{t} / M_{\infty}$ Versus $t^{1 / 2} / 2 l$ for samples containing $1 \mathrm{wt} \%$ Cloisite $10 \mathrm{~A}^{\circledR}$ immersed in $0.1 \mathrm{M} \mathrm{NaCl}$ solution at $28^{\circ} \mathrm{C}$

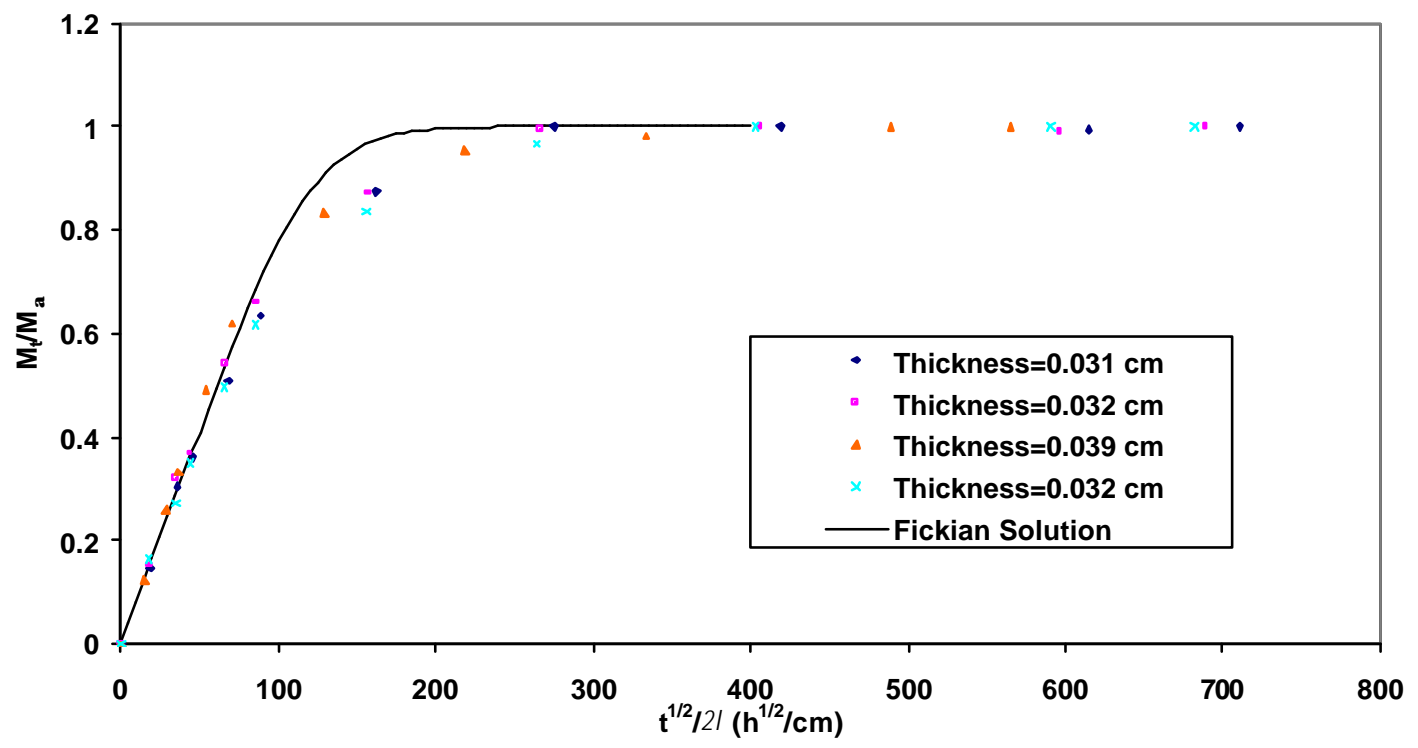

Figure 83. $M_{t} / M_{\infty}$ Versus $t^{1 / 2} / 2 l$ for samples containing $2 \mathrm{wt} \%$ Cloisite $10 \mathrm{~A}^{\circledR}$ immersed in $0.1 \mathrm{M} \mathrm{NaCl}$ solution at $28^{\circ} \mathrm{C}$ 


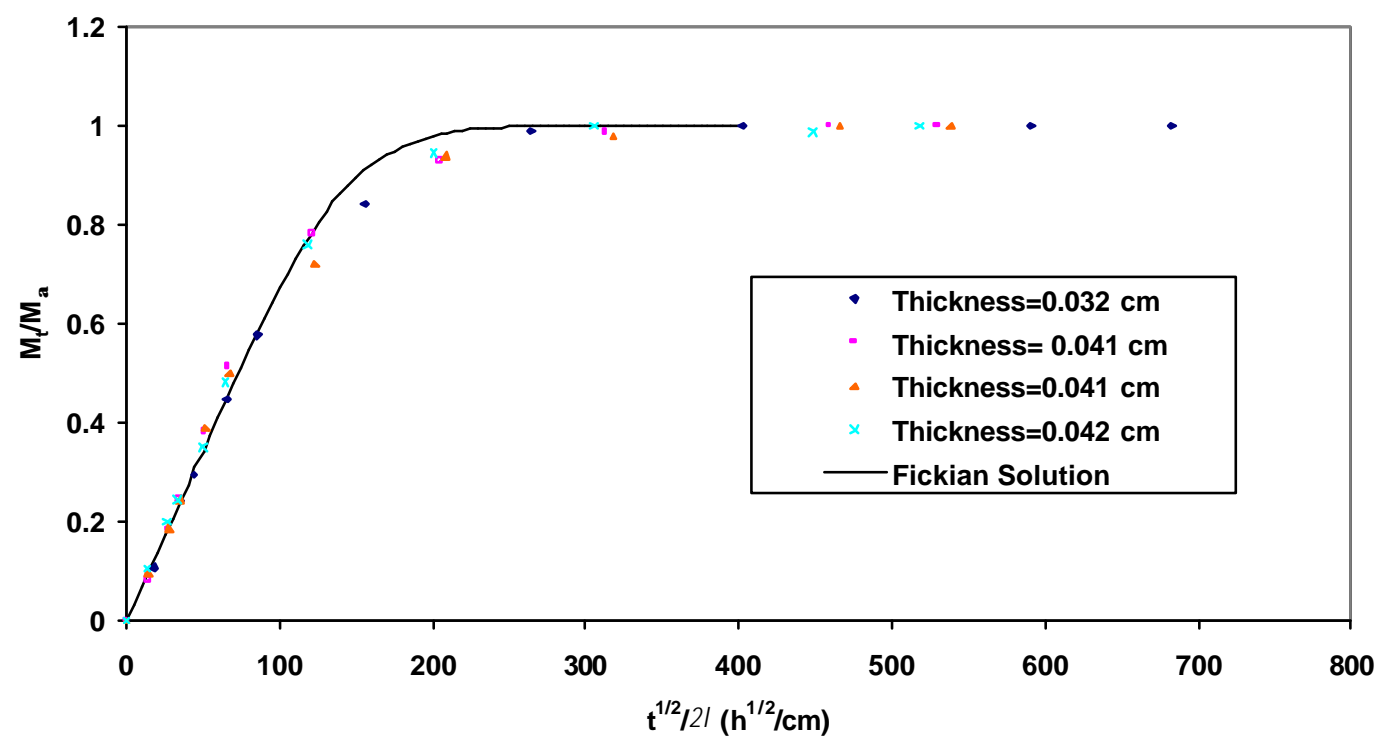

Figure 84. $M_{t} / M_{\infty}$ Versus $t^{1 / 2} / 2 l$ for samples containing $5 \mathrm{wt} \%$ Cloisite $10 \mathrm{~A}^{\circledR}$ immersed in $0.1 \mathrm{M} \mathrm{NaCl}$ solution at $28^{\circ} \mathrm{C}$

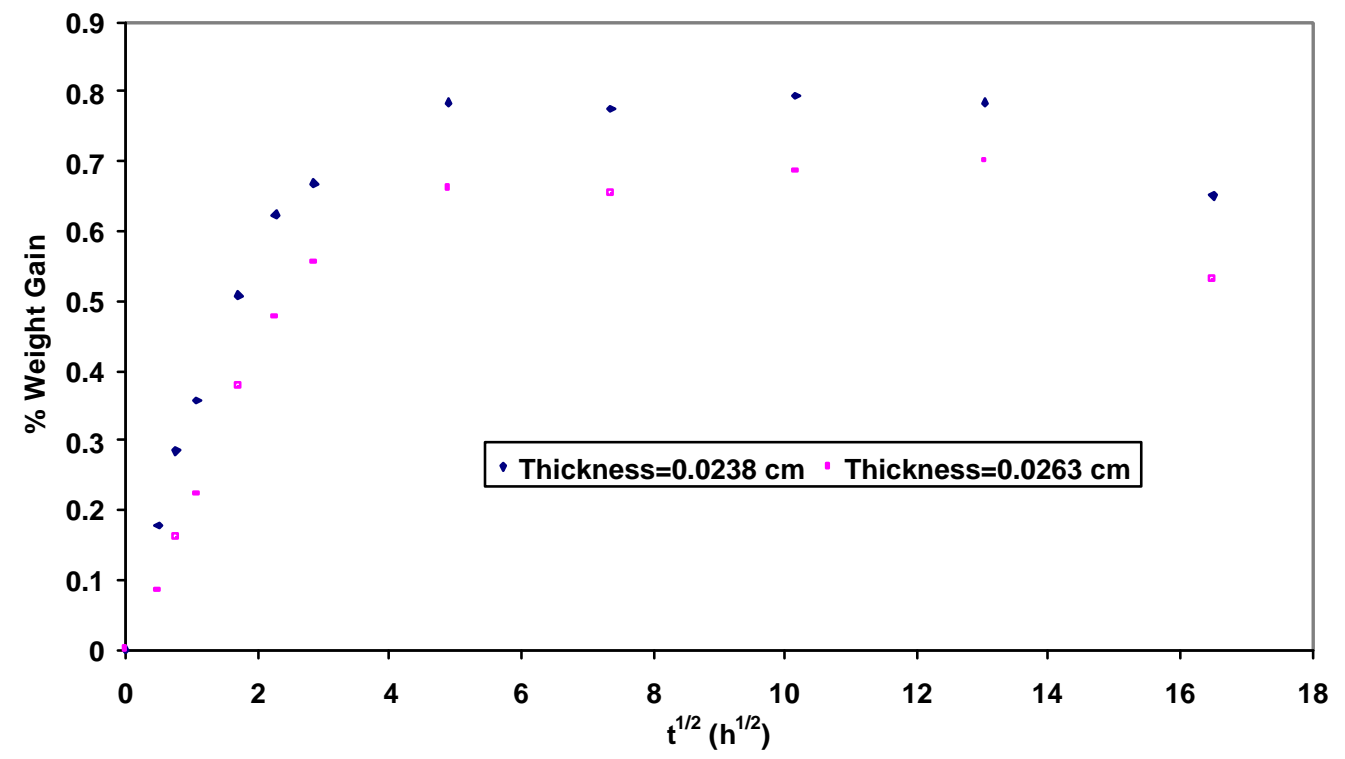

Figure 85. Percentage weight gain versus $t^{1 / 2}$ for samples containing 0 wt $\%$ Cloisite $10 A^{\circledR}$ immersed in $\mathrm{NaOH}$ solution having a $\mathrm{pH}$ of 13 at $28^{\circ} \mathrm{C}$ 


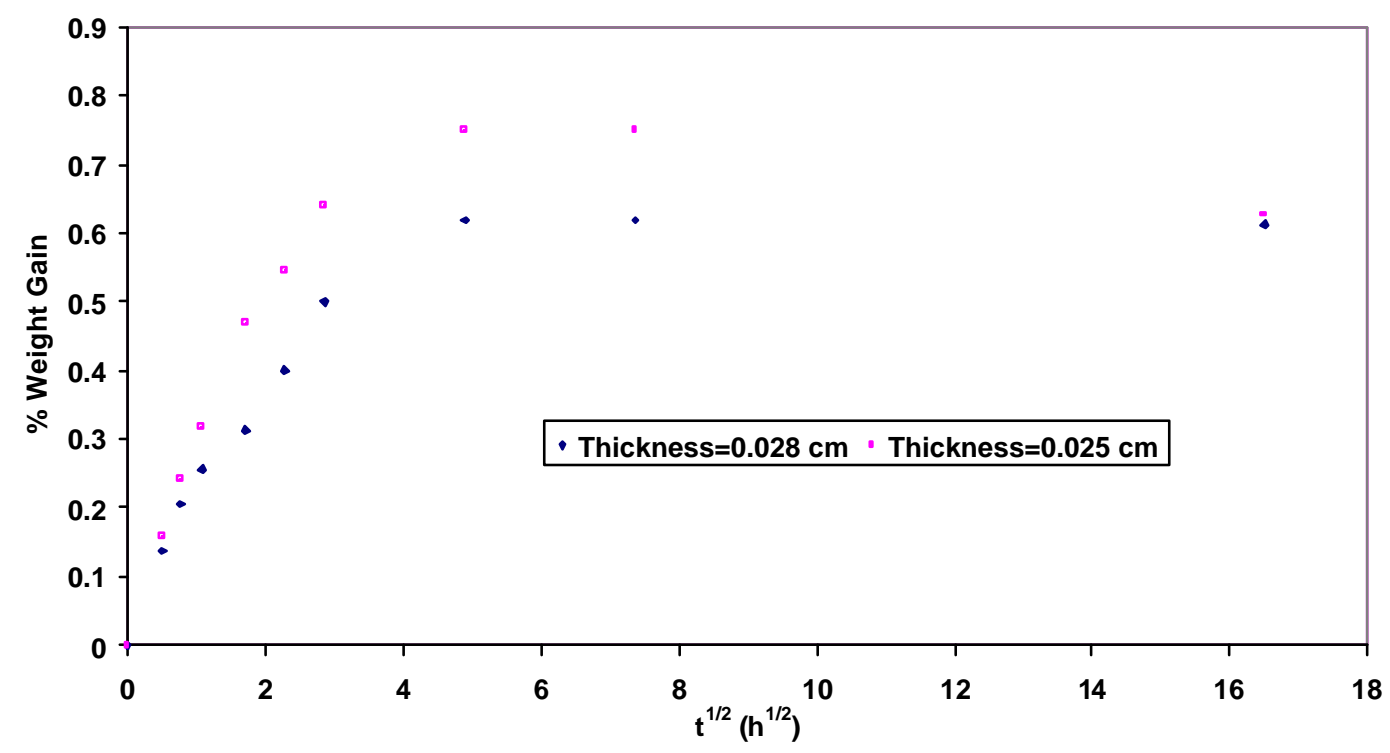

Figure 86. Percentage weight gain versus $t^{1 / 2}$ for samples containing $1 \mathrm{wt} \%$ Cloisite $10 \mathrm{~A}^{\circledR}$ immersed in $\mathrm{NaOH}$ solution having a $\mathrm{pH}$ of 13 at $28^{\circ} \mathrm{C}$

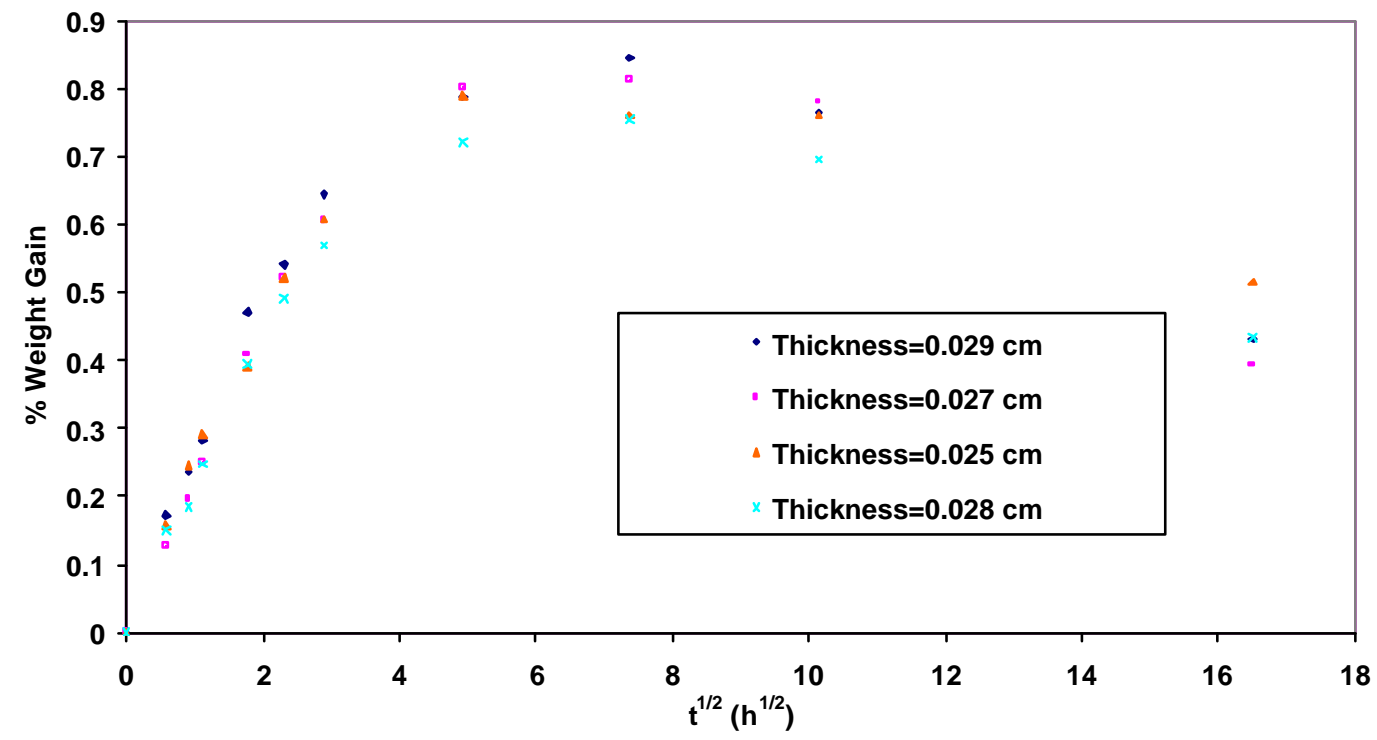

Figure 87. Percentage weight gain versus $t^{1 / 2}$ for samples containing 2 wt $\%$ Cloisite $10 A^{\circledR}$ immersed in $\mathrm{NaOH}$ solution having a $\mathrm{pH}$ of 13 at $28^{\circ} \mathrm{C}$ 


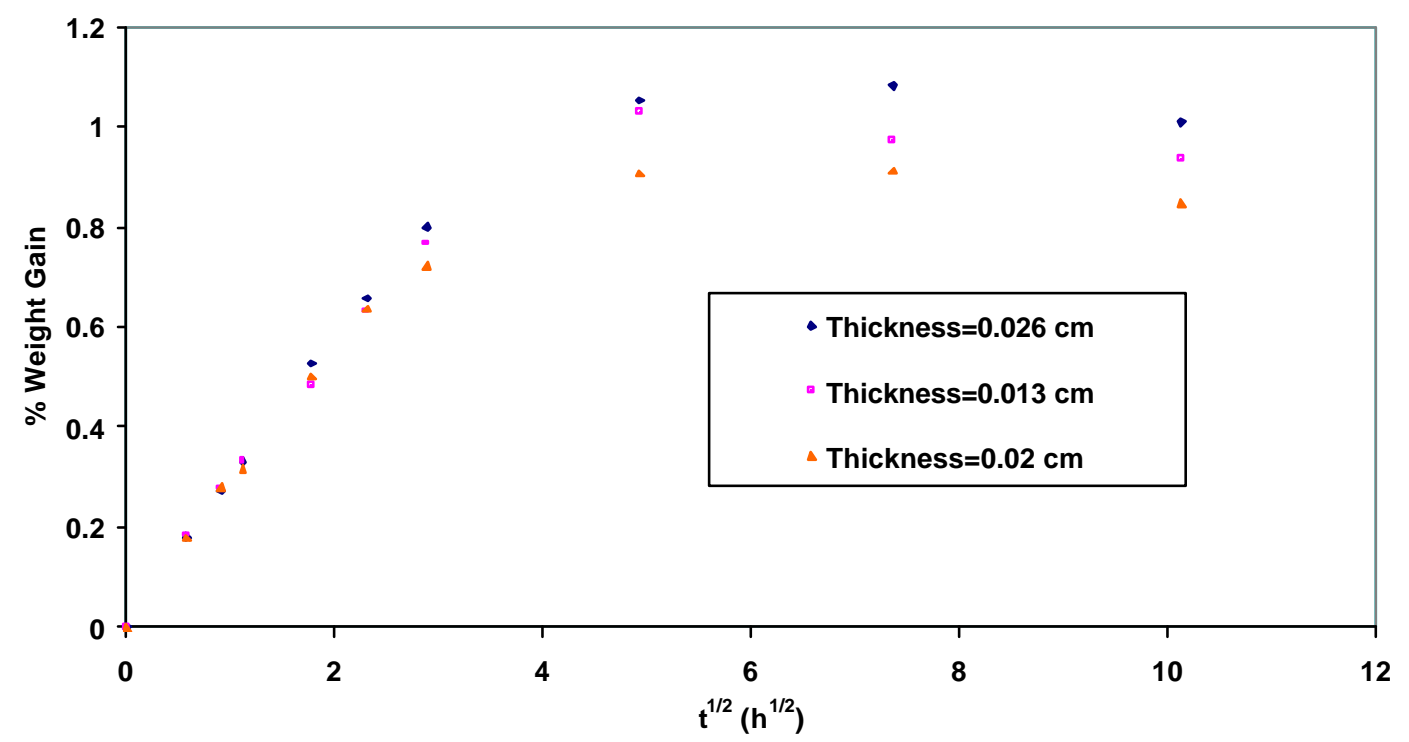

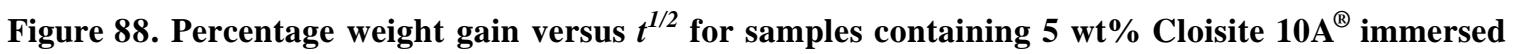
in $\mathrm{NaOH}$ solution having a $\mathrm{pH}$ of 13 at $28^{\circ} \mathrm{C}$

Experimental values of diffusion coefficients for experiments in $\mathrm{NaCl}$ and $\mathrm{NaOH}$ solutions are shown in Table XIV and corresponding equilibrium moisture contents are shown in Table XV. Since $M_{\infty}$ values were not obtained for samples immersed in alkaline solution, it was impossible to theoretically calculate the exact values of diffusion coefficients. It was found that a white, powder-like substance was formed on to the surface of the samples due to the reaction between $\mathrm{NaOH}$ solution and vinyl ester. This white substance was collected and then dissolved in a few drops of distilled water. When $\mathrm{pH}$ paper was dipped in these few drops of water, it showed basic $\mathrm{pH}$. To make sure these white substances were not $\mathrm{NaOH}$ crystals, a solution of $0.1 \mathrm{M} \mathrm{NaOH}$ solution was refrigerated at $4^{\circ} \mathrm{C}$ temperature. No crystallization was seen. This confirmed that the white powder-like substance was formed because of the reaction between $\mathrm{NaOH}$ and vinyl ester. Results for transient experiments in distilled water shown in Table XIV and $\mathrm{XV}$ are for the purpose of comparison. It is to be noted that the transient diffusion 
experiments in distilled water were carried out in winter when the lab temperature was reported to be $25^{\circ} \mathrm{C}$ throughout the experiments.

Table XIV . Diffusion Coefficients in 0.1M NaCl Solutions

\begin{tabular}{|c|c|c|c|c|}
\hline & \multicolumn{4}{|c|}{$\mathrm{D} \times 10^{+9}\left(\mathrm{~cm}^{2} / \mathrm{s}\right)$} \\
\hline Clay wt\% & $0 \mathrm{wt} \%$ & $1 \mathrm{wt} \%$ & $2 \mathrm{wt} \%$ & $5 \mathrm{wt} \%$ \\
\hline $0.1 \mathrm{M} \mathrm{NaCl}\left(28^{\circ} \mathrm{C}\right)$ & $6.56(0.43)$ & $4.27(0.53)$ & $3.67(0.27)$ & $2.55(0.09)$ \\
\hline Distilled Water $\left(25^{\circ} \mathrm{C}\right)$ & 7.36 & 4.01 & 2.76 & 0.61 \\
\hline
\end{tabular}

Note: Values in the brackets are standard deviations

Table XV. Equilibrium Moisture Contents in Alkaline and Saline Solutions

\begin{tabular}{|c|c|c|c|c|}
\hline & \multicolumn{4}{|c|}{ Equilibrium Moisture Content (\%) } \\
\hline Clay wt\% & $0 \mathrm{wt} \%$ & $1 \mathrm{wt} \%$ & $2 \mathrm{wt} \%$ & $5 \mathrm{wt} \%$ \\
\hline $13 \mathrm{pH} \mathrm{NaOH}\left(28^{\circ} \mathrm{C}\right)$ & $0.75^{*}$ & $0.70^{*}$ & $0.79^{*}$ & $1.00^{*}$ \\
\hline $0.1 \mathrm{M} \mathrm{NaCl}\left(28^{\circ} \mathrm{C}\right)$ & $0.68(0.05)$ & $0.88(0.02)$ & $0.95(0.02)$ & $1.09(0.08)$ \\
\hline Distilled Water $\left(25^{\circ} \mathrm{C}\right)$ & 0.669 & 1.151 & 1.341 & 2.081 \\
\hline
\end{tabular}

Note: Values shown in the brackets are standard deviations

*Note: Moisture content values for samples immersed in $\mathrm{NaOH}$ solutions are approximate values before the polymer started being dissolved in solution.

It was not possible to accurately calculate the diffusion coefficients for the samples immersed in $\mathrm{NaOH}$ solution because the polymer reacted with $\mathrm{NaOH}$. However, it was assumed for the calculation purpose that the equilibrium moisture content of a sample immersed in $\mathrm{NaOH}$ solution is same as that of a sample immersed in $\mathrm{NaCl}$ solution at that temperature (appendix A.1.7.). The diffusivities of water molecules in nanocomposites at $28^{\circ} \mathrm{C}$ were estimated using the experimental data for initial few hours and the estimated equilibrium moisture contents. The results are shown in Table XVI. 
Table XVI. Estimated Diffusion Coefficients and Equilibrium Moisture Contents at $28^{\circ} \mathrm{C}$ for samples immersed in 13 pH NaOH solution

\begin{tabular}{|c|c|c|}
\hline $\begin{array}{l}\text { Wt\% Cloisite } \\
10 A^{\circledR}\end{array}$ & $\begin{array}{l}\mathrm{D} \times 10^{+9} \\
\left(\mathrm{~cm}^{2} / \mathrm{s}\right)\end{array}$ & $\begin{array}{c}\text { Estimated } \\
\text { Equilibrium Moisture } \\
\text { Content }\end{array}$ \\
\hline 0 & $4.93(2.64)$ & $0.683 \%$ \\
\hline 1 & $3.72(0.44)$ & $0.884 \%$ \\
\hline 2 & $2.62(0.63)$ & $0.947 \%$ \\
\hline 5 & $1.64(0.60)$ & $1.093 \%$ \\
\hline
\end{tabular}

Note: Values shown in the brackets are standard deviations

Figure 89 shows graphical representation of variation in diffusion coefficient with nanoclay loading levels for various environments where as, Figure 90 shows the variations in equilibrium moisture contents with nanoclay loading. Once again, the data points for diffusion experiments in distilled water are shown for comparison.

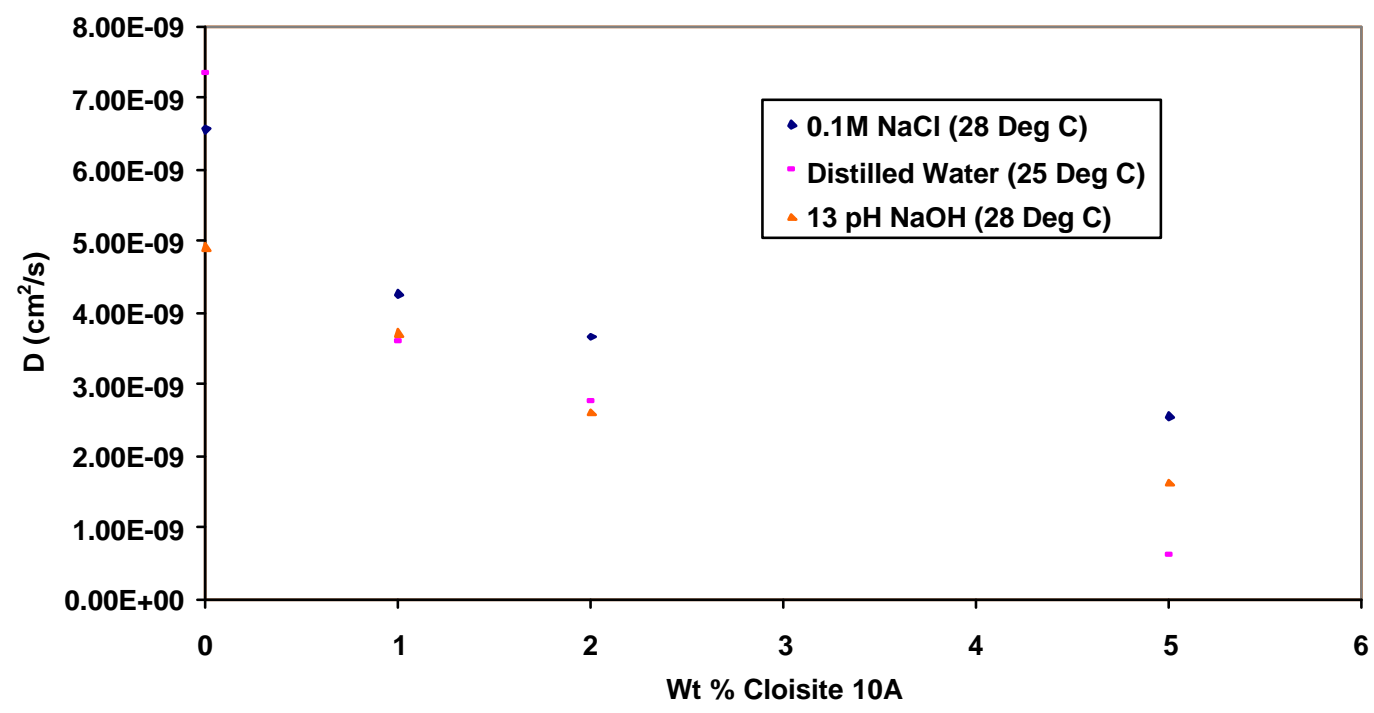

Figure 89. Variation in Diffusion coefficient with weight percent of Cloisite $10 \mathrm{~A}^{\circledR}$ 


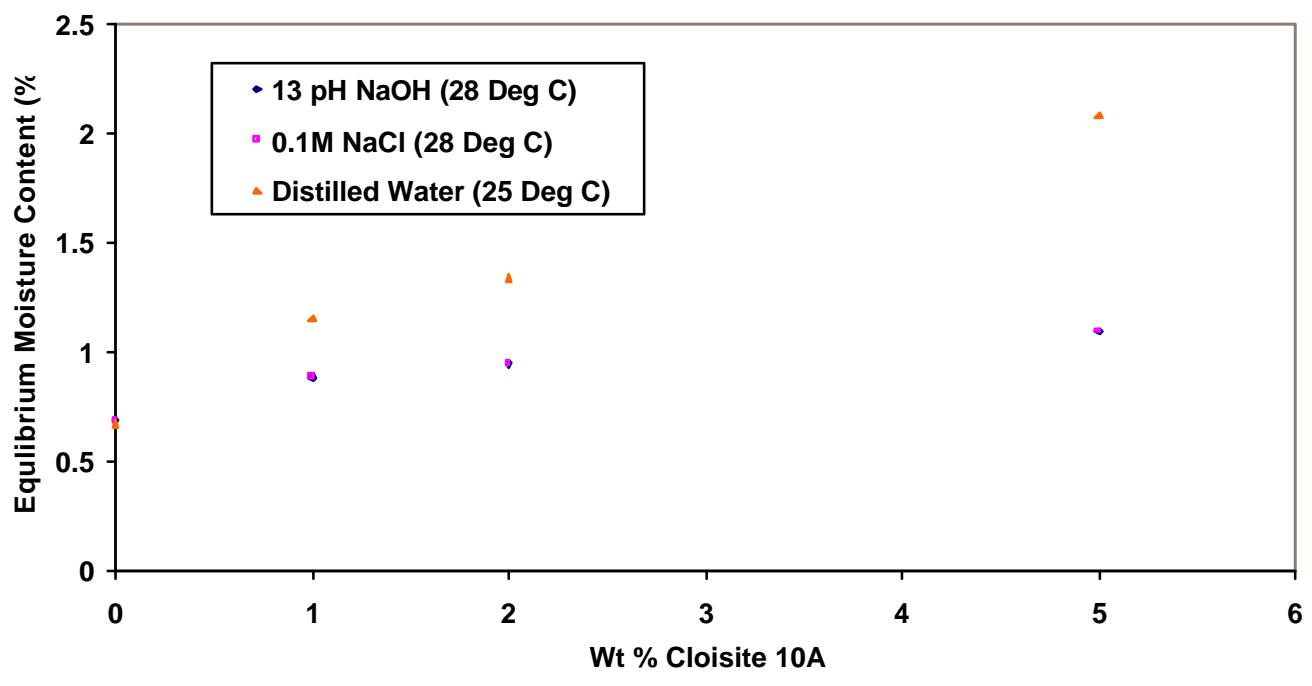

Figure 90. Variation in Equilibrium Moisture Content with weight percent of Cloisite $10 \mathrm{~A}^{\circledR}$

Note: It was assumed for calculation purpose that the equilibrium moisture content of a sample immersed in $\mathrm{NaOH}$ solution is same as that of a sample immersed in $\mathrm{NaCl}$ solution at that temperature.

It is clear from Figure 89 that the diffusion coefficient in $0.1 \mathrm{M} \mathrm{NaCl}$ solution decreased with increasing amount of clay in polymer. The trend was exactly similar to the trend observed in the diffusion experiments in distilled water at $28^{\circ} \mathrm{C}$. It can be inferred from Figure 90 that the equilibrium moisture content of the samples immersed in $0.1 \mathrm{M} \mathrm{NaCl}$ solutions is much lower than in the case of samples immersed in distilled water. This effect was more pronounced for nanocomposite samples. Two hypothesis were tested to explain this experimental fact:

Hypothesis 1: $\mathrm{Na}^{+}$competed with water molecules in occupying sites available on clay platelets

Verification Experiment 1: A 2 wt\% nanocomposite sample was saturated in $0.1 \mathrm{M} \mathrm{NaCl}$ solution at $25^{\circ} \mathrm{C}$ for 9 months. The sample showed equilibrium moisture content of $0.88 \%$. This is in close in agreement with the equilibrium moisture $(0.947 \%)$ of a similar type of sample immersed in $0.1 \mathrm{M} \mathrm{NaCl}$ solution at $28^{\circ} \mathrm{C}$. The difference 
could be attributed to the effect of temperature. If hypothesis 1 is true then the available sites on the clay platelets were partly occupied by $\mathrm{Na}^{+}$ions and partly occupied by water molecules. This sample was taken out of the $0.1 \mathrm{M} \mathrm{NaCl}$ solution, was wiped with lintfree tissue paper and was re-immersed in distilled water at the same temperature. The sample gained weight until a new equilibrium was established (see appendix A.2.). The new equilibrium moisture content of the sample was $1.39 \%$. This equilibrium moisture content was in agreement with that of similar samples immersed in distilled water at the same temperature (Table VII).

Verification experiment 1 meant that the additional water molecules entering into the sample were able to replace $\mathrm{Na}^{+}$(if at all $\mathrm{Na}^{+}$ions were there) from the surface of the platelets. This experimental observation negated hypothesis 1 and proved that $\mathrm{Na}^{+}$ions did not compete with water molecules to occupy available sites on the clay platelets. "Something Else" was the reason for the low equilibrium moisture contents of the samples immersed in $0.1 \mathrm{M} \mathrm{NaCl}$ solution.

Hypothesis 2: Lower chemical potential of water molecules in $\mathrm{NaCl}$ solution controlled the ingress of water into the samples.

Verification Experiment 2: A $5 \mathrm{wt} \%$ nanocomposite sample was immersed in distilled water at $25^{\circ} \mathrm{C}$ until it showed a moisture content of $1.8 \%$. The sample was, then, taken out and was re-immersed in $0.1 \mathrm{M} \mathrm{NaCl}$ solution. Earlier experiments showed that the equilibrium moisture content of similar samples immersed in $0.1 \mathrm{M} \mathrm{NaCl}$ solution at $28^{\circ} \mathrm{C}$ were $1.093 \%$. As expected, the samples used in verification experiment 2 showed 
weight loss until a new equilibrium was established. The sample retained $1.068 \%$ moisture at this new equilibrated condition (see appendix A.2.).

Verification experiment 2 proved that lower chemical potential of water molecules in $0.1 \mathrm{M} \mathrm{NaCl}$ controlled the process of diffusion. Since the sample was initially immersed in distilled water, water molecules inside the sample had nearly the same chemical potential as that of the distilled water molecules. When the same sample was re-immersed in $0.1 \mathrm{M} \mathrm{NaCl}$ solution, an osmosis effect was observed until the chemical potentials of water molecules inside and outside of the sample were equilibrated. This led to the conclusion that $\mathrm{NaCl}$ solution behaved as a regulatory device and controlled the amount of water molecules entering the sample. This was the reason why the presence of various amounts of clay had negligible effect on the equilibrium moisture content of the nanocomposite samples.

Transient diffusion experiments with FRP films containing various amounts of nanoclay were also performed in both $0.1 \mathrm{M} \mathrm{NaCl}$ solution and $0.1 \mathrm{M} \mathrm{NaOH}$ solution at $25^{\circ} \mathrm{C}$. The FRP samples were immersed in those solutions and weighed periodically as was done in all the transient experiments. A graph of $M_{t} / M_{\infty}$ versus $t^{1 / 2} / 2 l$ was plotted for all the samples that were immersed in $0.1 \mathrm{M} \mathrm{NaCl}$ solution. Figure 91 shows a plot of normalized mass uptake for FRP samples based on neat resin. 


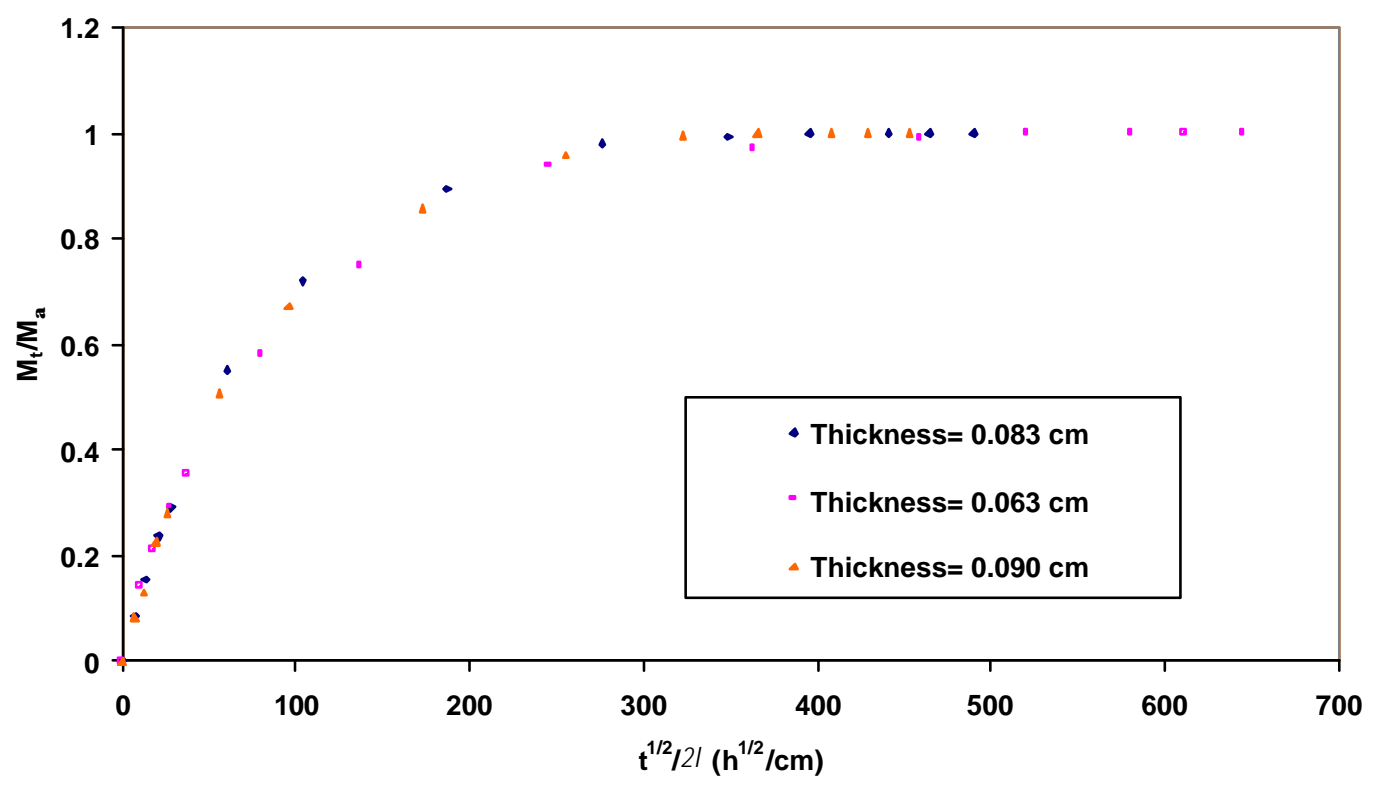

Figure 91. $M_{t} / M_{\infty}$ Versus $t^{1 / 2} / 2 l$ for FRP samples containing 0 wt $\%$ Cloisite $10 A^{\circledR}$ immersed in $0.1 M$ NaCl solution at $25^{\circ} \mathrm{C}$

The diffusivities and equilibrium moisture contents calculated from the asobtained experimental data are shown in the Tables XVII and XVIII.

Table XVII. Diffusion coefficients in $0.1 \mathrm{M} \mathrm{NaCl}$ solution

\begin{tabular}{|c|c|c|c|c|}
\hline & \multicolumn{4}{|c|}{$\mathrm{D} \times 10^{+9}\left(\mathrm{~cm}^{2} / \mathrm{s}\right)$} \\
\hline Clay wt\% & $0 \mathrm{wt} \%$ & $1 \mathrm{wt} \%$ & $2 \mathrm{wt} \%$ & $5 \mathrm{wt} \%$ \\
\hline FRP $\left(25^{\circ} \mathrm{C}\right)$ & $6.21(0.41)$ & $5.11(0.53)$ & $6.17(0.24)$ & $4.86(0.33)$ \\
\hline
\end{tabular}

Note: Values shown in the brackets are standard deviations

Table XVIII. Un-corrected equilibrium moisture contents in $0.1 \mathrm{M}$ NaCl solution

\begin{tabular}{|c|c|c|c|c|}
\hline & \multicolumn{4}{|c|}{ Equilibrium Moisture Content (\%) } \\
\hline Clay wt\% & $0 \mathrm{wt} \%$ & $1 \mathrm{wt} \%$ & $2 \mathrm{wt} \%$ & $5 \mathrm{wt} \%$ \\
\hline FRP $\left(25^{\circ} \mathrm{C}\right)(\mathrm{Un}$-corrected $)$ & $0.50(0.04)$ & $0.430(0.09)$ & $0.466(0.08)$ & $0.67(0.01)$ \\
\hline Un-reinforced $\left(28^{\circ} \mathrm{C}\right)$ & 0.68 & 0.88 & 0.95 & 1.09 \\
\hline
\end{tabular}

Note: Values shown in the brackets are standard deviations 
It can be seen from Table XVIII that un-corrected equilibrium moisture contents of FRP samples are much lower than the corresponding un-reinforced samples. In order to estimate the amount of moisture within the resin, the experimental readings were corrected for the weight of the glass-fibers in the samples (appendix A.1.4.). The corrected weight gain data showed the weight gain curves for the resin-clay mixture. A graph of corrected $M_{t} / M_{\infty}$ versus $t^{1 / 2} / 2 l$ was plotted for all the samples that were immersed in $0.1 \mathrm{M} \mathrm{NaCl}$ solution. These plots are shown in Figures 92 to 95.

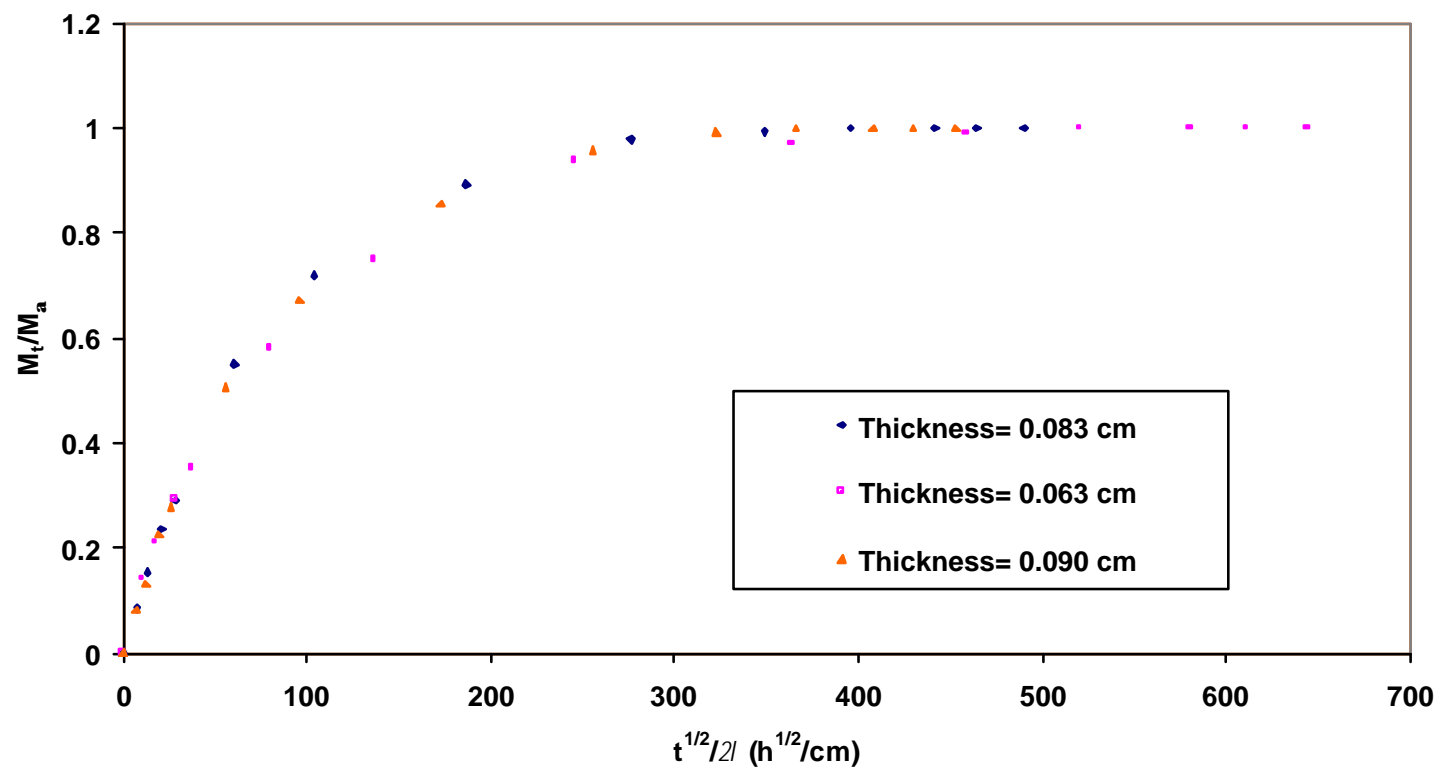

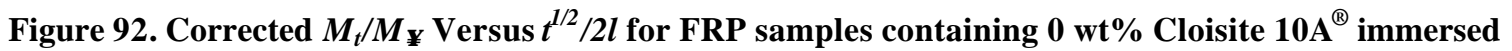
in $0.1 \mathrm{M} \mathrm{NaCl}$ solution at $25^{\circ} \mathrm{C}$ 


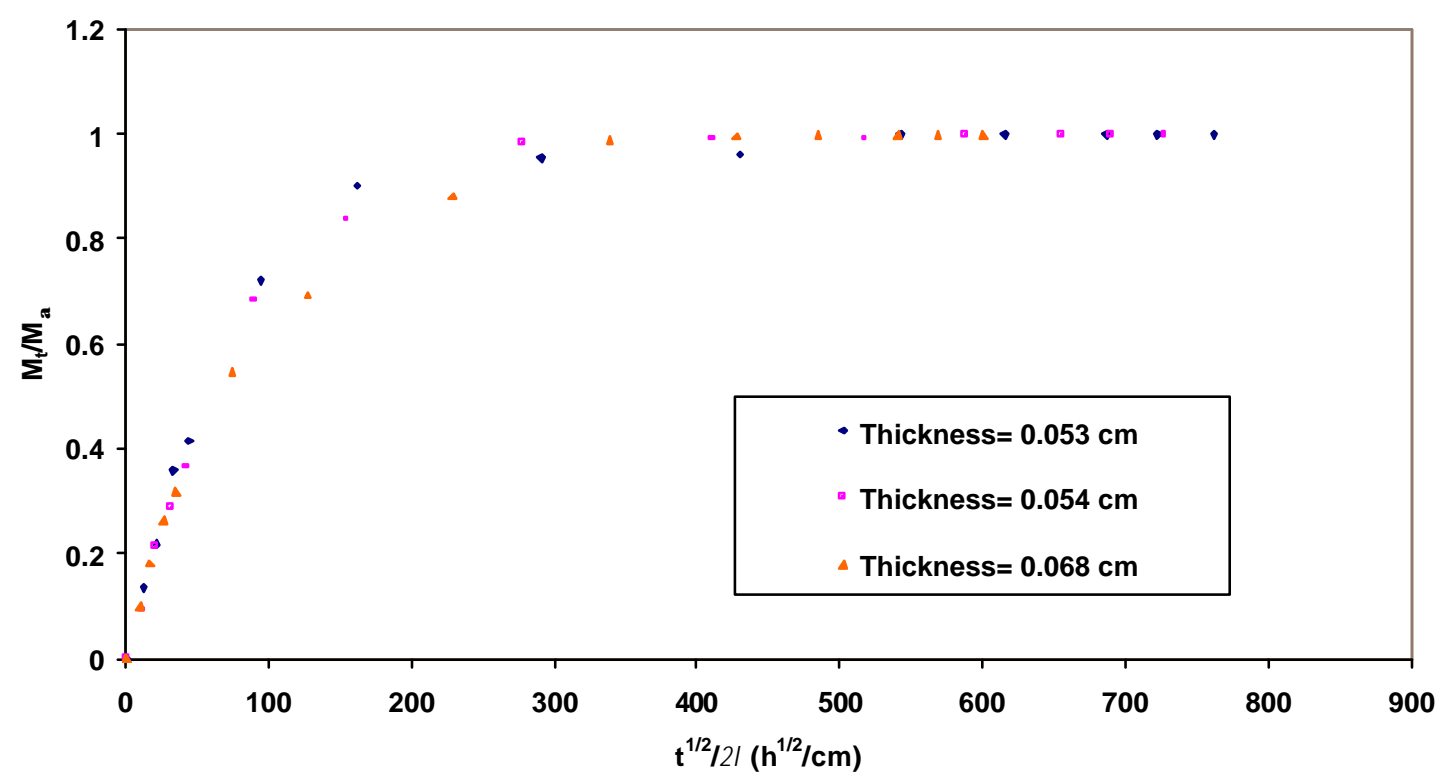

Figure 93. $M_{t} / M_{\infty}$ Versus $t^{1 / 2} / 2 l$ for FRP samples containing $1 \mathrm{wt} \%$ Cloisite $10 \mathrm{~A}^{\circledR}$ immersed in $0.1 \mathrm{M}$ $\mathrm{NaCl}$ solution at $25^{\circ} \mathrm{C}$

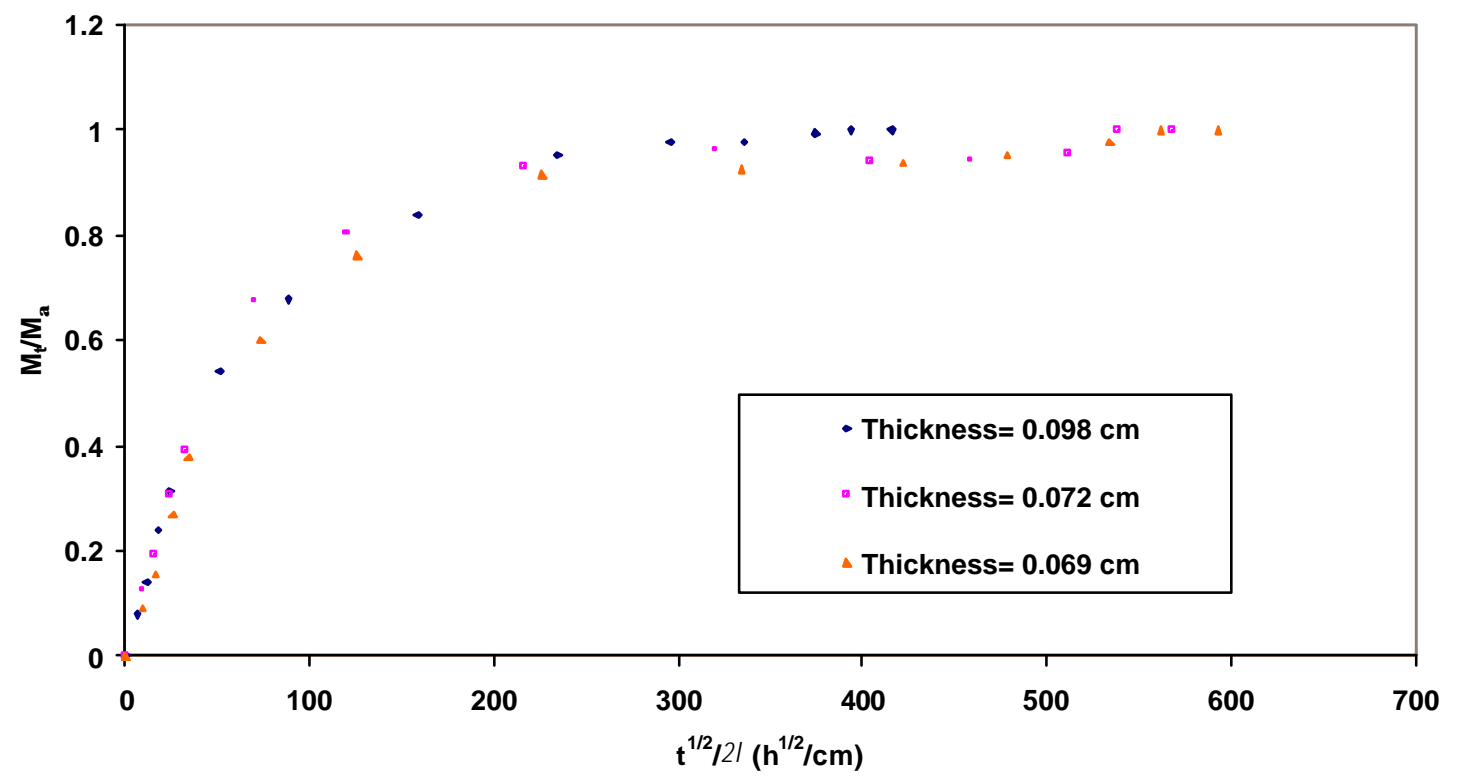

Figure 94. $M_{t} / M_{\infty}$ Versus $t^{1 / 2} / 2 l$ for FRP samples containing $2 \mathrm{wt} \%$ Cloisite $10 \mathrm{~A}^{\circledR}$ immersed in $0.1 \mathrm{M}$ $\mathrm{NaCl}$ solution at $25^{\circ} \mathrm{C}$ 


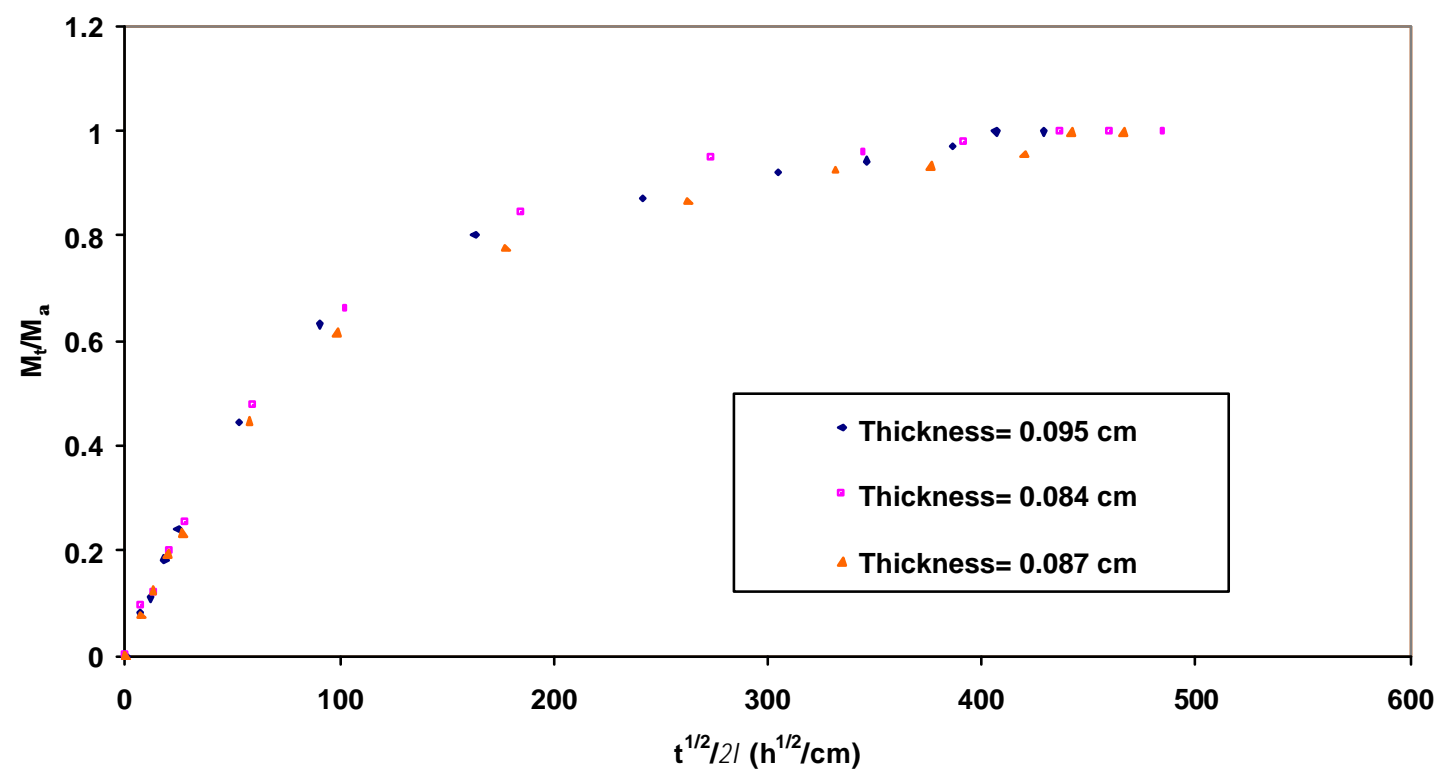

Figure 95. $M_{t} / M_{\infty}$ Versus $t^{1 / 2} / 2 l$ for FRP samples containing $5 \mathrm{wt} \%$ Cloisite $10 \mathrm{~A}^{\circledR}$ immersed in $0.1 \mathrm{M}$ $\mathrm{NaCl}$ solution at $25^{\circ} \mathrm{C}$

From Figures 92 to 95, it is clear that the process of calculating correction factor for the weight of the glass was reasonably accurate. Diffusivities were calculated using the initial slopes of these curves, according to the method explained in section 2.1. Table XIX shows diffusivity of FRP samples containing various amounts of clay immersed in $0.1 \mathrm{M} \mathrm{NaCl}$ solution at $25^{\circ} \mathrm{C}$. Diffusivities of un-reinforced samples are shown for the purpose of comparison. It can be inferred from the comparison of Tables XVII and XIX that the diffusivity values for FRPs remained unaffected when the experimental data were corrected for the weight of the glass-fibers. Corrected equilibrium moisture values are shown in Table XX. 
Table XIX. Diffusion coefficients in $0.1 \mathrm{M} \mathrm{NaCl}$ solution

\begin{tabular}{|c|c|c|c|c|}
\hline & \multicolumn{4}{|c|}{$\mathrm{D} \times 10^{+9}\left(\mathrm{~cm}^{2} / \mathrm{s}\right)$} \\
\hline Clay wt\% & $0 \mathrm{wt} \%$ & $1 \mathrm{wt} \%$ & $2 \mathrm{wt} \%$ & $5 \mathrm{wt} \%$ \\
\hline FRP $\left(25^{\circ} \mathrm{C}\right)$ & $6.21(0.41)$ & $5.11(0.53)$ & $6.17(0.24)$ & $4.86(0.33)$ \\
\hline Un-reinforced $\left(28^{\circ} \mathrm{C}\right)$ & 6.56 & 4.27 & 3.67 & 2.55 \\
\hline
\end{tabular}

Note: Values shown in the brackets are standard deviations

Table XX. Corrected equilibrium moisture contents in $0.1 \mathrm{M} \mathrm{NaCl}$ solution

\begin{tabular}{|c|c|c|c|c|}
\hline & \multicolumn{4}{|c|}{ Equilibrium Moisture Content (\%) } \\
\hline Clay wt\% & $0 \mathrm{wt} \%$ & $1 \mathrm{wt} \%$ & $2 \mathrm{wt} \%$ & $5 \mathrm{wt} \%$ \\
\hline FRP $\left(25^{\circ} \mathrm{C}\right)($ Corrected $)$ & $1.21(0.19)$ & $1.20(0.34)$ & $1.27(0.06)$ & $1.45(0.22)$ \\
\hline Un-reinforced $\left(28^{\circ} \mathrm{C}\right)$ & 0.68 & 0.88 & 0.95 & 1.09 \\
\hline
\end{tabular}

Note: Values shown in the brackets are standard deviations

As expected, the diffusivities of the FRP samples were higher than the corresponding un-reinforced nanocomposite samples as seen from Table XIX. These apparent differences were expected because of the probable inaccuracies involved in approximation of the weight of the glass-fibers. No correction factors were applied for the thickness of the fiber-mat in the FRP samples. As explained in section 6.4, the thickness correction could have affected the diffusion coefficient values of FRP samples. Nevertheless, trend of decreasing diffusion coefficient with increasing clay loading was apparent. There were obvious differences in the equilibrium moisture contents of FRP samples and corresponding un-reinforced nanocomposite samples (Table XX). The higher moisture contents of the FRP could be explained by the chemistry of sizing material.

Although Si has equal affinity for both $-\mathrm{OH}$ groups and $\mathrm{CI}$ ions, it seemed that in this case $\mathrm{Si}$ preferred $\mathrm{CI}^{-}$to $-\mathrm{OH}$ groups. Had $\mathrm{NaF}$ salt been used in this study instead of $\mathrm{NaCl}$ it could be said conclusively that $\mathrm{Si}$ preferred $\mathrm{F}^{-}$to $-\mathrm{OH}$ groups. 


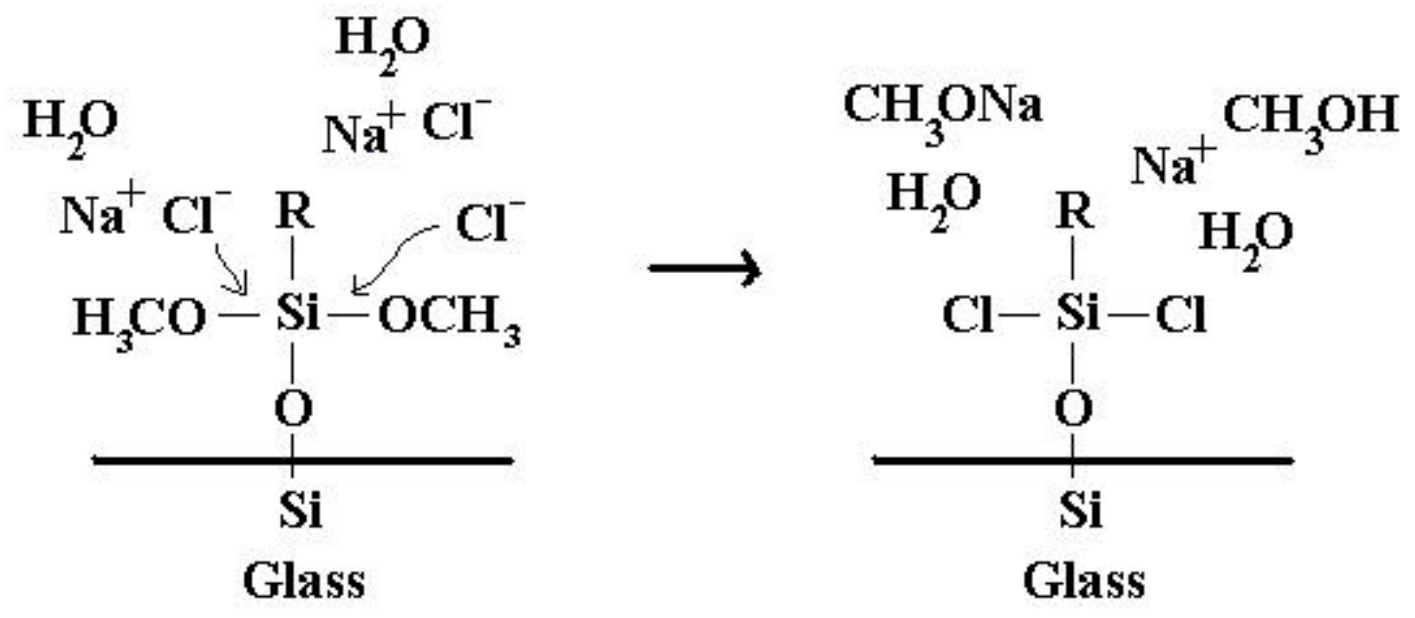

Figure 96. Chemistry between Silane and $\mathrm{Cl}^{-}$ions

As seen from Figure 96, CI ions got attached to the $\mathrm{Si}$ of silane. The unstable product $\mathrm{CH}_{3} \mathrm{ONa}$ was immediately converted to $\mathrm{CH}_{3} \mathrm{OH}$. Some water molecules formed hydrogen- bonds with these alcohol molecules. This might be the reason for the increase in the moisture content of FRP samples. Water molecules in the vicinity of the silane were not able to attack the strong $\mathrm{SiO}-\mathrm{Si}$ bond because the bond was shielded by the large size of $-\mathrm{Cl}$ groups. No voids were formed between the fiber and the matrix and no abnormal moisture uptake was recorded as was recorded in the transient diffusion experiments with FRPs in the distilled water at the same temperature.

Transient diffusion experiments in $13 \mathrm{pH} \mathrm{NaOH}$ solution were also conducted at $25^{\circ} \mathrm{C}$ on FRP samples containing various amounts of nanoclay. As expected, vinyl ester reacted with $\mathrm{NaOH}$ and formed a white powder-like substance. No obvious trend was seen in the experimental data. Figure 97 to 100 show the plots of percentage weight gain versus $t^{1 / 2}$. No correction factors were applied to the experimental data for the weight of the glass. 


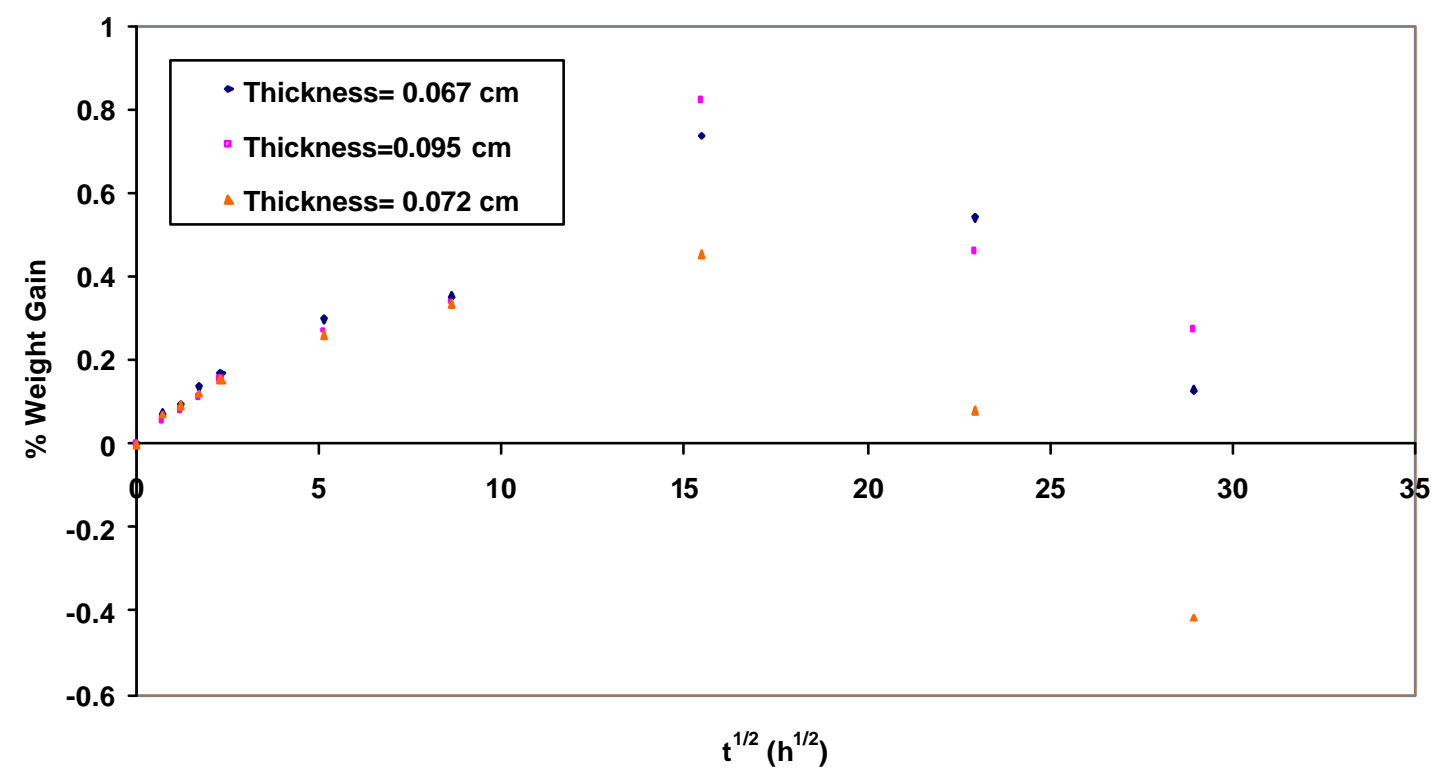

Figure 97. Percentage weight gain versus $t^{1 / 2}$ for FRP samples containing $0 \mathrm{wt} \%$ Cloisite $10 \mathrm{~A}^{\circledR}$ immersed in $13 \mathrm{pH} \mathrm{NaOH}$ solution at $25^{\circ} \mathrm{C}$

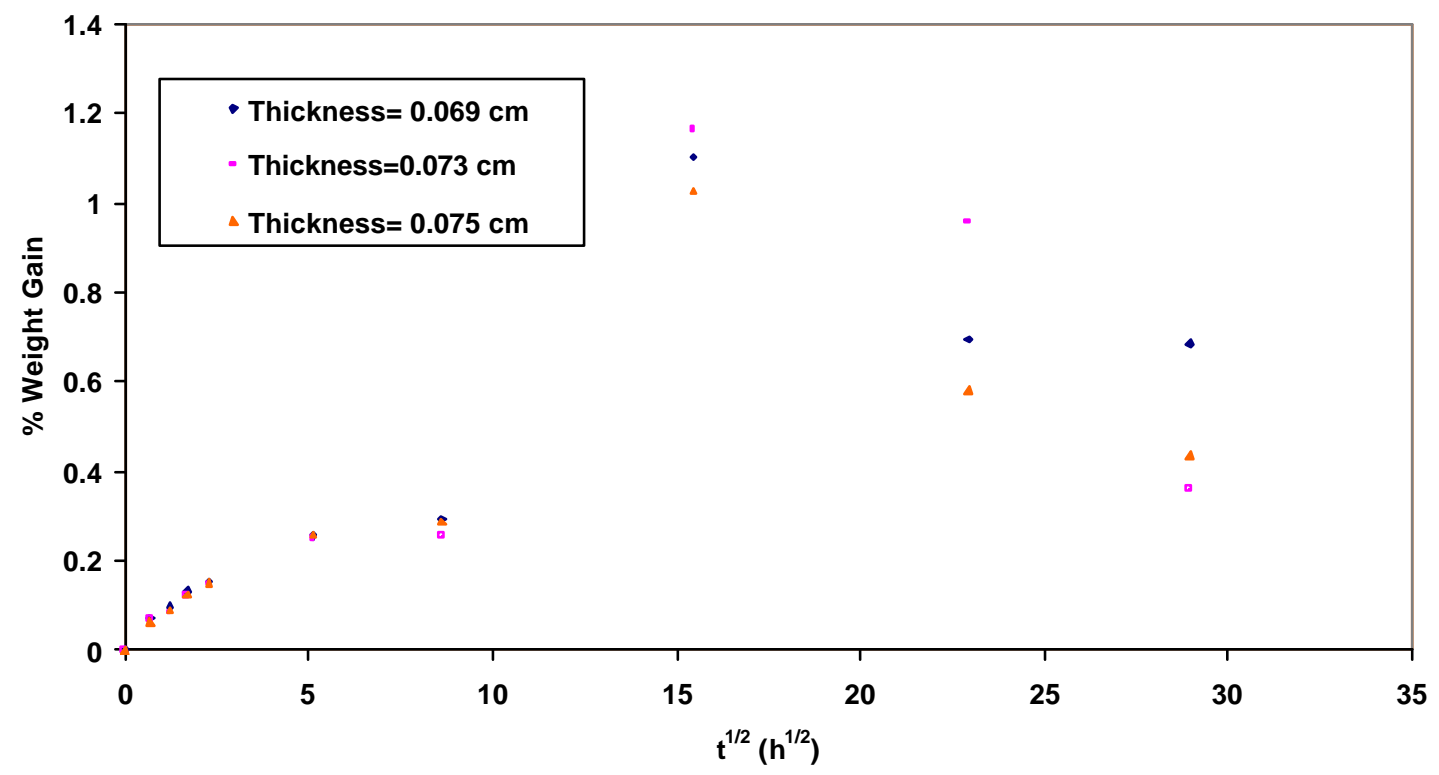

Figure 98. Percentage weight gain versus $t^{1 / 2}$ for FRP samples containing $1 \mathrm{wt} \%$ Cloisite $10 \mathrm{~A}^{\circledR}$ immersed in $13 \mathrm{pH} \mathrm{NaOH}$ solution at $25^{\circ} \mathrm{C}$ 


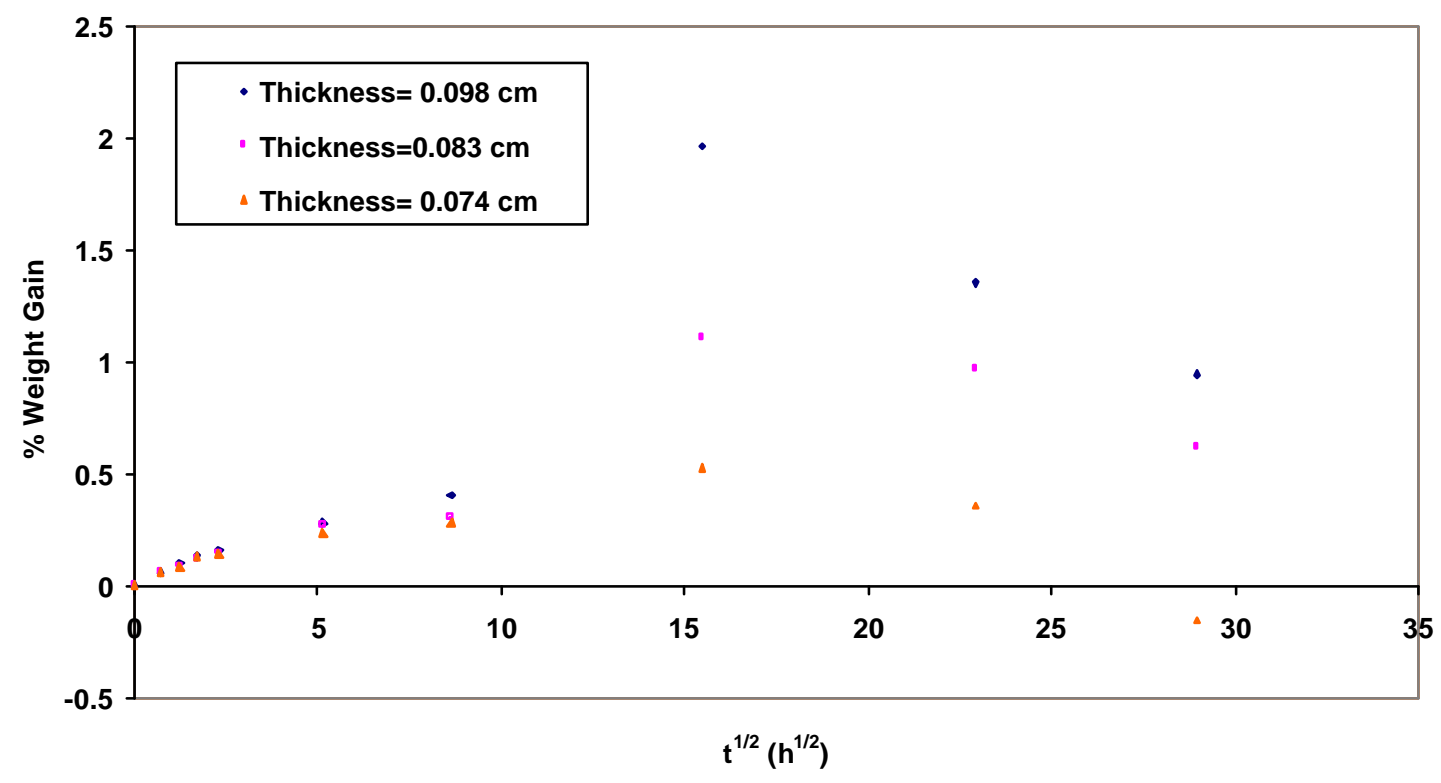

Figure 99. Percentage weight gain versus $t^{1 / 2}$ for FRP samples containing $2 \mathrm{wt} \%$ Cloisite $10 A^{\circledR}$ immersed in $13 \mathrm{pH} \mathrm{NaOH}$ solution at $25^{\circ} \mathrm{C}$

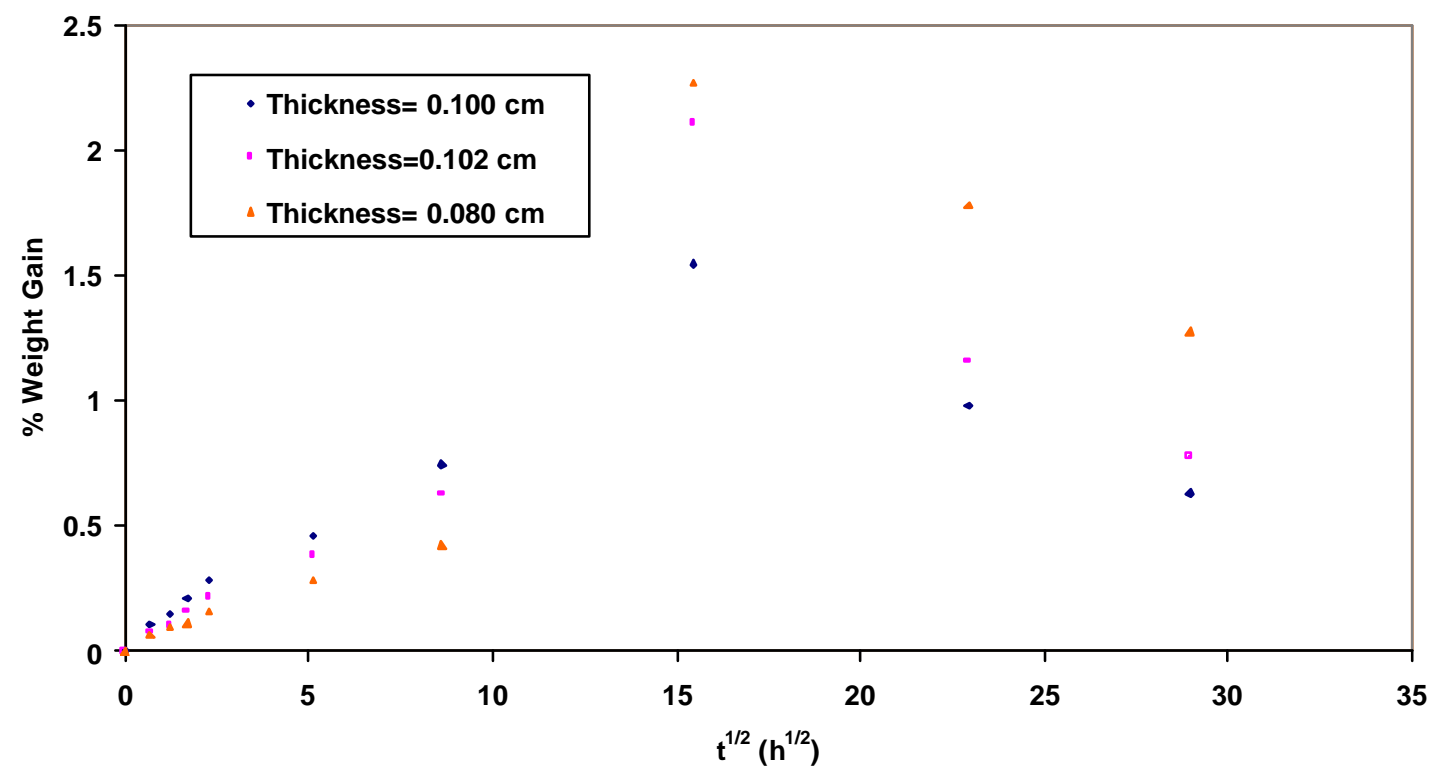

Figure 100. Percentage weight gain versus $t^{1 / 2}$ for FRP samples containing 5 wt $\%$ Cloisite $10 A^{\circledR}$ immersed in $13 \mathrm{pH} \mathrm{NaOH}$ solution at $25^{\circ} \mathrm{C}$ 
It is clear from Figures 97 to 100 that the $\mathrm{NaOH}$ reacted with vinyl ester at $25^{\circ} \mathrm{C}$. The sudden increase in \%weight gain between 100 and 225 hours suggested that sodium hydoroxide might have also interacted with the sizing material of the glass-fibers. It was not possible to accurately calculate the diffusivities from the experimental data. However, it is speculated that the diffusivity values in this case should be similar to those reported for the corresponding un-reinforced samples. The diffusivities for the un-reinforced samples can be found in Table XVI.

\subsection{Transient Diffusion Experiments in Alkaline and Saline solutions at $42.5^{\circ} \mathrm{C}$}

A $0.1 \mathrm{M} \mathrm{NaCl}$ solution was prepared by dissolving solid $\mathrm{NaCl}$ in distilled water; the $\mathrm{pH}$ of the resulting salt solution was 7.0. $\mathrm{NaOH}$ solution having a $\mathrm{pH}$ of 13 was also prepared by dissolving the appropriate amount of solid $\mathrm{NaOH}$ in distilled water. Polymer samples containing $0 \mathrm{wt} \%, 1 \mathrm{wt} \%, 2 \mathrm{wt} \%$, and $5 \mathrm{wt} \%$ of Cloisite $10 \mathrm{~A}^{\circledR}$ nanoclay were immersed in separate beakers containing these alkaline and saline solutions. The beakers were closed at the top using aluminum foils and were kept in a Fisher Scientific Isotemp ${ }^{\circledR}$ 500 Series oven. The control knob of oven was set in such a way that the temperature of the solutions remained at $42.5^{\circ} \mathrm{C}$ throughout the experiment. Periodic weight gains of the samples were noted. Results for some of the samples immersed in $\mathrm{NaCl}$ solution are shown in Figures 101 to 104. Similarly, preliminary results for samples immersed in $\mathrm{NaOH}$ solution are shown in Figure 105 to 108 . Once again, $M_{\infty}$ values are not known; therefore, percentage weight gains were plotted against $t^{1 / 2}$. 


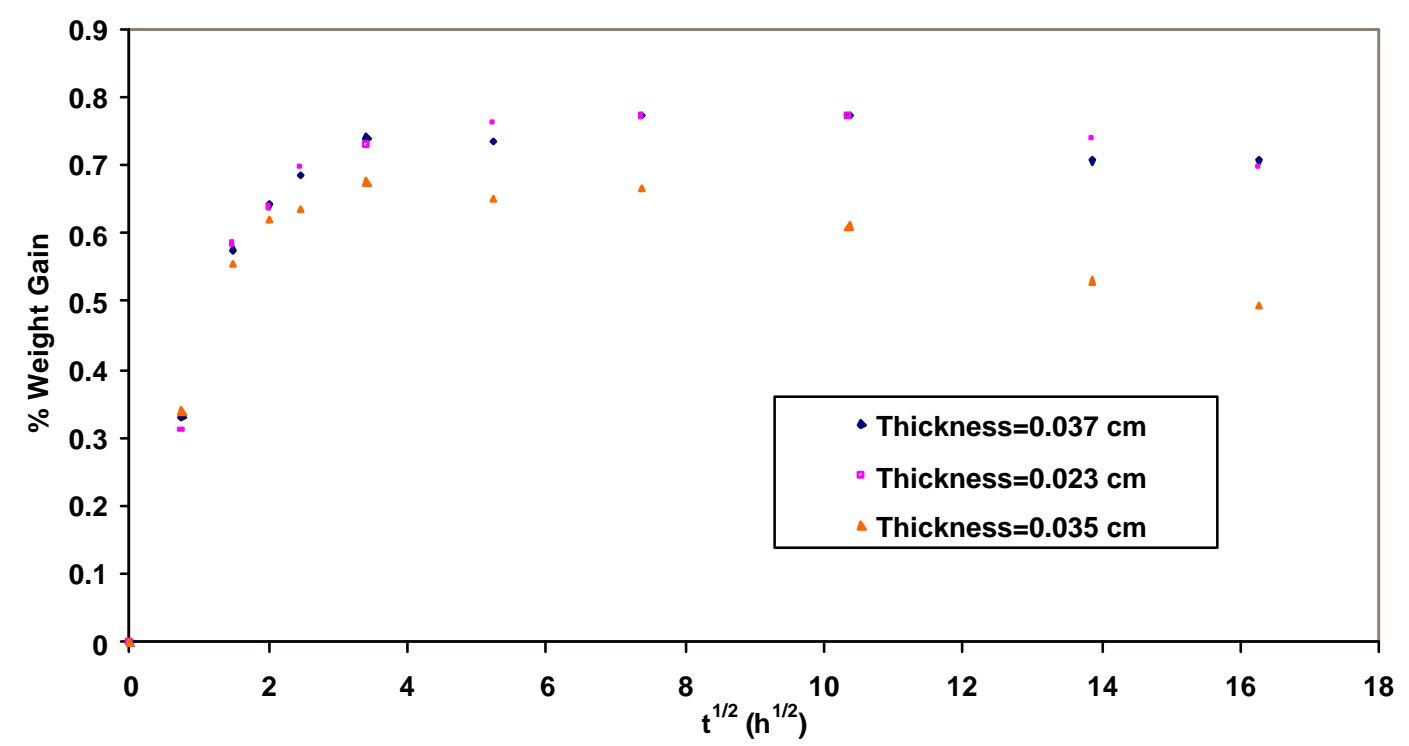

Figure 101. Percentage weight gain versus $t^{1 / 2}$ for samples containing $0 \mathrm{wt} \%$ Cloisite $10 \mathrm{~A}^{\circledR}$ immersed in $0.1 \mathrm{M} \mathrm{NaCl}$ solution at $42.5^{\circ} \mathrm{C}$

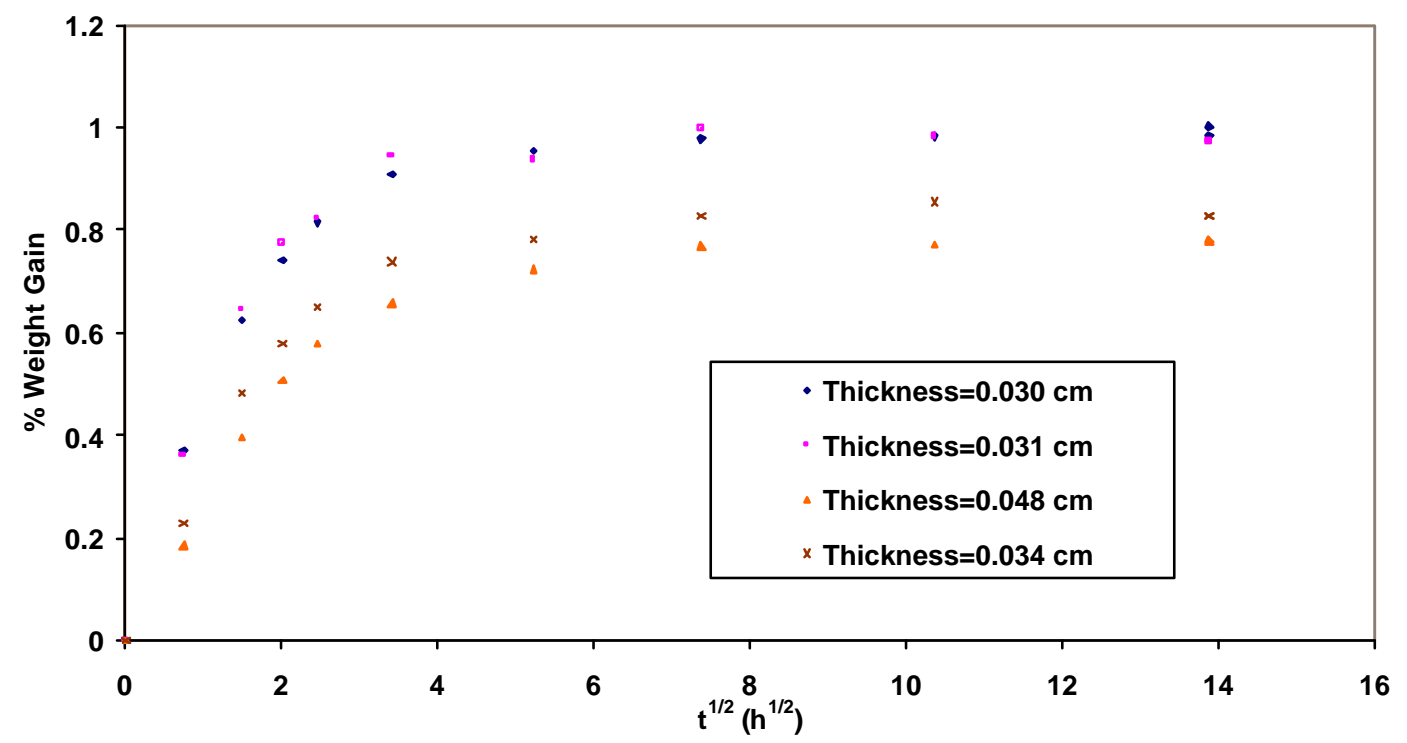

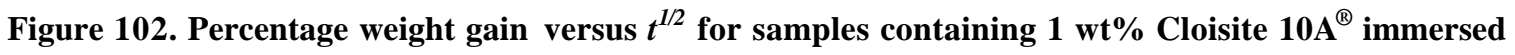
in $0.1 \mathrm{M} \mathrm{NaCl}$ solution at $42.5^{\circ} \mathrm{C}$ 


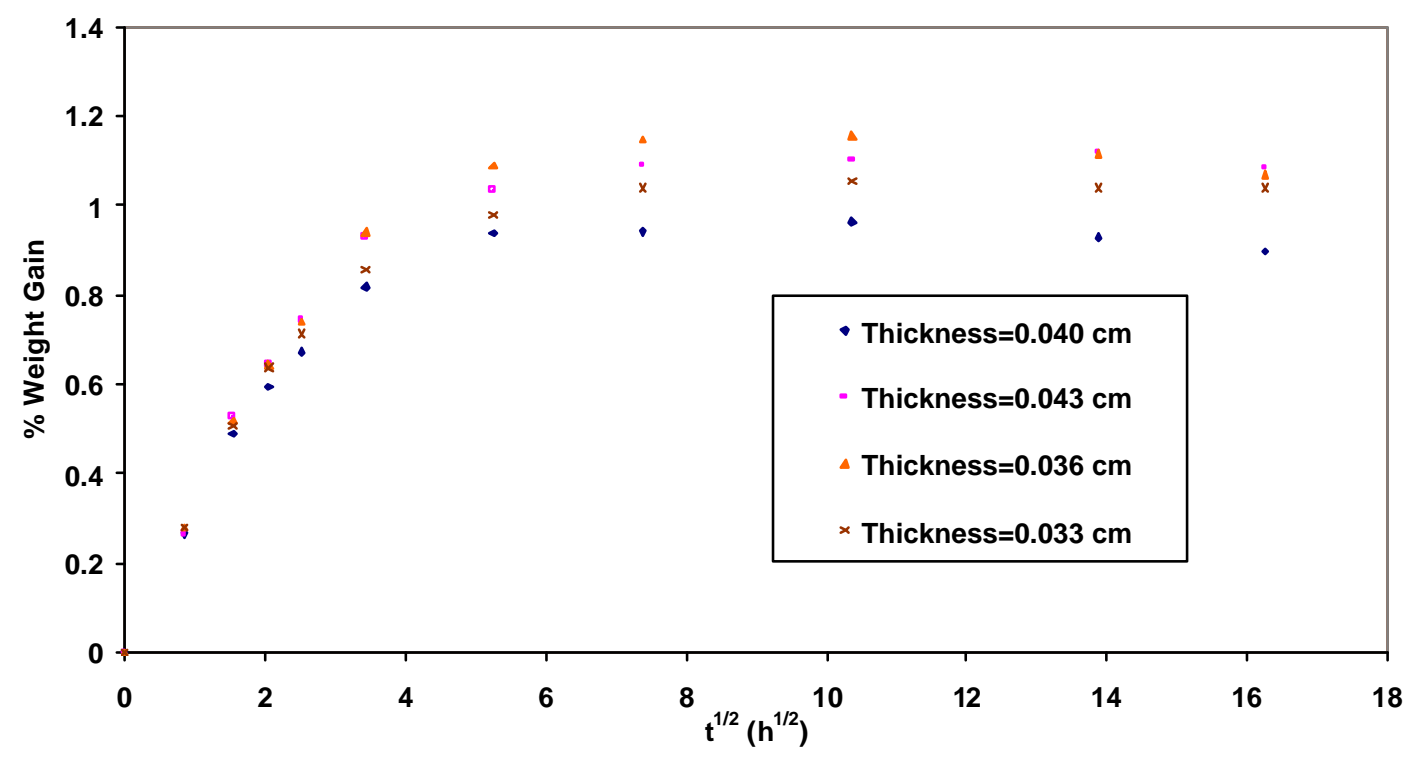

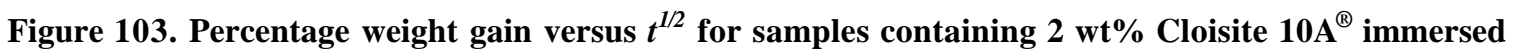
in $0.1 \mathrm{MNaCl}$ solution at $42.5^{\circ} \mathrm{C}$

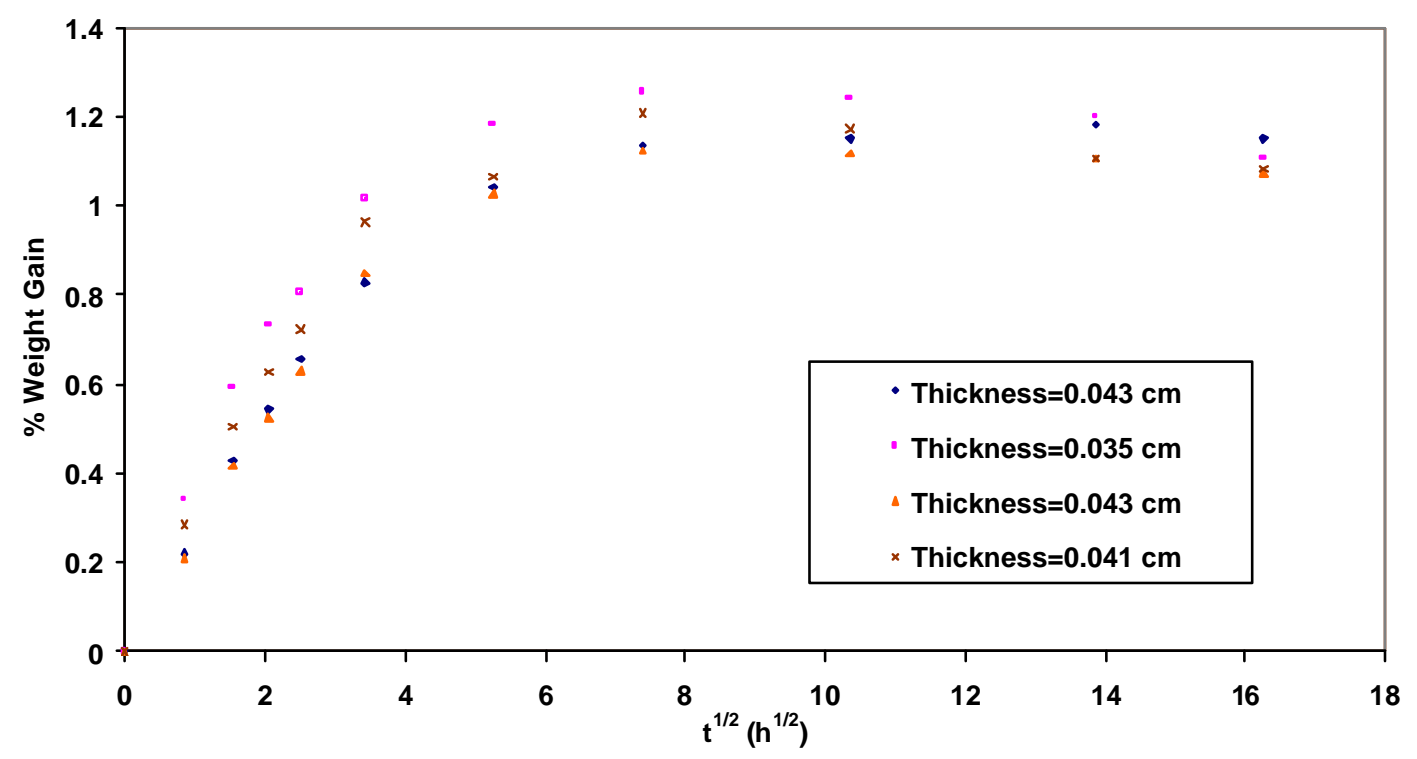

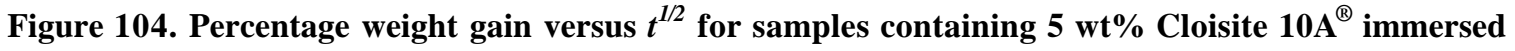
in $0.1 \mathrm{M} \mathrm{NaCl}$ solution at $42.5^{\circ} \mathrm{C}$ 
It is evident from Figures 101 to 104 that the samples immersed in $0.1 \mathrm{M} \mathrm{NaCl}$ solutions at $42.5^{\circ} \mathrm{C}$ showed weight loss after 6-8 days of immersion. Table XXI shows the approximate value of the moisture content before the samples started losing weight. It is interesting to note that the moisture content for neat samples immersed in distilled water was nearly $1.3 \%$ after 200 hours of immersion period but the same type of samples show moisture content of only $0.757 \%$ after same length of immersion in $0.1 \mathrm{M} \mathrm{NaCl}$ solution. This trend was seen at all clay loading levels. These results supported the hypothesis that the lower chemical potential of water molecules in $\mathrm{NaCl}$ solution controlled the diffusion process.

Table XXI. Moisture content of samples before they started being dissolve d in $0.1 \mathrm{M} \mathrm{NaCl}$ at $42.5^{\circ} \mathrm{C}$

\begin{tabular}{|l|l|l|l|l|}
\hline Sample & $0 \mathrm{wt} \%$ & $1 \mathrm{wt} \%$ & $2 \mathrm{wt} \%$ & $5 \mathrm{wt} \%$ \\
\hline Moisture content (\%) & $0.76(0.05)$ & $0.91(0.10)$ & $1.07(0.08)$ & $1.19(0.05)$ \\
\hline
\end{tabular}

Note: Values shown in the brackets are standard deviations

Note: Moisture content values for samples immersed in $\mathrm{NaCl}$ solution at $42.5^{\circ} \mathrm{C}$ are approximate values before the polymer started being dissolved in solution.

It was not possible to accurately calculate the diffusion coefficients for this case because the samples did not reach equilibrium. However, the equilibrium moisture contents were estimated using the available experimental data at $25^{\circ} \mathrm{C}$ and $4{ }^{\circ} \mathrm{C}$ (Appendix A.1.7.). The diffusivities of water molecules in nanocomposites at $42.5^{\circ} \mathrm{C}$ were estimated using the experimental data for initial few hours and the estimated equilibrium moisture contents. The results are shown in Table XXII. 
Table XXII. Estimated Diffusion Coefficients and Equilibrium Moisture Contents at $42.5^{\circ} \mathrm{C}$ for the samples immersed in $0.1 \mathrm{M} \mathrm{NaCl}$ solution

\begin{tabular}{|c|c|c|}
\hline Wt\% Cloisite $10 \mathrm{~A}^{\circledR}$ & $\begin{array}{c}\mathrm{D} \times 10^{+9} \\
\left(\mathrm{~cm}^{2} / \mathrm{s}\right)\end{array}$ & $\begin{array}{c}\text { Equilibrium Moisture } \\
\text { Content }\end{array}$ \\
\hline 0 & $19.30(1.81)$ & $0.75 \%$ \\
\hline 1 & $8.41(1.61)$ & $1.02 \%$ \\
\hline 2 & $5.54(0.71)$ & $1.16 \%$ \\
\hline 5 & $3.90(0.45)$ & $1.38 \%$ \\
\hline
\end{tabular}

All the samples immersed in $\mathrm{NaOH}$ solution having a $\mathrm{pH}$ of 13 at $42.5^{\circ} \mathrm{C}$ started to dissolve within the first 24 hours of immersion. Weight change curves for all types of samples are shown in Figures 105 to 108.

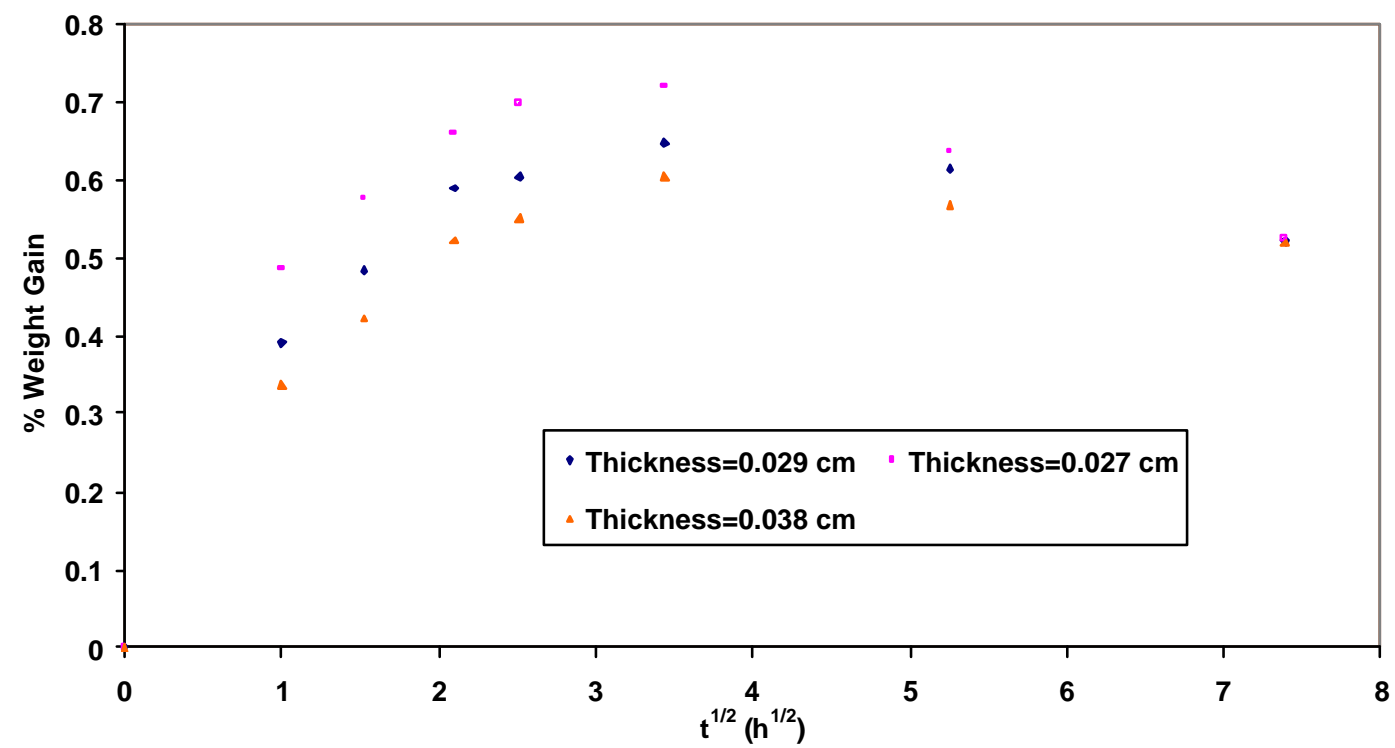

Figure 105. Percentage weight gain versus $t^{1 / 2}$ for samples containing $0 \mathrm{wt} \%$ Cloisite $10 \mathrm{~A}^{\circledR}$ immersed in $\mathrm{NaOH}$ solution having a $\mathrm{pH}$ of 13 at $42.5^{\circ} \mathrm{C}$ 


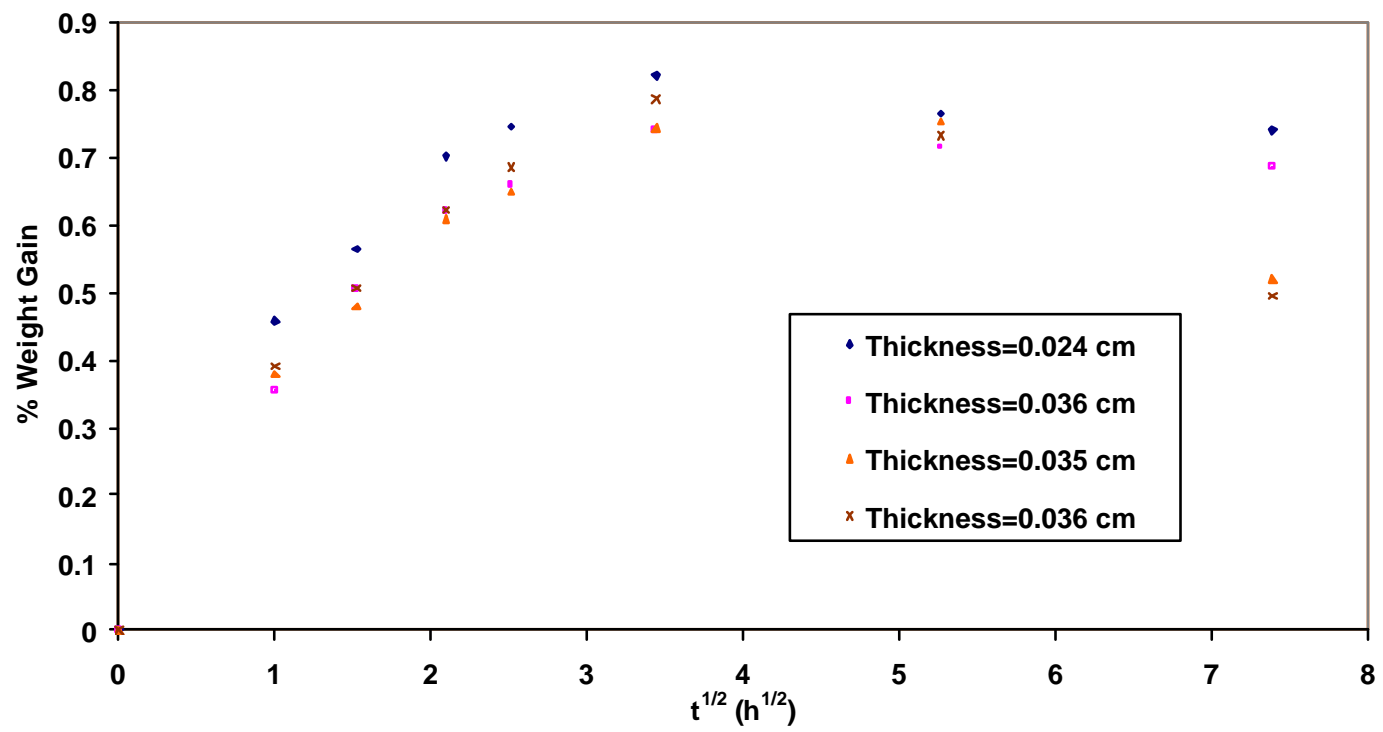

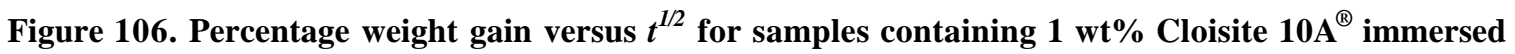
in $\mathrm{NaOH}$ solution having a $\mathrm{pH}$ of 13 at $42.5^{\circ} \mathrm{C}$

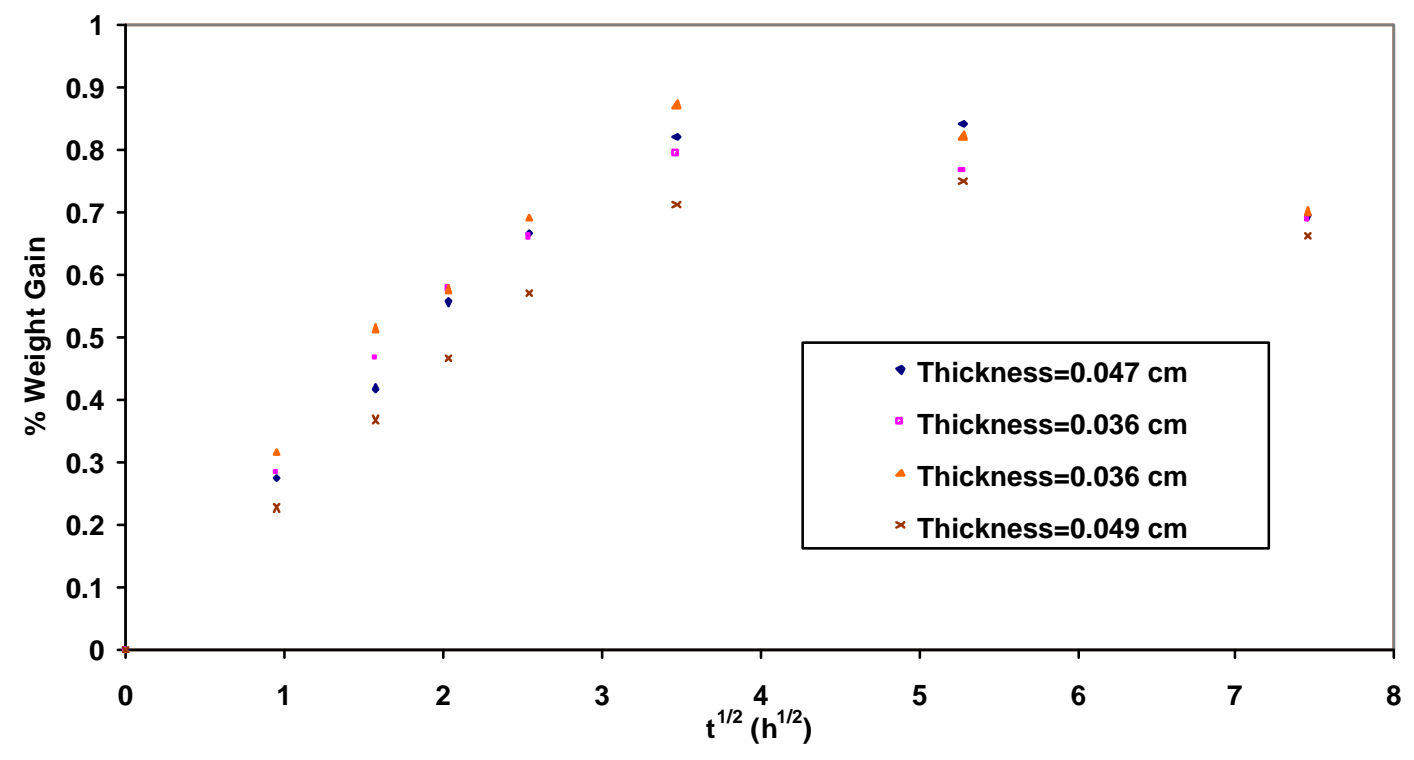

Figure 107. Percentage weight gain versus $t^{1 / 2}$ for samples containing $2 \mathrm{wt}^{\%} \mathrm{Cloisite}_{10 \mathrm{~A}}{ }^{\circledR}$ immersed in $\mathrm{NaOH}$ solution having a $\mathrm{pH}$ of 13 at $42.5^{\circ} \mathrm{C}$ 


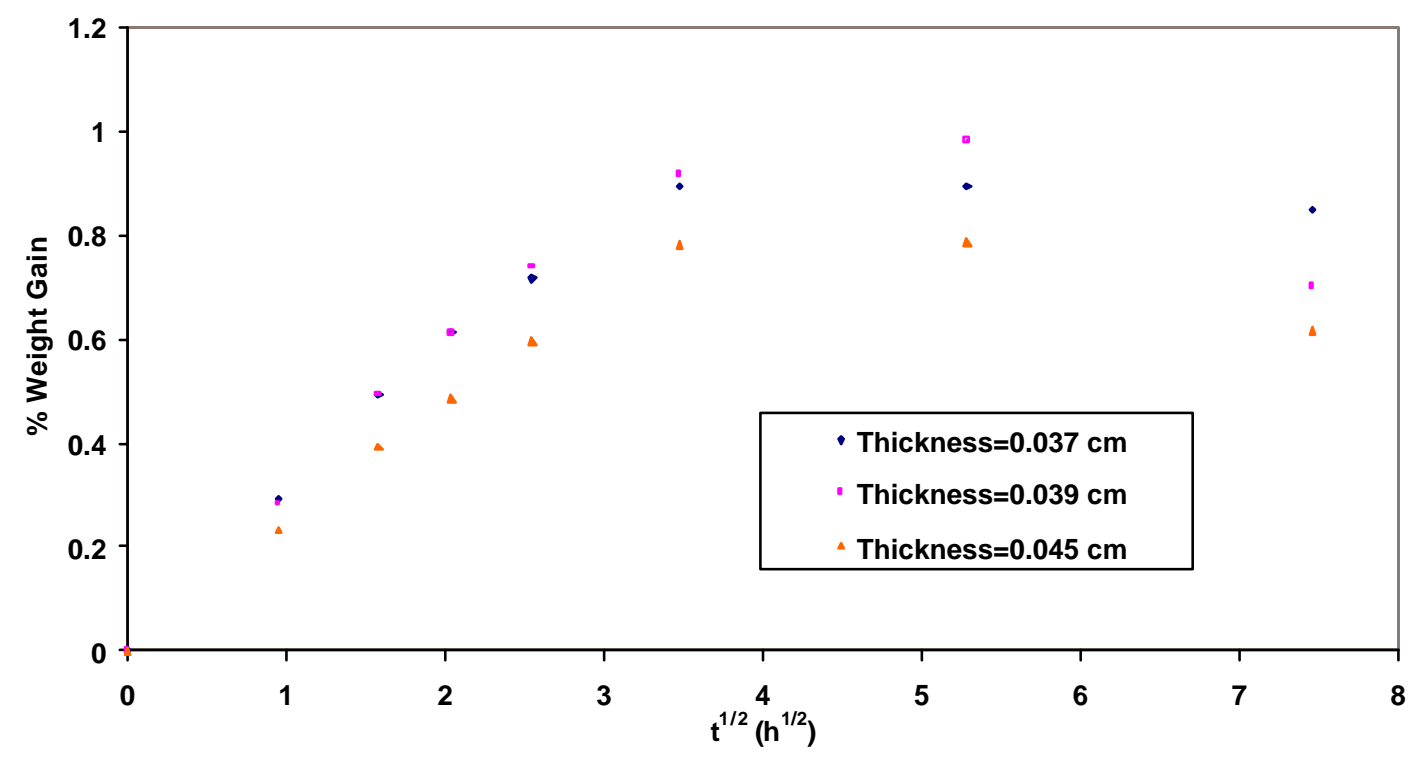

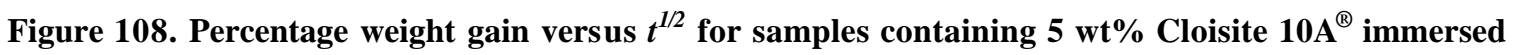
in $\mathrm{NaOH}$ solution having a pH of 13 at $42.5^{\circ} \mathrm{C}$

Approximate values of moisture content for various types of samples, before they started being dissolved, are shown in Table XXIII.

Table XXIII. Moisture content of samples at $42.5^{\circ} \mathrm{C}$ before they started being dissolved in $\mathrm{NaOH}$ solution having a $\mathrm{pH}$ of 13

\begin{tabular}{|l|l|l|l|l|}
\hline Sample & $0 \mathrm{wt} \%$ & $1 \mathrm{wt} \%$ & $2 \mathrm{wt} \%$ & $5 \mathrm{wt} \%$ \\
\hline Moisture content (\%) & $0.66(0.06)$ & $0.78(0.03)$ & $0.81(0.05)$ & $0.89(0.09)$ \\
\hline
\end{tabular}

Note: Values shown in the brackets are standard deviations

Note: Moisture content values at $42.5^{\circ} \mathrm{C}$ for samples immersed in $\mathrm{NaOH}$ solution having $\mathrm{pH}$ of 13 are approximate values before the polymer started being dissolved in solution.

It was not possible to accurately calculate the diffusion coefficients for this case because the samples did not reach equilibrium. However, the equilibrium moisture contents were estimated using the available experimental data for diffusion experiments in $\mathrm{NaCl}$ solution at $25^{\circ} \mathrm{C}$ and $4^{\circ} \mathrm{C}$ (appendix A.1.7.). It was assumed that the equilibrium 
moisture content of a sample immersed in $\mathrm{NaOH}$ solution is same as that of a sample immersed in $\mathrm{NaCl}$ solution at that temperature. The diffusivities of water molecules in nanocomposites at $42.5^{\circ} \mathrm{C}$ were estimated using the experimental data for initial few hours and the estimated equilibrium moisture contents. The results are shown in Table XXIV.

Table XXIV. Estimated Diffusion Coefficients and Equilibrium Moisture Contents for samples immersed in $13 \mathrm{pH} \mathrm{NaOH}$ at $42.5^{\circ} \mathrm{C}$

\begin{tabular}{|c|c|c|}
\hline $\begin{array}{c}\text { Wt\% Cloisite } \\
10 A^{\circledR}\end{array}$ & $\begin{array}{c}\mathrm{D} \times 10^{+9} \\
\left(\mathrm{~cm}^{2} / \mathrm{s}\right)\end{array}$ & $\begin{array}{c}\text { Equilibrium } \\
\text { Moisture Content }\end{array}$ \\
\hline 0 & $13.03(2.80)$ & $0.75 \%$ \\
\hline 1 & $7.07(1.57)$ & $1.02 \%$ \\
\hline 2 & $5.21(0.90)$ & $1.16 \%$ \\
\hline 5 & $3.70(0.37)$ & $1.38 \%$ \\
\hline
\end{tabular}

Note: Values shown in the brackets are standard deviations

Transient diffusion experiments in $0.1 \mathrm{M} \mathrm{NaCl}$ and $13 \mathrm{pH} \mathrm{NaOH}$ solutions were also conducted at $42.5^{\circ} \mathrm{C}$ on FRP samples containing various amounts of nanoclay. As expected, all the samples immersed in $\mathrm{NaCl}$ solution showed weight loss after 5-6 days of immersion. The weight change curves for the samples that were immersed in $0.1 \mathrm{M} \mathrm{NaCl}$ solution are shown in Figure 109 to 112. Samples immersed in $\mathrm{NaOH}$ solution showed a weight loss after 1-2 days of immersion. The corresponding weigh gain curves are shown in Figure 113 to 116. Once aga in, the experimental data were not corrected for the weight of the glass. 


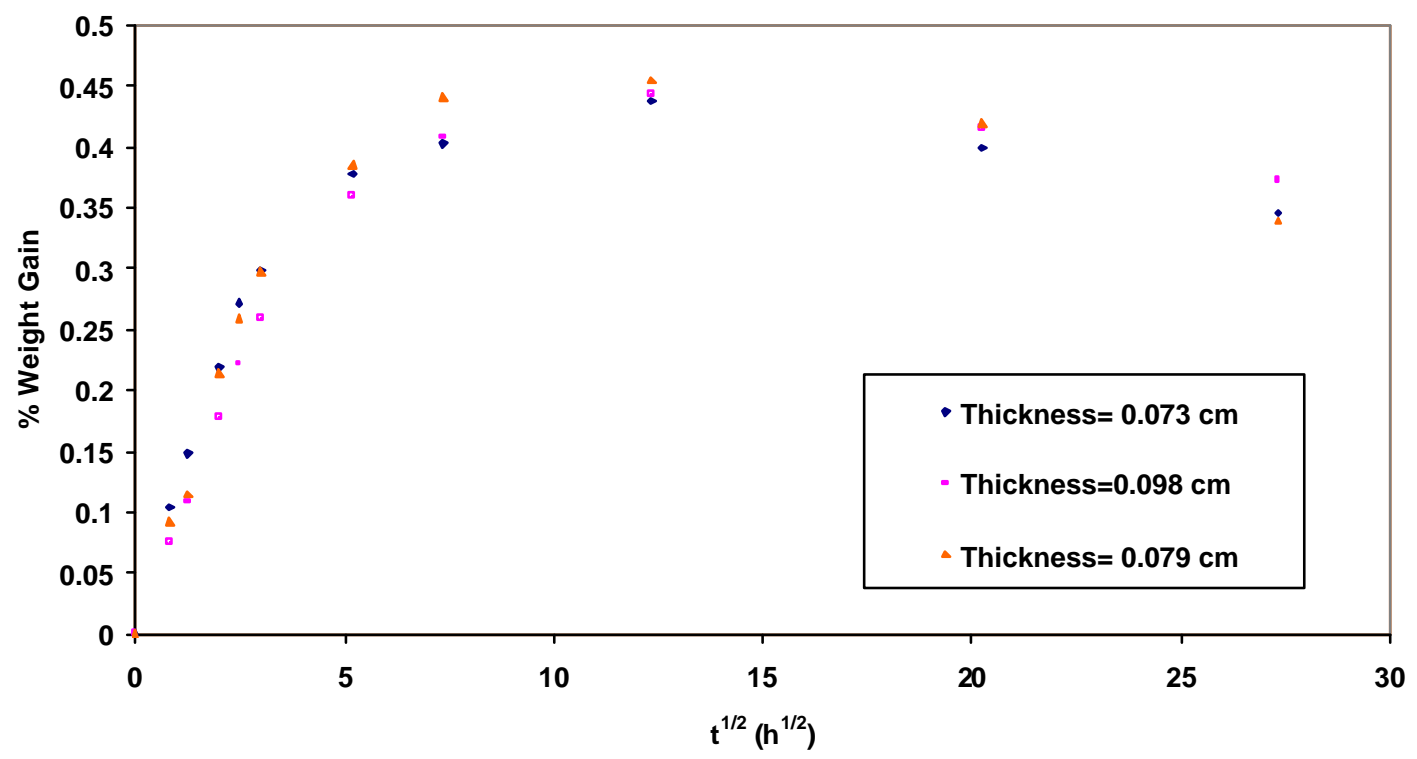

Figure 109. Percentage weight gain versus $t^{1 / 2}$ for FRP samples containing $0 \mathrm{wt}^{\%}$ Cloisite $10 \mathrm{~A}^{\circledR}$ immersed in $0.1 \mathrm{M} \mathrm{NaCl}$ solution at $42.5^{\circ} \mathrm{C}$

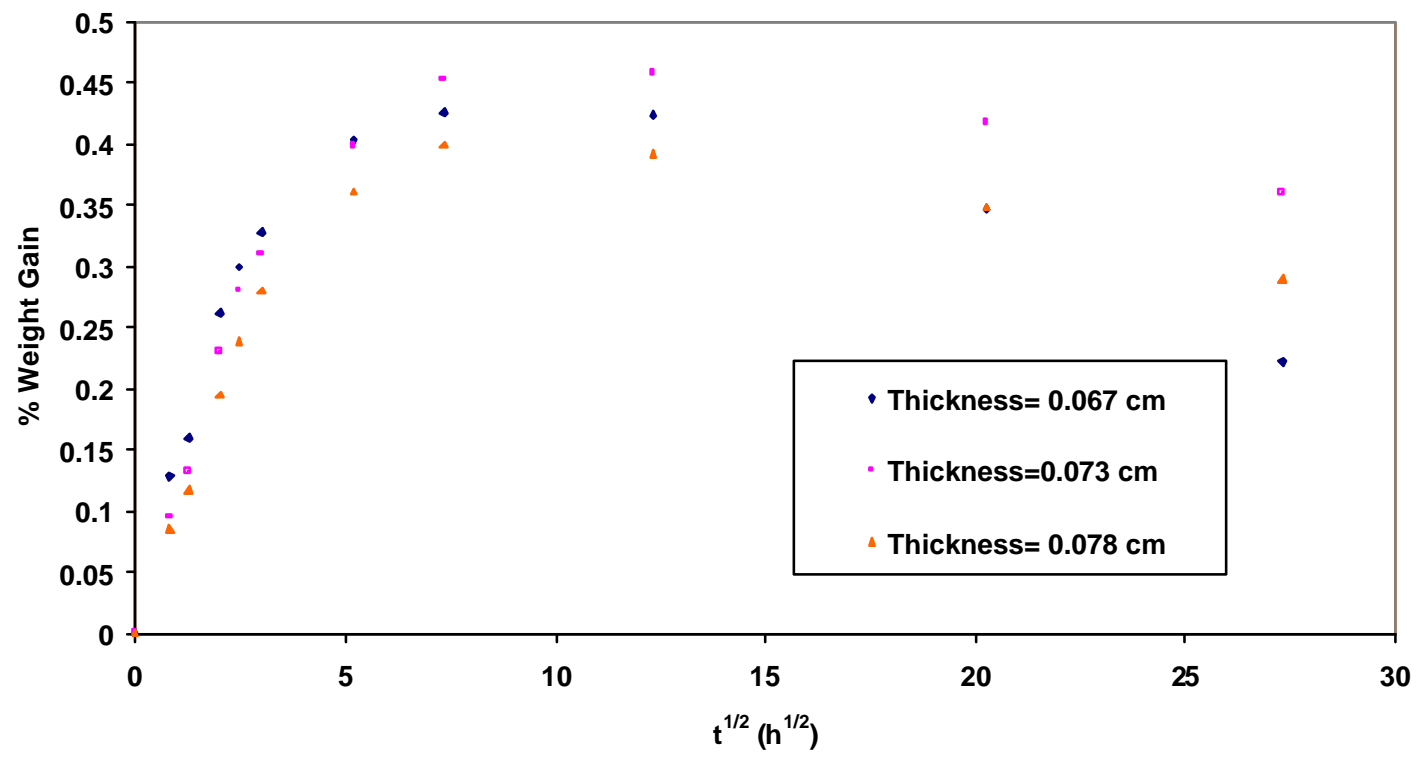

Figure 110. Percentage weight gain versus $t^{1 / 2}$ for FRP samples containing $1 \mathrm{wt} \%$ Cloisite $10 \mathrm{~A}^{\circledR}$ immersed in $0.1 \mathrm{M} \mathrm{NaCl}$ solution at $42.5^{\circ} \mathrm{C}$ 


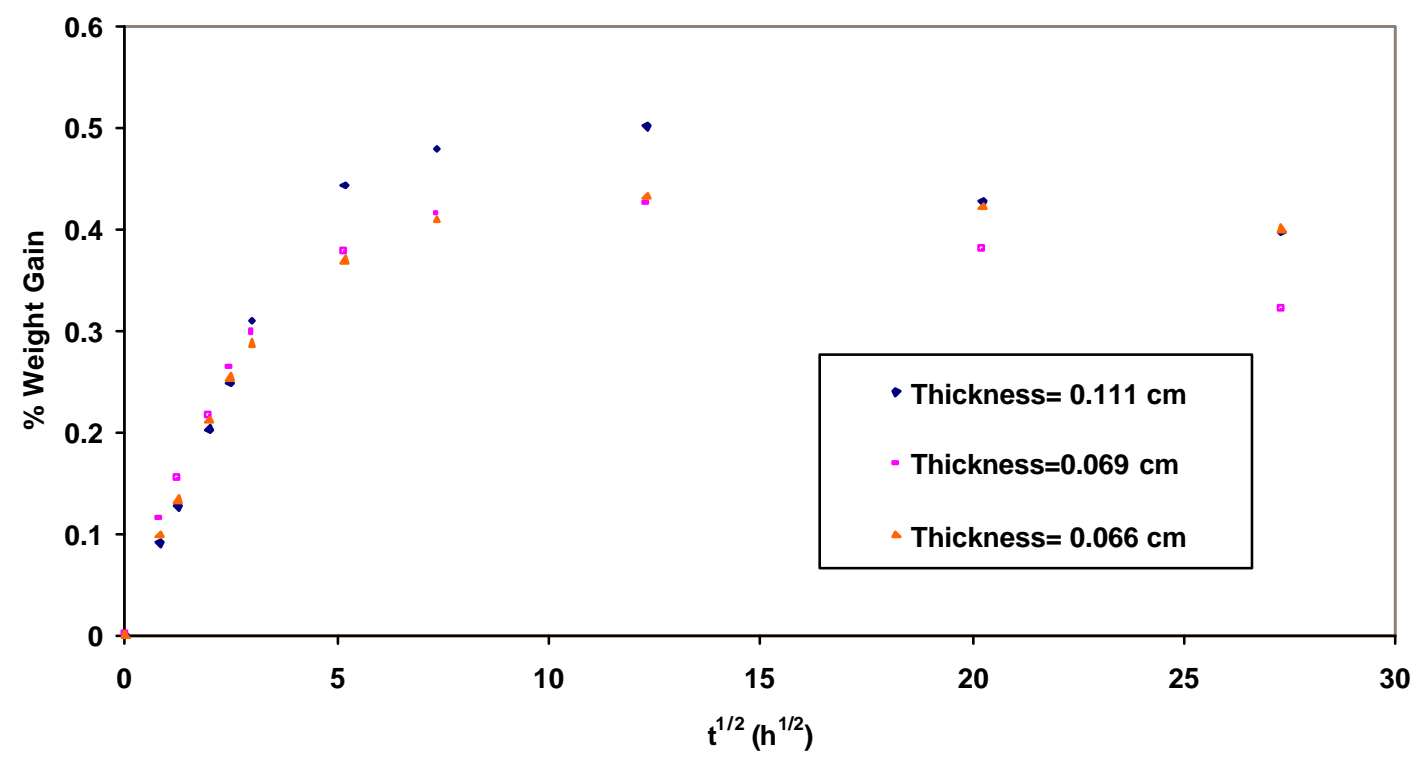

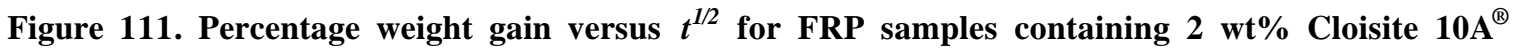
immersed in $0.1 \mathrm{M} \mathrm{NaCl}$ solution at $42.5^{\circ} \mathrm{C}$

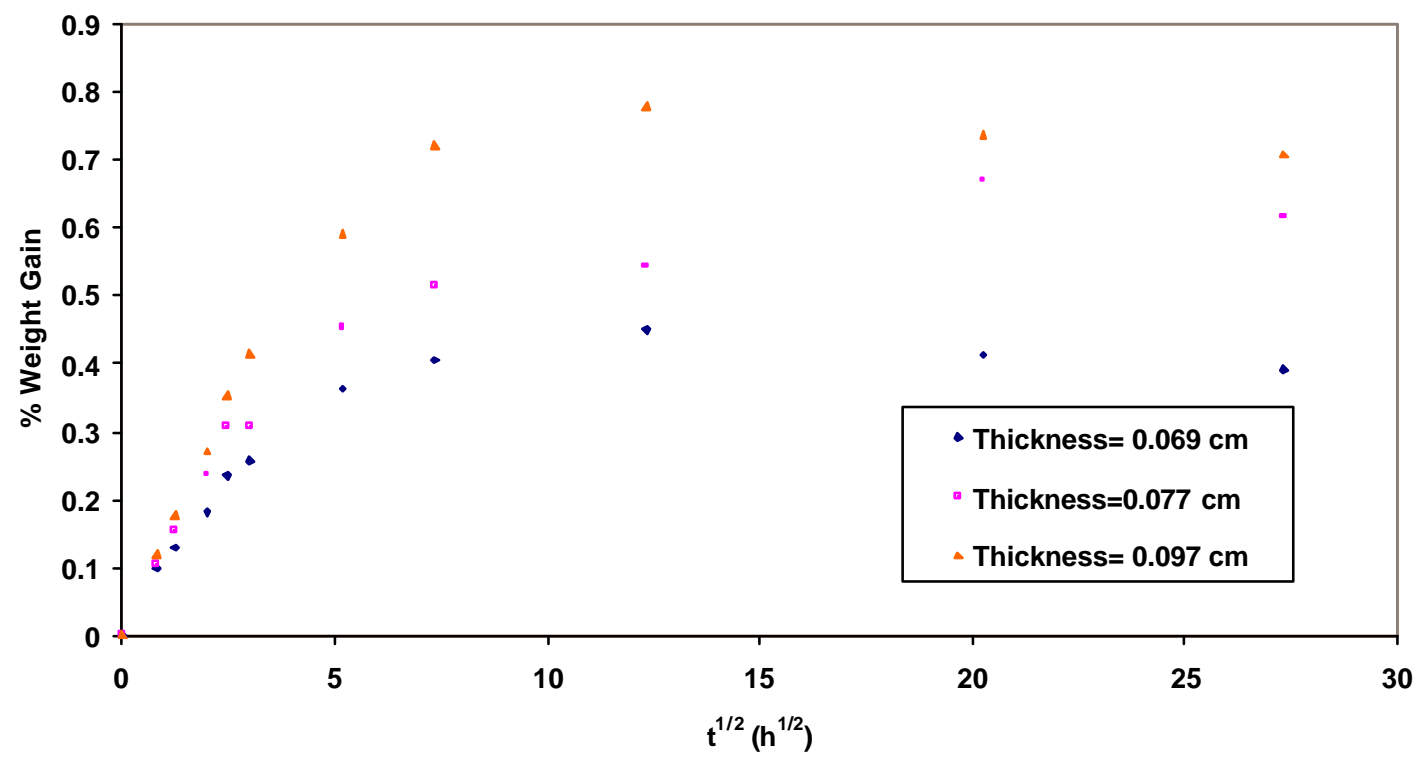

Figure 112. Percentage weight gain versus $t^{1 / 2}$ for FRP samples containing $5 \mathrm{wt}^{\%}$ Cloisite $10 \mathrm{~A}^{\circledR}$ immersed in $0.1 \mathrm{M} \mathrm{NaCl}$ solution at $42.5^{\circ} \mathrm{C}$ 


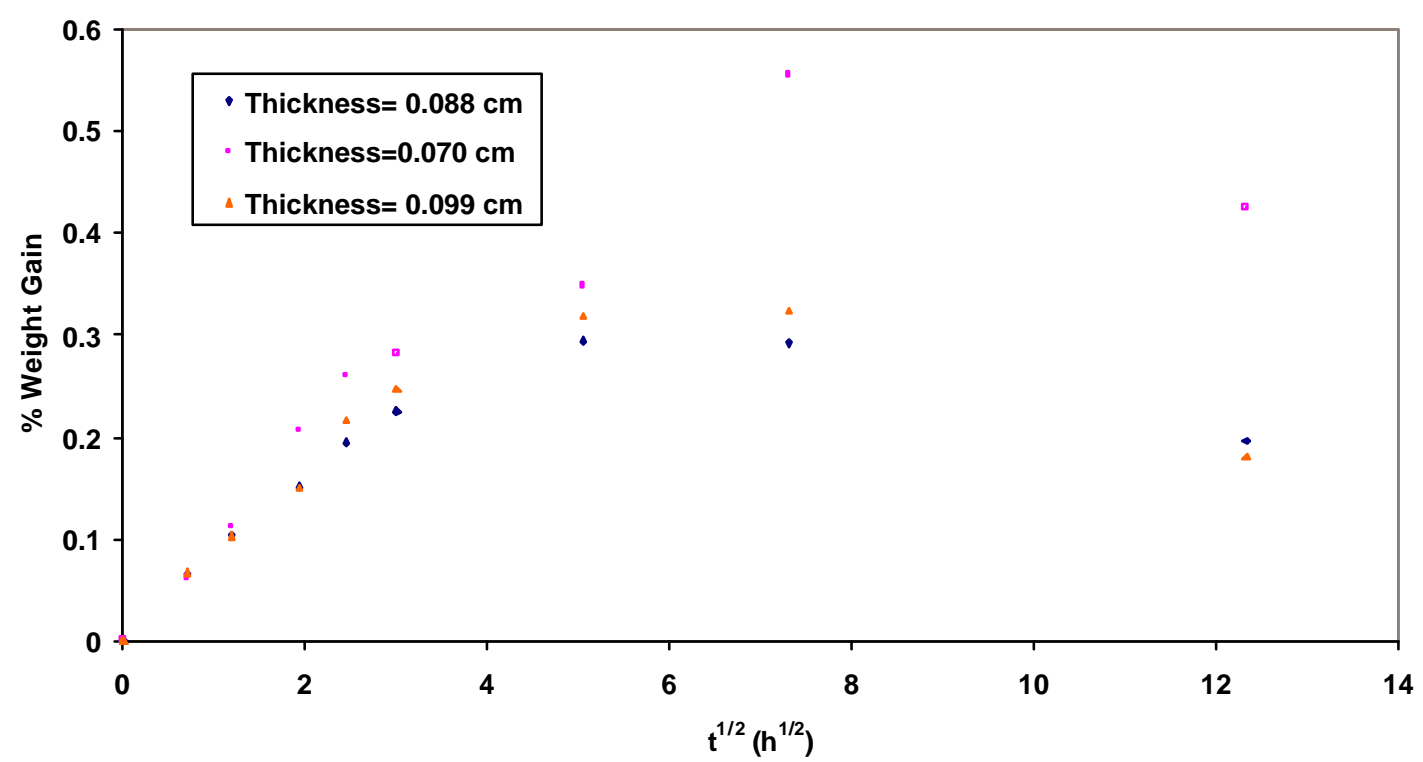

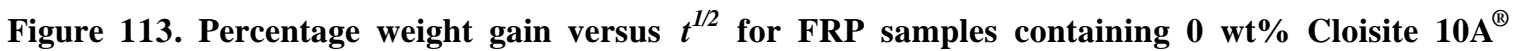
immersed in $13 \mathrm{pH} \mathrm{NaOH}$ solution at $42.5^{\circ} \mathrm{C}$

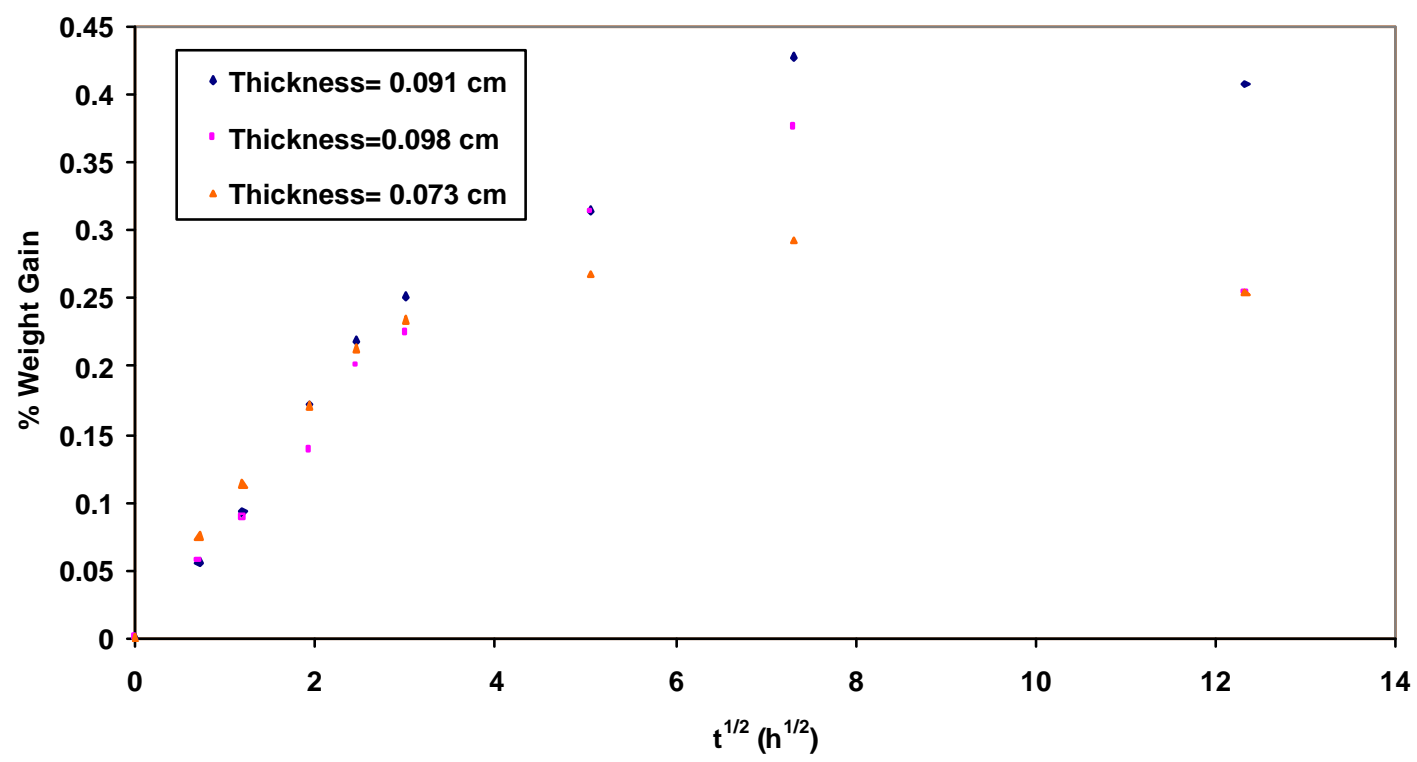

Figure 114. Percentage weight gain versus $t^{1 / 2}$ for FRP samples containing 1 wt $\%$ Cloisite $10 A^{\circledR}$ immersed in $13 \mathrm{pH} \mathrm{NaOH}$ solution at $42.5^{\circ} \mathrm{C}$ 


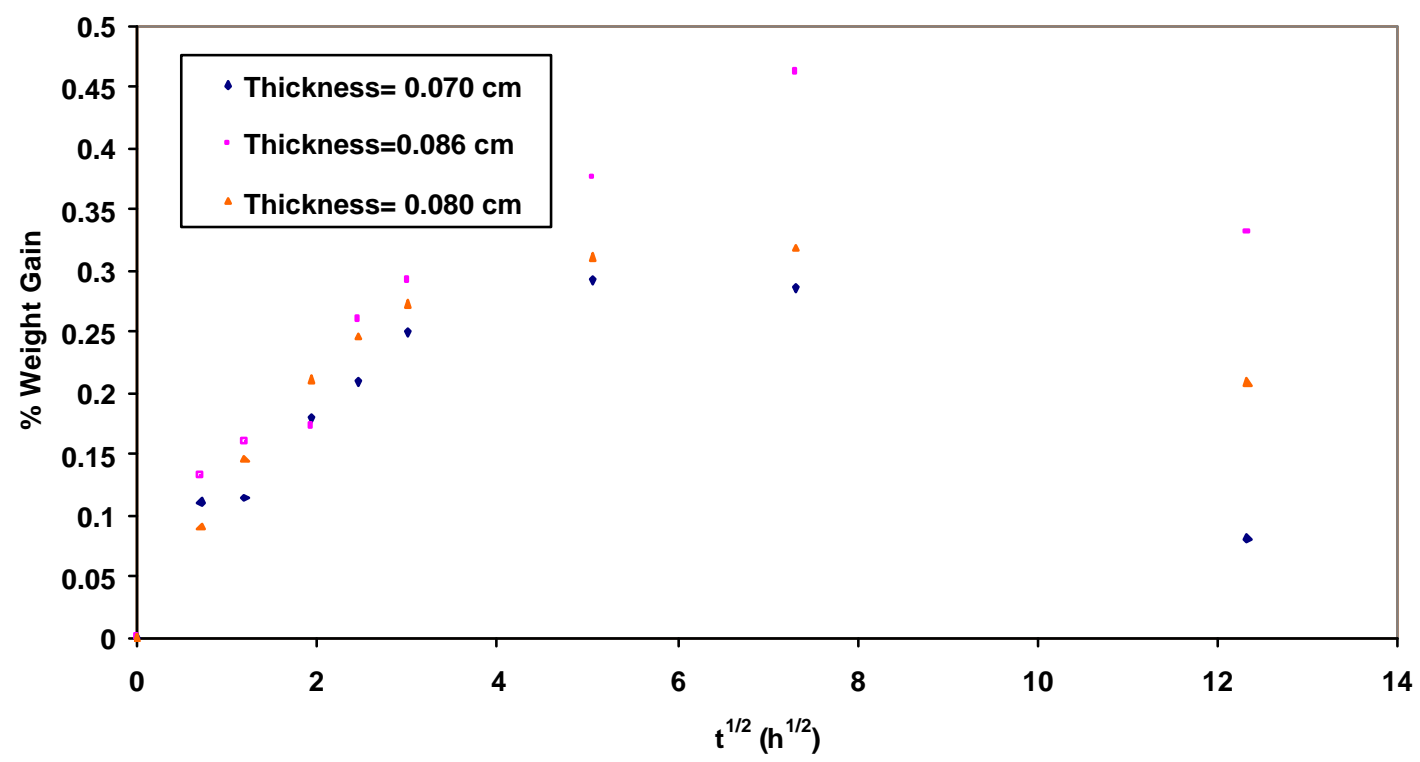

Figure 115. Percentage weight gain versus $t^{1 / 2}$ for FRP samples containing $2 \mathrm{wt} \%{\text { Cloisite } 10 A^{\circledR}}^{\circledR}$ immersed in $13 \mathrm{pH} \mathrm{NaOH}$ solution at $42.5^{\circ} \mathrm{C}$

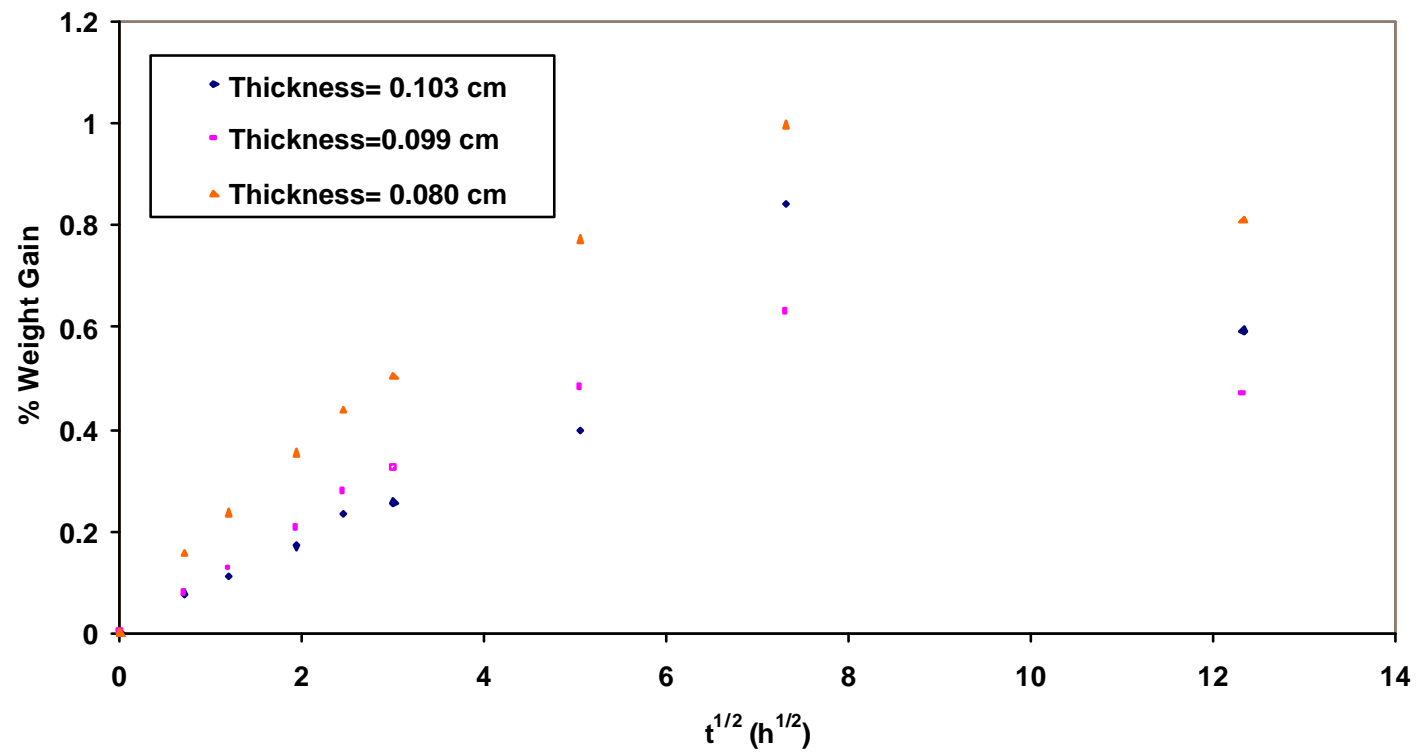

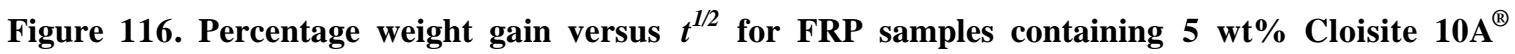
immersed in $13 \mathrm{pH} \mathrm{NaOH}$ solution at $42.5^{\circ} \mathrm{C}$ 


\subsection{Transient Diffusion Experiments in Alkaline and Saline solutions at $4^{\circ} \mathrm{C}$}

Transient diffusion experiments with un-reinforced nanocomposite samples were carried out at $4^{\circ} \mathrm{C}$ to understand the diffusion process in those solutions at lower temperatures. Plots of $M_{t} / M_{\infty}$ versus $t^{1 / 2} / 2 l$ were obtained according to the method explained in section 2.1. Diffusion coefficients were calculated from the initial slope of these curves. Figures 117 to 120 show the uptake curves for the samples immersed in $0.1 \mathrm{M} \mathrm{NaCl}$ solution at $4^{\circ} \mathrm{C}$. It was interesting to note that the vinyl ester did not react with $13 \mathrm{pH} \mathrm{NaOH}$ solution at $4 \mathrm{C}$ and consequently, it was possible to accurately calculate the diffusivity and equilibrium moisture content at this temperature. The uptake curves for the samples immersed in $13 \mathrm{pH} \mathrm{NaOH}$ solution are shown in Figure 121 to 124.

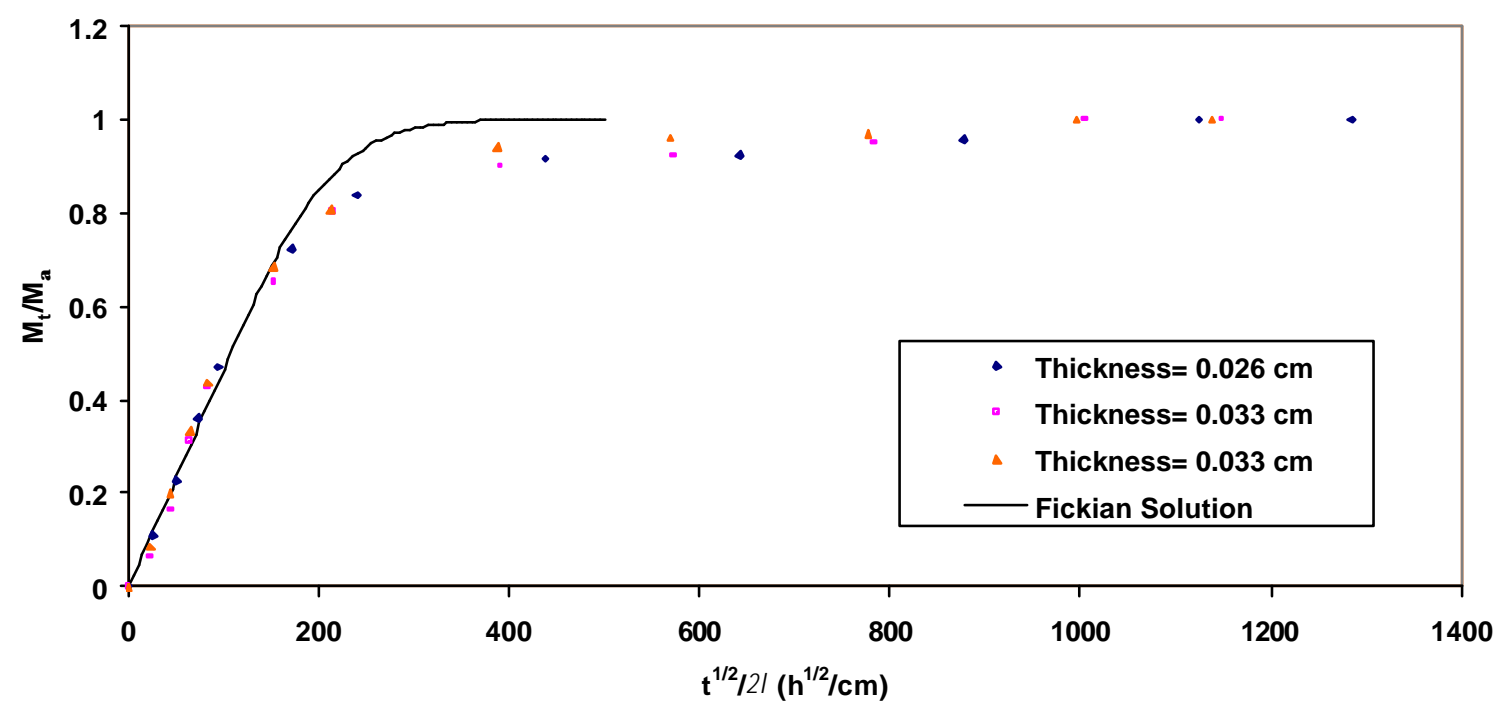

Figure 117. $M_{\downarrow} / M_{\infty}$ versus $t^{1 / 2} / 2 l$ for samples containing 0 wt $\%$ Cloisite $10 A^{\circledR}$ immersed in $0.1 \mathrm{M} \mathrm{NaCl}$ solution at $4^{\circ} \mathrm{C}$ 


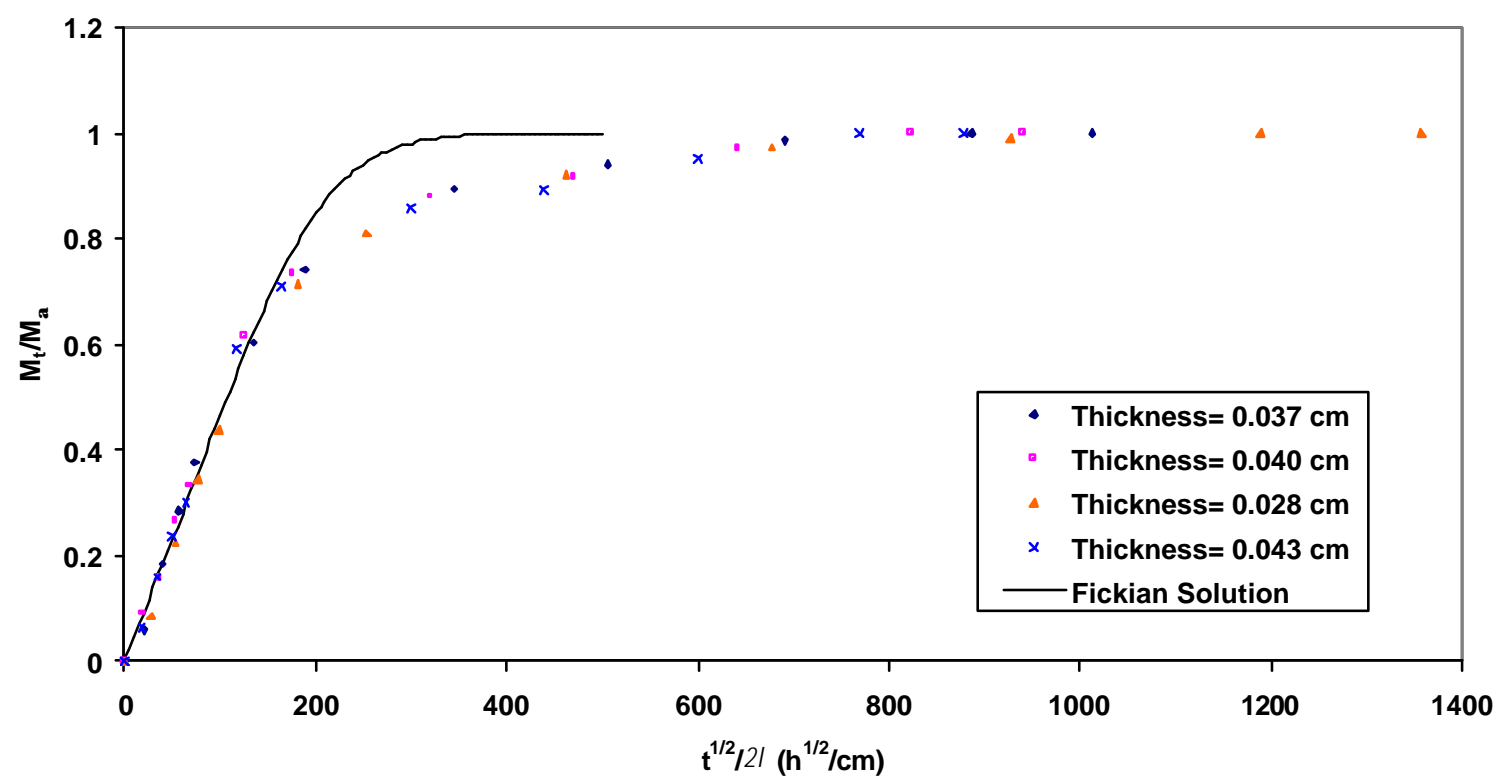

Figure 118. $M_{t} / M_{\infty}$ versus $t^{1 / 2} / 2 l$ for samples containing $1 \mathrm{wt} \%$ Cloisite $10 \mathrm{~A}^{\circledR}$ immersed in $0.1 \mathrm{M} \mathrm{NaCl}$ solution at $4^{\circ} \mathrm{C}$

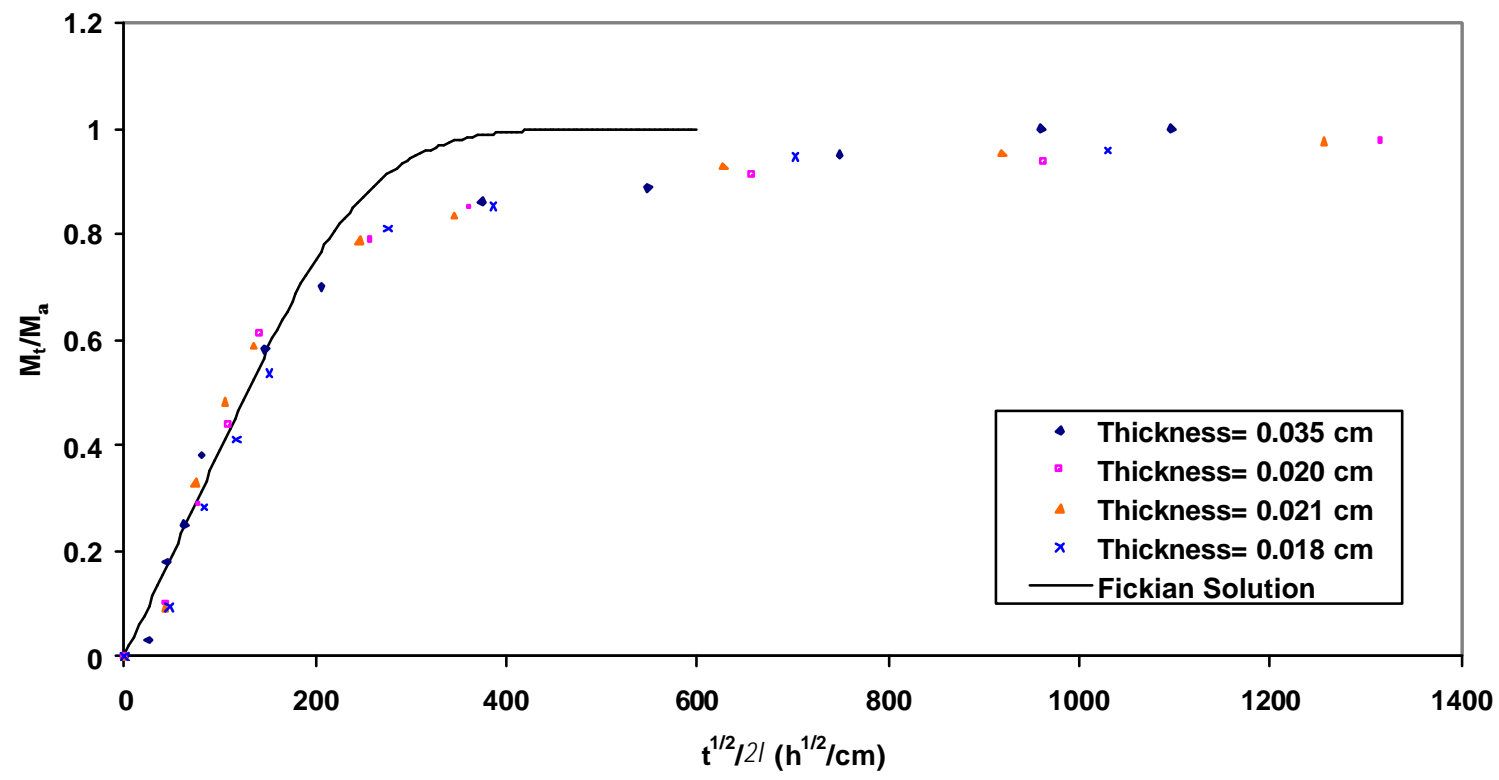

Figure 119. $M_{t} / M_{\infty}$ versus $t^{1 / 2} / 2 l$ for samples containing $2 \mathrm{wt} \%$ Cloisite $10 \mathrm{~A}^{\circledR}$ immersed in $0.1 \mathrm{M} \mathrm{NaCl}$ solution at $4^{\circ} \mathrm{C}$ 


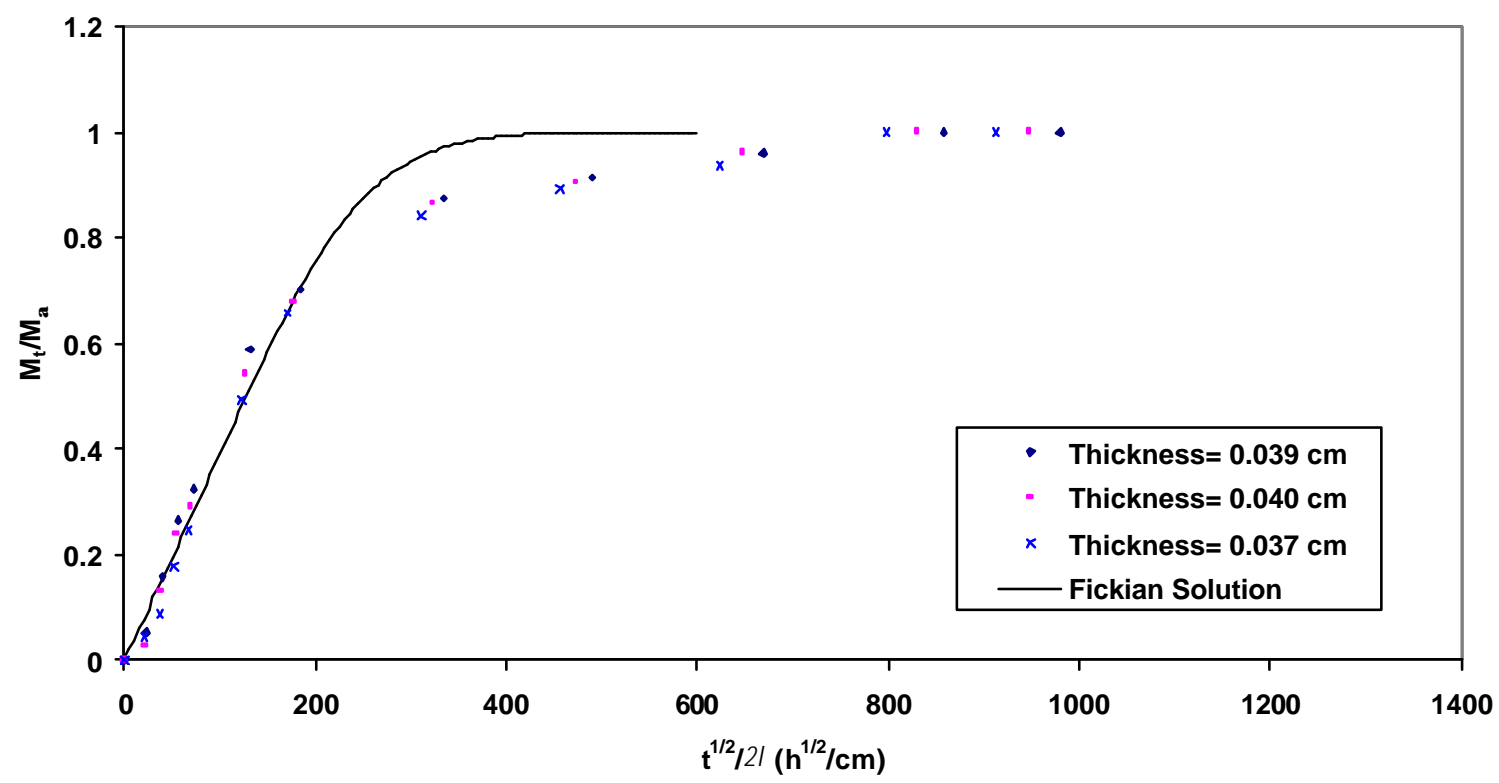

Figure 120. $M_{t} / M_{\infty}$ versus $t^{1 / 2} / 2 l$ for samples containing $5 \mathrm{wt} \%$ Cloisite $10 \mathrm{~A}^{\circledR}$ immersed in $0.1 \mathrm{M} \mathrm{NaCl}$ solution at $4^{\circ} \mathrm{C}$

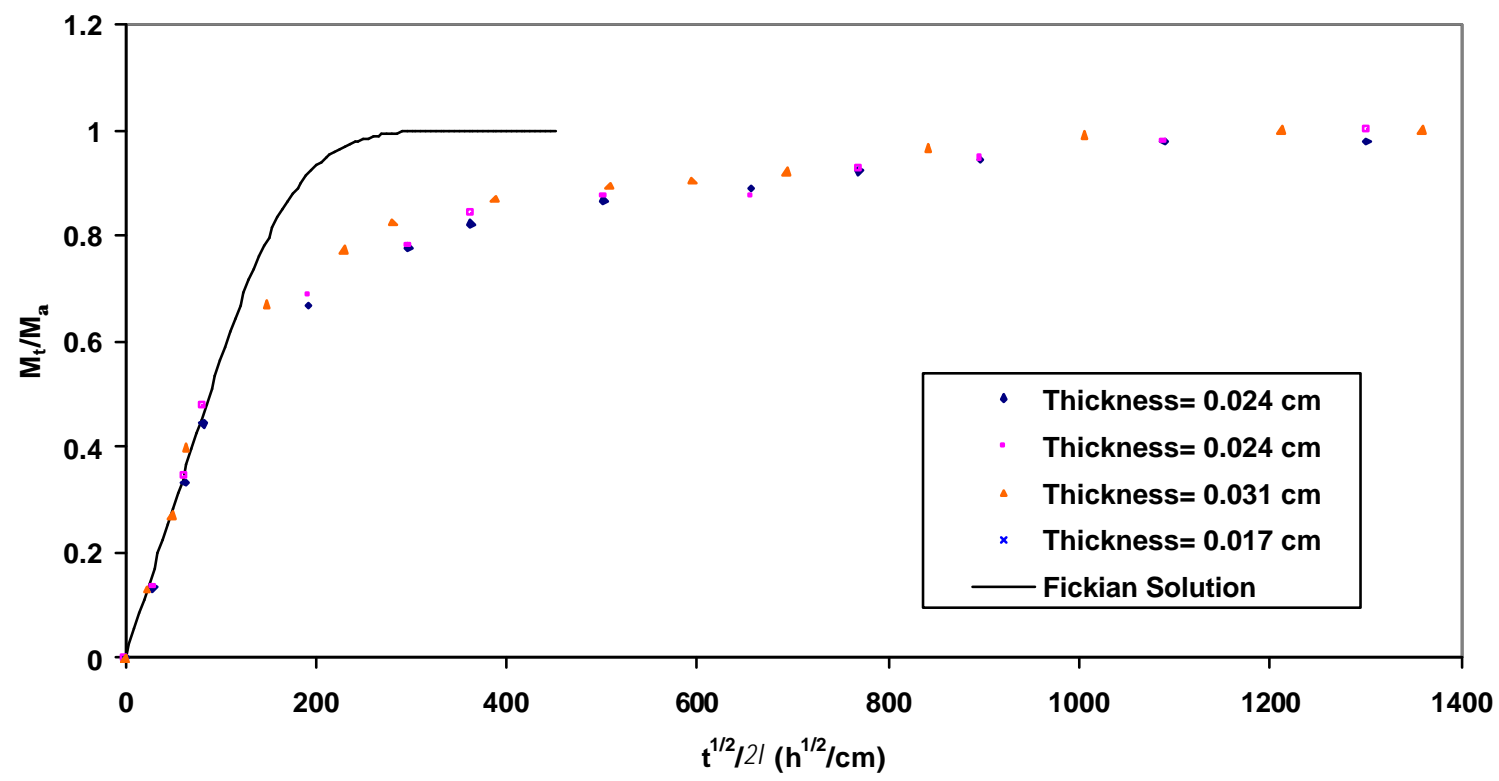

Figure 121. $M_{t} / M_{\infty}$ versus $t^{1 / 2} / 2 l$ for samples containing $0 \mathrm{wt} \%$ Cloisite $10 \mathrm{~A}^{\circledR}$ immersed in $13 \mathrm{pH}$ $\mathrm{NaOH}$ solution at $4^{\circ} \mathrm{C}$ 


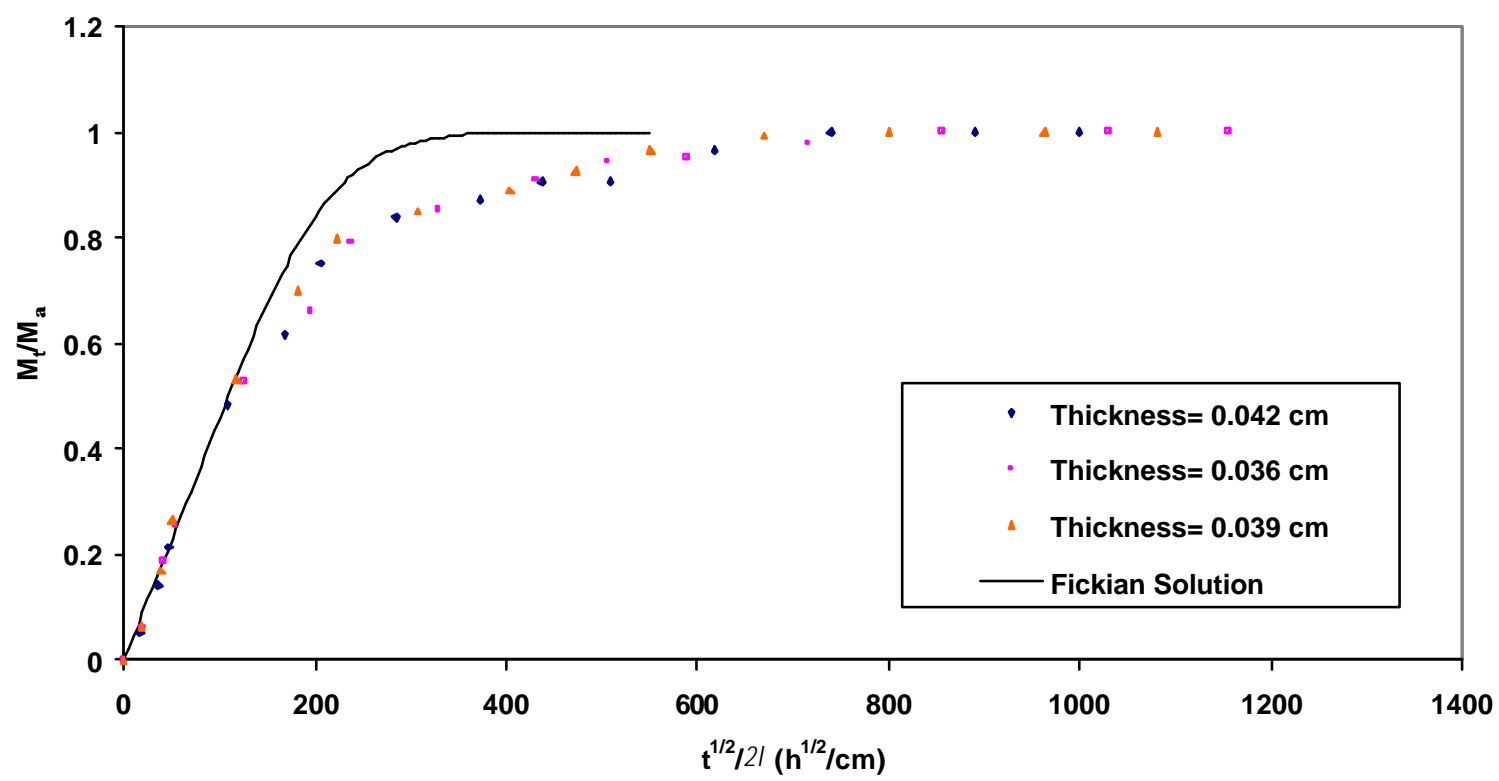

Figure 122. $M_{t} / M_{\infty}$ versus $t^{1 / 2} / 2 l$ for samples containing $1 \mathrm{wt} \%$ Cloisite $10 A^{\circledR}$ immersed in $13 \mathrm{pH}$ $\mathrm{NaOH}$ solution at $4^{\circ} \mathrm{C}$

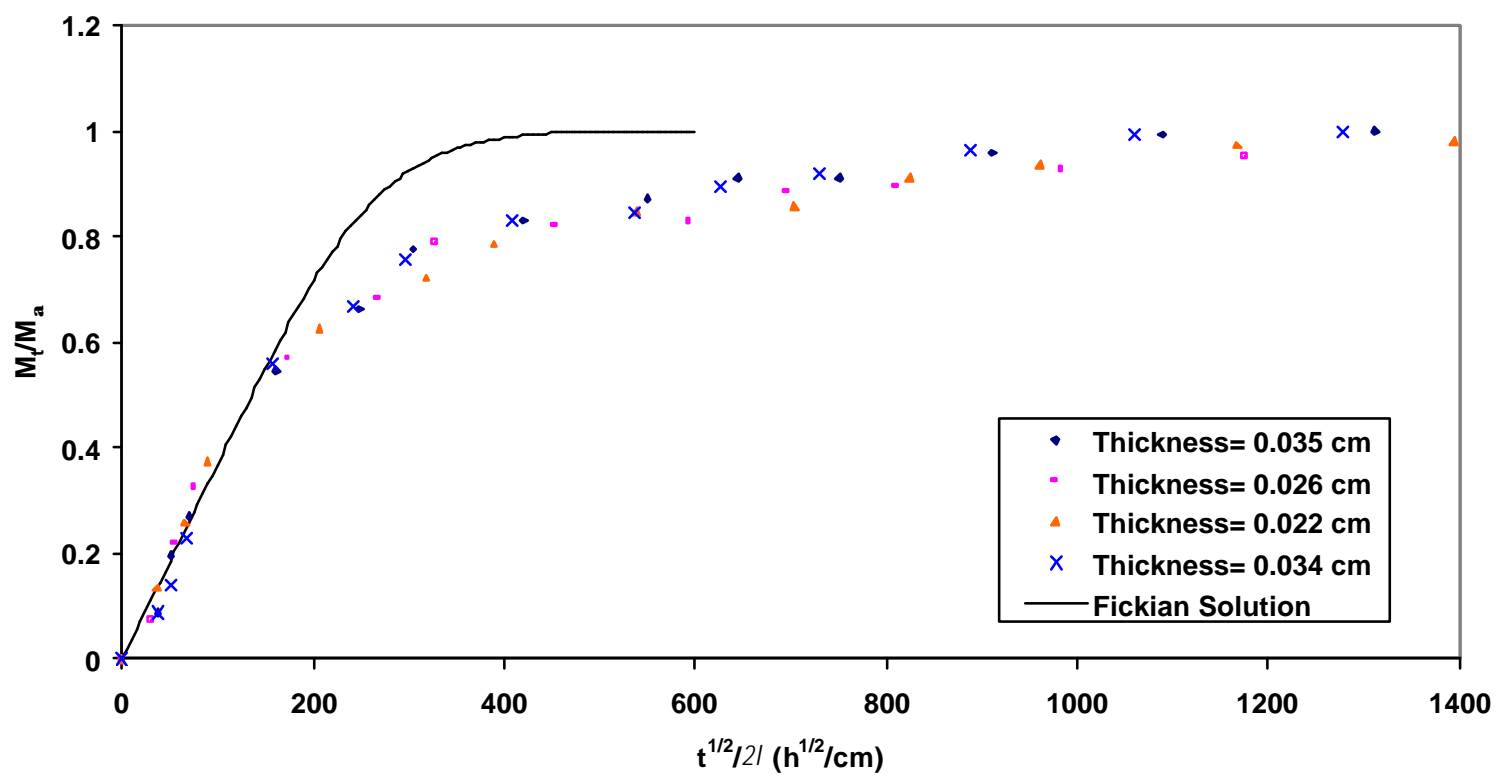

Figure 123. $M_{t} / M_{\infty}$ versus $t^{1 / 2} / 2 l$ for samples containing $2 \mathrm{wt} \%$ Coisite $10 \mathrm{~A}^{\circledR}$ immersed in $13 \mathrm{pH}$ $\mathrm{NaOH}$ solution at $4^{\circ} \mathrm{C}$ 


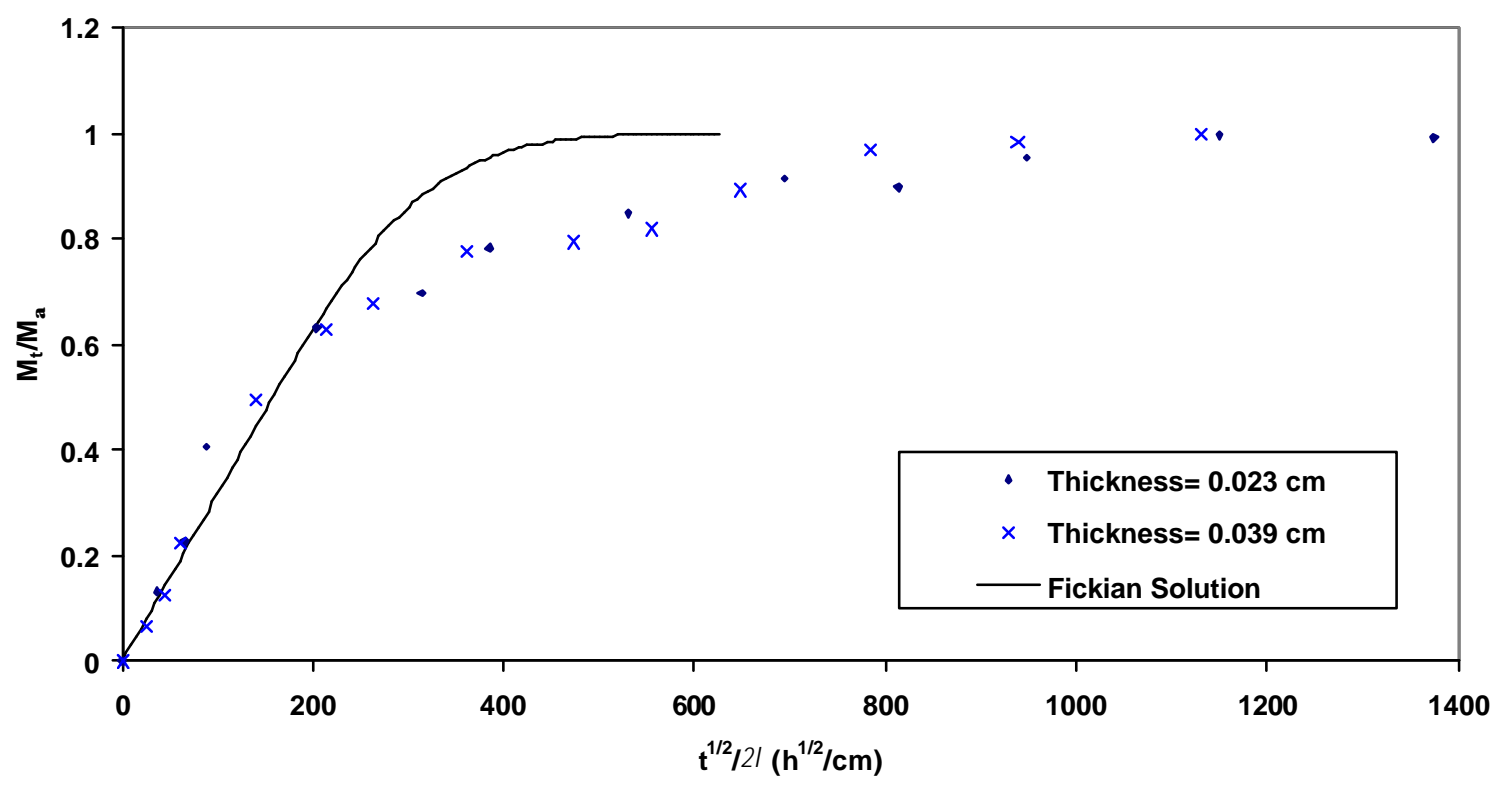

Figure 124. $M_{t} / M_{\infty}$ versus $t^{1 / 2} / 2 l$ for samples containing $5 \mathrm{wt} \%$ Cloisite $10 \mathrm{~A}^{\circledR}$ immersed in $13 \mathrm{pH}$ $\mathrm{NaOH}$ solution at $4^{\circ} \mathrm{C}$

Diffusivities were calculated from the initial slope of the normalized mass uptake curves and are shown in Table XXV. Equilibrium moisture contents were also calculated from the experimental data and are shown in Table XXVI. Variations in diffusion coefficient and equilibrium moisture uptake with various clay loadings for the samples immersed in $0.1 \mathrm{M} \mathrm{NaCl}$ solution are shown in Figure 125 and Figure 126 respectively.

Table XXV. Diffusion Coefficients in $0.1 \mathrm{M} \mathrm{NaCl}$ and $13 \mathrm{pH}$ NaOH Solutions at $4^{\circ} \mathrm{C}$

\begin{tabular}{|c|c|c|c|c|}
\hline & \multicolumn{4}{|c|}{$\mathrm{D} \times 10^{+9}\left(\mathrm{~cm}^{2} / \mathrm{s}\right)$} \\
\hline Clay wt\% & $0 \mathrm{wt} \%$ & $1 \mathrm{wt} \%$ & $2 \mathrm{wt} \%$ & $5 \mathrm{wt} \%$ \\
\hline $0.1 \mathrm{M} \mathrm{NaCl}$ & $1.19(0.16)$ & $1.18(0.08)$ & $0.83(0.19)$ & $0.84(0.23)$ \\
\hline $13 \mathrm{pH} \mathrm{NaOH}$ & $1.74(0.21)$ & $1.14(0.12)$ & $0.74(0.18)$ & $0.55(0.17)$ \\
\hline
\end{tabular}

Note: Values shown in the brackets are standard deviations 
Table XXVI. Equilibrium Moisture Content in $0.1 \mathrm{M} \mathrm{NaCl}$ and $13 \mathrm{pH} \mathrm{NaOH}$ solutions at $4^{\circ} \mathrm{C}$

\begin{tabular}{|c|c|c|c|c|}
\hline & \multicolumn{4}{|c|}{ Equilibrium Moisture Content (\%) } \\
\hline Clay wt\% & $0 \mathrm{wt} \%$ & $1 \mathrm{wt} \%$ & $2 \mathrm{wt} \%$ & $5 \mathrm{wt} \%$ \\
\hline $0.1 \mathrm{M} \mathrm{NaCl}$ & $0.58(0.02)$ & $0.66(0.04)$ & $0.59(0.01)$ & $0.61(0.03)$ \\
\hline $13 \mathrm{pH} \mathrm{NaOH}$ & $0.67(0.06)$ & $0.65(0.04)$ & $0.66(0.05)$ & $0.70(0.07)$ \\
\hline
\end{tabular}

Note: Values shown in the brackets are standard deviations

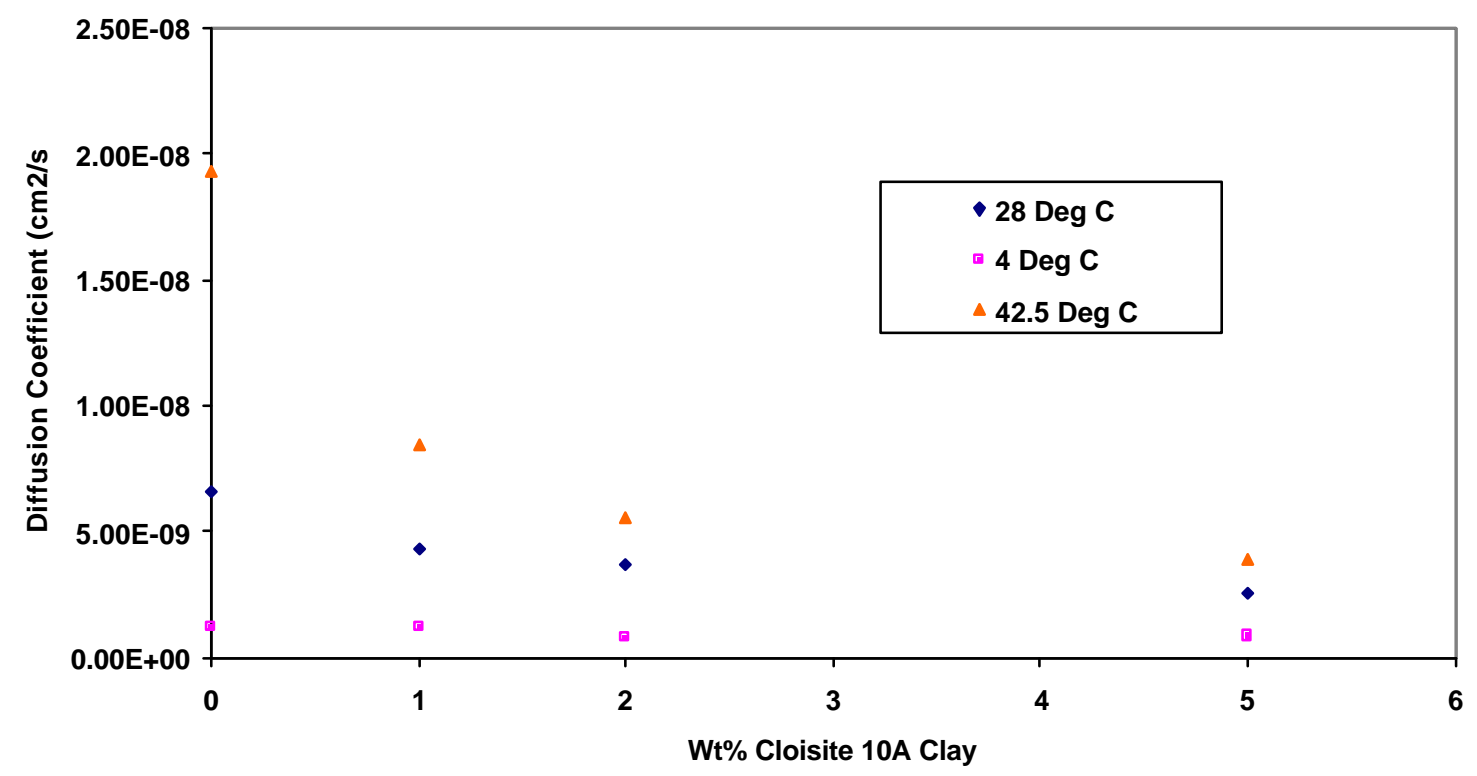

Figure 125. Variation in diffusion coefficient with wt $\%$ Cloisite $10 \mathrm{~A}^{\circledR}$ for the samples immersed in 0.1M NaCl solution 


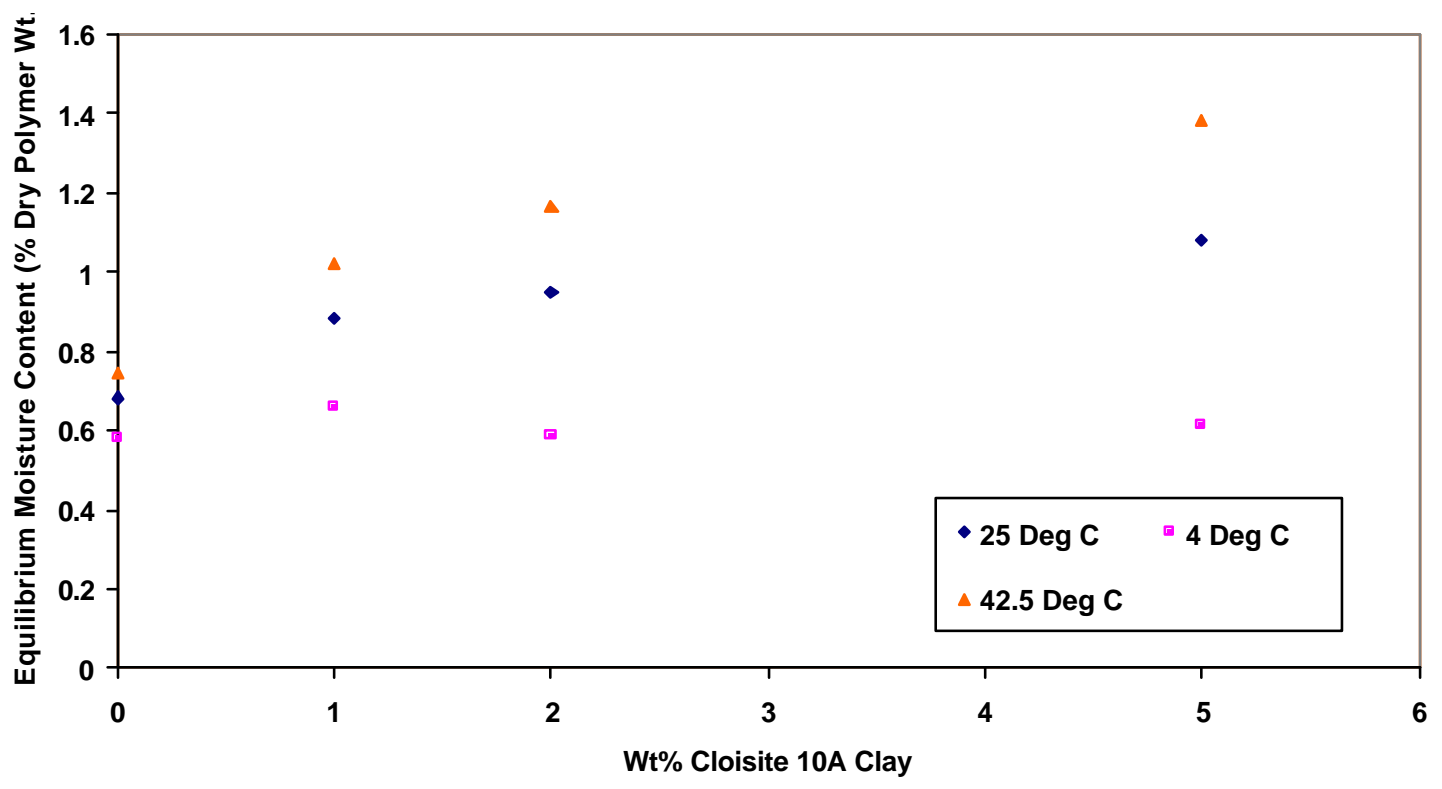

Figure 126. Variation in equilibrium moisture content with wt $\%$ Cloisite $10 A^{\circledR}$ for the samples immersed in $0.1 \mathrm{M} \mathrm{NaCl}$ solution

It can be seen from Figure 126 that the equilibrium moisture content of the samples immersed in $0.1 \mathrm{M} \mathrm{NaCl}$ solution at $4^{\circ} \mathrm{C}$ did not vary much with the various nanoclay loadings in the polymer. It can be inferred from Figure 126 that the nanoclay did not adsorb much moisture and this led to the conclusion that the adsorption of water on to the clay platelets is an energy activated process. Even though, there was not much difference in the equilibrium moisture content of nanocomposite samples at $4^{\circ} \mathrm{C}$, the diffusion coefficient dropped as much as $29 \%$ by incorporation of $5 \mathrm{wt} \%$ exfoliated nano clay.

Variations in diffusion coefficient and equilibrium moisture uptake with various clay loadings for the samples immersed in $13 \mathrm{pH} \mathrm{NaOH}$ solution are shown in Figures 127 and Figure 128 respectively. 


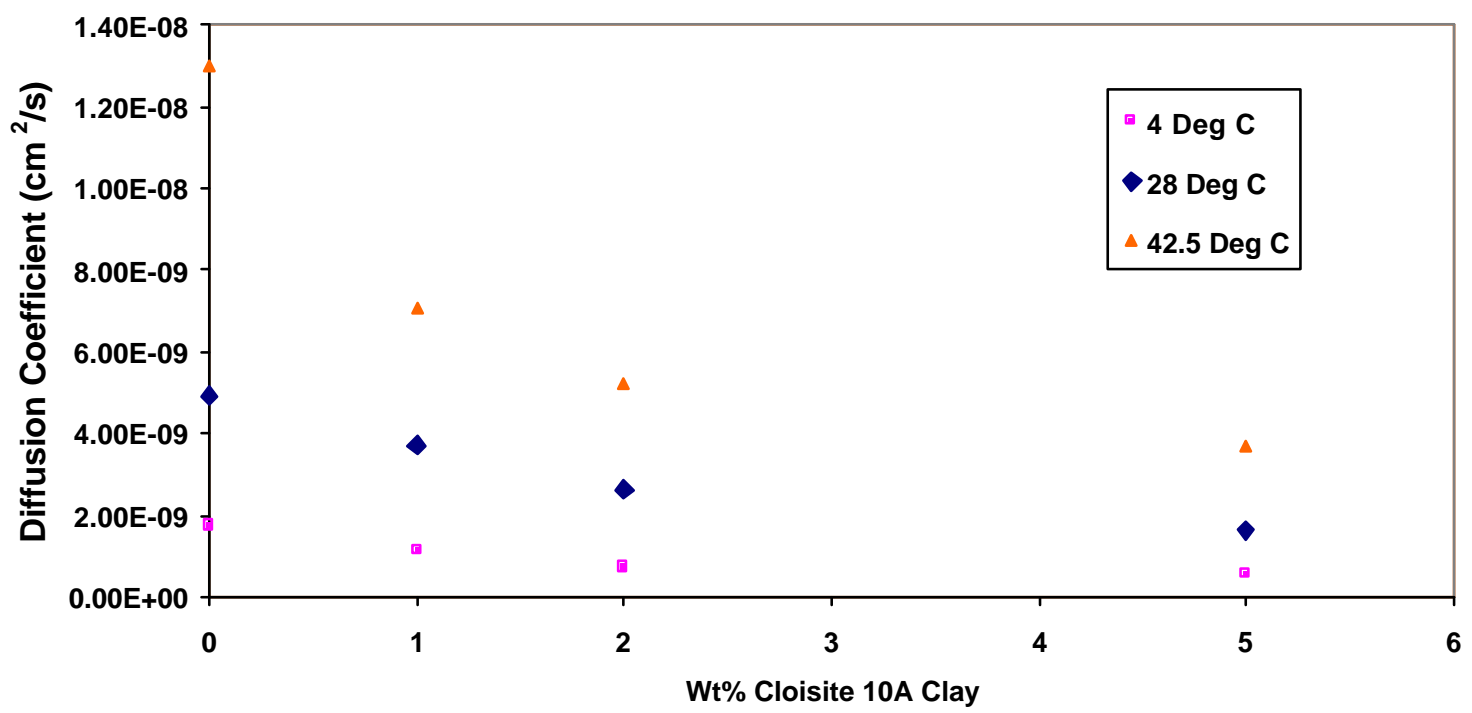

Figure 127. Variation in diffusion coefficient with wt $\%$ Cloisite $10 A^{\circledR}$ for the samples immersed in 13 pH NaOH solution

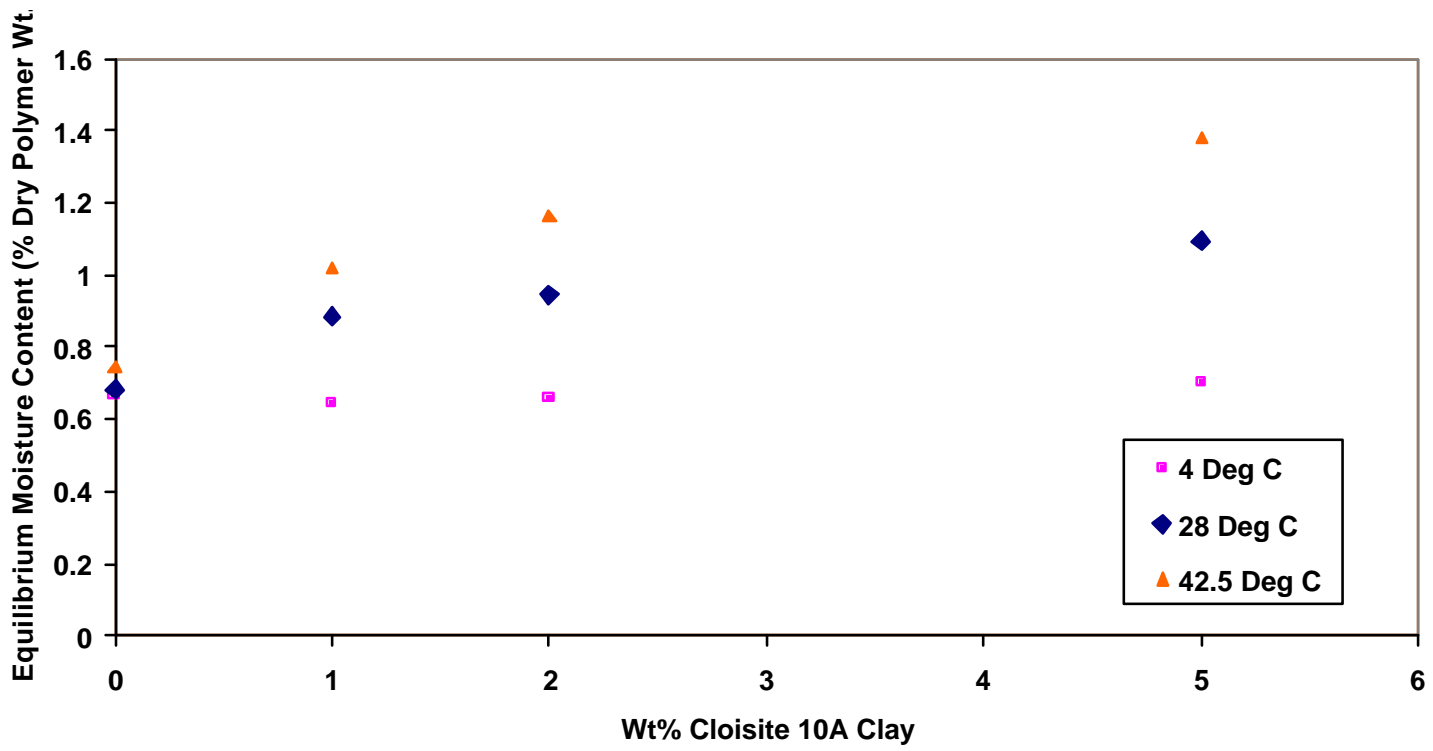

Figure 128. Variation in equilibrium moisture content with wt\% Cloisite $10 \mathrm{~A}^{\circledR}$ for the samples immersed in $13 \mathrm{pH} \mathrm{NaOH}$ solution 
Once again, little variation was recorded in the equilibrium moisture content of nanocomposite samples immersed in $13 \mathrm{pH} \mathrm{NaOH}$ solution at $4^{\circ} \mathrm{C}$. Nevertheless, diffusion coefficient dropped by approximately $69 \%$ by incorporation of 5 weight percent of nanoclay in polymer.

Assuming an Arrhenius dependence of diffusion coefficient on temperature (equation 8), the activation energy for diffusion of water in neat samples immersed in $0.1 \mathrm{M} \mathrm{NaCl}$ solution was calculated from the experimental data at $28^{\circ} \mathrm{C}, 42.5^{\circ} \mathrm{C}$ and $4^{\circ} \mathrm{C}$. The activation energy $(E)$ and $D_{o}$ were found to be $52.157 \mathrm{~kJ} / \mathrm{mol}$ and $7.9478 \mathrm{~cm}^{2} / \mathrm{s}$ respectively. Using the approximate data for neat samples immersed in $13 \mathrm{pH} \mathrm{NaOH}$ solution, the activation energy $(E)$ and $D_{o}$ were found to be $36.971 \mathrm{~kJ} / \mathrm{mol}$ and 0.0153 $\mathrm{cm}^{2} / \mathrm{s}$ respectively.

Transient diffusion experiments in alkaline and saline solutions at $4^{\circ} \mathrm{C}$ were also conducted on FRP films containing various amounts of nanoclay. FRP films were immersed in $0.1 \mathrm{M} \mathrm{NaCl}$ and $13 \mathrm{pH} \mathrm{NaOH}$ solutions at $4^{\circ} \mathrm{C}$ and periodic weight gains were recorded. Experimental data were corrected for the weight of the glass-fibers and corrected $M_{t} / M_{\infty}$ were plotted against $t^{1 / 2} / 2 l$. Once again, no correction was applied for the thickness of the glass-fiber mat. Corrected normalized weight gains for the FRP samples immersed in $0.1 \mathrm{M} \mathrm{NaCl}$ solution are shown in Figures 129 to 132 . Similar curves for the samples immersed in $13 \mathrm{pH} \mathrm{NaOH}$ solutions are shown in Figures 133 to 136. 


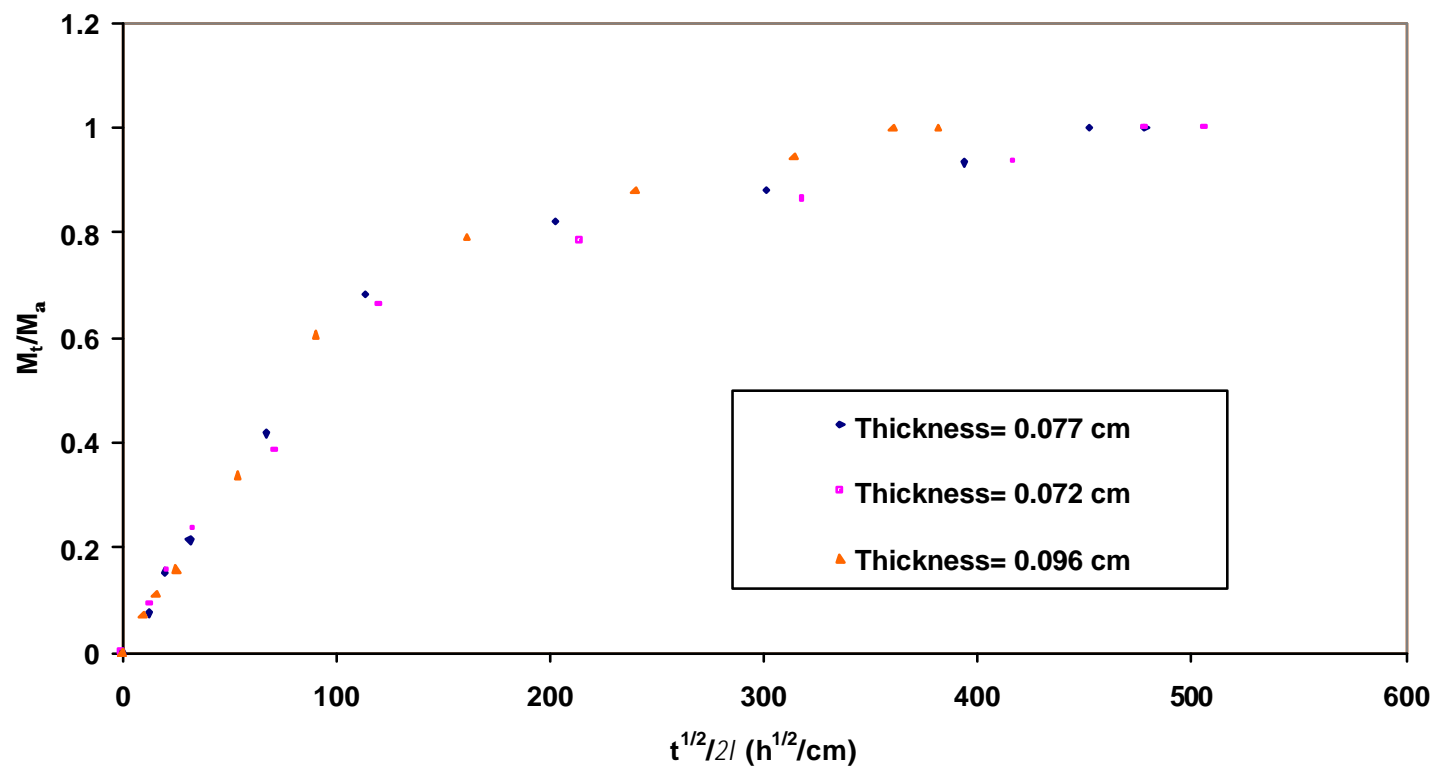

Figure 129. Corrected $M_{t} / M_{\infty}$ versus $t^{1 / 2} / 2 l$ for FRP samples containing 0 wt $\%$ Cloisite $10 A^{\circledR}$ immersed in $0.1 \mathrm{M} \mathrm{NaCl}$ solution at $4^{\circ} \mathrm{C}$

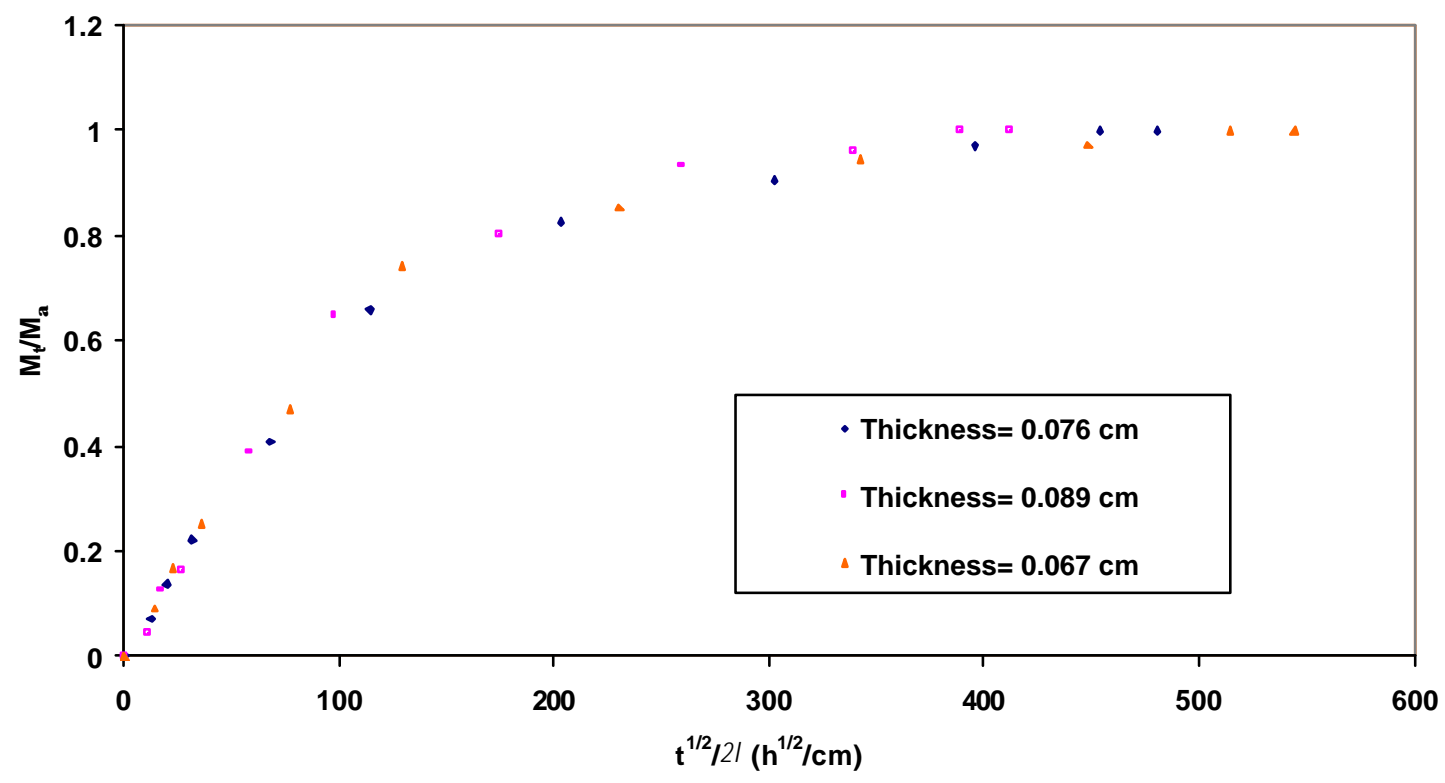

Figure 130. Corrected $M_{t} / M_{\infty}$ versus $t^{1 / 2} / 2 l$ for FRP samples containing 1 wt $\%$ Cloisite $10 A^{\circledR}$ immersed in $0.1 \mathrm{M} \mathrm{NaCl}$ solution at $4^{\circ} \mathrm{C}$ 


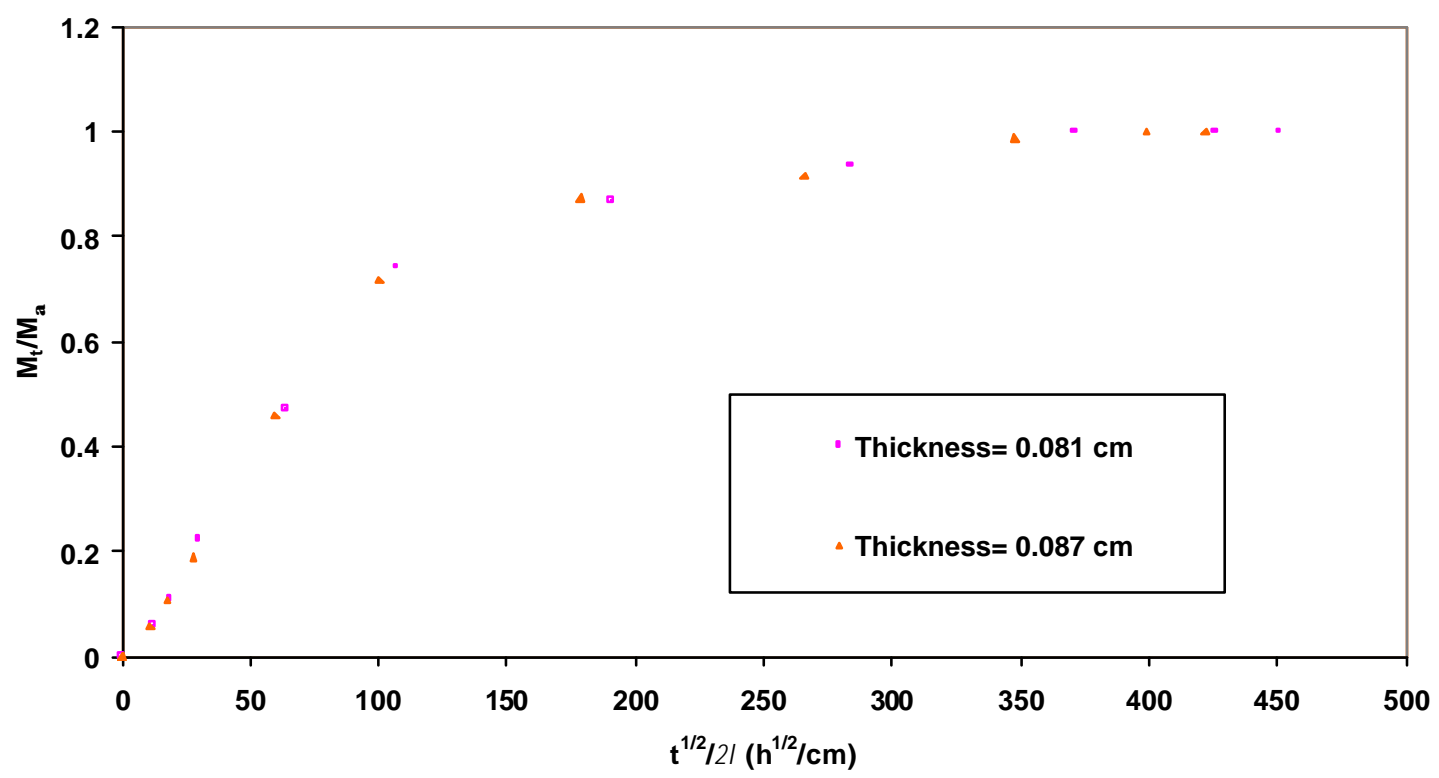

Figure 131. Corrected $M_{t} / M_{\infty}$ versus $t^{1 / 2} / 2 l$ for FRP samples containing 2 wt $\%$ Cloisite $10 A^{\circledR}$ immersed in $0.1 \mathrm{M} \mathrm{NaCl}$ solution at $4^{\circ} \mathrm{C}$

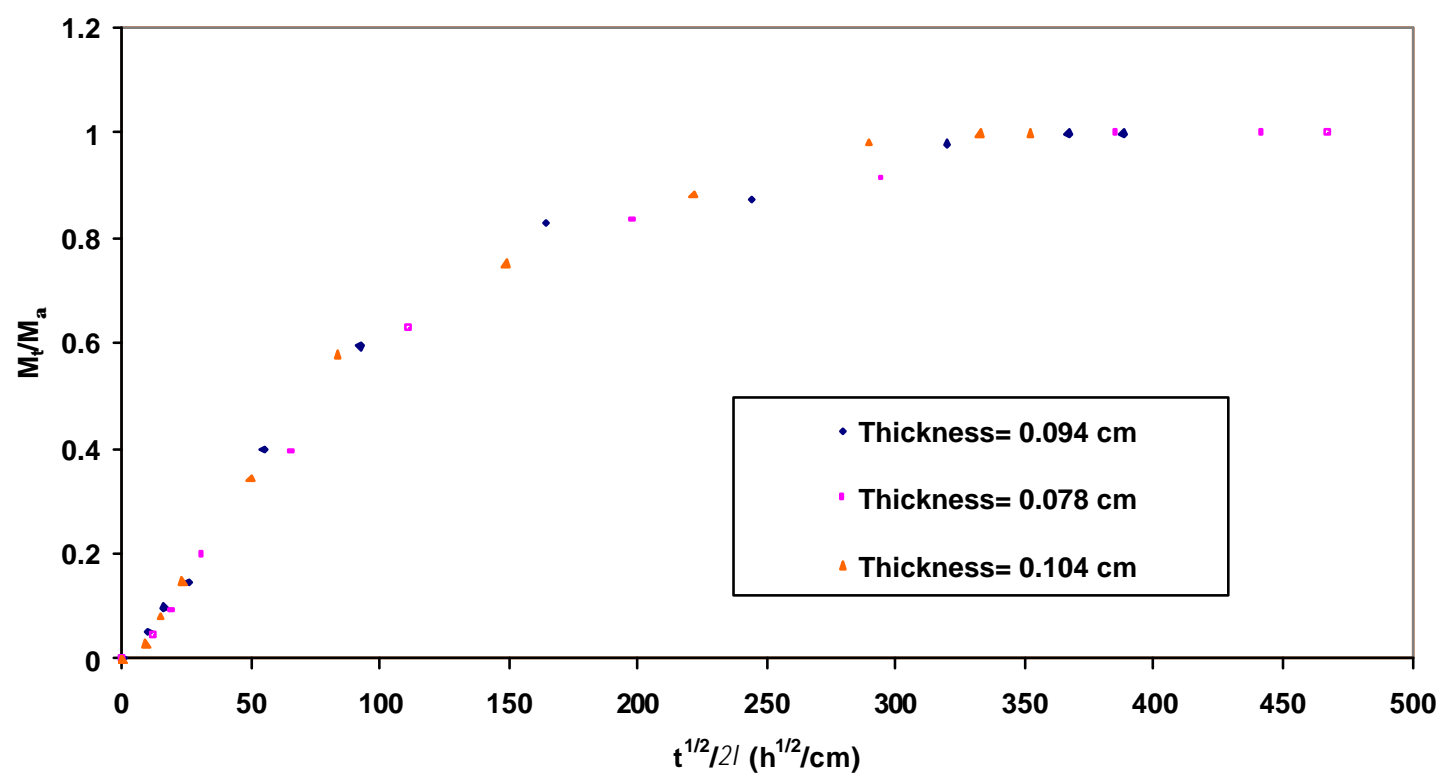

Figure 132. Corrected $M_{t} / M_{\infty}$ versus $t^{1 / 2} / 2 l$ for FRP samples containing 5 wt $\%$ Cloisite $10 A^{\circledR}$ immersed in $0.1 \mathrm{M} \mathrm{NaCl}$ solution at $4^{\circ} \mathrm{C}$ 


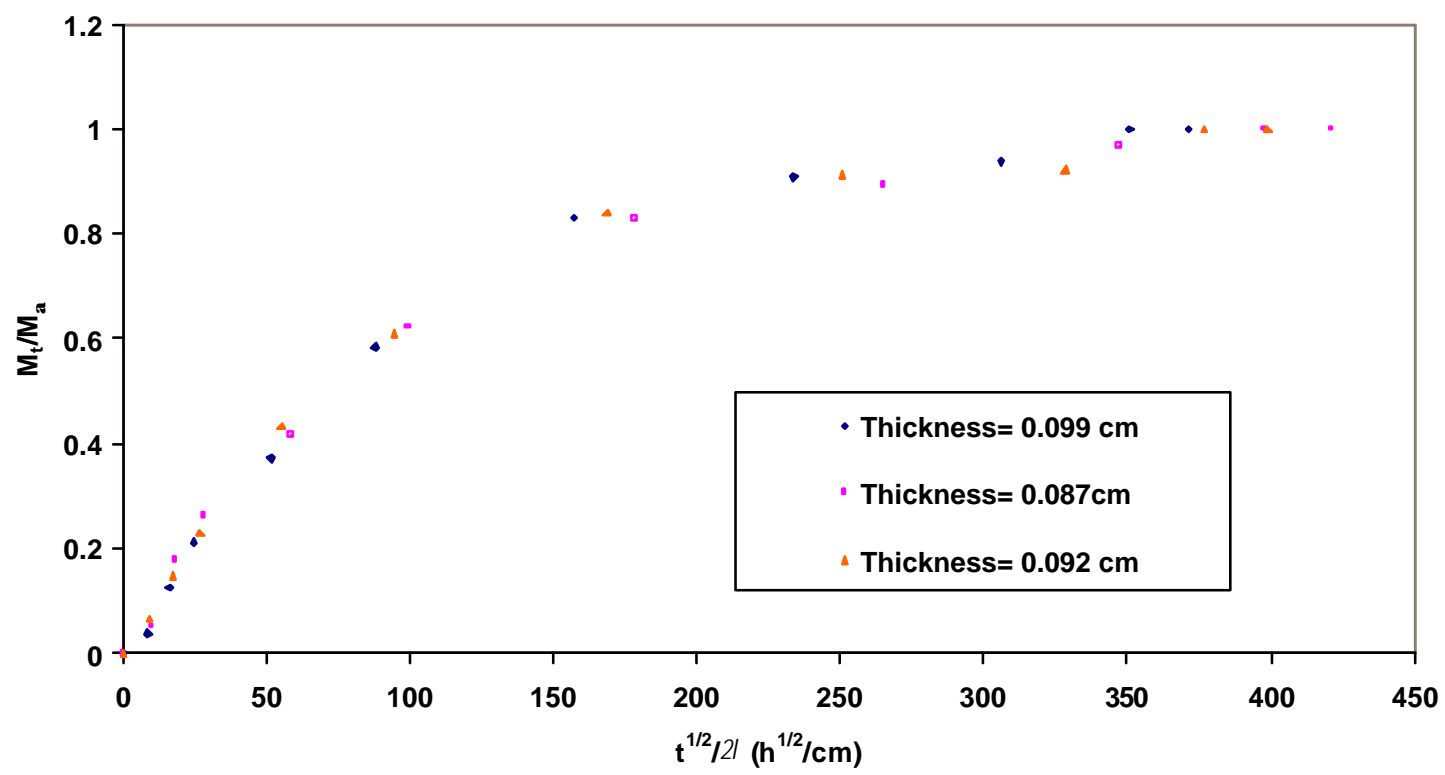

Figure 133. Corrected $M_{t} / M_{\infty}$ versus $t^{1 / 2} / 2 l$ for FRP samples containing 0 wt $\%$ Cloisite $10 A^{\circledR}$ immersed in $13 \mathrm{pH} \mathrm{NaOH}$ solution at $4^{\circ} \mathrm{C}$

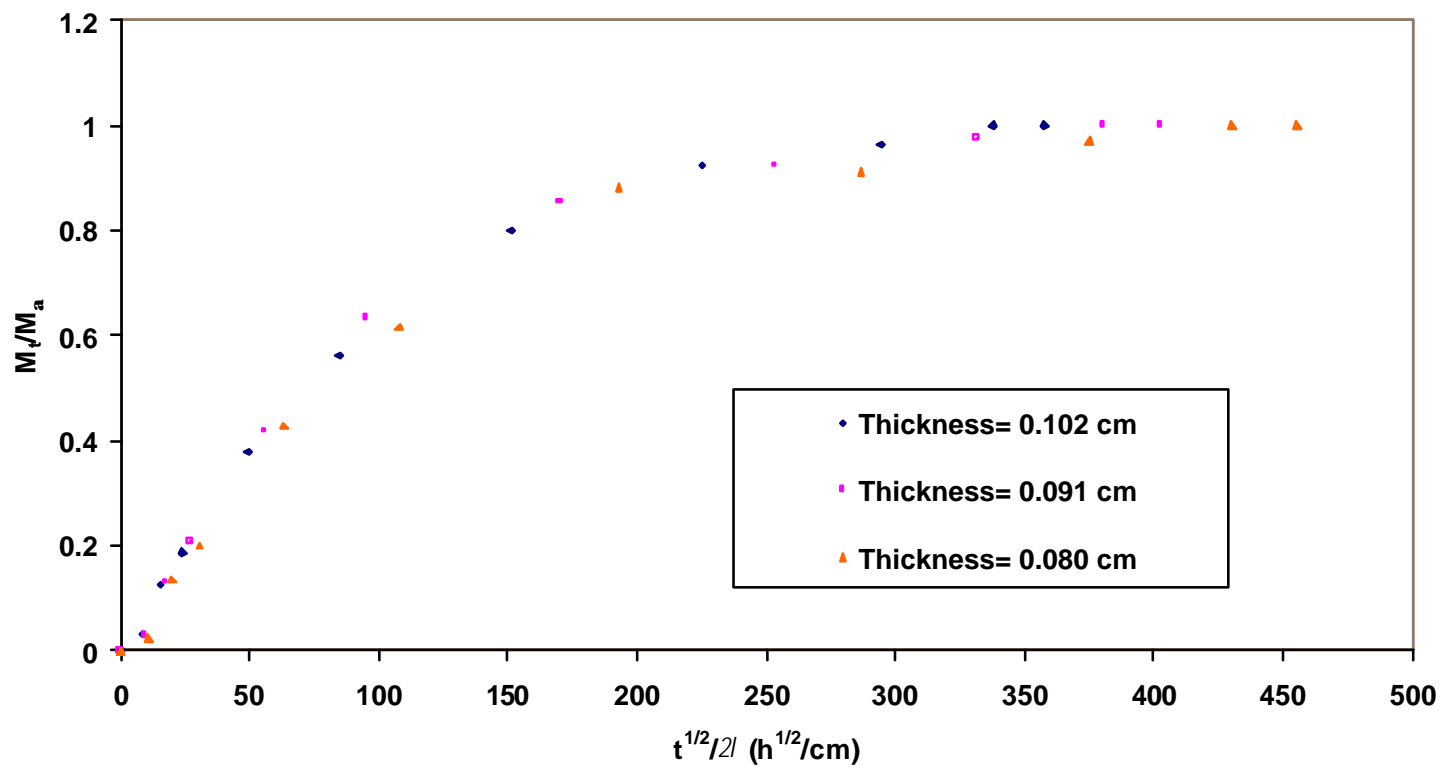

Figure 134. Corrected $M_{t} / M_{\infty}$ versus $t^{1 / 2} / 2 l$ for FRP samples containing $1 \mathrm{wt} \%$ Cloisite $10 \mathrm{~A}^{\circledR}$ immersed in $13 \mathrm{pH} \mathrm{NaOH}$ solution at $4^{\circ} \mathrm{C}$ 


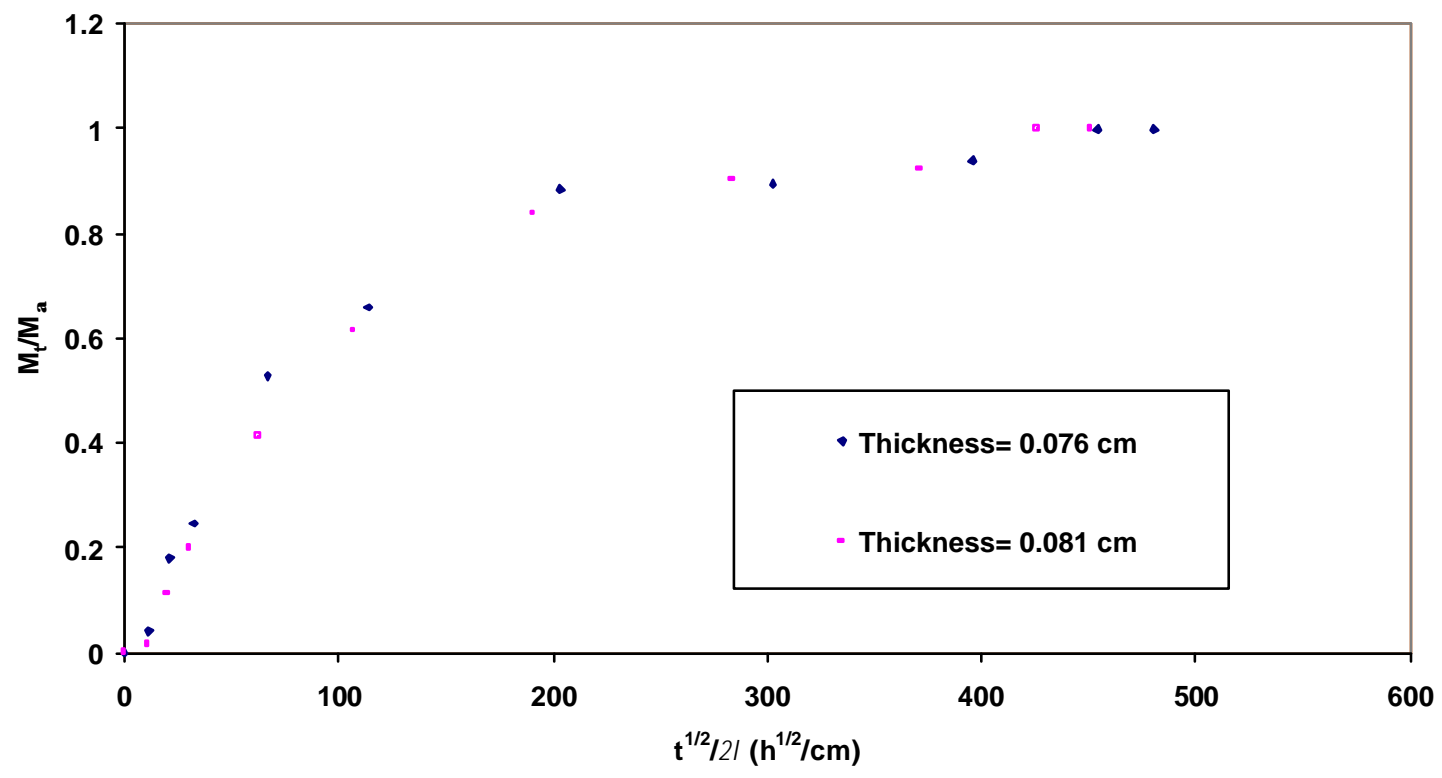

Figure 135. Corrected $M_{t} / M_{\infty}$ versus $t^{1 / 2} / 2 l$ for FRP samples containing 2 wt $\%$ Cloisite $10 A^{\circledR}$ immersed in $13 \mathrm{pH} \mathrm{NaOH}$ solution at $4^{\circ} \mathrm{C}$

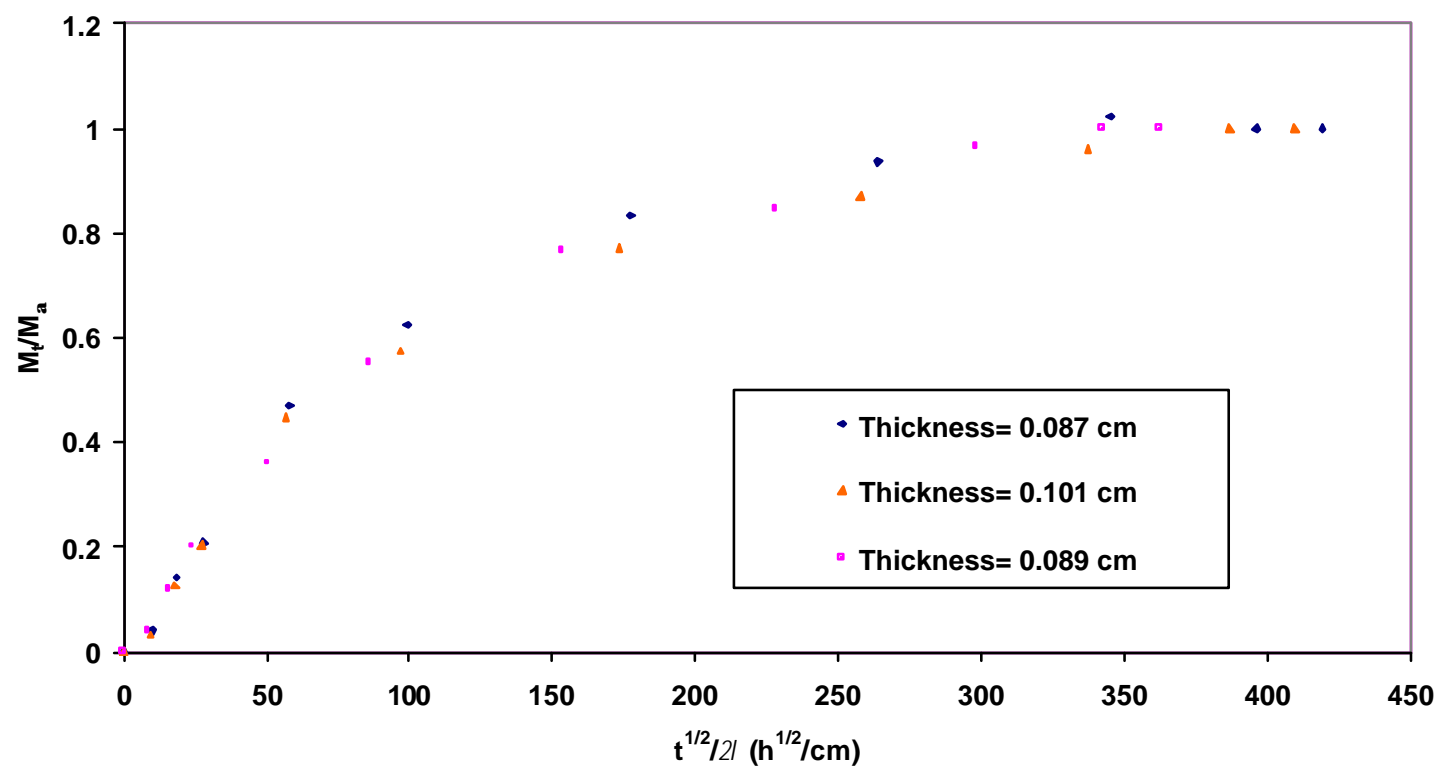

Figure 136. Corrected $M_{t} / M_{\infty}$ versus $t^{1 / 2} / 2 l$ for FRP samples containing 5 wt $\%$ Cloisite $10 A^{\circledR}$ immersed in $13 \mathrm{pH} \mathrm{NaOH}$ solution at $4^{\circ} \mathrm{C}$ 
The diffusion coefficients were calculated from the initial slopes of the corrected normalized weight gain curves. It is to be noted that the same diffusion coefficients can be obtained using non-corrected experimental data but the equilibrium moisture content thus calculated will be erroneous. The diffusion coefficients and the corrected equilibrium moisture contents are tabulated in Table XXVII and XXVIII respectively. Results for the un-reinforced samples are shown for the purpose of comparison.

Table XXVII. Diffusion Coefficients in $0.1 \mathrm{M} \mathrm{NaCl}$ and $13 \mathrm{pH}$ NaOH Solutions at $4^{\circ} \mathrm{C}$

\begin{tabular}{|c|c|c|c|c|}
\hline & \multicolumn{4}{|c|}{$\mathrm{D} \times 10^{+9}\left(\mathrm{~cm}^{2} / \mathrm{s}\right)$} \\
\hline Clay wt\% & $0 \mathrm{wt} \%$ & $1 \mathrm{wt} \%$ & $2 \mathrm{wt} \%$ & $5 \mathrm{wt} \%$ \\
\hline $0.1 \mathrm{M} \mathrm{NaCl}$ (FRP) & $2.65(0.19)$ & $2.46(0.33)$ & $2.45(0.21)$ & $1.84(0.06)$ \\
\hline $0.1 \mathrm{M} \mathrm{NaCl}$ (Un-reinforced) & 1.19 & 1.18 & 0.83 & 0.84 \\
\hline $13 \mathrm{pH} \mathrm{NaOH}$ (FRP) & $3.21(0.25)$ & $2.86(0.37)$ & $2.78(0.46)$ & $3.32(0.12)$ \\
\hline $13 \mathrm{pH} \mathrm{NaOH}$ (Un-reinforced) & 1.74 & 1.14 & 0.74 & 0.55 \\
\hline
\end{tabular}

Note: Values shown in the brackets are standard deviations

Table XXVIII. Equilibrium Moisture Contents in $0.1 \mathrm{M} \mathrm{NaCl}$ and $13 \mathrm{pH} \mathrm{NaOH}$ solutions at $4^{\circ} \mathrm{C}$

\begin{tabular}{|c|c|c|c|c|}
\hline & \multicolumn{4}{|c|}{ Equilibrium Moisture Content (\%) } \\
\hline Clay wt\% & 0 wt \% & 1 wt \% & 2 wt \% & 5 wt \% \\
\hline $0.1 \mathrm{M} \mathrm{NaCl}(\mathrm{FRP})$ & $0.83(0.21)$ & $0.79(0.11)$ & $0.96(0.10)$ & $0.95(0.07)$ \\
\hline $0.1 \mathrm{M} \mathrm{NaCl}$ (Un-reinforced) & 0.58 & 0.66 & 0.59 & 0.61 \\
\hline $13 \mathrm{pH} \mathrm{NaOH}$ (FRP) & $0.74(0.07)$ & $0.68(0.04)$ & $1.02(0.02)$ & $1.05(0.02)$ \\
\hline $13 \mathrm{pH} \mathrm{NaOH}$ (Un-reinforced) & 0.67 & 0.65 & 0.66 & 0.70 \\
\hline
\end{tabular}

Note: Values shown in the brackets are standard deviations 
It can be seen from Table XXVIII that the equilibrium moisture contents in the FRP samples were consistently higher than those values for the corresponding unreinforced nanocomposite samples in both the saline and the alkaline solutions. This indicated that some water molecules were able to interact with the sizing material even at a low temperature. Due to the lack of thickness correction factors, the diffusion coefficients of water in the FRP samples were consistently higher than those in the corresponding un-reinforced nanocomposites. Nevertheless, the trend of decreasing diffusion coefficient with increasing amount of clay in FRPs was apparent. Variations in diffusion coefficients and equilibrium moisture contents with various clay loadings are graphically shown in Figure 137 and 138 respectively for the reinforced samples immersed in $0.1 \mathrm{M} \mathrm{NaCl}$ solution at $4^{\circ} \mathrm{C}$.

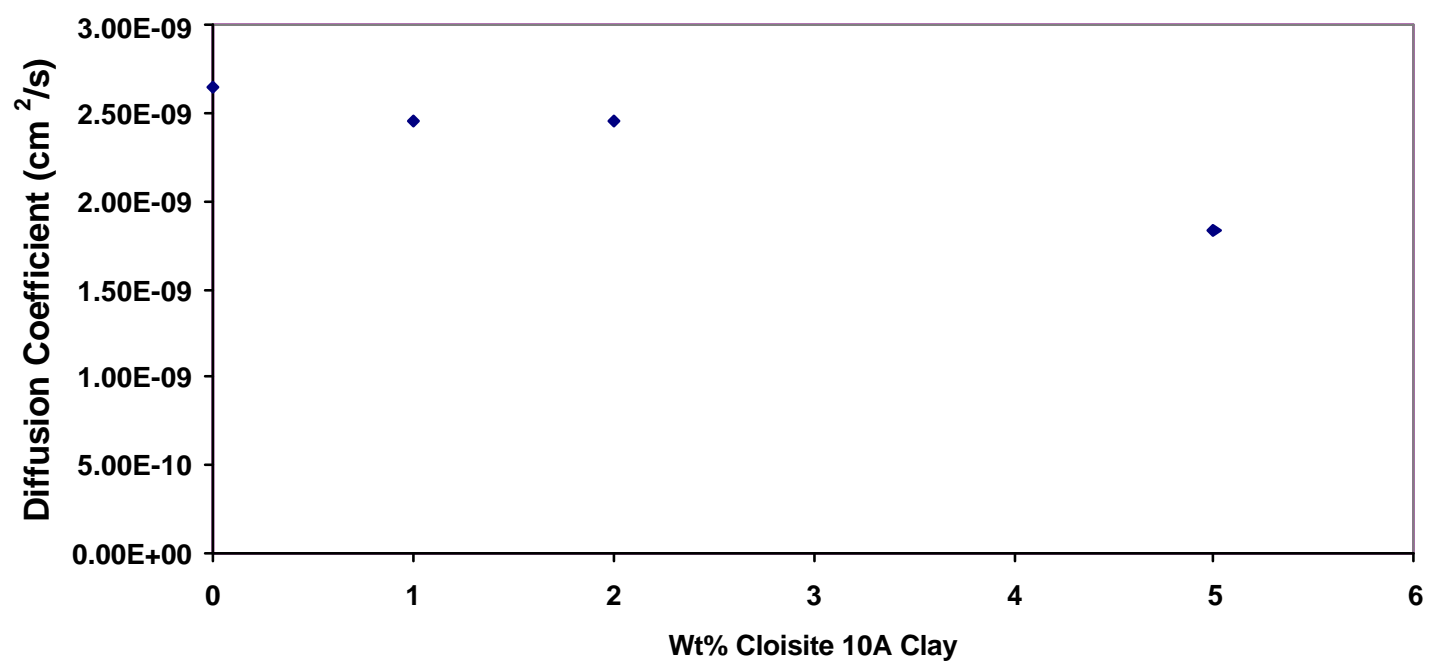

Figure 137. Variations in diffusion coefficients with various clay loadings for the FRP samples immersed in $0.1 \mathrm{M} \mathrm{NaCl}$ solution at $4^{\circ} \mathrm{C}$ 


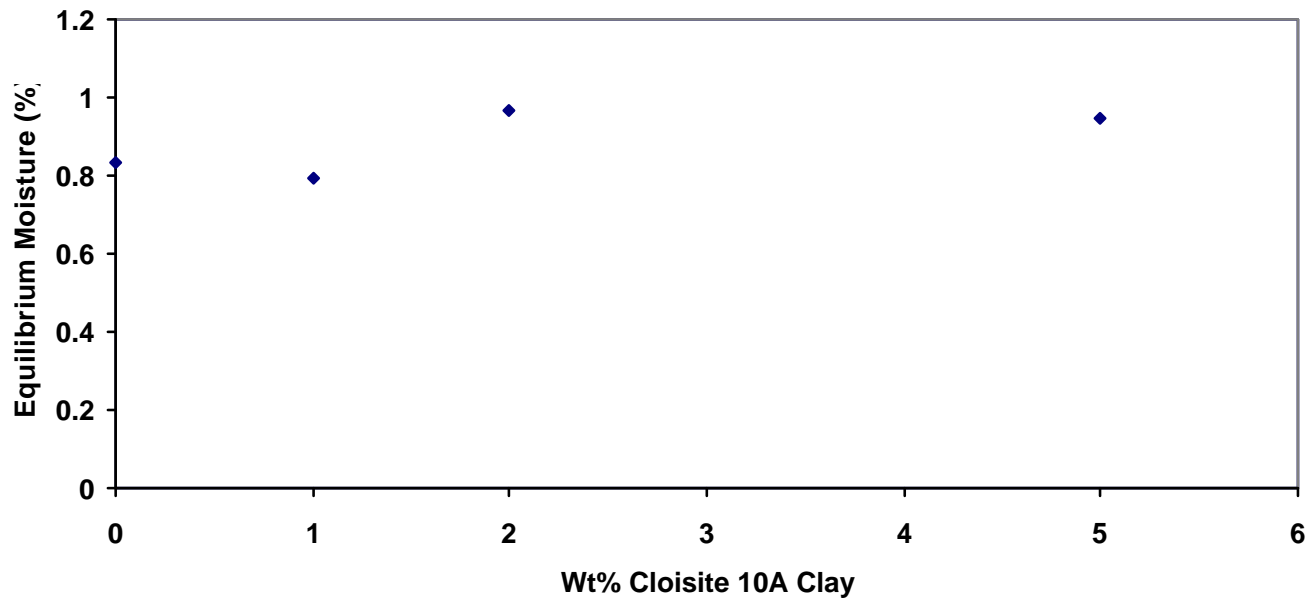

Figure 138. Variations equilibrium moisture contents with various clay loadings for the FRP samples immersed in $0.1 \mathrm{M} \mathrm{NaCl}$ solution at $4^{\circ} \mathrm{C}$

Variations in diffusion coefficients and equilibrium moisture contents with various clay loadings are graphically shown in Figure 139 and 140 respectively for the reinforced samples immersed in $13 \mathrm{pH} \mathrm{NaOH}$ solution at $4^{\circ} \mathrm{C}$.

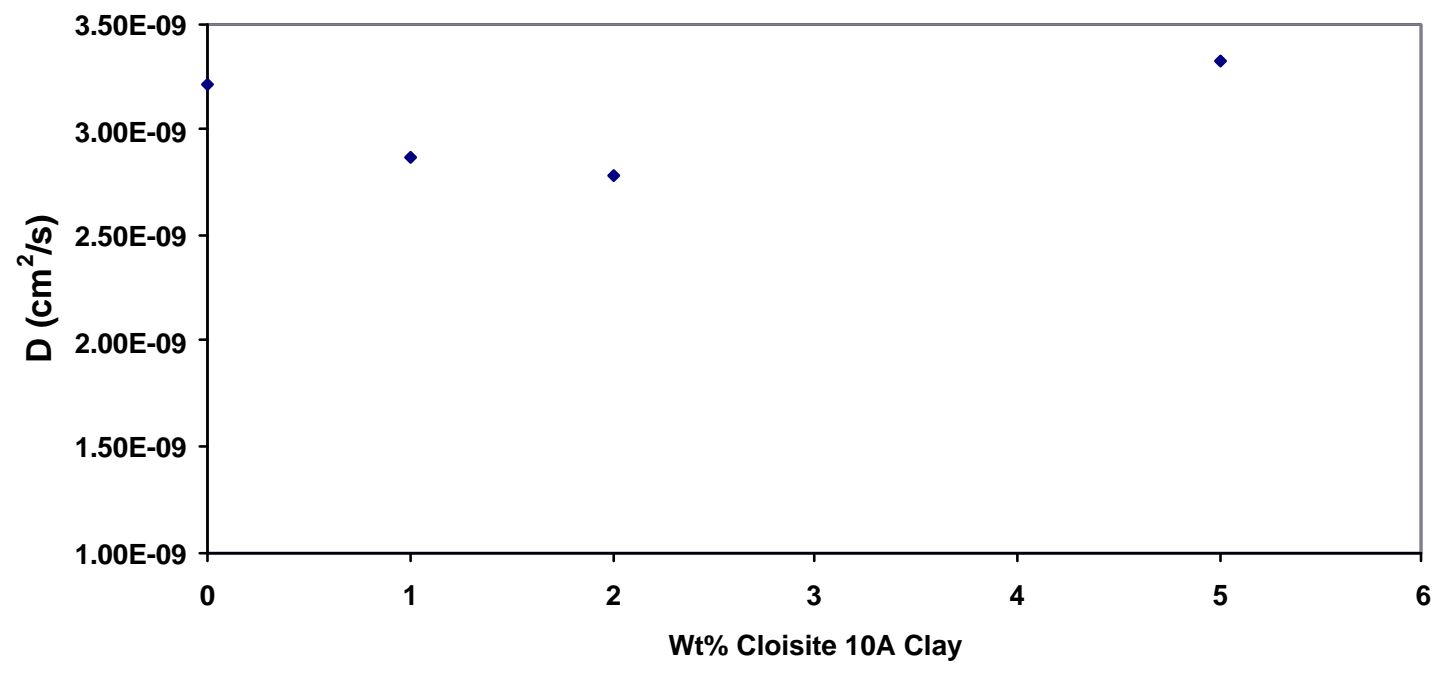

Figure 139. Variations in diffusion coefficients with various clay loadings for the FRP samples immersed in $13 \mathrm{pH} \mathrm{NaOH}$ solution at $4^{\circ} \mathrm{C}$ 


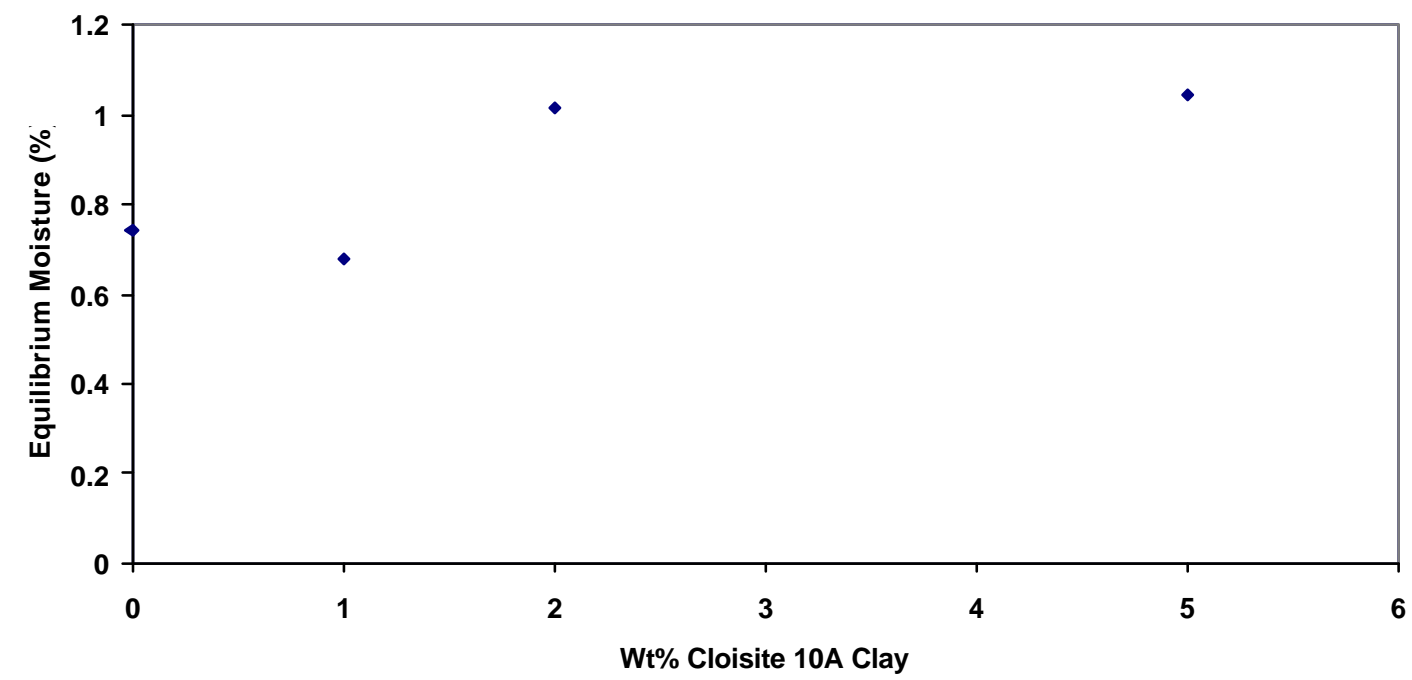

Figure 140. Variations equilibrium moisture contents with various clay loadings for the FRP samples immersed in $13 \mathrm{pH} \mathrm{NaOH}$ solution at $4^{\circ} \mathrm{C}$

It can be seen from Figure 139 that the diffusion coefficient decreased with increasing amount of clay in the FRP samples immersed in $13 \mathrm{pH} \mathrm{NaOH}$ solution at $4^{\circ} \mathrm{C}$ except for the samples containing $5 \mathrm{wt} \%$ of nanoclay. This anomaly can be attributed to some defects in the samples.

\subsection{Desorption Experiments}

A graph of $M_{t} / M_{\infty}$ versus $t^{1 / 2} / 2 l$ was plotted for all the un-reinforced samples. Here $M_{t}$ and $M_{\infty}$ are mass loss at time $t$ and at equilibrium respectively. $t$ is time and $2 l$ is the thickness of the sample. From the initial slopes of these curves, diffusion coefficients were calculated according to the method explained in section 2.1. Mass-loss curves are shown in Figure 141 to Figure 144 and the results are summarized in Table XXIX. 




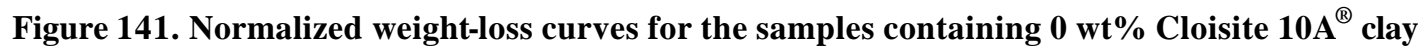

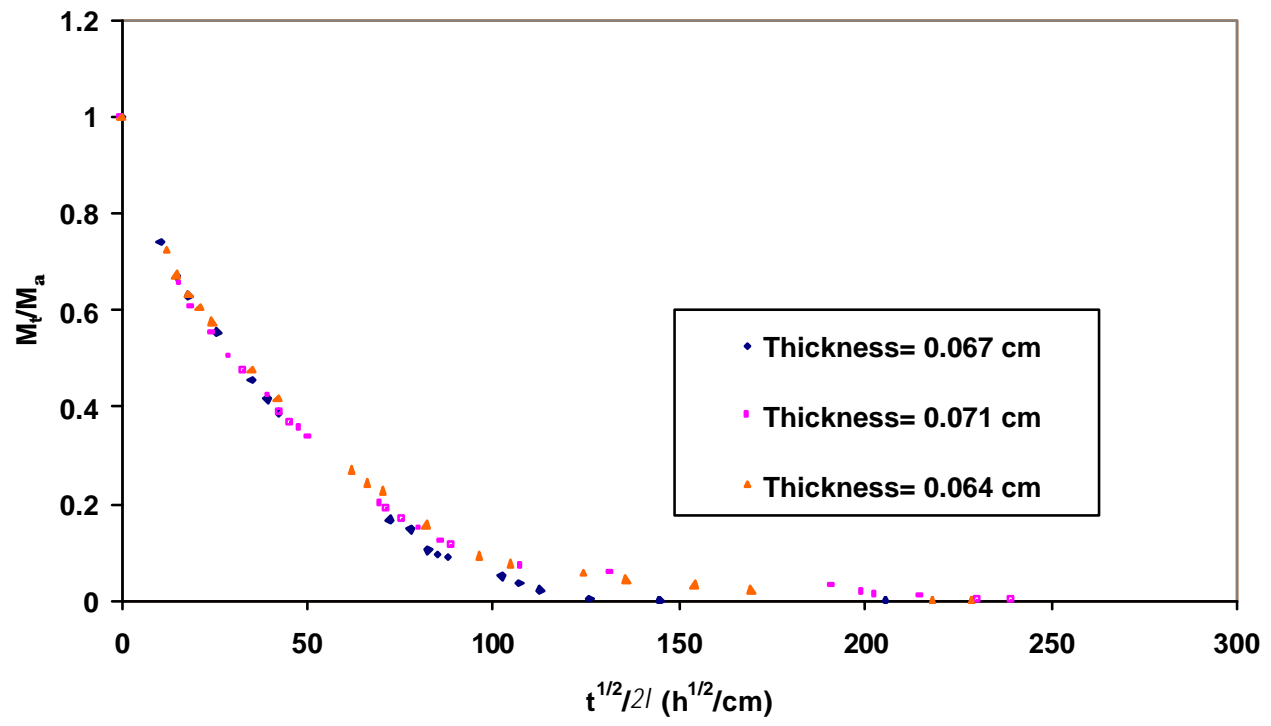

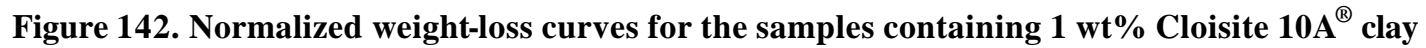




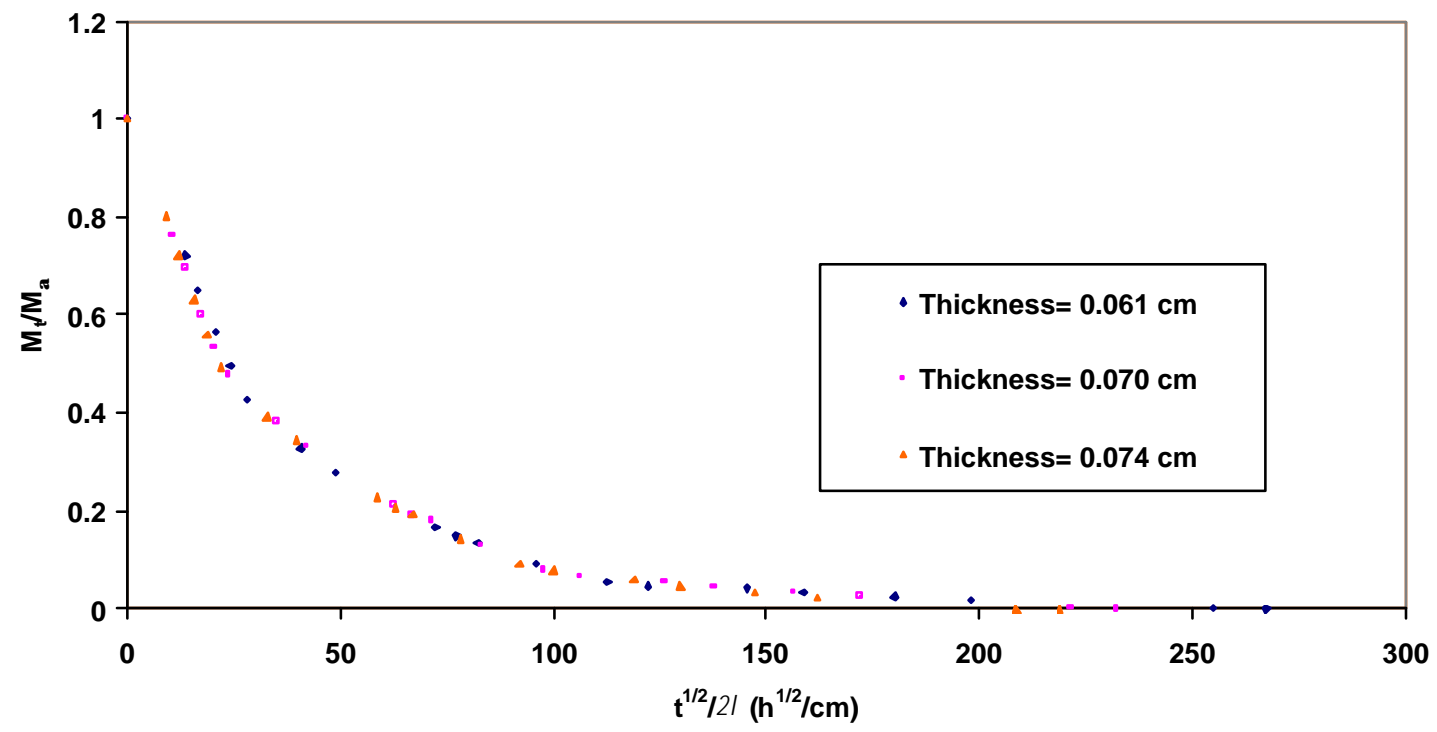

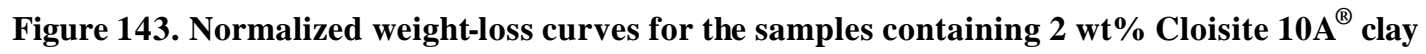

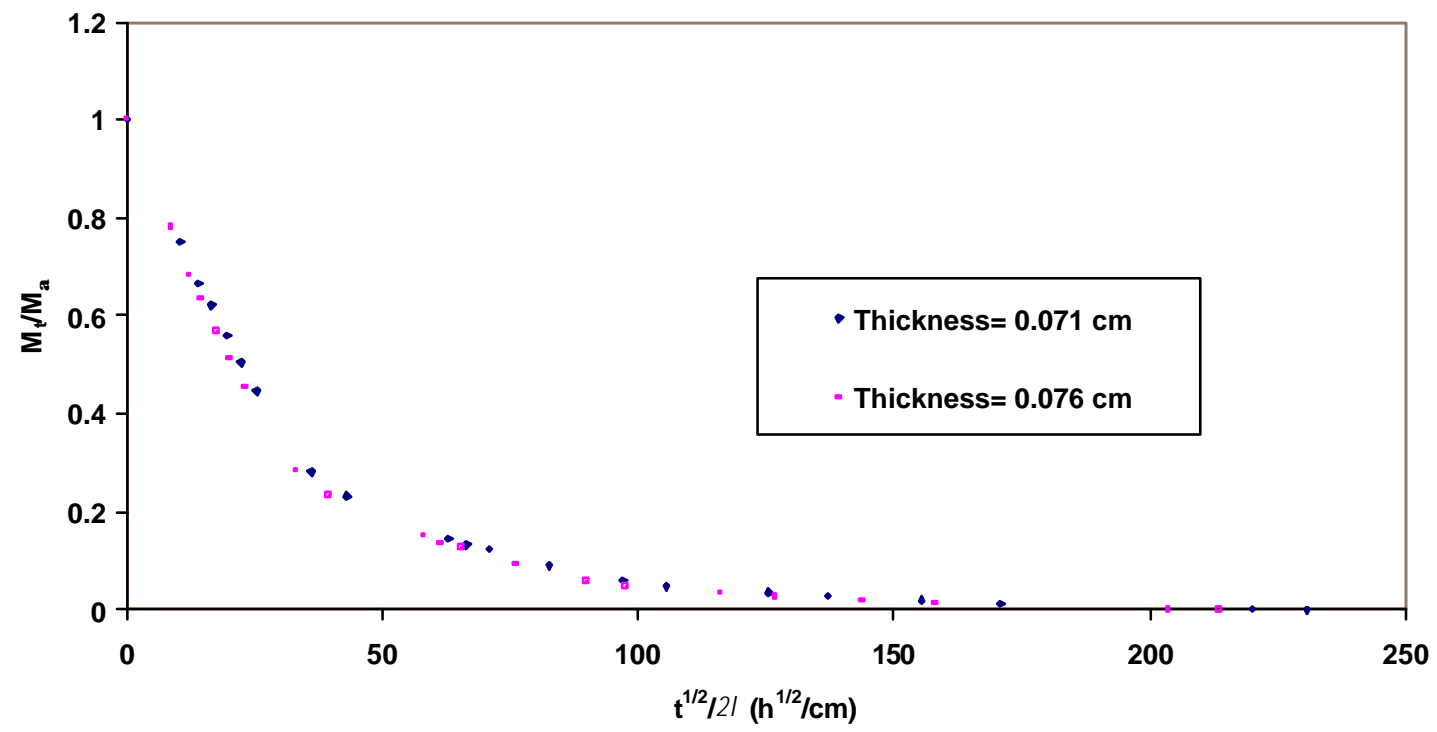

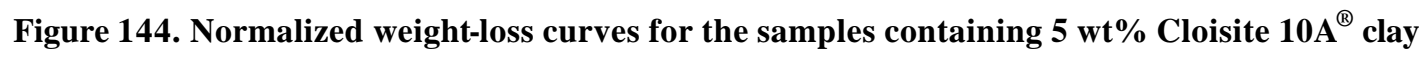


Table XXIX. Comparison of diffusion coefficients for desorption and absorption at $25^{\circ} \mathrm{C}$

\begin{tabular}{|c|c|c|}
\hline $\begin{array}{c}\text { Wt \% Cloisite } \\
10 A^{\circledR}\end{array}$ & $\begin{array}{c}\mathrm{D} \times 10^{+9}\left(\mathrm{~cm}^{2} / \mathrm{s}\right) \\
\text { Desorption }\end{array}$ & $\begin{array}{c}\mathrm{D} \times 10^{+9}\left(\mathrm{~cm}^{2} / \mathrm{s}\right) \\
\text { Absorption }\end{array}$ \\
\hline 0 & $10.70(0.75)$ & 7.36 \\
\hline 1 & $19.80(0.94)$ & 4.01 \\
\hline 2 & $27.00(3.01)$ & 2.76 \\
\hline 5 & $32.50(3.74)$ & 0.61 \\
\hline
\end{tabular}

Note: Values shown in the brackets are standard deviations

It is clearly seen from Table XXIX that the diffusion coefficient for absorption and desorption for the samples without nanoclay are comparable but not the same. The desorption diffusion coefficients for nanocomposite samples were much higher than the absorption diffusion coefficients for the same type of samples. The results indicated that the presence of nanoclay in the polymer had a strong effect on the desorption mechanism of the nanocomposite samples. Cyclic absorption-desorption experiments were conducted to give insight to this phenomenon. Neat resin samples and samples containing $5 \mathrm{wt} \%$ clay were immersed in distilled water at $25^{\circ} \mathrm{C}$ for 8 hours. Then they were taken out and were kept in a chamber maintained at $20 \% \mathrm{RH}$ at the same temperature for 16 hours. Immediately after that, all the samples were re-immersed in distilled water for 8 hours and the second absorption cycle was carried out. The second desorption, the third absorption and the third desorption was carried out exactly as they were done in the first cycle. The results of three consecutive absorption cycles for a neat resin sample are shown in Figure 145. Similar plot for a representative nanocomposite sample containing $5 \mathrm{wt} \%$ clay is shown in Figure 146. Experimental data can be found in appendix A.2. 


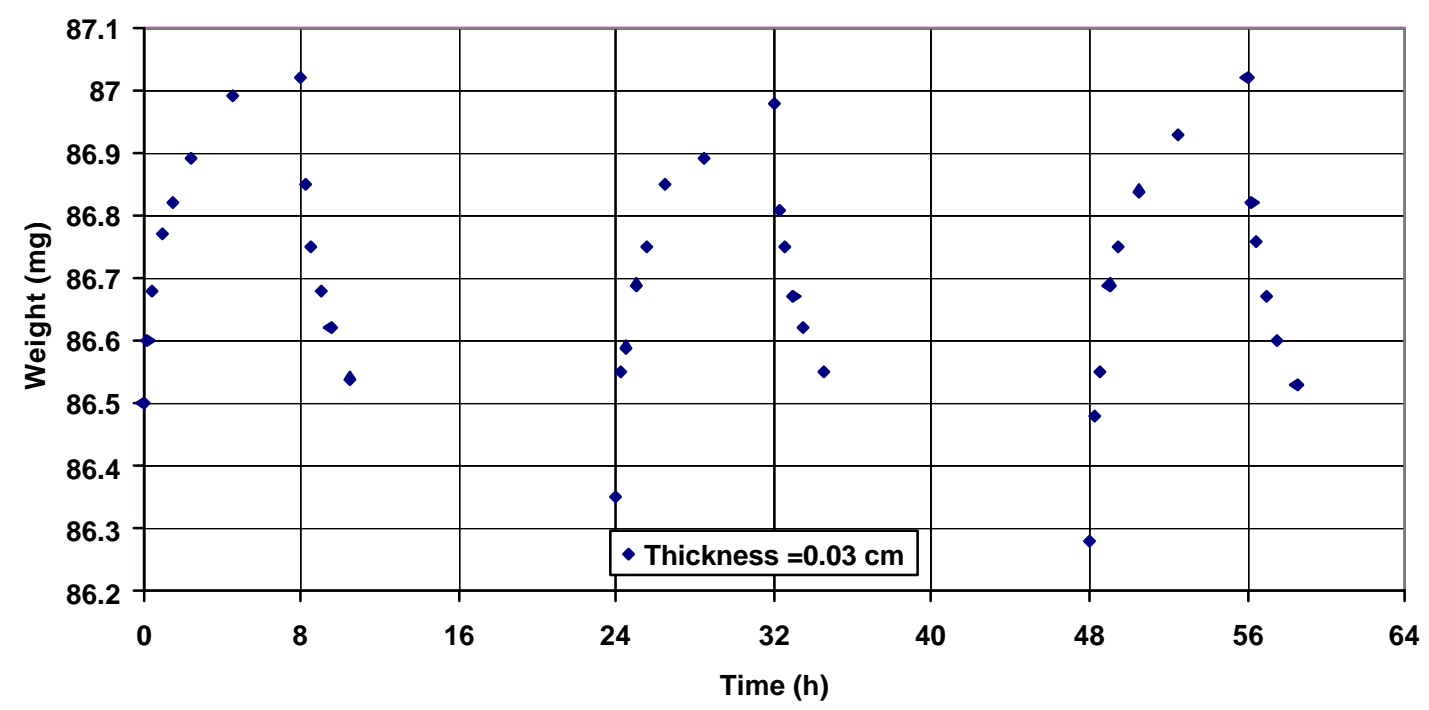

Figure 145. Weight change versus time for a neat resin sample

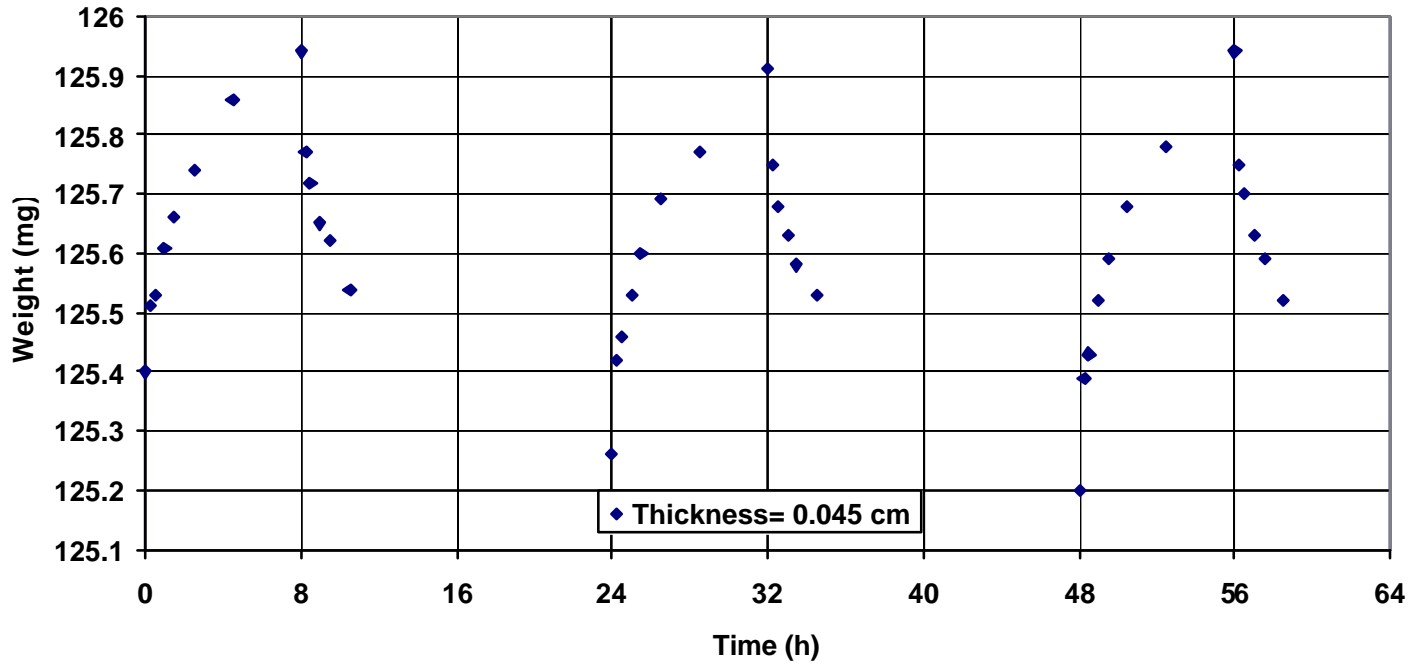

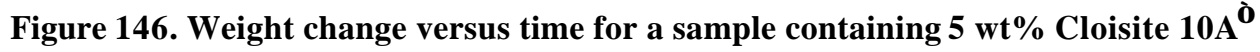

It can be clearly seen from Figures 145 and 146 that the there were no pronounced differences in the consecutive absorption or desorption cycles. Diffusivities for the consecutive absorption cycles were calculated and the results are shown in the Table XXX: 
Table XXX. Diffusivities of representative samples calculated for three consecutive absorption cycles

\begin{tabular}{|c|c|c|c|}
\hline Wt\% Clay & $\begin{array}{c}\text { First Absorption } \\
\mathrm{D} \times 10^{+9}\left(\mathrm{~cm}^{2} / \mathrm{s}\right)\end{array}$ & $\begin{array}{c}\text { Second Absorption } \\
\mathrm{D} \times 10^{+9}\left(\mathrm{~cm}^{2} / \mathrm{s}\right)\end{array}$ & $\begin{array}{c}\text { Third Absorption } \\
\mathrm{D} \times 10^{+9}\left(\mathrm{~cm}^{2} / \mathrm{s}\right)\end{array}$ \\
\hline $0 \mathrm{wt} \%$ Clay & 7.14 & 6.87 & 6.90 \\
\hline $5 \mathrm{wt} \%$ Clay & 0.63 & 0.77 & 0.91 \\
\hline
\end{tabular}

It can be seen from the above table that there were no large differences among the diffusivities obtained from repeated absorption experiments. The experimental values of diffusivities calculated with the complete absorption experiments (section 6.1) were $7.36 \times 10^{-9}$ and $0.61 \times 10^{-9} \mathrm{~cm}^{2} / \mathrm{s}$ for neat resin and $5 \mathrm{wt} \%$ nanocomposite respectively. This suggested that the absorption did not cause any irreversible damage to the chemical structure of the resin. The repeated desorption data for representative samples were superimposed on the complete normalized weight-loss curves obtained during the desorption experiments. The plots are shown in Figures 147 and 148.

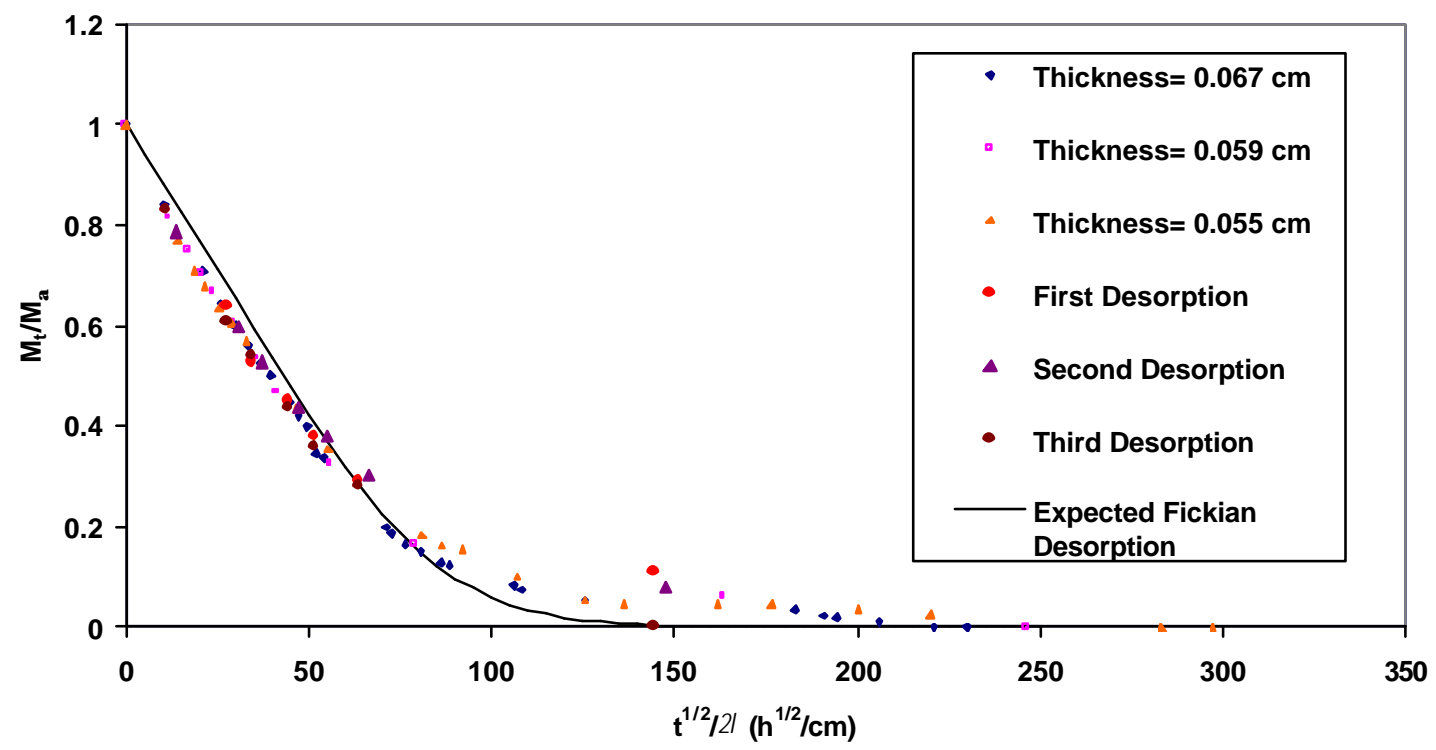

Figure 147. Superimposition of short-time desorption data for the neat resin sample on the complete desorption curve of neat resin 


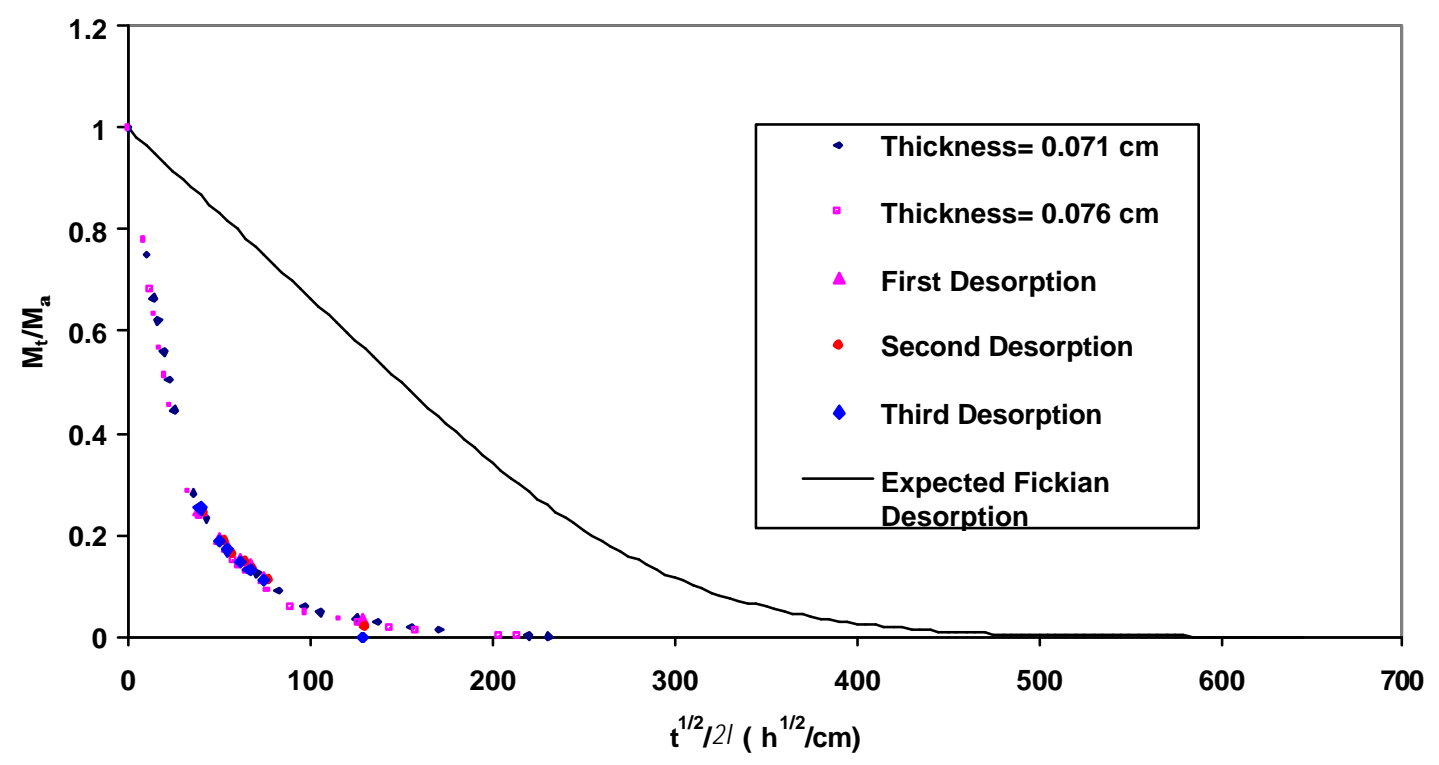

Figure 148 Superimposition of short-time desorption data for the 5 wt $\%$ clay containing sample on the complete desorption curve of for similar samples

It is clearly seen from Figure 147 and Figure 148 that the experimental data that the experimental data for the repeated desorption experiment superimposed very well on the complete desoption curves. Moreover, there were no pronounced differences between the consecutive desorption cycles. These results also indicated that there are no changes in the chemical structure of the resin during absorption or desorption. Ideally, it is expected that diffusion coefficients for the absorption and desorption process should be the same for a material that shows Fickian diffusion. Therefore, the expected Fickian weight-loss data calculated using the absoption diffusion coefficients are also shown in Figures 147 and 148. It is apparent from Figure 147 that there is a reasonable agreement between the Fickian desorption curve and the experimental data recorded for the desoption experiments for the neat resin. However, such agreement is not seen when the sample contained nanoclay (Figure 148). The diffusivities of desorption were found to be 
much higher than the diffusivity of absorption for the nanocomposite samples as mentioned earlier in this section. Further study is recommended to understand the desorption mechanism of nanocomposite samples.

\subsection{Steady State Diffusion Experiments}

Periodic weight gain of the assembly shown in Figure 37 was determined for each assembly after putting it in a chamber maintained at a relative humidity of $77 \%$ at $25^{\circ} \mathrm{C}$. Weight gain versus time plots for some of the samples are shown in Figures 149 to 152. It can be seen from the graphs that a steady state was achieved after approximately 200 hours. Diffusion coefficients for different samples calculated using equation 5 and average values of diffusion coefficients are shown in Table XXXI.

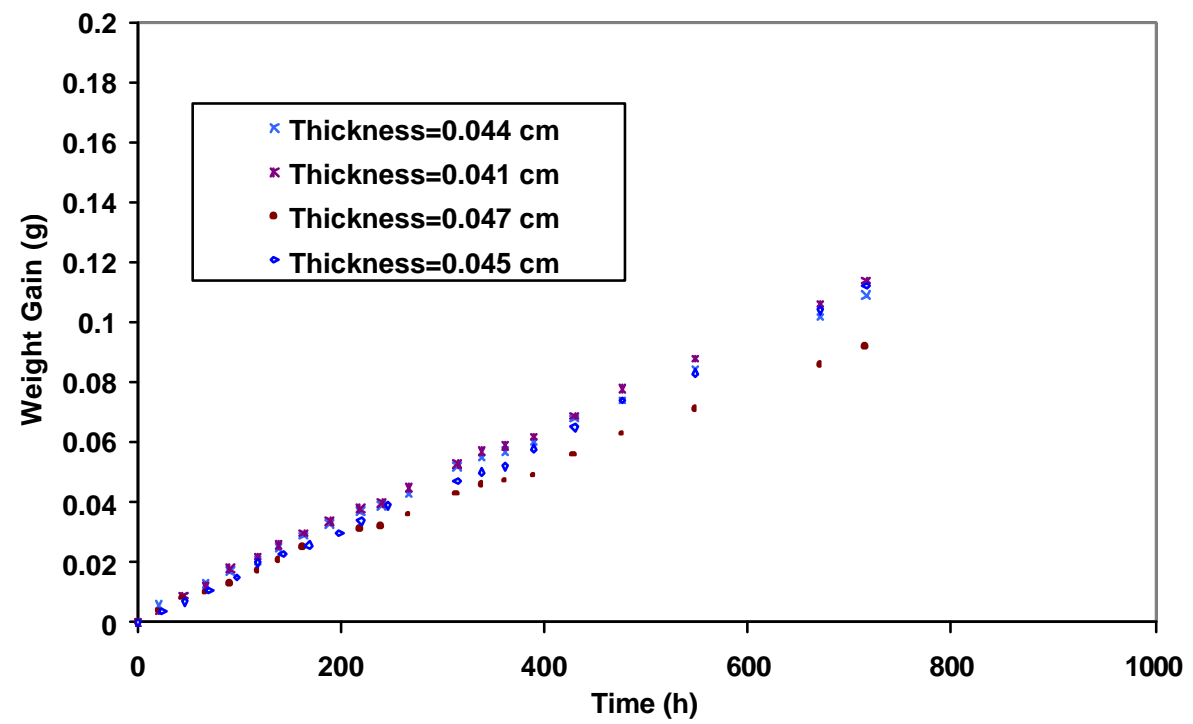

Figure 149. Weight gain versus time for assemblies covered with a polymeric film containing 0 wt $\%$ Cloisite 10A ${ }^{\circledR}$ 


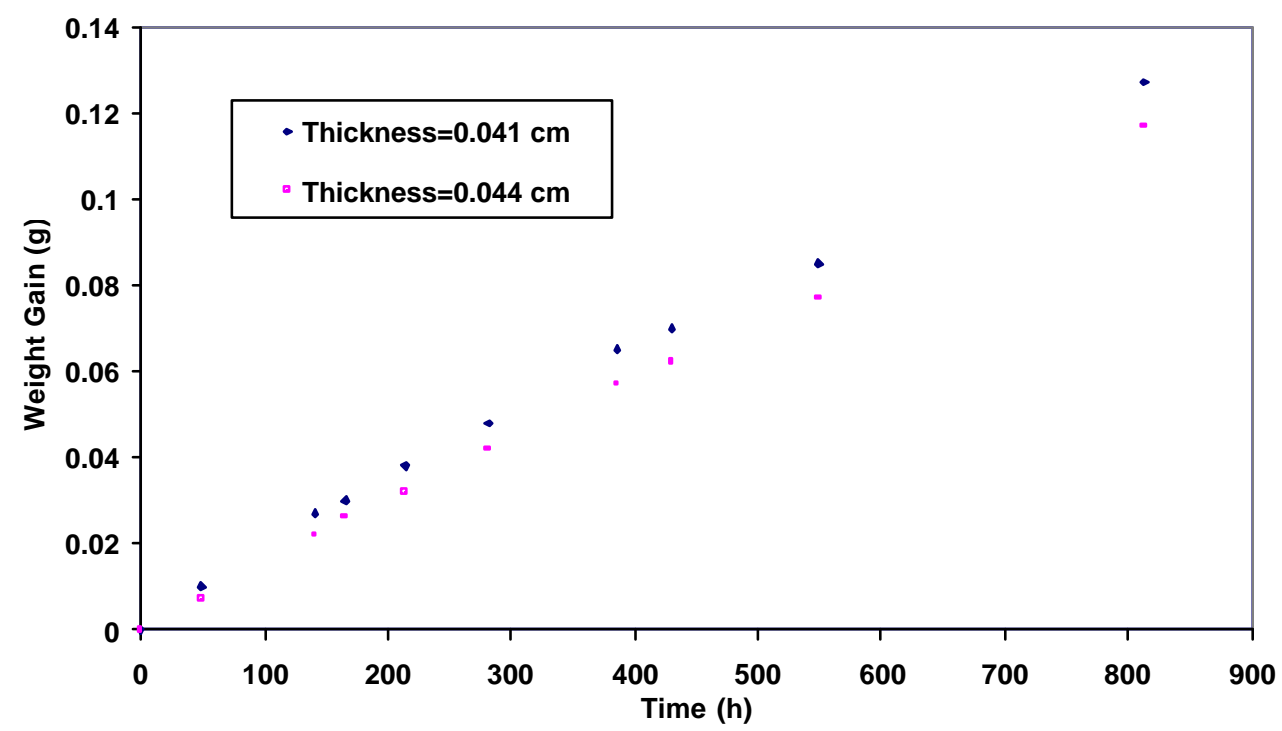

Figure 150. Weight gain versus time for assemblies covered with a polymeric film containing $1 \mathrm{wt} \%$ Cloisite 10A ${ }^{\circledR}$

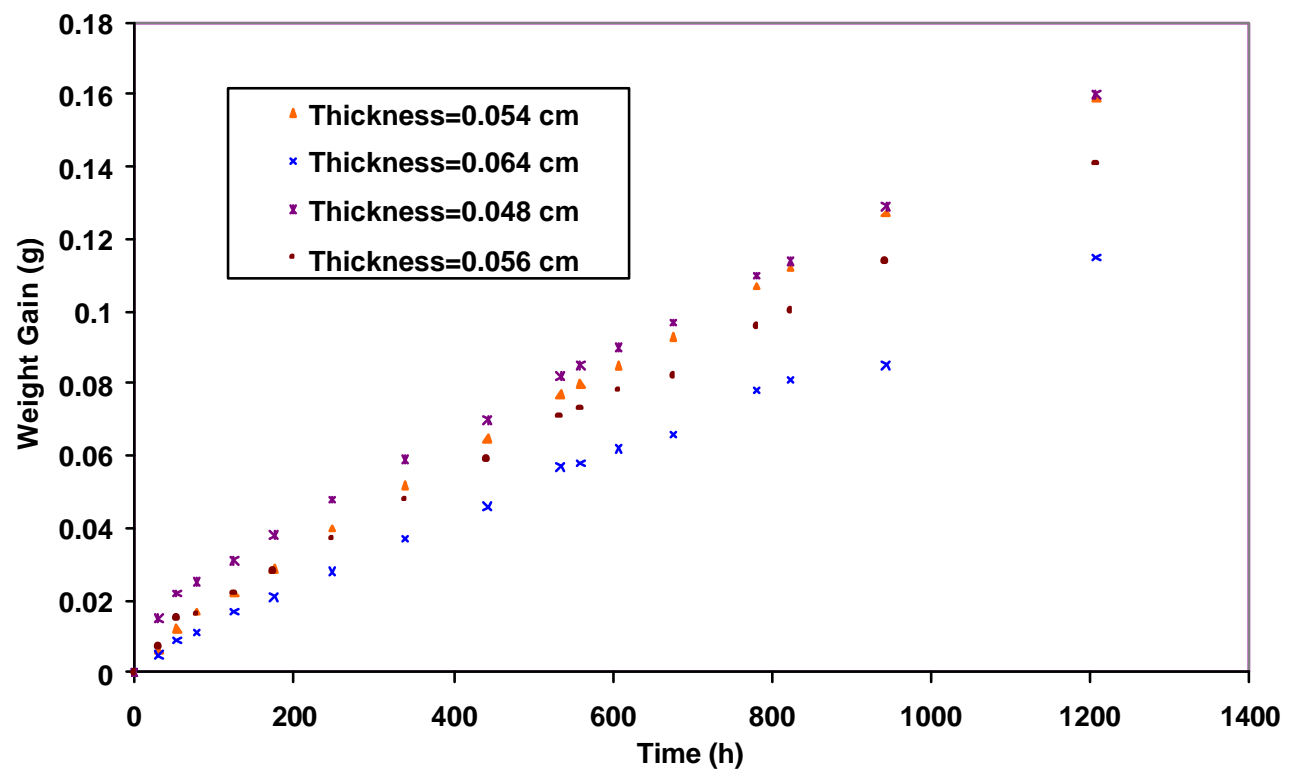

Figure 151. Weight gain versus time for assemblies covered with a polymeric film containing $2 \mathrm{wt} \%$ Cloisite 10A ${ }^{\circledR}$ 


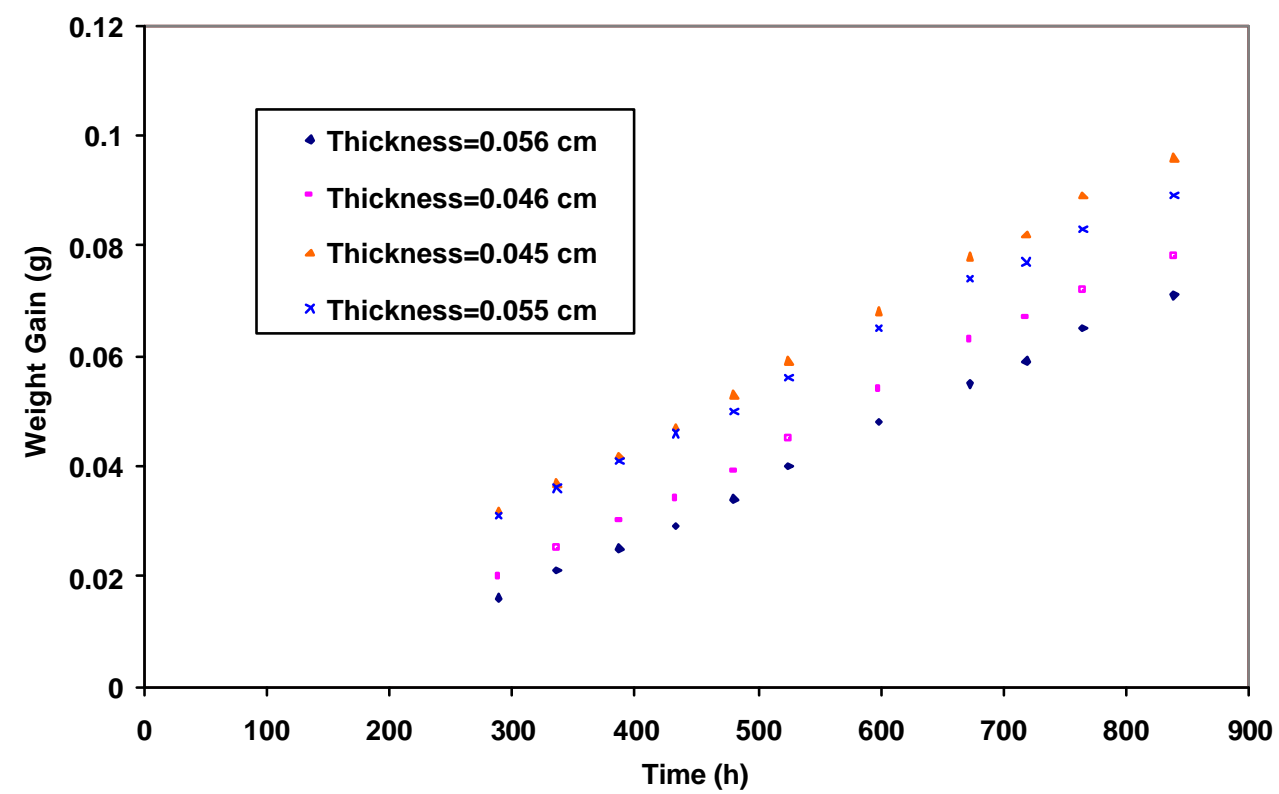

Figure 152. Weight gain versus time for assemblies covered with a polymeric film containing 5 wt $\%$ Cloisite 10A ${ }^{\circledR}$

Table XXXI. Diffusion coefficients calculated from steady state diffusion experiments

\begin{tabular}{|c|c|}
\hline Wt \% Cloisite 10A & D $\times 10^{+9}\left(\mathrm{~cm}^{2} / \mathrm{s}\right)$ \\
\hline 0 & $7.29(0.20)$ \\
\hline 1 & $6.50(0.09)$ \\
\hline 2 & $6.05(0.31)$ \\
\hline 5 & $5.76(0.30)$ \\
\hline
\end{tabular}

Note: Values shown in the brackets are standard de viations

It is evident from Table XXXI that as the weight percent of Cloisite $10 \mathrm{~A}^{\circledR}$ clay increased, the diffusion coefficient decreased. The diffusion coefficient decreased by $11 \%$ by addition of 1 wt $\%$ of clay in polymer. A $17 \%$ and $21 \%$ reduction in diffusion coefficient was achieved by the addition of $2 \mathrm{wt} \%$ and $5 \mathrm{wt} \%$ clay in polymer 
respectively. From equation 5, it was obvious that the value of diffusion coefficient is affected by two factors: 1) Flux of water molecules 2) Concentration gradient. According to equation 5, either an increase in the concentration gradient or decrease in flux helps to reduce the diffusion coefficient. The normalized flux (product of flux and thickness of sample) was plotted against the weight percent of clay. Table XXXII clearly shows that the normalized flux decreased with increasing amount of clay in polymer, which is graphically shown in Figure 153.

Table XXXII. Variation in Normalized flux with clay content

\begin{tabular}{|c|c|}
\hline Wt \% Cloisite $\left.10 A^{(}\right)$ & $\begin{array}{r}\text { Normalized Flux } \times 10^{+6} \\
=\text { Flux } * \text { Thickness } \\
(\mathrm{gm} * \mathrm{~cm} / \mathrm{h})\end{array}$ \\
\hline 0 & $6.51(0.21)$ \\
\hline 1 & $6.09(0.09)$ \\
\hline 2 & $5.79(0.37)$ \\
\hline 5 & $5.59(0.29)$ \\
\hline
\end{tabular}

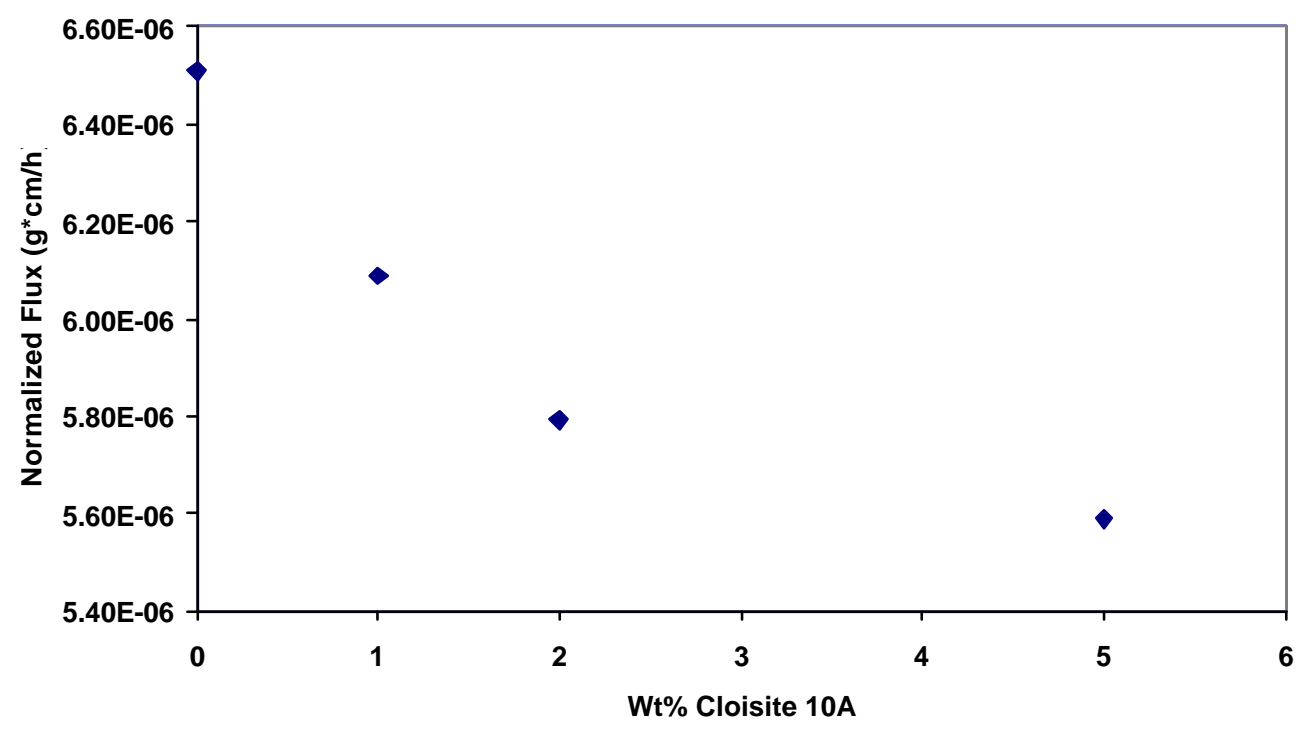

Figure 153. Normalized flux versus weight percent Cloisite $10 \mathrm{~A}^{\circledR}$ 
Weight-gain versus time plots for FRP films containing various amounts of nanoclay are shown in Figure 154 to 157 . The diffusion coefficients calculated using equation 5 are shown in Table XXXIII.

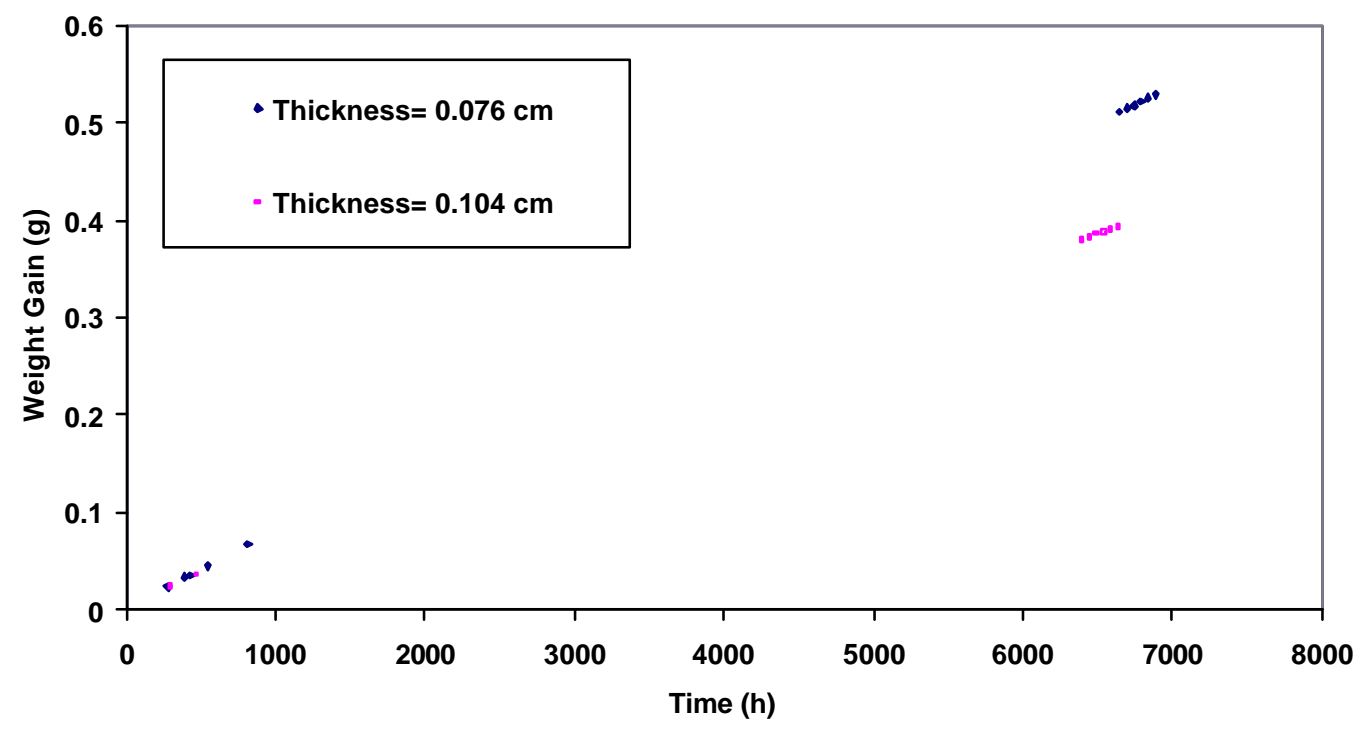

Figure 154. Weight gain versus time for assemblies covered with FRP film containing $0 \mathrm{wt} \%$ Cloisite $10 A^{\circledR}$

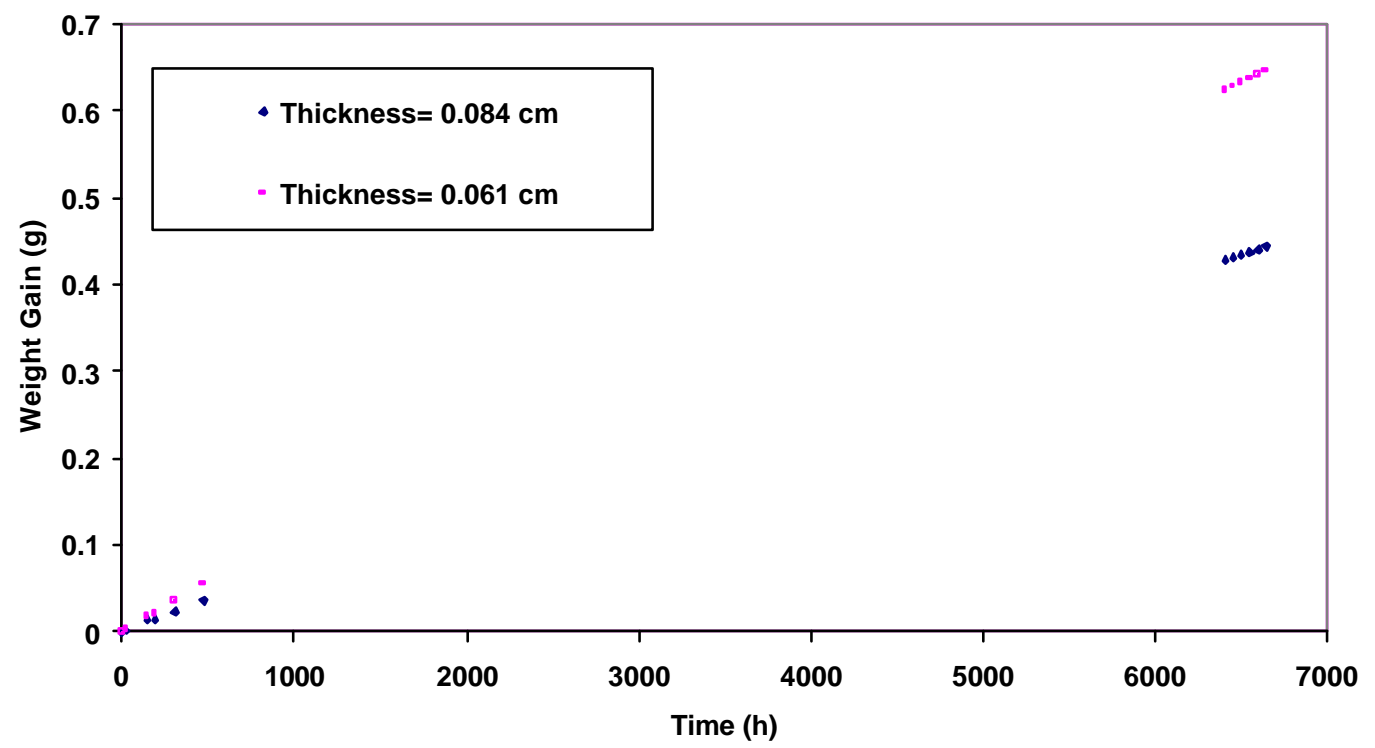

Figure 155. Weight gain versus time for assemblies covered with FRP film containing 1 wt \% Cloisite $10 A^{\circledR}$ 


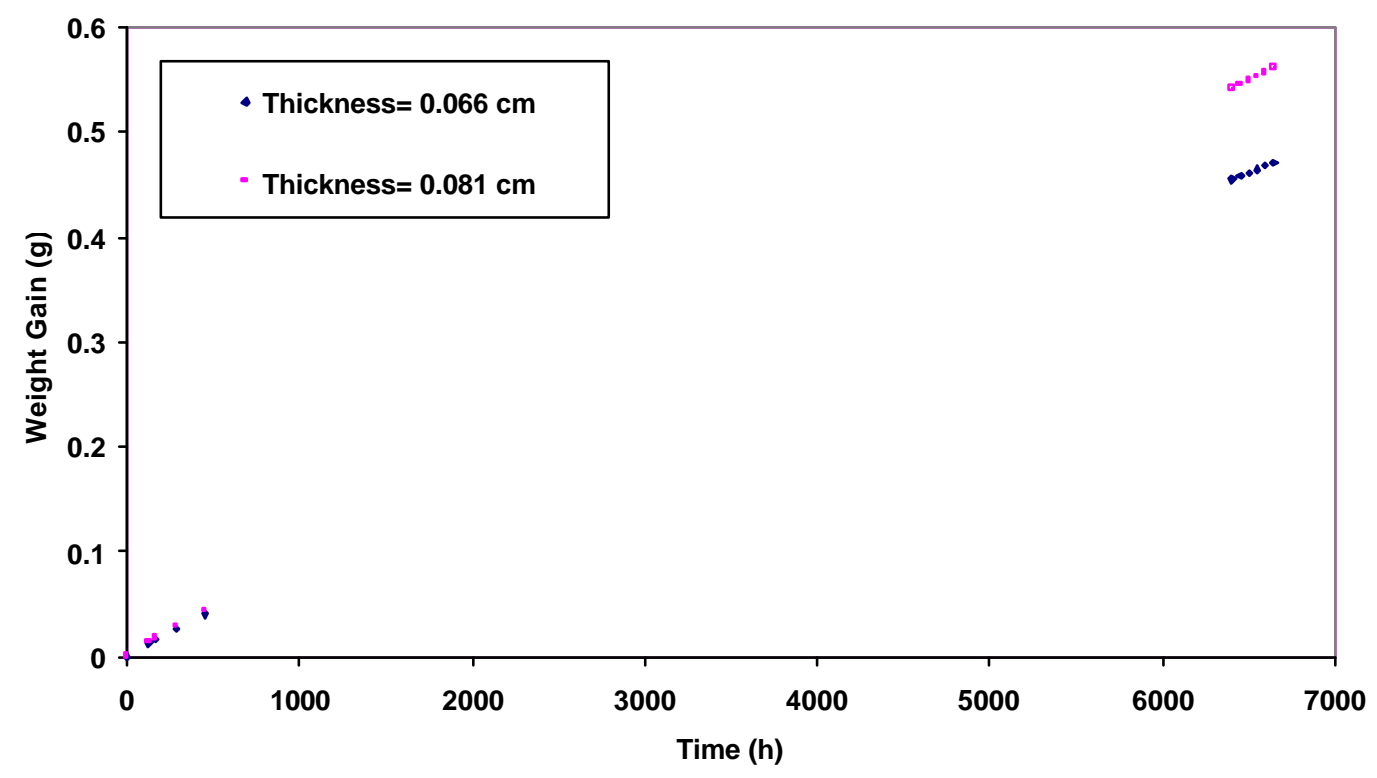

Figure 156. Weight gain versus time for assemblies covered with FRP film containing 2 wt \% Cloisite $10 \mathbf{A}^{\circledR}$

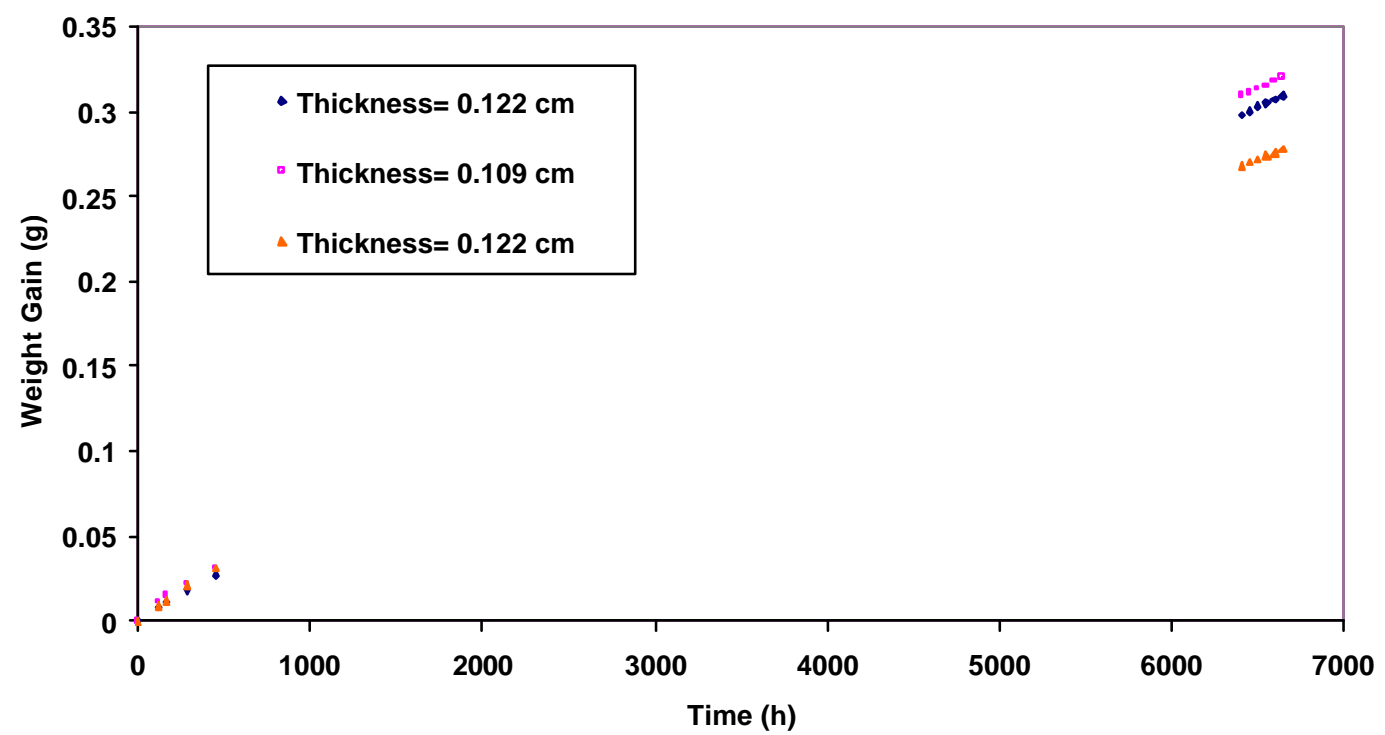

Figure 157. Weight gain versus time for assemblies covered with FRP film containing $5 \mathrm{wt} \%$ Cloisite $10 A^{\circledR}$ 
Table XXXIII. Steady-State diffusion coefficient of water molecules in FRP films

\begin{tabular}{|c|c|c|}
\hline Wt \% Cloisite $10 \mathrm{~A}^{\circledR}$ & $\begin{array}{c}\mathrm{D} \times 10^{+9}\left(\mathrm{~cm}^{2} / \mathrm{s}\right) \\
(\mathrm{FRP})\end{array}$ & $\begin{array}{c}\mathrm{D} \times 10^{+9}\left(\mathrm{~cm}^{2} / \mathrm{s}\right) \\
(\text { Un-reinforced })\end{array}$ \\
\hline 0 & $6.83(0.27)$ & 7.29 \\
\hline 1 & $6.09(0.32)$ & 6.50 \\
\hline 2 & $5.93(0.31)$ & 6.05 \\
\hline 5 & $5.33(0.26)$ & 5.76 \\
\hline
\end{tabular}

Note: Values shown in the brackets are standard deviations

Even though, experimental data collected for the first 400 hours were enough to calculate the diffusion coefficients, experiments were continued for more than 6000 hours to verify that, indeed, a steady-state was achieved. Table XXXIII shows the comparison of diffusion coefficients in FRP films and corresponding un-reinforced nanocomposite films. It is evident from Table XXXIII that the FRP films had somewhat lower diffusion coefficients than the corresponding un-reinforced nano-composite films. It was expected that the FRP film would have much lower permeability than the un-reinforced films because the impermeable glass-fibers had occupied a significant area through which the water molecules were diffusing. However, contrary to this expectation, a fiber mat reinforcement provided little resistance to water molecules. The geometry of fiber mat used in the present study is shown in Figure 36. It is seen from the schematic diagram of the mat that there were large gaps between the two adjacent strands. There was a gap of approximately $0.01 \mathrm{~cm}$ between the two layers of the mat. There were small slit gaps between the adjacent fibers. Taking all of these factors in consideration, the effective resistance to diffusion offered by the FRP film can be shown by the following schematic diagram (Figure 158): 


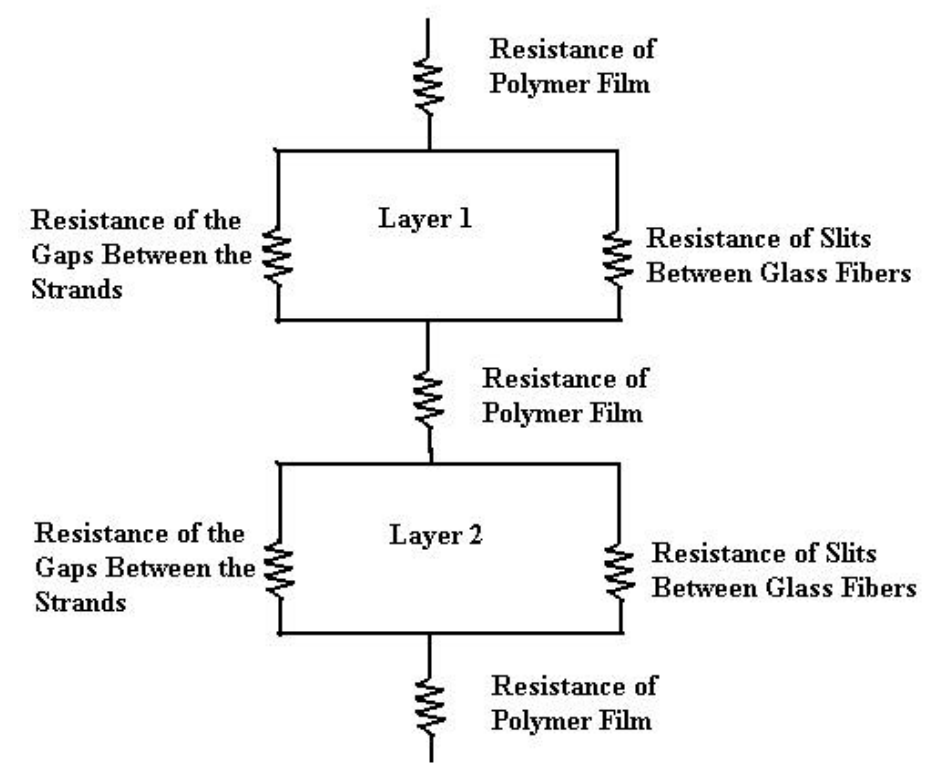

Figure 158. Schematic Diagram of Resistance provided by FRP film

The resistance offered by the slits between the glass fibers was calculated using the geometry of the fabric. Two theories were applied to estimate the resistance provided by the glass fibers. The first of which was the theory proposed by Cussler et al. (1988). The fibers were assumed to be flakes of infinite length. Equation 32 was, then, modified appropriately and the resistance offered by the glass-fiber strand was calculated. The equation for the flux variation is shown below and the derivation can be found in appendix A.1.9.

$\frac{J_{0}}{J_{N}}=1+\frac{d a}{2(a+b)}\left(\frac{2}{s}+\frac{1}{b}\right)$

Where, $a$ is the diameter of a glass-fiber and $2 s$ is the average slit gap between the adjacent fibers. Other symbols have the usual meanings as explained in chapter 4 . The above equation can be re-written in terms of the resistance offered by the fiber strand: 
$\frac{R_{N}}{R_{0}}=1+\frac{d a}{2(a+b)}\left(\frac{2}{s}+\frac{1}{b}\right)$

Where, $R_{N}$ is the resistance offered by fiber strand and $R_{0}$ is the resistance offered by polymer.

Similarly, theory proposed by Brydges et al. (1975) was also applied to estimate the resistance provided by the fiber strand. The theory was originally derived for glass-ribbon filled composites for the geometry shown in the Figure 159:

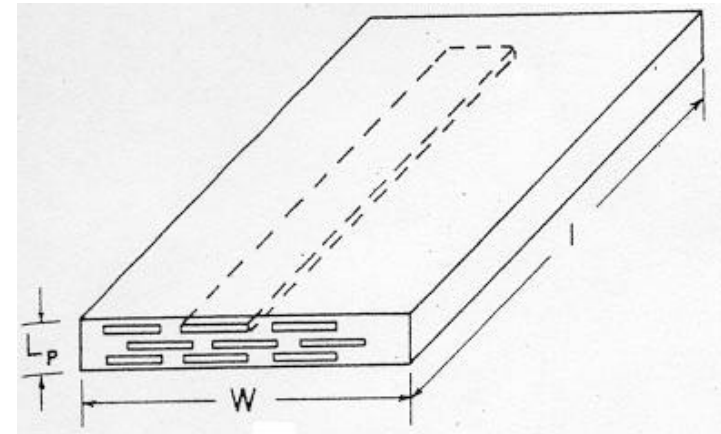

(a)

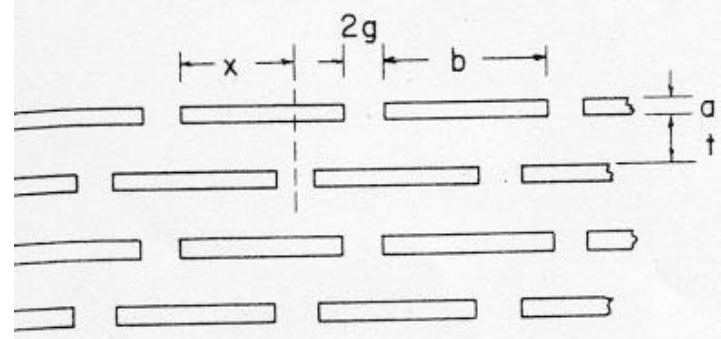

(b)

$$
y=\frac{x}{b}
$$

Figure 159. (a) Ribbon reinforced composite plate (b) Parameters describing plate construction

Diffusing molecules flow through the horizontal and vertical channels of polymer formed because of the presence of glass ribbons. For simplicity, glass ribbons were considered as relatively impermeable to diffusing molecules. The flow through vertical channel can be written as: 
$\dot{Q}_{v}=K_{m}\left(\frac{2 g l}{a+t}\right) \Delta P_{v}$

Where, $K_{m}$ is the permeation coefficient of the material and $\Delta P_{v}$ is the pressure drop in the vertical direction. The flow through horizontal channel can be written as a summation of flow in right direction and flow in left direction:

$\dot{Q}_{h}=\dot{Q}_{h l}+\dot{Q}_{h r}=K_{m}\left(\frac{t l}{b \gamma(1-\gamma)}\right) \Delta P_{h}$

Here, $\Delta P_{h}$ is the pressure drop in the horizontal direction. Conservation of mass requires that horizontal and vertical flow rates must be equal. Denoting the flow rate through each channel of width $2 \mathrm{~g}$ by $Q_{c h}$, the following equality is obtained:

$\dot{Q}_{c h}=\dot{Q}_{h}=\dot{Q}_{v}$

Using equation 53 and 54, the total pressure drop across $n$ layers of ribbons can be written as follows:

$$
\Delta P_{T}=\frac{Q_{c h} L_{p}}{K_{m} l}\left[\frac{1}{2 g}+\frac{b \gamma(1-\gamma)}{t(a+t)}\right]
$$

The total flow rate $\left(Q_{T}\right)$ through the reinforced plate is related to the flow rate through the channel by the following expression:

$$
\dot{Q}_{T}=\left(\frac{W}{b+2 g}\right) \dot{Q_{c h}}
$$


Making use of the above equality in the expression for the total pressure drop and rearranging the equation, the following relation is obtained:

$$
\dot{Q}_{T}=\left[\frac{K_{m}}{1+\frac{b}{2 g}+\frac{b}{a}\left(\frac{b+2 g}{t}\right)\left(\frac{a}{a+t}\right) \gamma(1-\gamma)}\right]\left(\frac{A_{p}}{L_{p}}\right) \Delta P_{T}
$$

Here $A_{p}(=W l)$ is the area of the reinforced plate.

The permeation of a fluid through a channel of material with permeation coefficient $K$ is given by:

$$
\dot{Q}=K\left(\frac{A}{L}\right) \Delta P
$$

Comparison of equation 58 and 59 shows that the effective permeation coefficient for flow through the composite plate $\left(K_{c}\right)$ can be given by:

$$
K_{c}=\left[\frac{K_{m}}{1+\frac{b}{2 g}+\frac{b}{a}\left(\frac{b+2 g}{t}\right)\left(\frac{a}{a+t}\right) \gamma(1-\gamma)}\right]
$$

When written in terms of resistance to flow, the above equation becomes:

$$
\frac{R_{N}}{R_{0}}=1+\frac{b}{2 g}+\frac{b}{a}\left(\frac{b+2 g}{t}\right)\left(\frac{a}{a+t}\right) \gamma(1-\gamma)
$$

Here, $R_{N}$ is the resistance with $N$ layers of ribbons and $R_{0}$ is the resistance of the material itself. Under the conditions $a=b$ and $2 g=t$, the above equation provides an estimate of the permeation resistance of the composite containing uniformly spaced fibers. In the present case, the equation provides the resistance of fiber strand shown in Figure 36. The 
variations in the flux were predicted using the schematic diagram of resistances shown in Figure 158. The calculations can be found in appendix A.1.9. A comparison of experimental and theoretical values of flux ratios for various samples is shown in Table XXXIV.

Table XXXIV. Comparison of Experimental and Theoretical Flux Ratio

\begin{tabular}{|c|c|c|c|c|}
\hline $\begin{array}{c}\text { Wt\% } \\
\text { Cloisite } \\
10 A^{\circledR}\end{array}$ & $\begin{array}{c}\text { Thickness } \\
\text { of FRP } \\
\text { film (cm) }\end{array}$ & $\begin{array}{c}J_{0} / J_{N} \\
\text { Experimental }\end{array}$ & $\begin{array}{c}J_{0} / J_{N} \\
\text { Cussler et al. } \\
(1988)\end{array}$ & $\begin{array}{c}J_{0} / J_{N} \\
\text { Brydges et } \\
\text { al. (1975) }\end{array}$ \\
\hline 0 & 0.07620 & 1.12 & 1.45 & 1.27 \\
\hline 0 & 0.10414 & 1.07 & 1.33 & 1.20 \\
\hline 1 & 0.08382 & 1.10 & 1.41 & 1.25 \\
\hline 1 & 0.06096 & 1.04 & 1.57 & 1.34 \\
\hline 2 & 0.06604 & 1.05 & 1.52 & 1.31 \\
\hline 2 & 0.08128 & 1.04 & 1.43 & 1.25 \\
\hline 5 & 0.10922 & 1.09 & 1.32 & 1.19 \\
\hline 5 & 0.12192 & 1.15 & 1.28 & 1.17 \\
\hline
\end{tabular}

It can be seen from the above table that, the theory proposed by Brydges et al. predicts the flux ratios that are closer to the measured experimental values. However, no perfect agreement between the measured and theoretical flux ratios was seen. The theory proposed by Cussler et al. inherently assumes very strong effect of slit constriction. It is speculated that the curved surface of the glass fiber might not have provided enough resistance as was assumed in the derivation of the equation. This is the reason why the theory over-predicts the flux ratios. There could be two reasons why the flux ratios predicted by the Brydges et al. theory are not in perfect agreement with the measured values.

1. The slit gap between the two adjacent fibers was calculated using the geometry of fiber-mat. When this fiber-mat is soaked in liquid resin and weight was applied to squeeze out the excess resin, it is likely that the fibers re-oriented themselves and 
the slit gap between the adjacent fibers increased. The following figure shows an SEM image of freshly prepared FRP sample:

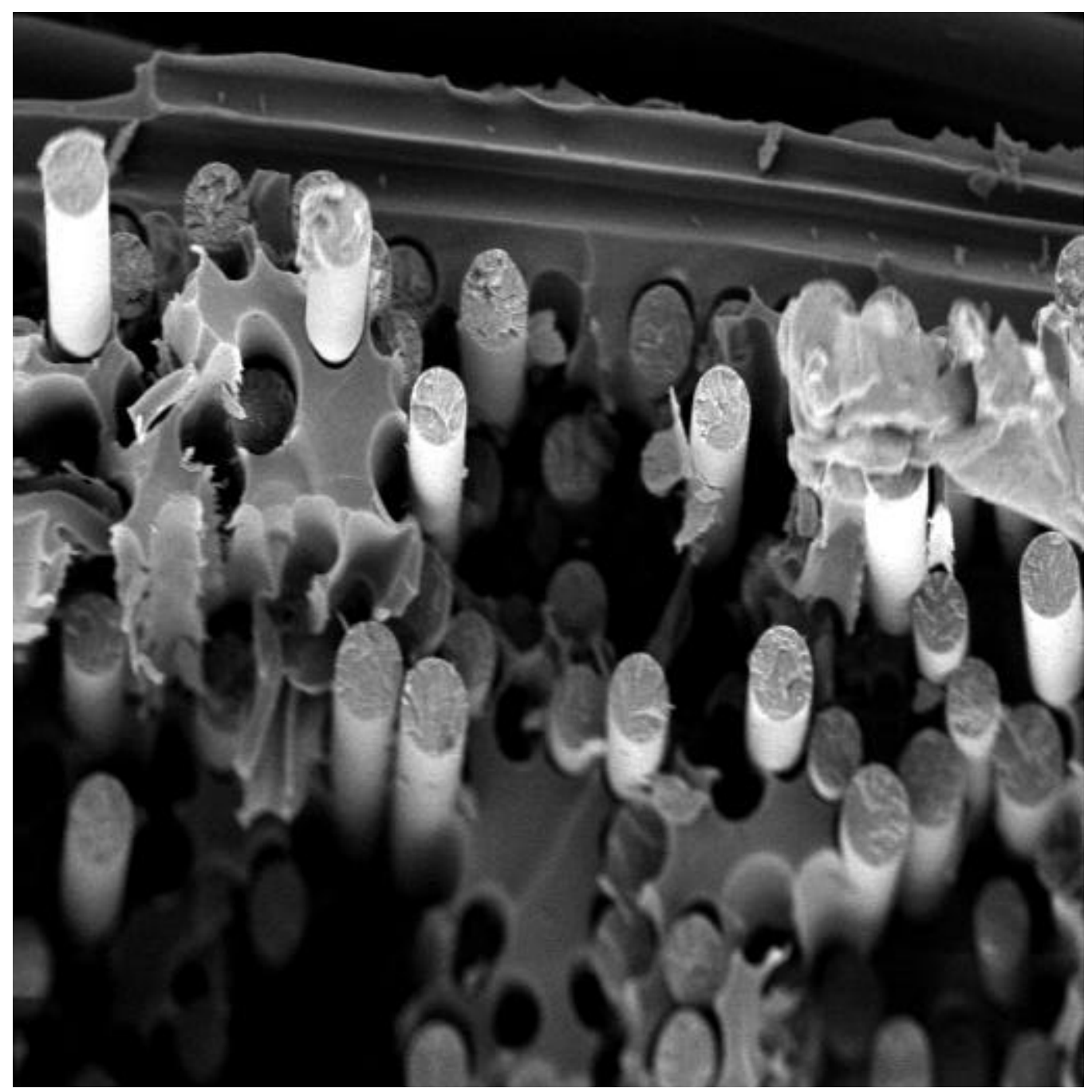

Figure 160. SEM image of freshly prepared FRP sample

The minimum gap between the adjacent fibers used in all theoretical flux calculations was $7 \mu \mathrm{m}$. The diameter of the fibers in Figure 160 is $13 \mu \mathrm{m}$. It is clearly seen from the above figure that the average value of minimum gap between the adjacent fibers is certainly greater than $7 \mu \mathrm{m}$. It is speculated that if the accurate value of gap is used in calculation, then it will yield theoretical flux ratios that are closer to the experimental flux ratios. 
2. It was concluded in the transient diffusion experiments at room temperature that the water reacted with the sizing material on the glass fibers. There might have been some interactions between the sizing and water molecules even in the steady-state experiments. However, no abnormalities were recorded in the weightgain versus time curve. Water molecules did not accumulate for a long time in the vicinity of the glass fibers during the steady-state experiments and this might have restricted the level of interaction between sizing material and water molecules.

The experimental flux ratios suggested that the glass-fiber mat used in the present study did not provide significant resistance to the flow of water molecules. In other words, the molecules diffused easily through the available channels between the fibers and the gaps between the adjacent fiber strands. It is speculated that a fabric with interwoven strands should provide much more resistance than the fabric used in the present study. To verify that the presence of fiber mat is not affecting the process of diffusion significantly, weight gain curves for fiber-reinforced and un-reinforced samples immersed in distilled water at $4^{\circ} \mathrm{C}$ were plotted on the same graph and are shown in the following figure: 


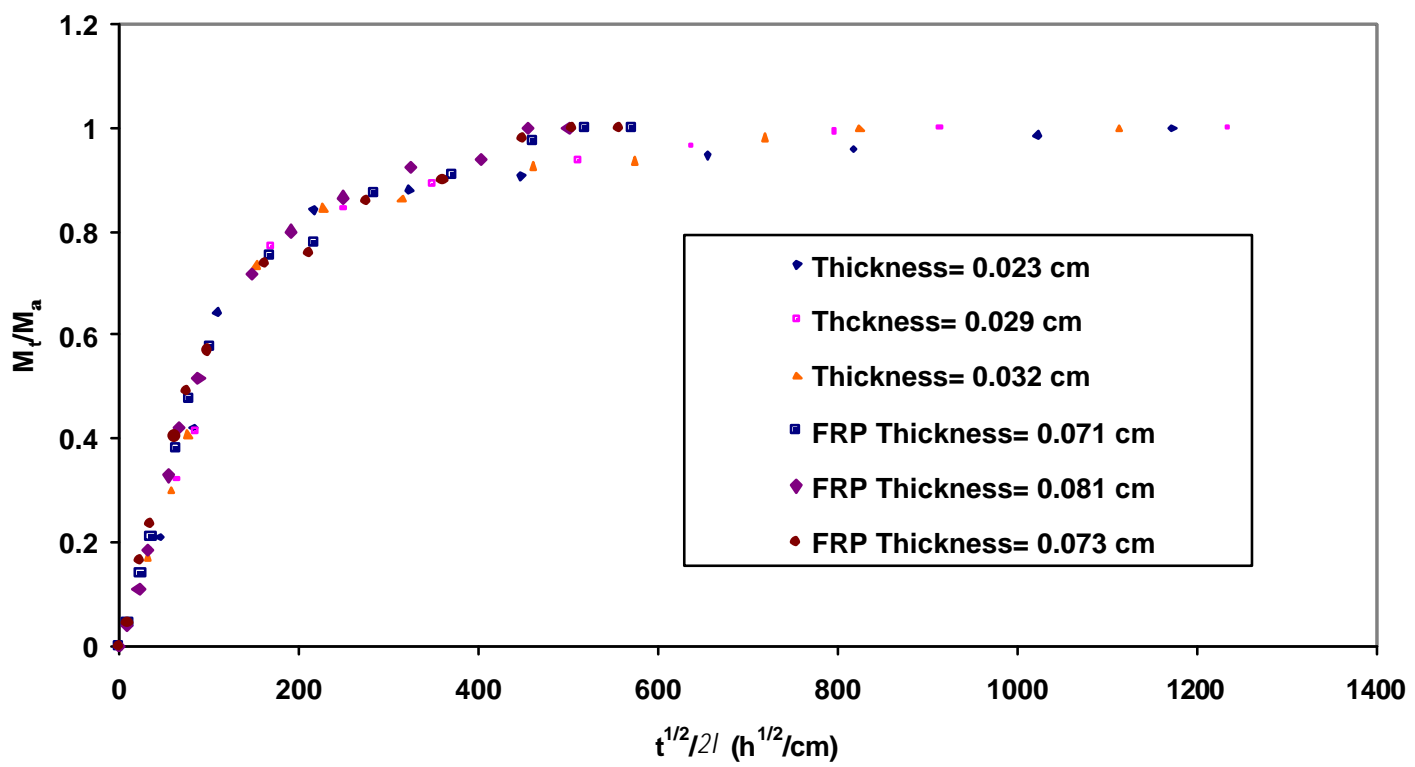

Figure 161. Normalized Weight Gain Curves for Glass-Reinforced as well as Un-reinforced Samples immersed in Distilled Water at $4^{\circ} \mathrm{C}$

It is clearly seen from the Figure 161 that the normalized mass uptake curves for the reinforced and un-reinforced samples superimposed fairly well. This supported the conclusion that the presence of glass fabric reinforcement provided little additional resistance to the diffusion of water molecules. 


\subsection{Comparison of Diffusion Coefficients obtained from Transient and Steady- State Diffusion Experiments}

Table XXXV . Comparison of Diffusion Coefficients obtained from Transient Diffusion Experiments and Steady-State Diffusion Experiments

\begin{tabular}{|c|c|c|}
\hline Wt $\%$ Cloisite $10 \mathrm{~A}^{\circledR}$ & $\begin{array}{c}\mathrm{D} \times 10^{+9} \\
\text { Transient Diffusion } \\
\text { Experiments }\left(\mathrm{cm}^{2} / \mathrm{s}\right)\end{array}$ & $\begin{array}{c}\mathrm{D} \times 10^{+9} \\
\text { Steady-State Diffusion } \\
\text { Experiments }\left(\mathrm{cm}^{2} / \mathrm{s}\right)\end{array}$ \\
\hline $0 \%$ & 7.36 & $\begin{array}{l}7.29 \\
\end{array}$ \\
\hline $1 \%$ & 4.01 & 6.50 \\
\hline $2 \%$ & 2.76 & 6.06 \\
\hline $5 \%$ & 0.61 & 5.76 \\
\hline
\end{tabular}

It is clear from Table XXXV that diffusion coefficients for neat resin samples obtained using two different methods agree with each other very well with a difference of less than $3 \%$. However, such agreement in the values of diffusion coefficients was not found for the samples containing nanoclay.

Crank (1975) has described a diffusion process accompanied by adsorption on to internal surfaces or sites as "linear adsorption isotherm". He suggested that the concentration $S$ of immobilized species is directly proportional to the concentration $C$ of species free to diffuse.

$S=R C$

Here $R$ is the proportionality constant. The concentration $S$ of immobilized water molecules on clay platelets can be defined as: 
$S=\frac{\text { Mass of Water Adsobed on Clay }}{\text { Total Volume of Clay Platelets Available for Adsorption }}$

The equation for diffusion in one dimension changes to the following:

$\frac{\partial C}{\partial t}=D \frac{\partial^{2} C}{\partial x^{2}}-\frac{\partial S}{\partial t}$

Substituting equation 62 in 64 , the following expression can be derived:

$\frac{\partial C}{\partial t}=\frac{D}{R+1} \frac{\partial^{2} C}{\partial x^{2}}$

The nature of the above equation similar to the usual diffusion equation with the diffusivity $D$ replaced by apparent diffusivity $\frac{D}{R+1}$. Crank also proved that if the linear relationship (equation 62) holds, solutions of the diffusion with internal adsorption for given initial and boundary conditions are same as for the corresponding problem in simple diffusion with $D$ replaced by apparent diffusivity $\frac{D}{R+1}$. The solution for mass uptake as a function of time is shown below:

$M_{t}=2 \int_{0}^{t}\left[2 \frac{D}{R+1} \frac{\left(C_{1}-C_{0}\right)}{l} \sum_{0}^{\infty} \exp \left[\frac{-\frac{D}{R+1}(2 n+1)^{2} \pi^{2} t}{4 l^{2}}\right] d t\right.$

In the present study, it has been proven that the nanoclay absorb significant amount of moisture. If the diffusion is accompanied by adsorption on to the sites on clay platelet then the diffusivities obtained from the transient diffusion experiments must be apparent diffusivities. 
During the steady-state experiments with nanocomposite films, the transport of diffusing molecules was not accompanied by adsorption on clay platelets since the platelets were pre-saturated. Therefore, it is reasonable to assume that the steady-state diffusivities are the "real" intrinsic diffusivities of the nanocomposite material. The steady-state diffusivity of nanocomposite sample containing $1 \mathrm{wt} \%$ clay was used to fit the experimental mass uptake curve and value of constant $R$ was estimated to be 0.61 . The following figure shows fit to the experimental data. The solid line in Figure 162 is the normalized mass uptake calculated using $R=0.61$ in equation 66 .

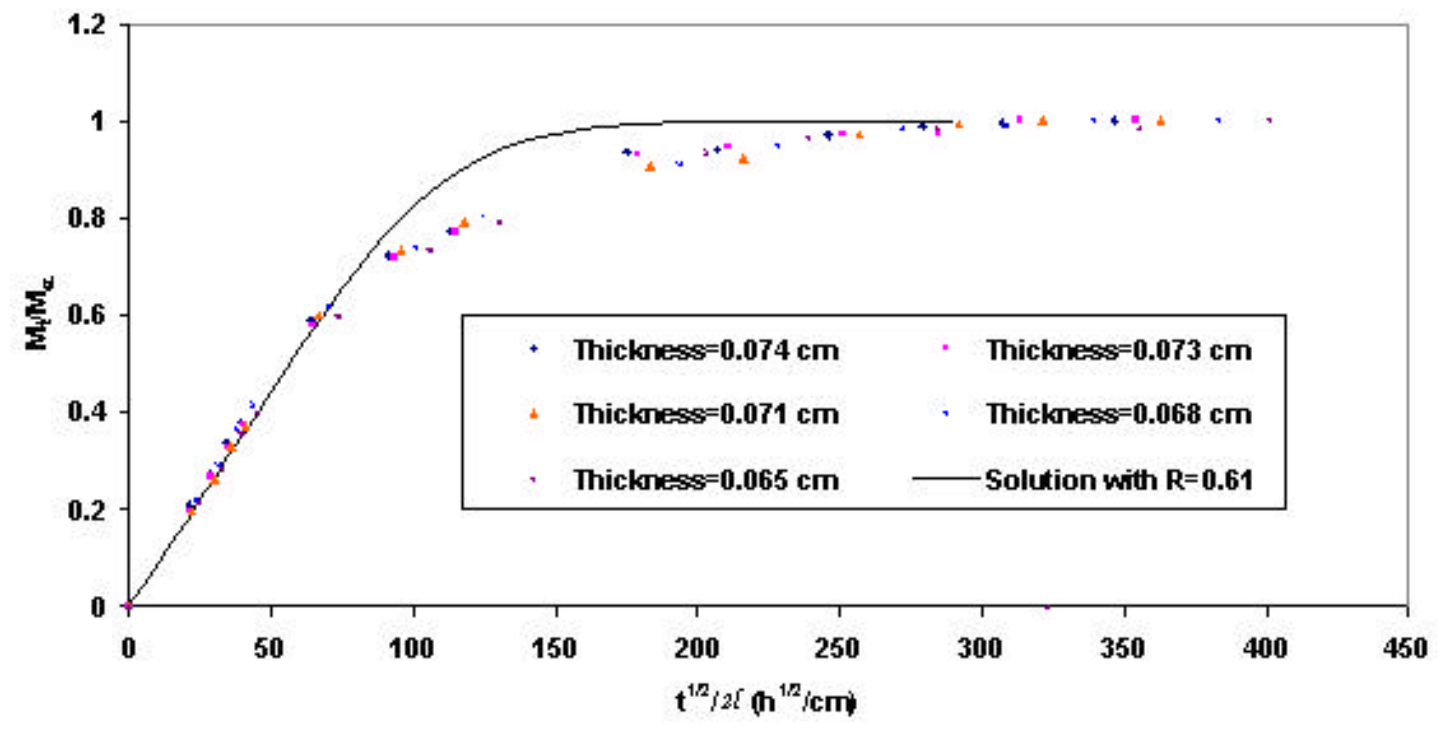

Figure 162. Normalized mass uptake for samples containing $1 \mathrm{wt} \%$ Cloisite $10 \mathrm{~A}^{\circledR}$ (Solid line: Fit of equation 15 with $R=0.61$

This value of $R$ was used to predict the mass uptake curves for the nanocomposite samples containing $2 \mathrm{wt} \%$ and $5 \mathrm{wt} \%$ clay. Figures 163 and 164 show the comparison of experimental mass uptake and those predicted using equation 66 for the samples containing $2 \mathrm{wt} \%$ and $5 \mathrm{wt} \%$ nanoclay respectively. 


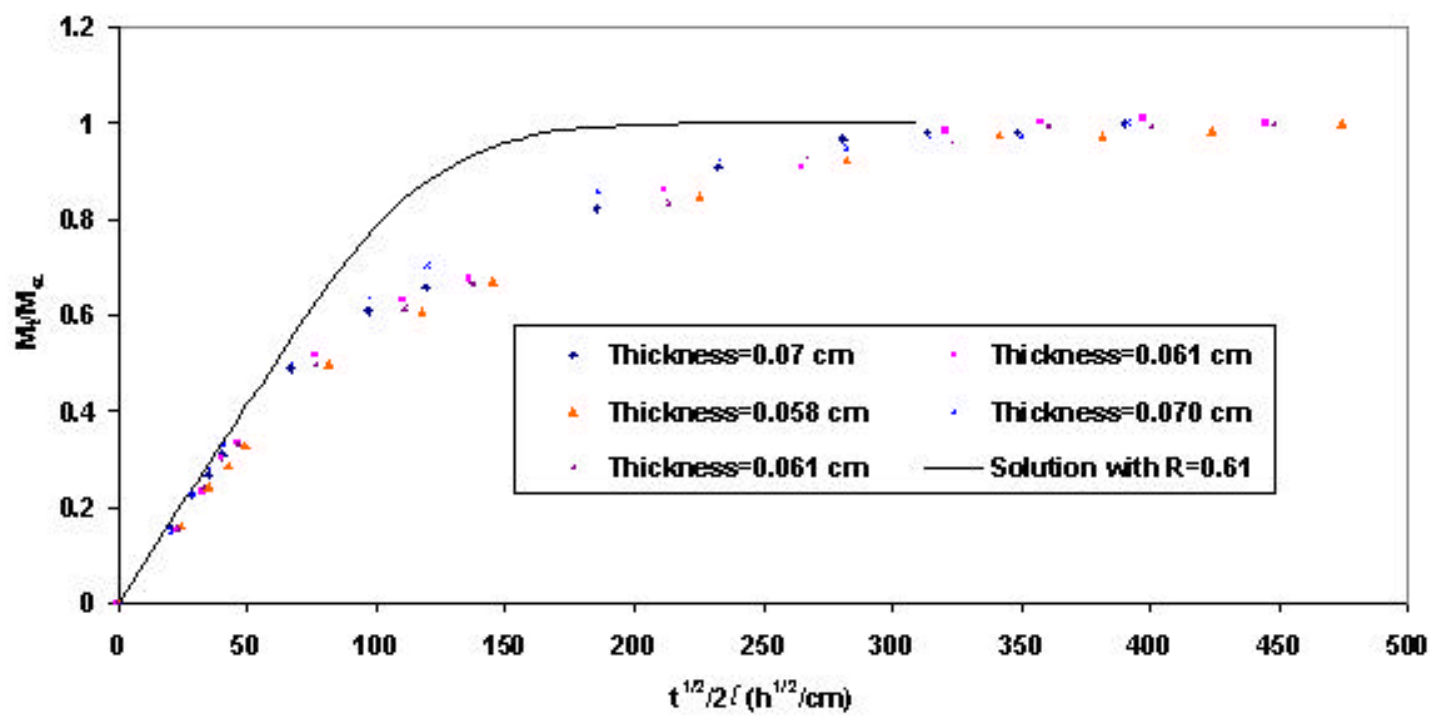

Figure 163. Normalized mass uptake for samples containing 2 wt $\%$ Cloisite $10 A^{\circledR}$ (Solid line: Predictions of equation 15 with $R=0.61$

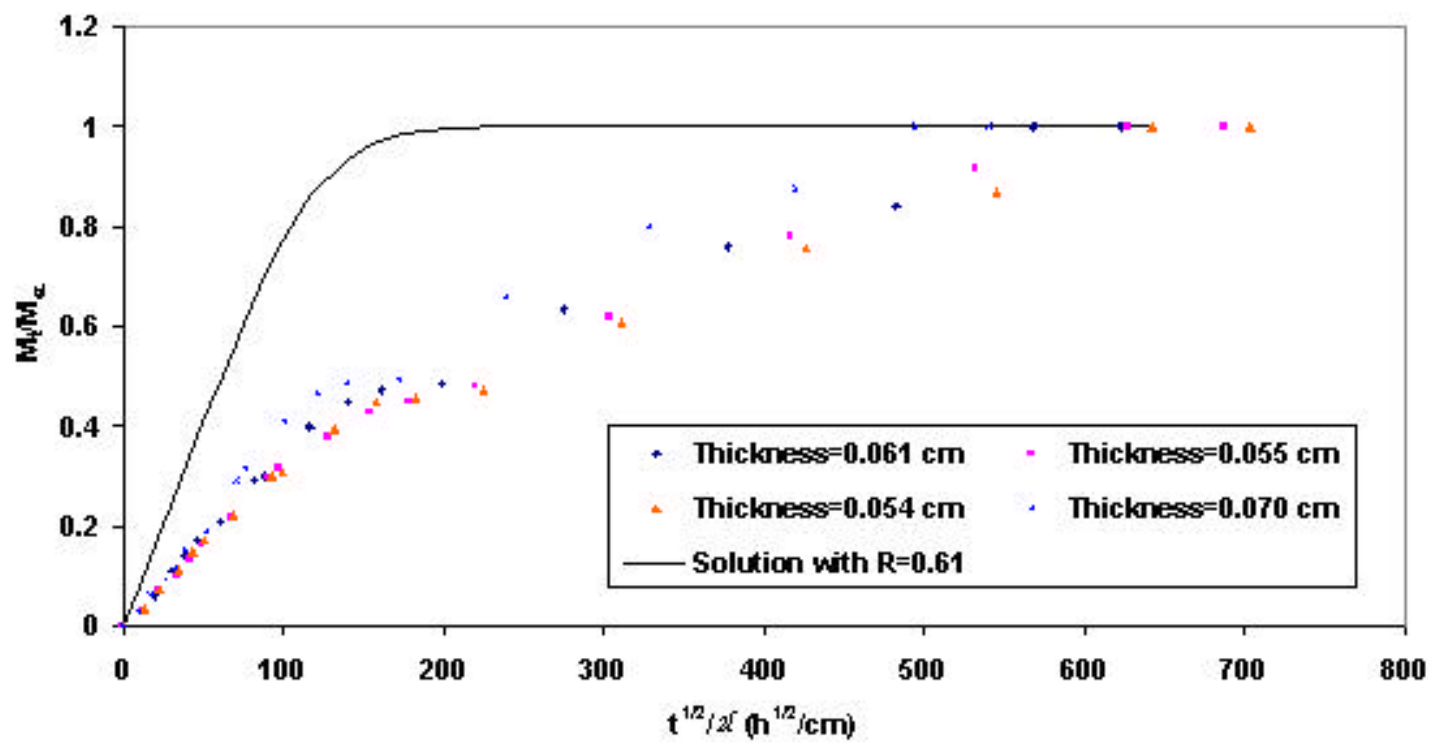

Figure 164. Normalized mass uptake for samples containing 5 wt $\%$ Cloisite $10 \mathrm{~A}^{\circledR}$ (Solid line: Predictions of equation 15 with $R=0.61$

It can be seen from the Figure 163 that the predictions made using equation 66 for the 2 wt $\%$ clay containing samples reasonably agreed with the experimental data. However, such agreement was not seen for the samples that contained $5 \mathrm{wt} \%$ clay (Figure 164). This suggested that the linear relationship (equation 62) between the concentration $S$ of immobilized substance and the concentration $C$ of the substance is not valid. 
Crank (1975) defined another form of relationship between $S$ and $C$ by the following equation, which is known as "Non-linear isotherm":

$S=R C^{n}$

Here $R$ and $n$ are constants. Once again, the equation for diffusion in this case is given by equation 64 but the solution to this diffusion equation can only be obtained by numerical methods of integration, which is beyond the scope of present research work. More sophisticated mathematical models are required to extract the "real" diffusivities from the transient diffusion experiments. The model developed by Drozdov et al. (2003) is one such model (chapter 4). The model takes the data of transient diffusion experiments as an input and mathematically separates the effect of hydrophilicity of clay. The diffusivities obtained from this model are expected superimpose the diffusivities obtained from the steady-state diffusion experiments. However, a limitation of the model is that the model fails when neat resin exhibits mn-Fickian diffusion. In the present study, mass uptake curves of the neat resin showed deviations from the Fickian behavior at large times. This is the reason why the model was not applied to explain the experimental results.

Fredrickson and Bicerano (1999) have done detailed analysis of the effect of dilute and semi-dilute concentrations of nanoclay on the steady-state diffusivities of the nanocomposites. They assumed the nano clay platelets to be circular disks of radius $R$ and thickness $2 a$. The aspect ratio of the disk was defined as $\alpha=R / 2 a$. They proposed the following equation for the dilute concentrations of clay in polymer.

$$
\frac{D}{D_{0}}=1-\frac{\pi}{3} \frac{\alpha \phi}{\ln \alpha}+O\left[(\alpha \phi)^{2}\right]
$$


Here, $D$ and $D_{0}$ are the diffusivities of the nanocomposite and the neat resin respectively and $\phi$ is the volume fraction of clay in polymer. Aspect ratio of nanoclay was calculated using the above equation and the available steady-state diffusivity data (appendix A.1.8.). The calculated aspect ratios for the disks were then converted appropriately for square clay platelets. Aspect ratio for square clay platelets are shown in the following table:

Table XXXVI. Aspect ratio of nanoclay in nanocomposites with various clay loadings

\begin{tabular}{|c|c|}
\hline $\begin{array}{c}\text { Wt\% Cloisite } \\
10 \mathrm{~A}^{\circledR}\end{array}$ & $\begin{array}{c}\text { Aspect } \\
\text { Ratio } \\
\alpha=L / 2 W\end{array}$ \\
\hline 1 & 184 \\
\hline 2 & 151 \\
\hline 5 & 62 \\
\hline
\end{tabular}

Aspect ratios in the above table indicate that the degree of exfoliation decreased with increasing amount of nanoclay in the polymer. TEM images taken by Shah (2001) also showed large agglomerates of clay platelets when the polymer contained $5 \mathrm{wt} \%$ Cloisite $10 \mathrm{~A}^{\circledR}$ clay. An average value of aspect ratio for square platelets was found to be approximately 132. This average value of aspect ratio was in agreement with value reported by Shah from his TEM images. Shah found the aspect ratio of Cloisite $10 \mathrm{~A}^{\circledR}$ to be approximately $90(\mathrm{~L}=180 \mathrm{~nm}, \mathrm{~W}=1 \mathrm{~nm})$. It is possible to calculate the total number of platelets $N$ in a given nanocomposite sample using the aspect ratios mentioned in the above table (appendix A.1.8.). If the thickness of each platelet is assumed to be $1 \mathrm{~nm}$, then the surface area $\left(A_{p}\right)$ of the clay platelet can also be calculated from the aspect ratio. The total surface area available for adsorption of water molecules can be given by the following relation: 
In the above equation the surface area of platelet $\left(A_{p}\right)$ is multiplied by a factor of 2 because water molecules can get adsorbed on both surfaces of the platelet. The rate of change of concentration in the immobile phase $(S)$ can now be written as:

$$
\frac{\partial S}{\partial t}=K\left(\frac{M_{c e}-M_{c}}{2 A_{p} \times N \times W}\right)
$$

Here, $K$ is the rate constant, $M_{c e}$ and $M_{c}$ are the total mass of water adsorbed on clay at saturation and at time $t$ respectively and $\mathrm{W}$ is the thickness of each platelet. From the transient diffusion experiment results, one can accurately determine the amount of water adsorbed on clay at saturation (appendix A.1.8). This amount of water can be used to substitute $M_{c e}$ in the above equation.

Combining equations 64 and 70, the diffusion equation changes to the following:

$$
\frac{\partial C}{\partial t}=D \frac{\partial^{2} C}{\partial x^{2}}-K\left(\frac{M_{c e}-M_{c}}{2 A_{p} \times N \times W}\right)
$$

The additional initial condition that can be used to solve the above-mentioned partial differential equation is the following:

$M_{c}(t=0)=0$

The numerical solution of above diffusion equation with known geometry of clay platelets is beyond the scope of current research work. A more detailed mathematical analysis will help to reproduce the mass uptake curves obtained in transient diffusion experiments using the platelet geometries obtained from steady-state experiments. 


\subsection{Tensile Tests}

Tensile tests on neat and nanocomposite samples were performed according to ASTM D-638 using a $100 \mathrm{kN}$ Instron machine, model 8501, at a displacement rate of $0.254 \mathrm{~mm} / \mathrm{min}$. The strain was measured independently using an Instron extensometer affixed to the mid-point of the specimen. A typical stress-strain curve obtained for the neat resin sample is shown in Figure 165.

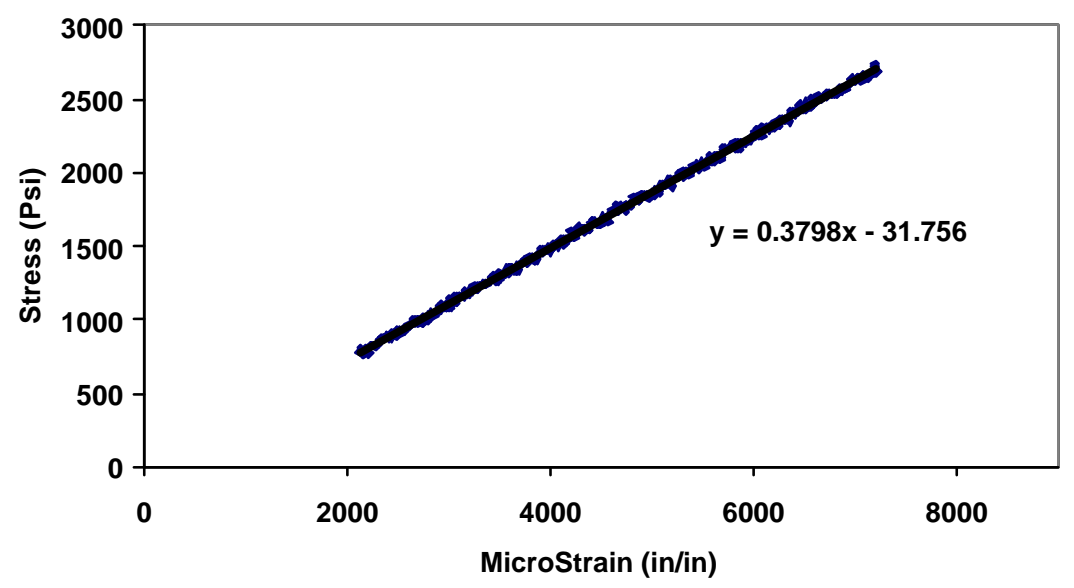

Figure 165. Typical Stress-Strain curve for the neat resin sample

Figure 166 shows the variation in Young's modulus with various clay-loading levels. The tensile modulus of neat DERAKANE 411-350 Momentum vinyl ester resin was found to be $2.88 \pm 0.18 \mathrm{GPa}$, which is $10 \%$ lower than the value reported by Dow Chemical Co. (www.dow.com/derakane/specific/product/m411350.htm) in the product data sheet. The stiffness increased by about $15 \%$ with the addition of 5 wt $\%$ Cloisite $10 \mathrm{~A}^{\circledR}$ clay. 


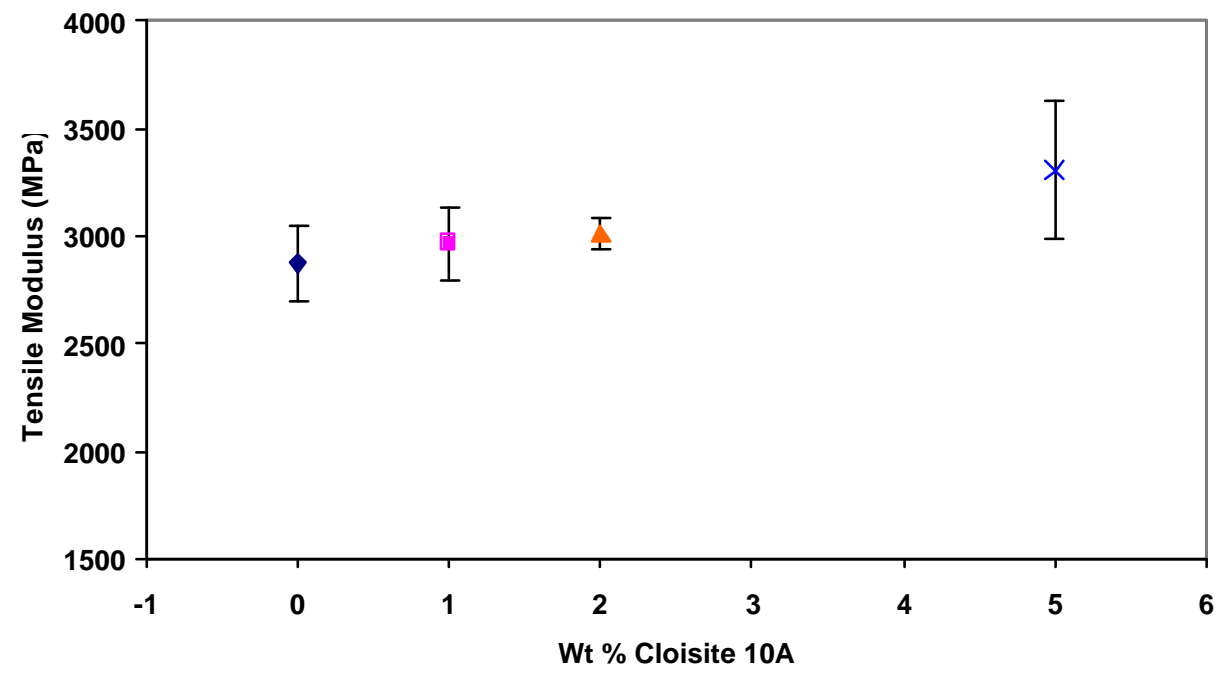

Figure 166. Variation in Tensile Modulus of Nanocomposites with weight percent of Cloisite $10 A^{\circledR}$

Figure 167 shows variation in tensile strength with various clay-loading levels.

Statistically, no change was observed in the tensile strength of the specimens due to the incorporation of nanoclay in polymer. The tensile strength value for this resin is reported to be $86 \mathrm{MPa}$ by the Dow Chemical Company, which is significantly higher than the experimental results of the present study. The results of the tensile tests are tabulated in Table XXXVII.

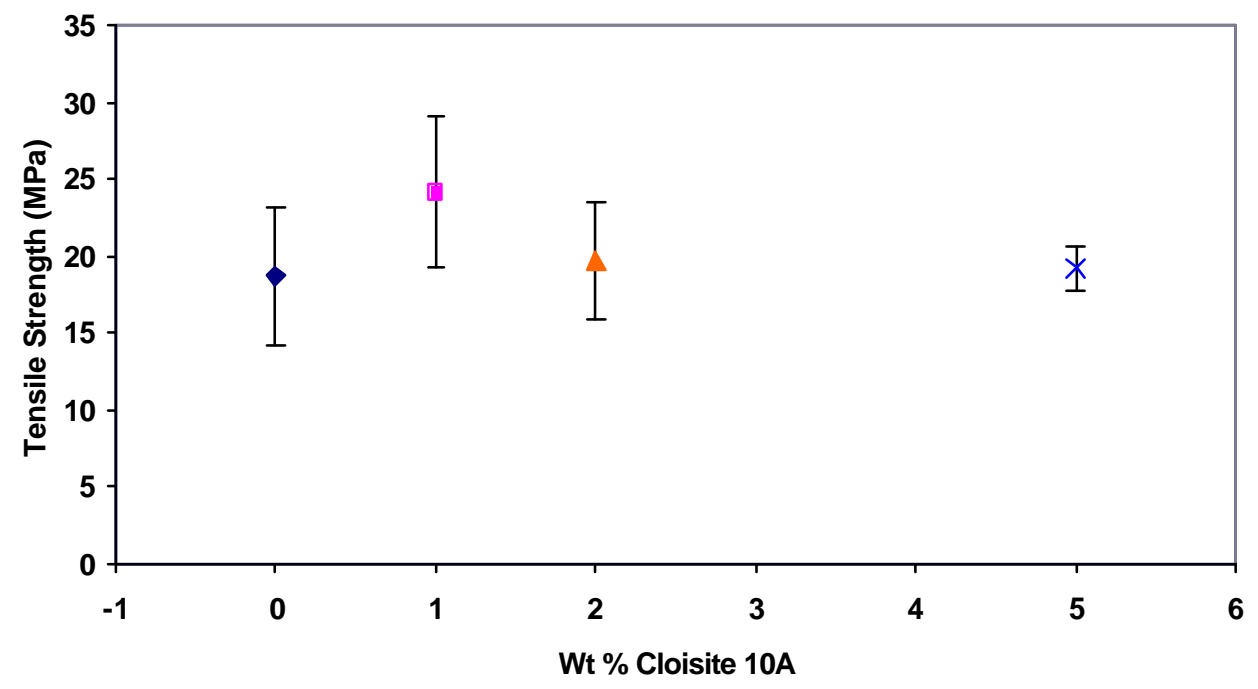

Figure 167. Variation in Tensile Strength of Nanocomposites with weight percent of Cloisite $10 \mathrm{~A}^{\circledR}$ 
Figure 168 shows variation in strain at break with various clay-loading levels. Strain at break increases by approxiamately $23 \%$ due to the incorporation of $1 \mathrm{wt} \%$ nanoclay in polymer. However, strain at break for the samples with higher clay loading levels is nearly the same as that of a neat sample. The strain at break value for this resin is reported to be 0.05 to 0.06 by the Dow Chemical Company, which is significantly higher than the experimental results of the present study. The results of the tensile tests are tabulated in Table XXXVII.

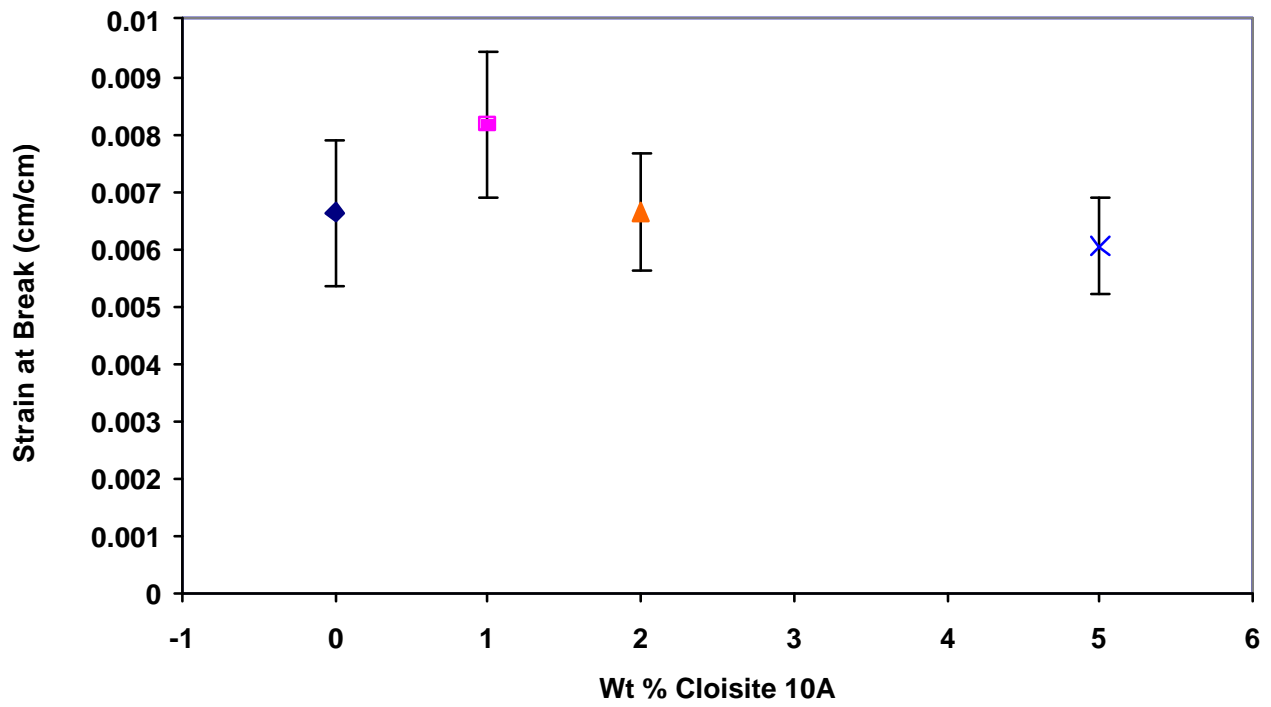

Figure 168. Variation in Strain at break with weight percent of Cloisite $10 \mathrm{~A}^{\circledR}$

Table XXXVII. Variation in Tensile Properties of Nanocomposites with weight percent of Cloisite $10 A^{\circledR}$

\begin{tabular}{|c|c|c|c|}
\hline $\begin{array}{c}\text { Wt\% Cloisite } \\
\mathbf{1 0 A}^{\circledR}\end{array}$ & $\begin{array}{c}\text { Tensile Modulus } \\
(\mathbf{G p a})\end{array}$ & $\begin{array}{c}\text { Tensile Strength } \\
(\mathbf{M p a})\end{array}$ & $\begin{array}{c}\text { Strain at break } \\
(\mathbf{c m} / \mathbf{c m})\end{array}$ \\
\hline 0 & $2.875 \pm 0.18$ & $18.704 \pm 4.46$ & $0.0066 \pm 0.0012$ \\
\hline 1 & $2.970 \pm 0.17$ & $24.176 \pm 4.94$ & $0.0082 \pm 0.0013$ \\
\hline 2 & $3.013 \pm 0.07$ & $19.739 \pm 3.78$ & $0.0066 \pm 0.0010$ \\
\hline 5 & $3.308 \pm 0.32$ & $19.195 \pm 1.46$ & $0.0060 \pm 0.0009$ \\
\hline
\end{tabular}


The above results were similar to those reported by other researchers. Shah (2001) reported 25\% increase in tensile modulus of DERAKANE 411-350 vinyl ester resin due to incorporation of 5 weight percent of Cloisite $10 \mathrm{~A}^{\circledR}$ clay. Kornmann et al. (1998) reported a linear increase in tensile modulus with Montmorillonite content of unsaturated polyester-MMT nanocomposites. They found an increase in modulus of as much as $23 \%$ for $5 \mathrm{wt} \%$ of MMT. On the other hand, the tensile strength was found to be relatively unchanged for all MMT-loadings below $10 \mathrm{wt} \%$. Lan et al. (1995) have reported a $35 \%$ increase in tensile modulus with 1 wt \% exfoliated montmorrilonite in EPON 828 epoxy resin. They also found that the d-spacing of the clay in the nanocomposite affected the level of property increase in the epoxy nanocomposites. Okada and Usuki (1995) reported no change in tensile strength and modulus for Nylon 6 nanocomposites where

the d-spacing did not change after incorporation of the clay, while for exfoliated nanocomposites the modulus increased from $1.1 \mathrm{GPa}$ to $2.1 \mathrm{GPa}$ for $4.2 \mathrm{wt} \%$ Montmorillonite.

\subsection{Notched Impact Tests}

Impact strength data for notched samples are tabulated in Table XXXVIII and are also shown in Figure 169. There was, clearly, 31\% increase in the IZOD impact strength at lower clay loading levels (1 wt $\%$ and $2 \mathrm{wt} \%)$. Impact strengths of samples containing 5 wt $\%$ of Cloisite $10 A^{\circledR}$ were nearly the same as those for the neat resin samples. Apparently, there was no loss of impact strength due to incorporation of nanoclay in the polymer at loadings less than $5 \mathrm{wt} \%$. 
Table XXXVIII. Variation in Impact Strength of Nanocomposites with weight prcent of Cloisite $10 A^{\circledR}$

\begin{tabular}{|c|c|}
\hline $\begin{array}{c}\text { Wt\% Cloisite } \\
\mathbf{1 0 A}^{\circledR}\end{array}$ & $\begin{array}{c}\text { Impact Strength } \\
(\mathbf{J} / \mathbf{m})\end{array}$ \\
\hline 0 & $20.61 \pm 2.74$ \\
\hline 1 & $27.13 \pm 3.73$ \\
\hline 2 & $26.92 \pm 2.54$ \\
\hline 5 & $20.51 \pm 1.37$ \\
\hline
\end{tabular}

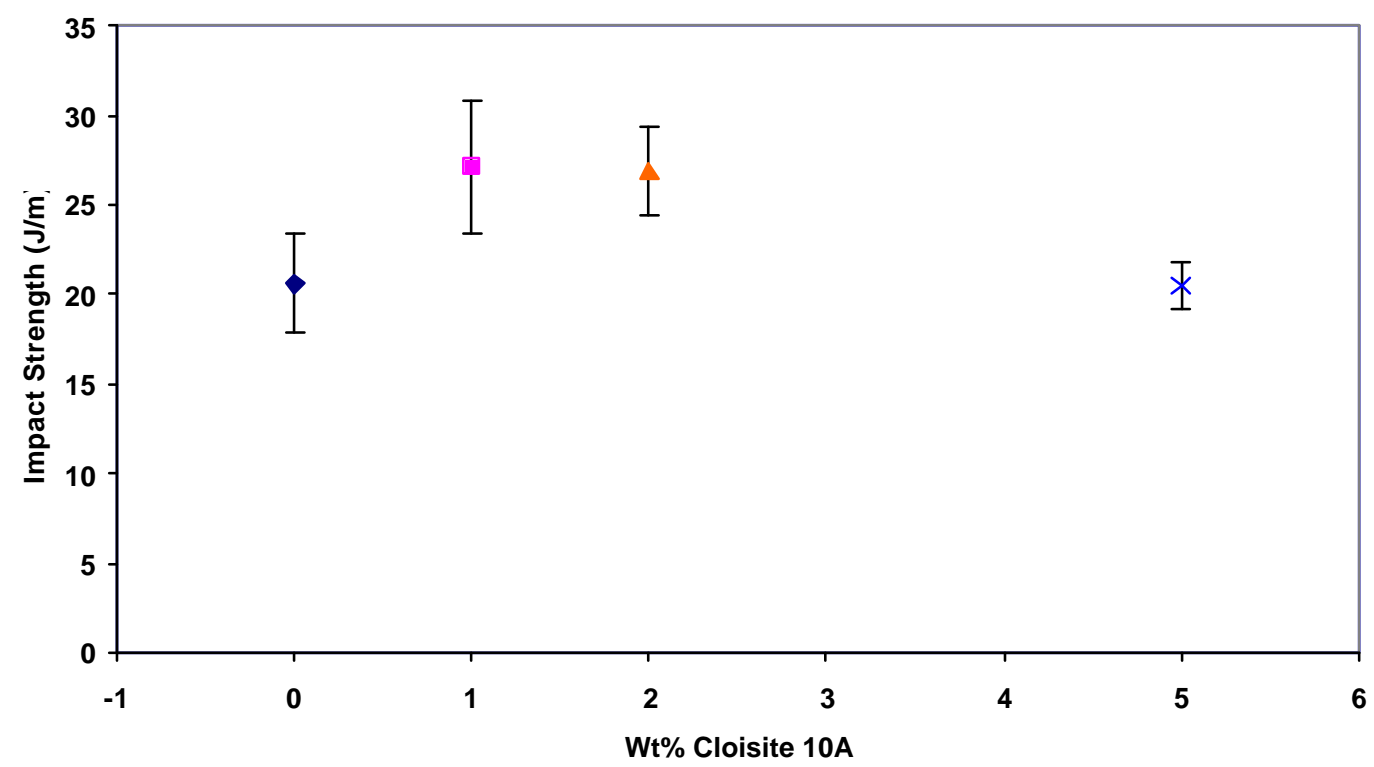

Figure 169. Variation in Impact Strength of Nanocomposites with weight percent of Cloisite $10 A^{\circledR}$

Shah (2001) also studied the impact strength of un-notched samples of DERAKANE 411-350 vinyl ester-clay nano-composites at similar clay-loading levels. He found no changes in the impact strength due to the addition of Cloisite $10 \mathrm{~A}^{\circledR}$ in the polymer. It was important to note that the Shah used un- notched specimens in his study. This might be the cause for the inconclusive trend in his experimental results. 


\subsection{Dynamic Mechanical Analysis}

Dynamic mechanical analysis of nanocomposite samples was carried out on a Rheometrics RMS-800 Instrument. Nanocomposite samples containing 1 wt $\%, 2$ wt $\%$ and $5 \mathrm{wt} \%$ clay were prepared along with neat resin samples. Rectangular torsion tests were carried out with temperature sweep from $40^{\circ} \mathrm{C}$ to $140^{\circ} \mathrm{C}$. All the samples were tested at 6.28 radian/second frequency and at $0.01 \%$ strain. Results of Dynamic Mechanical Analysis of nanocomposite samples are summarized in Figure 170 to 172. Figure 170 shows variation in storage modulus $\left(G^{\prime}\right)$ in torsion as a function of temperature and weight percent of Cloisite $10 \mathrm{~A}^{\circledR}$ clay in polymer. Approximately $58 \%$ increase in $\mathrm{G}^{\prime}$ was recorded at lower temperatures by incorporation of $5 \mathrm{wt} \%$ of Cloisite $10 \mathrm{~A}^{\circledR}$ clay in polymer. Although, torsional tests were not carried out in the present study, It was inferred from Figure 170 that the nanocomposites have higher torsional modulus than the neat resin. Even though, significant improvement is seen in the G' of the nanocomposite samples, the effects of nanoclay might not be pronounced for fiberreinforced nanocomposites because tortional modulus is a fiber-dominated property in a fiber-reinforced polymer. Nevertheless, the nanoclays are expected to improve the tortional properties of FRPs. It can also be concluded from the same graph that the glass transition temperatures $\left(\mathrm{T}_{\mathrm{g}}\right)$ of nanocomposite samples were significantly higher than the neat resin. $\mathrm{T}_{\mathrm{g}}$ of the nanocomposite containing $5 \mathrm{wt} \%$ clay was approximately $15^{\circ} \mathrm{C}$ higher than the neat resin. $\mathrm{T}_{\mathrm{g}}$ of nanocomposite samples containing $1 \mathrm{wt} \%$ and $2 \mathrm{wt} \%$ clay were approximately $8^{\circ} \mathrm{C}$ and $10^{\circ} \mathrm{C}$ higher than the neat resin respectively. 


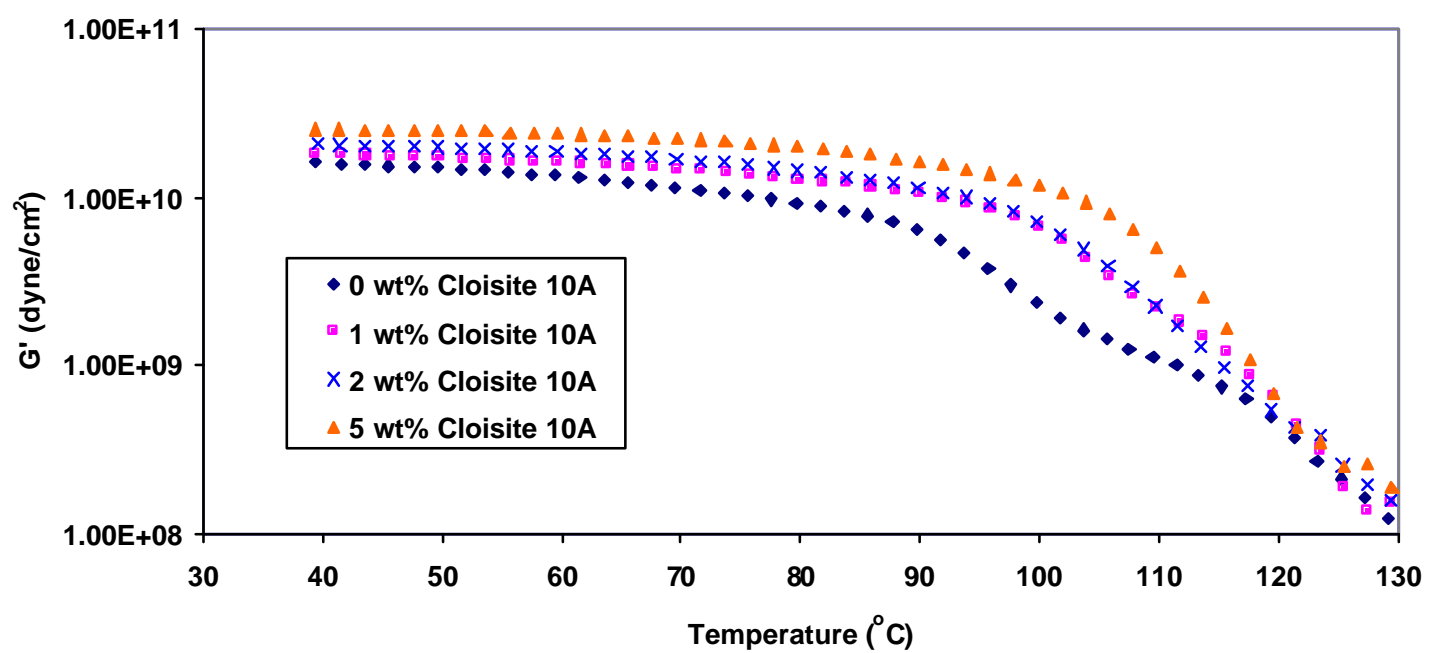

Figure 170. Variation in storage modulus (G') with temperature as a function of wt\% Cloisite $10 A^{\circledR}$ clay

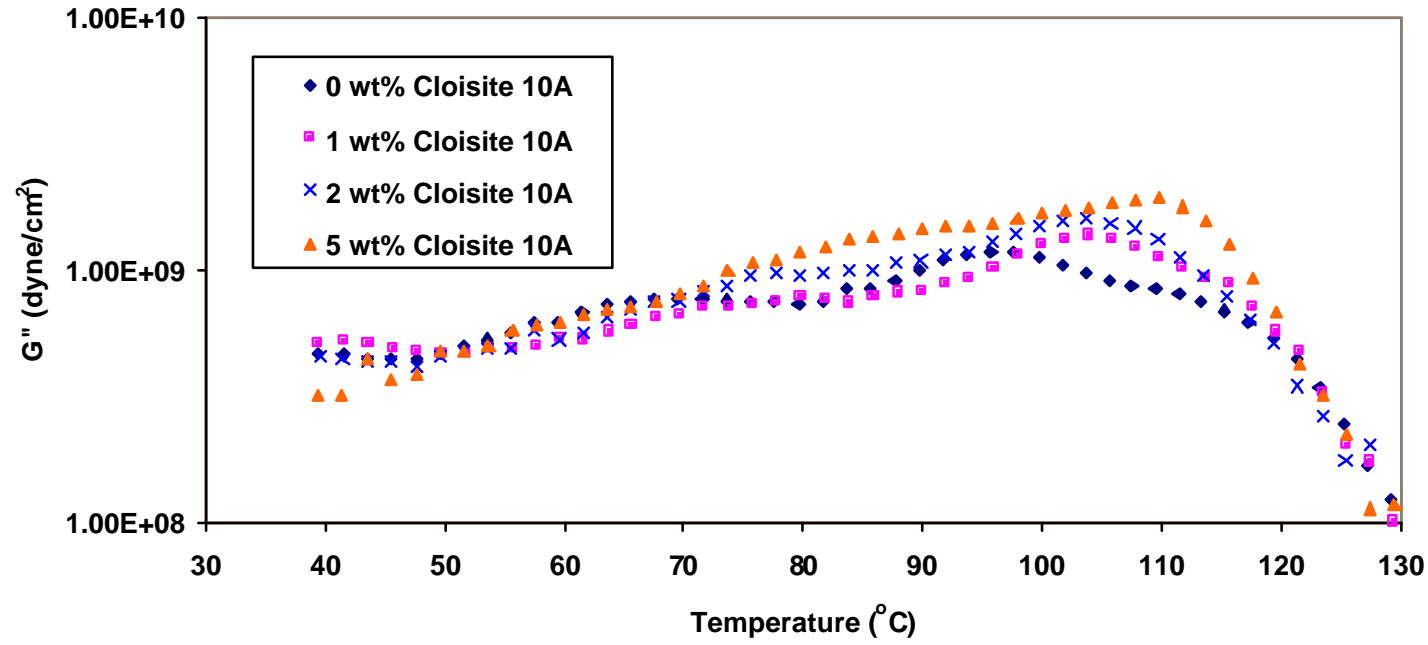

Figure 171. Variation in loss modulus (G”) with temperature as a function of wt $\%$ Cloisite $10 A^{\circledR}$ clay

Figure 171 shows variation in loss modulus (G') in torsion with temperature as a function of wt\% clay in polymer. It is seen that the peak in G" shifted to higher temperatures as the wt\% of clay in polymer was increased. This suggested that the 
nanocomposites had higher thermal stability than the neat resin. The peak for the neat resin sample was observed at approximately $95^{\circ} \mathrm{C}$ whereas, peak of the nanocomposite with $5 \mathrm{wt} \%$ clay was observed at $110^{\circ} \mathrm{C}$. This also indicated that the glass transition temperature of the nanocomposite with $5 \mathrm{wt} \%$ clay loading is approximately $15^{\circ} \mathrm{C}$ higher than the neat resin. Peaks of samples containing $1 \mathrm{wt} \%$ and $2 \mathrm{wt} \%$ clay were observed at $103^{\circ} \mathrm{C}$ and $105^{\circ} \mathrm{C}$ respectively indicating that $T_{g}$ of these samples were approximately $8^{\circ} \mathrm{C}$ and $10^{\circ} \mathrm{C}$ higher than the neat resin. The presence of clay platelets inside the polymer hindered the molecular motion of polymer chains. This increased constraint on molecular motion resulted in higher glass transition temperature of the nanocomposites. Shah (2001) also studied the glass transition of vinyl ester-clay nanocomposites using DSC. He reported $20^{\circ} \mathrm{C}$ increase in glass transition temperature by incorporation of 5 $\mathrm{wt} \%$ of exfoliated Cloisite $10 \mathrm{~A}^{\circledR}$ in a similar vinyl ester resin. Any increase in $\mathrm{T}_{\mathrm{g}}$ is a big advantage for the FRPs that are used in outdoor structural applications. The increased $\mathrm{T}_{\mathrm{g}}$ of the clay-filled resin will enable the structural FRPs to be used in warmer weathers where the FRPs based of neat resin cannot be used.

Figure 172 shows the variation in $\tan \delta$ with temperature as a function of wt $\%$ clay in polymer. Peak in tan $\delta$ occurred beyond $120^{\circ} \mathrm{C}$ for all the types of samples. However, experimental data beyond $120^{\circ} \mathrm{C}$ were not very reliable because the torque transducer of the instrument recorded numbers that were out of the range of the transducer. Nevertheless, the test provided valuable information that could be used for further investigation of torsional properties of vinyl ester-clay nanocomposites. 


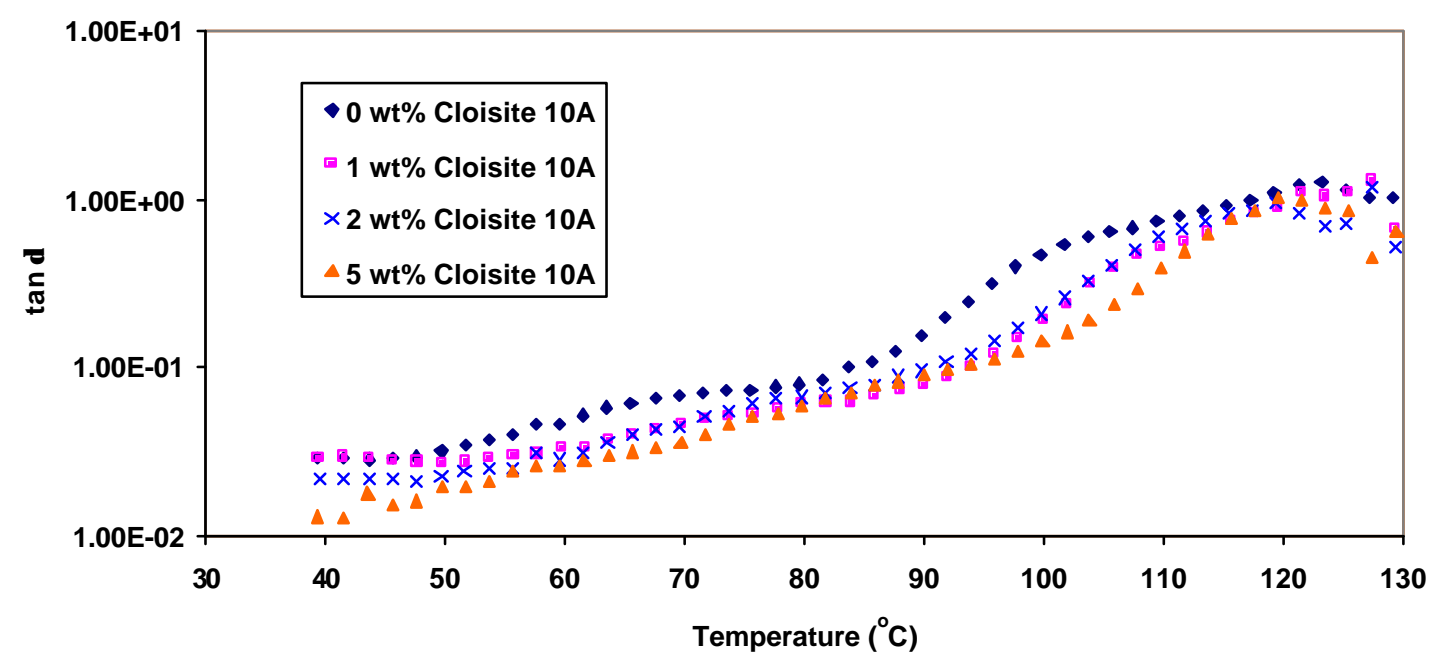

Figure 172. Variation in $\tan \delta$ with temperature as a function of wt $\%$ Cloisite $10 A^{\circledR}$ clay

\subsection{TGA Tests}

Thermo gravimetric analysis was carried out in Chemical Engineering Department at Ohio State University. Samples containing various amounts of nanoclay were heated in air from room temperature to $200^{\circ} \mathrm{C}$ at a heating rate of $10^{\circ} \mathrm{C}$ per minute. Thereafter, they were heated at $5^{\circ} \mathrm{C}$ per minute rate until the temperature reached $550^{\circ} \mathrm{C}$. Fractional weight losses as a function of temperature are shown in Figure 173. It is clear from the figure that there are no major differences in the weight loss patterns of nanocomposites containing different amounts of nanoclay. However, it is interesting to note that no harmful effects on the thermal properties were recorded during the experiments due to the incorporation of clay. 


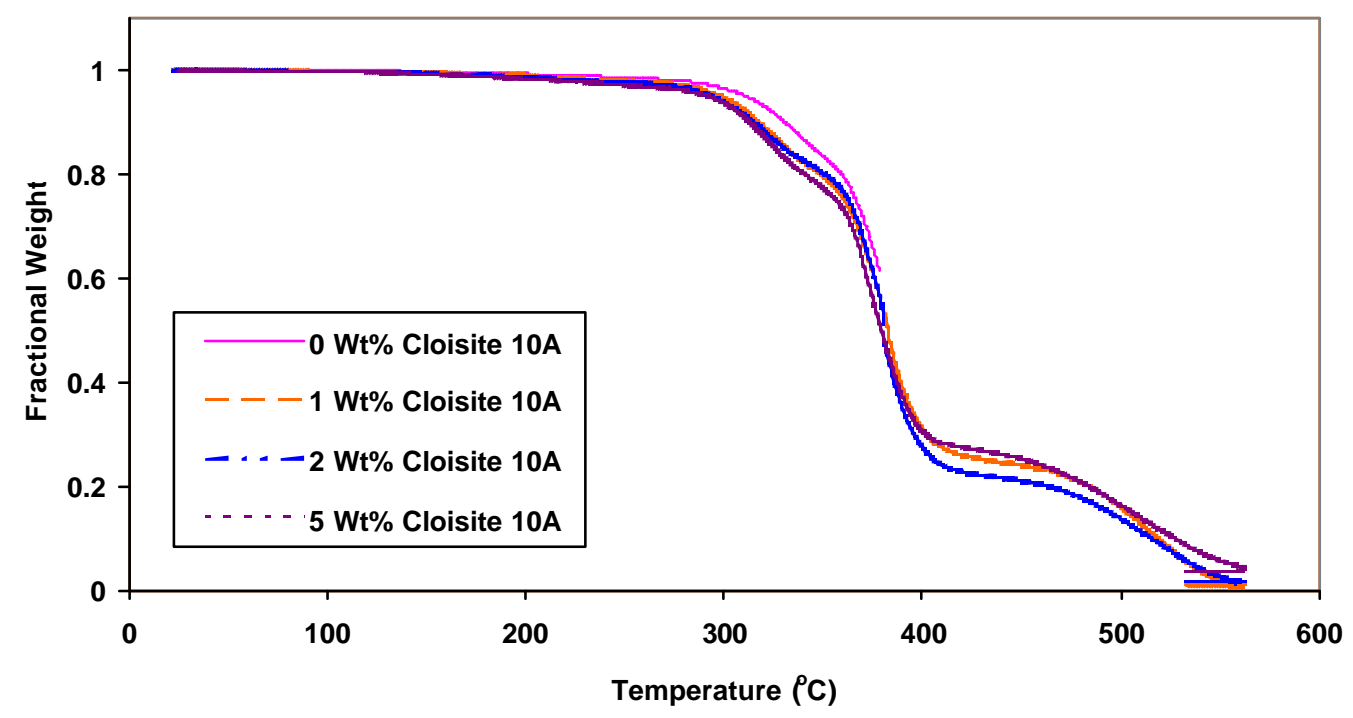

Figure 173. Fractional Weight loss versus Temperature

\subsection{Scanning Electron Microscopy}

Scanning electron micrographs of freshly made FRP samples, which did not contain nanoclay, were taken. Those were recognized as "Reference" samples. Figures 174 to 176 show the SEM images of the "Reference" Samples. There seems to be very good bonding between the fibers and the matrix polymer. All the images clearly show that the fibers were thoroughly wetted by the matrix. Polymer sticking on to the fiber surface can be clearly seen in Figure 175 and 176. Perfectly circular cross-section of the glass-fiber is clearly visible. 


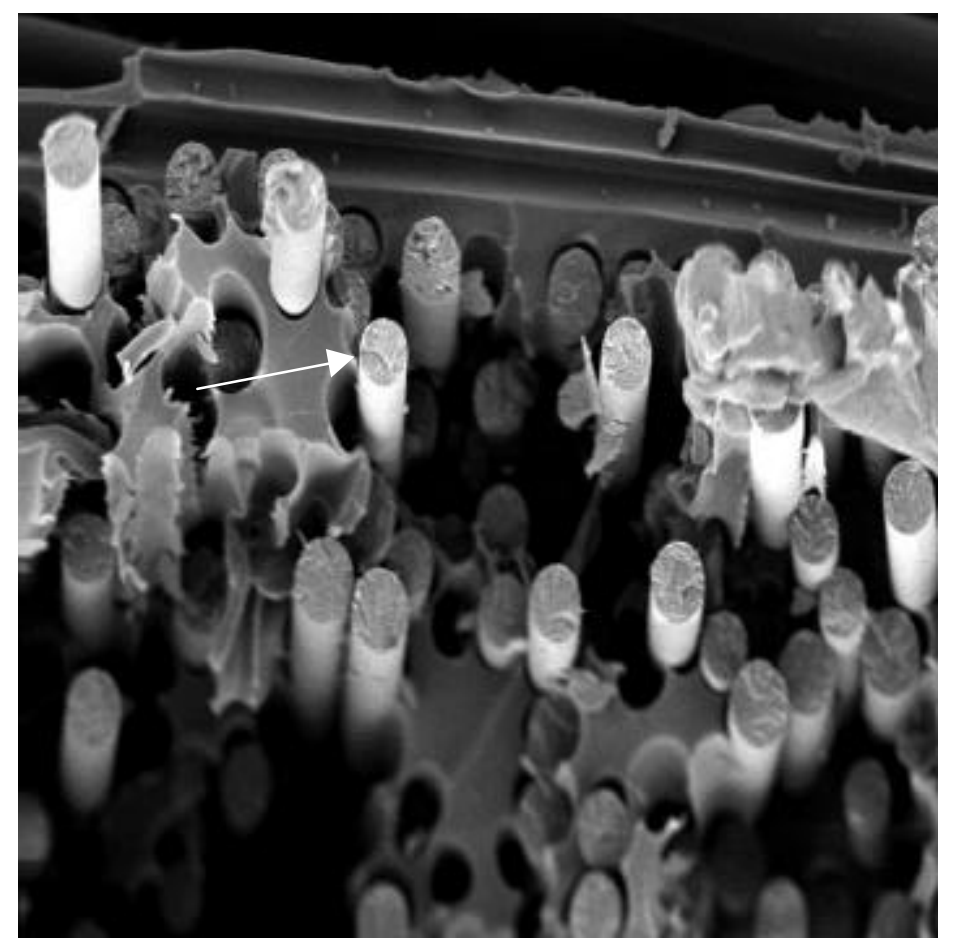

Figure 174. SEM of "Reference" Sample (900X) Arrow shows circular cross-section of a fiber

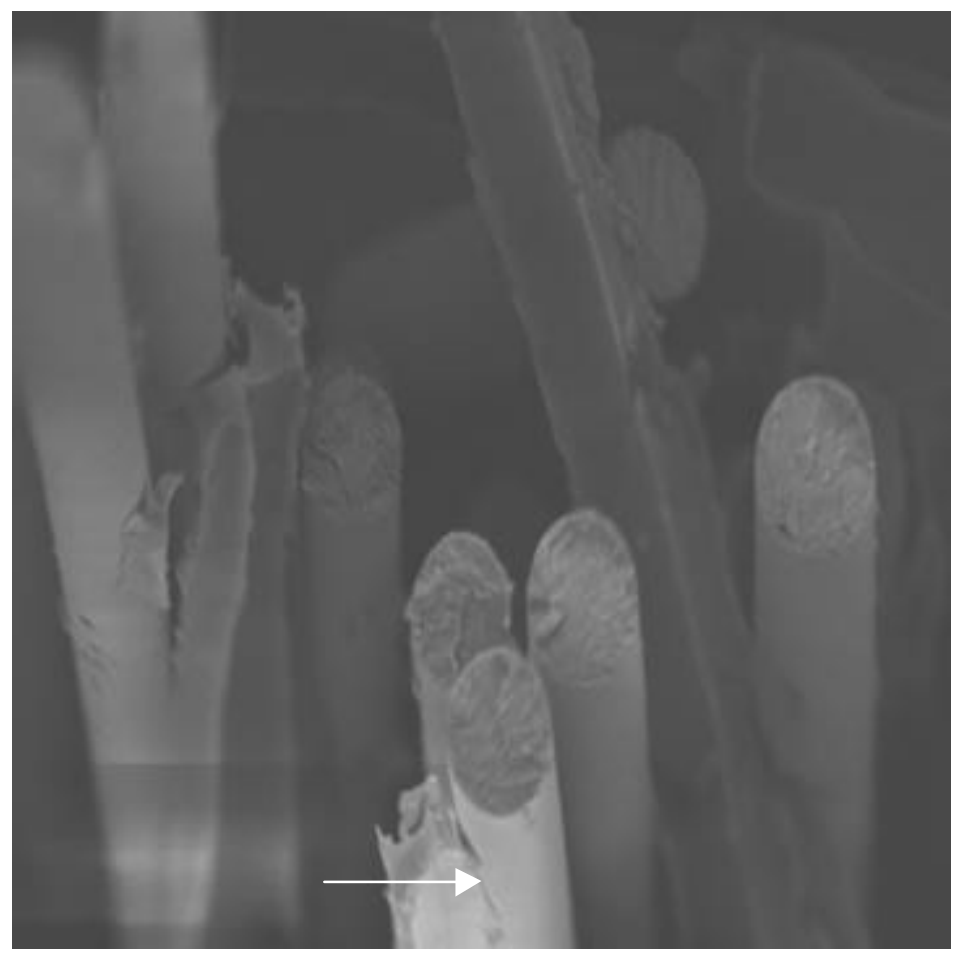

Figure 175. SEM of "Reference" Sample (1000X) Arrow shows adhesion between fiber and resin 


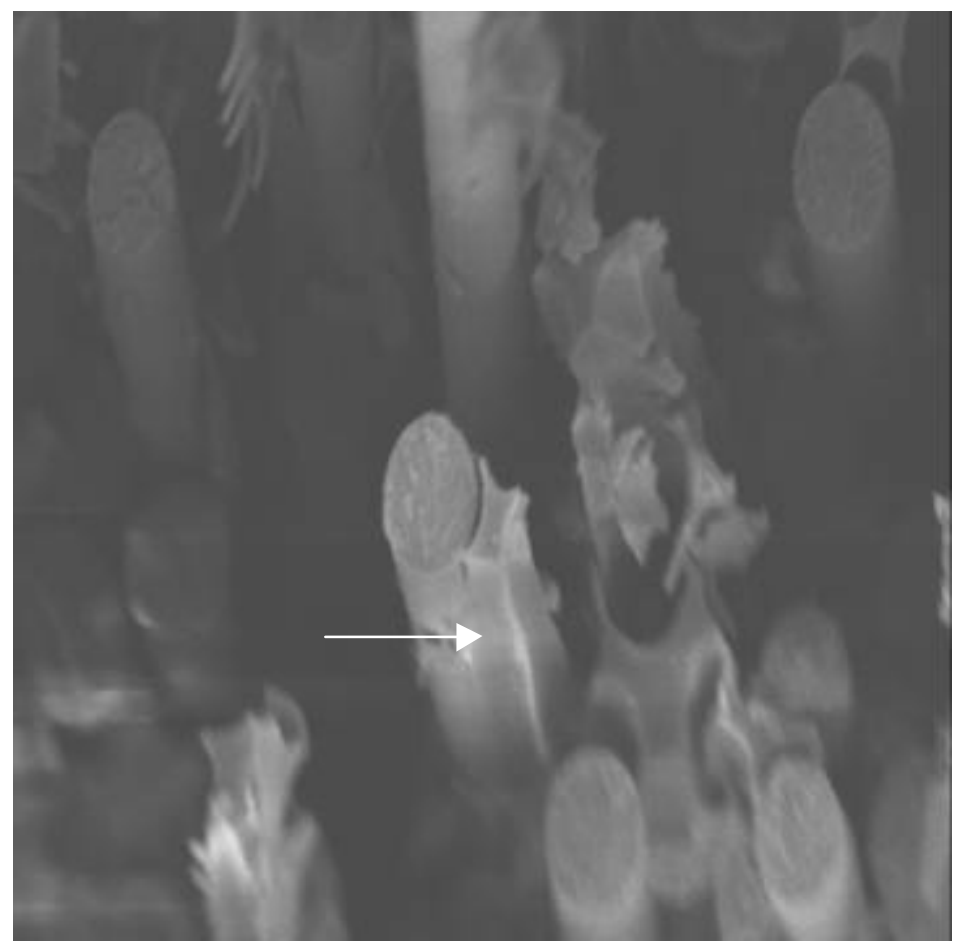

Figure 176. SEM of "Reference" Sample (1000X) Arrow shows adhesion between fiber and resin

SEM images of FRP samples without nanoclay taken after 2 months of immersion in distilled water revealed that there was severe damage to the fibers close to the surface of the sample. However, the damage to the fibers away from the surface was considerably less. Figures 177 to 179 show the damage to the glass-fibers found closer to the surface exposed to distilled water and Figures 180 to 182 show damage to the fibers away from the surface. It is clearly seen from Figure 177 to 182 that the cross section of the fibers no longer remained perfectly circular. 


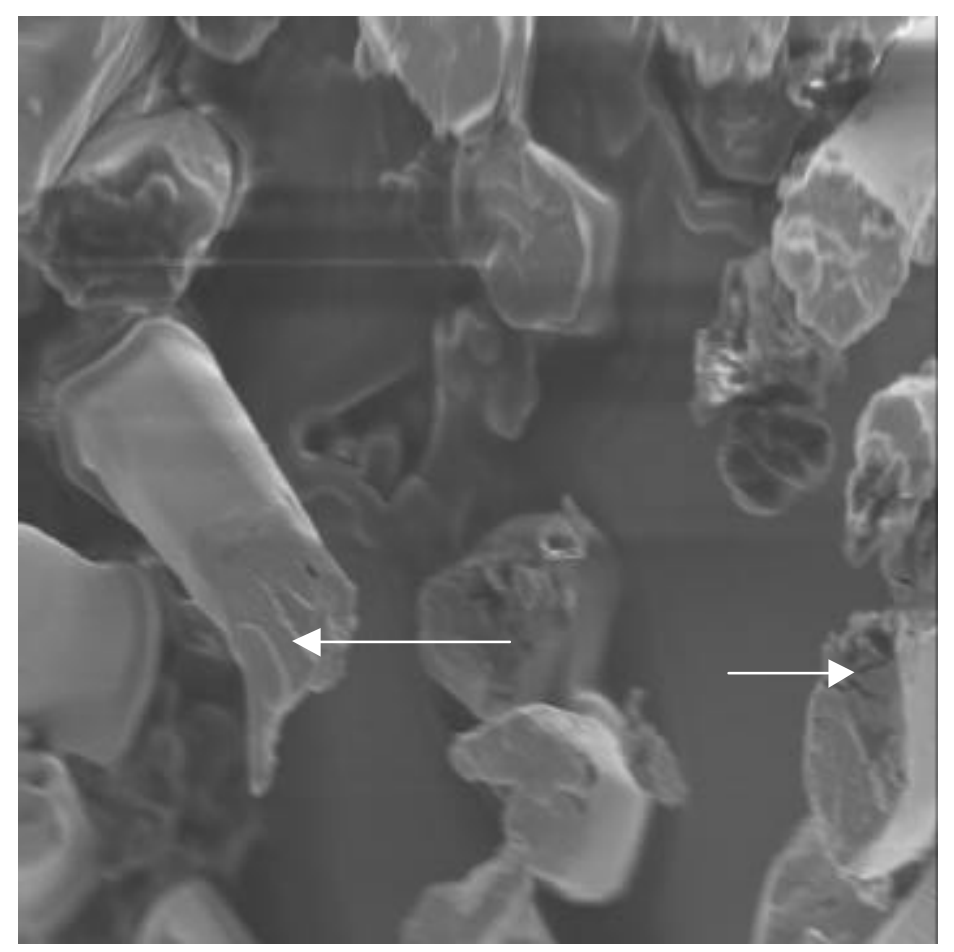

Figure 177. SEM of FRP sample containing no nanoclay (Location: Closer to the surface exposed to distilled water) (1000X) Arrows show damage and crack on fibers

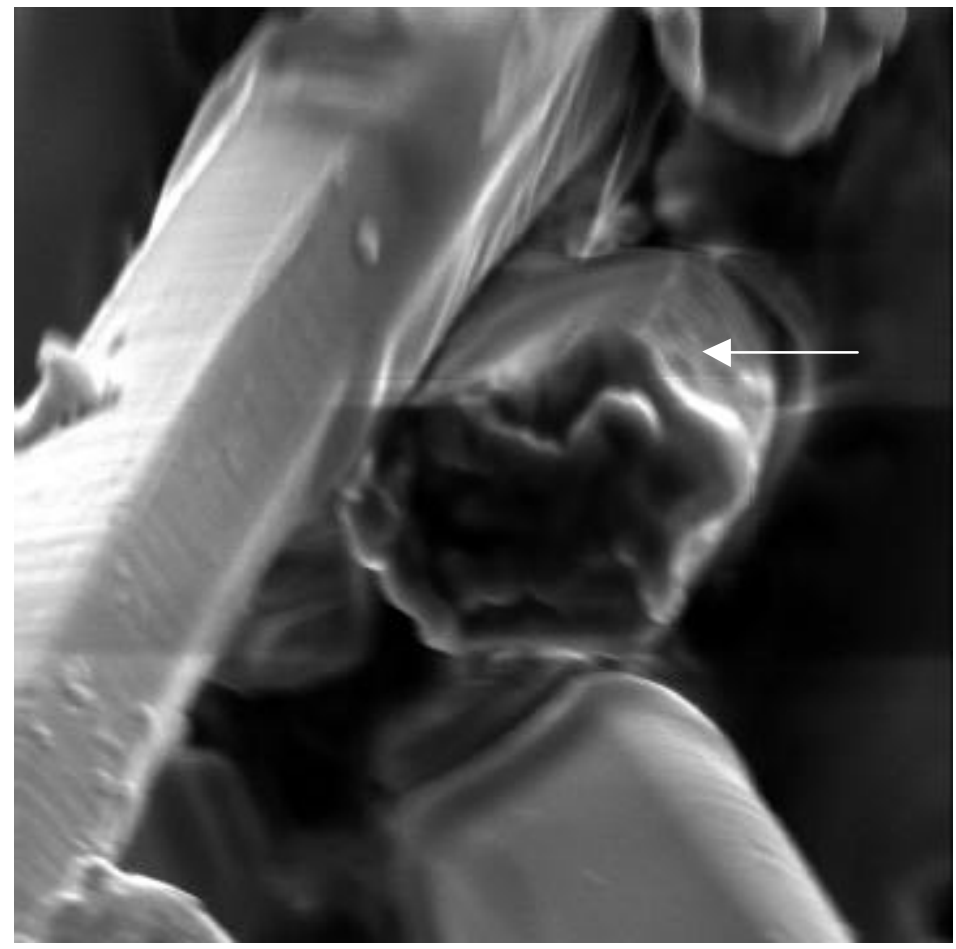

Figure 178. SEM of FRP sample containing no nanoclay (Location: Closer to the surface exposed to distilled water) (2000X) Arrow shows damage to fiber surface 


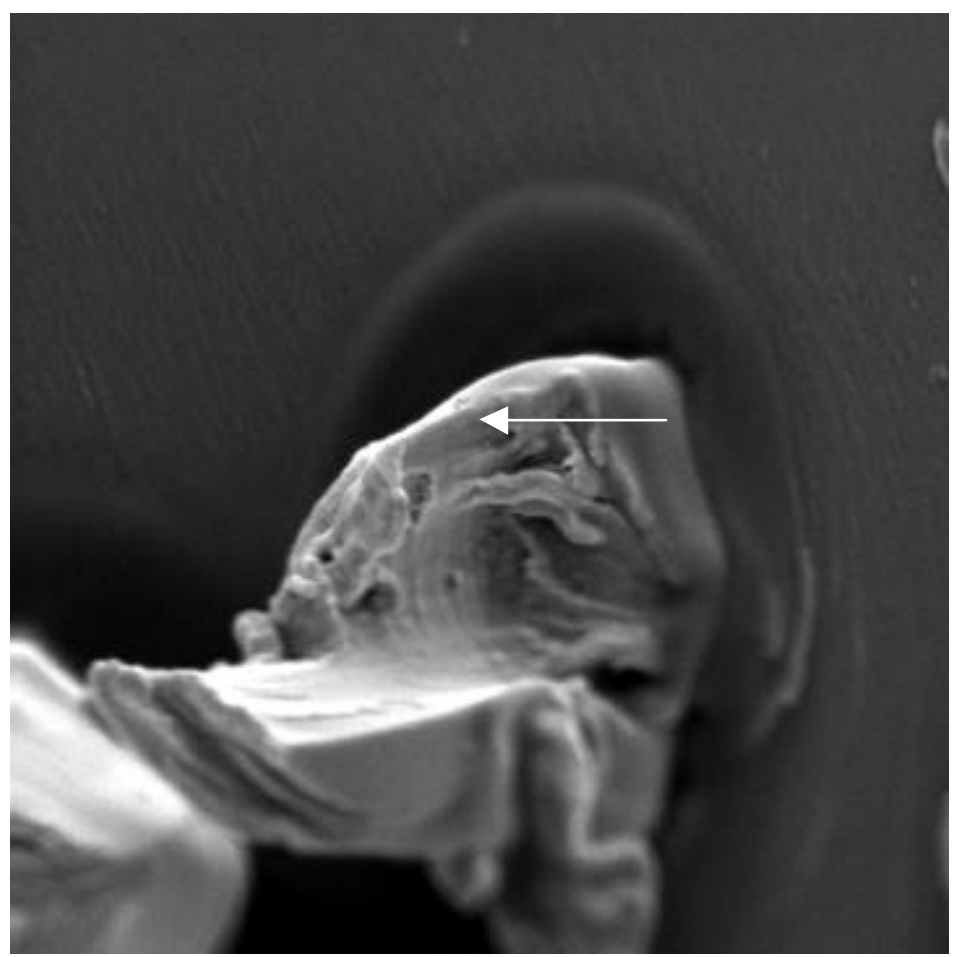

Figure 179. SEM of FRP sample containing no nanoclay (Location: Closer to the surface exposed to distilled water) (2000X) Arrow shows damage to glass-fiber

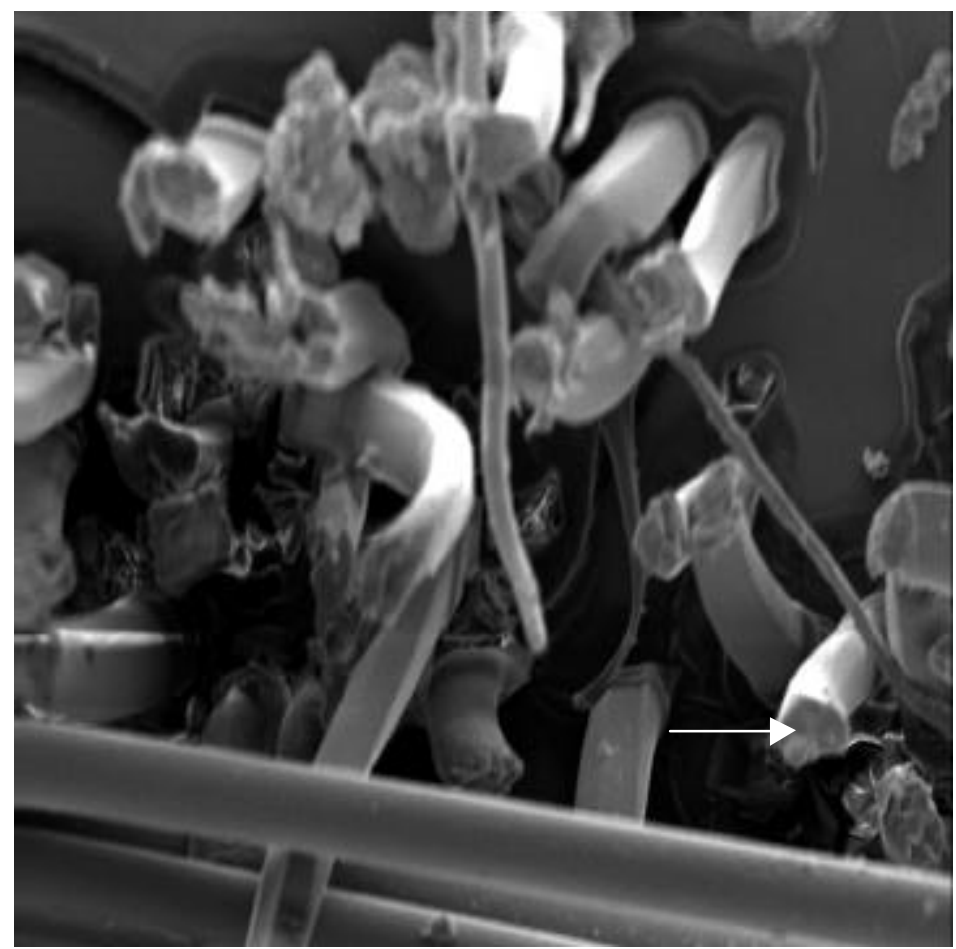

Figure 180. SEM of FRP sample containing no nanoclay (Location: Away from the surface exposed to distilled water) (1000X) Arrow shows distorted cross-section of glass-fiber 


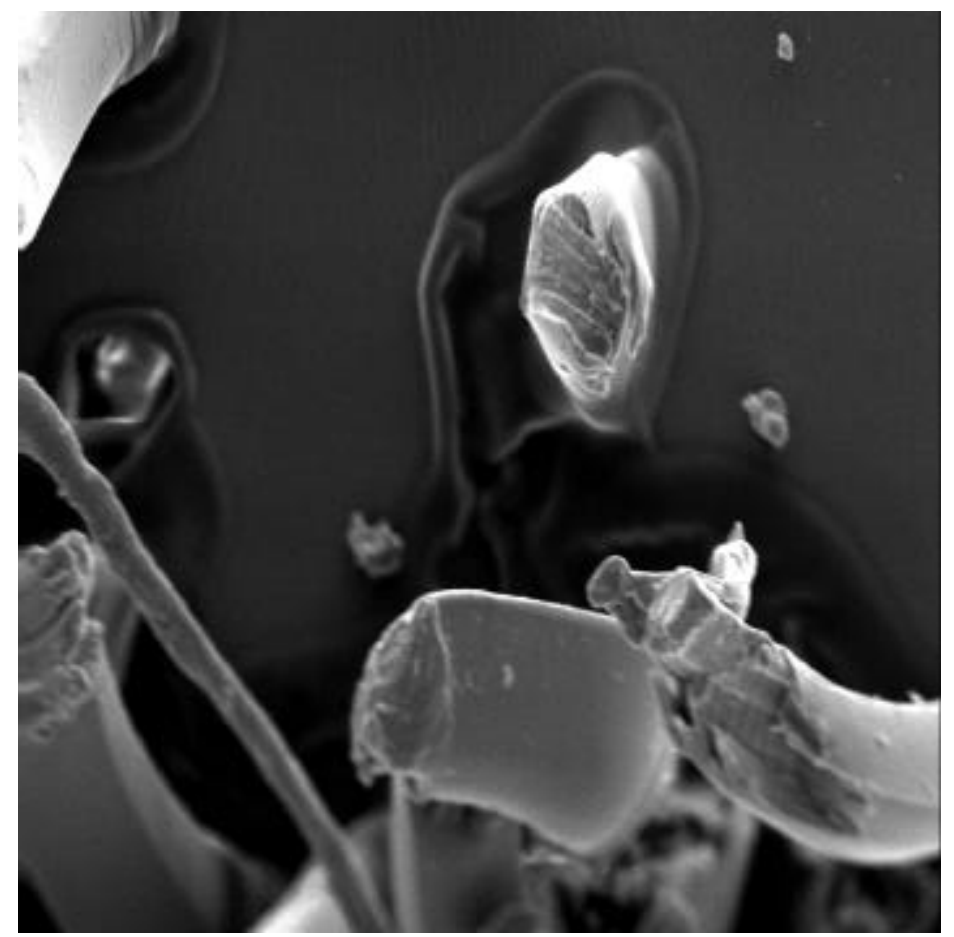

Figure 181. SEM of FRP sample containing no nanoclay (Location: Away from the surface exposed to distilled water) (1200X)

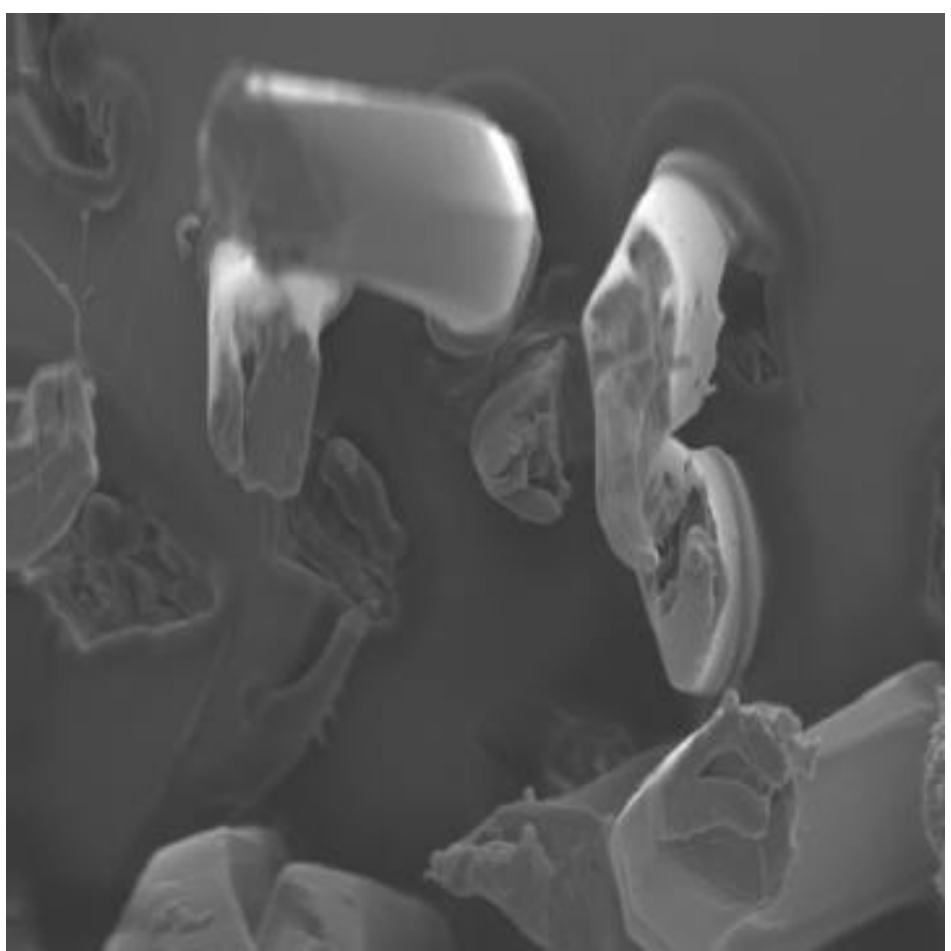

Figure 182. SEM of FRP sample containing no nanoclay (Location: Away from the surface exposed to distilled water) (1000X) 
Kajorncheappunngam (1999) also took SEM images of glass-fibers in glass/epoxy composites after extended immersion of FRP in distilled water as well as alkaline, acid and salt solutions. She reported that the interface debonding mechanisms in a composite immersed in water and alkaline solution are similar to the mechanism that occurs in a composite immersed in acid solution. Once the sizing is removed from the surface of the glass fibers (see section 6.1), the $\mathrm{H}^{+}$ions (protons) attack the glass-fibers. These protons leach out water-soluble alkaline components such as $\mathrm{Na}^{+}, \mathrm{Ca}^{2+}, \mathrm{Al}^{3+}$ and $\mathrm{K}^{+}$ions that are present in the glass-fiber. This ion-exchange reaction between $\mathrm{H}^{+}$and cationic species in the glass is shown in the following equation:

${ }^{*} \mathrm{M}^{\mathrm{n}+}+\mathrm{nH}^{+} \leftrightarrow \mathrm{n}^{*} \mathrm{H}^{+}+\mathrm{M}^{\mathrm{n}+}$

Where the ions denoted by the asterisk are in the glass phase and $\mathrm{M}^{\mathrm{n}}$ is the cation. Cationic species of the glass are replaced by $\mathrm{H}^{+}$ion from water because of the above mentioned ion-exchange reaction. Size of $\mathrm{H}^{+}$ion is much smaller than the cation replaced. Consequently, ion-exchange results in surface shrinkage and tensile stress is developed along the fiber that eventually initiates cracks in the fibers (Lhymn and Schultz, 1984). 
SEM images of the FRP samples containing $5 \mathrm{wt} \%$ Cloisite $10 \mathrm{~A}^{\circledR}$ clay, taken after 2 months of immersion in distilled water, are shown in Figure 183 to 186. No damage was seen on the surface of the fibers. Circular cross section of the fibers can be clearly seen in Figures 183 and 184 indicating that even the fibers closer to the surface were in excellent condition. Figure 185 shows that even after 2 months of immersion period, the adhesion between fiber and matrix was excellent. This was expected because the nanoclay was hydrophilic and it acted as a moisture scavenger. The material adhering to the surface of the glass-fibers in Figures 183 and 186 is nanoclay. The clay preferentially absorbed water and therefore, fewer water molecules interacted with glass fibers resulting in little or no damage to the glass-fibers.

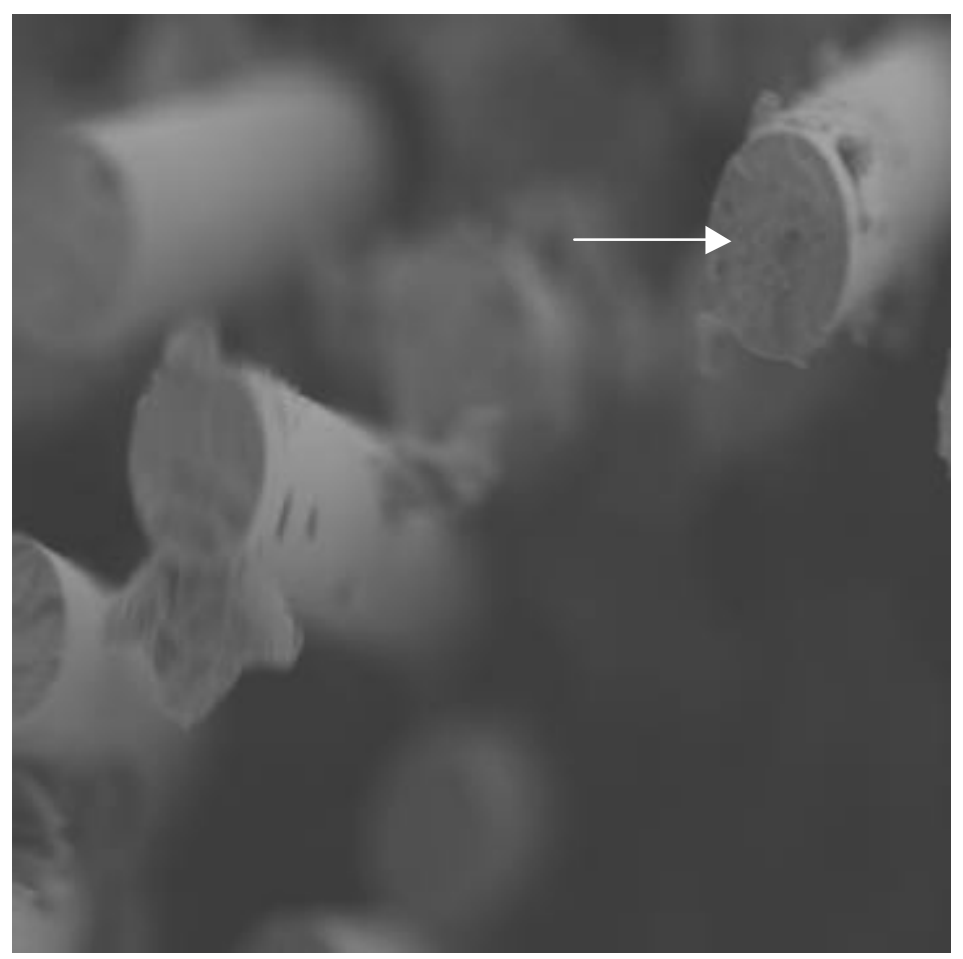

Figure 183. SEM of FRP sample containing $5 \mathrm{wt} \%$ Cloisite $10 \mathrm{~A}^{\circledR}$ Clay (Location: Closer to the surface exposed to distilled water) (1000X) Arrow shows circular cross-section of glass-fiber 


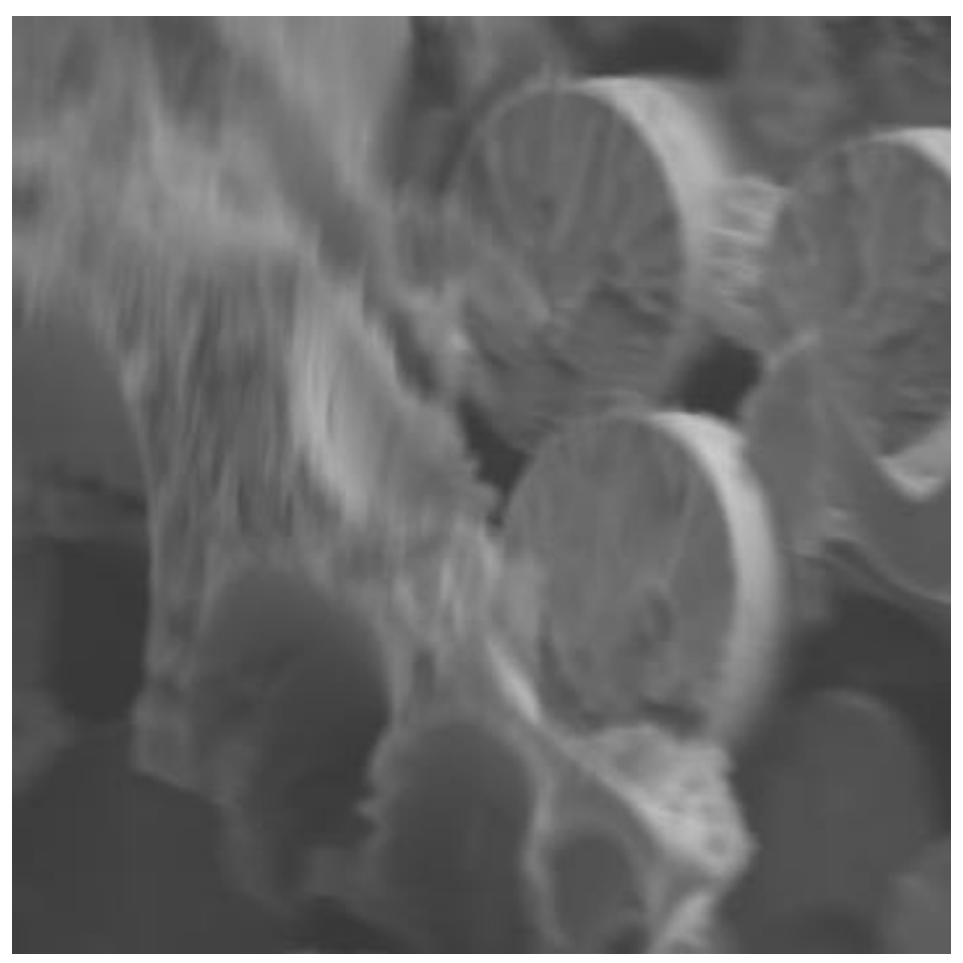

Figure 184. SEM of FRP sample containing $5 \mathrm{wt} \%$ Cloisite $10 \mathrm{~A}^{\circledR}$ Clay (Location: Closer to he surface exposed to distilled water) (2000X)

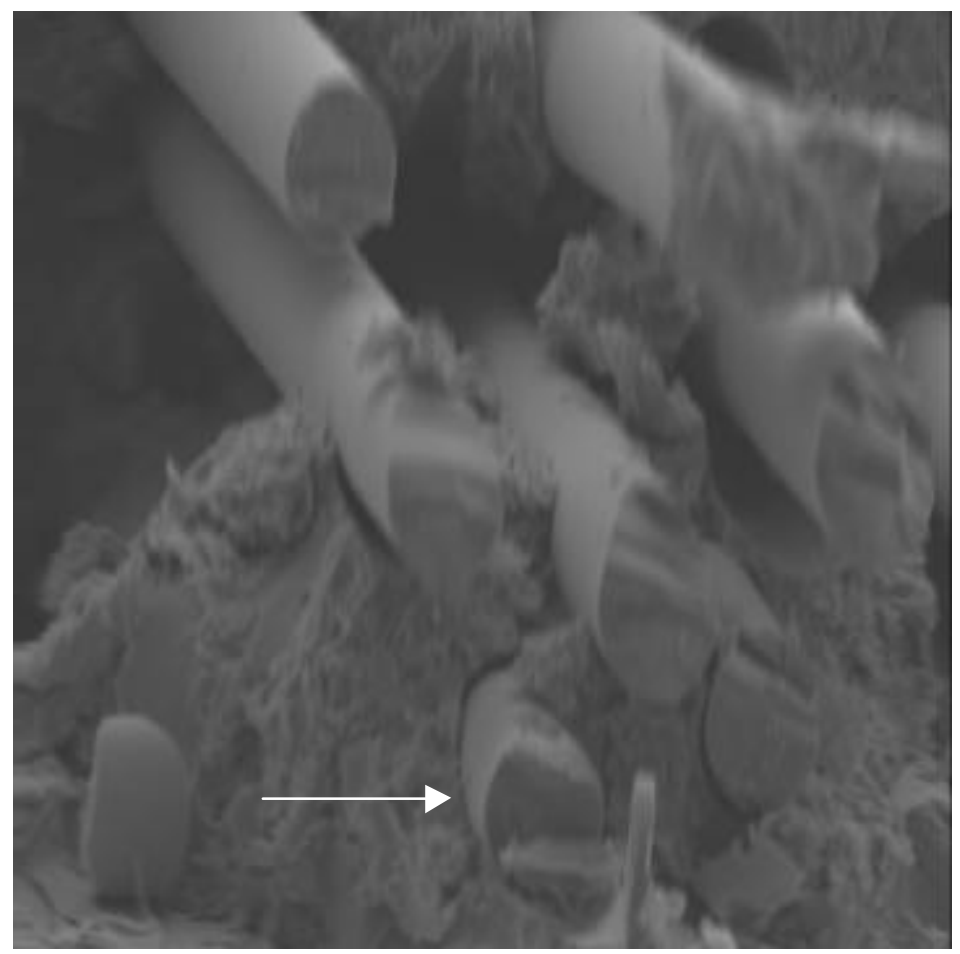

Figure 185. SEM of FRP sample containing 5 wt $\%$ Cloisite $10 \mathrm{~A}^{\circledR}$ Clay (Location: Away from the surface exposed to distilled water) (1200X) Arrow shows adhesion between fiber and resin 


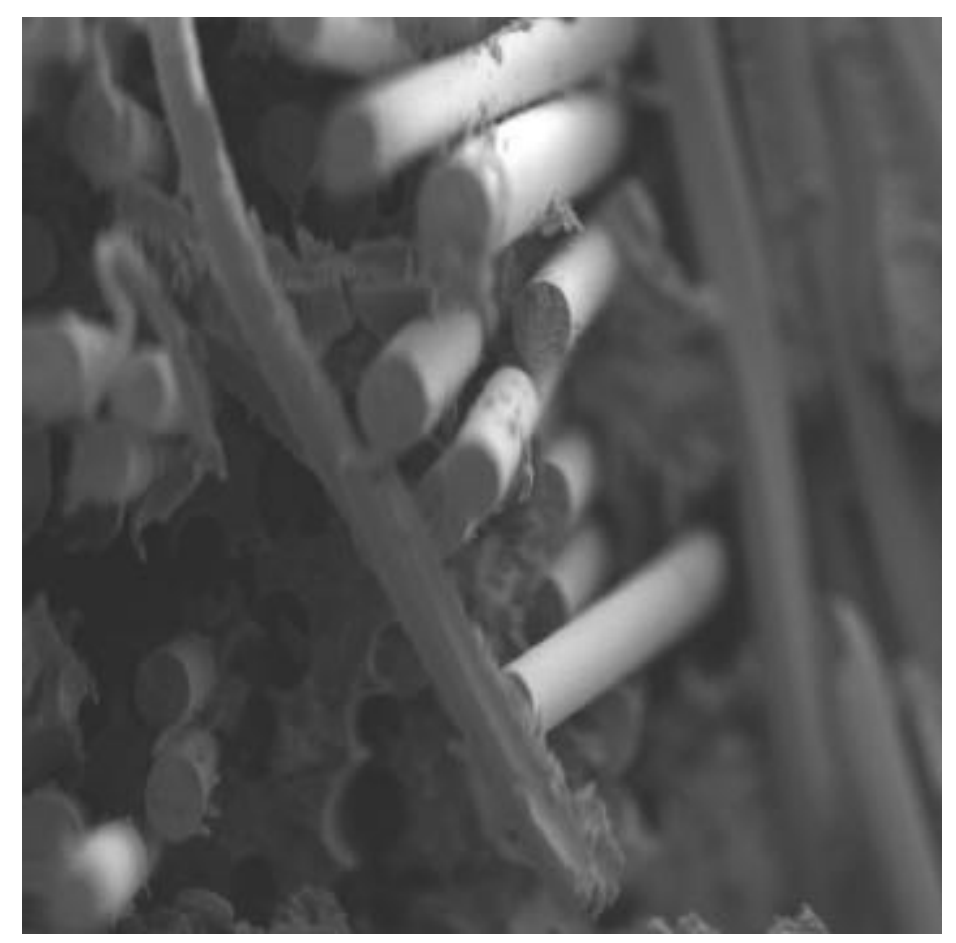

Figure 186. SEM of FRP sample containing $5 \mathrm{wt} \%$ Cloisite $10 \mathrm{~A}^{\circledR}$ Clay (Location: Away from the surface exposed to distilled water) $(900 \mathrm{X})$ 


\section{CHAPTER VII}

\section{CONCLUSIONS AND RECOMMENDATIONS}

\subsection{Conclusions}

Both the transient and steady-state diffusion experiments on the un-reinforced nanocomposite films showed that montmorillonite clay was effective in reducing the diffusion coefficient of water through the vinyl ester resin. The solubility of water in the nonocomposites appeared to increase with the amount of clay, as reflected in the equilibrium moisture content. This was due to water adsorption onto the clay. It is hypothesized that the clay acted as a moisture scavenger by trapping water and preventing it from reaching the glass-matrix interface in the FRPs. Transient diffusion experiments revealed that the diffusion coefficient of water at room temperature dropped by approximately $92 \%$ after incorporation of $5 \mathrm{wt} \%$ of Cloisite $10 \mathrm{~A}^{\circledR}$ clay. Also, as expected, the diffusion coefficients for the same type of samples dropped drastically with decrease in temperature. However, the steady-state experiments revealed that the drop in diffusion coefficient was approximately $21 \%$ after incorporation of $5 \mathrm{wt} \%$ of Cloisite $10 \mathrm{~A}^{\circledR}$ clay. The mechanism of diffusion in both type of experiments were different. In transient experiment, when a diffusing water molecule attached itself to a clay platelet as soon as it encountered one and water molecules marched ahead on a "tortuous path" only after the platelet was saturated with water. However, in steady-state experiments, all the clay platelets were saturated before the experiment started. Therefore, diffusing water molecule just followed the "tortuous path" to travel across the nanocomposite film.

Transient diffusion experiments in salt solution revealed that all the types of samples absorbed significantly less amount of water as compared to the water absorbed 
when they were immersed in distilled water at the same temperature. It seemed that lower chemical potential of water in salt solution resulted in lower ingress of water molecules in to the polymer. The trend of decreasing diffusion coefficient with increasing amount of montmorillonite in the vinyl ester was apparent. However, the equilibrium moisture contents remained nearly unchanged with various clay loadings indicating that fewer water molecules got adsorbed on clay platelets.

Transient diffusion experiments in alkaline solution having a $\mathrm{pH}$ of 13 showed that the vinyl ester had a little or no chemical resistance to alkaline environment at room temperature. The vinyl ester reacted rapidly with sodium hydroxide solution at room temperature. However, the matrix did not react with sodium hydroxide at relatively lower temperature $\left(4^{\circ} \mathrm{C}\right)$.

Transient diffusion experiments on GFRP samples in distilled water showed that the sizing material had high affinity for water molecules. The sizing material reacted with water and caused debonding between fiber and matrix. The additional water inside the sample, then, interacted with glass fibers. SEM images of various samples taken after 2 months of immersion revealed that the damage to the fibers could be very severe when the matrix did not contain nanoclay. In other words, the clay preferentially absorbed water and therefore, fewer water molecules interacted with glass fibers resulting in little or no damage to the glass-fibers. The nanoclay not only decreased the diffusion coefficient by increasing the path of diffusion but also acted as moisture scavenger and protected the glass- fibers. 
Steady-state diffusion experiments on GFRP showed that the presence of glass fibers had little effect on the diffusion coefficient of the GFRP films. This led to the conclusion that the process of diffusion is matrix dominated.

On the contrary to ones expectation, diffusion coefficients for desorption showed a reverse trend than the diffusion coefficients for absorption, i.e. desorption diffusion coefficients increased with increasing amount of clay loading. And also, the desorption diffusion coefficients were much higher than the absorption diffusion coefficients for the same type of samples. It is speculated that absorption of water in polymer caused some changes in the structure of polymer chains that was responsible for the faster desorption when the boundary conditions were changed. Further study is recommended in order to understand this abnormal desorption behavior.

As expected, the addition of nanoclay was accompanied by an increase in the polymer glass transition temperature and increase in other mechanical properties. Both thermal and mechanical properties increased due to interaction between the polymer chains and clay platelets. TGA tests revealed that there were no obvious differences in the weight loss patterns of various nanocomposite samples but it was important to note that there were no adverse effects due to the incorporation of nanoclay. Tensile modulus and notched impact strength were found to increase after incorporation of Cloisite $10 \mathrm{~A}^{\circledR}$. However, tensile strength and strain at failure remained nearly unchanged. Both the storage modulus in torsion $\left(\mathrm{G}^{\prime}\right)$ and the glass transition temperature $\left(\mathrm{T}_{\mathrm{g}}\right)$ increased significantly due to the incorporation of nanoclay in resin indicating that the presence of clay platelets in the matrix provides enhanced torsional properties. 
Finally, addition of nanoclay to vinyl ester matrix showed potential for improving barrier properties. Reduction of diffusion coefficient was evidently observed in both types of diffusion experiments. In addition, nanocomposites had enhanced mechanical and thermal properties as compared to neat resin. This would help in extending the utility and application of the composite in more severe environments.

\subsection{Recommendations}

Although use of nanoclays to enhance barrier properties of polymeric matrices has shown promising results, the following lists out some possible areas that may need to be addressed in future studies:

1. It is necessary to understand the nature of interactions between the sizing material applied to the glass-fibers and water molecules. Most of the commercial sizing materials are based on tri-methoxy silane or tri-ethoxy silane. These sizing materials have high affinity for $-\mathrm{OH}$ groups and hence, they react readily with water. These interactions can be investigated further by performing diffusion tests on various types of GFRP samples where the fibers are treated with different sizing materials.

2. It was found in the present study that the polymer reacted with sodium hydroxide solution during 45 hours of immersion. If the time scale of diffusion can be reduced to 45 hours then it is possible to calculate the diffusivities accurately. This can be practically possible if the experiments are conducted on polymer film having a thickness of approximately $50 \mu \mathrm{m}$. Alternatively, polymer fibers having $50 \mu \mathrm{m}$ diameter can also be used instead of films (see appendix A.1.10). 
3. Theory proposed by Drozdov et al. (2003) has a potential to explain the inherent consistency of transient and steady-state diffusion experiments. However, the theory fails when the neat resin shown non-fickian diffusion. More sophisticated mathematical models are required to prove the internal consistency between the two types of experiments.

4. Dynamic mechanical tests on nanocomposites in different geometries such as single cantilever, dual cantilever, three-point bending are recommended to understand the mechanical property enhancements in various loading situations.

5. Thorough study of cyclic absorption and desorption experiments is recommended to explain the mechanism of desorption process of nanocomposites.

6. Further enhancement in barrier and mechanical properties can be achieved by improving the exfoliation of clay platelets using higher shear mixing techniques. A detailed study on the effect of various mixing techniques on degree of exfoliation is highly recommended. 


\section{REFERENCES}

Adamson M.J., Thermal Expansion and Swelling of Cured Epoxy Resin used in Graphite/Epoxy composite materials, J. Mater. Sci., 15, no.4, 1736-1745 (1980)

Alexandre M. and Dubois P., Polymer-Layered Silicate Nanocomposites: Preparation, Properties and Uses of a New Class of Materials, Mater. Sci. and Eng., 28, 1-63 (2000)

Apicella A., Nicolais L. and C. De Cataldis, Characterization of the Morphological fine structure of commercial Thermosetting resins through Hygrothermal experiments, Adv. Polym. Sci., 66, 189-207 (1985)

Barrie J.A., Sagoo P.S. and Johncock P., Sorption and Diffusion of Water in Epoxy Resins, J. Membr. Sci., 18, 197-210 (1984)

Berens A.R. and Hopfenberg H.B., Induction and Measurement of Glassy State Relaxation by Vapor Sorption Techniques, J. Polym. Sci.: Polym. Phys. Ed., 17, 17571770 (1979)

Bonniau P. and Bunsell A.R., A Comparative Study of Water Absorption Theories Applied to Glass Epoxy Composites, J. Compos. Mater., 15, 272-293 (1981)

Brydges W.T., Gulati S.T. and Baum G., Permeability of Glass Ribbon-Reinforced Composites, J. Mater. Sci., 10, 2044-2049 (1975)

Carter H.G. and Kibler K.G., Langmuir-Type model for Anomalous Moisture Diffusion in Composite Resins, J. Compos. Mater., 12, 118-131 (1978)

Chen C., Han B., Li J., Shang T., Zou J. and Jiang W., A new Model on the Diffusion of Small Molecule Penetrants in Dense Polymer Membranes, J. Membrane Sci., 187, 109118 (2001)

Chin J.W., Nguyen T. and Aouadi K., Sorption and Diffusion of Water, Salt Water, and Concrete pore Solution in Composite Matrices, J. Polym. Sci., 71, 483-492 (1999)

Comyn J., Durability of Structural Adhesives, Kinloch, A. J., Ed., Applied Science Publishers, New York, 1983, Chapter 3

Crank J., Mathematics of Diffusion, $2^{\text {nd }}$ Ed., Oxford University Press, London, 1975, Chapter 3,4, and 14

Cussler E.L., Hughes S.E., Ward W.J. and Aris R., Barrier Membranes, J. Membrane Sci., 38, 161-174 (1988) 
Drozdov A.D., Christiansen J. DeC., Gupta R.K. and Shah A.P., Model for Anomalous Moisture Diffusion through a Polymer-Clay Nanocomposite, J. Polym. Sci. Pol. Phys., 41, 476-492 (2003)

Falla W.R., Mulski M. and Cussler E.L., Estimating Diffusion through flake-filled membranes, J. Membrane Sci., 119, 129-138 (1996)

Fornes T.D., Yoon P.J., Keskkula H. and Paul, D.R., Nylon 6 Nanocomposites: the Effect of Matrix Molecular Weight, Polymer, 42, 9929-9940 (2001)

Fredrickson G.H. and Bicerano J., Barrier Properties of Oriented Disk Composites, J. Chem. Phys., 110, 2181-2188 (1999)

GangaRao H.V.S. and Craigo C., IABSE-Structural Engineering International, 9, 286 (1999)

Ghorbel I. and Valentin D., Hydrothermal Effect on the Physico-Chemical Properties of Pure and Glass Fiber Reinforced Polyester and Vinyl Ester Resins, Polym. Composite, 14, 324-334 (1993)

Ishai O., Environmental Effects on Deformation, Strength, and Degradation of Unidirectional Glass-Fiber Reinforced Plastics II. Experimental Study, Polym. Eng. Sci., 15, no. 7, 491-499 (1975)

Kajorncheappunngam S., Gupta R.K. and Gangarao H.V.S., Effect of Aging Environment on Degradation of Glass-Reinforced Epoxy, J. Compos. Constr., 6, no. 1, 61-69 (2002)

Kajorncheappunngam S., The Effects of Environmental Aging on the Durability of Glass/Epoxy Composites, Doctoral Thesis, West Virginia University, Morgantown, USA, 1999

Klotz J., Brostow W., Hess M. and Veeman W.S., Epoxy and Glass Composites in Water studied with ${ }^{2} H-N M R$, Polym. Eng. Sci., 36, no. 8, 1129-1133 (1996)

Kornmann X., Berglund L.A. and Sterte J., Nanocomposites based on Montmorillonite and Unsaturated Polyester, Polym. Eng. Sci., 38, 1351-1358 (1998)

Kornmann X., Synthesis and Characterization of Thermoset-Clay Nanocomposites, Doctoral Thesis, Division of Polymer Engineering, Lule a University of Technology, Lule a , Sweden, 2001

Kshirsagar S., Lopez-Anido R.A., and Gupta R.K., Environmental Aging of Fiber Reinforced Polymer-Wrapped Concrete Cylinders, ACI Mater. J., 97, 703-712 (2000) 
Kumar A. and Gupta R.K., Fundamentals of Polymers, McGraw-Hill, New York, 1998, 407-441

Lhymn C. and Schultz J. M., Environmental Testing of a Glass-Fiber Reinforced Thermoplastic, Polym. Eng. Sci, 24, 1064-1070 (1984)

Litt M., Free Volume Concepts Connecting PVT Behavior and Gaseous Diffusion Through Polymers, J. Rheol., 30, no. 4, 853-868 (1986)

Liu L., Qi Z. and Zhu X., Studies on Nylon 6/Clay Nanocomposites by Melt-intercalation Process, J. Appl. Polym. Sci., 71, 1133-1138 (1999)

Long F.A. and Richman D., Concentration gradients for diffusion of vapors in glassy polymer and their relation to time dependent diffusion phenomena, J. Am. Chem. Soc., 82, 513-519 (1960)

Lan T., Kaviratna P. D. and Pinnavaia T. J., Mechanism of Clay Tactoid Exfoliation in Epoxy-Clay Nanocomposites, Chem. Mater., 7, 2144-2150 (1995)

Mallick P.K., Fiber-Reinforced Composites: Materials, Manufacturing and Design, $2^{\text {nd }}$ Ed., Marcel Dekker, Inc., New York, 1993, 41-64

Marsh L.L., Lasky R., Seraphim D.P. and Springer G.S., Moisture Solubility and Diffusion in Epoxy and Glass Epoxy Composites, IBM J. Res. Develop., 28, 655-661 (1984)

Massam J. and Pinnavaia T.J., Clay Nanolayer Reinforcement of a Glassy Epoxy Polymer, Mater. Res. Soc. Symp. Proc., 520, 223-232 (1998)

Maxwell J.C., Treatise on Electricity and Magnetism, 1, Claredon Press, London, 1881

McMaster M.G. and Soane D.S., Water Sorption in Epoxy thin Films, IEEE T. Compon. Hybr., 12, 373-386 (1989)

Messersmith P.B. and Giannelis E.P., Synthesis and Barrier Properties of Poly $(\varepsilon-$ caprolactone)-Layered Silicate Nanocomposites, J. Polym. Sci. A1, 33, 1047-1057 (1995)

Okada A. and Usuki A., The chemistry of polymer-clay hybrids, Mat. Sci. Eng., 3, 109115 (1995)

Peppas A., Lee M.C., Water Transport in Epoxy Resins, Prog. Polym. Sci., 18, 947-961 (1993)

Raleigh L., On the influence of obstacles arranged in rectangular order upon the properties of a medium, Philos. Mag., 34, 481-502 (1892) 
Sahlin J. and Peppas N.A., Penetrant Transport in Epoxy Resins, Ind. Eng. Chem. Res., 30, 211-217 (1991)

Selzer R., Friedrich K., Influence of Water Up-take on Interlaminar Fracture Properties of Carbon Fiber-Reinforced Polymer Composites, J. Mater. Sc., 30, 334-338 (1995)

Sen R., Mullins G. and Salem, T., Durability of E-Glass/Vinylester Reinforcement in Alkaline Solution, ACI Struct. J., 99, no. 3, 369-375 (2002)

Shah A.P., Gupta R.K., Gangarao H.V.S. and Powell C.E., Moisture Diffusion Through Vinyl Ester Nanocomposites Made with Montmorillonite Clay, Polym. Eng. Sci., 42, no.9, 1852-1863 (2002)

Shah A.P., Moisture Diffusion Through Vinyl Ester/Clay Nanocomposites, Master's Thesis, West Virginia University, Morgantown, USA, 2001

Singh K.S., Singh P.N. and Rao R.M.V.G.K., Hygrothermal Effects on Chopped Fiber/Woven Fabric Reinforced Epoxy Composites. Part A. Moisture Absorption Characteristics, J. Reinf. Plast. Comp., 10, 446-456 (1991)

Todo M., Nakamura T. and Takahashi K., Effects of Moisture Absorption on the Dynamic Interlaminar Fracture Toughness of Carbon/Epoxy Composites, J. Compos. Mater., 34, 630-648 (2000)

Tsotsis T.K. and Weitsman Y., A Simple Graphical Method for Determining Different Parameters for 2-Stage Sorption in Composites, J. Mat. Sci. Let., 13, 1635-1636 (1994)

Vanlandingham M.R., Eduljee R.F. and Gillespie J.W.Jr., Moisture Diffusion in Epoxy Systems, J. Appl. Polym. Sci., 71, 787-798 (1999)

Verghese K.N.E., Hayes M.D., Garcia K., Carrier C. Wood J. Riffle J.R. and Lesko J.J., Influence of Matrix Chemistry on the Short Term, Hydrothermal Aging of Vinyl Ester Matrix Composites under both Isothermal and Thermal Spiking Conditions, J. Compos. Mater., 33, 1918-1938 (1999)

Wakeham W.A. and Mason E.A., Diffusion through Multi-perforate laminate, Ind. Eng. Chem. Fund., 18, no. 4, 301-305 (1979)

Wang Z. and Pinnavaia T.J., Nanolayer Reinforcement of Elastomeric Polyurethane, Chem. Mater., 10, 3769-3771 (1998)

Wong T.C., Broutman L.J., Water in Epoxy Resins Part I. Non-Fickian Sorption Process, Polym. Eng. Sci., 25, no. 9, 529-534 (1985)

Wong T.C., Broutman L.J., Water in Epoxy Resins Part II. Diffusion Mechanism, Polym. Eng. Sci., 25, no. 9, 529-534 (1985) 
Yano K., Usuki A., Okada A., Toshio K. and Kamigaito, O., Synthesis and Properties of Polyimide-Clay Hybrid, J. Polym. Sci. A1., 31, 2493-2498 (1993) 


\title{
APPENDICES
}

\section{A.1. Sample Calculations}

\author{
A.1.1. Sample Calculation for Diffusion Coefficient in un-reinforced samples in Transient \\ Diffusion experiments
}

Table A. I. Diffusion Data for neat DERAKANE 411-350 MOMENTUM sample immersed in 0.1M $\mathrm{NaCl}$ solution at $28^{\circ} \mathrm{C}$

Thickness $2 \mathrm{l}=0.0314325 \mathrm{~cm}$

\begin{tabular}{rrrrrr} 
Time (h) & Weight (mg) & Weight Gain (mg) & $\frac{M_{t}-M_{0}}{M_{\infty}-M_{0}}$ & \multicolumn{1}{c}{$\begin{array}{l}\sqrt{t} / 2 l \\
\left(\mathrm{hr}^{1 / 2} / \mathrm{cm}\right)\end{array}$} \\
& & 0 & 0 & 0 \\
0 & $M_{0}=223.36$ & 0.3 & 0.196078431 & 18.36793985 \\
0.333333 & 223.66 & 0.6 & 0.392156863 & 36.73583377 \\
1.33333 & 223.96 & 0.74 & 0.483660131 & 45.91981288 \\
2.08333 & 224.1 & 1.03 & 0.673202614 & 67.48812037 \\
4.5 & 224.39 & 1.15 & 0.751633987 & 87.12678875 \\
7.5 & 224.51 & 1.37 & 0.895424837 & 159.0710252 \\
25 & 224.73 & 1.47 & 0.960784314 & 269.0135135 \\
71.5 & 224.83 & 1.48 & 0.967320261 & 411.1301355 \\
167 & 224.84 & 1.53 & 1 & 602.7931384 \\
359 & 224.89 & 1.53 & 1 & 696.2878749 \\
479 & $M_{\propto}=224.89$ & & &
\end{tabular}

Expression for Diffusion Coefficient was obtained by rearranging equation 4:

$D=\frac{\pi}{16}\left(\frac{M_{t} / M_{\infty}}{\sqrt{t} / 2 l}\right)^{2}$

Where $\left(\frac{M_{t} / M_{\infty}}{\sqrt{t} / 2 l}\right)$ is the slope of the straight line (Figure A.1) from the plot of $M_{t} / M_{\infty}$ versus $t^{1 / 2} / 2$ l drawn up to $M_{t} / M_{\infty}<0.5$. 


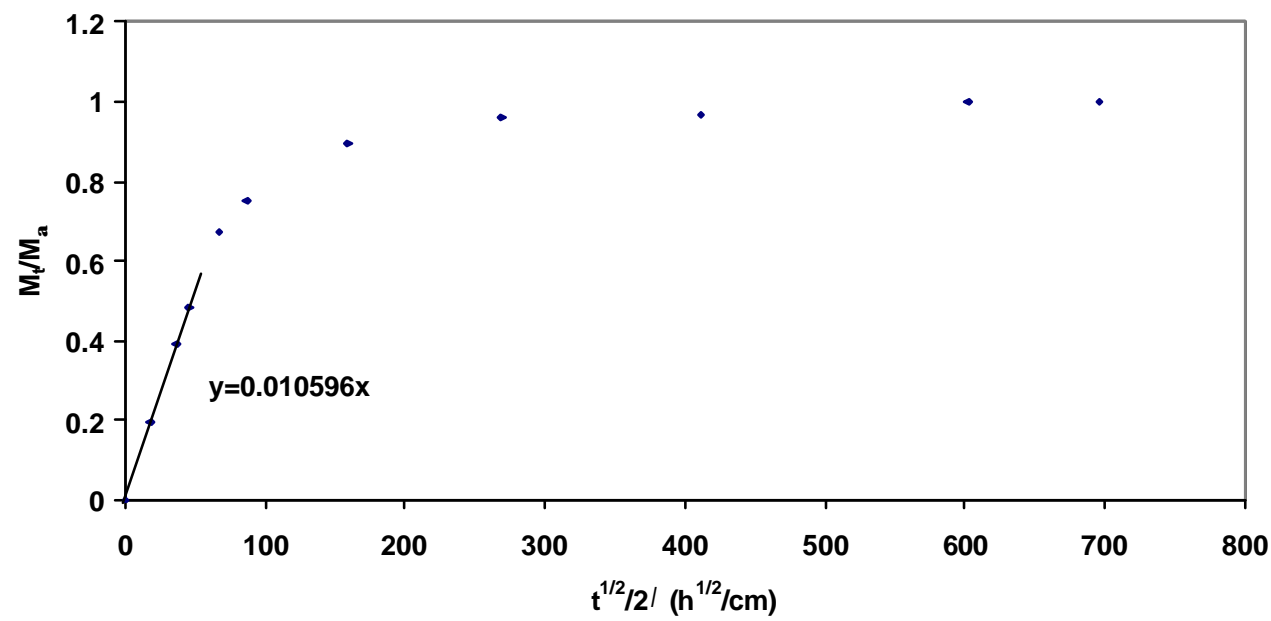

Figure A. 1. $M_{t} / M_{\infty}$ versus $\mathrm{t}^{1 / 2} / 2$ curve

$D=\frac{\pi}{16}(0.010596)^{2} / 3600=6.124 \times 10^{-9} \mathrm{~cm}^{2} / \mathrm{s}$

\section{A.1.2. Sample Calculation for Diffusion Coefficient in un-reinforced Sample in Steady}

State Diffusion Experiments

Table A. II. Steady State experiment data for neat DERAKANE 411-350 MOMENTUM sample

Thickness $L=0.041275 \mathrm{~cm}$

$\begin{array}{rrr}\text { Time (h) } & \text { Weight }(\mathrm{g}) & \begin{array}{c}\text { Weight Gain } \\ (\mathrm{g})\end{array} \\ 0 & 8.307 & 0 \\ 20.5 & 8.311 & 0.004 \\ 44.5 & 8.316 & 0.009 \\ 66.5 & 8.319 & 0.012 \\ 90.5 & 8.325 & 0.018 \\ 117.5 & 8.329 & 0.022 \\ 138.5 & 8.333 & 0.026 \\ 163.5 & 8.337 & 0.03 \\ 188.5 & 8.341 & 0.034 \\ 218.5 & 8.345 & 0.038 \\ 240 & 8.347 & 0.04 \\ 266.5 & 8.352 & 0.045 \\ 314 & 8.36 & 0.053 \\ 338.5 & 8.364 & 0.057 \\ 361.5 & 8.366 & 0.059 \\ 389.5 & 8.369 & 0.062 \\ 429 & 8.376 & 0.069 \\ 476 & 8.385 & 0.078 \\ 548 & 8.395 & 0.088 \\ 671 & 8.413 & 0.106 \\ 716 & 8.421 & 0.114\end{array}$




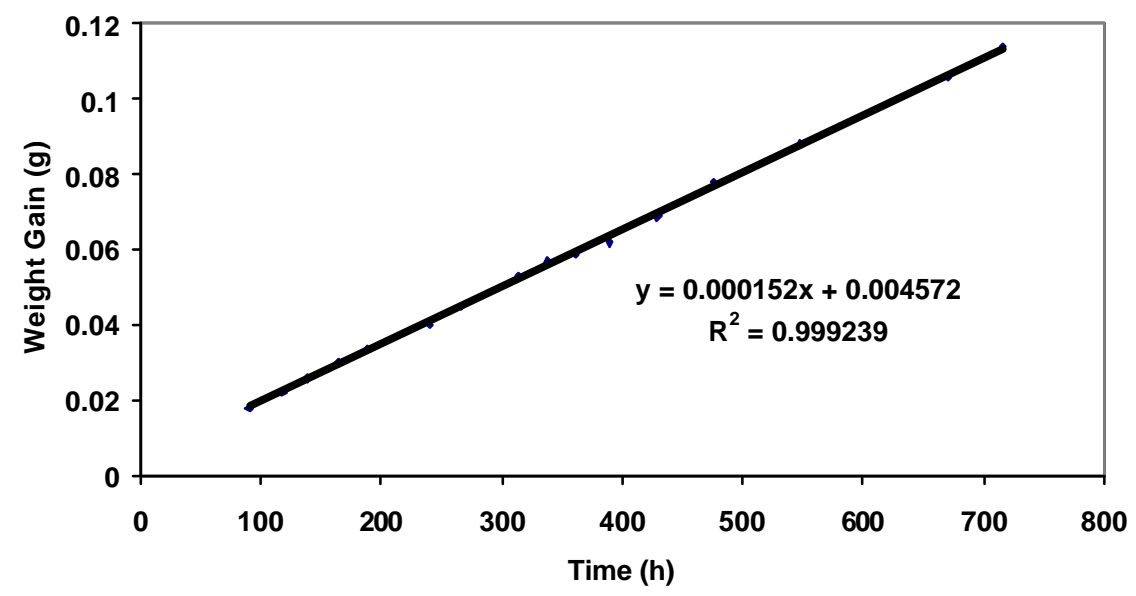

Figure A. 2. Weight gain versus time

Equilibrium Concentration at $77 \% \mathrm{RH}\left(C_{l}\right)=11.96 \mathrm{mg} / \mathrm{cm}^{3}$ (See Raw Data)

Equilibrium Concentration at $0 \% \mathrm{RH}\left(C_{2}\right)=0.00 \mathrm{mg} / \mathrm{cm}^{3}$ (See Raw Data)

Concentration gradient across the film $=\left(C_{1}-C_{2}\right) / L$

$$
\begin{aligned}
& =(11.96-0.00) / 0.041265 * 1000 \\
& =0.289 \mathrm{~g} / \mathrm{cm}^{4}
\end{aligned}
$$

Steady state slope (beyond $100 \mathrm{~h}$ ) of weight gain versus time curve $=0.00152 \mathrm{~g} / \mathrm{h}$

Diameter of circular aluminum dish $=5.07 \mathrm{~cm} \Rightarrow$ Area $=20.18858 \mathrm{~cm}^{2}$

Flux $=$ Slope $/$ Area $=0.00152 / 20.18858=7.28134 \times 10^{-6} \mathrm{~g} / \mathrm{h} . \mathrm{cm}^{2}$

$\mathrm{D}=$ Flux $/$ Concentration Gradient $=2.599 \times 10^{-5} \mathrm{~cm}^{2} / \mathrm{h}=7.219 \times 10^{-9} \mathrm{~cm}^{2} / \mathrm{s}$ 


\section{A.1.3. Sample Calculation for Tensile Tests}

Neat DERAKANE 411-350 MOMENTUM sample

Sample Thickness $=0.134$ inch

Sample Width $=0.500$ inch

Area of Cross-section $=0.067 \mathrm{in}^{2}$

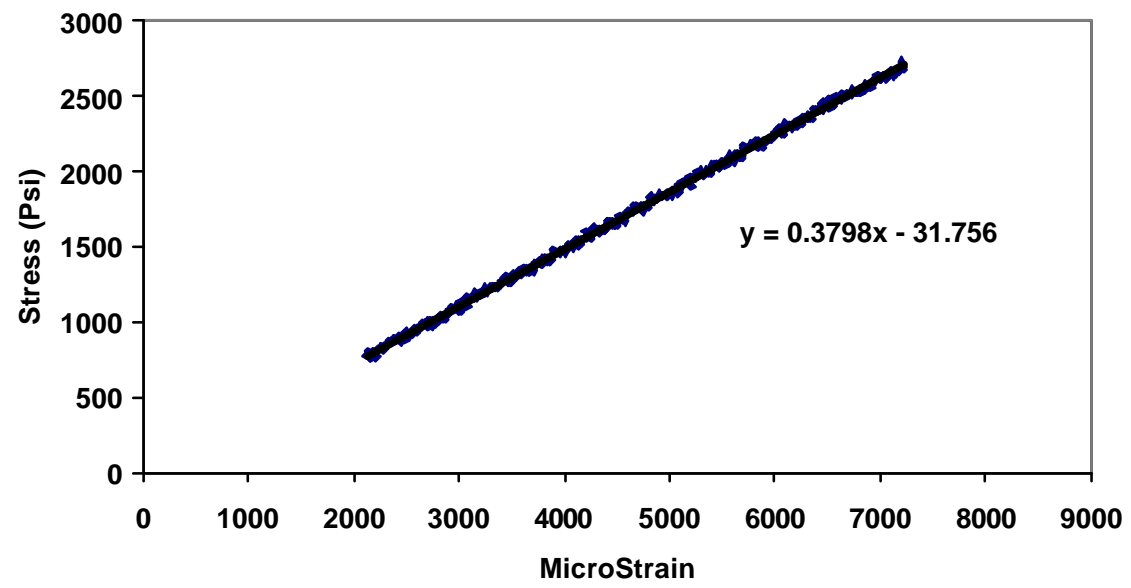

Figure A. 3. Stress-Strain Curve

Slope of the Stress Strain curve $=$ Tensile Modulus $=379.8 \mathrm{kPsi}=2618.62 \mathrm{MPa}$

Tensile Strength $=2.741 \mathrm{kPsi}=18.90 \mathrm{Mpa}$ 


\section{A.1.4. Sample Calculation for Diffusion Coefficient in FRP Sample in Transient Diffusion experiments}

Table A. III. Diffusion Data for neat FRP sample i mmersed in $0.1 \mathrm{M} \mathrm{NaCl}$ solution at $25^{\circ} \mathrm{C}$

Length $=2.8905 \mathrm{~cm}$

Width $=1.4376 \mathrm{~cm}$

Thickness $2 \mathrm{l}=0.08297 \mathrm{~cm}$

$\begin{array}{rr}\text { Time }(\mathrm{h}) & \text { Weight }(\mathrm{mg}) \\ 0 & 619.82 \\ 0.416667 & 620.07 \\ 1.25 & 620.27 \\ 3.083333 & 620.51 \\ 5.5 & 620.67 \\ 25.33333 & 621.43 \\ 74.33333 & 621.92 \\ 240.3333 & 622.43 \\ 525.8333 & 622.68 \\ 837.8333 & 622.72 \\ 1077.833 & 622.74 \\ 1341.833 & 622.74 \\ 1485.833 & 622.74 \\ 1653.833 & 622.74\end{array}$

$1 \mathrm{~cm}^{2}$ Glass Fabric $=79.2025 \mathrm{mg}$ of Glass

Surface area of the sample $=2.8905 \times 1.4376=4.1555 \mathrm{~cm}^{2}$

Weight of the glass fibers in the sample $=4.1555 \mathrm{~cm}^{2} \times 79.2025 \mathrm{mg} / \mathrm{cm}^{2}=329.128 \mathrm{mg}$

Weight of the glass was subtracted from all the experimental readings. The following table shows corrected diffusion data: 
Table A. IV. Corrected Diffusion Data for neat FRP sample immersed in 0.1M NaCl solution at $25^{\circ} \mathrm{C}$

\begin{tabular}{rrrr} 
Time (h) & Weight (mg) & $\frac{M_{t}-M_{0}}{M_{\infty}-M_{0}}$ & \multicolumn{1}{c}{$\begin{array}{l}\sqrt{t} / 2 l \\
\left(\mathrm{hr}^{1 / 2} / \mathrm{cm}\right)\end{array}$} \\
0 & 290.6918591 & 0 & 0 \\
0.416667 & 290.9418591 & 0.085616438 & 7.779574454 \\
1.25 & 291.1418591 & 0.154109589 & 13.47461822 \\
3.083333 & 291.3818591 & 0.23630137 & 21.1627305 \\
5.5 & 291.5418591 & 0.29109589 & 28.26459762 \\
25.33333 & 292.3018591 & 0.551369863 & 60.66072984 \\
74.33333 & 292.7918591 & 0.719178082 & 103.9090242 \\
240.3333 & 293.3018591 & 0.893835616 & 186.8394015 \\
525.8333 & 293.5518591 & 0.979452055 & 276.3665767 \\
837.8333 & 293.5918591 & 0.993150685 & 348.8512471 \\
1077.833 & 293.6118591 & 1 & 395.6737761 \\
1341.833 & 293.6118591 & 1 & 441.479712 \\
1485.833 & 293.6118591 & 1 & 464.5650254 \\
1653.833 & 293.6118591 & 1 & 490.125539
\end{tabular}

Diffusion coefficient was calculated using equation 37 and corrected experimental data.

$$
D=\frac{\pi}{16}\left(\frac{M_{t} / M_{\infty}}{\sqrt{t} / 2 l}\right)^{2}
$$

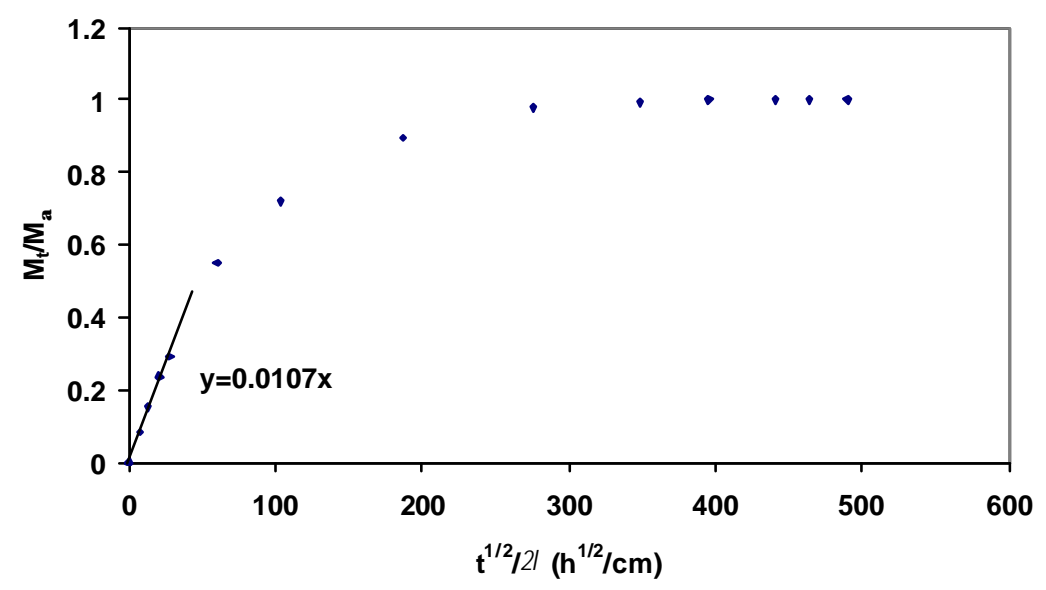

Figure A. 4. Corrected $M_{t} / M_{\infty}$ versus $\mathbf{t}^{1 / 2} / 2 \mid$ curve 
Where $\left(\frac{M_{t} / M_{\infty}}{\sqrt{t} / 2 l}\right)$ is the slope of the straight line (Figure A.4) from the plot of $M_{t} / M_{\infty}$ versus $t^{1 / 2} / 21$ drawn up to $M_{t} / M_{\infty}<0.5$.

$D=\frac{\pi}{16}(0.0107)^{2} / 3600=6.244 \times 10^{-9} \mathrm{~cm}^{2} / \mathrm{s}$

\section{A.1.5. Sample Calculation for Amount of Moisture interacted with glass fibers}

Table A. V. Diffusion Data for neat FRP sample immersed in Distilled Water at $25^{\circ} \mathrm{C}$

Length $=3.401 \mathrm{~cm}$

Width $=1.478 \mathrm{~cm}$

Thickness $2 \mathrm{l}=0.08594 \mathrm{~cm}$

$\begin{array}{rr}\text { Time }(\mathrm{h}) & \text { Weight }(\mathrm{mg}) \\ 0 & 685.97 \\ 0.5 & 686.42 \\ 1.25 & 686.46 \\ 3 & 686.79 \\ 5.5 & 687.22 \\ 21.5 & 688.12 \\ 31.5 & 688.51 \\ 51.5 & 689.05 \\ 76.5 & 689.62 \\ 146 & 691.22 \\ 198 & 691.52 \\ 406 & 694.16 \\ 678 & 696.7 \\ 1008 & 697.82 \\ 1248 & 698.99 \\ 1464 & 699.93\end{array}$

$1 \mathrm{~cm}^{2}$ Glass Fabric $=79.2025 \mathrm{mg}$ of Glass

Surface area of the sample $=3.401 \times 1.478=5.0277 \mathrm{~cm}^{2}$

Weight of the glass fibers in the sample $=5.0277 \mathrm{~cm}^{2} \times 79.2025 \mathrm{mg} / \mathrm{cm}^{2}=398.208 \mathrm{mg}$ 
Weight of the glass was subtracted from all the experimental readings. The following table shows corrected diffusion data:

Table A. VI. Corrected Diffusion Data for neat FRP sample immersed in Distilled Water at $25^{\circ} \mathrm{C}$

$\begin{array}{rrr}\text { Time }(\mathrm{h}) & \text { Weight }(\mathrm{mg}) & \text { \%Moisture } \\ 0 & 287.7621 & 0 \\ 0.5 & 288.2121 & 0.156379 \\ 1.25 & 288.2521 & 0.17028 \\ 3 & 288.5821 & 0.284958 \\ 5.5 & 289.0121 & 0.434387 \\ 21.5 & 289.9121 & 0.747145 \\ 31.5 & 290.3021 & 0.882674 \\ 51.5 & 290.8421 & 1.070329 \\ 76.5 & 291.4121 & 1.268409 \\ 146 & 293.0121 & 1.824424 \\ 198 & 293.3121 & 1.928677 \\ 406 & 295.9521 & 2.846101 \\ 678 & 298.4921 & 3.728775 \\ 1008 & 299.6121 & 4.117985 \\ 1248 & 300.7821 & 4.524571 \\ 1464 & 301.7221 & 4.85123\end{array}$

Sample absorbed $4.85 \%$ moisture over a period of 1464 hours. The resin alone can absorb only $0.659 \%$ moisture, i.e. the excess water in the FRP sample is interacting with the glass- fibers.

Amount of water interacted with glass- fibers $=(4.85123-0.659) *(287.7621 \mathrm{mg}) / 100$

$$
=12.064 \mathrm{mg}
$$

Amount of water interacted per unit weight of glass-fibers

$$
\begin{aligned}
& =12.064 \mathrm{mg} \text { water } / 398.208 \mathrm{mg} \text { glass } \\
& =0.0303 \mathrm{mg} \text { water } / \mathrm{mg} \text { glass }
\end{aligned}
$$




\section{A.1.6. Validity of Approximate Solution of Transient Diffusion Experiments}

Water Uptake Data for Neat DERAKANE ${ }^{\mathrm{TM}}$ 411-350 MOMENTUM Vinyl Ester Resin immersed in Distilled water at $25^{\circ} \mathrm{C}$

$\begin{array}{rr}\begin{array}{r}\text { Thickness } \\ (\mathrm{cm})\end{array} & 0.066675 \\ \text { Time }(\mathrm{h}) & \text { Weight }(\mathrm{mg}) \\ 0 & 392.13 \\ 2 & 392.78 \\ 4 & 393.04 \\ 6 & 393.24 \\ 9 & 393.4 \\ 28 & 393.95 \\ 49 & 394.19 \\ 73 & 394.31 \\ 122 & 394.43 \\ 192 & 394.45 \\ 268 & 394.49 \\ 335 & 394.64 \\ 435 & 394.64\end{array}$

Diffusion coefficient calculated from the approximate solution given by equation 4 is $7.36 \times 10^{-9} \mathrm{~cm}^{2} / \mathrm{s}$.

Accurate solution for transient diffusion problem defined by equation 1 :

$M_{t}=2 \int_{0}^{t}\left[2 D \frac{\left(C_{1}-C_{0}\right)}{l} \sum_{0}^{\infty} \exp \left[\frac{-D(2 n+1)^{2} \pi^{2} t}{4 l^{2}}\right]\right] d t$

$M_{t}=$ Mass of water absorbed in time $t$

$C_{l}=$ Saturation concentration

$C_{0}=$ Initial concentration

$2 l=$ Thickness of the sample

$D=$ Diffusivity

Sample Details:

Initial weight of the sample $=392.13 \mathrm{mg}$

Final weight of the sample $=394.64 \mathrm{mg}$ 
Dimensions of the sample $=1.25 \mathrm{~cm} \times 5 \mathrm{~cm} \times 0.0666 \mathrm{~cm}$

Surface area of the sample $=6.25 \mathrm{~cm}^{2}$

Final concentration $=\frac{2.51 \mathrm{mg}}{1.25 \mathrm{~cm} \times 5 \mathrm{~cm} \times 0.0666 \mathrm{~cm}}=6.030 \mathrm{mg} / \mathrm{cm}^{3}$

Equation A.1 was used along with the diffusivity obtained from the approximate solution to calculate the weight gain of this particular sample. The results are shown in the following table:

Table A. VII. Comparison of experimental and theoretical weight gain values

\begin{tabular}{|c|l|l|}
\hline Time (h) & $\begin{array}{c}\text { Weight Gain Predicted } \\
\text { by Equat ion [A.1] } \\
(\mathrm{mg})\end{array}$ & \multicolumn{1}{|c|}{$\begin{array}{c}\text { Experimental Weight } \\
\text { Gain } \\
(\mathrm{mg})\end{array}$} \\
\hline 1 & 0.433 & --- \\
\hline 2 & 0.612 & 0.65 \\
\hline 4 & 0.866 & 0.91 \\
\hline 6 & 1.06 & 1.11 \\
\hline 9 & 1.27 & 1.27 \\
\hline
\end{tabular}

\section{A.1.7. Extrapolated values of Equilibrium Moisture Contents}

It was not possible to practically attain saturation when the samples were immersed in different liquid media at $42.5^{\circ} \mathrm{C}$ temperature. Therefore it was assumed that the equilibrium moisture contents were directly proportional to the temperature. Moisture content values for the samples were known for immersion in liquid media at $4^{\circ} \mathrm{C}, 25^{\circ} \mathrm{C}$ or $28^{\circ} \mathrm{C}$. Following straight-line relationship was used to estimate the equilibrium moisture contents at $42.5^{\circ} \mathrm{C}$.

$\mathrm{M}=(\mathrm{A} * \mathrm{~T})+\mathrm{B}$

Where $\mathrm{M}$ is the equilibrium moisture content in percentage. $\mathrm{T}$ is the temperature in ${ }^{\circ} \mathrm{C}$. $\mathrm{A}$ and $\mathrm{B}$ are constants. The values of $\mathrm{A}$ and $\mathrm{B}$ were calculated using the available equilibrium moisture contents at $4^{\circ} \mathrm{C}$ and $25^{\circ} \mathrm{C} / 28^{\circ} \mathrm{C}$. 
Equilibrium Moisture Content (\%)

Un Reinforced Samples Water

\begin{tabular}{llll} 
& & & \multicolumn{2}{r}{ Extrapolated } \\
Wt\%Clay & $25^{\circ} \mathrm{C}$ & $4^{\circ} \mathrm{C}$ & $42.5^{\circ} \mathrm{C}$ \\
0 & 0.659 & 0.5980 .70965 \\
1 & 1.128 & 0.8511 .3592 \\
2 & 1.339 & 0.9021 .7028 \\
5 & 2.081 & 0.9663 .01035
\end{tabular}

Equilibrium Moisture Content (\%)

Un Reinforced Samples $\mathrm{NaCl}$

$\begin{array}{lccc} & & & \text { Extrapolated } \\ \text { Wt\%Clay } & 28^{\circ} \mathrm{C} & 4{ }^{\circ} \mathrm{C} & 42.5^{\circ} \mathrm{C} \\ 0 & 0.683 & 0.5830 .7448 \\ 1 & 0.884 & 0.6571 .02295 \\ 2 & 0.947 & 0.591 .16375 \\ 5 & 1.093 & 0.6131 .383\end{array}$

Equilibrium Moisture Content (\%)

Un Reinforced Samples $\mathrm{NaOH}$

\begin{tabular}{|cccc} 
& & & \multicolumn{2}{r}{ Extrapolated } \\
Wt\%Clay & $28^{\circ} \mathrm{C}$ & $4^{\circ} \mathrm{C}$ & $42.5^{\circ} \mathrm{C}$ \\
0 & 0.683 & 0.6670 .7448 \\
1 & 0.884 & 0.6461 .02295 \\
2 & 0.947 & 0.661 .16375 \\
5 & 1.093 & 0.7041 .383
\end{tabular}

\section{A.1.8. Estimating the value of aspect ratio $\alpha$}

Density of un-treated nanoclay $=2.86 \mathrm{~g} / \mathrm{cm}^{3}$ (from product data sheet www.scprod.com)

Density of Polymer $=1.135 \mathrm{~g} / \mathrm{cm}^{3}$

Cloisite $10 \mathrm{~A}^{\circledR}$ clay contains $39 \%$ organic material by weight, i.e. actual weight of clay in

$1 \mathrm{~g}$ of Cloisite $10 \mathrm{~A}^{\circledR}$ is $0.61 \mathrm{~g}$

Basis: $100 \mathrm{~g}$ mixture of resin and clay 
e.g.

$1 \mathrm{Wt} \%$ Cloisite $10 \mathrm{~A}^{\circledR}$ sample $=0.61 \mathrm{~g}$ clay $+99 \mathrm{~g}$ resin $+0.39 \mathrm{~g}$ organic material

$$
\begin{aligned}
& =0.213 \mathrm{~cm}^{3} \text { clay }+87.57 \mathrm{~cm}^{3} \text { resin } \\
& =87.78 \mathrm{~cm}^{3} \text { total }
\end{aligned}
$$

Volume fraction of clay $\phi=0.213 / 87.78=0.00599$

Similarly,

$\begin{array}{ll}\text { Wt\% Clay } & \phi \\ 0 & 0 \\ 1 & 0.0024 \\ 2 & 0.0049 \\ 5 & 0.0123\end{array}$

Fredrickson and Bicerano (1999) assumed the nano clay platelets to be circular disks of radius $R$ and thickness $2 a$. The aspect ratio of the disk was defined as $\alpha=R / 2 a$. They proposed the following equation for the dilute concentrations of clay in polymer.

$$
\frac{D}{D_{0}}=1-\frac{\pi}{3} \frac{\alpha \phi}{\ln \alpha}+O\left[(\alpha \phi)^{2}\right]
$$

Here, $D$ and $D_{0}$ are the diffusivities of the nanocomposite and the neat resin respectively and $\phi$ is the volume fraction of clay in polymer. When the product $(\alpha \phi)<1$ the other terms $O\left[(\alpha \phi)^{2}\right]$ can be neglected in the above equation. Aspect ratio of the disks can be calculated by inserting steady-state diffusivities and corresponding volume fractions in the above equation.

Steady State Diffusion Experiments:

Table A. VIII. Calculated aspect ratios

$\begin{array}{cccc}\text { Wt\% Clay } & \phi & \mathrm{D}\left(\mathrm{cm}^{2} / \mathrm{s}\right) & \alpha \text { (Disk) } \\ 1 & 0.0024 & 6.50 \times 10^{-09} & 208 \\ 2 & 0.0049 & 6.05 \times 10^{-09} & 171 \\ 5 & 0.0123 & 5.76 \times 10^{-09} & 70\end{array}$


The conditions $(\alpha \phi)<1$ is satisfied for all clay concentrations shown in the above table.

Average aspect ratio $\alpha($ Disk $)=150$

Surface area of the circular disk $=\pi R^{2}$

If we had square clay platelets instead of circular disk having the same surface area then

the length of the platelets would be $L_{p}=\sqrt{\pi R^{2}}=\sqrt{\pi} R$. Let the thickness of the platelet be the same as that of a disk, i.e. $2 a$.

Aspect ratio of square platelets is defined by:

$\alpha($ Square platele $\mathrm{t})=\frac{L_{p}}{2(2 a)}=\frac{\sqrt{\pi} R}{2(2 a)}=\frac{\sqrt{\pi}}{2} \alpha($ Disk $)$

Converted aspect ratios are shown in the following table:

Table A. IX. Converted aspect ratios for square platelets

$\begin{array}{cccc}\text { Wt\% Clay } & \phi & \mathrm{D}\left(\mathrm{cm}^{2} / \mathrm{s}\right) & \alpha \\ 1 & 0.0024 & 6.50 \times 10^{-09} & \begin{array}{c}\alpha \\ \text { (Square platelet) }\end{array} \\ 2 & 0.0049 & 6.05 \times 10^{-09} & 154 \\ 5 & 0.0123 & 5.76 \times 10^{-09} & 62\end{array}$

Calculation of total number of platelets in a given sample:

E.g. Sample weighing $100 \mathrm{~g}$ and containing $1 \mathrm{wt} \%$ Cloisite $10 \mathrm{~A}^{\circledR}$ clay

Weight of Cloisite $10 \mathrm{~A}^{\circledR}$ in the sample $=1 \mathrm{~g}$

Since $39 \mathrm{wt} \%$ of Cloisite $10 \mathrm{~A}^{\circledR}$ is organic material,

Actual weight of clay in the sample $=0.61 \mathrm{~g}$

If the thickness of each clay platelet is assumed to be $1 \mathrm{~nm}$, the length of a clay platelet in the sample can be calculated using the aspect ratio. 
$L_{p}=2 \times(1 \mathrm{~nm}) \times \alpha=2 \times(1 \mathrm{~nm}) \times 184=368 \mathrm{~nm}$

Volume of each clay platelet $=368 \times 368 \times 1=135424 \mathrm{~nm}^{3}=135424 \times 10^{-21} \mathrm{~cm}^{3}$

Weight of each clay platelet $=135424 \times 10^{-21} \mathrm{~cm}^{3} \times 2.86 \mathrm{~g} / \mathrm{cm}^{3}=3.873 \times 10^{-16} \mathrm{gm}$

Number of platelets in the sample $=0.61 \mathrm{~g} / 3.873 \times 10^{-16} \mathrm{gm}=1.575 \times 10^{15}$

\section{Calculation for amount of water adsorbed on each platelet:}

Neat polymer absorbs $0.659 \mathrm{wt} \%$ water at saturation and $1 \mathrm{wt} \%$ Cloisite $10 \mathrm{~A}^{\circledR}$ nanocomposite absorbs $1.128 \mathrm{wt} \%$ water at saturation.

E.g. Sample weighing $100 \mathrm{~g}$ and containing $1 \mathrm{wt} \%$ Cloisite $10 \mathrm{~A}^{\circledR}$ clay

Total amount of water absorbed by the sample at saturation would be $=1.128 \mathrm{~g}$

Weight of the polymer in the sample $=99.39 \mathrm{~g}$ (as explained earlier)

Amount of water absorbed by the polymer at saturation $=99.39 \times 0.00659=0.655 \mathrm{~g}$

Therefore, the amount of water adsorbed on clay platelets $=(1.128-0.655)=0.473 \mathrm{~g}$

Number of clay platelets in the sample $=1.575 \times 10^{15}$

Therefore, weight of water adsorbed on each platelet

$$
\begin{aligned}
M_{C} / N & =0.473 /\left(1.575 \times 10^{15}\right) \\
& =3.0 \times 10^{-16} \mathrm{~g} / \text { platelet }
\end{aligned}
$$




\section{A.1.9. Calculation of Theoretical Flux Ratios in Steady-State Experiments on FRP Films}

The geometry of glass-fabric used in the present study is shown in Figure 37.

Layer 1 strand is $2 \mathrm{~mm}$ wide and $0.2 \mathrm{~mm}$ thick.

Cross-sectional area of layer 1 strand $=0.4 \mathrm{~mm}^{2}$

Weight of layer 1 strand of $35.2 \mathrm{~mm}$ length $=25.211 \mathrm{mg}$

Weight of 5 fibers from layer 1 strand of length $35.2 \mathrm{~mm}=0.121 \mathrm{mg}$

Therefore, number of fibers in layer 1 strand $=\frac{25.211 \times 5}{0.121} \approx 1000$ fibers

1000 fibers are uniformly arranged over an area of $0.4 \mathrm{~mm}^{2}$

Therefore, number of fibers per unit $\mathrm{mm}^{2}$ area $=2500$

Number of fibers per unit mm width of strand $=\sqrt{2500}=50$ fibers $/ \mathrm{mm}$

Therefore, the number of fibers in $2 \mathrm{~mm}$ width of strand $=2 \times 50=100$ fibers

Diameter of each fiber $=13 \times 10^{-3} \mathrm{~mm}$

Out of $2 \mathrm{~mm}$ width of strand, $100 \times 13 \times 10^{-3} \mathrm{~mm}(=1.3 \mathrm{~mm})$ is occupied by fibers, i.e. the total gap is $0.7 \mathrm{~mm}$.

Therefore, the minimum gap between the two adjacent fibers $=0.7 / 100=7 \times 10^{-3} \mathrm{~mm}=7$

$\mu \mathrm{m}$

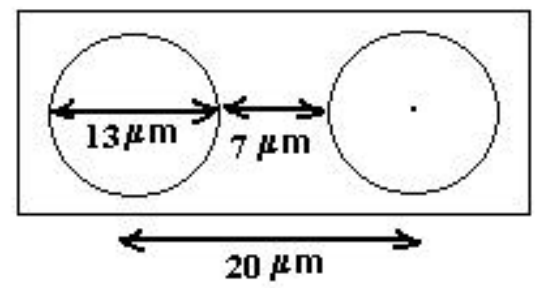

Figure A. 5. Gap between the adjacent fibers 
As seen from the above schematic diagram, the maximum gap between the two adjacent fibers $=20 \mu \mathrm{m}$.

Average gap between the fibers $=(20+7) / 2=13.5 \mu \mathrm{m}$.

\section{Theory proposed by Cussler et al. (1988)}

Resistance in the absence of glass- fiber mat is given by equation 28 . Where the symbols have the same meaning as explained in chapter 4.

$$
\frac{D \Delta C}{J_{0}}=\frac{l}{2 d W}
$$

Resistance offered by $N$ layers fibers can be written with slight modification in equation 30.

$$
\frac{D \Delta C}{J_{N}}=\frac{l}{2 d W}+\frac{b}{d W} \ln \left(\frac{b}{2 s}\right)+\frac{N a}{2 s W}+\frac{1}{2}(N-1) \frac{a}{2 b W}
$$

Here, $d$ in the last term of equation 30 has been replaced by $a / 2$ because the molecule encountering the glass-fiber has to travel distance $a / 2$ horizontally to bypass the fiber. Neglecting the entrance and exit resistance (Second term on right hand side of above equation) and taking a ratio of [A.4] and [A.3] yields:

$$
\frac{J_{0}}{J_{N}}=1+\frac{N d a}{s l}+\frac{1}{2} \frac{(N-1) a d}{b l}
$$

When $N$ is very large $N-1 \approx N$. Also, $\mathrm{N}(a+b)=l$. Making use of these equalities in the above equation and simplifying: 
$\frac{J_{0}}{J_{N}}=1+\frac{d a}{2(a+b)}\left(\frac{2}{s}+\frac{1}{b}\right)$

Substituting $d=20 \mu \mathrm{m}, a=13 \mu \mathrm{m}, b=7 \mu \mathrm{m}$ and $s_{a v g}=6.75 \mu \mathrm{m}$ gives:

$\frac{J_{0}}{J_{N}}=2.85$

In other words, the fiber-reinforced sample will provide 2.85 times more resistance to diffusion as compared to un-reinforced sample for a given area and the thickness of the film. Assume the resistance (per unit area per unit thickness) of un-reinforced material to be $R$. The corresponding resistance provided by the fiber strand, then, can be taken as $2.85 R$.

\section{Calculation for FRP film based on neat resin:}

Thickness of the film $=0.0762 \mathrm{~cm}$

Thickness of layer 1 of fabric is $0.02 \mathrm{~cm}$. Thickness of layer 2 of fabric is $0.02 \mathrm{~cm}$. Total thickness of fabric is $0.05 \mathrm{~cm}$. This means that there is a $0.01 \mathrm{~cm}$ gap between the two layers of fiber strands. There are also thin layers of polymer on the top and the bottom of the fabric. In layer 1, fiber strands occupy $87.50 \%$ area and the remaining area is occupied by gaps between the strand. In layer 2, fiber strands occupy $50.00 \%$ area and the remaining area is occupied by gaps. With this information, the schematic diagram of the resistance provided by this sample is shown in the following figure: 


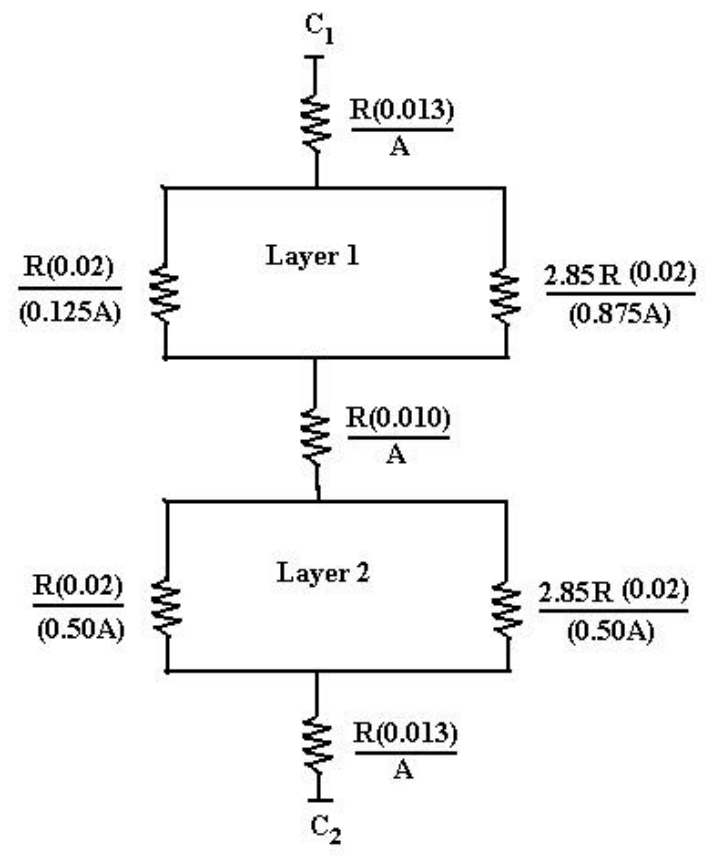

Figure A. 6. Schematic diagram of the resistance provided by the FRP sample

The equivalent resistance provided by the FRP film $R_{N}=0.111 R / A$

If this were an un-reinforced film with the same thickness then the resistance provided by the film $R_{0}=0.0762 R / A$

Theoretical $\frac{J_{0}}{J_{N}}=\frac{R_{N}}{R_{0}}=\frac{0.111 R / A}{0.0762 R / A}=1.45$ 


\section{Theory proposed by Brydges et al. (1975)}

The resistance provided by the fiber strand $\left(R_{N}\right)$ having uniformly distributed fibers is given by equation 60 :

$$
\frac{R_{N}}{R_{0}}=1+\frac{b}{2 g}+\frac{b}{a}\left(\frac{b+2 g}{t}\right)\left(\frac{a}{a+t}\right) \gamma(1-\gamma)
$$

Here, $R_{0}$ is the resistance of the material itself.

$a=b=$ diameter of the fiber $=13 \mu \mathrm{m}$

$2 g$ = average gap between the fibers $=13.5 \mu \mathrm{m}$

Since the average gap between two fibers is less than the diameter of the fiber, it can be safely assumed that the factor $\gamma$, which accounts for overlapping of fibers, is zero. The equation was originally derived for glass ribbon-filled composites where factor $\gamma$ affected the transport of water in horizontal direction. With this modification, the above equation reduces to:

$$
\frac{R_{N}}{R_{0}}=1+\frac{b}{2 g}
$$

When numerical values of $b$ and $2 g$ are substituted in above expression, it yields:

$$
\frac{R_{N}}{R_{0}}=1.96
$$




\section{Calculation for FRP film based on neat resin:}

Thickness of the FRP film $=0.0762 \mathrm{~cm}$

The schematic diagram of resistance provided by FRP film is shown in the following figure:

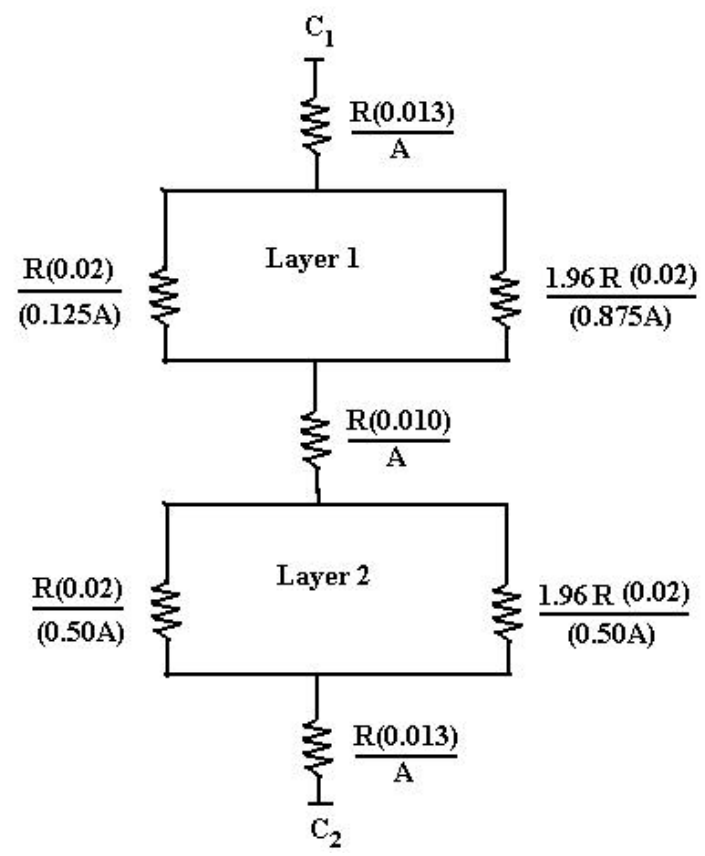

Figure A. 7. Schematic diagram of the resistance provided by the FRP sample

The equivalent resistance provided by the FRP film $=0.0972 R / A$

If this were an un-reinforced film with the same thickness then the resistance provided by the film $=0.0762 R / A$

Theoretical $\frac{J_{0}}{J_{N}}=\frac{0.0972 R / A}{0.0762 R / A}=1.27$

\section{Calculation for Experimental Flux Ratio:}

Thickness of the FRP film $=0.0762 \mathrm{~cm}$

Experimental value of flux through this sample $J_{N}=3.782 \times 10^{-6} \mathrm{~g} / \mathrm{h} . \mathrm{cm}^{2}$ 
The following relationship is known from the steady-state experiments with unreinforced samples without nanoclay:

Flux $\times$ thickness $=3.2245 \times 10^{-6}$ g.cm $/ \mathrm{h} . \mathrm{cm}^{2}$

For an un-reinforced sample having a thickness of $0.0762 \mathrm{~cm}$,

Flux $J_{0}=\left(3.2245 \times 10^{-6}\right) / 0.0762=4.23 \times 10^{-6} \mathrm{~g} / \mathrm{h} \cdot \mathrm{cm}^{2}$

Experimental $\frac{J_{0}}{J_{N}}=\left(4.23 \times 10^{-6}\right) /\left(3.2245 \times 10^{-6}\right)=1.12$

\section{A.1.10. Suggested Film Thickness for Experiments in Alkaline Solution}

It was found the time scale of diffusion with sample having a thickness of approximately $0.06 \mathrm{~cm}\left(=L_{l}\right)$ was 400 hours $\left(=t_{l}\right)$. However, the samples immersed in 13 $\mathrm{pH} \mathrm{NaOH}$ solution dissolved in 24 hours. Time scale of experiments is directly proportional to the square of the thickness of the polymer film. i.e. to achieve saturation in 24 hours $\left(=t_{2}\right)$ of immersion period the required thickness of the sample $\left(L_{2}\right)$ can be calculated using the following relation:

$$
\left(\frac{L_{2}}{L_{1}}\right)^{2}=\left(\frac{t_{2}}{t_{1}}\right)
$$

Substituting numerical values of $L_{1}, t_{1}$ and $t_{2}$ :

$$
L_{2}=50.0 \mu \mathrm{m}
$$




\section{A.2. Raw Data}

Table A. X. Water Uptake Data for Neat DERAKANE ${ }^{\mathrm{TM}}$ 411-350 MOMENTUM Vinyl Ester Resin immersed in Distilled water at $25^{\circ} \mathrm{C}$

Note: Initial moisture content in the samples was assumed to be zero for all transient diffusion experiments.

\begin{tabular}{|c|c|c|c|c|c|}
\hline & Sample 1 & Sample 2 & Sample 3 & Sample 4 & Sample 5 \\
\hline $\begin{array}{c}\text { Thickness } \\
\text { (cm) }\end{array}$ & 0.066675 & 0.06223 & 0.059436 & 0.057404 & 0.05588 \\
\hline Time (h) & Weight (mg) & Weight (mg) & Weight (mg) & Weight (mg) & Weight (mg) \\
\hline 0 & 392.13 & 352.85 & 327.37 & 272.96 & 275.84 \\
\hline 2 & 392.78 & 353.48 & 328.02 & 273.55 & 276.52 \\
\hline 4 & 393.04 & 353.77 & 328.29 & 273.77 & 276.66 \\
\hline 6 & 393.24 & 354.03 & 328.37 & 273.99 & 276.82 \\
\hline 9 & 393.4 & 354.08 & 328.49 & 274.02 & 276.92 \\
\hline 28 & 393.95 & 354.56 & 328.94 & 274.34 & 277.28 \\
\hline 49 & 394.19 & 354.75 & 329.13 & 274.5 & 277.43 \\
\hline 73 & 394.31 & 354.86 & 329.24 & 274.59 & 277.52 \\
\hline 122 & 394.43 & 354.88 & 329.26 & 274.61 & 277.53 \\
\hline 192 & 394.45 & 354.95 & 329.36 & 274.68 & 277.61 \\
\hline 268 & 394.49 & 355.05 & 329.39 & 274.74 & 277.66 \\
\hline 335 & 394.64 & 355.15 & 329.48 & 274.9 & 277.77 \\
\hline 435 & 394.64 & 355.15 & 329.49 & 274.9 & 277.77 \\
\hline
\end{tabular}

Table A. XI. Water Uptake for $1 \mathrm{wt} \%$ Cloisite $10 \mathrm{~A}^{\circledR}$ nanocomposite samples immersed in Distilled water at $25^{\circ} \mathrm{C}$

\begin{tabular}{|c|c|c|c|c|c|c|}
\hline & Sample 1 & Sample 2 & Sample 3 & Sample 4 & Sample 5 & Sample 6 \\
\hline $\begin{array}{l}\text { Thickness } \\
\text { (cm) }\end{array}$ & 0.064262 & 0.054864 & 0.064516 & 0.062484 & 0.06731 & 0.049022 \\
\hline Time (h) & Weight (mg) & Weight (mg) & Weight (mg) & Weight (mg) & Weight (mg) & Weight (mg) \\
\hline 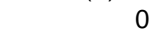 & 373.25 & 336.67 & 398.2 & 380.18 & 420.5 & 303.88 \\
\hline 2.5 & 374.12 & 337.6 & 399.16 & 381.06 & 421.44 & 304.81 \\
\hline 4.5 & 374.42 & 337.94 & 399.46 & 381.43 & 421.74 & 305.09 \\
\hline 6.5 & 374.71 & 338.2 & 399.78 & 381.72 & 422.06 & 305.37 \\
\hline 8.5 & 374.88 & 338.43 & 399.97 & 381.92 & 422.31 & 305.52 \\
\hline 22.5 & 375.72 & 339.17 & 400.86 & 382.78 & 423.23 & 306.19 \\
\hline 46.5 & 376.23 & 339.57 & 401.46 & 383.33 & 423.82 & 306.48 \\
\hline 70.5 & 376.39 & 339.68 & 401.72 & 383.53 & 424.08 & 306.67 \\
\hline 171 & 377.05 & 340.34 & 402.36 & 384.12 & 424.69 & 307.18 \\
\hline 238 & 377.19 & 340.52 & 402.49 & 384.23 & 424.76 & 307.3 \\
\hline 337 & & 340.52 & 402.58 & 384.35 & 424.94 & 307.48 \\
\hline 434.5 & 377.38 & 340.62 & & 384.46 & 425.07 & 307.61 \\
\hline 526 & 377.38 & 340.71 & 402.65 & 384.63 & 425.07 & 307.61 \\
\hline 671 & 377.38 & 340.71 & 402.65 & 384.63 & 425.07 & 307.61 \\
\hline
\end{tabular}


Table A. XII. Water Uptake for $2 \mathrm{wt} \%$ Cloisite $10 \mathrm{~A}^{\circledR}$ nanocomposite samples immersed in Distilled water at $25^{\circ} \mathrm{C}$

\begin{tabular}{|c|c|c|c|c|c|c|c|c|}
\hline & Sample 1 & Sample 2 & Sample 3 & Sample 4 & Sample 5 & Sample 6 & Sample 7 & Sample 8 \\
\hline $\begin{array}{l}\text { Thickness } \\
(\mathrm{cm})\end{array}$ & 0.070104 & 0.061468 & 0.057658 & 0.06985 & 0.06096 & 0.06604 & 0.057404 & 0.073914 \\
\hline Time $(\mathrm{h})$ & Weight (mg) & Weight (mg) & Weight (mg) & Weight (mg) & Weight (mg) & Weight (mg) & Weight (mg) & Weight (mg) \\
\hline 0 & 428.58 & 386.01 & 378.36 & 450.3 & 378.82 & 400.79 & 349.98 & 432.17 \\
\hline 2 & 429.46 & 386.8 & 379.21 & 451.15 & 379.61 & 401.6 & 350.83 & 432.98 \\
\hline 4 & 429.85 & 387.21 & 379.64 & 451.58 & 380.05 & 401.98 & 351.21 & 433.38 \\
\hline 6 & 430.07 & 387.58 & 379.88 & 451.9 & 380.35 & 402.35 & 351.49 & 433.74 \\
\hline 8 & 430.31 & 387.74 & 380.1 & 452.16 & 380.52 & 402.5 & 351.71 & 433.89 \\
\hline 22 & 431.3 & 388.69 & 380.99 & 453.14 & 381.38 & 403.38 & 352.48 & 434.84 \\
\hline 46 & 431.97 & 389.28 & 381.56 & 453.91 & 381.97 & 404.06 & 353.05 & 435.54 \\
\hline 70 & 432.24 & 389.51 & 381.9 & 454.28 & 382.23 & 404.35 & 353.31 & 435.94 \\
\hline 169 & 433.16 & 390.48 & 382.84 & 455.15 & 383.09 & 405.27 & 354 & 436.8 \\
\hline 265 & 433.64 & 390.72 & 383.23 & 455.54 & 383.58 & 405.71 & 354.43 & 437.28 \\
\hline 388 & 433.97 & 391.11 & 383.51 & 455.67 & 383.75 & 405.92 & 354.92 & 437.65 \\
\hline 483 & 434.04 & 391.21 & 383.49 & 455.8 & 383.91 & 406.12 & 354.94 & 437.68 \\
\hline 596.5 & 434.15 & 391.2 & 383.64 & 455.97 & 383.95 & 406.18 & 354.96 & 437.82 \\
\hline 747 & 434.15 & 391.2 & 383.64 & 455.97 & 383.95 & 406.18 & 354.96 & 437.82 \\
\hline
\end{tabular}

Table A. XIII. Water Uptake for $5 \mathrm{wt} \%$ Cloisite $10 \mathrm{~A}^{\circledR}$ nanocomposite samples immersed in Distilled water at $25^{\circ} \mathrm{C}$

\begin{tabular}{|c|c|c|c|c|}
\hline & Sample 1 & Sample 2 & Sample 3 & Sample 4 \\
\hline $\begin{array}{l}\text { Thickness } \\
\text { (cm) }\end{array}$ & 0.06096 & 0.055245 & 0.053975 & 0.0701675 \\
\hline Time (h) & Weight (mg) & Weight (mg) & Weight (mg) & Weight (mg) \\
\hline 0 & 442.88 & $\begin{array}{ll}-387 \\
\end{array}$ & 411.73 & 449.31 \\
\hline 0.5 & 443.16 & 387.26 & 412.04 & 449.56 \\
\hline 1.5 & 443.42 & 387.6 & 412.38 & 449.87 \\
\hline 3.5 & 443.86 & 387.84 & 412.73 & 450.12 \\
\hline 5.5 & 444.13 & 388.13 & 413.07 & 450.34 \\
\hline 7.5 & & 388.37 & 413.28 & 450.62 \\
\hline 8 & 444.42 & & & \\
\hline 13.75 & 444.74 & 388.84 & 413.71 & 450.98 \\
\hline 25 & 445.48 & 389.53 & 414.42 & 451.84 \\
\hline 29 & 445.55 & 389.68 & 414.48 & 452.04 \\
\hline 50.5 & 446.43 & 390.22 & 415.27 & 452.86 \\
\hline 73 & 446.88 & 390.63 & 415.76 & 453.35 \\
\hline 97 & 447.1 & 390.81 & 415.82 & 453.56 \\
\hline 147.5 & 447.2 & 391.08 & 415.96 & 453.59 \\
\hline 282.5 & 448.53 & 392.25 & 417.18 & 455.05 \\
\hline 530.5 & 449.65 & 393.64 & 418.51 & 456.24 \\
\hline 866.5 & 450.37 & 394.8 & 419.52 & 456.91 \\
\hline 1202.5 & 451.8 & 395.51 & 420.7 & 458 \\
\hline 1442.5 & 451.8 & 395.51 & 420.7 & 458 \\
\hline
\end{tabular}


Table A. XIV. Water Uptake Data for Neat DERAKANE ${ }^{\mathrm{TM}}$ 411-350 MOMENTUM Vinyl Ester Resin immersed in Distilled water at $4^{\circ} \mathrm{C}$

\begin{tabular}{|c|c|c|c|}
\hline & Sample 1 & Sample 2 & Sample 3 \\
\hline $\begin{array}{l}\text { Thickness } \\
\text { (cm) }\end{array}$ & 0.0225425 & 0.028893 & 0.032068 \\
\hline Time (h) & Weight (mg) & Weight (mg) & Weight (mg) \\
\hline 0 & 123.75 & 191.81 & 179.66 \\
\hline 1 & 123.91 & 192.01 & 179.85 \\
\hline 3.416667 & 124.07 & 192.16 & 179.99 \\
\hline 6 & 124.24 & 192.26 & 180.11 \\
\hline 23.75 & 124.39 & 192.65 & 180.47 \\
\hline 52.75 & 124.42 & 192.73 & 180.59 \\
\hline 101.75 & 124.44 & 192.78 & 180.61 \\
\hline 218.75 & 124.47 & 192.83 & 180.68 \\
\hline 339.75 & 124.48 & 192.86 & 180.69 \\
\hline 531.75 & 124.5 & 192.89 & 180.74 \\
\hline 699.75 & 124.51 & 192.9 & 180.76 \\
\hline 1275.75 & 124.51 & 192.9 & 180.76 \\
\hline
\end{tabular}

Table A. XV. Water Uptake for $1 \mathrm{wt} \%$ Cloisite $10 \mathrm{~A}^{\circledR}$ nanocomposite samples immersed in Distilled water at $4^{\circ} \mathrm{C}$

\begin{tabular}{|c|c|c|c|c|}
\hline & Sample 1 & Sample 2 & Sample 3 & Sample 4 \\
\hline $\begin{array}{l}\text { Thickness } \\
\text { (cm) }\end{array}$ & 0.03175 & 0.018415 & 0.02794 & 0.03048 \\
\hline Time (h) & Weight (mg) & Weight (mg) & Weight (mg) & Weight (mg) \\
\hline 0 & 168.28 & 108.16 & 162.94 & 135.2 \\
\hline 1 & 168.46 & 108.38 & 163.13 & 135.38 \\
\hline 3.416667 & 168.61 & 108.57 & 163.33 & 135.5 \\
\hline 6 & 168.76 & 108.67 & 163.47 & 135.61 \\
\hline 23.75 & 169.21 & 108.93 & 163.85 & 136.02 \\
\hline 52.75 & 169.37 & 109 & 163.99 & 136.1 \\
\hline 101.75 & 169.46 & 109.04 & 164.1 & 136.2 \\
\hline 218.75 & 169.52 & 109.1 & 164.18 & 136.26 \\
\hline 339.75 & 169.56 & 109.12 & 164.22 & 136.31 \\
\hline 531.75 & 169.59 & 109.12 & 164.23 & 136.3 \\
\hline 699.75 & 169.67 & 109.13 & 164.28 & 136.36 \\
\hline 1275.75 & 169.67 & 109.13 & 164.28 & 136.36 \\
\hline
\end{tabular}

Table A. XVI. Water Uptake for $2 \mathrm{wt} \%$ Cloisite $10 \mathrm{~A}^{\circledR}$ nanocomposite samples immersed in Distilled water at $4^{\circ} \mathrm{C}$

\begin{tabular}{rrrr}
$\begin{array}{c}\text { Thickness } \\
\text { (cm) }\end{array}$ & \multicolumn{1}{c}{ Sample 1 } & \multicolumn{1}{c}{ Sample 2 } & \multicolumn{1}{c}{ Sample 3 } \\
\multicolumn{1}{c}{ Time } & Weight $(\mathrm{mg})$ & \multicolumn{1}{c}{ Weight $(\mathrm{mg})$} & \multicolumn{1}{c}{ Weight $(\mathrm{mg})$} \\
1.166667 & 202.44 & 238.84 & 215.26 \\
3.583333 & 202.61 & 239.07 & 215.5 \\
6.25 & 202.85 & 239.37 & 215.76 \\
24 & 203.05 & 239.58 & 215.95 \\
53 & 203.5 & 240.05 & 216.44 \\
101.75 & 203.68 & 240.32 & 216.65 \\
218.75 & 203.81 & 240.47 & 216.77 \\
339.75 & 203.95 & 240.7 & 216.9 \\
531.75 & 204.11 & 240.8 & 216.95 \\
699.75 & 204.16 & 240.84 & 217.04 \\
1275.75 & 204.2 & 240.89 & 217.11 \\
1587.75 & 204.22 & 240.99 & 217.18 \\
1779.75 & 204.22 & 241.02 & 217.23 \\
& & & 217.23
\end{tabular}


Table A. XVII. Water Uptake for 5 wt\% Cloisite $10 A^{\circledR}$ nanocomposite samples immersed in Distilled water at $4^{\circ} \mathrm{C}$

\begin{tabular}{|c|c|c|c|}
\hline & Sample 1 & Sample 2 & Sample 3 \\
\hline $\begin{array}{l}\text { Thickness } \\
\text { (cm) }\end{array}$ & 0.03683 & 0.040958 & 0.03048 \\
\hline Time (h) & Weight (mg) & Weight (mg) & Weight (mg) \\
\hline 0 & 193.67 & 229.64 & 190.01 \\
\hline 1.166667 & 193.85 & 229.82 & 190.19 \\
\hline 3.583333 & 193.99 & 230 & 190.39 \\
\hline 6.25 & 194.16 & 230.18 & 190.55 \\
\hline 24 & 194.65 & 230.72 & 191.04 \\
\hline 53 & 194.9 & 231.01 & 191.23 \\
\hline 101.75 & 195.01 & 231.17 & 191.43 \\
\hline 218.75 & 195.23 & 231.31 & 191.56 \\
\hline 339.75 & 195.32 & 231.52 & 191.67 \\
\hline 531.75 & 195.38 & 231.61 & 191.71 \\
\hline 699.75 & 195.49 & 231.69 & 191.73 \\
\hline 1275.75 & 195.57 & 231.8 & 191.76 \\
\hline 1587.75 & 195.61 & 231.83 & 191.8 \\
\hline 1779.75 & 195.61 & 231.83 & 191.8 \\
\hline
\end{tabular}

Table A. XVIII. Water Uptake Data for Neat DERAKANE ${ }^{\mathrm{TM}}$ 411-350 MOMENTUM Vinyl Ester Resin immersed in Distilled water at $42.5^{\circ} \mathrm{C}$

\begin{tabular}{rrrr}
\multicolumn{1}{c}{$\begin{array}{c}\text { Thickness } \\
(\mathrm{cm})\end{array}$} & \multicolumn{1}{c}{ Sample 1 } & Sample 2 & \multicolumn{1}{c}{ Sample 3 } \\
Time $(\mathrm{h})$ & Weight $(\mathrm{mg})$ & Weight $(\mathrm{mg})$ & Weight $(\mathrm{mg})$ \\
0 & 252.85 & 153.51 & 243.35 \\
1.316667 & 253.79 & 154.4 & 244.2 \\
2.733333 & 254.02 & 154.51 & 244.45 \\
4.65 & 254.24 & 154.62 & 244.63 \\
6.483333 & 254.36 & 154.66 & 244.75 \\
12.15 & 254.69 & 154.9 & 245.03 \\
28.15 & 255 & 155.14 & 245.34 \\
54.65 & 255.28 & 155.49 & 245.63 \\
106.9 & 255.7 & 155.93 & 246.07 \\
191.9 & 256.1 & 156.6 & 246.65 \\
340.9 & 257.03 & 157.51 & 247.38 \\
700.9 & 258.78 & 158.68 & 249.18 \\
892.9 & 258.71 & 158.42 & 248.91 \\
1348.9 & 258.21 & 158.07 & 248.11
\end{tabular}

Table A. XIX. Water Uptake for $1 \mathrm{wt} \%$ Cloisite $10 \mathrm{~A}^{\circledR}$ nanocomposite samples immersed in Distilled water at $42.5^{\circ} \mathrm{C}$

\begin{tabular}{|c|c|c|c|c|}
\hline & Sample 1 & Sample 2 & Sample 3 & Sample 4 \\
\hline $\begin{array}{l}\text { Thickness } \\
(\mathrm{cm})\end{array}$ & 0.051118 & 0.043498 & 0.036195 & 0.037783 \\
\hline Time (h) & Weight (mg) & Weight (mg) & Weight (mg) & Weight (mg) \\
\hline 0 & 264.78 & 316.23 & 230.04 & 247.47 \\
\hline 1.316667 & 265.64 & 317.17 & 230.96 & 248.43 \\
\hline 2.733333 & 265.96 & 317.49 & 231.21 & 248.74 \\
\hline 4.65 & 266.29 & 317.77 & 231.48 & 249 \\
\hline 6.483333 & 266.4 & 318 & 231.6 & 249.18 \\
\hline 12.15 & 267.02 & 318.65 & 232.23 & 249.73 \\
\hline 28.15 & 267.75 & 319.38 & 233 & 250.52 \\
\hline 54.65 & 268.37 & 320.14 & 233.43 & 251.18 \\
\hline 106.9 & 269.29 & 321.13 & 234.6 & 253.29 \\
\hline 191.9 & 270.35 & 322.28 & 235.83 & 253.44 \\
\hline 340.9 & 272.07 & 323.67 & 237.35 & 255.02 \\
\hline 700.9 & 274.48 & 326.54 & 240.04 & 257.65 \\
\hline 892.9 & 274.18 & 326.34 & 239.64 & 257.35 \\
\hline 1348.9 & 273.32 & 325.66 & 239.02 & 256.88 \\
\hline
\end{tabular}


Table A. XX. Water Uptake for $2 \mathrm{wt} \%$ Cloisite $10 \mathrm{~A}^{\circledR}$ nanocomposite samples immersed in Distilled water at $42.5^{\circ} \mathrm{C}$

\begin{tabular}{rrrrr}
$\begin{array}{c}\text { Thickness } \\
(\mathrm{cm})\end{array}$ & \multicolumn{1}{c}{ Sample 1 } & Sample 2 & Sample 3 & Sample 4 \\
Time $(\mathrm{h})$ & Weight $(\mathrm{mg})$ & Weight $(\mathrm{mg})$ & Weight $(\mathrm{mg})$ & Weight $(\mathrm{mg})$ \\
0 & 248.3 & 231.03 & 236.13 & 340.29 \\
1 & 249.25 & 231.8 & 237.15 & 341.39 \\
2.566667 & 249.63 & 232.3 & 237.57 & 341.77 \\
4.4 & 249.94 & 232.67 & 237.89 & 342.29 \\
6.65 & 250.3 & 233.01 & 238.29 & 342.65 \\
12.31667 & 251.1 & 233.61 & 239.01 & 343.46 \\
28.4 & 252.02 & 234.53 & 240.07 & 344.73 \\
54.9 & 253.34 & 235.76 & 241.43 & 345.97 \\
106.9 & 255.03 & 237.46 & 243.05 & 347.88 \\
191.9 & 256.47 & 239.17 & 244.92 & 350.3 \\
340.9 & 258.76 & 241.38 & 247.57 & 352.58 \\
700.9 & 262.74 & 245.66 & 252.65 & 357.02 \\
892.9 & 262.42 & 245.39 & 252.44 & 356.85 \\
1372.9 & 259.22 & 243.11 & 248.07 & 353.99
\end{tabular}

Table A. XXI. Water Uptake for $5 \mathrm{wt} \%$ Cloisite $10 \mathrm{~A}^{\circledR}$ nanocomposite samples immersed in Distilled water at $42.5^{\circ} \mathrm{C}$

\begin{tabular}{rrrr}
\multicolumn{1}{c}{$\begin{array}{c}\text { Shickness } \\
(\mathrm{cm})\end{array}$} & \multicolumn{1}{c}{ 0.01905 } & 0.035243 & \multicolumn{1}{c}{ 0.035243 } \\
Time $(\mathrm{h})$ & Weight $(\mathrm{mg})$ & Weight $(\mathrm{mg})$ & Weight $(\mathrm{mg})$ \\
0 & 102.27 & 194.73 & 204.13 \\
1 & 102.82 & 195.46 & 205.07 \\
2.566667 & 103.09 & 195.73 & 205.49 \\
4.4 & 103.4 & 196.12 & 206 \\
6.65 & 103.6 & 196.45 & 206.32 \\
12.31667 & 104.08 & 197.09 & 207.15 \\
28.4 & 104.9 & 198.21 & 208.09 \\
54.9 & 105.88 & 199.24 & 209.87 \\
106.9 & 107.48 & 201.01 & 212.35 \\
191.9 & 109.35 & 203.05 & 214.96 \\
340.9 & 111.54 & 205.2 & 218.13 \\
700.9 & 114.48 & 208.98 & 223.77 \\
892.9 & 115.37 & 209.84 & 224.9 \\
1372.9 & 113.11 & 206.89 & 222.03
\end{tabular}

Table A. XXII. Water Uptake Data for Neat DERAKANE ${ }^{\mathrm{TM}}$ 411-350 MOMENTUM Vinyl Ister Resin immersed in $0.1 \mathrm{M} N a C l$ solution at $28^{\circ} \mathrm{C}$

Note: $5.84 \mathrm{~g}$ of solid $\mathrm{NaCl}$ was dissolved in $1000 \mathrm{ml}$ of distilled water to make $0.1 \mathrm{M}$ $\mathrm{NaCl}$ solution

\begin{tabular}{rrrrr}
\multicolumn{1}{c}{$\begin{array}{c}\text { Shickness } \\
\text { (cm) }\end{array}$} & 0.0314325 & \multicolumn{1}{c}{ 0.03937 } & 0.025095 & \multicolumn{1}{c}{0.033655} \\
$\begin{array}{rrrr}\text { Time }(\mathrm{h}) \\
\text { Teight }(\mathrm{mg})\end{array}$ & Weight $(\mathrm{mg})$ & Weight $(\mathrm{mg})$ & Weight $(\mathrm{mg})$ \\
0.333333 & 223.36 & 254.28 & 153.82 & 202.15 \\
1.33333 & 223.66 & 254.52 & 154.11 & 202.45 \\
2.08333 & 223.96 & 254.84 & 154.37 & 202.73 \\
4.5 & 224.1 & 254.91 & 154.47 & 202.85 \\
7.5 & 224.39 & 255.18 & 154.66 & 203.1 \\
25 & 224.51 & 255.38 & 154.83 & 203.27 \\
71.5 & 224.73 & 255.73 & 154.97 & 203.47 \\
167 & 224.83 & 255.84 & 155.05 & 203.59 \\
359 & 224.84 & 255.86 & 155.03 & 203.59 \\
479 & 224.89 & 255.9 & 155.03 & 203.62 \\
& 224.89 & 255.9 & 155.03 & 203.62
\end{tabular}


Table A. XXIII. Water Uptake for $1 \mathrm{wt} \%$ Cloisite $10 \mathrm{~A}^{\circledR}$ nanocomposite samples immersed in $0.1 \mathrm{M}$ $\mathrm{NaCl}$ solution at $28^{\circ} \mathrm{C}$

\begin{tabular}{|c|c|c|c|c|}
\hline & Sample 1 & Sample 2 & Sample 3 & Sample 4 \\
\hline $\begin{array}{l}\text { Thickness } \\
\text { (cm) }\end{array}$ & 0.0314325 & 0.029845 & 0.03683 & 0.028575 \\
\hline Time (h) & Weight (mg) & Weight (mg) & Weight (mg) & Weight (mg) \\
\hline 0 & 186.24 & 180.66 & 188.46 & 175.01 \\
\hline 0.333333 & 186.56 & 180.93 & 188.76 & 175.29 \\
\hline 1.33333 & 186.8 & 181.18 & 189.03 & 175.51 \\
\hline 2.08333 & 186.97 & 181.33 & 189.18 & 175.67 \\
\hline 4.5 & 187.18 & 181.6 & 189.42 & 175.91 \\
\hline 7.5 & 187.4 & 181.76 & 189.61 & 176.04 \\
\hline 25 & 187.72 & 182.06 & 189.95 & 176.33 \\
\hline 71.5 & 187.87 & 182.21 & 190.06 & 176.42 \\
\hline 167 & 187.91 & 182.27 & 190.12 & 176.52 \\
\hline 359 & 187.91 & 182.27 & 190.12 & 176.52 \\
\hline 479 & 187.91 & 182.27 & 190.12 & 176.52 \\
\hline
\end{tabular}

Table A. XXIV. Water Uptake for $2 \mathrm{wt} \%$ Cloisite $10 \mathrm{~A}^{\circledR}$ nanocomposite samples immersed in $0.1 \mathrm{M}$ $\mathrm{NaCl}$ solution at $28^{\circ} \mathrm{C}$

\begin{tabular}{rrrrr}
$\begin{array}{c}\text { Thickness } \\
\text { (cm) }\end{array}$ & Sample 1 & Sample 2 & Sample 3 & \multicolumn{1}{c}{ Sample 4 } \\
$\begin{array}{c}\text { Time }(\mathrm{h}) \\
\text { T) }\end{array}$ & Weight $(\mathrm{mg})$ & Weight $(\mathrm{mg})$ & Weight $(\mathrm{mg})$ & Weight $(\mathrm{mg})$ \\
0.333333 & 205.7 & 195.43 & 243.46 & 189.75 \\
1.25 & 205.98 & 195.71 & 243.73 & 190.05 \\
2 & 206.28 & 196.02 & 244.02 & 190.25 \\
4.416667 & 206.39 & 196.11 & 244.18 & 190.39 \\
7.5 & 206.67 & 196.43 & 244.52 & 190.66 \\
25 & 206.91 & 196.65 & 244.8 & 190.88 \\
71.75 & 207.37 & 197.04 & 245.26 & 191.28 \\
166.75 & 207.61 & 197.27 & 245.52 & 191.52 \\
358.75 & 207.61 & 197.28 & 245.58 & 191.58 \\
478.75 & 207.61 & 197.28 & 245.62 & 191.58 \\
& 207.61 & 197.28 & 245.62 & 191.58
\end{tabular}

Table A. XXV. Water Uptake for $5 \mathrm{wt} \%$ Cloisite $10 \mathrm{~A}^{\circledR}$ nanocomposite samples immersed in $0.1 \mathrm{M}$ $\mathrm{NaCl}$ solution at $28^{\circ} \mathrm{C}$

\begin{tabular}{|c|c|c|c|c|}
\hline & Sample 1 & Sample 2 & Sample 3 & Sample 4 \\
\hline $\begin{array}{l}\text { Thickness } \\
\text { (cm) }\end{array}$ & 0.0320675 & 0.041275 & 0.04064 & 0.042228 \\
\hline Time (h) & Weight (mg) & Weight (mg) & Weight (mg) & Weight (mg) \\
\hline 0 & 148.78 & 239.64 & 270.59 & 311.12 \\
\hline 0.333333 & 148.97 & 239.84 & 270.87 & 311.45 \\
\hline 1.25 & 149.21 & 240.1 & 271.12 & 311.74 \\
\hline 2 & 149.3 & 240.25 & 271.28 & 311.88 \\
\hline 4.416667 & 149.57 & 240.59 & 271.69 & 312.21 \\
\hline 7.5 & 149.8 & 240.92 & 272 & 312.62 \\
\hline 25 & 150.27 & 241.59 & 272.63 & 313.48 \\
\hline 71.75 & 150.53 & 241.96 & 273.25 & 314.06 \\
\hline 166.75 & 150.55 & 242.11 & 273.36 & 314.23 \\
\hline 358.75 & 150.55 & 242.14 & 273.42 & 314.23 \\
\hline 478.75 & 150.55 & 242.14 & 273.42 & 314.23 \\
\hline
\end{tabular}


Table A. XXVI. Water Uptake Data for Neat DERAKANE ${ }^{\mathrm{TM}}$ 411-350 MOMENTUM Vinyl Ester Resin immersed in $0.1 \mathrm{M} \mathrm{NaCl}$ solution at $4^{\circ} \mathrm{C}$

\begin{tabular}{|c|c|c|c|}
\hline & Sample 1 & Sample 2 & Sample 3 \\
\hline $\begin{array}{c}\text { Thickness } \\
\text { (cm) }\end{array}$ & 0.0295275 & 0.03302 & 0.033338 \\
\hline Time (h) & Weight (mg) & Weight (mg) & Weight (mg) \\
\hline 0 & 209.69 & 243.75 & 174.01 \\
\hline 0.583333 & 209.82 & 243.84 & 174.1 \\
\hline 2.166667 & 209.96 & 243.98 & 174.22 \\
\hline 4.583333 & 210.12 & 244.19 & 174.36 \\
\hline 7.666667 & 210.25 & 244.35 & 174.47 \\
\hline 25.66667 & 210.55 & 244.67 & 174.73 \\
\hline 50.16667 & 210.69 & 244.88 & 174.86 \\
\hline 167.1667 & 210.78 & 245.02 & 175 \\
\hline 359.1667 & 210.79 & 245.05 & 175.02 \\
\hline 671.1667 & 210.83 & 245.09 & 175.03 \\
\hline 1103.167 & 210.88 & 245.16 & 175.06 \\
\hline 1439.167 & 210.88 & 245.16 & 175.06 \\
\hline
\end{tabular}

Table A. XXVII. Water Uptake for $1 \mathrm{wt} \%$ Cloisite $10 \mathrm{~A}^{\circledR}$ nanocomposite samples immersed in $0.1 \mathrm{M}$ $\mathrm{NaCl}$ solution at $4^{\circ} \mathrm{C}$

\begin{tabular}{|c|c|c|c|c|}
\hline & Sample 1 & Sample 2 & Sample 3 & Sample 4 \\
\hline $\begin{array}{l}\text { Thickness } \\
\text { (cm) }\end{array}$ & 0.037465 & 0.040323 & 0.02794 & 0.04318 \\
\hline Time (h) & Weight (mg) & Weight (mg) & Weight (mg) & Weight (mg) \\
\hline 0 & 240.1 & 274.61 & 168.89 & 239.21 \\
\hline 0.583333 & 240.19 & 274.76 & 168.99 & 239.32 \\
\hline 2.166667 & 240.38 & 274.87 & 169.15 & 239.48 \\
\hline 4.583333 & 240.53 & 275.05 & 169.29 & 239.61 \\
\hline 7.666667 & 240.67 & 275.16 & 169.4 & 239.72 \\
\hline 25.66667 & 241.01 & 275.63 & 169.72 & 240.21 \\
\hline 50.16667 & 241.22 & 275.83 & 169.83 & 240.41 \\
\hline 167.1667 & 241.45 & 276.07 & 169.96 & 240.66 \\
\hline 359.1667 & 241.52 & 276.13 & 170.02 & 240.72 \\
\hline 671.1667 & 241.59 & 276.22 & 170.04 & 240.82 \\
\hline 1103.167 & 241.61 & 276.27 & 170.05 & 240.9 \\
\hline 1439.167 & 241.61 & 276.27 & 170.05 & 240.9 \\
\hline
\end{tabular}

Table A. XXVIII. Water Uptake for $2 \mathrm{wt} \%$ Cloisite $10 \mathrm{~A}^{\circledR}$ nanocomposite samples immersed in $0.1 \mathrm{M}$ $\mathrm{NaCl}$ solution at $4^{\circ} \mathrm{C}$

\begin{tabular}{rrrrr}
$\begin{array}{c}\text { Thickness } \\
(\mathrm{cm})\end{array}$ & \multicolumn{1}{c}{ Sample 1 } & \multicolumn{1}{c}{ Sample 2 } & Sample 3 & \multicolumn{1}{c}{ Sample 4 } \\
Time $(\mathrm{h})$ & Weight $(\mathrm{mg})$ & Weight $(\mathrm{mg})$ & Weight $(\mathrm{mg})$ & \multicolumn{1}{c}{ Weight $(\mathrm{mg})$} \\
0 & 266.15 & 138.37 & 141.17 & 163.7 \\
0.75 & 266.2 & 138.45 & 141.25 & 163.79 \\
2.333333 & 266.438 & 138.6 & 141.45 & 163.97 \\
4.666667 & 266.55 & 138.72 & 141.58 & 164.09 \\
7.833333 & 266.76 & 138.86 & 141.67 & 164.21 \\
25.83333 & 267.08 & 139 & 141.84 & 164.47 \\
50.66667 & 267.27 & 139.05 & 141.88 & 164.51 \\
167.6667 & 267.53 & 139.1 & 141.96 & 164.6 \\
359.6667 & 267.57 & 139.12 & 141.98 & 164.61 \\
671.6667 & 267.67 & 139.15 & 142 & 164.63 \\
1103.667 & 267.75 & 139.17 & 142.02 & 164.65 \\
1439.667 & 267.75 & 139.17 & 142.02 & 164.65
\end{tabular}


Table A. XXIX. Water Uptake for $5 \mathrm{wt} \%$ Cloisite $10 \mathrm{~A}^{\circledR}$ nanocomposite samples immersed in $0.1 \mathrm{M}$ $\mathrm{NaCl}$ solution at $4^{\circ} \mathrm{C}$

\begin{tabular}{|c|c|c|c|}
\hline & Sample 1 & Sample 2 & Sample 3 \\
\hline $\begin{array}{l}\text { Thickness } \\
(\mathrm{cm})\end{array}$ & 0.038735 & 0.040005 & 0.041593 \\
\hline Time (h) & Weight (mg) & Weight (mg) & Weight (mg) \\
\hline (2) & 234.88 & 253.81 & 269.98 \\
\hline 0.75 & 234.96 & 253.85 & 270.05 \\
\hline 2.333333 & 235.12 & 254.01 & 270.12 \\
\hline 4.666667 & 235.28 & 254.18 & 270.26 \\
\hline 7.833333 & 235.37 & 254.26 & 270.37 \\
\hline 25.83333 & 235.77 & 254.65 & 270.76 \\
\hline 50.66667 & 235.94 & 254.86 & 271.02 \\
\hline 167.6667 & 236.2 & 255.15 & 271.31 \\
\hline 359.6667 & 236.26 & 255.21 & 271.39 \\
\hline 671.6667 & 236.33 & 255.3 & 271.46 \\
\hline 1103.667 & 236.39 & 255.36 & 271.56 \\
\hline 1439.667 & 236.39 & 255.36 & 271.56 \\
\hline
\end{tabular}

Table A. XXX. Water Uptake Data for Neat DERAKANE ${ }^{\mathrm{TM}}$ 411-350 MOMENTUM Vinyl Ester Resin immersed in $0.1 \mathrm{M} \mathrm{NaCl}$ solution at $42.5^{\circ} \mathrm{C}$

$\begin{array}{rrrrr}\begin{array}{c}\text { Thickness } \\ (\mathrm{cm})\end{array} & \begin{array}{r}\text { Sample 1 } \\ \text { Time }(\mathrm{h})\end{array} & \text { Sample 2 } & \text { Sample 3 } & \text { Sample 4 } \\ \text { Weight }(\mathrm{mg}) & \text { Weight }(\mathrm{mg}) & \text { Weight }(\mathrm{mg}) & \text { Weight }(\mathrm{mg}) \\ 0 & 182.5 & 186.74 & 198.19 & 152.12 \\ 0.55 & 183.1 & 187.32 & 198.86 & 152.76 \\ 2.216667 & 183.55 & 187.83 & 199.29 & 153.13 \\ 4.05 & 183.67 & 187.93 & 199.42 & 153.26 \\ 6.05 & 183.75 & 188.04 & 199.45 & 153.34 \\ 11.63333 & 183.85 & 188.1 & 199.53 & 153.35 \\ 27.38333 & 183.84 & 188.16 & 199.48 & 153.27 \\ 54.3 & 183.91 & 188.18 & 199.51 & 153.25 \\ 107.3 & 183.91 & 188.18 & 199.4 & 153.08 \\ 192.3 & 183.79 & 188.12 & 199.24 & 152.92 \\ 264.3 & 183.79 & 188.04 & 199.17 & 152.85\end{array}$

Table A. XXXI. Water Uptake for $1 \mathrm{wt} \%$ Cloisite $10 \mathrm{~A}^{\circledR}$ nanocomposite samples immersed in $0.1 \mathrm{M}$ $\mathrm{NaCl}$ solution at $42.5^{\circ} \mathrm{C}$

\begin{tabular}{rrrrr}
$\begin{array}{c}\text { Thickness } \\
(\mathrm{cm})\end{array}$ & $\begin{array}{r}\text { Sample 1 } \\
\text { Time }(\mathrm{h})\end{array}$ & Seighte 2 & Sample 3 & \multicolumn{1}{c}{ Sample 4 } \\
Weight $(\mathrm{mg})$ & Weight $(\mathrm{mg})$ & Weight $(\mathrm{mg})$ & Weight $(\mathrm{mg})$ \\
0.55 & 172.76 & 164.05 & 309.58 & 249.03 \\
2.216667 & 173.4 & 164.64 & 310.15 & 249.6 \\
4.05 & 173.84 & 165.11 & 310.81 & 250.23 \\
6.05 & 174.04 & 165.32 & 311.15 & 250.47 \\
11.63333 & 174.17 & 165.4 & 311.37 & 250.65 \\
27.38333 & 174.43 & 165.6 & 311.62 & 250.87 \\
54.3 & 174.45 & 165.59 & 311.82 & 250.98 \\
107.3 & 174.46 & 165.69 & 311.96 & 251.09 \\
192.3 & 174.49 & 165.66 & 311.97 & 251.16 \\
264.3 & 174.46 & 165.64 & 311.99 & 251.09 \\
504.3 & 174.34 & 165.52 & 311.89 & 250.95
\end{tabular}


Table A. XXXII. Water Uptake for $2 \mathrm{wt} \%$ Cloisite $10 \mathrm{~A}^{\circledR}$ nanocomposite samples immersed in $0.1 \mathrm{M}$ $\mathrm{NaCl}$ solution at $42.5^{\circ} \mathrm{C}$

\begin{tabular}{rrrrr}
$\begin{array}{c}\text { Thickness } \\
(\mathrm{cm})\end{array}$ & $\begin{array}{r}\text { Sample 1 } \\
\text { Time }(\mathrm{h})\end{array}$ & $\begin{array}{r}\text { Sample 2 } \\
\text { Weight }(\mathrm{mg})\end{array}$ & Sample 3 & \multicolumn{1}{c}{ Sample 4 } \\
0 & 282.28 & 262.24 & 189.13 & 131.83 \\
0.716667 & 283.03 & 262.94 & 189.66 & 132.2 \\
2.383333 & 283.66 & 263.62 & 190.11 & 132.5 \\
4.216667 & 283.96 & 263.93 & 190.35 & 132.67 \\
6.3 & 284.18 & 264.19 & 190.53 & 132.77 \\
11.8 & 284.59 & 264.68 & 190.91 & 132.96 \\
27.63333 & 284.93 & 264.95 & 191.19 & 133.12 \\
54.55 & 284.94 & 265.1 & 191.3 & 133.2 \\
107.3 & 285 & 265.13 & 191.32 & 133.22 \\
192.3 & 284.9 & 265.17 & 191.24 & 133.2 \\
264.3 & 284.81 & 265.08 & 191.15 & 133.2 \\
504.3 & 284.71 & 264.96 & 191.01 & 133.02
\end{tabular}

Table A. XXXIII. Water Uptake for $5 \mathrm{wt} \%$ Cloisite $10 \mathrm{~A}^{\circledR}$ nanocomposite samples immersed in $0.1 \mathrm{M}$ $\mathrm{NaCl}$ solution at $42.5^{\circ} \mathrm{C}$

\begin{tabular}{|c|c|c|c|c|}
\hline & Sample 1 & Sample 2 & Sample 3 & Sample 4 \\
\hline $\begin{array}{l}\text { Thickness } \\
\text { (cm) }\end{array}$ & 0.042863 & 0.034608 & 0.042863 & 0.041275 \\
\hline $\begin{array}{l}\text { Time }(\mathrm{h}) \\
0\end{array}$ & $\begin{array}{r}\text { Weight }(\mathrm{mg}) \\
186.01\end{array}$ & $\begin{array}{r}\text { Weight }(\mathrm{mg}) \\
222.47\end{array}$ & $\begin{array}{r}\text { Weight }(\mathrm{mg}) \\
292.65\end{array}$ & $\begin{array}{r}\text { Weight }(\mathrm{mg}) \\
225.31\end{array}$ \\
\hline 0.716667 & 186.42 & 223.23 & 293.26 & 225.95 \\
\hline 2.383333 & 186.81 & 223.79 & 293.87 & 226.45 \\
\hline 4.216667 & 187.02 & 224.1 & 294.19 & 226.72 \\
\hline 6.3 & 187.23 & 224.26 & 294.49 & 226.94 \\
\hline 11.8 & 187.55 & 224.73 & 295.14 & 227.48 \\
\hline 27.63333 & 187.95 & 225.1 & 295.66 & 227.71 \\
\hline 54.55 & 188.12 & 225.26 & 295.94 & 228.03 \\
\hline 107.3 & 188.15 & 225.23 & 295.92 & 227.95 \\
\hline 192.3 & 188.21 & 225.14 & 295.89 & 227.8 \\
\hline 264.3 & 188.15 & 224.93 & 295.79 & 227.75 \\
\hline 504.3 & 187.95 & 224.71 & 295.56 & 227.5 \\
\hline
\end{tabular}

Table A. XXXIV. Water Uptake Data for Neat DERAKANE ${ }^{\mathrm{TM}}$ 411-350 MOMENTUM Vinyl Ester Resin immersed in $13 \mathrm{pH}$ NaOH solution at $28^{\circ} \mathrm{C}$

Note: $4.0 \mathrm{~g}$ of solid $\mathrm{NaOH}$ was dissolved in $1000 \mathrm{ml}$ of distilled water to make a $13 \mathrm{pH}$ $\mathrm{NaOH}$ solution

\begin{tabular}{|c|c|c|c|c|}
\hline & Sample 1 & Sample 2 & Sample 3 & Sample 4 \\
\hline $\begin{array}{l}\text { Thickness } \\
\text { (cm) }\end{array}$ & 0.023813 & 0.036513 & 0.026353 & 0.03048 \\
\hline Time (h) & Weight (mg) & Weight (mg) & Weight (mg) & Weight (mg) \\
\hline 0 & 112.17 & 186.93 & 129.78 & 174.4 \\
\hline 0.25 & 112.37 & 186.61 & 129.89 & 174.55 \\
\hline 0.583333 & 112.49 & 186.65 & 129.99 & 174.66 \\
\hline 1.166667 & 112.57 & 186.68 & 130.07 & 174.72 \\
\hline 2.916667 & 112.74 & 186.91 & 130.27 & 174.98 \\
\hline 5.166667 & 112.87 & 187.06 & 130.4 & 175.05 \\
\hline 8.166667 & 112.92 & 187.18 & 130.5 & 175.08 \\
\hline 24 & 113.05 & 187.39 & 130.64 & 175.17 \\
\hline 32.3333 & 113.04 & 187.4 & 130.67 & 175.13 \\
\hline 54.16667 & 113.04 & 187.39 & 130.63 & 175.06 \\
\hline 103.1667 & 113.06 & 187.39 & 130.67 & 175 \\
\hline 170.1667 & 113.05 & 187.43 & 130.69 & 174.98 \\
\hline 272.1667 & 112.9 & 187.25 & 130.47 & 174.91 \\
\hline
\end{tabular}


Table A. XXXV. Water Uptake for $1 \mathrm{wt} \%$ Cloisite $10 \mathrm{~A}^{\circledR}$ nanocomposite samples immersed in $13 \mathrm{pH}$ $\mathrm{NaOH}$ solution at $28^{\circ} \mathrm{C}$

\begin{tabular}{rrr}
$\begin{array}{c}\text { Thickness } \\
(\mathrm{cm})\end{array}$ & Sample 1 & \multicolumn{1}{c}{ Sample 2 } \\
Time $(\mathrm{h})$ & 0.02794 & \multicolumn{1}{c}{0.025083} \\
0 & Weight $(\mathrm{mg})$ & Weight $(\mathrm{mg})$ \\
0.25 & 160.02 & 145.38 \\
0.583333 & 160.24 & 145.61 \\
1.166667 & 160.35 & 145.73 \\
2.916667 & 160.43 & 145.84 \\
5.166667 & 160.52 & 146.06 \\
8.166667 & 160.86 & 146.17 \\
24 & 161.01 & 146.31 \\
32.3333 & 161.01 & 146.47 \\
54.16667 & 161.01 & 146.52 \\
103.1667 & 161.02 & 146.57 \\
170.1667 & 161.06 & 146.49 \\
272.1667 & 161 & 146.29
\end{tabular}

Table A. XXXVI. Water Uptake for $2 \mathrm{wt} \%$ Cloisite $10 \mathrm{~A}^{\circledR}$ nanocomposite samples immersed in 13 $\mathrm{pH} \mathrm{NaOH}$ solution at $28^{\circ} \mathrm{C}$

\begin{tabular}{crrrr} 
& \multicolumn{1}{c}{ Sample 1 } & Sample 2 & \multicolumn{1}{c}{ Sample 3 } & \multicolumn{1}{c}{ Sample 4 } \\
$\begin{array}{c}\text { Thickness } \\
(\mathrm{cm})\end{array}$ & 0.028893 & 0.02667 & 0.025083 & 0.027623 \\
Time $(\mathrm{h})$ & Weight $(\mathrm{mg})$ & Weight $(\mathrm{mg})$ & Weight $(\mathrm{mg})$ & Weight $(\mathrm{mg})$ \\
0 & 173.86 & 188.29 & 170.95 & 205.31 \\
0.333333 & 174.16 & 188.53 & 171.22 & 205.62 \\
0.833333 & 174.27 & 188.66 & 171.37 & 205.69 \\
1.25 & 174.35 & 188.76 & 171.45 & 205.82 \\
3.166667 & 174.68 & 189.06 & 171.62 & 206.12 \\
5.333333 & 174.8 & 189.27 & 171.84 & 206.32 \\
8.333333 & 174.98 & 189.43 & 171.99 & 206.48 \\
24.33333 & 175.23 & 189.8 & 172.3 & 206.79 \\
54.33333 & 175.33 & 189.82 & 172.25 & 206.86 \\
102.8333 & 175.19 & 189.76 & 172.25 & 206.74 \\
272.3333 & 174.61 & 189.03 & 171.83 & 206.2
\end{tabular}

Table A. XXXVII. Water Uptake for 5 wt\% Cloisite $10 A^{\circledR}$ nanocomposite samples immersed in 13 pH $\mathrm{NaOH}$ solution at $28^{\circ} \mathrm{C}$

\begin{tabular}{crrr}
\multicolumn{1}{c}{ Thickness } & \multicolumn{1}{c}{ Sample 1 } & \multicolumn{1}{c}{ Sample 2 } & \multicolumn{1}{c}{ Sample 3 } \\
$(\mathrm{cm})$ & 0.026035 & 0.013018 & 0.02032 \\
Time $(\mathrm{h})$ & Weight $(\mathrm{mg})$ & Weight $(\mathrm{mg})$ & Weight $(\mathrm{mg})$ \\
0 & 138.65 & 140.9 & 167.79 \\
0.333333 & 138.9 & 141.16 & 168.09 \\
0.833333 & 139.03 & 141.29 & 168.26 \\
1.25 & 139.11 & 141.37 & 168.32 \\
3.166667 & 139.38 & 141.58 & 168.63 \\
5.333333 & 139.56 & 141.79 & 168.86 \\
8.333333 & 139.76 & 141.98 & 169 \\
24.33333 & 140.11 & 142.35 & 169.31 \\
54.33333 & 140.15 & 142.27 & 169.32 \\
102.8333 & 140.05 & 142.22 & 169.21
\end{tabular}


Table A. XXXVIII. Water Uptake Data for Neat DERAKANE ${ }^{\mathrm{TM}}$ 411-350 MOMENTUM Vinyl Ester Resin immersed in $13 \mathrm{pH} \mathrm{NaOH}$ solution at $4^{\circ} \mathrm{C}$

\begin{tabular}{rrrr}
$\begin{array}{c}\text { Thickness } \\
(\mathrm{cm})\end{array}$ & $\begin{array}{c}\text { Sample 1 } \\
\text { Time }(\mathrm{h})\end{array}$ & $\begin{array}{c}\text { Sample 2 } \\
\text { Weight }(\mathrm{mg})\end{array}$ & \multicolumn{1}{c}{ Sample 3 } \\
Weight $(\mathrm{mg})$ & Weight $(\mathrm{mg})$ \\
0.5 & 130.49 & 134.77 & 191.82 \\
2.25 & 130.61 & 134.9 & 191.97 \\
3.833333 & 130.79 & 135.1 & 192.13 \\
20.91667 & 130.89 & 135.23 & 192.28 \\
49.91667 & 131.09 & 135.43 & 192.59 \\
74.41667 & 131.19 & 135.52 & 192.71 \\
142.4167 & 131.23 & 135.58 & 192.77 \\
244.4167 & 131.27 & 135.61 & 192.82 \\
335.4167 & 131.29 & 135.61 & 192.85 \\
455.9167 & 131.32 & 135.66 & 192.86 \\
671.9167 & 131.34 & 135.68 & 192.88 \\
959.9167 & 131.37 & 135.71 & 192.93 \\
1391.917 & 131.39 & 135.73 & 192.96 \\
1751.917 & 131.39 & 135.73 & 192.97 \\
& & 135.73 & 192.97
\end{tabular}

Table A. XXXIX. Water Uptake for $1 \mathrm{wt} \%$ Cloisite $10 \mathrm{~A}^{\circledR}$ nanocomposite samples immersed in 13 pH $\mathrm{NaOH}$ solution at $4^{\circ} \mathrm{C}$

\begin{tabular}{|c|c|c|c|}
\hline & Sample 1 & Sample 2 & Sample 3 \\
\hline $\begin{array}{l}\text { Thickness } \\
\text { (cm) }\end{array}$ & 0.04191 & 0.036195 & 0.038735 \\
\hline Time (h) & Weight (mg) & Weight (mg) & Weight (mg) \\
\hline 0 & 244.33 & 223.56 & 224.66 \\
\hline 0.5 & 244.41 & 223.65 & 224.76 \\
\hline 2.25 & 244.54 & 223.83 & 224.92 \\
\hline 3.833333 & 244.65 & 223.93 & 225.07 \\
\hline 20.91667 & 245.05 & 224.32 & 225.48 \\
\hline 49.91667 & 245.25 & 224.51 & 225.74 \\
\hline 74.41667 & 245.45 & 224.7 & 225.89 \\
\hline 142.4167 & 245.58 & 224.79 & 225.97 \\
\hline 244.4167 & 245.63 & 224.87 & 226.03 \\
\hline 335.4167 & 245.68 & 224.92 & 226.09 \\
\hline 455.9167 & 245.68 & 224.93 & 226.15 \\
\hline 671.9167 & 245.77 & 224.97 & 226.19 \\
\hline 959.9167 & 245.82 & 225 & 226.2 \\
\hline 1391.917 & 245.82 & 225 & 226.2 \\
\hline 1751.917 & 245.82 & 225 & 226.2 \\
\hline
\end{tabular}

Table A. XL. Water Uptake for 2 wt\% Cloisite $10 A^{\circledR}$ nanocomposite samples immersed in 13 pH $\mathrm{NaOH}$ solution at $4^{\circ} \mathrm{C}$

\begin{tabular}{rrrrr}
$\begin{array}{c}\text { Thickness } \\
(\mathrm{cm})\end{array}$ & \multicolumn{1}{c}{ Sample 1 } & \multicolumn{1}{c}{ Sample 2 } & \multicolumn{1}{c}{ Sample 3 } & \multicolumn{1}{c}{ Sample 4 } \\
Time $(\mathrm{h})$ & Weight $(\mathrm{mg})$ & Weight $(\mathrm{mg})$ & Weight $(\mathrm{mg})$ & Weight $(\mathrm{mg})$ \\
0 & 233.58 & 225.88 & 176.39 & 158.69 \\
0.666667 & & & 176.48 & 158.84 \\
1.166667 & 233.71 & 226 & & \\
2.166667 & 233.87 & 226.07 & 176.66 & 158.98 \\
4 & 233.98 & 226.19 & 176.79 & 159.11 \\
21.08333 & 234.39 & 226.64 & 177.09 & 159.39 \\
50.08333 & 234.56 & 226.79 & 177.23 & 159.5 \\
75.08333 & 234.73 & 226.91 & 177.36 & 159.57 \\
143.0833 & 234.81 & 227.01 & 177.4 & 159.64 \\
245.0833 & 234.87 & 227.03 & 177.41 & 159.65 \\
336.0833 & 234.93 & 227.1 & 177.48 & 159.71 \\
456.5833 & 234.93 & 227.13 & 177.49 & 159.74 \\
672.5833 & 235 & 227.19 & 177.53 & 159.78 \\
960.5833 & 235.05 & 227.23 & 177.56 & 159.79 \\
1392.583 & 235.06 & 227.24 & 177.62 & 159.81 \\
1752.583 & 235.06 & 227.24 & 177.62 & 159.81
\end{tabular}


Table A. XLI. Water Uptake for $5 \mathrm{wt} \%$ Cloisite $10 \mathrm{~A}^{\circledR}$ nanocomposite samples immersed in $13 \mathrm{pH}$ $\mathrm{NaOH}$ solution at $4^{\circ} \mathrm{C}$

\begin{tabular}{rrr}
$\begin{array}{c}\text { Thickness } \\
(\mathrm{cm})\end{array}$ & \multicolumn{1}{c}{$\begin{array}{c}\text { Sample 1 } \\
\text { Time }(\mathrm{h})\end{array}$} & \multicolumn{1}{c}{ Sample 2 } \\
Weight $(\mathrm{mg})$ & \multicolumn{1}{c}{ Weight $(\mathrm{mg})$} \\
0 & 140.72 & 184.78 \\
0.666667 & 140.86 & 184.86 \\
2.166667 & 140.96 & 184.93 \\
4 & 141.15 & 185.05 \\
21.08333 & 141.39 & 185.38 \\
50.08333 & 141.46 & 185.54 \\
75.08333 & 141.55 & 185.6 \\
143.0833 & 141.62 & 185.72 \\
245.0833 & 141.69 & 185.74 \\
336.0833 & 141.672 & 185.77 \\
456.5833 & 141.73 & 185.86 \\
672.5833 & 141.775 & 185.95 \\
960.5833 & 141.77 & 185.97 \\
1392.583 & 141.78 & 185.99 \\
1752.583 & 141.78 & 185.99
\end{tabular}

Table A. XLII. Water Uptake Data for Neat DERAKANE ${ }^{\mathrm{TM}}$ 411-350 MOMENTUM Vinyl Ester Resin immersed in $13 \mathrm{pH} \mathrm{NaOH}$ solution at $42.5^{\circ} \mathrm{C}$

\begin{tabular}{rrrr}
$\begin{array}{c}\text { Thickness } \\
(\mathrm{cm})\end{array}$ & $\begin{array}{r}\text { Sample 1 } \\
\text { Time }(\mathrm{h})\end{array}$ & $\begin{array}{c}\text { Sample 2 } \\
\text { Weight }(\mathrm{mg})\end{array}$ & \multicolumn{1}{c}{ Sample 3 } \\
0 & 207.2 & Weight $(\mathrm{mg})$ & \multicolumn{1}{c}{ Weight $(\mathrm{mg})$} \\
1 & 208.01 & 132.02 & 220.15 \\
2.316667 & 208.2 & 132.66 & 220.89 \\
4.4 & 208.42 & 132.89 & 221.08 \\
6.316667 & 208.45 & 132.94 & 221.3 \\
11.81667 & 208.54 & 132.97 & 221.36 \\
27.65 & 208.47 & 132.86 & 221.48 \\
54.56667 & 208.28 & 132.71 & 221.29
\end{tabular}

Table A. XLIII. Water Uptake for $1 \mathrm{wt} \%$ Cloisite $10 \mathrm{~A}^{\circledR}$ nanocomposite samples immersed in $13 \mathrm{pH}$ $\mathrm{NaOH}$ solution at $42.5^{\circ} \mathrm{C}$

\begin{tabular}{|c|c|c|c|c|}
\hline & Sample 1 & Sample 2 & Sample 3 & Sample 4 \\
\hline $\begin{array}{l}\text { Thickness } \\
(\mathrm{cm})\end{array}$ & 0.02413 & 0.036195 & 0.035243 & 0.036195 \\
\hline Time (h) & Weight (mg) & Weight (mg) & Weight (mg) & Weight (mg) \\
\hline 0 & 159.62 & 200.19 & 200.51 & 189.74 \\
\hline 1 & 160.35 & 200.9 & 201.27 & 190.48 \\
\hline 2.316667 & 160.52 & 201.2 & 201.47 & 190.7 \\
\hline 4.4 & 160.74 & 201.43 & 201.73 & 190.92 \\
\hline 6.316667 & 160.81 & 201.51 & 201.81 & 191.04 \\
\hline 11.81667 & 160.93 & 201.67 & 202 & 191.23 \\
\hline 27.65 & 160.84 & 201.62 & 202.02 & 191.13 \\
\hline 54.56667 & 160.8 & 201.56 & 201.55 & 190.68 \\
\hline
\end{tabular}


Table A. XLIV. Water Uptake for $2 \mathrm{wt} \%$ Cloisite $10 \mathrm{~A}^{\circledR}$ nanocomposite samples immersed in $13 \mathrm{pH}$ $\mathrm{NaOH}$ solution at $42.5^{\circ} \mathrm{C}$

\begin{tabular}{|c|c|c|c|c|}
\hline & Sample 1 & Sample 2 & Sample 3 & Sample 4 \\
\hline $\begin{array}{c}\text { Thickness } \\
(\mathrm{cm})\end{array}$ & 0.046567 & 0.036195 & 0.035878 & 0.049213 \\
\hline Time (h) & Weight (mg) & Weight (mg) & Weight (mg) & Weight (mg) \\
\hline 0 & 188.97 & 180.34 & 253.37 & $\quad 356.4$ \\
\hline 0.9 & 189.49 & 180.85 & 254.17 & 357.21 \\
\hline 2.483333 & 189.76 & 181.18 & 254.67 & 357.71 \\
\hline 4.15 & 190.02 & 181.38 & 254.83 & 358.06 \\
\hline 6.483333 & 190.23 & 181.53 & 255.12 & 358.43 \\
\hline 12.06667 & 190.52 & 181.77 & 255.58 & 358.94 \\
\hline 27.9 & 190.56 & 181.72 & 255.45 & 359.07 \\
\hline 55.56667 & 190.28 & 181.58 & 255.15 & 358.76 \\
\hline
\end{tabular}

Table A. XLV. Water Uptake for $5 \mathrm{wt} \%$ Cloisite $10 A^{\circledR}$ nanocomposite samples immersed in $13 \mathrm{pH}$ $\mathrm{NaOH}$ solution at $42.5^{\circ} \mathrm{C}$

\begin{tabular}{rrrrr}
\multicolumn{1}{c}{$\begin{array}{c}\text { Thickness } \\
(\mathrm{cm})\end{array}$} & 0.03683 & 0.03937 & 0.045085 & 0.035983 \\
Time $(\mathrm{h})$ & Weight $(\mathrm{mg})$ & Weight $(\mathrm{mg})$ & Weight $(\mathrm{mg})$ & Weight $(\mathrm{mg})$ \\
0 & 277.84 & 243.72 & 305.9 & 132.51 \\
0.9 & 278.65 & 244.41 & 306.61 & 133.1 \\
2.483333 & 279.21 & 244.92 & 307.1 & 133.52 \\
4.15 & 279.54 & 245.21 & 307.38 & 133.73 \\
6.483333 & 279.83 & 245.52 & 307.72 & 133.99 \\
12.06667 & 280.32 & 245.95 & 308.29 & 134.34 \\
27.9 & 280.32 & 246.11 & 308.3 & 134.41 \\
55.56667 & 280.2 & 245.43 & 307.78 & 134.3
\end{tabular}

Table A. XLVI. Steady state weight gain of assembly having Neat DERAKANE ${ }^{\mathrm{TM}}$ 411-350 MOMENTUM Vinyl ester resin film

Note: All the samples were pre-saturated with water to achieve the steady-state quickly

\begin{tabular}{|c|c|c|}
\hline Thickness & 0.036195 & $\mathrm{~cm}$ \\
\hline Time(h) & Weight (g) & Gain (g) \\
\hline 0 & 9.357 & 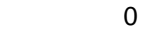 \\
\hline 20.5 & 9.362 & 0.005 \\
\hline 44.5 & 9.366 & 0.009 \\
\hline 66.5 & 9.37 & 0.013 \\
\hline 90.5 & 9.376 & 0.019 \\
\hline 117.5 & 9.38 & 0.023 \\
\hline 138.5 & 9.387 & 0.03 \\
\hline 163.5 & 9.391 & 0.034 \\
\hline 188.5 & 9.395 & 0.038 \\
\hline 218.5 & 9.401 & 0.044 \\
\hline 240 & 9.405 & 0.048 \\
\hline 266.5 & 9.41 & 0.053 \\
\hline 314 & 9.419 & 0.062 \\
\hline 338.5 & 9.422 & 0.065 \\
\hline 361.5 & 9.424 & 0.067 \\
\hline 389.5 & 9.432 & 0.075 \\
\hline 429 & 9.437 & 0.08 \\
\hline 476 & 9.447 & 0.09 \\
\hline 548 & 9.459 & 0.102 \\
\hline 671 & 9.48 & 0.123 \\
\hline 716 & 9.488 & 0.131 \\
\hline
\end{tabular}

\begin{tabular}{rrr}
$\begin{array}{r}\text { Thickness } \\
\text { Time(h) }\end{array}$ & $\begin{array}{r}\text { 0.045085 } \\
\text { Weight }(\mathrm{g})\end{array}$ & \multicolumn{2}{c}{$\mathrm{cm}$ Gain $(\mathrm{g})$} \\
0 & 8.551 & 0 \\
20.5 & 8.557 & 0.006 \\
44.5 & 8.56 & 0.009 \\
66.5 & 8.564 & 0.013 \\
90.5 & 8.568 & 0.017 \\
117.5 & 8.572 & 0.021 \\
138.5 & 8.576 & 0.025 \\
163.5 & 8.58 & 0.029 \\
188.5 & 8.584 & 0.033 \\
218.5 & 8.588 & 0.037 \\
240 & 8.59 & 0.039 \\
266.5 & 8.594 & 0.043 \\
314 & 8.603 & 0.052 \\
338.5 & 8.606 & 0.055 \\
361.5 & 8.608 & 0.057 \\
389.5 & 8.611 & 0.06 \\
429 & 8.619 & 0.068 \\
476 & 8.625 & 0.074 \\
548 & 8.635 & 0.084 \\
671 & 8.653 & 0.102 \\
716 & 8.66 & 0.109
\end{tabular}




Thickness
Time $(\mathrm{h})$

20.5
44.5
66.5
90.5
117.5
138.5
163.5
188.5
218.5
240
266.5
314
338.5
361.5
389.5
429
476
548
671
716

Thickness

Time(h)
$0.041275 \quad \mathrm{~cm}$

Weight (g)

8.307

8.311

8.316

8.319

8.325

8.329

8.333

8.337

8.341

8.345

8.347

8.352

8.36

8.364

8.366

8.369

8.376

8.385

8.395

8.413

8.421

0.036195

Weight (g)

9.357

9.362

9.366

9.37

9.376

9.38

9.387

9.391

9.395

9.401

9.405

9.41

9.419

9.422

9.424

9.432

9.437

9.447

9.459

9.48

9.488
Gain (g)

0
0.004
0.009

0.012
0.018

0.022

0.026

0.03

0.034

0.038

0.04

0.045

0.053

0.057

0.059

0.062

0.069

0.078

0.088

0.106

0.114

$\mathrm{cm}$

Gain (g)

0
0.005

0.009

0.013

0.019

0.023

0.03

0.034

0.038

0.044

0.048

0.053

0.062

0.065

0.067

0.075

0.08

0.09

0.102

0.123

0.131
Thickness

Time(h)

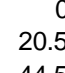

44.5

66.5

90.5

117.5

138.5

163.5

218.5

240

266.5

314

338.5

361.5

389.5

429

476

548

671

716
0.04953

Weight (g)

8.524

8.528

8.532

8.534

8.537

8.541

8.545

8.549

8.555

8.556

8.56

8.567

8.57

8.571

8.573

8.58

8.587

8.595

8.61

8.616

Thickness

Time(h)

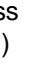

0.045085

Weight $(\mathrm{g})$

8.876
8.88

8.883

8.887

8.891

8.896

8.899

8.902

8.906

8.91

8.915

8.923

8.926

8.928

8.934

8.941

8.95

8.959 $\mathrm{cm}$

Gain (g)

0.004

0.008

0.01

0.013

0.017

0.021

0.025

0.031

0.032

0.036

0.043

0.046

0.047

0.049

0.056

0.063

0.071

0.086

0.092

$\mathrm{cm}$

Gain (g)

0
0.004

0.007

0.011

0.015

0.02

0.023

0.026

0.03

0.034

0.039

0.047

0.05

0.052

0.058

0.065

0.074

0.083 
Table A. XLVII. Steady state weight gain of assembly having 1 wt\% Cloisite $10 \mathrm{~A}^{\circledR}$ nanocomposite film

\begin{tabular}{rrrrrr}
\multicolumn{1}{c}{$\begin{array}{c}\text { Thickness } \\
\text { Time }(\mathrm{h})\end{array}$} & $\begin{array}{c}\text { 0.04099 } \\
\text { Weight }(\mathrm{g})\end{array}$ & \multicolumn{1}{c}{$\begin{array}{c}\text { cm } \\
\text { Gain }(\mathrm{g})\end{array}$} & $\begin{array}{c}\text { Thickness } \\
\text { Time }(\mathrm{h})\end{array}$ & $\begin{array}{c}0.043815 \\
\text { Weight }(\mathrm{g})\end{array}$ & $\begin{array}{c}\mathrm{cm} \\
\text { Gain }(\mathrm{g})\end{array}$ \\
49 & 8.601 & 0 & 0 & 8.745 & 0 \\
141 & 8.611 & 0.01 & 49 & 8.752 & 0.007 \\
166 & 8.628 & 0.027 & 141 & 8.767 & 0.022 \\
214 & 8.631 & 0.03 & 166 & 8.771 & 0.026 \\
282 & 8.639 & 0.038 & 214 & 8.777 & 0.032 \\
386.5 & 8.649 & 0.048 & 282 & 8.787 & 0.042 \\
430 & 8.666 & 0.065 & 386.5 & 8.802 & 0.057 \\
549 & 8.671 & 0.07 & 430 & 8.807 & 0.062 \\
813 & 8.686 & 0.085 & 549 & 8.822 & 0.077 \\
& 8.728 & 0.127 & 813 & 8.862 & 0.117
\end{tabular}

Table A. XLVIII. Steady state weight gain of assembly having 2 wt $\%$ Cloisite $10 A^{\circledR}$ nanocomposite film

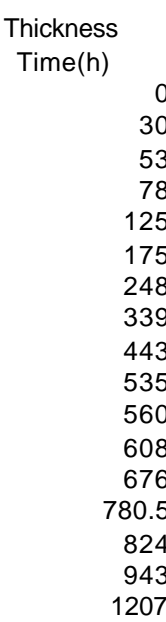

Thickness

Time(h) $\begin{array}{cc}0.0449 & \mathrm{~cm} \\ \text { Weight }(\mathrm{g}) \quad \text { Gain }(g)\end{array}$

9.483

9.489

9.495

9.5
9.505

9.512

9.523

9.535

9.548

9.56

9.563

9.568

9.576

9.59

9.595

9.61

9.642

0.056134
Weight $(\mathrm{g})$
10.212
10.219
10.227
10.228
10.234
10.24
10.249
10.26
10.271
10.283
10.285
10.29
10.294
10.308
10.312
10.326
9.642

$\mathrm{cm}$
Thickness

Time(h)

0.006

0.012

0.017

0.022

0.029

0.04

0.052

0.065

0.077

0.08

0.085

0.093

0.107

0.112

0.127

0.159

Gain (g)

0
0.007
0.015
0.016
0.022
0.028
0.037
0.048
0.059
0.071
0.073
0.078
0.082
0.096
0.1
0.114
0.159
$0.047549 \quad \mathrm{~cm}$

Weight (g) Gain (g)

9.378

9.393

9.4

9.403

9.409

9.416

9.426

9.437

9.448

9.46

9.463

9.468

9.475

9.488

9.492

9.507

9.538 
Table A. XLIX. Steady state weight gain of assembly having 5 wt\% Cloisite $10 A^{\circledR}$ nanocomposite film

\begin{tabular}{|c|c|c|c|c|c|}
\hline $\begin{array}{l}\text { Thickness } \\
\text { Time(h) }\end{array}$ & $\begin{array}{c}0.05625 \\
\text { Weight }(\mathrm{g})\end{array}$ & $\begin{array}{c}\mathrm{cm} \\
\text { Gain }(\mathrm{g})\end{array}$ & $\begin{array}{c}\text { Thickness } \\
\text { Time(h) }\end{array}$ & $\begin{array}{c}0.04857 \\
\text { Weight }(\mathrm{g})\end{array}$ & $\begin{array}{c}\mathrm{cm} \\
\text { Gain }(\mathrm{g})\end{array}$ \\
\hline 0 & 9.986 & 0 & 0 & 10.211 & $=2=101$ \\
\hline 24 & 9.974 & -0.012 & 24 & 10.201 & -0.01 \\
\hline 71 & 9.981 & -0.005 & 71 & 10.208 & -0.003 \\
\hline 121 & 9.985 & -0.001 & 121 & 10.213 & 0.002 \\
\hline 139 & 9.988 & 0.002 & 139 & 10.215 & 0.004 \\
\hline 168 & 9.992 & 0.006 & 168 & 10.219 & 0.008 \\
\hline 288.5 & 10.002 & 0.016 & 288.5 & 10.231 & 0.02 \\
\hline 336 & 10.007 & 0.021 & 336 & 10.236 & 0.025 \\
\hline 386.5 & 10.011 & 0.025 & 386.5 & 10.241 & 0.03 \\
\hline 432.5 & 10.015 & 0.029 & 432.5 & 10.245 & 0.034 \\
\hline 480.5 & 10.02 & 0.034 & 480.5 & 10.25 & 0.039 \\
\hline 524.5 & 10.026 & 0.04 & 524.5 & 10.256 & 0.045 \\
\hline 598.5 & 10.034 & 0.048 & 598.5 & 10.265 & 0.054 \\
\hline 672.5 & 10.041 & 0.055 & 672.5 & 10.274 & 0.063 \\
\hline 718.5 & 10.045 & 0.059 & 718.5 & 10.278 & 0.067 \\
\hline 764.5 & 10.051 & 0.065 & 764.5 & 10.283 & 0.072 \\
\hline 838.5 & 10.057 & 0.071 & 838.5 & 10.289 & 0.078 \\
\hline Thickness & 0.04500 & $\mathrm{~cm}$ & Thickness & 0.05469 & $\mathrm{~cm}$ \\
\hline Time(h) & Weight (g) & Gain (g) & Time(h) & Weight (g) & Gain (g) \\
\hline 0 & 9.993 & (y) & 0 & 10.074 & - 151 \\
\hline 24 & 9.992 & -0.001 & 24 & 10.076 & 0.002 \\
\hline 71 & 9.999 & 0.006 & 71 & 10.083 & 0.009 \\
\hline 121 & 10.006 & 0.013 & 121 & 10.088 & 0.014 \\
\hline 139 & 10.008 & 0.015 & 139 & 10.091 & 0.017 \\
\hline 168 & 10.012 & 0.019 & 168 & 10.094 & 0.02 \\
\hline 288.5 & 10.025 & 0.032 & 288.5 & 10.105 & 0.031 \\
\hline 336 & 10.03 & 0.037 & 336 & 10.11 & 0.036 \\
\hline 386.5 & 10.035 & 0.042 & 386.5 & 10.115 & 0.041 \\
\hline 432.5 & 10.04 & 0.047 & 432.5 & 10.12 & 0.046 \\
\hline 480.5 & 10.046 & 0.053 & 480.5 & 10.124 & 0.05 \\
\hline 524.5 & 10.052 & 0.059 & 524.5 & 10.13 & 0.056 \\
\hline 598.5 & 10.061 & 0.068 & 598.5 & 10.139 & 0.065 \\
\hline 672.5 & 10.071 & 0.078 & 672.5 & 10.148 & 0.074 \\
\hline 718.5 & 10.075 & 0.082 & 718.5 & 10.151 & 0.077 \\
\hline 764.5 & 10.082 & 0.089 & 764.5 & 10.157 & 0.083 \\
\hline 838.5 & 10.089 & 0.096 & 838.5 & 10.163 & 0.089 \\
\hline
\end{tabular}

Table A. L. Saturation concentrations of neat polymer and nanocomposite films

\begin{tabular}{|c|c|c|c|c|c|c|c|c|c|c|c|c|}
\hline Wt\% Clay & $5 \mathrm{Wt} \%$ & $5 \mathrm{Wt} \%$ & $5 \mathrm{Wt} \%$ & $2 \mathrm{Wt} \%$ & $2 \mathrm{Wt} \%$ & $2 \mathrm{Wt} \%$ & $1 \mathrm{Wt} \%$ & $1 \mathrm{Wt} \%$ & $1 \mathrm{Wt} \%$ & $0 \mathrm{Wt} \%$ & $0 \mathrm{Wt} \%$ & $0 \mathrm{Wt} \%$ \\
\hline $\begin{array}{l}\text { Mass of sample }(\mathrm{mg}) \\
\text { equilibrated at } \\
0 \% \mathrm{RH}\end{array}$ & 499.38 & 392.42 & 442.48 & 377.46 & 449.77 & 427.19 & 455.6 & 372.26 & 422.11 & 354.33 & 390.2 & 325.85 \\
\hline Density $\mathrm{mg} / \mathrm{cm}^{3}$ & 1135 & 1135 & 1135 & 1135 & 1135 & 1135 & 1135 & 1135 & 1135 & 1135 & 1135 & 1135 \\
\hline $\begin{array}{l}\text { Sample } \\
\text { Volume }\end{array} \quad\left(\mathrm{cm}^{3}\right)$ & 0.439982 & 0.34574 & 0.38985 & 0.332564 & 0.396273 & 0.376379 & 0.40141 & 0.327982 & 0.371903 & 0.312185 & 0.343789 & 0.287093 \\
\hline $\begin{array}{l}\text { Conc }(77 \% R H) \\
\left(\mathrm{mg} / \mathrm{cm}^{3}\right)\end{array}$ & 13.21 & 13.39 & 13.54 & 13.06 & 12.84 & 13.08 & 12.73 & 13.00 & 12.97 & 11.97 & 12.07 & 11.84 \\
\hline
\end{tabular}




\begin{tabular}{|c|c|}
\hline $\mathrm{Wt} \%$ Cloisite $10 \mathrm{~A}^{\circledR}$ & $\begin{array}{c}\text { Saturation concentration at } \\
77 \% \mathrm{RH}\left(\mathrm{mg} / \mathrm{cm}^{3}\right)\end{array}$ \\
\hline 0 & 11.96 \\
\hline 1 & 12.90 \\
\hline 2 & 12.99 \\
\hline 5 & 13.38 \\
\hline
\end{tabular}

Table A. LI. Impact test data

Sample Dimensions for all the samples are $6 \mathrm{~cm} \times 1.25 \mathrm{~cm}$

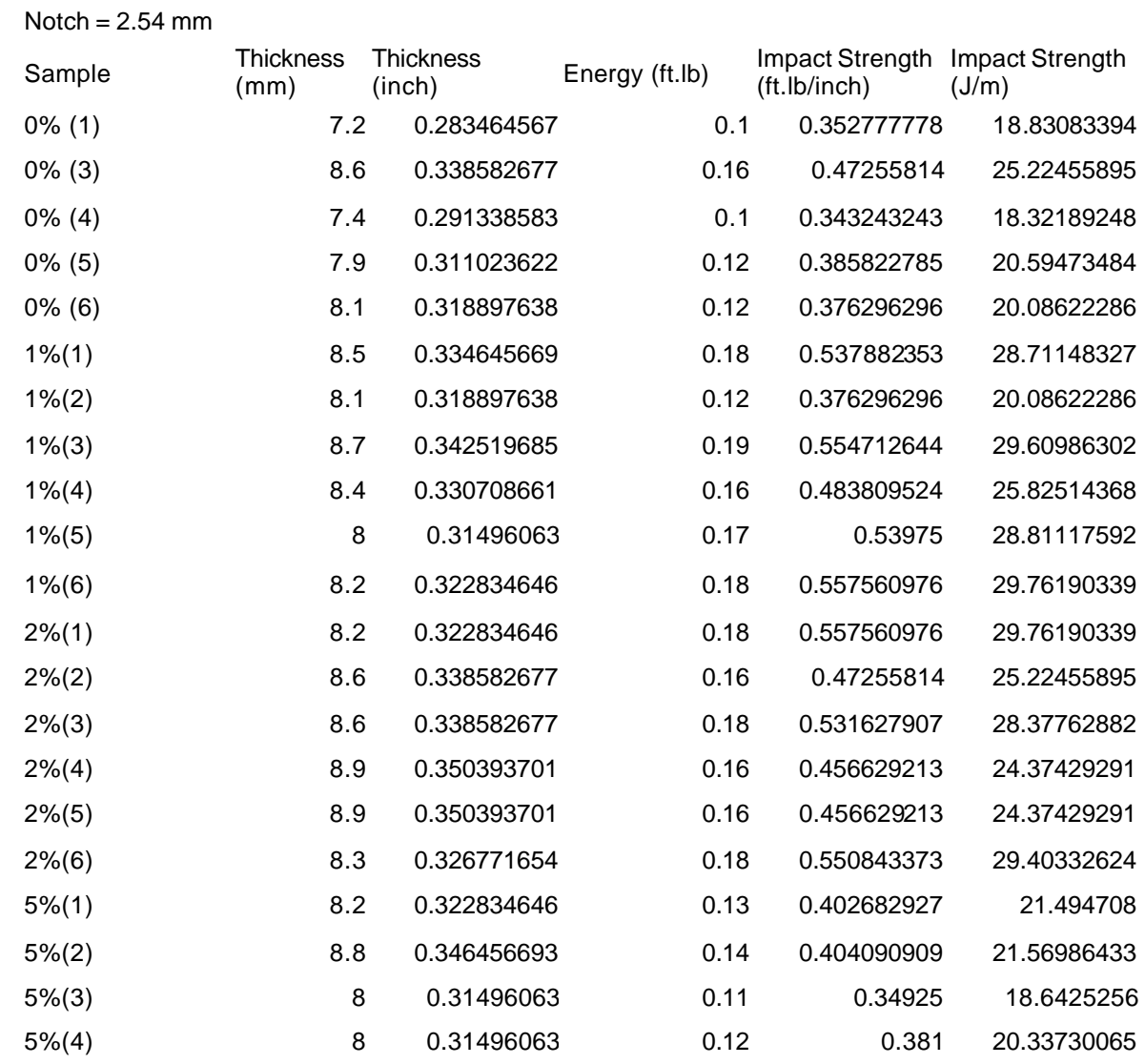


Table A. LII. Tensile test data Testing temperature $=29^{\circ} \mathrm{C}$

\begin{tabular}{|c|c|c|c|c|c|c|c|c|}
\hline Wt\% Clay & & kness & $\begin{array}{l}\text { Width } \\
(\mathrm{cm})\end{array}$ & $\begin{array}{l}\text { Slope } \\
\text { (Psi) }\end{array}$ & $\begin{array}{l}\text { Tensile } \\
\text { Modulus } \\
\text { (kPsi) }\end{array}$ & $\begin{array}{l}\text { Tensile } \\
\text { Modulus (Mpa) }\end{array}$ & $\begin{array}{ll}\text { Tensile } & \text { Tensile } \\
\text { Strength } & \text { Strength } \\
\text { (Psi) } & \text { (Mpa) }\end{array}$ & $\begin{array}{r}\text { Microstrain } \\
\text { At break } \\
\text { (absolute) }\end{array}$ \\
\hline & 0 & 0.2489 & 1.27 & 0.4228 & 422.8 & 2915.103 & $\begin{array}{ll}3 & 1792.54612 .35917\end{array}$ & 4761 \\
\hline & 0 & 0.3404 & 1.27 & 0.3798 & 379.8 & 2618.629 & 2740.73718 .89672 & 7224 \\
\hline & 0 & 0.2591 & 1.27 & 0.4263 & 426.3 & 2939.235 & 3233.17722 .29197 & 7515 \\
\hline & 0 & 0.3251 & 1.27 & 0.4392 & 439.2 & 3028.177 & $7 \quad 3085.12821 .27121$ & 6999 \\
\hline & 1 & 0.4140 & 1.27 & 0.4137 & 413.7 & 2852.361 & $1 \quad 3202.9222 .08336$ & 7940 \\
\hline & 1 & 0.3150 & 1.27 & 0.4743 & 474.3 & 3270.183 & $3 \quad 4465.28430 .78705$ & 9118 \\
\hline & 1 & 0.3302 & 1.27 & 0.4234 & 423.4 & 2919.24 & 2981.81320 .55888 & 7163 \\
\hline & 1 & 0.3988 & 1.27 & 0.4217 & 421.7 & 2907.519 & $9 \quad 4057.81127 .97762$ & 9806 \\
\hline & 1 & 0.3886 & 1.27 & 0.4212 & 421.2 & 2904.072 & 2824.42419 .47372 & 6803 \\
\hline & 2 & 0.4216 & 1.27 & 0.4494 & 449.4 & 3098.504 & $4 \quad 3360.9123 .17266$ & 7536 \\
\hline & 2 & 0.4343 & 1.27 & 0.4432 & 443.2 & 3055.756 & 2913.36820.08696 & 6631 \\
\hline & 2 & 0.4064 & 1.27 & 0.424 & 424 & 2923.377 & 2087.514 .39281 & 5189 \\
\hline & 2 & 0.4191 & 1.27 & 0.4361 & 436.1 & 3006.804 & $4 \quad 3090.28321 .30675$ & 7181 \\
\hline & 5 & 0.4166 & 1.27 & 0.5529 & 552.9 & 3812.111 & $1 \quad 2916.32620 .10736$ & 5212 \\
\hline & 5 & 0.5004 & 1.27 & 0.4933 & 493.3 & 3401.184 & 2604.95317 .96052 & 5570 \\
\hline & 5 & 0.3708 & 1.27 & 0.4325 & 432.5 & 2981.982 & 23086.57521 .28118 & 7426 \\
\hline & 5 & 0.4369 & 1.27 & 0.4481 & 448.1 & 3089.541 & 12609.10617 .98915 & 6180 \\
\hline & 5 & 0.4547 & 1.27 & 0.4725 & 472.5 & 3257.773 & $3 \quad 2703.34518 .63891$ & 5829 \\
\hline
\end{tabular}

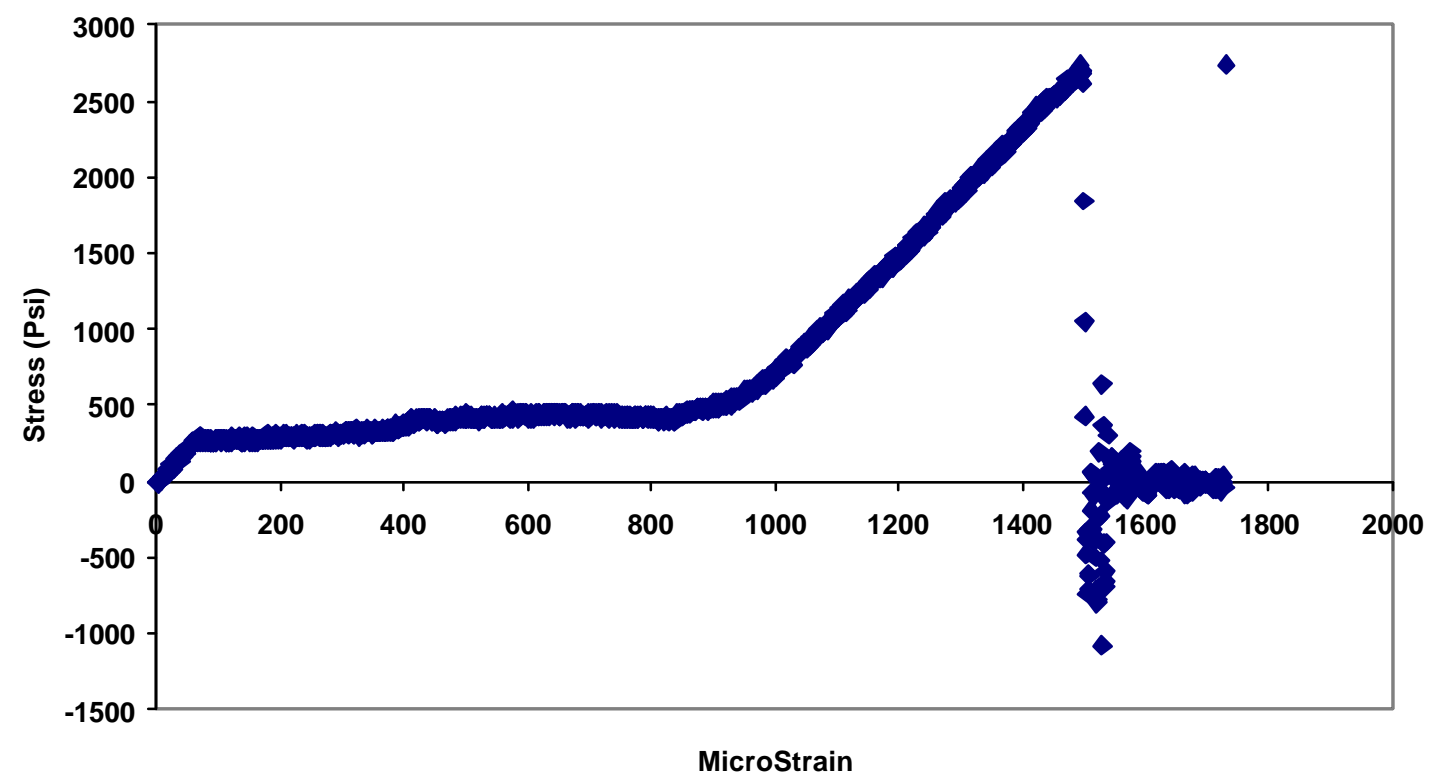

Figure A. 8. Stress-strain curve for a representative neat resin sample $($ Thickness $=0.3404 \mathrm{~cm})$ 


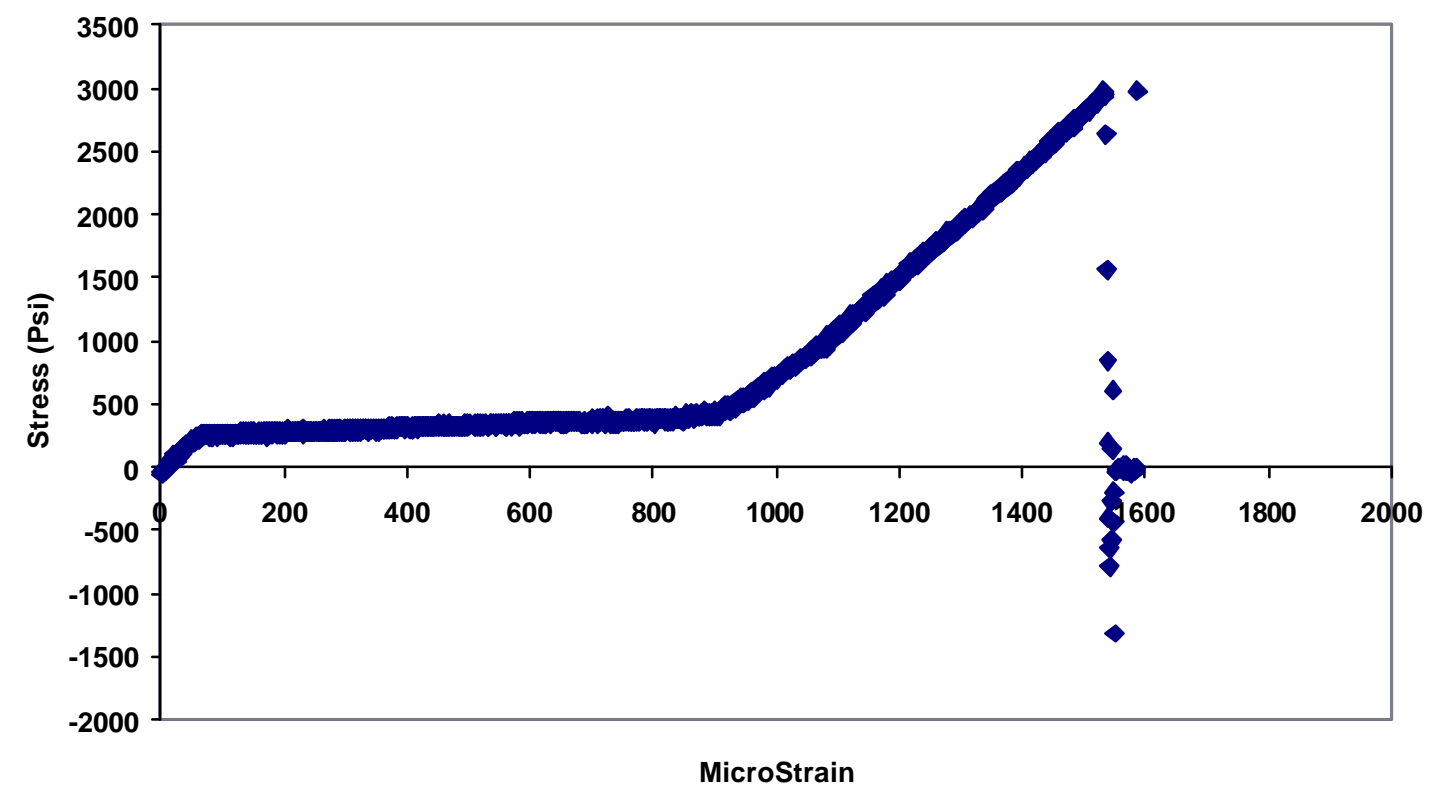

Figure A. 9. Stress-strain curve for a representative $1 \mathrm{wt} \%$ nanocomposite sample (Thickness = $0.3302 \mathrm{~cm})$

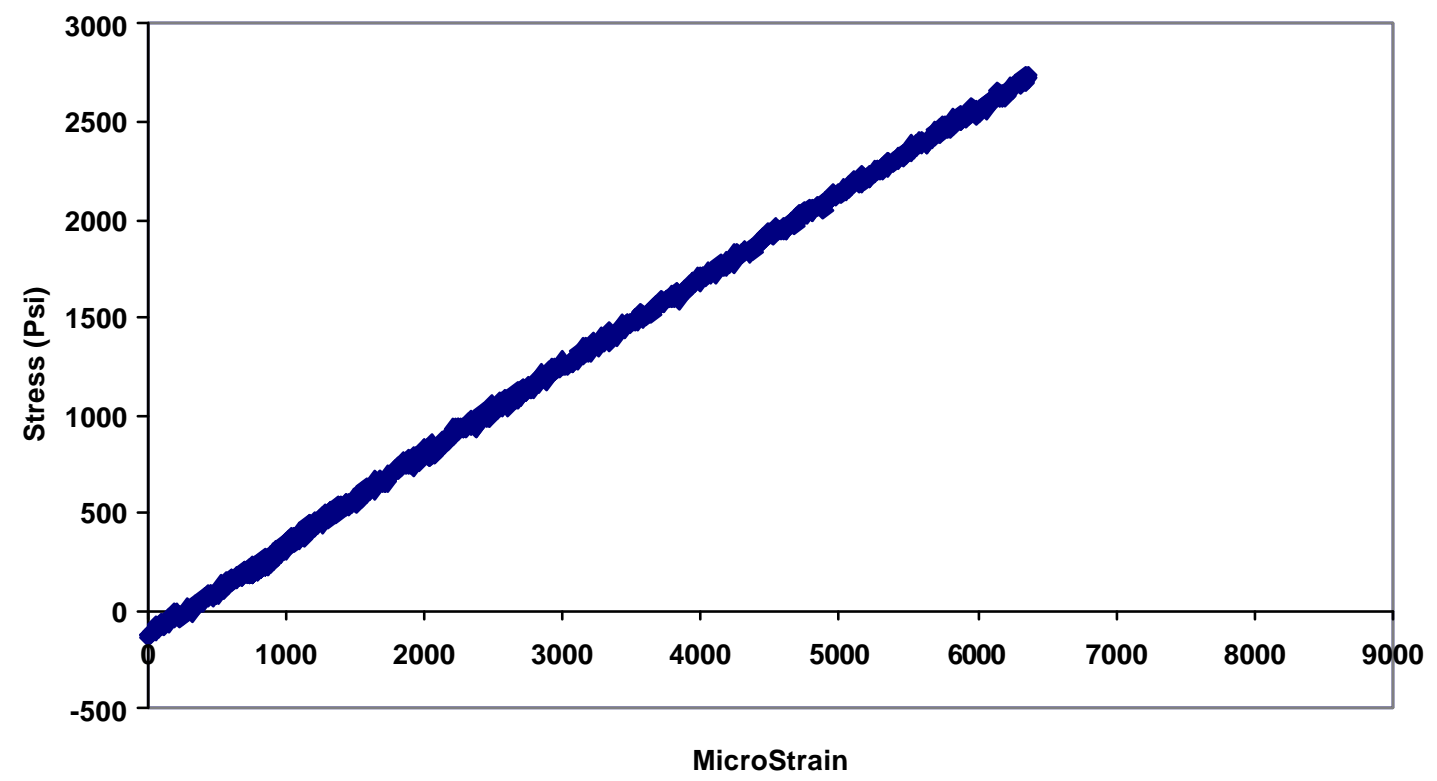

Figure A. 10. Stress-strain curve for a representative 2 wt $\%$ nanocomposite sample (Thickness = $0.4191 \mathrm{~cm})$ 


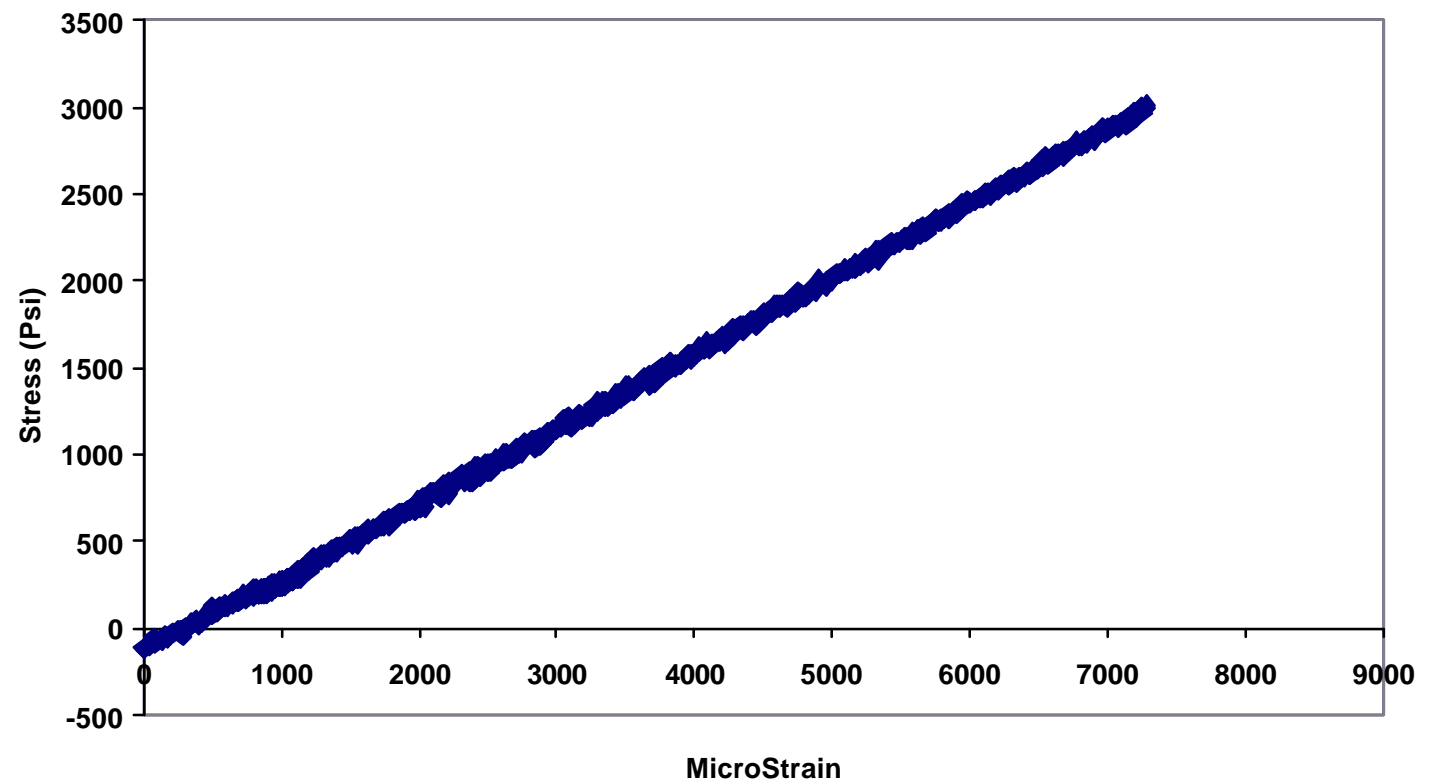

Figure A. 11. Stress-strain curve for a representative $5 \mathrm{wt} \%$ nanocomposite sample (Thickness = $0.3708 \mathrm{~cm})$ 
Table A. LIII. DMA test data $\left(0\right.$ wt $\%$ Cloisite $\left.10 A^{\circledR}\right)$

Sample 1

\begin{tabular}{|c|c|c|c|}
\hline $\begin{array}{l}\text { TEMP } \\
{ }^{\circ} \mathrm{C}\end{array}$ & $\begin{array}{l}\mathrm{G}^{\prime} \\
\mathrm{dyn} / \mathrm{cm}^{2}\end{array}$ & $\begin{array}{l}\text { G" } \\
\text { dyn/cm }{ }^{2}\end{array}$ & an Delta \\
\hline $3.95 \mathrm{E}+01$ & $1.48 \mathrm{E}+10$ & $4.44 \mathrm{E}+08$ & $3.01 \mathrm{E}-02$ \\
\hline $4.16 \mathrm{E}+01$ & $1.45 \mathrm{E}+10$ & $4.42 \mathrm{E}+08$ & 3.05E-02 \\
\hline 4.37E+01 & $1.43 \mathrm{E}+10$ & $4.37 \mathrm{E}+08$ & 3.05E-02 \\
\hline $4.57 \mathrm{E}+01$ & $1.41 \mathrm{E}+10$ & $4.01 E+08$ & 2.85E-02 \\
\hline 4.77E+01 & $1.39 \mathrm{E}+10$ & $4.23 E+08$ & 3.04E-02 \\
\hline $4.97 \mathrm{E}+01$ & $1.37 \mathrm{E}+10$ & $4.22 \mathrm{E}+08$ & $3.08 \mathrm{E}-02$ \\
\hline $5.18 \mathrm{E}+01$ & $1.35 \mathrm{E}+10$ & $4.63 E+08$ & 3.44E-02 \\
\hline $5.38 \mathrm{E}+01$ & $1.32 \mathrm{E}+10$ & $5.01 E+08$ & 3.79E-02 \\
\hline $5.57 \mathrm{E}+01$ & $1.29 \mathrm{E}+10$ & $5.03 E+08$ & $3.88 \mathrm{E}-02$ \\
\hline $5.77 \mathrm{E}+01$ & $1.24 \mathrm{E}+10$ & $6.61 E+08$ & $5.32 \mathrm{E}-02$ \\
\hline $5.97 \mathrm{E}+01$ & $1.24 \mathrm{E}+10$ & $5.61 \mathrm{E}+08$ & $4.54 \mathrm{E}-02$ \\
\hline $6.17 \mathrm{E}+01$ & $1.20 \mathrm{E}+10$ & $6.24 \mathrm{E}+08$ & 5.20E-02 \\
\hline $6.37 \mathrm{E}+01$ & $1.16 \mathrm{E}+10$ & $6.80 \mathrm{E}+08$ & $5.85 \mathrm{E}-02$ \\
\hline $6.57 \mathrm{E}+01$ & $1.12 \mathrm{E}+10$ & $7.02 \mathrm{E}+08$ & $6.27 \mathrm{E}-02$ \\
\hline $6.78 \mathrm{E}+01$ & $1.08 \mathrm{E}+10$ & $7.47 \mathrm{E}+08$ & $6.93 \mathrm{E}-02$ \\
\hline $6.97 \mathrm{E}+01$ & $1.04 \mathrm{E}+10$ & $7.31 \mathrm{E}+08$ & 7.06E-02 \\
\hline $7.17 \mathrm{E}+01$ & $9.89 \mathrm{E}+09$ & $7.32 E+08$ & 7.40E-02 \\
\hline $7.37 \mathrm{E}+01$ & $9.47 \mathrm{E}+09$ & $7.31 \mathrm{E}+08$ & $7.72 \mathrm{E}-02$ \\
\hline $7.57 \mathrm{E}+01$ & $9.08 \mathrm{E}+09$ & $6.94 \mathrm{E}+08$ & $7.64 \mathrm{E}-02$ \\
\hline $7.77 \mathrm{E}+01$ & $8.68 \mathrm{E}+09$ & $6.88 \mathrm{E}+08$ & 7.93E-02 \\
\hline $7.98 \mathrm{E}+01$ & $8.32 \mathrm{E}+09$ & $6.74 \mathrm{E}+08$ & $8.10 \mathrm{E}-02$ \\
\hline $8.18 \mathrm{E}+01$ & $7.87 \mathrm{E}+09$ & $6.49 \mathrm{E}+08$ & $8.25 \mathrm{E}-02$ \\
\hline $8.38 \mathrm{E}+01$ & $7.45 \mathrm{E}+09$ & $8.88 E+08$ & $1.19 \mathrm{E}-01$ \\
\hline $8.58 \mathrm{E}+01$ & $7.06 \mathrm{E}+09$ & $6.46 \mathrm{E}+08$ & $9.16 \mathrm{E}-02$ \\
\hline $8.79 \mathrm{E}+01$ & $6.52 \mathrm{E}+09$ & $7.28 \mathrm{E}+08$ & $1.12 \mathrm{E}-01$ \\
\hline $8.99 \mathrm{E}+01$ & $5.95 \mathrm{E}+09$ & $8.04 \mathrm{E}+08$ & $1.35 \mathrm{E}-01$ \\
\hline $9.19 \mathrm{E}+01$ & $5.28 \mathrm{E}+09$ & $9.25 \mathrm{E}+08$ & $1.75 \mathrm{E}-01$ \\
\hline $9.39 \mathrm{E}+01$ & $4.51 \mathrm{E}+09$ & $9.53 E+08$ & $2.11 \mathrm{E}-01$ \\
\hline $9.59 \mathrm{E}+01$ & $3.67 \mathrm{E}+09$ & $1.01 \mathrm{E}+09$ & $2.74 \mathrm{E}-01$ \\
\hline $9.78 \mathrm{E}+01$ & $2.88 \mathrm{E}+09$ & $1.05 \mathrm{E}+09$ & 3.64E-01 \\
\hline $9.99 \mathrm{E}+01$ & $2.24 \mathrm{E}+09$ & $9.63 E+08$ & 4.29E-01 \\
\hline $1.02 \mathrm{E}+02$ & $1.75 \mathrm{E}+09$ & $8.82 \mathrm{E}+08$ & $5.05 \mathrm{E}-01$ \\
\hline $1.04 \mathrm{E}+02$ & $1.45 \mathrm{E}+09$ & $8.09 E+08$ & $5.59 \mathrm{E}-01$ \\
\hline $1.06 \mathrm{E}+02$ & $1.27 \mathrm{E}+09$ & $7.67 \mathrm{E}+08$ & $6.05 \mathrm{E}-01$ \\
\hline $1.08 \mathrm{E}+02$ & $1.12 \mathrm{E}+09$ & $6.69 \mathrm{E}+08$ & 5.97E-01 \\
\hline $1.10 \mathrm{E}+02$ & $1.02 \mathrm{E}+09$ & $7.10 \mathrm{E}+08$ & $6.98 \mathrm{E}-01$ \\
\hline $1.12 \mathrm{E}+02$ & $8.52 \mathrm{E}+08$ & $5.94 \mathrm{E}+08$ & $6.98 \mathrm{E}-01$ \\
\hline $1.14 \mathrm{E}+02$ & $7.23 \mathrm{E}+08$ & $5.85 \mathrm{E}+08$ & $8.08 \mathrm{E}-01$ \\
\hline $1.15 \mathrm{E}+02$ & $6.23 \mathrm{E}+08$ & $5.43 \mathrm{E}+08$ & $8.71 \mathrm{E}-01$ \\
\hline 1.17E+02 & $5.33 E+08$ & $5.14 \mathrm{E}+08$ & $9.66 \mathrm{E}-01$ \\
\hline $1.19 \mathrm{E}+02$ & $4.22 E+08$ & $4.19 E+08$ & $9.95 \mathrm{E}-01$ \\
\hline $1.21 \mathrm{E}+02$ & $2.72 \mathrm{E}+08$ & $3.25 \mathrm{E}+08$ & $1.20 \mathrm{E}+00$ \\
\hline $1.23 \mathrm{E}+02$ & $2.08 \mathrm{E}+08$ & $2.43 \mathrm{E}+08$ & $1.17 \mathrm{E}+00$ \\
\hline $1.25 \mathrm{E}+02$ & $1.92 \mathrm{E}+08$ & $1.74 \mathrm{E}+08$ & $9.07 \mathrm{E}-01$ \\
\hline $1.27 \mathrm{E}+02$ & $1.38 \mathrm{E}+08$ & $1.04 \mathrm{E}+08$ & $7.54 \mathrm{E}-01$ \\
\hline $1.29 \mathrm{E}+02$ & $1.04 \mathrm{E}+08$ & $9.45 \mathrm{E}+07$ & $9.11 \mathrm{E}-01$ \\
\hline
\end{tabular}

Sample 2

\begin{tabular}{|c|c|c|c|}
\hline $\begin{array}{l}\text { TEMP } \\
{ }^{\circ} \mathrm{C}\end{array}$ & $\begin{array}{l}\text { G' } \\
\text { dyn/cm }{ }^{2}\end{array}$ & $\begin{array}{l}\text { G" } \\
\text { dyn/cm }{ }^{2}\end{array}$ & Tan Delta \\
\hline $3.93 \mathrm{E}+01$ & $1.74 \mathrm{E}+10$ & 4.77E+08 & $2.74 \mathrm{E}-02$ \\
\hline $4.14 \mathrm{E}+01$ & $1.72 E+10$ & $5.07 E+08$ & $2.94 \mathrm{E}-02$ \\
\hline 4.35E+01 & $1.70 \mathrm{E}+10$ & $4.45 \mathrm{E}+08$ & 2.62E-02 \\
\hline $4.55 \mathrm{E}+01$ & $1.68 \mathrm{E}+10$ & $4.83 \mathrm{E}+08$ & $2.88 \mathrm{E}-02$ \\
\hline $4.76 \mathrm{E}+01$ & $1.65 \mathrm{E}+10$ & $4.63 \mathrm{E}+08$ & 2.81E-02 \\
\hline $4.96 \mathrm{E}+01$ & $1.63 \mathrm{E}+10$ & $5.03 E+08$ & $3.10 \mathrm{E}-02$ \\
\hline $5.16 \mathrm{E}+01$ & $1.59 \mathrm{E}+10$ & $5.20 \mathrm{E}+08$ & $3.26 \mathrm{E}-02$ \\
\hline $5.36 \mathrm{E}+01$ & $1.57 \mathrm{E}+10$ & $5.79 E+08$ & $3.69 \mathrm{E}-02$ \\
\hline $5.55 \mathrm{E}+01$ & $1.54 \mathrm{E}+10$ & $6.03 E+08$ & $3.91 \mathrm{E}-02$ \\
\hline $5.75 \mathrm{E}+01$ & $1.51 \mathrm{E}+10$ & $6.37 \mathrm{E}+08$ & $4.23 \mathrm{E}-02$ \\
\hline $5.95 \mathrm{E}+01$ & $1.47 \mathrm{E}+10$ & $6.72 \mathrm{E}+08$ & $4.59 \mathrm{E}-02$ \\
\hline $6.15 \mathrm{E}+01$ & $1.43 \mathrm{E}+10$ & $7.20 \mathrm{E}+08$ & 5.04E-02 \\
\hline $6.35 E+01$ & $1.39 E+10$ & $8.27 E+08$ & 5.96E-02 \\
\hline $6.55 \mathrm{E}+01$ & $1.34 \mathrm{E}+10$ & $8.29 E+08$ & $6.21 \mathrm{E}-02$ \\
\hline $6.75 \mathrm{E}+01$ & $1.29 \mathrm{E}+10$ & $8.39 E+08$ & $6.49 \mathrm{E}-02$ \\
\hline $6.95 \mathrm{E}+01$ & $1.24 \mathrm{E}+10$ & $8.49 E+08$ & $6.83 \mathrm{E}-02$ \\
\hline $7.15 \mathrm{E}+01$ & $1.20 \mathrm{E}+10$ & $8.36 \mathrm{E}+08$ & $6.99 \mathrm{E}-02$ \\
\hline $7.35 \mathrm{E}+01$ & $1.15 \mathrm{E}+10$ & $8.48 \mathrm{E}+08$ & 7.39E-02 \\
\hline $7.55 \mathrm{E}+01$ & $\mathrm{E}+10$ & $8.42 \mathrm{E}+08$ & $7.65 \mathrm{E}-02$ \\
\hline $7.76 \mathrm{E}+01$ & $1.05 \mathrm{E}+10$ & $8.45 \mathrm{E}+08$ & 8.07E-02 \\
\hline $7.96 \mathrm{E}+01$ & $1.00 \mathrm{E}+10$ & $8.70 E+08$ & 8.69E-02 \\
\hline $8.16 \mathrm{E}+01$ & $9.44 \mathrm{E}+09$ & $8.80 E+08$ & $9.32 \mathrm{E}-02$ \\
\hline $8.36 \mathrm{E}+01$ & $8.81 E+09$ & $9.42 \mathrm{E}+08$ & 1.07E-01 \\
\hline $8.56 \mathrm{E}+01$ & $8.08 E+09$ & $1.08 E+09$ & 1.33E-01 \\
\hline $8.77 \mathrm{E}+01$ & $7.22 \mathrm{E}+09$ & $1.13 \mathrm{E}+09$ & 1.57E-01 \\
\hline $8.97 \mathrm{E}+01$ & $6.31 \mathrm{E}+09$ & $1.24 \mathrm{E}+09$ & $1.96 \mathrm{E}-01$ \\
\hline $9.17 \mathrm{E}+01$ & $5.32 \mathrm{E}+09$ & $1.35 E+09$ & $2.54 \mathrm{E}-01$ \\
\hline $9.37 \mathrm{E}+01$ & $4.29 \mathrm{E}+09$ & $1.37 \mathrm{E}+09$ & $3.20 \mathrm{E}-01$ \\
\hline $9.56 \mathrm{E}+01$ & $3.39 E+09$ & $1.31 \mathrm{E}+09$ & 3.87E-01 \\
\hline $9.77 \mathrm{E}+01$ & $2.73 \mathrm{E}+09$ & $1.27 \mathrm{E}+09$ & $4.65 \mathrm{E}-01$ \\
\hline $9.97 \mathrm{E}+01$ & $2.27 E+09$ & $1.21 E+09$ & 5.32E-01 \\
\hline $1.02 \mathrm{E}+02$ & $2.00 \mathrm{E}+09$ & $1.13 \mathrm{E}+09$ & $5.65 \mathrm{E}-01$ \\
\hline $1.04 \mathrm{E}+02$ & $1.79 \mathrm{E}+09$ & $1.13 \mathrm{E}+09$ & 6.33E-01 \\
\hline $1.05 \mathrm{E}+02$ & $1.58 \mathrm{E}+09$ & $1.05 E+09$ & $6.66 \mathrm{E}-01$ \\
\hline $1.07 \mathrm{E}+02$ & $1.46 \mathrm{E}+09$ & $1.01 \mathrm{E}+09$ & $6.92 \mathrm{E}-01$ \\
\hline $1.09 \mathrm{E}+02$ & $1.32 \mathrm{E}+09$ & $9.67 \mathrm{E}+08$ & 7.35E-01 \\
\hline $1.11 \mathrm{E}+02$ & $1.20 \mathrm{E}+09$ & $9.61 \mathrm{E}+08$ & $8.04 \mathrm{E}-01$ \\
\hline $1.13 \mathrm{E}+02$ & $1.01 \mathrm{E}+09$ & $9.01 \mathrm{E}+08$ & $8.90 \mathrm{E}-01$ \\
\hline $1.15 \mathrm{E}+02$ & $8.70 \mathrm{E}+08$ & $8.08 \mathrm{E}+08$ & $9.29 \mathrm{E}-01$ \\
\hline $1.17 \mathrm{E}+02$ & $7.11 \mathrm{E}+08$ & $7.09 E+08$ & 9.97E-01 \\
\hline $1.19 \mathrm{E}+02$ & $5.67 E+08$ & $6.26 \mathrm{E}+08$ & $1.10 \mathrm{E}+00$ \\
\hline $1.21 \mathrm{E}+02$ & $4.20 E+08$ & $5.01 E+08$ & $1.19 \mathrm{E}+00$ \\
\hline $1.23 E+02$ & $2.98 \mathrm{E}+08$ & $3.69 E+08$ & $1.24 \mathrm{E}+00$ \\
\hline $1.25 \mathrm{E}+02$ & $1.95 \mathrm{E}+08$ & $2.52 \mathrm{E}+08$ & $1.29 \mathrm{E}+00$ \\
\hline $1.27 \mathrm{E}+02$ & $1.81 \mathrm{E}+08$ & $1.80 \mathrm{E}+08$ & 9.97E-01 \\
\hline $1.29 \mathrm{E}+02$ & $1.26 \mathrm{E}+08$ & $1.22 \mathrm{E}+08$ & $9.75 \mathrm{E}-01$ \\
\hline
\end{tabular}


Sample 3

\begin{tabular}{|c|c|c|c|}
\hline $\begin{array}{l}\text { TEMP } \\
{ }^{\circ} \mathrm{C}\end{array}$ & $\begin{array}{l}\mathrm{G}^{\prime} \\
\mathrm{dyn} / \mathrm{cm}^{2}\end{array}$ & $\begin{array}{l}\text { G" } \\
\text { dyn/cm }{ }^{2}\end{array}$ & Tan Delta \\
\hline $3.93 \mathrm{E}+01$ & $1.39 \mathrm{E}+10$ & $\quad 3.89 E+08$ & $2.80 \mathrm{E}-02$ \\
\hline $4.15 \mathrm{E}+01$ & $1.37 \mathrm{E}+10$ & $3.48 \mathrm{E}+08$ & $2.54 \mathrm{E}-02$ \\
\hline $4.35 \mathrm{E}+01$ & $1.35 \mathrm{E}+10$ & $3.57 E+08$ & 2.64E-02 \\
\hline $4.55 \mathrm{E}+01$ & $1.33 \mathrm{E}+10$ & $3.83 E+08$ & 2.88E-02 \\
\hline $4.75 \mathrm{E}+01$ & $1.31 \mathrm{E}+10$ & $3.81 E+08$ & $2.90 \mathrm{E}-02$ \\
\hline $4.96 \mathrm{E}+01$ & $1.29 \mathrm{E}+10$ & $4.17 \mathrm{E}+08$ & $3.24 \mathrm{E}-02$ \\
\hline $5.16 \mathrm{E}+01$ & $1.27 \mathrm{E}+10$ & $4.31 E+08$ & 3.39E-02 \\
\hline $5.35 \mathrm{E}+01$ & $1.24 \mathrm{E}+10$ & $4.61 E+08$ & $3.71 \mathrm{E}-02$ \\
\hline $5.55 \mathrm{E}+01$ & $1.21 \mathrm{E}+10$ & $5.08 \mathrm{E}+08$ & $4.19 \mathrm{E}-02$ \\
\hline $5.75 \mathrm{E}+01$ & $1.19 \mathrm{E}+10$ & $5.06 \mathrm{E}+08$ & 4.26E-02 \\
\hline $5.95 \mathrm{E}+01$ & $1.15 \mathrm{E}+10$ & $5.32 \mathrm{E}+08$ & 4.61E-02 \\
\hline $6.15 \mathrm{E}+01$ & $1.12 \mathrm{E}+10$ & $5.95 E+08$ & 5.29E-02 \\
\hline $6.34 \mathrm{E}+01$ & $1.09 E+10$ & $6.24 \mathrm{E}+08$ & 5.71E-02 \\
\hline $6.54 \mathrm{E}+01$ & $1.06 \mathrm{E}+10$ & $6.41 \mathrm{E}+08$ & 6.06E-02 \\
\hline $6.74 \mathrm{E}+01$ & $1.02 \mathrm{E}+10$ & $6.30 \mathrm{E}+08$ & $6.16 \mathrm{E}-02$ \\
\hline $6.94 \mathrm{E}+01$ & $9.84 \mathrm{E}+09$ & $6.40 \mathrm{E}+08$ & $6.51 \mathrm{E}-02$ \\
\hline $7.14 \mathrm{E}+01$ & $9.48 \mathrm{E}+09$ & $6.53 E+08$ & $6.89 \mathrm{E}-02$ \\
\hline $7.34 \mathrm{E}+01$ & $9.16 \mathrm{E}+09$ & $6.27 E+08$ & $6.85 \mathrm{E}-02$ \\
\hline $7.55 \mathrm{E}+01$ & $8.79 E+09$ & $6.31 E+08$ & 7.18E-02 \\
\hline $7.75 \mathrm{E}+01$ & $8.48 \mathrm{E}+09$ & $6.31 \mathrm{E}+08$ & 7.45E-02 \\
\hline $7.95 \mathrm{E}+01$ & $8.15 \mathrm{E}+09$ & $6.02 \mathrm{E}+08$ & 7.39E-02 \\
\hline $8.15 E+01$ & $7.80 E+09$ & $6.23 E+08$ & 7.99E-02 \\
\hline $8.35 \mathrm{E}+01$ & $7.43 \mathrm{E}+09$ & $6.54 \mathrm{E}+08$ & $8.80 \mathrm{E}-02$ \\
\hline $8.55 \mathrm{E}+01$ & $6.98 \mathrm{E}+09$ & $6.88 \mathrm{E}+08$ & $9.86 \mathrm{E}-02$ \\
\hline $8.76 \mathrm{E}+01$ & $6.50 \mathrm{E}+09$ & $7.54 \mathrm{E}+08$ & 1.16E-01 \\
\hline $8.97 \mathrm{E}+01$ & $5.91 \mathrm{E}+09$ & $8.23 E+08$ & $1.39 \mathrm{E}-01$ \\
\hline $9.16 \mathrm{E}+01$ & $5.23 E+09$ & $8.82 E+08$ & 1.69E-01 \\
\hline $9.36 \mathrm{E}+01$ & $4.45 \mathrm{E}+09$ & $9.78 \mathrm{E}+08$ & $2.20 \mathrm{E}-01$ \\
\hline $9.56 \mathrm{E}+01$ & $3.62 \mathrm{E}+09$ & $1.06 \mathrm{E}+09$ & $2.94 \mathrm{E}-01$ \\
\hline $9.76 \mathrm{E}+01$ & $2.83 E+09$ & $1.07 \mathrm{E}+09$ & 3.77E-01 \\
\hline $9.95 \mathrm{E}+01$ & $2.20 E+09$ & $1.01 E+09$ & 4.57E-01 \\
\hline $1.02 \mathrm{E}+02$ & $1.74 \mathrm{E}+09$ & $9.41 E+08$ & 5.42E-01 \\
\hline $1.03 \mathrm{E}+02$ & $1.44 \mathrm{E}+09$ & $8.51 \mathrm{E}+08$ & $5.91 \mathrm{E}-01$ \\
\hline $1.05 \mathrm{E}+02$ & $1.21 \mathrm{E}+09$ & $7.92 \mathrm{E}+08$ & $6.53 \mathrm{E}-01$ \\
\hline $1.07 \mathrm{E}+02$ & $1.06 \mathrm{E}+09$ & $7.40 \mathrm{E}+08$ & $6.99 \mathrm{E}-01$ \\
\hline $1.09 \mathrm{E}+02$ & $9.51 \mathrm{E}+08$ & $7.28 \mathrm{E}+08$ & 7.66E-01 \\
\hline $1.11 \mathrm{E}+02$ & $8.45 \mathrm{E}+08$ & $7.04 \mathrm{E}+08$ & 8.33E-01 \\
\hline 1.13E+02 & $7.11 \mathrm{E}+08$ & $6.41 \mathrm{E}+08$ & $9.02 \mathrm{E}-01$ \\
\hline $1.15 \mathrm{E}+02$ & $6.17 \mathrm{E}+08$ & $5.84 \mathrm{E}+08$ & $9.46 \mathrm{E}-01$ \\
\hline $1.17 \mathrm{E}+02$ & $5.25 E+08$ & $5.30 E+08$ & $1.01 E+00$ \\
\hline $1.19 \mathrm{E}+02$ & $3.99 \mathrm{E}+08$ & $4.46 \mathrm{E}+08$ & $1.12 \mathrm{E}+00$ \\
\hline $1.21 \mathrm{E}+02$ & $2.82 \mathrm{E}+08$ & $3.75 E+08$ & $1.33 E+00$ \\
\hline $1.23 \mathrm{E}+02$ & $2.17 \mathrm{E}+08$ & $2.71 E+08$ & $1.25 \mathrm{E}+00$ \\
\hline $1.25 \mathrm{E}+02$ & $1.65 \mathrm{E}+08$ & $1.85 \mathrm{E}+08$ & $1.12 \mathrm{E}+00$ \\
\hline $1.27 \mathrm{E}+02$ & $1.09 \mathrm{E}+08$ & $1.28 \mathrm{E}+08$ & $1.17 \mathrm{E}+00$ \\
\hline $1.29 \mathrm{E}+02$ & $9.19 E+07$ & $9.45 E+07$ & $1.03 E+00$ \\
\hline
\end{tabular}


Table A. LIV. DMA test data $\left(1 \mathrm{wt} \%\right.$ Cloisite $\left.10 \mathrm{~A}^{\circledR}\right)$

Sample 1

\begin{tabular}{|c|c|c|c|}
\hline $\begin{array}{l}\text { TEMP } \\
{ }^{\circ} \mathrm{C}\end{array}$ & $\begin{array}{l}\mathrm{G}^{\prime} \\
\mathrm{dyn} / \mathrm{cm}^{2}\end{array}$ & $\begin{array}{l}\text { G" } \\
\text { dyn/cm }{ }^{2}\end{array}$ & an Delta \\
\hline $3.94 \mathrm{E}+01$ & $1.71 \mathrm{E}+10$ & $4.79 \mathrm{E}+08$ & $2.81 \mathrm{E}-02$ \\
\hline 4.16E+01 & $1.68 \mathrm{E}+10$ & $4.91 \mathrm{E}+08$ & $2.92 \mathrm{E}-02$ \\
\hline 4.37E+01 & $1.66 \mathrm{E}+10$ & $4.72 \mathrm{E}+08$ & $2.84 \mathrm{E}-02$ \\
\hline $4.57 \mathrm{E}+01$ & $1.64 \mathrm{E}+10$ & $4.64 \mathrm{E}+08$ & $2.83 \mathrm{E}-02$ \\
\hline $4.78 \mathrm{E}+01$ & $1.63 \mathrm{E}+10$ & $4.63 \mathrm{E}+08$ & $2.85 \mathrm{E}-02$ \\
\hline $4.98 \mathrm{E}+01$ & $1.61 \mathrm{E}+10$ & $4.22 \mathrm{E}+08$ & 2.62E-02 \\
\hline $5.18 \mathrm{E}+01$ & $1.59 \mathrm{E}+10$ & $4.33 \mathrm{E}+08$ & $2.72 \mathrm{E}-02$ \\
\hline $5.38 \mathrm{E}+01$ & $1.57 \mathrm{E}+10$ & $4.55 \mathrm{E}+08$ & 2.89E-02 \\
\hline $5.58 \mathrm{E}+01$ & $1.55 \mathrm{E}+10$ & $4.54 \mathrm{E}+08$ & $2.93 \mathrm{E}-02$ \\
\hline $5.78 \mathrm{E}+01$ & $1.53 E+10$ & $4.83 \mathrm{E}+08$ & $3.15 \mathrm{E}-02$ \\
\hline $5.98 \mathrm{E}+01$ & $1.51 \mathrm{E}+10$ & $4.97 \mathrm{E}+08$ & $3.28 \mathrm{E}-02$ \\
\hline $6.18 \mathrm{E}+01$ & $1.49 \mathrm{E}+10$ & $4.98 \mathrm{E}+08$ & $3.35 \mathrm{E}-02$ \\
\hline $6.38 \mathrm{E}+01$ & $1.46 \mathrm{E}+10$ & $5.44 \mathrm{E}+08$ & $3.72 \mathrm{E}-02$ \\
\hline $6.57 \mathrm{E}+01$ & $1.44 \mathrm{E}+10$ & $5.65 \mathrm{E}+08$ & $3.93 \mathrm{E}-02$ \\
\hline $6.77 \mathrm{E}+01$ & $1.41 \mathrm{E}+10$ & $6.14 \mathrm{E}+08$ & 4.36E-02 \\
\hline $6.98 \mathrm{E}+01$ & $1.37 \mathrm{E}+10$ & $6.51 \mathrm{E}+08$ & $4.75 \mathrm{E}-02$ \\
\hline $7.18 \mathrm{E}+01$ & $1.34 \mathrm{E}+10$ & $6.78 \mathrm{E}+08$ & $5.05 \mathrm{E}-02$ \\
\hline $7.38 \mathrm{E}+01$ & $1.30 \mathrm{E}+10$ & $6.90 \mathrm{E}+08$ & $5.30 \mathrm{E}-02$ \\
\hline $7.58 \mathrm{E}+01$ & $1.27 \mathrm{E}+10$ & $6.99 \mathrm{E}+08$ & $5.52 \mathrm{E}-02$ \\
\hline $7.78 \mathrm{E}+01$ & $1.22 \mathrm{E}+10$ & $7.13 \mathrm{E}+08$ & $5.83 \mathrm{E}-02$ \\
\hline $7.98 \mathrm{E}+01$ & $1.19 \mathrm{E}+10$ & $7.40 \mathrm{E}+08$ & $6.25 \mathrm{E}-02$ \\
\hline $8.19 \mathrm{E}+01$ & $1.14 \mathrm{E}+10$ & $7.18 \mathrm{E}+08$ & $6.28 \mathrm{E}-02$ \\
\hline $8.39 E+01$ & $1.11 \mathrm{E}+10$ & $7.02 \mathrm{E}+08$ & $6.35 \mathrm{E}-02$ \\
\hline $8.60 \mathrm{E}+01$ & $1.06 \mathrm{E}+10$ & $7.17 \mathrm{E}+08$ & $6.75 \mathrm{E}-02$ \\
\hline $8.80 \mathrm{E}+01$ & $1.02 \mathrm{E}+10$ & $7.83 \mathrm{E}+08$ & $7.69 \mathrm{E}-02$ \\
\hline $9.00 \mathrm{E}+01$ & $9.72 \mathrm{E}+09$ & $7.81 \mathrm{E}+08$ & 8.03E-02 \\
\hline $9.20 \mathrm{E}+01$ & $9.15 \mathrm{E}+09$ & $8.28 \mathrm{E}+08$ & $9.05 \mathrm{E}-02$ \\
\hline $9.40 \mathrm{E}+01$ & $8.54 \mathrm{E}+09$ & $8.84 \mathrm{E}+08$ & $1.04 \mathrm{E}-01$ \\
\hline $9.59 \mathrm{E}+01$ & $7.83 \mathrm{E}+09$ & $9.71 \mathrm{E}+08$ & $1.24 \mathrm{E}-01$ \\
\hline $9.79 \mathrm{E}+01$ & $6.94 \mathrm{E}+09$ & $1.09 E+09$ & 1.57E-01 \\
\hline $9.99 \mathrm{E}+01$ & $5.95 \mathrm{E}+09$ & $1.17 \mathrm{E}+09$ & $1.96 \mathrm{E}-01$ \\
\hline $1.02 \mathrm{E}+02$ & $4.88 \mathrm{E}+09$ & $1.22 \mathrm{E}+09$ & $2.50 \mathrm{E}-01$ \\
\hline $1.04 \mathrm{E}+02$ & $3.85 E+09$ & $1.26 \mathrm{E}+09$ & 3.27E-01 \\
\hline $1.06 \mathrm{E}+02$ & $3.01 \mathrm{E}+09$ & $1.20 \mathrm{E}+09$ & $3.99 \mathrm{E}-01$ \\
\hline $1.08 \mathrm{E}+02$ & $2.44 \mathrm{E}+09$ & $1.11 \mathrm{E}+09$ & 4.53E-01 \\
\hline $1.10 \mathrm{E}+02$ & $2.01 \mathrm{E}+09$ & $1.02 E+09$ & 5.06E-01 \\
\hline $1.12 \mathrm{E}+02$ & $1.72 \mathrm{E}+09$ & $9.23 \mathrm{E}+08$ & $5.38 \mathrm{E}-01$ \\
\hline $1.14 \mathrm{E}+02$ & $1.44 \mathrm{E}+09$ & $8.72 E+08$ & 6.07E-01 \\
\hline $1.16 \mathrm{E}+02$ & $1.19 \mathrm{E}+09$ & $8.31 E+08$ & $6.98 \mathrm{E}-01$ \\
\hline $1.18 \mathrm{E}+02$ & $8.87 \mathrm{E}+08$ & $6.75 \mathrm{E}+08$ & $7.60 \mathrm{E}-01$ \\
\hline $1.20 \mathrm{E}+02$ & $6.40 \mathrm{E}+08$ & $5.44 \mathrm{E}+08$ & $8.51 \mathrm{E}-01$ \\
\hline $1.21 \mathrm{E}+02$ & $4.52 \mathrm{E}+08$ & $4.56 \mathrm{E}+08$ & $1.01 \mathrm{E}+00$ \\
\hline $1.24 \mathrm{E}+02$ & $3.31 \mathrm{E}+08$ & $3.14 \mathrm{E}+08$ & $9.47 \mathrm{E}-01$ \\
\hline $1.25 \mathrm{E}+02$ & $1.86 \mathrm{E}+08$ & $1.93 \mathrm{E}+08$ & $1.04 \mathrm{E}+00$ \\
\hline $1.27 \mathrm{E}+02$ & $1.41 \mathrm{E}+08$ & $1.85 \mathrm{E}+08$ & $1.31 \mathrm{E}+00$ \\
\hline $1.29 \mathrm{E}+02$ & $1.51 \mathrm{E}+08$ & $1.10 \mathrm{E}+08$ & $7.26 \mathrm{E}-01$ \\
\hline $1.31 \mathrm{E}+02$ & $1.13 E+08$ & $5.95 E+07$ & $5.25 \mathrm{E}-01$ \\
\hline $1.33 E+02$ & $1.15 E+08$ & $2.82 E+07$ & $2.46 \mathrm{E}-01$ \\
\hline $1.35 \mathrm{E}+02$ & $1.08 \mathrm{E}+08$ & $6.40 \mathrm{E}+06$ & 5.93E-02 \\
\hline 1.37E+02 & $1.09 \mathrm{E}+08$ & $3.26 \mathrm{E}+06$ & $3.00 \mathrm{E}-02$ \\
\hline $1.39 \mathrm{E}+02$ & $1.07 \mathrm{E}+08$ & $1.26 \mathrm{E}+06$ & 1.18E-02 \\
\hline
\end{tabular}

Sample 2

TEMP
${ }^{\circ} \mathrm{C}$.

$3.93 \mathrm{E}+01$

$4.14 \mathrm{E}+01$

$4.35 \mathrm{E}+01$

$4.55 \mathrm{E}+01$

$4.76 \mathrm{E}+01$

$4.96 \mathrm{E}+01$

$5.16 \mathrm{E}+01$

$5.36 \mathrm{E}+01$

$5.56 \mathrm{E}+0$

$5.76 \mathrm{E}+01$

$5.96 \mathrm{E}+01$

$6.16 \mathrm{E}+01$

$6.36 \mathrm{E}+01$

$6.56 \mathrm{E}+01$

$6.76 \mathrm{E}+01$

$6.96 \mathrm{E}+01$

7.16E+01

$7.36 \mathrm{E}+01$

7.57E+0

7.77E+01

$7.98 \mathrm{E}+01$

$8.18 \mathrm{E}+01$

$8.38 \mathrm{E}+01$

$8.59 \mathrm{E}+01$

$8.80 \mathrm{E}+01$

$9.00 \mathrm{E}+0$

$9.19 \mathrm{E}+01$

$9.39 \mathrm{E}+01$

$9.60 \mathrm{E}+01$

$9.79 \mathrm{E}+01$

$9.99 \mathrm{E}+01$

$1.02 \mathrm{E}+02$

$1.04 \mathrm{E}+02$

$1.06 \mathrm{E}+02$

$1.08 \mathrm{E}+02$

$1.10 \mathrm{E}+02$

$1.12 \mathrm{E}+02$

$1.14 \mathrm{E}+02$

$1.16 \mathrm{E}+02$

$1.18 \mathrm{E}+02$

$1.20 \mathrm{E}+02$

$1.22 \mathrm{E}+02$

$1.24 \mathrm{E}+02$

$1.26 \mathrm{E}+02$

$1.28 \mathrm{E}+02$

$1.30 \mathrm{E}+02$

$1.32 \mathrm{E}+02$

$1.34 \mathrm{E}+02$

$1.36 \mathrm{E}+02$

$1.38 \mathrm{E}+02$

$1.40 \mathrm{E}+02$
$\mathrm{G}^{\prime} \quad \mathrm{G}^{\prime}$ $\begin{array}{ll}\text { G' } & \text { G" } \\ \text { dyn } / \mathrm{cm}^{2} & \text { dyn } / \mathrm{cm}^{2} \\ 1.92 \mathrm{E}+10 & 5.51\end{array}$ $1.90 \mathrm{E}+10$ $1.88 \mathrm{E}+10$ $1.86 \mathrm{E}+10$ $1.84 \mathrm{E}+10$ $1.82 \mathrm{E}+10$ $1.80 \mathrm{E}+10$ $1.78 \mathrm{E}+10$ $1.76 \mathrm{E}+10$ $1.73 \mathrm{E}+10$ $1.71 \mathrm{E}+10$ $1.68 \mathrm{E}+10$ $1.66 \mathrm{E}+10$ $1.63 \mathrm{E}+10$

$1.60 \mathrm{E}+10$

$1.56 \mathrm{E}+10$

$1.53 \mathrm{E}+10$

$1.49 \mathrm{E}+10$

$1.45 \mathrm{E}+10$

$1.41 \mathrm{E}+10$

$1.37 \mathrm{E}+10$

$1.33 \mathrm{E}+10$

$1.28 \mathrm{E}+10$

$1.24 \mathrm{E}+10$

$1.18 \mathrm{E}+10$

$1.13 \mathrm{E}+10$

$1.08 \mathrm{E}+10$

$1.01 \mathrm{E}+10$

$9.30 \mathrm{E}+09$

$8.41 \mathrm{E}+09$

$7.34 \mathrm{E}+09$

$6.13 \mathrm{E}+09$

$4.86 \mathrm{E}+09$

$3.74 \mathrm{E}+09$

$2.88 \mathrm{E}+09$

$2.31 \mathrm{E}+09$

$1.89 \mathrm{E}+09$

$1.51 \mathrm{E}+09$

$1.19 \mathrm{E}+09$

$8.74 \mathrm{E}+08$

$6.49 \mathrm{E}+08$

$4.19 \mathrm{E}+08$

$2.99 \mathrm{E}+08$

$1.86 \mathrm{E}+08$

$1.28 \mathrm{E}+08$

$1.55 \mathrm{E}+08$

$9.23 \mathrm{E}+07$

$1.02 \mathrm{E}+08$

$1.10 \mathrm{E}+08$

$1.07 \mathrm{E}+08$

$7.13 \mathrm{E}+07$ $5.51 \mathrm{E}+08 \quad 2.88 \mathrm{E}-02$ $5.59 \mathrm{E}+08 \quad 2.94 \mathrm{E}-02$ $5.54 \mathrm{E}+08 \quad 2.95 \mathrm{E}-02$ $5.19 \mathrm{E}+08 \quad 2.79 \mathrm{E}-02$ $4.80 \mathrm{E}+08 \quad 2.61 \mathrm{E}-02$ $5.05 \mathrm{E}+08 \quad 2.77 \mathrm{E}-02$ $4.92 \mathrm{E}+08 \quad 2.74 \mathrm{E}-02$ $5.12 \mathrm{E}+08 \quad 2.88 \mathrm{E}-02$ $5.18 \mathrm{E}+08 \quad 2.95 \mathrm{E}-02$ $5.08 \mathrm{E}+08 \quad 2.94 \mathrm{E}-02$ $5.67 \mathrm{E}+08 \quad 3.32 \mathrm{E}-02$ $5.60 \mathrm{E}+08 \quad 3.33 \mathrm{E}-02$ $5.94 \mathrm{E}+08 \quad 3.58 \mathrm{E}-02$ $6.46 \mathrm{E}+08 \quad 3.96 \mathrm{E}-02$ $6.70 \mathrm{E}+08 \quad 4.20 \mathrm{E}-02$ $6.67 \mathrm{E}+08 \quad 4.27 \mathrm{E}-02$ $7.33 \mathrm{E}+08 \quad 4.80 \mathrm{E}-02$ $7.46 \mathrm{E}+08 \quad 5.02 \mathrm{E}-02$ $7.52 \mathrm{E}+08 \quad 5.19 \mathrm{E}-02$ $7.85 \mathrm{E}+08 \quad 5.56 \mathrm{E}-02$ $8.30 \mathrm{E}+08 \quad 6.06 \mathrm{E}-02$ $8.13 \mathrm{E}+08 \quad 6.12 \mathrm{E}-02$ $7.78 \mathrm{E}+08 \quad 6.06 \mathrm{E}-02$ $8.59 \mathrm{E}+08 \quad 6.94 \mathrm{E}-02$ $8.42 \mathrm{E}+08 \quad 7.11 \mathrm{E}-02$ $8.60 \mathrm{E}+08 \quad 7.58 \mathrm{E}-02$ $9.24 \mathrm{E}+08 \quad 8.60 \mathrm{E}-02$ $9.81 \mathrm{E}+08 \quad 9.72 \mathrm{E}-02$ $1.08 \mathrm{E}+09 \quad 1.16 \mathrm{E}-01$ $1.21 \mathrm{E}+09 \quad 1.44 \mathrm{E}-01$ $1.34 \mathrm{E}+09 \quad 1.83 \mathrm{E}-01$ $1.41 \mathrm{E}+09 \quad 2.29 \mathrm{E}-01$ $1.48 \mathrm{E}+09 \quad 3.04 \mathrm{E}-01$ $1.42 \mathrm{E}+09 \quad 3.81 \mathrm{E}-01$ $1.36 \mathrm{E}+09 \quad 4.72 \mathrm{E}-01$ $1.22 \mathrm{E}+09 \quad 5.28 \mathrm{E}-01$ $1.09 \mathrm{E}+09 \quad 5.80 \mathrm{E}-01$ $9.84 \mathrm{E}+08 \quad 6.53 \mathrm{E}-01$ $9.32 \mathrm{E}+08 \quad 7.85 \mathrm{E}-01$ $7.66 \mathrm{E}+08 \quad 8.76 \mathrm{E}-01$ $5.94 \mathrm{E}+08 \quad 9.15 \mathrm{E}-01$ $4.94 \mathrm{E}+08 \quad 1.18 \mathrm{E}+00$ $3.35 \mathrm{E}+08 \quad 1.12 \mathrm{E}+00$ $2.10 \mathrm{E}+08 \quad 1.13 \mathrm{E}+00$ $1.61 \mathrm{E}+08 \quad 1.26 \mathrm{E}+00$ $9.06 \mathrm{E}+07 \quad 5.86 \mathrm{E}-01$ 8.16E+07 8.84E-01 $5.79 \mathrm{E}+07 \quad 5.67 \mathrm{E}-01$ $1.19 \mathrm{E}+07 \quad 1.08 \mathrm{E}-01$ $1.19 \mathrm{E}+07 \quad 1.12 \mathrm{E}-01$

$1.21 \mathrm{E}+07 \quad 1.70 \mathrm{E}-01$ 
Table A. LV. DMA test data $\left(2 \mathrm{wt} \%\right.$ Cloisite $\left.10 \mathrm{~A}^{\circledR}\right)$

Sample 1

\begin{tabular}{|c|c|c|c|}
\hline $\begin{array}{l}\text { TEMP } \\
{ }^{\circ} \mathrm{C}\end{array}$ & $\begin{array}{l}\mathrm{G}^{\prime} \\
\mathrm{dyn} / \mathrm{cm}^{2}\end{array}$ & $\begin{array}{l}\text { G" } \\
\text { dyn/ } / \mathrm{cm}^{2}\end{array}$ & anDelta \\
\hline $3.98 \mathrm{E}+01$ & $1.98 \mathrm{E}+10$ & 3.60E +08 & $1.82 \mathrm{E}-02$ \\
\hline $4.15 \mathrm{E}+01$ & $1.96 \mathrm{E}+10$ & $3.12 \mathrm{E}+08$ & $1.59 \mathrm{E}-02$ \\
\hline $4.37 \mathrm{E}+01$ & $1.94 \mathrm{E}+10$ & $3.33 \mathrm{E}+08$ & $1.72 \mathrm{E}-02$ \\
\hline $4.57 \mathrm{E}+01$ & $1.92 \mathrm{E}+10$ & $3.22 E+08$ & 1.67E-02 \\
\hline 4.77E+01 & $1.91 \mathrm{E}+10$ & $2.92 \mathrm{E}+08$ & $1.53 \mathrm{E}-02$ \\
\hline $4.97 \mathrm{E}+01$ & $1.89 \mathrm{E}+10$ & $3.25 E+08$ & $1.72 \mathrm{E}-02$ \\
\hline $5.17 \mathrm{E}+01$ & $1.87 \mathrm{E}+10$ & $3.70 \mathrm{E}+08$ & $1.98 \mathrm{E}-02$ \\
\hline $5.36 \mathrm{E}+01$ & $1.85 \mathrm{E}+10$ & $4.00 \mathrm{E}+08$ & $2.16 \mathrm{E}-02$ \\
\hline $5.57 \mathrm{E}+01$ & $1.83 E+10$ & $3.88 \mathrm{E}+08$ & $2.12 \mathrm{E}-02$ \\
\hline $5.77 \mathrm{E}+01$ & $1.80 \mathrm{E}+10$ & $4.59 \mathrm{E}+08$ & $2.55 \mathrm{E}-02$ \\
\hline $5.97 \mathrm{E}+01$ & $1.77 \mathrm{E}+10$ & $4.02 E+08$ & $2.26 \mathrm{E}-02$ \\
\hline $6.16 \mathrm{E}+01$ & $1.74 \mathrm{E}+10$ & $4.78 \mathrm{E}+08$ & $2.74 \mathrm{E}-02$ \\
\hline $6.36 \mathrm{E}+01$ & $1.72 \mathrm{E}+10$ & $5.54 \mathrm{E}+08$ & $3.22 \mathrm{E}-02$ \\
\hline $6.56 \mathrm{E}+01$ & $1.68 \mathrm{E}+10$ & $6.00 \mathrm{E}+08$ & $3.58 \mathrm{E}-02$ \\
\hline $6.76 \mathrm{E}+01$ & $1.64 \mathrm{E}+10$ & $6.63 E+08$ & $4.05 \mathrm{E}-02$ \\
\hline $6.96 \mathrm{E}+01$ & $1.60 \mathrm{E}+10$ & $6.44 \mathrm{E}+08$ & $4.02 \mathrm{E}-02$ \\
\hline $7.17 \mathrm{E}+01$ & $1.56 \mathrm{E}+10$ & $7.31 \mathrm{E}+08$ & 4.70E-02 \\
\hline 7.37E+01 & $1.51 \mathrm{E}+10$ & $7.99 E+08$ & 5.29E-02 \\
\hline $7.57 \mathrm{E}+01$ & $1.46 \mathrm{E}+10$ & $8.57 \mathrm{E}+08$ & $5.88 \mathrm{E}-02$ \\
\hline $7.77 \mathrm{E}+01$ & $1.40 \mathrm{E}+10$ & $8.73 \mathrm{E}+08$ & $6.23 \mathrm{E}-02$ \\
\hline $7.98 \mathrm{E}+01$ & $1.35 \mathrm{E}+10$ & $8.68 \mathrm{E}+08$ & $6.44 \mathrm{E}-02$ \\
\hline $8.18 \mathrm{E}+01$ & $1.30 \mathrm{E}+10$ & $8.74 \mathrm{E}+08$ & $6.71 \mathrm{E}-02$ \\
\hline $8.38 \mathrm{E}+01$ & $1.24 \mathrm{E}+10$ & $9.28 \mathrm{E}+08$ & $7.48 \mathrm{E}-02$ \\
\hline $8.59 \mathrm{E}+01$ & $1.18 \mathrm{E}+10$ & $9.19 \mathrm{E}+08$ & 7.75E-02 \\
\hline $8.79 \mathrm{E}+01$ & $1.12 \mathrm{E}+10$ & $9.99 \mathrm{E}+08$ & OE-02 \\
\hline $8.99 \mathrm{E}+01$ & $1.06 \mathrm{E}+10$ & $1.03 \mathrm{E}+09$ & $9.72 \mathrm{E}-02$ \\
\hline $9.19 \mathrm{E}+01$ & $9.95 \mathrm{E}+09$ & $1.10 \mathrm{E}+09$ & $1.10 \mathrm{E}-01$ \\
\hline $9.39 \mathrm{E}+01$ & $9.23 \mathrm{E}+09$ & $1.14 \mathrm{E}+09$ & $1.23 \mathrm{E}-01$ \\
\hline $9.59 \mathrm{E}+01$ & $8.38 \mathrm{E}+09$ & $1.24 \mathrm{E}+09$ & $1.49 \mathrm{E}-01$ \\
\hline $9.78 \mathrm{E}+01$ & $7.47 \mathrm{E}+09$ & $1.36 \mathrm{E}+09$ & $1.82 \mathrm{E}-01$ \\
\hline $9.99 \mathrm{E}+01$ & $6.50 \mathrm{E}+09$ & $1.44 \mathrm{E}+09$ & 2.22E-01 \\
\hline $1.02 \mathrm{E}+02$ & $5.52 \mathrm{E}+09$ & $1.52 \mathrm{E}+09$ & $2.75 \mathrm{E}-01$ \\
\hline $1.04 \mathrm{E}+02$ & $4.53 \mathrm{E}+09$ & $1.54 \mathrm{E}+09$ & $3.40 \mathrm{E}-01$ \\
\hline $1.06 \mathrm{E}+02$ & $3.66 \mathrm{E}+09$ & $1.50 \mathrm{E}+09$ & 4.10E-01 \\
\hline $1.08 \mathrm{E}+02$ & $2.91 \mathrm{E}+09$ & $1.44 \mathrm{E}+09$ & 4.92E-01 \\
\hline $1.10 \mathrm{E}+02$ & $2.25 \mathrm{E}+09$ & $1.31 E+09$ & 5.82E-01 \\
\hline $1.12 \mathrm{E}+02$ & $1.73 E+09$ & $1.08 \mathrm{E}+09$ & $6.26 \mathrm{E}-01$ \\
\hline $1.14 \mathrm{E}+02$ & $1.41 \mathrm{E}+09$ & $9.42 \mathrm{E}+08$ & $6.70 \mathrm{E}-01$ \\
\hline $1.15 \mathrm{E}+02$ & $1.04 \mathrm{E}+09$ & $8.33 \mathrm{E}+08$ & 7.99E-01 \\
\hline $1.17 \mathrm{E}+02$ & $8.36 \mathrm{E}+08$ & $6.32 \mathrm{E}+08$ & $7.56 \mathrm{E}-01$ \\
\hline 1.19E+02 & $6.15 \mathrm{E}+08$ & $5.57 \mathrm{E}+08$ & $9.06 \mathrm{E}-01$ \\
\hline $1.21 \mathrm{E}+02$ & $4.60 \mathrm{E}+08$ & $3.64 \mathrm{E}+08$ & $7.91 \mathrm{E}-01$ \\
\hline $1.23 \mathrm{E}+02$ & $4.53 E+08$ & $3.21 E+08$ & 7.10E-01 \\
\hline $1.25 \mathrm{E}+02$ & $2.90 E+08$ & $1.50 \mathrm{E}+08$ & 5.19E-01 \\
\hline $1.27 \mathrm{E}+02$ & $2.41 E+08$ & $1.24 \mathrm{E}+08$ & $5.14 \mathrm{E}-01$ \\
\hline $1.29 \mathrm{E}+02$ & $1.74 \mathrm{E}+08$ & $1.05 E+08$ & $6.05 \mathrm{E}-01$ \\
\hline $1.31 \mathrm{E}+02$ & $9.51 \mathrm{E}+07$ & $9.82 \mathrm{E}+07$ & $1.03 \mathrm{E}+00$ \\
\hline $1.33 \mathrm{E}+02$ & $2.19 E+08$ & $4.85 E+07$ & $2.21 \mathrm{E}-01$ \\
\hline 1.35E+02 & $1.23 \mathrm{E}+08$ & $5.90 \mathrm{E}+07$ & $4.78 \mathrm{E}-01$ \\
\hline $1.37 \mathrm{E}+02$ & $1.29 \mathrm{E}+08$ & $2.11 \mathrm{E}+07$ & 1.63E-01 \\
\hline $1.39 \mathrm{E}+02$ & $1.13 \mathrm{E}+08$ & & \\
\hline
\end{tabular}

Sample 2

\begin{tabular}{|c|c|c|c|}
\hline $\begin{array}{l}\text { TEMP } \\
{ }^{\circ} \mathrm{C}\end{array}$ & $\begin{array}{l}\mathrm{G}^{\prime} \\
\mathrm{dyn} / \mathrm{cm}^{2}\end{array}$ & $\begin{array}{l}\text { G" } \\
\text { dyn/ } / \mathrm{cm}^{2}\end{array}$ & nDelta \\
\hline $3.93 \mathrm{E}+01$ & 2. $14 \mathrm{E}+10$ & $5.43 E+08$ & 2.53E-02 \\
\hline $4.14 \mathrm{E}+01$ & $2.12 \mathrm{E}+10$ & $5.68 \mathrm{E}+08$ & 2.67E-02 \\
\hline $4.34 \mathrm{E}+01$ & $2.11 \mathrm{E}+10$ & $5.38 \mathrm{E}+08$ & $2.55 \mathrm{E}-02$ \\
\hline $4.54 \mathrm{E}+01$ & $2.09 \mathrm{E}+10$ & $5.49 \mathrm{E}+08$ & 2.63E-02 \\
\hline $4.75 \mathrm{E}+01$ & $2.06 \mathrm{E}+10$ & $5.37 \mathrm{E}+08$ & 2.60E-02 \\
\hline $4.95 \mathrm{E}+01$ & $2.04 \mathrm{E}+10$ & $5.81 E+08$ & 2.85E-02 \\
\hline $5.15 \mathrm{E}+01$ & $2.02 \mathrm{E}+10$ & $5.76 \mathrm{E}+08$ & 2.85E-02 \\
\hline $5.35 \mathrm{E}+01$ & $2.00 \mathrm{E}+10$ & $5.69 \mathrm{E}+08$ & 2.84E-02 \\
\hline $5.54 \mathrm{E}+01$ & $1.97 \mathrm{E}+10$ & $5.76 \mathrm{E}+08$ & 2.92E-02 \\
\hline $5.75 \mathrm{E}+01$ & $1.95 \mathrm{E}+10$ & $7.03 \mathrm{E}+08$ & 3.60E-02 \\
\hline $5.94 \mathrm{E}+01$ & $1.93 \mathrm{E}+10$ & $6.55 \mathrm{E}+08$ & 3.40E-02 \\
\hline $6.14 \mathrm{E}+01$ & $1.89 \mathrm{E}+10$ & $6.55 \mathrm{E}+08$ & 3.46E-02 \\
\hline $6.35 \mathrm{E}+01$ & $1.87 \mathrm{E}+10$ & $7.32 \mathrm{E}+08$ & 3.92E-02 \\
\hline $6.55 \mathrm{E}+01$ & $1.84 \mathrm{E}+10$ & $8.09 \mathrm{E}+08$ & 4.40E-02 \\
\hline $6.75 \mathrm{E}+01$ & $1.80 \mathrm{E}+10$ & $8.18 \mathrm{E}+08$ & 4.55E-02 \\
\hline $6.95 \mathrm{E}+01$ & $1.76 \mathrm{E}+10$ & $8.65 \mathrm{E}+08$ & 4.92E-02 \\
\hline $7.16 \mathrm{E}+01$ & $1.72 \mathrm{E}+10$ & $9.26 \mathrm{E}+08$ & 5.39E-02 \\
\hline $7.35 \mathrm{E}+01$ & $1.67 \mathrm{E}+10$ & $9.27 \mathrm{E}+08$ & 5.56E-02 \\
\hline $7.56 \mathrm{E}+01$ & $1.62 \mathrm{E}+10$ & $1.03 \mathrm{E}+09$ & $6.34 \mathrm{E}-02$ \\
\hline $7.76 \mathrm{E}+01$ & $1.57 \mathrm{E}+10$ & $1.06 \mathrm{E}+09$ & $6.75 \mathrm{E}-02$ \\
\hline $7.97 \mathrm{E}+01$ & $1.52 \mathrm{E}+10$ & $1.04 \mathrm{E}+09$ & $6.88 \mathrm{E}-02$ \\
\hline $8.17 \mathrm{E}+01$ & $1.46 \mathrm{E}+10$ & $1.08 \mathrm{E}+09$ & 7.38E-02 \\
\hline $8.37 \mathrm{E}+01$ & $1.40 \mathrm{E}+10$ & $1.05 \mathrm{E}+09$ & 7.53E-02 \\
\hline $8.57 \mathrm{E}+01$ & $1.34 \mathrm{E}+10$ & $1.08 \mathrm{E}+09$ & 8.05E-02 \\
\hline $8.78 \mathrm{E}+01$ & $1.28 \mathrm{E}+10$ & $1.12 \mathrm{E}+09$ & 8.77E-02 \\
\hline $8.98 \mathrm{E}+01$ & $1.22 \mathrm{E}+10$ & $1.14 \mathrm{E}+09$ & $9.36 \mathrm{E}-02$ \\
\hline $9.18 \mathrm{E}+01$ & $1.15 \mathrm{E}+10$ & $1.20 \mathrm{E}+09$ & $1.04 \mathrm{E}-01$ \\
\hline $9.38 \mathrm{E}+01$ & $1.07 \mathrm{E}+10$ & $1.22 \mathrm{E}+09$ & $1.14 \mathrm{E}-01$ \\
\hline $9.58 \mathrm{E}+01$ & $9.87 \mathrm{E}+09$ & $1.35 \mathrm{E}+09$ & 1.37E-01 \\
\hline $9.78 \mathrm{E}+01$ & $8.83 \mathrm{E}+09$ & $1.40 \mathrm{E}+09$ & $1.59 \mathrm{E}-01$ \\
\hline $9.98 \mathrm{E}+01$ & $7.78 \mathrm{E}+09$ & $1.51 \mathrm{E}+09$ & 1.94E-01 \\
\hline $1.02 \mathrm{E}+02$ & $6.54 \mathrm{E}+09$ & $1.60 \mathrm{E}+09$ & $2.44 \mathrm{E}-01$ \\
\hline $1.04 \mathrm{E}+02$ & $5.27 \mathrm{E}+09$ & $1.63 \mathrm{E}+09$ & 3.09E-01 \\
\hline $1.06 \mathrm{E}+02$ & $4.05 \mathrm{E}+09$ & $1.58 \mathrm{E}+09$ & $3.90 \mathrm{E}-01$ \\
\hline $1.08 \mathrm{E}+02$ & $2.99 \mathrm{E}+09$ & $1.50 \mathrm{E}+09$ & $5.02 \mathrm{E}-01$ \\
\hline $1.10 \mathrm{E}+02$ & $2.23 \mathrm{E}+09$ & $1.33 \mathrm{E}+09$ & $5.96 \mathrm{E}-01$ \\
\hline $1.12 \mathrm{E}+02$ & $1.68 \mathrm{E}+09$ & $1.15 \mathrm{E}+09$ & $6.85 \mathrm{E}-01$ \\
\hline $1.14 \mathrm{E}+02$ & $1.20 \mathrm{E}+09$ & $9.65 \mathrm{E}+08$ & 8.06E-01 \\
\hline $1.16 \mathrm{E}+02$ & $8.74 \mathrm{E}+08$ & $7.44 \mathrm{E}+08$ & $8.52 \mathrm{E}-01$ \\
\hline 1.17E+02 & $6.58 \mathrm{E}+08$ & $6.27 \mathrm{E}+08$ & $9.52 \mathrm{E}-01$ \\
\hline $1.19 \mathrm{E}+02$ & $4.63 \mathrm{E}+08$ & $4.63 \mathrm{E}+08$ & $1.00 \mathrm{E}+00$ \\
\hline $1.21 \mathrm{E}+02$ & $3.87 \mathrm{E}+08$ & $3.27 \mathrm{E}+08$ & $8.44 \mathrm{E}-01$ \\
\hline $1.24 \mathrm{E}+02$ & $3.02 \mathrm{E}+08$ & $2.01 \mathrm{E}+08$ & 6.67E-01 \\
\hline $1.25 \mathrm{E}+02$ & $2.18 \mathrm{E}+08$ & $2.01 \mathrm{E}+08$ & $9.20 \mathrm{E}-01$ \\
\hline 1.27E+02 & $1.52 \mathrm{E}+08$ & $2.77 \mathrm{E}+08$ & $1.82 \mathrm{E}+00$ \\
\hline $1.29 \mathrm{E}+02$ & $1.40 \mathrm{E}+08$ & $6.10 \mathrm{E}+07$ & 4.34E-01 \\
\hline $1.31 \mathrm{E}+02$ & $8.22 \mathrm{E}+07$ & $5.96 \mathrm{E}+07$ & $7.25 \mathrm{E}-0$ \\
\hline $1.33 \mathrm{E}+02$ & $1.26 \mathrm{E}+08$ & $8.52 \mathrm{E}+07$ & $6.74 \mathrm{E}-0$ \\
\hline $1.35 \mathrm{E}+02$ & $1.33 \mathrm{E}+08$ & $4.36 \mathrm{E}+07$ & $3.29 \mathrm{E}-0$ \\
\hline 1.37E+02 & $1.27 \mathrm{E}+08$ & & \\
\hline $1.39 \mathrm{E}+02$ & $1.50 \mathrm{E}+08$ & $2.75 \mathrm{E}+07$ & $1.83 \mathrm{E}-0$ \\
\hline
\end{tabular}


Table A. LVI. DMA test data $\left(5 \mathrm{wt} \%\right.$ Cloisite $\left.10 \mathrm{~A}^{\circledR}\right)$

Sample 1

\begin{tabular}{|c|c|c|c|}
\hline $\begin{array}{l}\text { TEMP } \\
{ }^{\circ} \mathrm{C}\end{array}$ & $\begin{array}{l}\mathrm{G}^{\prime} \\
\mathrm{dyn} / \mathrm{cm}^{2}\end{array}$ & $\begin{array}{l}\text { G" } \\
\text { dyn/cm }{ }^{2}\end{array}$ & nDelta \\
\hline $3.94 \mathrm{E}+01$ & $2.83 E+10$ & 1.12E+08 & 3.97E-03 \\
\hline $4.16 \mathrm{E}+01$ & $2.81 E+10$ & $3.27 E+08$ & 1.17E-02 \\
\hline 4.37E+01 & $2.80 \mathrm{E}+10$ & $4.63 \mathrm{E}+08$ & 1.65E-02 \\
\hline $4.58 \mathrm{E}+01$ & $2.81 E+10$ & $1.60 \mathrm{E}+08$ & $5.68 \mathrm{E}-03$ \\
\hline $4.78 \mathrm{E}+01$ & $2.84 \mathrm{E}+10$ & $1.56 \mathrm{E}+08$ & 5.49E-03 \\
\hline $4.98 \mathrm{E}+01$ & $2.85 \mathrm{E}+10$ & $4.24 \mathrm{E}+08$ & 1.49E-02 \\
\hline $5.18 \mathrm{E}+01$ & $2.83 E+10$ & $4.79 E+08$ & 1.69E-02 \\
\hline $5.38 \mathrm{E}+01$ & $2.81 E+10$ & $4.97 \mathrm{E}+08$ & 1.77E-02 \\
\hline $5.57 \mathrm{E}+01$ & $2.78 \mathrm{E}+10$ & $5.73 \mathrm{E}+08$ & 2.06E-02 \\
\hline $5.78 \mathrm{E}+01$ & $2.76 \mathrm{E}+10$ & $7.30 \mathrm{E}+08$ & 2.65E-02 \\
\hline $5.98 \mathrm{E}+01$ & $2.72 E+10$ & $7.11 \mathrm{E}+08$ & 2.61E-02 \\
\hline $6.18 \mathrm{E}+01$ & $2.69 \mathrm{E}+10$ & $7.91 \mathrm{E}+08$ & 2.94E-02 \\
\hline $6.38 \mathrm{E}+01$ & $2.66 \mathrm{E}+10$ & $8.07 E+08$ & 3.04E-02 \\
\hline $6.58 \mathrm{E}+01$ & $2.63 \mathrm{E}+10$ & $8.52 E+08$ & $3.24 \mathrm{E}-02$ \\
\hline $6.78 \mathrm{E}+01$ & $2.59 \mathrm{E}+10$ & $9.73 \mathrm{E}+08$ & $3.76 \mathrm{E}-02$ \\
\hline $6.98 \mathrm{E}+01$ & $2.54 \mathrm{E}+10$ & $9.46 \mathrm{E}+08$ & $3.72 \mathrm{E}-02$ \\
\hline $7.18 \mathrm{E}+01$ & $2.49 E+10$ & $1.04 \mathrm{E}+09$ & 4.16E-02 \\
\hline $7.38 \mathrm{E}+01$ & $2.44 \mathrm{E}+10$ & $1.18 \mathrm{E}+09$ & 4.81E-02 \\
\hline 7.59E+01 & $2.38 \mathrm{E}+10$ & 1.17E+09 & 4.90E-02 \\
\hline 7.79E+01 & $2.32 \mathrm{E}+10$ & $1.23 E+09$ & 5.28E-02 \\
\hline $8.00 \mathrm{E}+01$ & $2.25 E+10$ & $1.34 \mathrm{E}+09$ & 5.96E-02 \\
\hline $8.20 \mathrm{E}+01$ & $2.19 \mathrm{E}+10$ & 1.37E+09 & 6.26E-02 \\
\hline $8.40 \mathrm{E}+01$ & $2.11 \mathrm{E}+10$ & $1.48 \mathrm{E}+09$ & 7.01E-02 \\
\hline $8.60 \mathrm{E}+01$ & $2.02 \mathrm{E}+10$ & $1.54 \mathrm{E}+09$ & 7.64E-02 \\
\hline $8.80 \mathrm{E}+01$ & $1.94 \mathrm{E}+10$ & $1.58 \mathrm{E}+09$ & 8.14E-02 \\
\hline $9.01 \mathrm{E}+01$ & $1.85 E+10$ & $1.63 E+09$ & 8.80E-02 \\
\hline $9.21 \mathrm{E}+01$ & $1.76 \mathrm{E}+10$ & $1.65 \mathrm{E}+09$ & 9.38E-02 \\
\hline $9.41 \mathrm{E}+01$ & $1.66 \mathrm{E}+10$ & $1.71 \mathrm{E}+09$ & $1.03 \mathrm{E}-01$ \\
\hline $9.61 \mathrm{E}+01$ & $1.57 \mathrm{E}+10$ & $1.78 \mathrm{E}+09$ & 1.13E-01 \\
\hline $9.80 \mathrm{E}+01$ & $1.46 \mathrm{E}+10$ & $1.81 \mathrm{E}+09$ & 1.24E-01 \\
\hline $1.00 \mathrm{E}+02$ & $1.34 \mathrm{E}+10$ & $1.92 \mathrm{E}+09$ & $1.43 \mathrm{E}-01$ \\
\hline $1.02 \mathrm{E}+02$ & $1.20 \mathrm{E}+10$ & $1.98 \mathrm{E}+09$ & $1.64 \mathrm{E}-01$ \\
\hline 1.04E+02 & $1.06 \mathrm{E}+10$ & $2.09 E+09$ & $1.98 \mathrm{E}-01$ \\
\hline 1.06E+02 & $8.96 \mathrm{E}+09$ & $2.26 \mathrm{E}+09$ & $2.52 \mathrm{E}-01$ \\
\hline $1.08 \mathrm{E}+02$ & $7.29 E+09$ & $2.29 \mathrm{E}+09$ & $3.14 \mathrm{E}-01$ \\
\hline 1.10E+02 & $5.71 \mathrm{E}+09$ & $2.37 E+09$ & 4.15E-01 \\
\hline 1.12E+02 & $4.25 E+09$ & $2.13 E+09$ & $5.02 \mathrm{E}-01$ \\
\hline $1.14 \mathrm{E}+02$ & $3.06 E+09$ & $1.85 E+09$ & 6.04E-01 \\
\hline 1.16E+02 & $1.96 \mathrm{E}+09$ & $1.52 \mathrm{E}+09$ & 7.73E-01 \\
\hline $1.18 \mathrm{E}+02$ & $1.28 \mathrm{E}+09$ & $1.05 E+09$ & $8.18 \mathrm{E}-01$ \\
\hline $1.20 \mathrm{E}+02$ & $8.94 \mathrm{E}+08$ & $8.82 \mathrm{E}+08$ & $9.86 \mathrm{E}-01$ \\
\hline 1.22E+02 & $4.00 \mathrm{E}+08$ & $5.47 \mathrm{E}+08$ & $1.37 \mathrm{E}+00$ \\
\hline $1.24 \mathrm{E}+02$ & $4.33 E+08$ & $3.94 \mathrm{E}+08$ & 9.09E-01 \\
\hline 1.26E+02 & $2.95 E+08$ & $3.20 E+08$ & $1.08 \mathrm{E}+00$ \\
\hline $1.28 \mathrm{E}+02$ & $3.35 E+08$ & $1.03 E+08$ & 3.09E-01 \\
\hline 1.30E+02 & $1.92 \mathrm{E}+08$ & $2.04 \mathrm{E}+08$ & $1.06 \mathrm{E}+00$ \\
\hline 1.32E+02 & $1.75 E+08$ & $1.36 \mathrm{E}+08$ & $7.80 \mathrm{E}-01$ \\
\hline 1.34E+02 & $1.57 \mathrm{E}+08$ & & \\
\hline 1.36E+02 & $2.53 E+08$ & $1.09 \mathrm{E}+08$ & 4.30E-01 \\
\hline 1.38E+02 & $3.46 \mathrm{E}+08$ & $2.21 \mathrm{E}+08$ & $6.38 \mathrm{E}-01$ \\
\hline $1.40 \mathrm{E}+02$ & $2.52 E+08$ & & \\
\hline
\end{tabular}

Sample 2

TEMP
${ }^{\circ} \mathrm{C}$

G' $\mathrm{dyn} / \mathrm{cm}^{2}$

G" $\quad \operatorname{tanDelta}$

4.15E+01

$2.23 \mathrm{E}+10$

$\mathrm{dyn} / \mathrm{cm}^{2}$

4.30E $+08 \quad 1.93 \mathrm{E}-02$

$3.44 \mathrm{E}+08 \quad 1.54 \mathrm{E}-02$

$4.49 \mathrm{E}+08 \quad 2.01 \mathrm{E}-02$

$\begin{array}{llll}4.57 \mathrm{E}+01 & 2.20 \mathrm{E}+10 & 4.36 \mathrm{E}+08 & 1.98 \mathrm{E}-02 \\ 4.78 \mathrm{E}+01 & 2.20 \mathrm{E}+10 & 5.36 \mathrm{E}+08 & 2.44 \mathrm{E}-02\end{array}$

4.97E+01 2.17E+10 $5.15 \mathrm{E}+08 \quad 2.37 \mathrm{E}-02$

$\begin{array}{lll}5.17 \mathrm{E}+01 & 2.15 \mathrm{E}+10 \quad 4.50 \mathrm{E}+08 \quad 2.09 \mathrm{E}-02\end{array}$

$5.38 \mathrm{E}+01 \quad 2.13 \mathrm{E}+10 \quad 5.26 \mathrm{E}+08 \quad 2.47 \mathrm{E}-02$

$\begin{array}{lll}5.58 \mathrm{E}+01 & 2.10 \mathrm{E}+10 \quad 5.26 \mathrm{E}+08 \quad 2.50 \mathrm{E}-02\end{array}$

$\begin{array}{lll}5.77 \mathrm{E}+01 & 2.08 \mathrm{E}+10 \quad 5.71 \mathrm{E}+08 \quad 2.75 \mathrm{E}-02\end{array}$

$\begin{array}{lll}5.97 \mathrm{E}+01 & 2.05 \mathrm{E}+10 \quad 6.07 \mathrm{E}+08 \quad 2.95 \mathrm{E}-02\end{array}$

$\begin{array}{lll}6.17 \mathrm{E}+01 & 2.03 \mathrm{E}+10 \quad 5.83 \mathrm{E}+08 \quad 2.88 \mathrm{E}-02\end{array}$

$\begin{array}{llll}6.37 \mathrm{E}+01 & 2.00 \mathrm{E}+10 & 5.85 \mathrm{E}+08 & 2.92 \mathrm{E}-02\end{array}$

$\begin{array}{llll}6.57 \mathrm{E}+01 & 1.96 \mathrm{E}+10 & 7.37 \mathrm{E}+08 & 3.76 \mathrm{E}-02\end{array}$

$6.77 \mathrm{E}+01 \quad 1.93 \mathrm{E}+10 \quad 6.92 \mathrm{E}+08 \quad 3.58 \mathrm{E}-02$

$6.98 \mathrm{E}+01-1.90 \mathrm{E}+10 \quad 7.24 \mathrm{E}+08 \quad 3.81 \mathrm{E}-02$

$\begin{array}{llll}7.18 \mathrm{E}+01 & 1.87 \mathrm{E}+10 & 7.19 \mathrm{E}+08 & 3.85 \mathrm{E}-02\end{array}$

$\begin{array}{llll}7.38 \mathrm{E}+01 & 1.82 \mathrm{E}+10 & 8.92 \mathrm{E}+08 & 4.90 \mathrm{E}-02\end{array}$

$\begin{array}{llll}7.58 \mathrm{E}+01 & 1.77 \mathrm{E}+10 & 9.54 \mathrm{E}+08 & 5.38 \mathrm{E}-02\end{array}$

$\begin{array}{llll}7.79 \mathrm{E}+01 & 1.73 \mathrm{E}+10 & 1.03 \mathrm{E}+09 & 5.98 \mathrm{E}-02\end{array}$

$7.99 \mathrm{E}+01 \quad 1.67 \mathrm{E}+10 \quad 1.03 \mathrm{E}+09 \quad 6.18 \mathrm{E}-02$

$8.19 \mathrm{E}+01 \quad 1.62 \mathrm{E}+10 \quad 1.13 \mathrm{E}+09 \quad 6.97 \mathrm{E}-02$

$8.39 \mathrm{E}+01 \quad 1.55 \mathrm{E}+10 \quad 1.18 \mathrm{E}+09 \quad 7.61 \mathrm{E}-02$

$8.60 \mathrm{E}+01 \quad 1.48 \mathrm{E}+10 \quad 1.22 \mathrm{E}+09 \quad 8.25 \mathrm{E}-02$

$8.80 \mathrm{E}+01 \quad 1.41 \mathrm{E}+10 \quad 1.25 \mathrm{E}+09 \quad 8.82 \mathrm{E}-02$

$9.01 \mathrm{E}+01 \quad 1.34 \mathrm{E}+10 \quad 1.32 \mathrm{E}+09 \quad 9.85 \mathrm{E}-02$

$9.21 \mathrm{E}+01 \quad 1.27 \mathrm{E}+10 \quad 1.37 \mathrm{E}+09 \quad 1.08 \mathrm{E}-01$

$9.40 \mathrm{E}+01 \quad 1.19 \mathrm{E}+10 \quad 1.30 \mathrm{E}+09 \quad 1.09 \mathrm{E}-01$

$9.59 \mathrm{E}+01 \quad 1.11 \mathrm{E}+10 \quad 1.28 \mathrm{E}+09 \quad 1.16 \mathrm{E}-01$

$9.80 \mathrm{E}+01 \quad 1.03 \mathrm{E}+10 \quad 1.41 \mathrm{E}+09 \quad 1.37 \mathrm{E}-01$

$1.00 \mathrm{E}+02 \quad 9.34 \mathrm{E}+09 \quad 1.41 \mathrm{E}+09 \quad 1.51 \mathrm{E}-01$

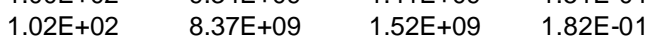

$1.04 \mathrm{E}+02 \quad 7.25 \mathrm{E}+09 \quad 1.49 \mathrm{E}+09 \quad 2.06 \mathrm{E}-01$

$\begin{array}{llll}1.06 \mathrm{E}+02 & 6.04 \mathrm{E}+09 & 1.58 \mathrm{E}+09 & 2.63 \mathrm{E}-01\end{array}$

$1.08 \mathrm{E}+02 \quad 4.82 \mathrm{E}+09 \quad 1.44 \mathrm{E}+09 \quad 2.98 \mathrm{E}-01$

$1.10 \mathrm{E}+02 \quad 3.55 \mathrm{E}+09 \quad 1.52 \mathrm{E}+09 \quad 4.29 \mathrm{E}-01$

$1.12 \mathrm{E}+02 \quad 2.46 \mathrm{E}+09 \quad 1.36 \mathrm{E}+09 \quad 5.52 \mathrm{E}-01$

$1.14 \mathrm{E}+02 \quad 1.60 \mathrm{E}+09 \quad 1.10 \mathrm{E}+09 \quad 6.87 \mathrm{E}-01$

$1.16 \mathrm{E}+02 \quad 1.04 \mathrm{E}+09 \quad 8.48 \mathrm{E}+08 \quad 8.17 \mathrm{E}-01$

$1.18 \mathrm{E}+02 \quad 6.99 \mathrm{E}+08 \quad 6.11 \mathrm{E}+08 \quad 8.74 \mathrm{E}-01$

$1.20 \mathrm{E}+02 \quad 4.11 \mathrm{E}+08 \quad 4.33 \mathrm{E}+08 \quad 1.05 \mathrm{E}+00$

$1.22 \mathrm{E}+02 \quad 3.12 \mathrm{E}+08 \quad 2.48 \mathrm{E}+08 \quad 7.96 \mathrm{E}-01$

$1.24 \mathrm{E}+02 \quad 2.49 \mathrm{E}+08 \quad 1.99 \mathrm{E}+08 \quad 8.02 \mathrm{E}-01$

$1.26 \mathrm{E}+02 \quad 1.99 \mathrm{E}+08 \quad 1.15 \mathrm{E}+08 \quad 5.76 \mathrm{E}-01$

$1.28 \mathrm{E}+02 \quad 2.15 \mathrm{E}+08 \quad 7.85 \mathrm{E}+07 \quad 3.65 \mathrm{E}-01$

$1.30 \mathrm{E}+02 \quad 2.16 \mathrm{E}+08 \quad 7.94 \mathrm{E}+07 \quad 3.68 \mathrm{E}-01$

$1.32 \mathrm{E}+02 \quad 1.76 \mathrm{E}+08 \quad 6.22 \mathrm{E}+07 \quad 3.53 \mathrm{E}-01$

$1.34 \mathrm{E}+02 \quad 1.50 \mathrm{E}+08 \quad 3.53 \mathrm{E}+07 \quad 2.36 \mathrm{E}-01$

$1.36 \mathrm{E}+02 \quad 1.43 \mathrm{E}+08 \quad 9.42 \mathrm{E}+07 \quad 6.60 \mathrm{E}-01$

$1.38 \mathrm{E}+02 \quad 1.23 \mathrm{E}+08 \quad 2.82 \mathrm{E}+06 \quad 2.28 \mathrm{E}-02$ 
Sample 3

\begin{tabular}{|c|c|c|c|}
\hline $\begin{array}{l}\text { TEMP } \\
{ }^{\circ} \mathrm{C}\end{array}$ & $\begin{array}{l}\text { G' } \\
\text { dyn } / \mathrm{cm}^{2}\end{array}$ & $\begin{array}{l}\text { G" } \\
\text { dyn/cm }{ }^{2}\end{array}$ & Delta \\
\hline $3.92 \mathrm{E}+01$ & $2.47 \mathrm{E}+10$ & $5.13 \mathrm{E}+08$ & $2.08 \mathrm{E}-02$ \\
\hline $4.13 E+01$ & $2.45 \mathrm{E}+10$ & $4.96 \mathrm{E}+08$ & 2.03E-02 \\
\hline $4.34 \mathrm{E}+01$ & $2.43 \mathrm{E}+10$ & $5.13 \mathrm{E}+08$ & 2.11E-02 \\
\hline $4.56 \mathrm{E}+01$ & $2.41 \mathrm{E}+10$ & 4.97E+08 & 2.06E-02 \\
\hline $4.75 \mathrm{E}+01$ & $2.39 \mathrm{E}+10$ & $4.71 \mathrm{E}+08$ & 1.97E-02 \\
\hline $4.96 \mathrm{E}+01$ & $2.37 \mathrm{E}+10$ & $5.42 \mathrm{E}+08$ & $2.29 \mathrm{E}-02$ \\
\hline $5.16 \mathrm{E}+01$ & $2.35 \mathrm{E}+10$ & $5.28 \mathrm{E}+08$ & 2.24E-02 \\
\hline $5.36 \mathrm{E}+01$ & $2.33 \mathrm{E}+10$ & $5.11 \mathrm{E}+08$ & $2.20 \mathrm{E}-02$ \\
\hline $5.56 \mathrm{E}+01$ & $2.30 \mathrm{E}+10$ & $5.96 \mathrm{E}+08$ & $2.59 \mathrm{E}-02$ \\
\hline $5.76 \mathrm{E}+01$ & $2.28 \mathrm{E}+10$ & $6.21 \mathrm{E}+08$ & $2.73 E-02$ \\
\hline $5.96 \mathrm{E}+01$ & $2.25 \mathrm{E}+10$ & $5.53 \mathrm{E}+08$ & $2.45 \mathrm{E}-02$ \\
\hline $6.16 \mathrm{E}+01$ & $2.23 \mathrm{E}+10$ & $6.28 \mathrm{E}+08$ & 2.82E-02 \\
\hline $6.36 \mathrm{E}+01$ & $2.21 \mathrm{E}+10$ & $7.03 E+08$ & $3.19 E-02$ \\
\hline $6.55 \mathrm{E}+01$ & $2.17 \mathrm{E}+10$ & $6.80 \mathrm{E}+08$ & 3.13E-02 \\
\hline $6.76 \mathrm{E}+01$ & $2.14 \mathrm{E}+10$ & $6.86 \mathrm{E}+08$ & $3.20 \mathrm{E}-02$ \\
\hline $6.96 \mathrm{E}+01$ & $2.12 \mathrm{E}+10$ & $7.14 \mathrm{E}+08$ & 3.36E-02 \\
\hline $7.16 \mathrm{E}+01$ & $2.08 \mathrm{E}+10$ & $8.12 \mathrm{E}+08$ & $3.91 \mathrm{E}-02$ \\
\hline $7.36 \mathrm{E}+01$ & $2.04 \mathrm{E}+10$ & $8.90 \mathrm{E}+08$ & 4.36E-02 \\
\hline $7.57 \mathrm{E}+01$ & $2.00 \mathrm{E}+10$ & $9.67 \mathrm{E}+08$ & 4.83E-02 \\
\hline 7.77E+01 & $1.95 \mathrm{E}+10$ & $9.33 E+08$ & 4.78E-02 \\
\hline $7.97 \mathrm{E}+01$ & $1.95 \mathrm{E}+10$ & $1.04 \mathrm{E}+09$ & 5.36E-02 \\
\hline $8.18 \mathrm{E}+01$ & $1.85 \mathrm{E}+10$ & $1.07 \mathrm{E}+09$ & $5.78 \mathrm{E}-02$ \\
\hline $8.38 \mathrm{E}+01$ & $1.79 \mathrm{E}+10$ & $1.19 \mathrm{E}+09$ & $6.64 \mathrm{E}-02$ \\
\hline $8.59 \mathrm{E}+01$ & $1.73 \mathrm{E}+10$ & $1.24 \mathrm{E}+09$ & 7.18E-02 \\
\hline $8.79 \mathrm{E}+01$ & $1.66 \mathrm{E}+10$ & $1.27 \mathrm{E}+09$ & 7.65E-02 \\
\hline $8.99 \mathrm{E}+01$ & $1.59 \mathrm{E}+10$ & $1.32 \mathrm{E}+09$ & 8.33E-02 \\
\hline $9.19 \mathrm{E}+01$ & $1.51 \mathrm{E}+10$ & $1.34 \mathrm{E}+09$ & 8.89E-02 \\
\hline $9.39 \mathrm{E}+01$ & $1.43 \mathrm{E}+10$ & $1.43 \mathrm{E}+09$ & $1.00 \mathrm{E}-01$ \\
\hline $9.59 \mathrm{E}+01$ & $1.35 \mathrm{E}+10$ & $1.44 \mathrm{E}+09$ & $1.06 \mathrm{E}-01$ \\
\hline $9.79 \mathrm{E}+01$ & $1.26 \mathrm{E}+10$ & $1.48 \mathrm{E}+09$ & $1.18 \mathrm{E}-01$ \\
\hline $9.99 \mathrm{E}+01$ & $1.17 \mathrm{E}+10$ & $1.55 \mathrm{E}+09$ & 1.33E-01 \\
\hline $1.02 \mathrm{E}+02$ & $1.06 \mathrm{E}+10$ & $1.59 \mathrm{E}+09$ & $1.50 \mathrm{E}-01$ \\
\hline $1.04 \mathrm{E}+02$ & $9.47 \mathrm{E}+09$ & $1.59 \mathrm{E}+09$ & $1.68 \mathrm{E}-01$ \\
\hline $1.06 \mathrm{E}+02$ & $8.24 \mathrm{E}+09$ & $1.66 \mathrm{E}+09$ & 2.02E-01 \\
\hline $1.08 \mathrm{E}+02$ & $6.79 \mathrm{E}+09$ & $1.78 \mathrm{E}+09$ & 2.62E-01 \\
\hline $1.10 \mathrm{E}+02$ & $5.37 \mathrm{E}+09$ & $1.86 \mathrm{E}+09$ & 3.46E-01 \\
\hline $1.12 \mathrm{E}+02$ & $4.10 \mathrm{E}+09$ & $1.76 \mathrm{E}+09$ & 4.29E-01 \\
\hline $1.14 \mathrm{E}+02$ & $2.93 \mathrm{E}+09$ & 1.67E+09 & $5.68 \mathrm{E}-01$ \\
\hline $1.16 \mathrm{E}+02$ & $2.07 \mathrm{E}+09$ & $1.42 \mathrm{E}+09$ & $6.83 \mathrm{E}-01$ \\
\hline $1.18 \mathrm{E}+02$ & $1.31 \mathrm{E}+09$ & 1.11E+09 & $8.45 \mathrm{E}-01$ \\
\hline $1.20 \mathrm{E}+02$ & $7.74 \mathrm{E}+08$ & $7.90 \mathrm{E}+08$ & $1.02 \mathrm{E}+00$ \\
\hline $1.22 \mathrm{E}+02$ & $5.38 \mathrm{E}+08$ & $4.93 \mathrm{E}+08$ & $9.17 \mathrm{E}-01$ \\
\hline $1.24 \mathrm{E}+02$ & $3.76 \mathrm{E}+08$ & $3.54 \mathrm{E}+08$ & $9.42 \mathrm{E}-01$ \\
\hline $1.26 \mathrm{E}+02$ & $2.50 \mathrm{E}+08$ & $2.27 \mathrm{E}+08$ & $9.10 \mathrm{E}-01$ \\
\hline $1.28 \mathrm{E}+02$ & $2.32 \mathrm{E}+08$ & $1.74 \mathrm{E}+08$ & 7.47E-01 \\
\hline $1.29 \mathrm{E}+02$ & $1.61 \mathrm{E}+08$ & $1.22 \mathrm{E}+08$ & 7.59E-01 \\
\hline $1.31 \mathrm{E}+02$ & $1.90 \mathrm{E}+08$ & $1.18 \mathrm{E}+08$ & $6.22 \mathrm{E}-01$ \\
\hline $1.33 \mathrm{E}+02$ & $9.81 \mathrm{E}+07$ & $1.21 \mathrm{E}+07$ & $1.23 \mathrm{E}-01$ \\
\hline $1.35 \mathrm{E}+02$ & $1.81 \mathrm{E}+08$ & $6.27 \mathrm{E}+07$ & $3.47 \mathrm{E}-01$ \\
\hline 1.37E+02 & $1.54 \mathrm{E}+08$ & 2.70E+07 & $1.75 \mathrm{E}-01$ \\
\hline $1.39 \mathrm{E}+02$ & $1.59 \mathrm{E}+08$ & $6.90 \mathrm{E}+07$ & 4.35E-01 \\
\hline
\end{tabular}

Sample 4

\begin{tabular}{|c|c|c|c|}
\hline $\begin{array}{l}\text { TEMP } \\
{ }^{\circ} \mathrm{C}\end{array}$ & $\begin{array}{l}\text { G' } \\
\text { dyn/cm }{ }^{2}\end{array}$ & $\begin{array}{l}\text { G" } \\
\text { dyn/cm }{ }^{2}\end{array}$ & Delta \\
\hline $3.90 \mathrm{E}+01$ & $2.60 \mathrm{E}+10$ & $2.04 \mathrm{E}+08$ & 7.84E-03 \\
\hline $4.12 \mathrm{E}+01$ & $2.62 \mathrm{E}+10$ & $1.05 \mathrm{E}+08$ & 4.03E-03 \\
\hline $4.32 \mathrm{E}+01$ & $2.59 \mathrm{E}+10$ & $3.42 \mathrm{E}+08$ & 1.32E-02 \\
\hline $4.53 \mathrm{E}+01$ & $2.55 \mathrm{E}+10$ & $3.67 \mathrm{E}+08$ & 1.44E-02 \\
\hline $4.74 \mathrm{E}+01$ & $2.54 \mathrm{E}+10$ & $3.59 \mathrm{E}+08$ & $1.42 \mathrm{E}-02$ \\
\hline $4.95 \mathrm{E}+01$ & $2.53 \mathrm{E}+10$ & $4.38 \mathrm{E}+08$ & 1.73E-02 \\
\hline $5.13 \mathrm{E}+01$ & $2.50 \mathrm{E}+10$ & $4.30 \mathrm{E}+08$ & $1.72 \mathrm{E}-02$ \\
\hline $5.33 \mathrm{E}+01$ & $2.49 \mathrm{E}+10$ & $4.67 \mathrm{E}+08$ & 1.87E-02 \\
\hline $5.54 \mathrm{E}+01$ & $2.46 \mathrm{E}+10$ & $5.89 \mathrm{E}+08$ & 2.39E-02 \\
\hline $5.74 \mathrm{E}+01$ & $2.44 \mathrm{E}+10$ & $5.09 \mathrm{E}+08$ & 2.09E-02 \\
\hline $5.94 \mathrm{E}+01$ & $2.44 \mathrm{E}+10$ & $5.81 \mathrm{E}+08$ & $2.38 \mathrm{E}-02$ \\
\hline $6.13 \mathrm{E}+01$ & $2.43 \mathrm{E}+10$ & $6.41 \mathrm{E}+08$ & 2.63E-02 \\
\hline $6.33 \mathrm{E}+01$ & $2.39 E+10$ & $6.78 \mathrm{E}+08$ & 2.84E-02 \\
\hline $6.54 \mathrm{E}+01$ & $2.34 \mathrm{E}+10$ & $5.80 \mathrm{E}+08$ & $2.48 \mathrm{E}-02$ \\
\hline $6.74 \mathrm{E}+01$ & $2.35 \mathrm{E}+10$ & $6.66 \mathrm{E}+08$ & 2.83E-02 \\
\hline $6.94 \mathrm{E}+01$ & $2.34 \mathrm{E}+10$ & $8.25 \mathrm{E}+08$ & 3.52E-02 \\
\hline $7.15 \mathrm{E}+01$ & $2.31 \mathrm{E}+10$ & $9.09 \mathrm{E}+08$ & 3.93E-02 \\
\hline $7.35 \mathrm{E}+01$ & $2.27 \mathrm{E}+10$ & $1.03 \mathrm{E}+09$ & $4.52 \mathrm{E}-02$ \\
\hline $7.55 \mathrm{E}+01$ & $2.21 \mathrm{E}+10$ & $1.16 \mathrm{E}+09$ & $5.23 \mathrm{E}-02$ \\
\hline $7.75 \mathrm{E}+01$ & $2.15 \mathrm{E}+10$ & $1.15 \mathrm{E}+09$ & 5.36E-02 \\
\hline $7.95 \mathrm{E}+01$ & $2.09 \mathrm{E}+10$ & $1.28 \mathrm{E}+09$ & $6.14 \mathrm{E}-02$ \\
\hline $8.15 \mathrm{E}+01$ & $2.03 E+10$ & $1.41 \mathrm{E}+09$ & $6.95 \mathrm{E}-02$ \\
\hline $8.36 \mathrm{E}+01$ & $1.94 \mathrm{E}+10$ & $1.38 \mathrm{E}+09$ & 7.09E-02 \\
\hline $8.57 \mathrm{E}+01$ & $1.87 \mathrm{E}+10$ & $1.44 \mathrm{E}+09$ & 7.72E-02 \\
\hline 8.77E+01 & $1.79 \mathrm{E}+10$ & $1.50 \mathrm{E}+09$ & $8.41 \mathrm{E}-02$ \\
\hline $8.98 \mathrm{E}+01$ & $1.70 \mathrm{E}+10$ & $1.52 \mathrm{E}+09$ & $8.95 \mathrm{E}-02$ \\
\hline $9.18 \mathrm{E}+01$ & $1.63 \mathrm{E}+10$ & $1.55 \mathrm{E}+09$ & $9.53 \mathrm{E}-02$ \\
\hline $9.38 \mathrm{E}+01$ & $1.53 \mathrm{E}+10$ & $1.56 \mathrm{E}+09$ & $1.02 \mathrm{E}-01$ \\
\hline $9.58 \mathrm{E}+01$ & $1.45 \mathrm{E}+10$ & $1.64 \mathrm{E}+09$ & $1.13 \mathrm{E}-01$ \\
\hline $9.78 \mathrm{E}+01$ & $1.35 \mathrm{E}+10$ & $1.69 \mathrm{E}+09$ & $1.26 \mathrm{E}-01$ \\
\hline $9.98 \mathrm{E}+01$ & $1.24 \mathrm{E}+10$ & $1.77 \mathrm{E}+09$ & $1.43 \mathrm{E}-01$ \\
\hline $1.02 \mathrm{E}+02$ & $1.13 \mathrm{E}+10$ & $1.73 \mathrm{E}+09$ & $1.53 \mathrm{E}-01$ \\
\hline $1.04 \mathrm{E}+02$ & $9.92 \mathrm{E}+09$ & $1.91 \mathrm{E}+09$ & 1.92E-01 \\
\hline $1.06 \mathrm{E}+02$ & $8.42 \mathrm{E}+09$ & $1.94 \mathrm{E}+09$ & 2.31E-01 \\
\hline $1.08 \mathrm{E}+02$ & $6.87 \mathrm{E}+09$ & $2.05 \mathrm{E}+09$ & $2.98 \mathrm{E}-01$ \\
\hline $1.10 \mathrm{E}+02$ & $5.37 \mathrm{E}+09$ & $1.96 \mathrm{E}+09$ & $3.65 \mathrm{E}-01$ \\
\hline $1.12 \mathrm{E}+02$ & $3.85 E+09$ & $1.86 \mathrm{E}+09$ & $4.83 \mathrm{E}-01$ \\
\hline $1.14 \mathrm{E}+02$ & $2.60 \mathrm{E}+09$ & $1.61 \mathrm{E}+09$ & $6.18 \mathrm{E}-01$ \\
\hline $1.16 \mathrm{E}+02$ & $1.60 \mathrm{E}+09$ & $1.23 \mathrm{E}+09$ & 7.71E-01 \\
\hline $1.18 \mathrm{E}+02$ & $1.00 \mathrm{E}+09$ & $9.26 \mathrm{E}+08$ & $9.24 \mathrm{E}-01$ \\
\hline $1.19 \mathrm{E}+02$ & $6.63 \mathrm{E}+08$ & $6.40 \mathrm{E}+08$ & $9.65 \mathrm{E}-01$ \\
\hline $1.21 \mathrm{E}+02$ & $4.73 \mathrm{E}+08$ & $4.09 \mathrm{E}+08$ & $8.65 \mathrm{E}-01$ \\
\hline $1.23 \mathrm{E}+02$ & $3.45 E+08$ & $3.11 \mathrm{E}+08$ & $9.01 \mathrm{E}-01$ \\
\hline $1.25 \mathrm{E}+02$ & $2.52 \mathrm{E}+08$ & $2.23 \mathrm{E}+08$ & 8.87E-01 \\
\hline $1.27 \mathrm{E}+02$ & $2.39 \mathrm{E}+08$ & $9.48 \mathrm{E}+07$ & 3.96E-01 \\
\hline $1.29 \mathrm{E}+02$ & $1.74 \mathrm{E}+08$ & $6.34 \mathrm{E}+07$ & $3.65 \mathrm{E}-01$ \\
\hline $1.31 \mathrm{E}+02$ & $1.84 \mathrm{E}+08$ & $1.43 \mathrm{E}+07$ & 7.78E-02 \\
\hline $1.33 \mathrm{E}+02$ & $2.36 \mathrm{E}+08$ & $6.86 \mathrm{E}+07$ & 2.90E-01 \\
\hline $1.35 \mathrm{E}+02$ & $2.21 \mathrm{E}+08$ & $1.09 \mathrm{E}+08$ & 4.94E-01 \\
\hline 1.37E+02 & $1.91 \mathrm{E}+08$ & $9.03 \mathrm{E}+07$ & $4.72 \mathrm{E}-01$ \\
\hline
\end{tabular}


Table A. LVII. Water Uptake for FRP samples immersed in Distilled water at $25^{\circ} \mathrm{C}$

Note: Amount of glass in each sample was calculated using the surface area of the sample. From the geometry of the glass-fabric the following relationship was known:

$1 \mathrm{~cm}^{2}$ fabric $=79.2025 \mathrm{mg}$ glass

\begin{tabular}{|c|c|c|c|c|c|c|c|c|c|c|c|c|}
\hline $\mathrm{Wt} \%$ & 0 & 0 & 0 & 1 & 1 & 1 & 2 & 2 & 2 & 5 & 5 & 5 \\
\hline hickness $(\mathrm{cm}) 0$ & 0.085937 & 0.07916 & 0.088477 & 0.07408 & 0.07027 & 0.074083 & 0.062653 & 0.063923 & 0.07239 & 0.07874 & \multicolumn{2}{|c|}{0.0897470 .081703} \\
\hline Length $(\mathrm{cm})$ & 3.40106 & 2.94386 & 3.09118 & 3.44424 & 2.90322 & 3.21564 & 3.29184 & 2.9337 & 3.18516 & 3.03022 & 3.03022 & 2.87782 \\
\hline \multirow[t]{2}{*}{ Width (cm) } & 1.47828 & 1.48082 & 1.48082 & 1.5113 & 1.49098 & 1.47574 & 1.67132 & 1.65608 & 1.70688 & 1.68148 & 1.68148 & 1.69418 \\
\hline & \multicolumn{4}{|c|}{ Sample 1 Sample 2 Sample 3 Sample 1} & Sample 2 & Sample 3 & Sample 1 & Sample 2 & Sample 3 & Sample 1 & Sample 2 & Sample 3 \\
\hline Time (h) & $\begin{array}{l}\text { Weight } \\
\text { (mg) }\end{array}$ & $\begin{array}{l}\text { Weight } \\
(\mathrm{mg})\end{array}$ & $\begin{array}{l}\text { Weight } \\
(\mathrm{mg})\end{array}$ & $\begin{array}{l}\text { Weight } \\
(\mathrm{mg})\end{array}$ & $\begin{array}{l}\text { Weight } \\
\text { (mg) }\end{array}$ & $\begin{array}{c}\text { Weight } \\
\text { (mg) }\end{array}$ & $\begin{array}{l}\text { Weight } \\
(\mathrm{mg})\end{array}$ & $\begin{array}{c}\text { Weight } \\
\text { (mg) }\end{array}$ & $\begin{array}{c}\text { Weight } \\
(\mathrm{mg})\end{array}$ & $\begin{array}{l}\text { Weight } \\
\text { (mg) }\end{array}$ & $\begin{array}{l}\text { Weight } \\
\text { (mg) }\end{array}$ & $\begin{array}{l}\text { Weight } \\
\text { (mg) }\end{array}$ \\
\hline 0 & 685.97 & 561.14 & 619.96 & 627.44 & 503.62 & 564.42 & 587.57 & 515.4 & 632.65 & 641.06 & 641.16 & 646.88 \\
\hline 0.5 & 686.42 & 561.49 & 620.3 & 627.78 & 503.92 & 564.75 & 588.06 & 515.72 & 633.08 & 641.6 & 641.76 & 647.43 \\
\hline 1.25 & 686.46 & 561.56 & 620.42 & 627.94 & 503.98 & 564.83 & 588.12 & 515.84 & 633.17 & 641.7 & 641.82 & 647.66 \\
\hline 3 & 686.79 & 561.78 & 620.66 & 628.06 & 504.18 & 565.01 & 588.33 & 516.11 & 633.54 & 642.11 & 642.19 & 647.9 \\
\hline 5.5 & 687.22 & 562.06 & 621.03 & 628.33 & 504.35 & 565.21 & 588.58 & 516.29 & 633.8 & 642.69 & 642.55 & 648.44 \\
\hline 21.5 & 688.12 & 562.84 & 621.93 & 629.18 & 505.23 & 566.22 & 589.57 & 517.27 & 634.93 & 644.46 & 644.15 & 650.49 \\
\hline 31.5 & 688.51 & 563.1 & 622.33 & 629.5 & 505.55 & 566.51 & 589.95 & 517.45 & 635.32 & 645.28 & 645.06 & 651.3 \\
\hline 51.5 & 689.05 & 563.56 & 622.86 & 629.91 & 506.08 & 567 & 590.53 & 517.78 & 635.88 & 646.22 & 645.78 & 652.28 \\
\hline 76.5 & 689.62 & 564.05 & 623.42 & 630.32 & 506.47 & 567.55 & 591.03 & 518.26 & 636.58 & 647.21 & 646.77 & 653.55 \\
\hline 146 & 691.22 & 565.21 & 625.03 & 631.65 & 507.88 & 568.18 & 592.4 & 519.37 & 638.26 & 648.74 & 647.26 & 654.45 \\
\hline 198 & 691.52 & 565.48 & 625.39 & 631.86 & 507.98 & 569.49 & 592.92 & 519.59 & 638.53 & 650.19 & 648.41 & 655.85 \\
\hline 406 & 694.16 & 567.32 & 627.55 & 633.88 & 509.07 & 571.34 & 593.47 & 520.12 & 639.42 & 651.5 & 649.47 & 656.94 \\
\hline 678 & 696.7 & 569.03 & 629.97 & 635.84 & 510.26 & 572.31 & 594.36 & 520.87 & 640.58 & 652.63 & 651.22 & 657.83 \\
\hline 1008 & 697.82 & 570.09 & 630.58 & 636.68 & 510.94 & 573.09 & 595.02 & 521.25 & 641.51 & 653.43 & 651.71 & 658.82 \\
\hline 1248 & 698.99 & 571.23 & 631.79 & 637.33 & 511.26 & 573.88 & 595.85 & 521.95 & 642.2 & 653.91 & 652.23 & 659.33 \\
\hline 1464 & 699.93 & 572.56 & 632.62 & 638.02 & 512.24 & 574.49 & 595.49 & 522.68 & 642.81 & 654.19 & 653.58 & 660.31 \\
\hline
\end{tabular}

Table A. LVIII. Water Uptake for FRP samples immersed in Distilled water at $4^{\circ} \mathrm{C}$

\begin{tabular}{|c|c|c|c|c|c|c|c|c|c|c|c|}
\hline Wt\% Clay & 0 & 0 & 0 & 1 & 1 & 1 & 2 & 2 & 2 & 5 & 5 \\
\hline Thickness (cm) & 0.07112 & 0.08128 & 0.073237 & 0.057997 & 0.05842 & 0.07366 & 0.06096 & 0.05334 & 0.067733 & 0.065617 & 0.08001 \\
\hline Length (cm) & 2.91338 & 2.98704 & 3.29946 & 3.11912 & 3.25882 & 3.12674 & 2.98196 & 2.794 & 2.94132 & 3.04038 & 2.58064 \\
\hline \multirow{2}{*}{ Width (cm) } & 1.50368 & 1.48336 & 1.50114 & 1.55702 & 1.48082 & 1.49352 & 1.69164 & 1.23952 & 1.70688 & 1.6764 & 1.7272 \\
\hline & Sample 1 & Sample 2 & Sample 3 & Sample 1 & Sample 2 & Sample 3 & Sample 1 & Sample 2 & Sample 3 & Sample 1 & Sample 2 \\
\hline Time (h) & $\begin{array}{l}\text { Weight } \\
\text { (mg) }\end{array}$ & $\begin{array}{l}\text { Weight } \\
\text { (mg) }\end{array}$ & $\begin{array}{l}\text { Weight } \\
\text { (mg) }\end{array}$ & $\begin{array}{l}\text { Weight } \\
\text { (mg) }\end{array}$ & $\begin{array}{l}\text { Weight } \\
\text { (mg) }\end{array}$ & $\begin{array}{l}\text { Weight } \\
\text { (mg) }\end{array}$ & $\begin{array}{l}\text { Weight } \\
\text { (mg) }\end{array}$ & $\begin{array}{l}\text { Weight } \\
\text { (mg) }\end{array}$ & $\begin{array}{c}\text { Weight } \\
\text { (mg) }\end{array}$ & $\begin{array}{l}\text { Weight } \\
(\mathrm{mg})\end{array}$ & $\begin{array}{l}\text { Weight } \\
\text { (mg) }\end{array}$ \\
\hline 0 & 521.25 & 545.15 & 613.48 & 497.89 & 522.52 & 539.19 & 579.44 & 377.21 & 540.38 & 548.24 & 537.62 \\
\hline 0.5 & 521.34 & 545.23 & 613.58 & 497.93 & 522.56 & 539.23 & 579.52 & 377.27 & 540.44 & 548.3 & 537.65 \\
\hline 3 & 521.53 & 545.37 & 613.85 & 498.04 & 522.7 & 539.32 & 579.73 & 377.46 & 540.55 & 548.44 & 537.79 \\
\hline 6.5 & 521.67 & 545.52 & 614.02 & 498.14 & 522.81 & 539.46 & 579.95 & 377.65 & 540.8 & 548.71 & 538 \\
\hline 20.5 & 522.01 & 545.81 & 614.4 & 498.36 & 523.05 & 539.73 & 580.34 & 377.92 & 541.16 & 549.17 & 538.3 \\
\hline 30 & 522.2 & 546 & 614.6 & 498.46 & 523.25 & 539.89 & 580.51 & 378.03 & 541.2 & 549.48 & 538.57 \\
\hline 51 & 522.4 & 546.19 & 614.78 & 498.56 & 523.41 & 539.99 & 580.68 & 378.13 & 541.42 & 549.66 & 538.72 \\
\hline 141.5 & 522.75 & 546.59 & 615.16 & 498.75 & 523.6 & 540.26 & 581.14 & 378.35 & 541.86 & 550 & 539.1 \\
\hline 240.5 & 522.8 & 546.76 & 615.21 & 498.82 & 523.64 & 540.32 & 581.2 & 378.38 & 541.98 & 550.08 & 539.15 \\
\hline 407.5 & 522.99 & 546.89 & 615.44 & 498.87 & 523.8 & 540.44 & 581.35 & 378.51 & 542.1 & 550.2 & 539.38 \\
\hline 699.5 & 523.06 & 547.01 & 615.53 & 498.92 & 523.82 & 540.49 & 581.46 & 378.64 & 542.18 & 550.41 & 539.53 \\
\hline 1078.5 & 523.19 & 547.04 & 615.71 & 498.96 & 523.84 & 540.57 & 581.55 & 378.64 & 542.25 & 550.45 & 539.67 \\
\hline 1366.5 & 523.24 & 547.16 & 615.76 & 498.99 & 523.87 & 540.62 & 581.64 & 378.68 & 542.36 & 550.53 & 539.74 \\
\hline 1654.5 & 523.24 & 547.16 & 615.76 & 498.99 & 523.87 & 540.62 & 581.64 & 378.68 & 542.36 & 550.53 & 539.74 \\
\hline
\end{tabular}


Table A. LIX. Water Uptake for FRP samples immersed in Distilled water at $42.5^{\circ} \mathrm{C}$

\begin{tabular}{|c|c|c|c|c|c|c|c|c|c|c|c|c|}
\hline Wt\% Clay & 0 & 0 & 0 & 1 & 1 & 1 & 2 & 2 & 2 & 5 & 5 & 5 \\
\hline hickness (cm) & 0.075777 & 295673 & 0.079163 & 0.09144 & 0.107527 & 0.0889 & 0.08382 & 0.097367 & 0.097367 & 0.128693 & 0.10668 & 0.10033 \\
\hline & Sample 1 & & Sample 3 & imple 1 & Sample 2 & & & & & Sample 1 & Sample 2 & Sample 3 \\
\hline Time (h) & $\begin{array}{l}\text { Weight } \\
\text { (mg) }\end{array}$ & $\begin{array}{c}\text { Weight } \\
\text { (mg) }\end{array}$ & $\begin{array}{c}\text { Weight } \\
\text { (mg) }\end{array}$ & $\begin{array}{c}\text { Weight } \\
\text { (mg) }\end{array}$ & $\begin{array}{c}\text { Weight } \\
\text { (mg) }\end{array}$ & $\begin{array}{c}\text { Weight } \\
\text { (mg) }\end{array}$ & $\begin{array}{c}\text { Weight } \\
\text { (mg) }\end{array}$ & $\begin{array}{c}\text { Weight } \\
\text { (mg) }\end{array}$ & $\begin{array}{c}\text { Weight } \\
\text { (mg) }\end{array}$ & $\begin{array}{c}\text { Weight } \\
\text { (mg) }\end{array}$ & $\begin{array}{c}\text { Weight } \\
\text { (mg) }\end{array}$ & $\begin{array}{c}\text { Weight } \\
\text { (mg) }\end{array}$ \\
\hline 0 & 540.22 & 715.14 & 532.48 & 603.12 & 810.48 & 594.77 & 752.86 & 799.1 & 791.17 & 797.57 & 849.09 & 774.18 \\
\hline 0.416667 & 540.83 & 715.84 & 533.02 & 603.65 & 811.29 & 595.37 & 753.68 & 799.89 & 792 & 798.23 & 849.92 & 774.97 \\
\hline 1.083333 & 541.02 & 716.04 & 533.18 & 603.86 & 811.46 & 595.51 & 753.97 & 800.12 & 792.25 & 798.45 & 850.22 & 775.2 \\
\hline 3.083333 & 541.79 & 716.75 & 533.75 & 604.59 & 812.37 & 596.01 & 754.99 & 801.02 & 793.14 & 799.34 & 851.02 & 776.12 \\
\hline 6.083333 & 542.45 & 717.37 & 534.32 & 605.09 & 813.05 & 596.55 & 755.77 & 801.65 & 793.85 & 800.2 & 851.93 & 777.06 \\
\hline 22.5 & 544.56 & 719.24 & 536.06 & 606.53 & 815.56 & 597.98 & 758.05 & 804.14 & 796.92 & 803.59 & 854.94 & 779.96 \\
\hline 30 & 544.85 & 719.57 & 536.42 & 606.74 & 815.71 & 598.18 & 758.46 & 804.62 & 797.26 & 804.17 & 855.25 & 780.81 \\
\hline 51 & 546.4 & 720.81 & 537.63 & 607.32 & 816.97 & 598.86 & 759.39 & 806.15 & 798.95 & 806.4 & 857.11 & 783.26 \\
\hline 121 & 548.95 & 724.02 & 539.96 & 608.81 & 819.04 & 600.29 & 761.27 & 809.24 & 803.31 & 811.43 & 860.4 & 787.3 \\
\hline 172 & 549.36 & 725.13 & 540.36 & 609.18 & 819.44 & 600.75 & 761.58 & 810.37 & 804.77 & 812.66 & 861.73 & 788.87 \\
\hline 220 & 549.53 & 725.79 & 541.13 & 609.19 & 819.47 & 600.95 & 761.6 & 811.35 & 805.74 & 813.35 & 861.12 & 790.26 \\
\hline 381 & 550.07 & 727.26 & 541.6 & 609.59 & 820.43 & 602.38 & 762.03 & 813.8 & 808.72 & 815.73 & 862.56 & 792.71 \\
\hline 671 & 548.84 & 729.24 & 540.87 & 609.95 & 819.35 & 602.82 & 761.3 & 815.69 & 809.97 & 817.65 & 862.08 & 795.5 \\
\hline 887 & 546.68 & 728.37 & 538.66 & 608.92 & 817.27 & 602.01 & 760.83 & 812.86 & 807.93 & 813.57 & 859.65 & 787.75 \\
\hline 1223 & 545.11 & 726.52 & 536.89 & 606.84 & 815.05 & 599.93 & 758.5 & 810.17 & 805.53 & 811.11 & 856.33 & 784.46 \\
\hline
\end{tabular}

Table A. LX. Water Uptake for FRP samples immersed in $0.1 \mathrm{M} \mathrm{NaCl}$ solution at $25^{\circ} \mathrm{C}$

\begin{tabular}{|c|c|c|c|c|c|c|c|c|c|c|c|c|}
\hline Wt\% Clay & 0 & 0 & 0 & 1 & 1 & 1 & 2 & 2 & 2 & 5 & 5 & 5 \\
\hline ickness $(\mathrm{cm})$ & 0.082973 & 0.063076 & 0.089747 & 0.05334 & 0.05588 & 0.067733 & 0.09779 & 0.071543 & 0.06858 & 0.094827 & 0.08382 & 0.087207 \\
\hline Length $(\mathrm{cm})$ & 2.89052 & 2.5654 & 2.88544 & 3.4925 & 3.3909 & 3.29692 & 3.43916 & 3.37312 & 2.88544 & 2.8702 & 2.42824 & 3.04292 \\
\hline Width (c & 1.43764 & 1.4224 & 1.4859 & 1.65608 & 1.57988 & 1.36652 & 1.66116 & 1.65608 & 1.68656 & 1.67132 & 1.65354 & 1.67894 \\
\hline Time (h) & $\begin{array}{c}\text { Sample } 1 \\
\text { Weight } \\
(\mathrm{mg})\end{array}$ & $\begin{array}{c}\text { Sample } 2 \\
\text { Weight } \\
(\mathrm{mg})\end{array}$ & $\begin{array}{c}\text { Sample } 3 \\
\text { Weight } \\
(\mathrm{mg})\end{array}$ & $\begin{array}{c}\text { Sample } 1 \\
\text { Weight } \\
(\mathrm{mg})\end{array}$ & $\begin{array}{c}\text { Sample } 2 \\
\text { Weight } \\
(\mathrm{mg})\end{array}$ & $\begin{array}{c}\text { Sample } 3 \\
\text { Weight } \\
(\mathrm{mg})\end{array}$ & $\begin{array}{l}\text { Sample } 1 \\
\text { Weight } \\
(\mathrm{mg})\end{array}$ & $\begin{array}{c}\text { Sample } 2 \\
\text { Weight } \\
(\mathrm{mg})\end{array}$ & $\begin{array}{c}\text { Sample } 3 \\
\text { Weight } \\
(\mathrm{mg})\end{array}$ & $\begin{array}{l}\text { Sample } 1 \\
\text { Weight } \\
(\mathrm{mg})\end{array}$ & $\begin{array}{c}\text { Sample } 2 \\
\text { Weight } \\
(\mathrm{mg})\end{array}$ & $\begin{array}{c}\text { Sample } 3 \\
\text { Weight } \\
(\mathrm{mg})\end{array}$ \\
\hline 0 & 619.82 & 442.3 & 607.82 & 721.33 & 686.42 & 538.92 & 798.65 & 660.01 & 582.82 & 689.75 & 692.62 & 688.37 \\
\hline 0.416667 & 620.07 & 442.6 & 608.1 & 721.69 & 686.66 & 539.21 & 799.01 & 660.34 & 583.05 & 690.12 & 693.05 & 688.73 \\
\hline 1.25 & 620.27 & 442.75 & 608.26 & 721.91 & 686.98 & 539.45 & 799.28 & 660.51 & 583.22 & 690.26 & 693.16 & 688.96 \\
\hline 3.083333 & 620.51 & 442.92 & 608.58 & 722.28 & 687.18 & 539.69 & 799.73 & 660.81 & 583.51 & 690.6 & 693.53 & 689.28 \\
\hline 5.5 & 620.67 & 443.05 & 608.76 & 722.43 & 687.38 & 539.85 & 800.06 & 661.03 & 583.79 & 690.87 & 693.77 & 689.47 \\
\hline 25.33333 & 621.43 & 443.53 & 609.52 & 723.24 & 688.22 & 540.51 & 801.09 & 661.77 & 584.36 & 691.81 & 694.78 & 690.47 \\
\hline 74.33333 & 621.92 & 443.89 & 610.08 & 723.72 & 688.62 & 540.94 & 801.7 & 662.11 & 584.77 & 692.68 & 695.62 & 691.26 \\
\hline 240.3333 & 622.43 & 444.29 & 610.7 & 723.86 & 689.01 & 541.49 & 802.42 & 662.44 & 585.16 & 693.47 & 696.46 & 692.02 \\
\hline 525.8333 & 622.68 & 444.36 & 611.04 & 723.88 & 689.03 & 541.8 & 802.94 & 662.52 & 585.19 & 693.79 & 696.93 & 692.44 \\
\hline 837.8333 & 622.72 & 444.4 & 611.16 & 723.98 & 689.03 & 541.82 & 803.05 & 662.46 & 585.22 & 694.02 & 696.98 & 692.72 \\
\hline 1077.833 & 622.74 & 444.42 & 611.18 & 723.98 & 689.05 & 541.83 & 803.05 & 662.47 & 585.26 & 694.12 & 697.06 & 692.75 \\
\hline 1341.833 & 622.74 & 444.42 & 611.18 & 723.98 & 689.05 & 541.83 & 803.12 & 662.5 & 585.32 & 694.25 & 697.16 & 692.86 \\
\hline 1485.833 & 622.74 & 444.42 & 611.18 & 723.98 & 689.05 & 541.83 & 803.15 & 662.62 & 585.38 & 694.38 & 697.16 & 693.06 \\
\hline 1653.833 & 622.74 & 444.42 & 611.18 & 723.98 & 689.05 & 541.83 & 803.15 & 662.62 & 585.38 & 694.38 & 697.16 & 693.06 \\
\hline
\end{tabular}


Table A. LXI. Water Uptake for FRP samples immersed in $0.1 \mathrm{M} \mathrm{NaCl}$ solution at $4^{\circ} \mathrm{C}$

\begin{tabular}{|c|c|c|c|c|c|c|c|c|c|c|c|c|}
\hline Wt\% Clay & 0 & 0 & 0 & 1 & 1 & 1 & 2 & 2 & 2 & 5 & 5 & 5 \\
\hline Thickness $(\mathrm{cm}) 0$ & 0.076623 & $0.07239 \mathrm{c}$ & 0.096097 & 0.0762 & 0.0889 & 0.06731 & 0.089323 & 0.08128 & 0.086783 & 0.094403 & 0.078316 & 0.10414 \\
\hline Length (cm) & 3.01498 & 2.73304 & 2.62128 & 3.2258 & 2.97942 & 3.07848 & 3.22834 & 3.38328 & 3.53822 & 2.73812 & 2.75844 & 2.95148 \\
\hline Width $(\mathrm{cm})$ & 1.50876 & 1.50114 & 1.46558 & 1.48336 & 1.48844 & 1.47828 & 1.70942 & 1.651 & 1.67132 & 1.6383 & 1.65608 & 1.65354 \\
\hline Time (h) & $\begin{array}{c}\text { Sample } 1 \\
\text { Weight } \\
(\mathrm{mg})\end{array}$ & $\begin{array}{c}\text { Sample } 2 \text { s } \\
\text { Weight } \\
(\mathrm{mg})\end{array}$ & $\begin{array}{c}\text { Sample } 3 \text { S } \\
\text { Weight } \\
(\mathrm{mg})\end{array}$ & $\begin{array}{l}\text { Sample } 1 \\
\text { Weight } \\
(\mathrm{mg})\end{array}$ & $\begin{array}{c}\text { Sample } 2 \text { s } \\
\text { Weight } \\
(\mathrm{mg})\end{array}$ & $\begin{array}{c}\text { Sample } 3 \\
\text { Weight } \\
(\mathrm{mg})\end{array}$ & $\begin{array}{c}\text { Sample } 1 \\
\text { Weight } \\
(\mathrm{mg})\end{array}$ & $\begin{array}{c}\text { Sample } 2 \\
\text { Weight } \\
(\mathrm{mg})\end{array}$ & $\begin{array}{c}\text { Sample } 3 \\
\text { Weight } \\
(\mathrm{mg})\end{array}$ & $\begin{array}{c}\text { Sample } 1 \\
\text { Weight } \\
(\mathrm{mg})\end{array}$ & $\begin{array}{c}\text { Sample } 2 \\
\text { Weight } \\
(\mathrm{mg})\end{array}$ & $\begin{array}{c}\text { Sample } 3 \\
\text { Weight } \\
(\mathrm{mg})\end{array}$ \\
\hline 0 & 577.73 & 465.21 & 583.2 & 601.73 & 662.7 & 516.03 & 780.97 & 763.74 & 786.63 & 647.84 & 591.03 & 851.12 \\
\hline 0.916667 & 577.88 & 465.34 & 583.32 & 601.85 & 662.8 & 516.16 & 781.27 & 763.94 & 786.79 & 647.99 & 591.13 & 851.24 \\
\hline 2.333333 & 578.03 & 465.43 & 583.39 & 601.96 & 662.98 & 516.27 & 781.46 & 764.1 & 786.93 & 648.12 & 591.24 & 851.45 \\
\hline 5.833333 & 578.15 & 465.54 & 583.47 & 602.1 & 663.06 & 516.39 & 781.49 & 764.48 & 787.16 & 648.26 & 591.48 & 851.71 \\
\hline 26.83333 & 578.55 & 465.75 & 583.77 & 602.41 & 663.56 & 516.7 & 782.51 & 765.29 & 787.91 & 648.98 & 591.93 & 852.49 \\
\hline 75.83333 & 579.07 & 466.14 & 584.22 & 602.83 & 664.13 & 517.09 & 783.43 & 766.18 & 788.63 & 649.54 & 592.47 & 853.43 \\
\hline 240.3333 & 579.34 & 466.31 & 584.53 & 603.11 & 664.47 & 517.25 & 784.19 & 766.6 & 789.07 & 650.21 & 592.94 & 854.12 \\
\hline 531.3333 & 579.46 & 466.42 & 584.68 & 603.24 & 664.76 & 517.38 & 784.21 & 766.82 & 789.19 & 650.34 & 593.12 & 854.64 \\
\hline 910.3333 & 579.56 & 466.52 & 584.79 & 603.35 & 664.82 & 517.42 & 784.38 & 767.03 & 789.39 & 650.64 & 593.32 & 855.04 \\
\hline 1198.333 & 579.69 & 466.61 & 584.88 & 603.4 & 664.91 & 517.46 & 784.38 & 767.03 & 789.42 & 650.7 & 593.32 & 855.11 \\
\hline 1342.333 & 579.69 & 466.61 & 584.88 & 603.4 & 664.91 & 517.46 & 784.38 & 767.03 & 789.42 & 650.7 & 593.32 & 855.11 \\
\hline
\end{tabular}

Table A. LXII. Water Uptake for FRP samples immersed in $0.1 \mathrm{M} \mathrm{NaCl}$ solution at $42.5^{\circ} \mathrm{C}$

$\begin{array}{llllllllllll}\text { Wt\% Clay } & 0 & 0 & 0 & 1 & 1 & 1 & 2 & 2 & 2 & 5 & 5\end{array}$

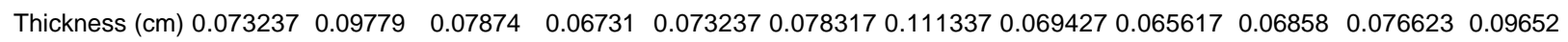

\begin{tabular}{|c|c|c|c|c|c|c|c|c|c|c|c|c|}
\hline ime (h) & $\begin{array}{l}\text { Weight } \\
\text { (mg) }\end{array}$ & $\begin{array}{l}\text { Weight } \\
\text { (mg) }\end{array}$ & $\begin{array}{l}\text { Weight } \\
\text { (mg) }\end{array}$ & $\begin{array}{l}\text { Weight } \\
(\mathrm{mg})\end{array}$ & $\begin{array}{l}\text { Weight } \\
\text { (mg) }\end{array}$ & $\begin{array}{c}\text { Weight } \\
\text { (mg) }\end{array}$ & $\begin{array}{l}\text { Weight } \\
\text { (mg) }\end{array}$ & $\begin{array}{l}\text { Weight } \\
\text { (mg) }\end{array}$ & $\begin{array}{c}\text { Weight } \\
\text { (mg) }\end{array}$ & $\begin{array}{l}\text { Weight } \\
(\mathrm{mg})\end{array}$ & $\begin{array}{c}\text { Weight } \\
(\mathrm{mg})\end{array}$ & $\begin{array}{l}\text { Weight } \\
\text { (mg) }\end{array}$ \\
\hline 0 & 566.22 & 681.53 & 521.3 & 481.16 & 573.92 & 528.12 & 843.7 & 532.17 & 522.24 & 551.77 & 567.51 & 688.72 \\
\hline 0.666667 & 566.81 & 682.04 & 521.78 & 481.78 & 574.47 & 528.57 & 844.47 & 532.78 & 522.76 & 552.31 & 568.11 & 689.55 \\
\hline 1.583333 & 567.06 & 682.27 & 521.9 & 481.93 & 574.68 & 528.74 & 844.77 & 532.99 & 522.94 & 552.48 & 568.38 & 689.94 \\
\hline 4 & 567.46 & 682.74 & 522.42 & 482.42 & 575.24 & 529.15 & 845.41 & 533.32 & 523.35 & 552.77 & 568.85 & 690.59 \\
\hline 6.166667 & 567.76 & 683.04 & 522.65 & 482.6 & 575.53 & 529.38 & 845.79 & 533.57 & 523.57 & 553.07 & 569.26 & 691.16 \\
\hline 9 & 567.91 & 683.3 & 522.85 & 482.74 & 575.7 & 529.6 & 846.31 & 533.76 & 523.74 & 553.19 & 569.25 & 691.58 \\
\hline 27 & 568.36 & 683.98 & 523.31 & 483.1 & 576.21 & 530.03 & 847.44 & 534.18 & 524.17 & 553.77 & 570.08 & 692.79 \\
\hline 54 & 568.5 & 684.31 & 523.6 & 483.21 & 576.52 & 530.23 & 847.74 & 534.38 & 524.38 & 554.01 & 570.43 & 693.68 \\
\hline 152 & 568.7 & 684.55 & 523.67 & 483.2 & 576.55 & 530.19 & 847.93 & 534.43 & 524.5 & 554.25 & 570.59 & 694.08 \\
\hline 410 & 568.48 & 684.36 & 523.49 & 482.83 & 576.32 & 529.96 & 847.3 & 534.19 & 524.45 & 554.05 & 571.31 & 693.8 \\
\hline 746 & 568.18 & 684.07 & 523.07 & 482.23 & 575.99 & 529.65 & 847.05 & 533.88 & 524.33 & 553.93 & 571.01 & 693.6 \\
\hline
\end{tabular}


Table A. LXIII. Water Uptake for FRP samples immersed in $13 \mathrm{pH} \mathrm{NaOH}$ solution at $25^{\circ} \mathrm{C}$

\begin{tabular}{|c|c|c|c|c|c|c|c|c|c|c|c|c|}
\hline Wt\% Clay & 0 & 0 & 0 & 1 & 1 & 1 & 2 & 2 & 2 & 5 & 5 & 5 \\
\hline & 0.066887 & 0.09525 & 0.07239 & 0.069003 & 0.072813 & 0.075353 & 0.098213 & 0.08255 & 0.07366 & 0.10033 & 0.1016 & 0.080433 \\
\hline & Sample 1 & & & & & & & Sample 2 & Sample 3 & Sample & Sample 2 & Sample 3 \\
\hline Time (h) & $\begin{array}{l}\text { Weight } \\
\text { (mg) }\end{array}$ & $\begin{array}{l}\text { Weight } \\
\text { (mg) }\end{array}$ & $\begin{array}{l}\text { Weight } \\
(\mathrm{mg})\end{array}$ & $\begin{array}{l}\text { Weight } \\
(\mathrm{mg})\end{array}$ & $\begin{array}{l}\text { Weight } \\
\text { (mg) }\end{array}$ & $\begin{array}{l}\text { Weight } \\
\text { (mg) }\end{array}$ & $\begin{array}{l}\text { Weight } \\
(\mathrm{mg})\end{array}$ & $\begin{array}{c}\text { Weight } \\
(\mathrm{mg})\end{array}$ & $\begin{array}{c}\text { Weight } \\
(\mathrm{mg})\end{array}$ & $\begin{array}{c}\text { Weight } \\
(\mathrm{mg})\end{array}$ & $\begin{array}{l}\text { Weight } \\
(\mathrm{mg})\end{array}$ & $\begin{array}{c}\text { Weight } \\
(\mathrm{mg})\end{array}$ \\
\hline 0 & 512.56 & 644.17 & 558.64 & 551.4 & 583.08 & 560.75 & 773.14 & 642.5 & 705.33 & 589.02 & 788.9 & 603.61 \\
\hline 0.5 & 512.93 & 644.52 & 559.03 & 551.79 & 583.48 & 561.1 & 773.59 & 642.88 & 705.77 & 589.66 & 789.51 & 604 \\
\hline 1.5 & 513.04 & 644.68 & 559.15 & 551.94 & 583.57 & 561.25 & 773.94 & 643.06 & 705.94 & 589.89 & 789.7 & 604.2 \\
\hline 2.916667 & 513.26 & 644.89 & 559.32 & 552.13 & 583.78 & 561.44 & 774.15 & 643.27 & 706.27 & 590.25 & 790.15 & 604.3 \\
\hline 5.25 & 513.42 & 645.16 & 559.5 & 552.24 & 583.94 & 561.6 & 774.32 & 643.44 & 706.32 & 590.69 & 790.59 & 604.58 \\
\hline 26.33333 & 514.09 & 645.9 & 560.09 & 552.81 & 584.53 & 562.2 & 775.29 & 644.22 & 707 & 591.73 & 791.92 & 605.32 \\
\hline 74.33333 & 514.37 & 646.35 & 560.52 & 553.01 & 584.56 & 562.36 & 776.25 & 644.47 & 707.33 & 593.41 & 793.85 & 606.17 \\
\hline 239.3333 & 516.34 & 649.45 & 561.17 & 557.47 & 589.86 & 566.5 & 788.31 & 649.6 & 709.04 & 598.13 & 805.51 & 617.3 \\
\hline 525.8333 & 515.33 & 647.12 & 559.08 & 555.23 & 588.66 & 564 & 783.6 & 648.7 & 707.85 & 594.79 & 798.04 & 614.37 \\
\hline 837.8333 & 513.22 & 645.92 & 556.31 & 555.17 & 585.18 & 563.2 & 780.42 & 646.47 & 704.25 & 592.74 & 795.01 & 611.3 \\
\hline
\end{tabular}

Table A. LXIV. Water Uptake for FRP samples immersed in $13 \mathrm{pH} \mathrm{NaOH}$ solution at $4^{\circ} \mathrm{C}$

\begin{tabular}{|c|c|c|c|c|c|c|c|c|c|c|c|}
\hline Wt $\%$ Clay & 0 & 0 & 0 & 1 & 1 & 1 & 2 & 2 & 5 & 5 & 5 \\
\hline hickness $(\mathrm{cm}) 0$ & 0.0986360 & 0.086918 & 0.091863 & & 0.091016 & 0.080433 & 0.0762 & 0.08128 & 0.087376 & م 0101092 & \\
\hline Length $(\mathrm{cm})$ & 2.89306 & 3.17246 & 2.72034 & 3.05816 & 3.55346 & 3.59918 & 2.77114 & 3.18262 & 3.19786 & 2.76606 & 2.96672 \\
\hline & 1.48082 & 1.48844 & 1.4859 & 1.50368 & 1.50622 & 1.54432 & 1.72466 & 1.69672 & 1.651 & 1.67386 & 1.64846 \\
\hline & $\begin{array}{c}\text { Sample } 1 \text { s } \\
\text { Weight } \\
(\mathrm{mg})\end{array}$ & $\begin{array}{c}\text { Sample } 2 \\
\text { Weight } \\
(\mathrm{mg})\end{array}$ & $\begin{array}{c}\text { Sample } 3 \\
\text { Weight } \\
(\mathrm{mg})\end{array}$ & $\begin{array}{l}\text { Sample } 1 \\
\text { Weight } \\
(\mathrm{mg})\end{array}$ & $\begin{array}{c}\text { Sample } 2 \\
\text { Weight } \\
(\mathrm{mg})\end{array}$ & $\begin{array}{c}\text { Sample } 3 \\
\text { Weight } \\
(\mathrm{mg})\end{array}$ & $\begin{array}{c}\text { Sample } 1 \\
\text { Weight } \\
(\mathrm{mg})\end{array}$ & $\begin{array}{c}\text { Sample } 2 \\
\text { Weight } \\
(\mathrm{mg})\end{array}$ & & $\begin{array}{c}\text { Sample } 2 \text { s } \\
\text { Weight } \\
(\mathrm{mg})\end{array}$ & $\begin{array}{c}\text { Sample } 3 \\
\text { Weight } \\
(\mathrm{mg})\end{array}$ \\
\hline 0 & 651.63 & 569.22 & 557.33 & 705.63 & 742.4 & 674.02 & 576.33 & 679.44 & 766.67 & 785.21 & 641.66 \\
\hline 0.75 & 651.71 & 569.3 & 557.45 & 705.7 & 742.46 & 674.06 & 576.41 & 679.48 & 766.82 & 785.38 & 641.75 \\
\hline 2.583333 & 651.89 & 569.5 & 557.6 & 705.91 & 742.67 & 674.25 & 576.69 & 679.73 & 767.19 & 785.72 & 642.01 \\
\hline 6 & 652.07 & 569.63 & 557.75 & 706.05 & 742.83 & 674.36 & 576.82 & 679.96 & 767.43 & 786.07 & 642.22 \\
\hline 25.83333 & 652.4 & 569.87 & 558.12 & 706.48 & 743.27 & 674.75 & 577.38 & 680.51 & 768.39 & 786.75 & 642.88 \\
\hline 75.33333 & 652.84 & 570.19 & 558.44 & 706.89 & 743.72 & 675.07 & 577.64 & 681.03 & 768.95 & 787.56 & 643.23 \\
\hline 240.3333 & 653.35 & 570.51 & 558.86 & 707.42 & 744.18 & 675.52 & 578.09 & 681.61 & 769.71 & 788.47 & 643.77 \\
\hline 531.3333 & 653.51 & 570.61 & 558.99 & 707.7 & 744.32 & 675.57 & 578.11 & 681.78 & 770.09 & 788.81 & 644.04 \\
\hline 910.3333 & 653.57 & 570.73 & 559.01 & 707.79 & 744.43 & 675.67 & 578.2 & 681.83 & 770.4 & 789.32 & 644.28 \\
\hline 1198.333 & 653.7 & 570.78 & 559.15 & 707.87 & 744.48 & 675.72 & 578.32 & 682.03 & 770.32 & 789.46 & 644.39 \\
\hline 1342.333 & 653.7 & 570.78 & 559.15 & 707.87 & 744.48 & 675.72 & 578.32 & 682.03 & 770.32 & 789.46 & 644.35 \\
\hline
\end{tabular}


Table A. LXV. Water Uptake for FRP samples immersed in $13 \mathrm{pH} \mathrm{NaOH}$ solution at $42.5^{\circ} \mathrm{C}$

$\begin{array}{llllllllllll}\text { Wt\% Clay } & 0 & 0 & 0 & 1 & 1 & 1 & 2 & 2 & 2 & 5 & 5\end{array}$

Thickness $(\mathrm{cm}) \quad 0.08763 \quad 0.070273 \quad 0.09906 \quad 0.091017 \quad 0.09779 \quad 0.0728130 .0702730 .085937 \quad 0.08001 \quad 0.10287 \quad 0.09906 \quad 0.079587$

\begin{tabular}{|c|c|c|c|c|c|c|c|c|c|c|c|c|}
\hline Time (h) & $\begin{array}{l}\text { Weight } \\
(\mathrm{mg})\end{array}$ & $\begin{array}{l}\text { Weight } \\
(\mathrm{mg})\end{array}$ & $\begin{array}{l}\text { Weight } \\
(\mathrm{mg})\end{array}$ & $\begin{array}{l}\text { Weight } \\
(\mathrm{mg})\end{array}$ & $\begin{array}{l}\text { Weight } \\
(\mathrm{mg})\end{array}$ & $\begin{array}{c}\text { Weight } \\
(\mathrm{mg})\end{array}$ & $\begin{array}{l}\text { Weight } \\
\text { (mg) }\end{array}$ & $\begin{array}{l}\text { Weight } \\
(\mathrm{mg})\end{array}$ & $\begin{array}{l}\text { Weight } \\
(\mathrm{mg})\end{array}$ & $\begin{array}{l}\text { Weight } \\
\text { (mg) }\end{array}$ & $\begin{array}{l}\text { Weight } \\
(\mathrm{mg})\end{array}$ & $\begin{array}{l}\text { Weight } \\
(\mathrm{mg})\end{array}$ \\
\hline 0 & 622.46 & 537.32 & 666.08 & 645.38 & 663.33 & 601.46 & 639.88 & 664.04 & 678.31 & 774.75 & 720.54 & 570.02 \\
\hline 0.5 & 622.87 & 537.65 & 666.53 & 645.74 & 663.71 & 601.91 & 640.59 & 664.92 & 678.93 & 775.35 & 721.11 & 570.91 \\
\hline 1.416667 & 623.1 & 537.92 & 666.77 & 645.98 & 663.92 & 602.14 & 640.61 & 665.1 & 679.3 & 775.62 & 721.45 & 571.36 \\
\hline 3.75 & 623.4 & 538.43 & 667.08 & 646.49 & 664.25 & 602.49 & 641.03 & 665.19 & 679.74 & 776.07 & 722.01 & 572.04 \\
\hline 6 & 623.67 & 538.72 & 667.52 & 646.79 & 664.66 & 602.74 & 641.22 & 665.77 & 679.98 & 776.56 & 722.53 & 572.52 \\
\hline 9 & 623.86 & 538.83 & 667.73 & 647 & 664.82 & 602.87 & 641.48 & 665.98 & 680.16 & 776.74 & 722.87 & 572.89 \\
\hline 25.5 & 624.29 & 539.19 & 668.2 & 647.41 & 665.41 & 603.07 & 641.75 & 666.54 & 680.42 & 777.82 & 724.01 & 574.42 \\
\hline 53.5 & 624.28 & 540.3 & 668.24 & 648.14 & 665.82 & 603.22 & 641.71 & 667.11 & 680.47 & 781.28 & 725.07 & 575.71 \\
\hline 152 & 623.68 & 539.6 & 667.28 & 648.01 & 665.02 & 602.99 & 640.4 & 666.24 & 679.73 & 779.34 & 723.92 & 574.64 \\
\hline
\end{tabular}

Table A. LXVI. Steady state weight gain of assembly having 0 wt $\%$ Cloisite $10 A^{\circledR}$ FRP film

\begin{tabular}{|c|c|c|c|c|c|}
\hline Thickness & \multicolumn{2}{|c|}{$0.0762 \mathrm{~cm}$} & Thickness & \multicolumn{2}{|c|}{$0.10414 \mathrm{~cm}$} \\
\hline Time(h) & Weight $(\mathrm{g})$ & Gain (g) & Time(h) & Weight (g) & Gain (g) \\
\hline - & 11.424 & 年 & 等 & 11.617 & (5) \\
\hline 49 & 11.428 & 0.004 & 22 & 11.618 & 0.001 \\
\hline 141 & 11.438 & 0.014 & 145.5 & 11.63 & 0.013 \\
\hline 166 & 11.439 & 0.015 & 189 & 11.633 & 0.016 \\
\hline 214 & 11.443 & 0.019 & 307 & 11.64 & 0.023 \\
\hline 282 & 11.448 & 0.024 & 475 & 11.653 & 0.036 \\
\hline 386.5 & 11.458 & 0.034 & 6403 & 11.996 & 0.379 \\
\hline 430 & 11.46 & 0.036 & 6451 & 11.999 & 0.382 \\
\hline 550 & 11.469 & 0.045 & 6499 & 12.002 & 0.385 \\
\hline 814 & 11.491 & 0.067 & 6547 & 12.004 & 0.387 \\
\hline 6646 & 11.935 & 0.511 & 6595 & 12.007 & 0.39 \\
\hline 6694 & 11.939 & 0.515 & 6643 & 12.01 & 0.393 \\
\hline 6742 & 11.942 & 0.518 & & & \\
\hline 6790 & 11.946 & 0.522 & & & \\
\hline 6838 & 11.95 & 0.526 & & & \\
\hline 6886 & 11.953 & 0.529 & & & \\
\hline
\end{tabular}

Table A. LXVII. Steady state weight gain of assembly having $1 \mathrm{wt} \%$ Cloisite $10 A^{\circledR}$ FRP film

\begin{tabular}{|c|c|c|c|c|c|}
\hline Thickness & \multicolumn{2}{|c|}{$0.08382 \mathrm{~cm}$} & \multirow{2}{*}{$\begin{array}{l}\text { Thickness } \\
\text { Time(h) }\end{array}$} & \multicolumn{2}{|c|}{$0.06096 \mathrm{~cm}$} \\
\hline Time(h) & Weight (g) & Gain (g) & & Weight (g) & Gain (g) \\
\hline 0 & 13.268 & 0 & 0 & 14.2 & 0 \\
\hline 22 & 13.269 & 0.001 & 22 & 14.202 & 0.002 \\
\hline 145.5 & 13.282 & 0.014 & 145.5 & 14.217 & 0.017 \\
\hline 189 & 13.282 & 0.014 & 189 & 14.221 & 0.021 \\
\hline 307 & 13.291 & 0.023 & 307 & 14.235 & 0.035 \\
\hline 475 & 13.304 & 0.036 & 475 & 14.255 & 0.055 \\
\hline 6403 & 13.696 & 0.428 & 6403 & 14.824 & 0.624 \\
\hline 6451 & 13.699 & 0.431 & 6451 & 14.828 & 0.628 \\
\hline 6499 & 13.702 & 0.434 & 6499 & 14.833 & 0.633 \\
\hline 6547 & 13.705 & 0.437 & 6547 & 14.837 & 0.637 \\
\hline 6595 & 13.708 & 0.44 & 6595 & 14.842 & 0.642 \\
\hline 6643 & 13.712 & 0.444 & 6643 & 14.846 & 0.646 \\
\hline
\end{tabular}


Table A. LXVIII. Steady state weight gain of assembly having 2 wt \% Cloisite $10 A^{\circledR}$ FRP film

\begin{tabular}{|c|c|c|}
\hline Thickness & 0.06604 & \\
\hline Time(h) & Weight (g) & Gain (g) \\
\hline 0 & 12.803 & $5=-107$ \\
\hline 123.5 & 12.817 & 0.014 \\
\hline 167 & 12.82 & 0.017 \\
\hline 285 & 12.831 & 0.028 \\
\hline 453 & 12.846 & 0.043 \\
\hline 6405 & 13.344 & 0.541 \\
\hline 6453 & 13.348 & 0.545 \\
\hline 6501 & 13.352 & 0.549 \\
\hline 6549 & 13.356 & 0.553 \\
\hline 6597 & 13.36 & 0.557 \\
\hline 6645 & 13.364 & 0.561 \\
\hline
\end{tabular}

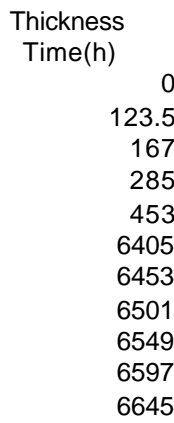

\begin{tabular}{cr}
$\begin{array}{c}0.08128 \mathrm{~cm} \\
\text { Weight }(\mathrm{g})\end{array}$ & \multicolumn{2}{c}{ Gain $(\mathrm{g})$} \\
13.748 & 0.013 \\
13.761 & 0.016 \\
13.764 & 0.026 \\
13.774 & 0.04 \\
13.788 & 0.455 \\
14.203 & 0.458 \\
14.206 & 0.461 \\
14.209 & 0.464 \\
14.212 & 0.468 \\
14.216 & 0.471
\end{tabular}

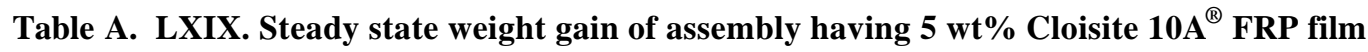

\begin{tabular}{rrr} 
Thickness & \multicolumn{3}{c}{$0.12192 \mathrm{~cm}$} & \\
Time(h) & Weight $(\mathrm{g})$ & Gain $(\mathrm{g})$ \\
0 & 14.379 & 0 \\
123.5 & 14.387 & 0.008 \\
167 & 14.39 & 0.011 \\
285 & 14.397 & 0.018 \\
453 & 14.406 & 0.027 \\
6405 & 14.677 & 0.298 \\
6453 & 14.679 & 0.3 \\
6501 & 14.682 & 0.303 \\
6549 & 14.684 & 0.305 \\
6597 & 14.686 & 0.307 \\
6645 & 14.688 & 0.309
\end{tabular}

\begin{tabular}{rrr} 
Thickness & \multicolumn{3}{c}{$0.10922 \mathrm{~cm}$} & \\
Time(h) & Weight $(\mathrm{g})$ & Gain $(\mathrm{g})$ \\
0 & 14.091 & 0 \\
123.5 & 14.102 & 0.011 \\
167 & 14.106 & 0.015 \\
285 & 14.113 & 0.022 \\
453 & 14.122 & 0.031 \\
6405 & 14.4 & 0.309 \\
6453 & 14.402 & 0.311 \\
6501 & 14.404 & 0.313 \\
6549 & 14.406 & 0.315 \\
6597 & 14.409 & 0.318 \\
6645 & 14.411 & 0.32
\end{tabular}

$\begin{array}{rrr}\text { Thickness } & 0.12192 \mathrm{~cm} & \\ \text { Time }(\mathrm{h}) & \text { Weight }(\mathrm{g}) & \text { Gain }(\mathrm{g}) \\ 0 & 13.729 & 0 \\ 123.5 & 13.738 & 0.009 \\ 167 & 13.741 & 0.012 \\ 285 & 13.75 & 0.021 \\ 453 & 13.76 & 0.031 \\ 6405 & 13.997 & 0.268 \\ 6453 & 13.999 & 0.27 \\ 6501 & 14.001 & 0.272 \\ 6549 & 14.003 & 0.274 \\ 6597 & 14.005 & 0.276 \\ 6645 & 14.007 & 0.278\end{array}$

Table A. LXX. Verification Experiment 1 data

Dry weight of the $2 \mathrm{wt} \%$ nanocomposite sample $=393.07 \mathrm{mg}$

Thickness $=0.0701 \mathrm{~cm}$

Saturated in $0.1 \mathrm{M} \mathrm{NaCl}$ for 9 months and then immersed in distilled water at $25^{\circ} \mathrm{C}$.

$\begin{array}{ccc}\text { Time }(\mathrm{h}) & \text { Weight }(\mathrm{mg}) & \text { \%Moisture } \\ 0 & 396.54 & 0.882794 \\ 4 & 396.73 & 0.931132 \\ 21 & 397.05 & 1.012542 \\ 46 & 397.62 & 1.157555 \\ 101 & 398.01 & 1.256774 \\ 120 & 398.16 & 1.294935 \\ 143 & 398.54 & 1.39161 \\ 167 & 398.54 & 1.39161\end{array}$


Table A. LXXI. Verification Experiment 2 data

Dry weight of the $5 \mathrm{wt} \%$ nanocomposite sample $=343.35 \mathrm{mg}$

Thickness $=0.04572 \mathrm{~cm}$

Sub-saturated in distilled water and then immersed in $0.1 \mathrm{M} \mathrm{NaCl}$ solution at $25^{\circ} \mathrm{C}$.

\begin{tabular}{|c|c|c|}
\hline Time (h) & Weight (mg) & \%Moisture \\
\hline c & 349.52 & 1.797 \\
\hline 4 & 348.93 & 1.625164 \\
\hline 54 & 347.64 & 1.249454 \\
\hline 73 & 347.47 & 1.199942 \\
\hline 96 & 347.4 & 1.179554 \\
\hline 120 & 347.09 & 1.089268 \\
\hline 143 & 347.02 & 1.06888 \\
\hline 167 & 347.02 & 1.06888 \\
\hline
\end{tabular}

Table A. LXXII. Silane treated glass-fiber mat Exposed to 77\% RH humidity

\begin{tabular}{rrr} 
Wt of Pan $=$ & $751.22 \mathrm{mg}$ & \\
Time $(\mathrm{h})$ & \multicolumn{3}{c}{ Weight $(\mathrm{mg})$} & \multicolumn{2}{l}{ Weight $(\mathrm{mg})$} \\
& \multicolumn{3}{c}{ (Pan+Glass) } & Glass \\
0 & 1559.17 & 807.95 \\
2 & 1559.32 & 808.1 \\
4 & 1559.41 & 808.19 \\
5.25 & 1559.43 & 808.21 \\
25.25 & 1559.5 & 808.28 \\
146 & 1559.5 & 808.28 \\
338 & 1559.15 & 807.93 \\
362 & 1559.14 & 807.92 \\
578 & 1559.13 & 807.91 \\
698 & 1559.12 & 807.9
\end{tabular}


Table A. LXXIII. Desorption of saturated neat resin samples

\begin{tabular}{|c|c|c|c|c|c|}
\hline $\begin{array}{l}\text { Sample } 1 \\
\text { Thickness }\end{array}$ & $0.0594 \mathrm{~cm}$ & $\begin{array}{l}\text { Sample } 2 \\
\text { Thickness }\end{array}$ & $0.05494 \mathrm{~cm}$ & $\begin{array}{l}\text { Sample } 3 \\
\text { Thickness }\end{array}$ & $0.0667 \mathrm{~cm}$ \\
\hline Time (h) & Weight (mg) & Time (h) & Weight (mg) & Time (h) & Weight (mg) \\
\hline $\begin{array}{c}0 \\
0.5\end{array}$ & $\begin{array}{l}329.75 \\
329.03\end{array}$ & $\begin{array}{c}0 \\
0.61666667\end{array}$ & $\begin{array}{l}307.23 \\
306.42\end{array}$ & $\begin{array}{c}0 \\
0.5\end{array}$ & $\begin{array}{l}394.89 \\
394.23\end{array}$ \\
\hline 1 & 328.78 & 1.04993333 & 306.21 & 2 & 393.68 \\
\hline 1.5 & 328.6 & 1.43323333 & 306.1 & 3 & 393.42 \\
\hline 2 & 328.45 & 1.99966667 & 305.96 & 4 & 393.23 \\
\hline $\begin{array}{c}3 \\
4.5\end{array}$ & $\begin{array}{l}328.22 \\
327.94\end{array}$ & $\begin{array}{l}2.549 \\
3.299\end{array}$ & $\begin{array}{l}305.85 \\
305.72\end{array}$ & $\begin{array}{l}5 \\
6\end{array}$ & $\begin{array}{l}393.07 \\
392.92\end{array}$ \\
\hline 6 & 327.68 & 6.549 & 305.25 & 7 & 392.82 \\
\hline 11 & 327.12 & 9.299 & 304.97 & 9 & 392.6 \\
\hline 22 & 326.49 & 19.799 & 304.37 & 10 & 392.49 \\
\hline 94 & 326.09 & 22.549 & 304.3 & 11 & 392.4 \\
\hline 214 & 325.85 & 25.549 & 304.27 & 12 & 392.18 \\
\hline \multirow[t]{16}{*}{225} & 325.85 & 34.549 & 304.08 & 13 & 392.14 \\
\hline & & 47.549 & 303.92 & 22.5 & 391.57 \\
\hline & & 56.049 & 303.89 & 23.5 & 391.52 \\
\hline & & 79.049 & 303.89 & 26 & 391.43 \\
\hline & & 94.049 & 303.89 & 29 & 391.37 \\
\hline & & 121.049 & 303.85 & 33 & 391.28 \\
\hline & & 146.049 & 303.82 & 35 & 391.26 \\
\hline & & 242.049 & 303.73 & 50 & 391.09 \\
\hline & & 266.049 & 303.73 & 52 & 391.06 \\
\hline & & & & 70 & 390.97 \\
\hline & & & & 149 & 390.89 \\
\hline & & & & 162 & 390.84 \\
\hline & & & & 168 & 390.83 \\
\hline & & & & 189 & 390.79 \\
\hline & & & & 217 & 390.75 \\
\hline & & & & 235 & 390.75 \\
\hline
\end{tabular}

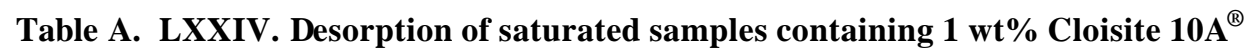

\begin{tabular}{|c|c|c|c|c|c|}
\hline Sample 1 & & Sample 2 & & Sample 3 & \\
\hline Thickness & $0.06731 \mathrm{~cm}$ & Thickness & $0.07137 \mathrm{~cm}$ & Thickness & $0.06426 \mathrm{~cm}$ \\
\hline Time (h) & Weight (mg) & Time (h) & Weight (mg) & Time (h) & Weight (mg) \\
\hline 0 & 425.71 & 0 & 462.35 & 0 & 377.81 \\
\hline 0.5 & 424.31 & 0.766667 & 460.74 & 1 & 376.2 \\
\hline 1 & 423.91 & 1.099993 & 460.45 & 1.5 & 375.98 \\
\hline 1.5 & 423.7 & 1.683233 & 460.21 & 2.5 & 375.72 \\
\hline 3 & 423.29 & 2.266333 & 460.06 & 3.5 & 375.5 \\
\hline 5.58 & 422.76 & 3.016 & 459.88 & 4.5 & 375.36 \\
\hline 7 & 422.54 & 6.266 & 459.3 & 6.5 & 375.12 \\
\hline 8.17 & 422.39 & 9.016 & 458.96 & 7.5 & 374.95 \\
\hline 23.59 & 421.19 & 19.516 & 458.09 & 8.5 & 374.86 \\
\hline 27.34 & 421.08 & 22.266 & 457.94 & 9.5 & 374.8 \\
\hline 30.84 & 420.85 & 25.266 & 457.84 & 10.5 & 374.72 \\
\hline 32.84 & 420.8 & 34.266 & 457.44 & 20 & 374.08 \\
\hline 34.84 & 420.77 & 47.266 & 457.06 & 21 & 374.03 \\
\hline 47.34 & 420.55 & 55.766 & 456.96 & 23.5 & 373.93 \\
\hline 51.84 & 420.47 & 78.766 & 456.85 & 26.5 & 373.84 \\
\hline 57.34 & 420.4 & 93.766 & 456.78 & 30.5 & 373.71 \\
\hline 71.84 & 420.3 & 120.766 & 456.71 & 32.5 & 373.68 \\
\hline 94.84 & 420.28 & 145.766 & 456.65 & 47.5 & 373.47 \\
\hline 190.84 & 420.28 & 241.766 & 456.52 & 71.5 & 373.41 \\
\hline & & 265.766 & 456.52 & 150.5 & 373.29 \\
\hline & & & & 163.5 & 373.23 \\
\hline & & & & 169.5 & 373.2 \\
\hline & & & & 190.5 & 373.18 \\
\hline & & & & 218.5 & 373.14 \\
\hline & & & & 236.5 & 373.14 \\
\hline
\end{tabular}


Table A. LXXV. Desorption of saturated samples containing 2 wt $\%$ Cloisite $10 \mathrm{~A}^{\circledR}$

\begin{tabular}{|c|c|c|c|c|c|}
\hline $\begin{array}{l}\text { Sample } 1 \\
\text { Thickness }\end{array}$ & $0.06096 \mathrm{~cm}$ & $\begin{array}{l}\text { Sample } 2 \\
\text { Thickness }\end{array}$ & $0.07010 \mathrm{~cm}$ & $\begin{array}{l}\text { Sample } 3 \\
\text { Thickness }\end{array}$ & $0.07442 \mathrm{~cm}$ \\
\hline Time (h) & Weight (mg) & Time (h) & Weight (mg) & Time (h) & Weight (mg) \\
\hline 0 & 385.68 & 0 & 435.52 & 0 & $\quad 458.37$ \\
\hline 0.7 & 383.62 & 0.583333 & 433.75 & 0.466667 & 456.84 \\
\hline 1.033333 & 383.1 & 0.916333 & 433.26 & 0.799933 & 456.21 \\
\hline 1.613333 & 382.47 & 1.496333 & 432.56 & 1.379933 & 455.51 \\
\hline 2.196667 & 381.95 & 2.079667 & 432.07 & 1.963267 & 454.95 \\
\hline 2.946667 & 381.46 & 2.829667 & 431.66 & 2.713267 & 454.45 \\
\hline 6.196667 & 380.72 & 6.079667 & 430.94 & 5.963267 & 453.65 \\
\hline 8.947 & 380.36 & 8.83 & 430.57 & 8.7136 & 453.28 \\
\hline 19.447 & 379.53 & 19.33 & 429.68 & 19.2136 & 452.37 \\
\hline 22.197 & 379.39 & 22.08 & 429.52 & 21.9636 & 452.21 \\
\hline 25.197 & 379.3 & 25.08 & 429.44 & 24.9636 & 452.11 \\
\hline 34.197 & 378.98 & 34.08 & 429.08 & 33.9636 & 451.72 \\
\hline 47.197 & 378.71 & 47.08 & 428.71 & 46.9636 & 451.34 \\
\hline 55.697 & 378.64 & 55.58 & 428.61 & 55.4636 & 451.22 \\
\hline 78.697 & 378.61 & 78.58 & 428.52 & 78.4636 & 451.08 \\
\hline 93.697 & 378.54 & 93.58 & 428.44 & 93.4636 & 450.99 \\
\hline 120.697 & 378.48 & 120.58 & 428.36 & 120.4636 & 450.88 \\
\hline 145.697 & 378.43 & 145.58 & 428.3 & 145.4636 & 450.79 \\
\hline 241.697 & 378.31 & 241.58 & 428.13 & 241.4636 & 450.62 \\
\hline 265.697 & 378.31 & 265.58 & 428.12 & 265.4636 & 450.62 \\
\hline
\end{tabular}

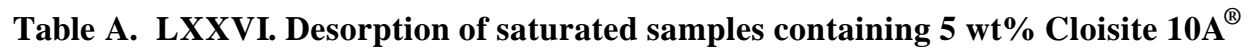

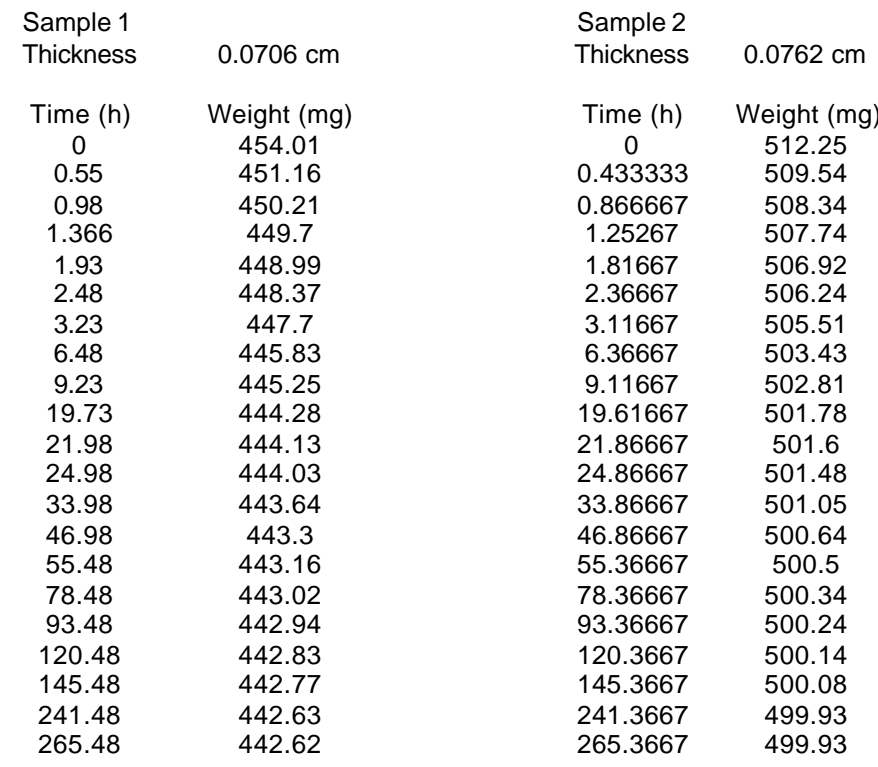


Table A. LXXVII. Repeated Absorption-Desorption Experiment

Absorption: Samples were immersed in distilled water at $25^{\circ} \mathrm{C}$

Desorption: Sample were kept in controlled humidity chamber at $20 \% \mathrm{RH}$

Equilibrium moisture content values for the samples were predicted using the available experimental values shown in Table VII.

e.g. $0 \%$ Sample weighing $85.7 \mathrm{mg}$

Equilibrium moisture $=0.66 \%$ (Table VII)

Final weight of the sample (if completely saturated $)=85.7+(0.0066 \times 85.7)=86.27 \mathrm{mg}$

The normalized mass-gain for the initial few data points were calculated using the estimated saturation weight of the sample. Diffusivities were calculated as explained in appendix A.1.1.

\begin{tabular}{|c|c|c|c|c|c|}
\hline $\begin{array}{l}\text { Thickness } \\
(\mathrm{cm})\end{array}$ & 0.030 & 0.030 & 0.030 & 0.045 & 0.060 \\
\hline Time (h) & 0\% Sample 1 & $0 \%$ Sample 2 & 0\% Sample 3 & $5 \%$ Sample 1 & $5 \%$ Sample 2 \\
\hline 0 & 86.5 & 85.7 & 90.57 & 125.4 & 157.31 \\
\hline 0.25 & 86.6 & 85.77 & 90.66 & 125.51 & 157.42 \\
\hline 0.5 & 86.68 & 85.82 & 90.68 & 125.53 & 157.46 \\
\hline 1 & 86.77 & 85.91 & 90.76 & 125.61 & 157.55 \\
\hline 1.5 & 86.82 & 85.96 & 90.82 & 125.66 & 157.64 \\
\hline 2.5 & 86.89 & 86.06 & 90.9 & 125.74 & 157.76 \\
\hline $\begin{array}{c}4.5 \\
8\end{array}$ & $\begin{array}{l}86.99 \\
87.02\end{array}$ & $\begin{array}{l}86.16 \\
86.22\end{array}$ & $\begin{array}{c}91 \\
91.07\end{array}$ & $\begin{array}{l}125.86 \\
125.94\end{array}$ & $\begin{array}{c}157.87 \\
158\end{array}$ \\
\hline 8.25 & 86.85 & 86.05 & 90.93 & 125.77 & 157.83 \\
\hline 8.5 & 86.75 & 86 & 90.86 & 125.72 & 157.75 \\
\hline 9 & 86.68 & 85.9 & 90.79 & 125.65 & 157.65 \\
\hline 9.5 & 86.62 & 85.86 & 90.75 & 125.62 & 157.6 \\
\hline 10.5 & 86.54 & 85.77 & 90.66 & 125.54 & 157.51 \\
\hline 24 & 86.38 & 85.61 & 90.45 & 125.3 & 157.21 \\
\hline 24.25 & 86.55 & 85.73 & 90.57 & 125.42 & 157.33 \\
\hline 24.5 & 86.59 & 85.79 & 90.62 & 125.46 & 157.38 \\
\hline 25 & 86.69 & 85.89 & 90.71 & 125.53 & 157.49 \\
\hline 25.5 & 86.75 & 85.95 & 90.77 & 125.6 & 157.57 \\
\hline 26.5 & 86.85 & 86.04 & 90.85 & 125.69 & 157.68 \\
\hline 28.5 & 86.89 & 86.11 & 90.93 & 125.77 & 157.79 \\
\hline 32 & 86.98 & 86.2 & 91.05 & 125.91 & 157.95 \\
\hline 32.25 & 86.81 & 86.06 & 90.9 & 125.75 & 157.78 \\
\hline 32.5 & 86.75 & 85.98 & 90.85 & 125.68 & 157.7 \\
\hline 33 & 86.67 & 85.93 & 90.8 & 125.63 & 157.64 \\
\hline 33.5 & 86.62 & 85.86 & 90.73 & 125.58 & 157.58 \\
\hline 34.5 & 86.55 & 85.78 & 90.66 & 125.53 & 157.51 \\
\hline 48 & 86.35 & 85.58 & 90.43 & 125.26 & 157.15 \\
\hline 48.25 & 86.48 & 85.71 & 90.54 & 125.39 & 157.29 \\
\hline 48.5 & 86.55 & 85.78 & 90.63 & 125.43 & 157.34 \\
\hline 49 & 86.69 & 85.88 & 90.72 & 125.52 & 157.46 \\
\hline 49.5 & 86.75 & 85.95 & 90.78 & 125.59 & 157.54 \\
\hline 50.5 & 86.84 & 86.04 & 90.87 & 125.68 & 157.68 \\
\hline 52.5 & 86.93 & 86.12 & 90.95 & 125.78 & 157.8 \\
\hline 56 & 87.02 & 86.22 & 91.04 & 125.94 & 157.99 \\
\hline 56.25 & 86.82 & 86.07 & 90.92 & 125.75 & 157.8 \\
\hline 56.5 & 86.76 & 86.01 & 90.86 & 125.7 & 157.73 \\
\hline 57 & 86.67 & 85.91 & 90.79 & 125.63 & 157.64 \\
\hline 57.5 & 86.6 & 85.85 & 90.73 & 125.59 & 157.59 \\
\hline 58.5 & 86.53 & 85.77 & 90.65 & 125.52 & 157.49 \\
\hline 72 & 86.28 & 85.52 & 90.38 & 125.2 & 157.08 \\
\hline
\end{tabular}


Table A. LXXVIII. Repeated Absorption-Desorption Experiment (72 hour cycle)

\begin{tabular}{|c|c|c|c|c|c|c|c|c|}
\hline $\begin{array}{r}\text { Thickness } \\
(\mathrm{cm})\end{array}$ & 0.037 & 0.038 & 0.031 & 0.040 & 0.045 & 0.029 & 0.043 & 0.043 \\
\hline Time & $0 \%$ & $0 \%$ & $1 \%$ & $1 \%$ & $2 \%$ & $2 \%$ & $5 \%$ & $5 \%$ \\
\hline (h) & Sample 1 & Sample 2 & Sample 1 & Sample 2 & Sample 1 & Sample 2 & Sample 1 & Sample 2 \\
\hline 0 & 131.56 & 209.99 & 169.93 & 232.92 & 320.33 & 232.12 & 277.59 & 328.44 \\
\hline 0.58 & 131.84 & 210.37 & 170.24 & 233.2 & 320.68 & 232.47 & 277.98 & 328.75 \\
\hline 1 & 132.05 & 210.47 & 170.45 & 233.44 & 320.91 & 232.74 & 278.15 & 329.01 \\
\hline 3.66 & 132.37 & 211.03 & 170.86 & 233.95 & 321.54 & 233.29 & 278.74 & 329.5 \\
\hline 5.58 & 132.49 & 211.38 & 170.95 & 234.23 & 321.82 & 233.6 & 279.02 & 329.8 \\
\hline 24.58 & 132.75 & 211.65 & 171.44 & 234.89 & 323.01 & 234.64 & 280.27 & 331.17 \\
\hline 31.58 & 132.79 & 211.69 & 171.55 & 234.92 & 323.21 & 234.82 & 280.46 & 331.41 \\
\hline 48.58 & 132.89 & 211.73 & 171.6 & 235.06 & 323.61 & 235.12 & 280.84 & 331.78 \\
\hline 72 & 132.95 & 211.87 & 171.82 & 235.33 & 324.01 & 235.35 & 281.52 & 332.42 \\
\hline 72.58 & 132.39 & 211.4 & 171.09 & 234.63 & 323.09 & 234.25 & 280.12 & 331.12 \\
\hline 73 & 132.18 & 211.17 & 170.84 & 234.38 & 322.68 & 233.77 & 279.54 & 330.53 \\
\hline 73.92 & 131.98 & 210.93 & 170.6 & 234.13 & 322.3 & 233.36 & 279.11 & 330.13 \\
\hline 76.58 & 131.74 & 210.55 & 170.26 & 233.71 & 321.81 & 232.88 & 278.62 & 329.65 \\
\hline 93.58 & 131.39 & 209.92 & 169.74 & 232.9 & 320.58 & 231.93 & 277.61 & 328.45 \\
\hline 100.08 & 131.35 & 209.87 & 169.7 & 232.81 & 320.39 & 231.8 & 277.49 & 328.25 \\
\hline 120.91 & 131.32 & 209.8 & 169.64 & 232.68 & 320.09 & 231.69 & 277.31 & 328.03 \\
\hline 144 & 131.32 & 209.79 & 169.64 & 232.66 & 319.99 & 231.67 & 277.26 & 327.93 \\
\hline 144.66 & 131.69 & 210.13 & 170.05 & 233.03 & 320.4 & 232.14 & 277.66 & 328.35 \\
\hline 145.17 & 132 & 210.49 & 170.33 & 233.4 & 320.8 & 232.44 & 278.01 & 328.7 \\
\hline 148.33 & 132.41 & 211.05 & 170.86 & 234.02 & 321.47 & 233.14 & 278.75 & 329.39 \\
\hline 149.75 & 132.55 & 211.23 & 170.98 & 234.24 & 321.78 & 233.41 & 279.01 & 329.68 \\
\hline 168.58 & 132.91 & 211.71 & 171.67 & 235.01 & 323.14 & 234.58 & 280.38 & 331.18 \\
\hline 172.58 & 132.97 & 211.77 & 171.73 & 235.15 & 323.28 & 234.66 & 280.52 & 331.36 \\
\hline 192.58 & 132.97 & 211.8 & 171.94 & 235.26 & 323.83 & 235.02 & 281.07 & 331.99 \\
\hline 216 & & 211.8 & 172.03 & 235.32 & 324.07 & 235.24 & 281.35 & 332.37 \\
\hline 216.58 & & 211.33 & 171.06 & 234.63 & 323.07 & 234.05 & 280.04 & 330.99 \\
\hline 217 & & 211.15 & 170.85 & 234.41 & 322.67 & 233.63 & 279.49 & 330.48 \\
\hline 218.17 & & 210.89 & 170.59 & 234.14 & 322.32 & 233.2 & 279.06 & 330.07 \\
\hline 221.08 & & 210.52 & 170.25 & 233.69 & 321.78 & 232.7 & 278.58 & 329.55 \\
\hline 241.58 & & 209.98 & 169.79 & 232.93 & 320.61 & 231.84 & 277.61 & 328.42 \\
\hline 262.08 & & 209.84 & 169.66 & 232.75 & 320.21 & 231.63 & 277.35 & 328.01 \\
\hline 292.58 & & 209.82 & 169.63 & 232.71 & 320.06 & 231.58 & 277.27 & 327.94 \\
\hline 436.58 & & 209.79 & 169.64 & 232.68 & 319.98 & 231.55 & 277.24 & 327.87 \\
\hline
\end{tabular}

